\title{
Progressive Enlightenment:
}

\section{The Origins of the Gaslight Industry $1780-1820$}

\author{
by \\ Leslie Tomory \\ A thesis submitted in conformity with the requirements \\ for the degree of Ph.D. \\ Institute for the History and Philosophy of Science and Technology \\ University of Toronto
}

(c) Copyright by Leslie Tomory (2009) 


\section{Abstract}

Title: Progressive Enlightenment: The Origins of the Gaslight Industry 1780-1820

Ph.D. thesis (2009) by Leslie Tomory, completed at the Institute for the History and Philosophy of Science and Technology at the University of Toronto

Gaslight, an Industrial Revolution technology, developed in the period 1780-1820. The foundations for the technology are partly found in the pneumatic chemistry of the eighteenth century, both in terms of the knowledge of gases and their properties, and the instruments used to manipulate them, such as the gasometer, making gaslight one of the earliest instances of a technology heavily based on science. Although many people experimented with lighting with gases in the late eighteenth century, the move to a commercial technology began with Philippe Lebon and William Murdock who had a clear commercial purpose in mind. The technology in its early phases was found everywhere in Europe, but it was at Boulton \& Watt in Birmingham that it was first successfully applied. As Boulton \& Watt developed the technology they identified many and solved some of the problems associated with scaling up the technology. They were not, however, very interested in gaslight and only sporadically gave attention to it, before effectively abandoning it around 1812 . They nevertheless had an important role to play in its development not only because if their technical work, but also because they demonstrated the technology's viability to the broad public, and by giving people experience in gas engineering. The technology's final form as a network utility was partly as a result of a battle fought between Boulton \& Watt and Frederick Winsor's Gas Light and Coke Company in London during 1807-1810. Boutlon \& Watt did not want a 
large limited-liability corporation as a competitor, and the contest in Parliament between the two groups resulted in a negotiated compromise where the Gas Light and Coke Company gave up all rights to manufacture apparatus, and focused exclusively on gas provision, effectively making it a utility. The years from 1812-1820 saw the technology mature into a large network which included not only technical development, such as the pressure balancing with valves and regulators, but also political and social elements, such as the control of user expectations through education and usage enforcement through inspectors. By 1820 , the technology was sufficiently developed to be transferred to the Continent. 


\section{Acknowledgments}

The work on this thesis has been supported by many people in various ways. There has been the encouragement, support, and patience of my family and friends as I spent hours reading, researching, and writing. Librarians and archivists in various places, and most especially the London Metropolitan Archives, have been of the invaluable help. The University of Toronto's interlibrary loans staff has also proved to be irreplaceable as they hunted down obscure eighteenth and early nineteenth century sources, a number of which came from Germany. Without their help, most of the first and second chapters of the thesis could not have been written. I would like to thank my committee, Bert Hall and Trevor Levere, who read through this long and detailed thesis more than once and who provided thoughtful feedback. My external examiner, Chris Hamlin, also gave some insightful and valuable comments. Finally, I would like to thank particularly my supervisor, Janis Langins, whose example, friendship, and discussion have been an important part of getting this thesis finished. 


\section{Table of Contents}

Introduction: Gaslight in the Industrial Revolution

Chapter 1: $\quad$ The roots of gaslight in pneumatic chemistry

Chapter 2: $\quad$ The road to gaslight: coal mines, distillation processes, and natural philosophy

Chapter 3: $\quad$ Boulton \& Watt: a question of scale

Chapter 4: $\quad$ Frederick Winsor, Boulton \& Watt, and the National Heat and Light Company

Chapter 5:

The Gas Light and Coke Company

Conclusion: Gaslight, a technology worthy of study 


\section{List of Figures}

\section{Chapter 1}

Figure 1.1 An inflammable air lamp, from the Oekonomische-Technologische Encyclopädie

Figure 1.2 Retorts, from Glauber A Description of New Philosophical Furnaces

Figure 1.3 A pneumatic trough, from Hales Vegetable Staticks

Figure 1.4 Pneumatic apparatus from Cavendish, "Three Papers on Factitious Air" 42

Figure 1.5 Plate from the 1778 German edition of Volta's letters on marsh gas. Briefe über die natürlich entstehende entzündbare Sumpfluft

Figure 1.6 Sketch of an inflammable air lamp, drawn by Volta. "Due Lettere a Jean Senebier"

Figure 1.7 Sketch of an inflammable air lighter, from Volta "Descrizione ed uso di un accendilume ad aria infiammabile"

Figure 1.8 A series of inflammable air lamps, from Ehrmann, Déscription et usage de quelques lampes à air inflammable

Figure 1.9 Table from Minckelers Mémoire sur l'air inflammable tiré de différentes Substances

Figure 1.10 Lavoisier's gasometer, taken from the Traité élémentaire de chimie

Figure 1.11 Meusnier's gasometer, from the Histoire de l'Académie royale des sciences 
Figure 1.12 Van Marum's hydrostatic gasometer, from Description de quelques appareils chimiques nouveaux

\section{Chapter 2}

Figure 2.1 Lebon's themolamp, from Magnier, Nouveau manuel complet de l'éclairage et du chauffage au gaz

Figure 2.2 Plate from Chaussier "Mémoire de physique expérimentale, sur quelques propriétés de l'air inflammable"

Figure 2.3 A bladder from Diller's apparatus, take from Brisson, Traité élémentaire ou principes de physique

Figure 2.4 Inflammable air engine from "Specification of the Patent Granted to Mr. Robert Street"

Figure 2.5 Lebon's furnace from his patent application (1799), from Magnier, Nouveau manuel complet de l'éclairage et du chauffage au gaz

Figure 2.6 A Woulfe apparatus, from Lavoisier, Traité élémentaire de chimie 172

Figure 2.7 A Woulfe apparatus, from Woulfe, "Experiments on the Distillation of Acids" 173

Figure 2.8 Gas-holder from Winzler Die Thermolampe in Deutschland

Figure 2.9 Retort oven from Winzler Die Thermolampe in Deutschland 


\section{Chapter 3}

Figure 3.1 Retort cross section.

Figure 3.2 Early retort design from Creighton "Gas-Lights."

Figure 3.3 Early retort designs from Creighton "Gas-Lights."

Figure 3.4 Pneumatic apparatus, from Beddoes Considerations on the medicinal use, and on the production of factitious airs

Figure 3.5 Sketches of gasometers for Philips \& Lee prepared in 1805 or 1806

Figure 3.6 Cross section of Wood, Daintry \& Wood's New Mill, from July 1805, showing beams in the building

Figure 3.7 Ground plans of Philips \& Lee's, dated September 1805. The plans show proposed locations for gasometers, retorts, and pipes.

Figure 3.8 Vertical retorts used at Philips \& Lee, from Creighton "Gas-Lights." 240

Figure 3.9 Gasometer cross section from March 1806

Figure 3.10 Cockspur burners from Creighton "Gas-Lights"

Figure 3.11 Above: side view of the gasometers at Philips \& Lee

Figure 3.12 Below: Top view of the retorts with crane bases and swing arm radius 
Figure 3.15 Results from coal carbonization experiments, sent by Creighton to Boulton \& Watt

Figure 3.16 Apparatus from Henry, "Description of an Apparatus for the Analysis of the Compound Inflammable Gases by Slow Combustion"

Figure 3.17 Calculation of candle equivalencies, from Creighton to Boulton \& Watt 286

Figure 3.18 Argand burner from Creighton "Gas-Lights"

291

Figure 3.19 Suggestion for a new retort design, from Creighton to Boulton \& Watt 293

Figure 3.20 Gasometer pipe, from Creighton 304

Figure 3.21 Retorts at James Kennedy, side view 305

Figure 3.22 Retorts at James Kennedy, front view. 306

Figure 3.23 Retorts at James Kennedy, top view. 307

Figure 3.24 Side of gasometer at James Kennedy, all from 1808 308

Figure 3.25 Top view of installation at James Kennedy 1808

Figure 3.26 A cotton mill lit by gaslights. From Andrew Ure, The Philosophy of Manufactures, (1835)

Figure 3.27 Table of Boulton \& Watt profits and costs of gas apparatus, from Falkus. "The Early Development of the British Gas Industry, 1790-1815." 


\section{Chapter 4}

Figure 4.1 A demonstration gas apparatus, from Cooper, Some information concerning gas lights

Figure 4.2 The Strangers Guide Through the Streets of London and Westminster \& C

Figure 4.3 The Opera House Colonnade and Waterloo Place, Pall Mall, from the frontispiece of The European Magazine and London Review

Figure 4.4. London around Pall Mall, from Wallis's Plan Of The Cities Of London And Westminster

Figure 4.5 Carlton House in the early nineteenth century

Figure 4.6 Carlton House Gardens in the early nineteenth century

Figure 4.7 George Cruikshank. "The good effects of carbonic gas!!!"

Figure 4.8 A display of gaslight, from Samuel Parkes. The Chemical Catechism

Figure 4.9 Samuel De Wilde. "Opposition lights"

Figure 4.10 George Woodward and Thomas Rowlandson. "A Peep at the Gas Lights in Pall-Mall." 


\section{Chapter 5}

Figure 5.1 Mr. Clegg's Apparatus for making Carbonated Hydrogen Gas from Pit Coal, from Transactions of the Society for the Encouragement of Arts

Figure 5.2 Clegg's apparatus at Ackermann's printshop, from Accum, A practical treatise on gas-light

Figure 5.3 Bowles's One-Sheet Plan of the Cities of London and Westminster

Figure 5.4 St. John's church in the eighteenth century 456

Figure 5.5 The Blessed Effects of Gas Lights or a new method of Lighting as practised in Great Peter Street, London.'

Figure 5.6 Retort on the flue plan, Creighton, "Gas-Lights."

Figure 5.7 Retorts on the flue plan, from Accum, A practical treatise on gas-light

Figure 5.8 Flue plan, with protection from fire bricks, from Creighton, "Gas-Lights." 487

Figure 5.9 Front view of elliptical retorts set on the oven plan, from Peckston The theory and practice of gas-lighting

Figure 5.10 Hydraulic main, from Peckston, The theory and practice of gas-lighting 492

Figure 5.11 Gas apparatus from Accum, A practical treatise on gas-light

Figure 5.12 A Perks condenser, from Peckston, The theory and practice of gas-lighting

Figure 5.13 Lime purifiers, from Creighton "Gas-Lights." 
Figure 5.14 Malam's three stage purifier, from Peckston, The theory and practice of gas-lighting

Figure 5.15 Tar well, from Peckston, The theory and practice of gas-lighting

Figure 5.16 Syphon, from Peckston, The theory and practice of gas-lighting

Figure 5.17 House syphon, from Peckston, The theory and practice of gas-lighting

Figure 5.18 Hydraulic valve, from Creighton, "Gas-Lights"

Figure 5.19 Pneumatic valve, from Peckston, The theory and practice of gas-lighting 525

Figure 5.20 Small regulator, from Creighton, "Gas-Lights"

Figure 5.21 Gasometer with three counterweights, from Creighton, "Gas-Lights"

Figure 5.22 Gasometer with no counterweights from Creighton, "Gas-Lights"

Figure 5.23 Large regulator, from "Specification of the Patent granted to Samuel Clegg"

Figure 5.24 George Cruikshank. "Introduction of gas!! Or throwing a new light on the subject."

Figure 5.25 Pipe connections, from Peckston, The theory and practice of gas-lighting

Figure 5.26 An oil-gas plant, from Matthews, Compendium of gas-lighting

Figure 5.27 Gas burners, from Accum, A practical treatise on gas-light (1815) 


\section{Abbreviations}

AM-IR Adam Matthew publishers, Industrial Revolution Series

B+W Boulton \& Watt

BWA Boulton \& Watt Archives at the Brimingham Central Library

CA Creighton's letter of answers, Creighton to B+W 1808/01/25, BWA MS

3147/3/247 \#43, AM-IR series 1 part 12 reel 212

GLCC Gas Light and Coke Company

JWP James Watt papers

LB Letter book

LMA London Metropolitan Archives

MII Muirhead II collection at the Birmingham Central Library

MIV Muirhead IV collection at the Birmingham Central Library

MCD Minutes of the court of directors of the GLCC

MCW Minutes of the committee of works of the GLCC

All dates in footnotes are given as YYYY/MM/DD 


\section{Introduction: Gaslight in the Industrial Revolution}

The most prominent features in the skyline of nineteenth century London included some monuments which continue to hold a prominent visual place in the city. The dome of St. Paul's Cathedral, the Parliament buildings, Tower Bridge, and other buildings are as important today as they were then. The largest edifices of the nineteenth century, however, are no longer present, except as a few skeletal frames. They never had any aesthetic value, and long ago passed into desuetude, to be torn down, cut up, and sold as scrap. These dominant landmarks were the gas-holders of the manufactured gas industry, built to store a day's supply of gas for the light hungry metropolis of London. By the end of the nineteenth century, some of these iron containers were indeed bigger than St. Paul's Cathedral.

The size of the gas-holders was a testament to the prominent place the industry had in the city, as it provided gas for light in home, public buildings, and streets. It had a pervasive effect on society as it changed patterns of work and social life. Historians such as Wolfgang Schivelbusch and Lynda Nead have described how the progressive development of lighting technology in the nineteenth century transformed the way people lived and worked, allowing for a brighter and new extended nightlife. ${ }^{1}$ The industry was the subject of much political attention, with many laws directed at regulating it in various ways. In terms of business and the economy, manufactured gas

\footnotetext{
1 Wolfgang Schivelbusch, Disenchanted night : the industrialization of light in the nineteenth century (Berkeley: University of California Press, 1988). Lynda Nead, Victorian Babylon : people, streets and images in nineteenth-century London (New Haven: Yale University Press, 2000).
} 
loomed large, present by 1821 in every urban agglomerations of more than 50,000 people in the United Kingdom, and spreading to the Continent. By 1826, only two towns with more than 10,000 people were without a gas company in England. ${ }^{2}$ Gas companies were usually large joint-stock companies employing thousands of people with invested capital running into the tens of millions of pounds in Britain by midcentury. ${ }^{3}$ The technology the industry used was an active subject of research and development throughout the century, and a new discipline of gas engineering supported it.

For all its importance in the nineteenth century, however, it has been relatively neglected by historians of technology, as compared to, for example, railways or electricity. This neglect is all the more remarkable given that the roots of the technology and the industry go back to the Industrial Revolution, with most directly related development work occurring between 1784 and 1820. Technological and industrial development are among the mainstays of historical research into the Industrial Revolution and figure prominently in historical debates. With a few exceptions, however, gaslight is usually not considered. David Landes, for example, in his sweeping work The Unbound Prometheus in which technology plays a central role, does not mention the gas industry except for a few minor passing references. The same holds true for A. E. Musson and Eric Robinson's Science and Technology in the Industrial Revolution. It is likewise absent from T. S. Ashton's classic survey The

\footnotetext{
2 Malcolm E. Falkus, "The British Gas Industry before 1850," The Economic History Review 20, no. 3 (1967): 496-8.

3 - - -, "The Early Development of the British Gas Industry, 1790-1815," The Economic History Review 35, no. 2 (1982): 217. Falkus, "The British Gas Industry before 1850," 504-5.
} 
Industrial Revolution 1760-1830, and Donald Cardwell's History of Technology. Joel Mokyr is an important exception to this trend, and has mentioned gaslight in a number of places, calling it 'one of the most neglected of the "great inventions"'.4

Many other examples could be cited and the important point is that this relative neglect has meant that manufactured gas has been left out of much of the discussion surrounding the technology of the Industrial Revolution, such as the influence of science on technological development, the role of coal in the development of new skills and technologies, and the reasons why England industrialized before other countries. Whereas, for example, the steam engine and textiles are rightly a staple in these debates, gaslight has not yet really been considered except in internal histories of gaslight, and even then, only briefly. That manufactured gas has come in for such neglect is somewhat puzzling. It is a truly novel technology of the Industrial Revolution, emerging well within what is usually considered to be the revolution's timeframe. Joel Mokyr has described gaslight as one of the important macroinventions of the Industrial Revolution. ${ }^{5}$ Gaslight technology was generally not derived from technology already in use, such as with textiles, nor is this a case of an industry transforming itself gradually with a series of more or less significant inventions, a happened with the iron industry. The new manufactured gas industry was based on very new technology with little

\footnotetext{
4 Joel Mokyr, "Editor's Introduction: The New Economic History and the Industrial Revolution," in The British industrial revolution : an economic assessment, ed. Joel Mokyr (Boulder, Colo.: Oxford, 1999), $14 .$. See also - - - The Lever of Riches: Technological Creativity and Economic Progress (New York: Oxford University Press, 1990), 109-10.

5 Joel Mokyr, "Technological Change, 1700-1830," in The Economic history of Britain since 1700. Volume 1: 1700-1860, ed. Roderick Floud and Deirdre N. McCloskey (Cambridge, New York: Cambridge University Press 2nd ed, 1994), 27. Mokyr, The Lever of Riches: Technological Creativity and Economic Progress, 109, 294. - - -, "Editor's Introduction."
} 
relation to the oil lamps and candles, the technologies it replaced. Nor were the players bringing in the new technology found within the oil or candle trade.

However, it is not only to the historiography of the Industrial Revolution that gaslight has something to offer. There are elements in its development that are relevant to themes that have been normally associated with Second Industrial Revolution technologies, where the development of large technological systems has been an important matter of study. Thomas Hughes has described how the evolution of large technological systems in the period 1870-1940 display patterns of growth whereby an emerging technological system was made stable - technologically, socially and politically - by its builders who adapted it to its environment in these various ways. ${ }^{6} \mathrm{~A}$ literature on large technical systems has followed his work, and the focus technologies are typically, although not exclusively, from Hughes' chosen period and later. ${ }^{7}$ Manufactured gas, as a large integrated system, has much to offer in this regard because it predates most the better studied systems. In the same vein, Alfred Chandler has also presented an important argument about the rise of modern corporate structures based on the characteristics of the technologies that underlay the new businesses of the second half of the nineteenth century. An extensive debate has ensued from Chandler's thesis, but to what extent gaslight as an integrated technological system of the early nineteenth century can serve as a possible

6 Thomas Parke Hughes, "The evolution of large technological systems," in The Social construction of technological systems : new directions in the sociology and history of technology, ed. Wiebe E. Bijker, Thomas Parke Hughes, and T. J. Pinch (Cambridge, Mass.: MIT Press, 1987), 56.

${ }^{7}$ For an overview of the field, see Erik Van Der Vleuten, "Infrastructures and Societal Change. A View from the Large Technical Systems Field," Technology Analysis \& Strategic Management 16, no. 3 (2004). 
counterexample to the timing proposed in Chandler's thesis likewise has to be examined in greater detail.

I hope to begin to redress this neglect of gaslight with this thesis. By examining the origins of the manufactured gas industry, I try to show that it has much to offer to the historiography of both the Industrial Revolution and of the large technological systems of the Second Industrial Revolution.

\section{Historiography of the origins of gaslight}

Even in terms of internal histories, there are relatively few works devoted to the subject in comparison to other technologies and industries of the Industrial Revolution. There is only a single book length study devoted to the origins of the manufactured gas industry: Dean Chandler and A. Douglas Lacey's The Rise of the Gas Industry in Britain. It was published in 1949 and suffers from many inadequacies, being based only on published sources. Stirling Everard's detailed The History of the Gas Light and Coke Company, 1812-1949 was published the same year. It is a valuable overview, derived from research on surviving corporate minutes. ${ }^{8}$ The book is, however, a strongly internal corporate history with little analysis. In addition to these two monographs, there are three essay length studies that are well researched. The first of these is Archibald and Nan Clow's chapter in The Chemical Revolution: A Contribution to Social Technology, (1952). Arthur Elton's article "Gas for Light and Heat" in the Oxford History of Technology, Volume IV: The Industrial Revolution c. 1750 to c. 1850 (1958) is an

${ }^{8}$ Everard unfortunately cites none of his sources. 
excellent and detailed survey of the some of the variations of gaslight prior to and contemporary with Lebon and Murdock. Malcolm Falkus' "The Early Development of the British Gas Industry, 1790-1815" in The Economic History Review (1982) is based on research in the Boulton \& Watt archives at the Birmingham Public Library and contains important insights. John Griffiths worked from the same archival material for his book, The Third Man: the Life and Times of William Murdoch, 1754-1839, the Inventor of Gas Lighting (1992). While the work is well researched, Griffiths is not a historian, and his chapter on gaslight is primarily concerned with the chronology of the invention, rather than technical details or analysis about the origins of the technology. There are finally a number of biographies of Philippe Lebon, but the only recent one, François Veillerette's Philippe Lebon, ou, l'homme aux mains de lumière (1987), does not cite any of its sources and seeks to make Lebon into a national hero. The only study that in any way goes more deeply into the Boulton \& Watt archives in regard to technical details is a chapter in Peter Austerfield's unpublished PhD thesis at the University of London, "The development of large-scale production and utilisation of lighter-than-air gases in France, Britain and the low countries from 1783 to 1821 with reference to aeronautics and the coal-gas industry." (1981), devoting 40 pages to the subject. Beyond this, there is little of substance with any original contribution to make on the origins of gaslight technology.

There are some nineteenth century works on the history of gaslight, the most important of which is William Matthews' An Historical Sketch of the Origin, Progress, \& Present State of Gas-lighting (1827, 2nd edition 1832). Matthews was a witness to many of the events he describes, and was personally acquainted with people such as 
Samuel Clegg, an important early gas engineer. ${ }^{9}$ His history gathers many details used by subsequent historians, sometimes too closely, and Matthews himself collected some of his information from items that had appeared in books and journals in the years 1805-1815. This has meant that in general outline, the story of the origins of the manufactured gas industry goes back to the very years when the industry was being founded, a problematic point because the industry's origins featured some intense rivalries. Priority claims were important for political and economic reasons as competing groups battled one another over the control of the industry. Many of the names of precursors thrown out then and repeated by Matthews, such as Charles Diller, Lord Dundonald, and Richard Watson, have appeared in just about every history since, without, however, a proper assessment of their importance in the history of the technology's development. Simon Werret has discussed how the relative place in the historiography of William Murdock, gaslight's canonical English inventor, and Frederick Winsor, the promoter of the Gas Light and Coke Company, the world's first gas utility, was established within these political battles. Murdock has been been seen as the heroic inventor, with Winsor as a something of a charlatan and projector. ${ }^{10}$ Subsequently, the rival nationalistic priority claims between the Belgians, the French, and the English, making claims for Jan-Pieters Minckelers, Philippe Lebon, or Mudock

\footnotetext{
9 See Arthur Matthews, A biography of William Matthews, the expositor of gas and water engineering (London [The Author: privately printed], 1899).

10 See Simon Werrett, "From the grand whim to the gasworks: 'philosophical fireworks' in Georgian England," in The mindful hand : inquiry and invention from the late Renaissance to early industrialisation, ed. Lissa Louise Roberts, Simon Schaffer, and Peter Robert Dear (Amsterdam : Edita: Bristol, 2007), 344.
} 
respectively have also had an effect on the historiography. ${ }^{11}$ As people have sought to establish one or the other as the 'true inventor' of gaslight, the story of its invention has been reduced to a 'eureka' moment, when the discoverer suddenly realizes that gas from coal or wood is inflammable, and apprehends that it can be used for illumination. From this first momentous insight, a new industry was born. The effect of these stories is to reduce the invention to something that can be given a very specific date, and also trivializes the technology to being little more than putting together plumbing for inflammable gases. ${ }^{12}$

\section{Two question and two threads}

The basic outline for the development of gaslight as drawn up by Matthews is, however, problematic. His list of contemporaries and precursors, to which later historians added more, ${ }^{13}$ is in glaring contradiction to the eureka invention stories which present gaslight as without antecedents. Some of the precursors, who are mostly clustered in the last decades of the eighteenth century, even used inflammable gases for lighting purposes. The existence of the contemporaries and precursors prompt

\footnotetext{
11 Christine MacLeod has also discussed how Murdock was 'rescued from oblivion' and made into a hero by his local village and gas associations around 1890. See Christine MacLeod, Heroes of invention : technology, liberalism and British identity : 1750 - 1914 (Cambridge UK: Cambridge University Press, 2007), 339-400..

12 For some discussion on the heroic view, see Nathan Rosenberg, Inside the black box : technology and economics (New York, 1982), 48-9. See also Davide Philip Miller, Discovering Water: James Watt, Henry Cavendish, and the Nineteenth Century 'Water Controversy' (Ashgate Publishing, Ltd., 2004)., chapter two.

${ }^{13}$ Arthur Elton, "Gas for Light and Heat," in A History of Technology, Volume IV: The Industrial Revolution c. 1750 to c. 1850, ed. Charles Singer, et al. (Oxford, England: Oxford University Press, 1958). contains the best list of precursors as it includes French and German sources.
} 
questions in two important areas about the origins of gaslight. The first of these concerns the relative importance of Murdock and Lebon. If Lebon and Murdock were preceded in some cases by decades in observing the inflammability of gas from wood and coal, and even in using it for lighting, what was their true contribution? The complement of this is: what was the importance and contribution of the precursors to the development of gaslight?

The second important subject raised from consideration of the precursors concerns timing. Why were there so many people experimenting with gas as an illuminant at the end of the eighteenth century, and how do Murdock and Lebon fit into this group? Is it just by chance that gaslight was invented at the end of the eighteenth century, and that so many people were experimenting with inflammable gases at the time? The eureka stories would suggest that it is. According to these stories, all that was needed was the observation of inflammablity, the idea of using gas for light, and some development work. This then prompts the question as to why did gaslight not develop earlier. Some have indeed suggested it was not for technical or scientific reasons that it did not do so. The Clows, who ironically wrote The Chemical Revolution to argue that the theoretical chemistry of the eighteenth century fostered the development of industry, suggested that the reason gaslight did not emerge in the seventeenth century was that work hours were not yet long enough to need it; that the iron industry 'would have found it still very difficult to supply the necessary equipment'; and that there was prejudice against coal gas. ${ }^{14}$ Another similar answer was suggested

\footnotetext{
${ }^{14}$ Archibald Clow and Nan L. Clow, The Chemical Revolution; a Contribution to Social Technology (Freeport: N.Y., Books for Libraries Press, 1970), 426.
} 
by Morris Berman, who argued that it was 'only a converging set of social needs that could render [gaslight] popular or deem it necessary; and from 1809, owing to such needs, the gas industry emerged in England in full force.' 15 The needs he identifies as driving the development of gaslight are the desire for the security and social order, and the need to escape fear of crime on the part of the upper and middle classes. For the Clows and for Berman, the scientific and technological aspects of the invention fade into the background, and the emergence of gaslight as an industry was a product of social forces. This sort of view is possible only if the technology is trivialized.

The answers to these questions bring into relief the true origins of the gaslight technology, which proves to be much more complicated than the standard historical narrative, and bring with them many other very interesting elements that shed light on the broader historiographic questions of the Industrial Revolution. There are two major threads that run together and that capture Lebon and Murdock's work, as well as most of their precursors and contemporaries, and from which the answers to the above mentioned questions emerge. The first of these threads is the development of pneumatic chemistry in the eighteenth century. The reason why so many people were experimenting with inflammable gases in the second half of the eighteenth century was that pneumatic chemistry had emerged as a new science. Inflammable gases were but a small portion of this Europe-wide research program. It comes as no surprise that some people found some practical uses for the newly discovered gases. Lighting was one of these uses. It was no fluke that so many natural philosophers and instrument

\footnotetext{
15 Morris Berman, Social Change and Scientific Organization: the Royal Institution, 1799-1844 (Ithaca, N.Y.: Cornell University Press, 1978), 146.
} 
makers tried lighting with gases. In this way, gaslight emerges as one of the few Industrial Revolution technologies that depend heavily and clearly on the theoretical and experimental science of the time. As is demonstrated in the first chapter, the concepts, techniques, and instruments of pneumatic chemistry were used by the early pioneers of the gas industry. These concepts, techniques, and instruments date to various points in the eighteenth century. As an Industrial Revolution technology with a firm basis in theoretical science, gaslight is unique because of how clear the connections actually are.

With this broader view of the origins of gaslight, there is then no room left for the eureka story. Not only was the inflammability of coal and wood gas a piece of common knowledge among chemists before the 1790s, more than one kind of inflammable gas were well known. If Lebon or Murdock had announced to the world that they had discovered inflammable gases in 1792, they would have been regarded as ignoramuses out of touch with contemporary chemistry.

The second thread which answers the three questions posed above is the interest in distillation as an industrial process. What set Murdock and Lebon apart from the most others who were also interested in inflammable gases was first, they were interested in industrial processes, and second they were interested in creating a viable, commercial technology. With the exception of George Dixon, none of the long list of precursors or contemporaries had these characteristics. Lebon and Murdock both got into researching inflammable gases because they had been investigating large scale distillation. Both these men took out patents for distillation processes before their work 
on gaslight. Both were engineers thinking in terms of a commercial process, and not coming at the subject from the point of view of chemical research. Unlike their precursors, Murdock and Lebon had a primary interest in commercial applications, and a willingness and ability to see it through, at least to the point of going public with some version of gaslight technology.

\section{Why Britain?}

The subsequent history of gaslight poses further interesting questions, and as with the immediate origin of the technology, some important questions remain unanswered. Once gaslight (or more specifically, the industrial production of inflammable gases) got a start, interest in it picked up, especially in Germany and Britain. Both points of origin, Lebon and Murdock, were at the head of a trail of development. In Lebon's case, his thermolamp generated great interest and enthusiasm in Germany, as well as in Britain via Frederick Winsor, who moved there from Germany taking the idea of the thermolamp with him. In Murdock's case, the development path was internal to the firm that employed him, Boulton \& Watt, before it spread out to other manufacturers and engineers. Despite the interest in the technology on the Continent and in Britain, it was only in Britain that the invention flourished. By 1812, a large gas utility, the Gas Light and Coke Company, had been chartered in London. From there the technology spread throughout Britain and by 1820 , visitors from the continent were amazed at the lighting of English cities with gas. From England, it was transplanted back to the continent by English engineers and capital. 
Why did it happen this way? French histories of gaslight often lament Lebon's failure, usually blaming the lack of interest in his work. There may be a small grain of truth of this in France, but certainly not in Germany, where there seems to have been even more interest in gaslight than in Britain from 1802-1808, judging by publications on the subject. Why, if there was so much interest in the technology in Germany, did it not develop into an enduring industry there? What was it about the English situation that made it different? This of course touches on another of the key historiographical questions of the Industrial Revolution, which is why did it take place in Britain, and not elsewhere? Previous histories of gaslight have passed this question by, usually without comment, or by accepting the early nineteenth century answer given by French commentators, that it was simply a missed opportunity on the part of the French.

The answer, however, is more complicated. The German interest in the technology belies any recourse to an explanation based on a lack of support, and the cause must be found elsewhere. The answer I give agrees with some of the traditional answers to the broader question as to why England was first in the Industrial Revolution. In the second chapter, I discuss how the Napoleonic Wars had a detrimental effect on the technology in Germany through the repeated destruction of apparatus and the financial burdens placed on some of the patrons of the technology. The presence of cheap coal in large quantities in England undoubtedly favoured the technology's development there, as even contemporary German and British commentators observed. In Germany as in France, thermolamps used wood, not coal which was not readily available in significant quantities. In the long run, the gasification of wood was simply not as efficient and interesting as coal. The technology on the 
Continent was then directed towards making charcoal, rather than gas, and gaslight was not in the offing.

Other factors made a difference as well. The presence of many skilled artisans in Britain, especially in the iron industry, seems to have been important. The technology used a lot of iron, as almost the entire apparatus, once it had been transformed from scientific apparatus scale to industrial sizes, was made of iron. Both Boulton \& Watt and later the Gas Light and Coke Company relied heavily on founders as well as skilled craftsman to develop and build gaslight apparatus, suggesting that the iron industry was instrumental in the birth of gaslight technology. While all the early workers in gaslight, whether in Germany, France or England, had access to the same pneumatic chemistry, it was in Britain that the iron industry was the most developed. Historians such as J. U. Nef, and J. R. Harris have argued that artisanal skills ultimately derived from the growing use of coal in Britain were fundamental to the Industrial Revolution. These sorts of arguments seem to hold true in the case of gaslight.

\section{A question of scale}

One further question that has been debated by some historians of gaslight is the relative importance of Murdock and Boulton \& Watt on one hand, and Winsor and the Gas Light and Coke Company on the other. Boulton \& Watt took Murdock's basic prototype, and from 1802 to 1809 developed it and scaled it up into working system in a number of textile mills. They did not, however, give the technology its ultimate, 
dominant form, which was as a network utility, and Boulton \& Watt lost interest and effectively abandoned the technology by 1812 .

Malcom Falkus, in comparing the relative contributions of the two camps, took an extreme position and concluded that Boulton \& Watt were dispensable from the story: 'Had Murdock not experimented with gas, Winsor would still have witnessed Lebon's demonstrations in Paris and would have tried to promote gaslighting in England. ${ }^{16}$ Falkus was countering the heroic model present in most histories that gives pride of place to Murdock and Boulton \& Watt. John Griffith, Murdock's biographer, disagreed with this assessment, arguing that 'without William's years of painstaking research and development on effective and economical gas-making apparatus, and without his solid practical achievements in factory lighting, other engineers would not have refined gas production so quickly, nor would the necessary capital have been attracted'. ${ }^{17}$

What then was Boulton \& Watt's contribution to the development of the technology? Were they really as superfluous as Falkus suggests? In chapter three, through a close examination of what Boulton \& Watt did, I show that there are three ways in which their work was important. First, in their collaboration with George Augustus Lee, a textile mill owner, they gave an effective proof of concept to the general public. The broader public came to learn about the technology and believe in its viability first because of Boulton \& Watt's prestige, and more importantly later on when the Royal Society celebrated Murdock and his invention by awarding him a medal. Ironically, this

\footnotetext{
16 Falkus, "The Early Development of the British Gas Industry, 1790-1815," 233.

17 John Charles Griffiths, The Third Man: the Life and Times of William Murdoch, 1754-1839, the Inventor of Gas Lighting (London: A. Deutsch, 1992), 278.
} 
was done to strike a blow against Boulton \& Watt's rivals in the Winsor group, but they effectively helped them by bringing the technology to prominent public notice decorated with the approbation of the country's leading scientific society. The second way Boulton \& Watt are important is that they made the first steps in expanding the apparatus up from a laboratory prototype to an industrial pilot plant, and in the process identified many and solved some problems that became apparent during the scaling exercise. Many of these solutions were later adopted by the gas industry as a whole. It was their technology, not Winsor's comparatively paltry and impractical efforts, that formed the foundations of later developments. Third, Boulton \& Watt and their customers gave experience in gas matters to a host of tradesmen, contractors, and engineers, many of whom would become important in gas industry. The most famous of these Boulton \& Watt inspired gas engineers was Samuel Clegg, but he was by no means the only one. Many skilled artisans such as the iron founder Josiah Pemberton were suppliers to Boulton \& Watt before going into the gaslight business themselves. Many unnamed skilled artisans were also recruited by the Gas Light and Coke Company from Manchester where a number of Boulton \& Watt's customers were located.

I believe therefore that Falkus was wrong in his assessment of the importance of Boulton \& Watt, but his point is, however, well taken. The emphasis given to specific individuals, such as Murdock and Samuel Clegg in histories of gaslight can obscure the importance of others in the technology's development. My research indicates that people like Henry Creighton, another Boulton \& Watt engineer, and Richard Leadbetter, a supervisor at the Gas Light and Coke Company, made many important contributions to the technology, but Leadbetter in particular has only been mentioned by Stirling 
Everard, the company's official historian. The neglect is understandable: Leadbetter wrote no books, took out no patents, was mentioned in no contemporary publications, and can only be known through the company's minute books.

\section{A gas network}

Falkus made another important observation in his paper, which is that Winsor and the Gas Light and Coke promoted a utility model for gas supply, ${ }^{18}$ with gas being generated at a central plant and piped under the streets to shops, homes, and street lamps for consumption. This model is in contrast with the individual installations that Boulton \& Watt and others had been promoting up until then. That they were able to do this successfully was the Gas Light and Coke Company's most important achievement. ${ }^{19}$ The way they came to this idea and it successful implementation was not direct, however. In chapter four, I detail how Winsor initially was thinking in terms of distillation processes, just as Lebon had been before him, and only later placed greater emphasis on gaslight. The later move to an exclusively utility model for gaslight was actually the result of a negotiated compromise between Boulton \& Watt and Winsor's promoters. Had Boulton \& Watt not resisted Winsor's efforts so fiercely, the utility model would have been a smaller part of the new gas company's mandate. With Boulton \& Watt's resistance, the Gas Light and Coke Company ceded all rights to manufacture apparatus, and focused its efforts on being a gas utility. Winsor's true achievement was

\footnotetext{
18 I use the word anachronistically, as it was really at the beginning of the twentieth century that it acquired a meaning referring to this model of company.

19 Falkus, "The Early Development of the British Gas Industry, 1790-1815," 228.
} 
that he had the energy to motivate an influential and wealthy group of backers to form a large joint-stock gaslight company.

Once the utility model had been settled on through a somewhat tortuous process, its promoters tried to implement it. This final stage of growth into a mature industry took place from 1812 to 1820 and is outlined in chapter five. Traditional histories of the period tend to focus on the many new and sometime quite different inventions in gaslight apparatus, such as Clegg's rotary retort. Some of these new inventions, including the gas meter, were indeed very important. But the process of becoming a large scale utility occurred at many levels, and not simply with a few new inventions. In Networks of Power, Thomas Hughes described how the electrical network was shaped by Thomas Edison and others into a large, stable structure not only by technological development, but also by creating links with and ensconcing the new technology into the political and social environments it which had to function. ${ }^{20}$ A similar process also took place with gas in these years in London, as the gas network developed technologically, socially, and politically. Gaslight's system builders were not, however, quite as effective as Edison was, at least initially. Perhaps this was partly because, unlike Edison, they did not have an existing system to use as a model.

Technologically, gaslight's development involved refining the means of generating, purifying, and distributing gas. These included a whole host of inventions and procedures, most of which were developed slowly over the years, rather than in a single

\footnotetext{
20 See also Hughes, "The evolution of large technological systems."
} 
stroke. In the end, the network became more robust in terms of even supply and pressure.

The company had to work on the human elements as well. It found that its customers used gas in ways very different than what it expected. Customers quite naturally saw gas as a substitute for the oil lamps and candles it was replacing, and burned gas whenever they pleased. The company, however, could not deliver a constant supply of gas and burning in off hours caused it no end of supply problems. The resulting clash of expectations led the company to institute an escalating series of control mechanisms, both technological and procedural, to get its domestic users especially to conform to its idea of how to use gas. This conflict was important in determining various aspects of how the system functioned, such as the use of inspectors. The control of gas use, however, was not the only consideration for the company in determining how it treated its customers. Large customers, especially important public buildings sometimes came in for very different treatment than smaller users because the company's concern for its public image trumped its willingness to enter into a public dispute by cutting off a delinquent public building.

The large scale of the new gas utilities also brought with it some problems that threatened to destabilize the industry. Purifying large quantities of gas of sulphur by using lime generated a constant stream of spent lime and sulphuric acid which the companies had little inclination to dispose of in any way other than dumping it into the nearest watercourse. This soon led to some very irate (and in some case sick) neighbours and lawsuits. The gas industry had a serious pollution problem for decades 
that caused a political reaction and eventually legislation that threatened to cripple its ability to function.

Those affected by pollution were not the only source of opposition to the rising gas industry. The whale oil interests also fought a battle against the new technology that threatened to displace the existing dominant forms of illumination. They did so at first by charges of danger in the press and publications, and then by reinventing themselves with the introduction of oil gas. The battle raged for over a decade, but coal gas was victorious in the end.

Similarly, Alfred Chandler has looked at how the technology that underpinned the railway companies of the second half of the nineteenth century brought about changes in corporate structure due to the demands of co-ordinating a large network. He argued that the invisible market forces that organized the economy had to be replaced with managers within the large new firms growing in the US. While he has been criticized for his determinism and for the various factors he chose to pass over, such as politics, his overall point has generally been accepted, and most criticisms have concerned the details and nuances of his thesis, rather than attempting a complete rebuttal. In the same vein, the gas industry offers a possible nuance to Chandler's thesis, and that it that they were companies before the railways that needed somewhat more developed corporate structures because of their underlying technology. The gas companies that grew in the 1810 s required co-ordination on level that, while not reaching that of the railways a few decades later, was nevertheless greater than the other companies of the period. 


\section{A mature technology}

By 1820 , the new technology had matured into a large industry in England with significant momentum. From there, it was transferred back to the continent. For much of the 1810s, continental publications reported on the developments in gaslight taking place in England. This produced some emulation, such as when Winsor tried to found a company in Paris in 1817, but these either failed, as with Winsor, or remained small. In 1820, the situation changed. A new company was established in Paris and hired an English gas engineer. The industry was there to stay. The story in Germany also featured technology transfer from England, but in this case, it was English investors led by Sir William Congreve who founded the Imperial Continental Gas Association to establish gas utilities in Europe. By 1823, they had set up in Hannover, bringing their experience and technology with them. Gaslight had matured with so much momentum that it flourished in all of Europe over the next years. 


\section{Chapter 1: \\ The roots of gaslight in pneumatic chemistry}

1.1 Introduction 2

1.2 The Development of Pneumatic Chemistry 9

1.3 Alessandro Volta: Marsh gas and the Inflammable Air Lamps 28

$\begin{array}{ll}1.4 \text { Volta's instruments } & 37\end{array}$

1.5 Carbonated Hydrogen I 1777-1785 50

$\begin{array}{ll}1.6 \text { Ballooning } & 64\end{array}$

1.7 Carbonated hydrogen II 1785-1800 70

1.8 The Gasometer $\quad 82$

$\begin{array}{ll}1.9 \text { Sulphuretted Hydrogen } & 88\end{array}$

$\begin{array}{ll}1.10 \text { Conclusion } & 90\end{array}$

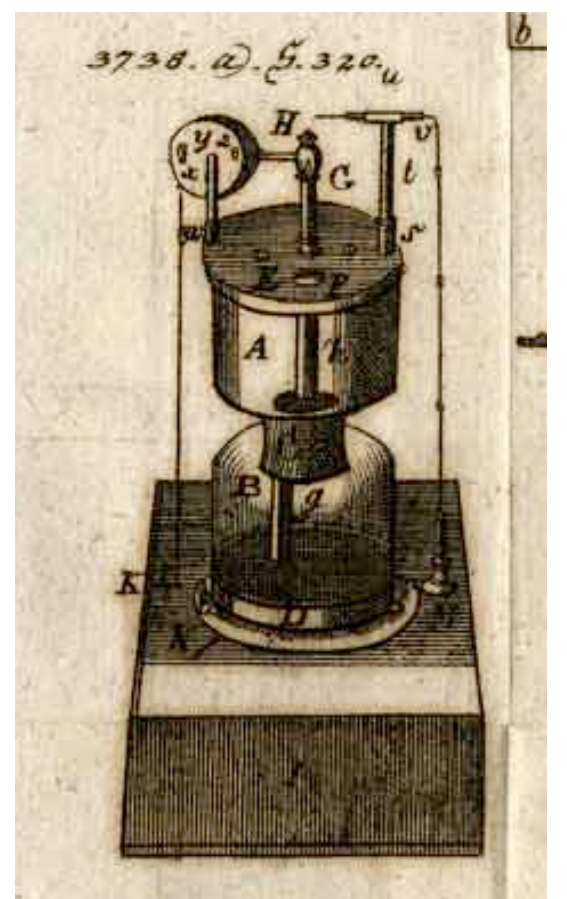

Figure 1.1 An inflammable air lamp, from the Oekonomische-

Technologische Encyclopädie (1793), vol. 59, plate 19 


\section{Chapter 1: \\ The Roots of Gaslight in Pneumatic Chemistry}

\subsection{Introduction}

That the roots of gaslight technology are found in the pneumatic chemistry of the eighteenth century is of particular importance for a long-standing debate among historians of the Industrial Revolution concerning what the technologies of the period owed to science. Taking inspiration from T. S. Ashton who remarked that some growth in industrial production in this period was derived from new scientific knowledge, ${ }^{1} \mathrm{~A}$. E. Musson and Eric Robinson argued in the 1960s that there was a 'fruitful ... collaboration between science and technology during the Industrial Revolution. Contrary to longaccepted ideas, the latter was not simply a product of illiterate practical craftsmen, devoid of scientific training.'2 In addition to their own studies on chlorine bleaching, dyeing, alkali production, and other technologies, they pointed to the work of historians such as Archibald and Nan Clow in regard to chemical industries which were claimed to be based on science. The Clows, in The Chemical Revolution (1952), had set themselves the task of of reinterpreting 'what we already know of the history of chemical manufacture, and of such industries as made use of chemical knowledge during this period, in their relation to advancing theoretical knowledge'.3

1 T. S. Ashton, The Industrial Revolution, 1760-1830, 1st revised ed. (New York: Oxford University Press, 1964), 56.

${ }^{2}$ A. E. Musson and Eric Robinson, Science and technology in the Industrial Revolution (Toronto: University of Toronto Press, 1969), 7.

${ }^{3}$ Archibald Clow and Nan L. Clow, The Chemical Revolution; a Contribution to Social Technology (Freeport: N.Y., Books for Libraries Press, 1970), xii. 
Not all historians, however, agreed that they had succeeded. Charles C. Gillispie wrote two articles not long after the Clows' work came out to refute their broader claims, arguing that 'it proves extraordinarily difficult to trace the course of any significant theoretical concept from abstract formulation to actual use in industrial operations.' In regard to Chemical Revolution in particular, Gillispie stated that 'although the chemical industry was no doubt closer to science than any other, their discussion does not suffer in the slightest from the fact that its references to the revolution in theoretical chemistry are fleeting - to have brought this into an account of Scottish industry would have been to introduce an extraneous element.'4 David Landes rejected the thesis as well, writing that 'in spite of some efforts to tie the Industrial Revolution to the Scientific Revolution ... the link would seem to have been an extremely diffuse one. ${ }^{5}$ Landes allowed that perhaps a link existed at the level of interest in material realities or the systematization of empirical searching, but not at the theoretical level. If anything, science learned from technology, as happened with thermodynamics and the steam engine.

In 1974, A. Rupert Hall wrote a strong rebuttal of the Musson and Robinson thesis of a direct link from theoretical science to technological development, one from which the linear model as it is sometimes called has not really recovered. Hall argued that despite all the rhetoric and attempts of eighteenth century scientists and government official to find practical applications of sciences, the results were fleeting. The only 'hints' from science that were applied by inventors were in chlorine bleaching, the

\footnotetext{
${ }^{4}$ Charles C. Gillispie, "The Natural History of Industry," Isis 48, no. 4 (1957): 399. The first article was a case study: Charles C. Gillispie, "The Discovery of the Leblanc Process," Isis 48, no. 2 (1957).

5 David S. Landes, The unbound Prometheus : technological change and industrial development in Western Europe from 1750 to the present, 2nd ed. (Cambridge, New York: Cambridge University Press, 2003), 61.
} 
manufacture of soda, and the steam engine. But even in these cases, the role of science was not that important, and other factors dominate, leading Hall to conclude that 'if, then, the application of science consisted in exploiting direct suggestion concerning utility coming from scientists themselves, its role in the Industrial Revolution would seem to be rather trivial. ${ }^{6}$ Like Landes, he granted the possibility of a link on the methodological level, 'without presupposing the injection of important elements of abstract theory, or of pure scientific discovery. ${ }^{7}$

More recently, the debate has moved to a different level, with Margaret Jacob and Larry Stewart framing the link on a cultural plane. ${ }^{8}$ They argued that it was in Britain in particular that a culture formed in the wake of the Scientific Revolution that was particularly conducive to technological development. This 'culture of practical science' as Jacob calls it was set in motion by the Newtonian mechanical world view that diffused throughout British society, through the tenuous and permeable boundaries that separated natural philosophy from the practical arts and engineering. However, as with Musson and Robinson before them, Stewart and Jacob have not been the final word on the subject. There are many historians who believe that however scientific the culture surrounding the practical men of the Industrial Revolution might have been, there is still

\footnotetext{
${ }^{6}$ A. Rupert Hall, "What did the Industrial Revolution in Britain owe to Science?," in Historical perspectives : studies in English thought and society, in honour of J. H. Plumb, ed. Neil McKendrick (London: Europa, 1974), 141.

7 Ibid., 145.

8 Margaret C. Jacob, The cultural meaning of the scientific revolution, 1st ed. (Philadelphia: Temple University Press, 1988). Margaret C. Jacob, Scientific culture and the making of the industrial West (Oxford University Press, 1997). Larry Stewart, The rise of public science : rhetoric, technology, and natural philosophy in Newtonian Britain (New York: Cambridge University Press, 1992). Margaret C. Jacob and Larry Stewart, Practical matter : Newton's science in the service of industry and empire, 1687-1851 (Harvard University Press, 2004).
} 
scant evidence for technological and industrial development based on science in this period. As Ulrich Wengeroth recently put it: 'it is hard to find positive evidence for Jacob's assertion. Proximity to science by prominent engineers is demonstrated more by association and mutual respect than by demonstrable input of scientific knowledge. [...] Hall's paradigmatic criticism of Musson and Robinson is still applicable and the issue remains unresolved.' ${ }^{9}$

Joel Mokyr has expanded on Jacob's and Stewart's work, especially in The Gifts of Athena, where he argues that there was an 'Industrial Enlightenment' spread throughout Europe in the eighteenth century. The Baconian and later Enlightenment ideal that science should be at the service of society by helping the development of technology and industry was strong and sustained, and ultimately led to persistent economic growth founded primarily on useful knowledge driving technological development. In his presentation, rather than relying on the terms 'science' and 'technology' which he considers too narrow, Mokyr uses the concept of 'propositional knowledge' and 'prescriptive knowledge', which together make up useful knowledge. Propositional knowledge includes not only natural philosophy, but also 'catalogues of facts, based on experience and experiment rather than on understanding or careful analysis and testing.' 10 Prescriptive knowledge subsumes the knowledge about how to do things. During the Industrial Enlightenment, the connections between propositional and prescriptive were stronger than ever before, and knowledge passed between them more

\footnotetext{
9 Ulrich Wengenroth, "Science, Technology, and Industry," in From natural philosophy to the sciences : writing the history of nineteenth-century science, ed. David Cahan (Chicago: University of Chicago Press, 2003), 229.

10 Joel Mokyr, "The Intellectual Origins of Modern Economic Growth," The Journal of Economic History 65, no. 2 (2005): 290.
} 
easily than had ever been the case. After 1830, the connections had strengthened to point that the Industrial Revolution ushered an era of sustained growth in useful knowledge which has continued to this day. In regard to the science and technology in the Industrial Revolution debate, Mokyr writes that '[f]ormal and generalized propositional knowledge-what today we would call science-was a factor in the Industrial Revolution primarily through the incidental spillovers from the scientific endeavour on the properties of [prescriptive knowledge]. ${ }^{11}$ By this he means that the societal attitudes towards propositional knowledge shifted to make the development of new knowledge, including prescriptive knowledge, easier. Just as important, it also reduced what Mokyr calls the access costs of information through institutions and communications. Enlightenment projects for the classification and propagation of useful knowledge abounded, not just with the Encyclopédie, but in many other publications and forums for communications. All these created a 'community of knowledge' that reached a critical mass. By expanding the concept of science to useful propositional knowledge, Mokyr evades the problem that Wengenroth has pointed out: actual cases of technological development based on scientific theory in the Industrial Revolution are not very common.

In this chapter and the next, I propose to contribute to this discussion by showing that the roots of technology used for gaslight in the early nineteenth century lie firmly in the pneumatic chemistry of the second half of the eighteenth century. I hope to show how Mokyr's Industrial Enlightenment operated in the birth of the gaslight industry. Not

\footnotetext{
11 Joel Mokyr, The Gifts of Athena: Historical Origins of the Knowledge Economy (Princeton: Princeton University Press, 2002), 35-6.
} 
only does the emergence of the industry display the pan-European characteristics that Mokyr and others, such as Christine MacLeod have pointed out, ${ }^{12}$ but also the relatively easy flow of information throughout Europe, and the Enlightenment ideal of using science for practical ends in action. I also believe that gaslight is a rare Industrial Revolution case where technology can be shown to depend rather heavily on theoretical science, perhaps more so than any other of this period. Gaslight may be the earliest case of a whole new industry born out of theoretical science. By this I do not mean to minimize the role of development work. The third and fifth chapter of this thesis are devoted to it, and there theoretical science plays a much smaller part. I do, however, claim that the gaslight industry was based on prior extensive work in pneumatic chemistry, long before anyone thought of applying it in some industrial application. The concepts, subject matter, experience and laboratory apparatus of pneumatic chemistry provided the basis upon which gaslight was established.

The pneumatic chemistry of the eighteenth century contributed to the broad change in chemistry known as the Chemical Revolution that was primarily centred on Lavoisier's new ideas and reforms, but also included a new awareness of the nature of gases as a third state of matter, many in number, and each with distinct chemical and physical properties. Until the eighteenth century, with the exception of a few isolated cases such as John Mayow, gases were not included in the lists of chemical agents. ${ }^{13}$

\footnotetext{
12 On this point see as well Christine MacLeod, "The European Origins of British technological predominance," in Exceptionalism and industrialisation : Britain and its European rivals, 1688-1815, ed. Leandro Prados de la Escosura (New York: Cambridge University Press, 2004).

13 J. R. Partington, A History of Chemistry (London: Macmillan; New York, St. Martin's Press, 1961), vol 2, 587-613. Trevor Harvey Levere, Transforming matter : a history of chemistry from alchemy to the buckyball (Johns Hopkins University Press, 2001), 51-65.
} 
Spirits, airs and exhalations of all kinds were known, but they were not treated as chemical agents in the same way as solids and liquids, and were generally observed and passed over without much further investigation. Had the interest been present, which in some cases clearly was, no apparatus was available to produce, and especially to separate, contain, measure, manipulate and test gases, all of which are much more difficult tasks to accomplish than with solids and liquid. Inflammable gases constitute no exception to this situation. ${ }^{14}$ The spectacle of ignitable exhalations from mines and marshes were objects of curiosity, and had been seen, described, and written about. The standard histories of gaslight record observations of these inflammable exhalations from the seventeenth century or even earlier, seeing them as distant precursors of gaslight. It is not these observations, however, that provided the foundations of the gas industry, but pneumatic chemistry as it developed in the eighteenth century. It was the knowledge, experience, and apparatus that natural philosophers built up and refined during the eighteenth century that provided the conceptual and physical tools used by the pioneers of gaslight.

In terms of instruments, four pieces of laboratory apparatus stand out: the retort, the pneumatic trough, the inflammable air lighter, and the gasometer. Excepting the retort, which was in any case a constant element in the pneumatic chemists' arsenal, these pieces of apparatus were developed in the course of investigations into pneumatics by chemists concerned with theoretical speculation. Of these, all except the lighter became indispensable elements of the pneumatic chemists' laboratory and were the direct ancestors of technology of the gas industry. The inflammable air lighter was a

\footnotetext{
14 Mayow again is somewhat exceptional, see Partington, A History of Chemistry, vol 2, 594.
} 
scientific instrument that showed the possibility of using inflammable airs for illuminating purposes, as well as demonstrating what their limitations were in this regard.

The concepts of pneumatic chemistry elucidated over the course of the century were just as valuable for the gaslight industry. Knowledge of the existence and properties of inflammable gases, and in particular the heavy inflammable gases which are distilled from coal, were the basis of the nineteenth techniques of manufacturing gas for illumination. Inflammable gases were collected in a small way at the start of the eighteenth century, and by the century's close, chemists were able to produce them in large volumes from many materials, with an understanding of their natures and what distinguished the varieties of inflammable gases. They knew that they were usually mixtures of gases and suspended liquids, and had an idea how to remove the impurities from inflammable gases. The acquisition of this knowledge make up a chapter in the history of eighteenth century pneumatic chemistry.

\subsection{The Development of Pneumatic Chemistry}

Before the seventeenth century, and really until the eighteenth century, air was generally treated either as one of the fundamental elements in the Aristotelian tradition, or in its derivative Paracelsian tradition, excluded from the list of elements altogether, and was for this reason not seen as subject to decomposition. Different kinds of airs were observed, such as those emanating from rotting matter or produced during chemical reactions. They were regarded as modified common air, much in the way that water solutions could be created with the addition of foreign substances into pure water. 
Gases were not understood as distinct chemicals. Even seventeenth century experiments with the air pump, exemplified by the work of Robert Boyle (1627-1691), did not recognize different kinds of gases, but rather dealt with the mechanical properties of gases.

The awareness of the existence and importance of gases, however, was growing at the end of the seventeenth century, based on the work of people like Boyle, Joan Baptista van Helmont (1579-1644), Johann Glauber (1604-1670), and others. Natural philosophers turned their attention to them more frequently and developed pneumatic apparatus to make their research possible. 


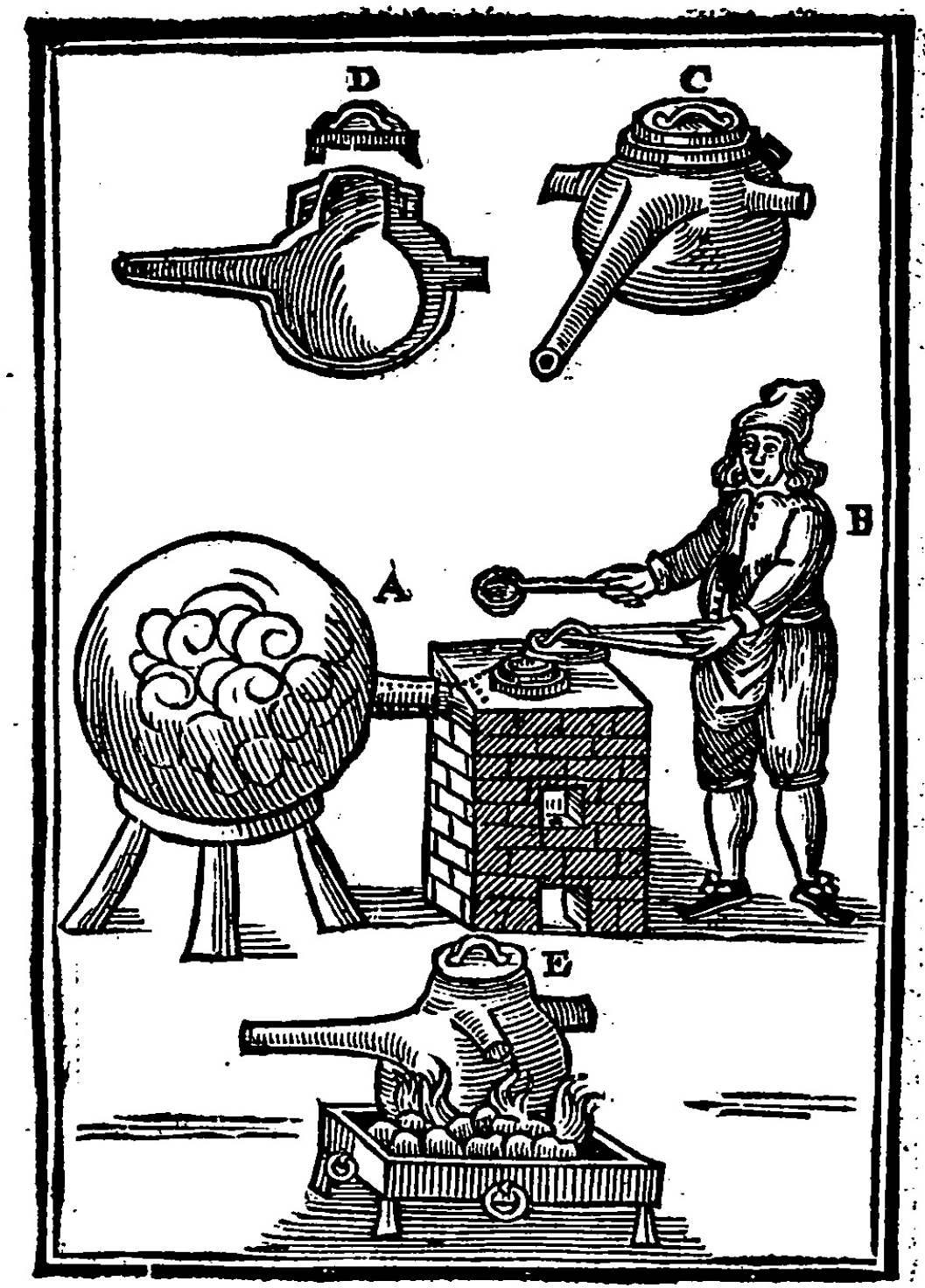

- A. The furnace togcther with the iron diffilling-veffel fnftened into it, whoreunto a tecciver is applyed. B. The diffillor with his left hand taking cff the lid, and with his right cafting in hisprepared matter. C. The cxierasll form of the diftilling veffel. D. The iniernal form of the veffel. 7. Another diftilling veAful, which is not faltened to, a furnace, but only.
I.nd itb upon coals,

Figure 1.2 Retorts, from Johann Glauber. A Description of New Philosophical

Furnaces (1651) 
The earliest item of chemical laboratory apparatus eventually incorporated into the gas plant was the retort. Retorts were closed furnaces which were used to heat materials while avoiding direct contact with flame. The subject materials broke down to varying degrees under the action of the heat in a process called destructive distillation, or more commonly just distillation. Retorts in some form, such as closed crucibles, had long been part of the alchemists' repertory of tools. It was in the seventeenth and especially the eighteenth century with greater interest in the ultimate principles of matter that analytic chemistry and hence distillation became increasingly important, and chemists designed more complex retorts for their analytic experiments. ${ }^{15}$

Although the retort had been used by alchemists for centuries, Johann Glauber (1604-1670) was one of the first chemists to write about it. Glauber was a German who eventually settled in Holland to escape the devastation of the Thirty Years War (16181648). He was not university trained and following a pre-Paraceslsian alchemical tradition. Glauber was interested primarily in practical and medicinal chemistry, as the many references in his treatises to the medicinal properties of materials demonstrate. He wrote extensively and was widely cited in the seventeenth century. Glauber designed and in 1646 publicized a new 'Philosophical Furnace' which allowed for much higher temperatures than previous retorts. The engraving from Furni philosophici shows the new retort in two configurations: one built into a brick furnace with an

\footnotetext{
15 Mi Gyung Kim, "The Analytic Ideal of Chemical Elements: Robert Boyle and the French Didactic Tradition of Chemistry," Science in Context 14, no. 3 (2001): 370. Ferenc Szabadváry, History of analytical chemistry, 1st English ed. (Oxford: New York, Pergamon Press, 1966).
} 
adjoining receptacle to capture the escaping gases, and another free-standing model sitting directly on coals. Since the higher temperatures were more difficult to handlethe retorts cracked more easily unless well-made, and were more prone to leakage they were not practical in all situations, ${ }^{16}$ leaving a place for a simpler glass retorts in many applications. The higher temperatures available through the clay retort, however, allowed Glauber to distil many substances more thoroughly, including coal, ${ }^{17}$ as well as the salts which earned him his greatest fame..$^{18}$ It was Glauber's high temperature retorts with all their variations that were the ancestors of the retorts used in coal distillation experiments. The lower temperature retorts, such as the closed glass ones, remained in use but they are less important in the context of history of gaslight.

\footnotetext{
${ }_{16}$ See, for example, Robert Boyle and Robert Sharrock, Some considerations touching the vsefulnesse of experimental naturall philosophy propos'd in familiar discourses to a friend, by way of invitation to the study of it (Oxford: Printed by Hen. Hall ... for Ric. Davis, 1663), 348.

17 Johann Rudolf Glauber and John French, A description of new philosophical furnaces, or $A$ new art of distilling, divided into five parts. Whereunto is added a description of the tincture of gold, or the true aurum potabile; also, the first part of the mineral work. Set forth and published for the sakes of them that are studious of the truth. By John Rudolph Glauber. Set forth in English, by J.F. D.M (London: Printed by Richard Coats, for Tho: Williams, at the signe of the Bible in Little-Britain, 1651), 101.

18 Robert Siegfried, From elements to atoms: a history of chemical composition, vol. 92, part 4 (Philadelphia: American Philosophical Society, 2002), 37-38.
} 


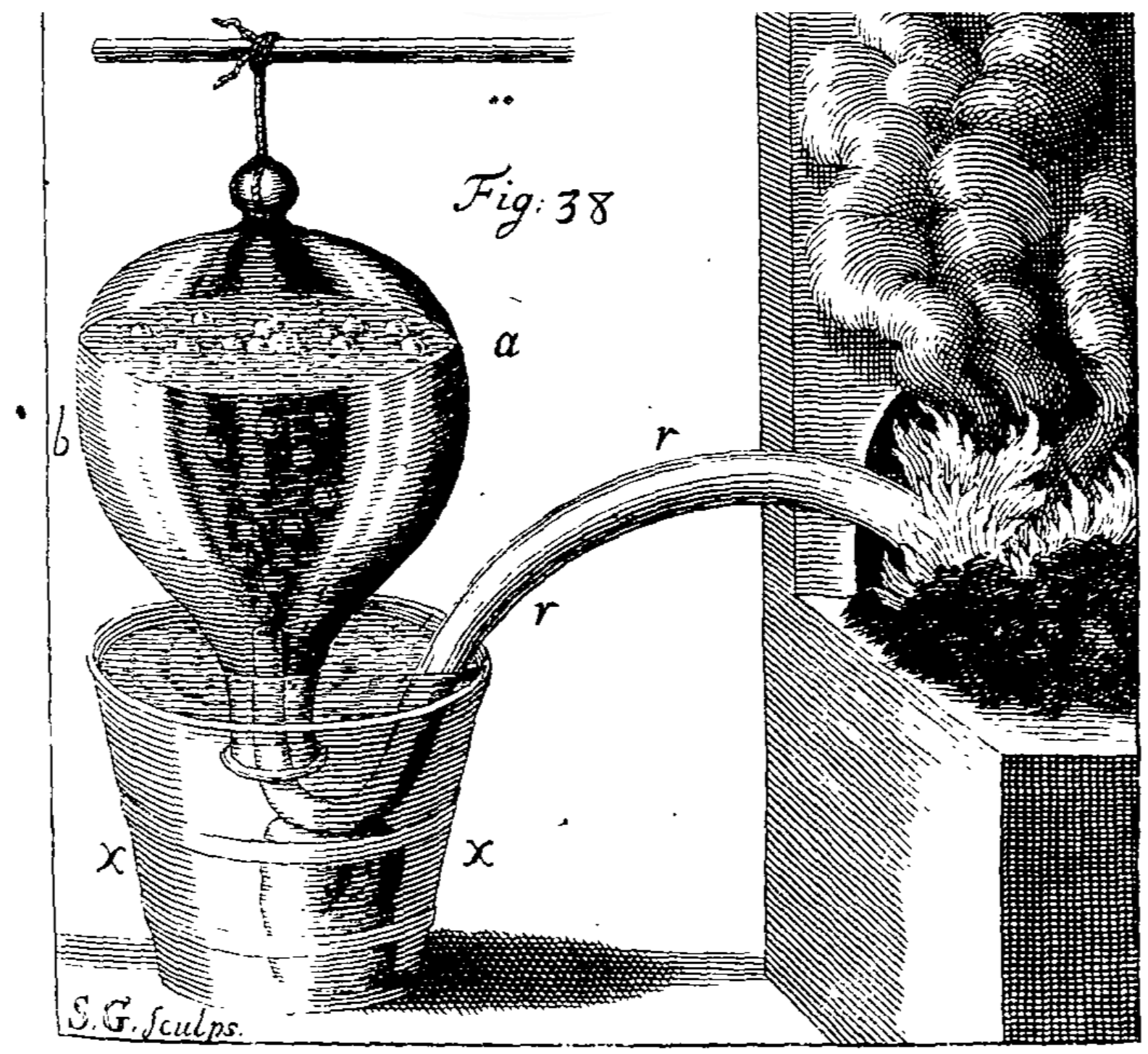

Figure 1.3 A pneumatic trough, from Stephen Hales Vegetable Staticks (1727) 
Stephen Hales (1677-1771) figures importantly in the history of pneumatic chemistry. He was a clergyman who pursued his interest in biology and other subjects as curate in Teddington in Middlesex north of London. He is best known work for his numerous investigations of plant physiology in which he showed the importance of air for plant growth. Over the course of his investigations he made many distillations to ascertain the compositions of various materials. His most important contributions for the history of gas lighting are the invention of the pneumatic trough and his work with producing airs, including inflammable ones.

Hales' pneumatic trough became an invaluable and omnipresent apparatus for later pneumatic chemists. Boyle, Glauber, and others before Hales' time used apparatus in which the gas receptacle was immediately linked to the production site, such as a retort. Since gases were regarded as a form of common air, no particular importance was given to purifying evolved gases, nor to evacuating the receptacle of common air. Hales, however, isolated the vessel receiving and storing gases from the site of production using the pneumatic trough. The trough consisted simply of an airtight container inverted over water and containing water itself, into which gas was bubbled from underneath through the water. Some later incarnations, beginning with those used by Henry Cavendish, would use mercury instead of water since gases are far less soluble in mercury. The pneumatic trough ensured that only the gases entering the water are stored in the readied container, as well as washing the gases of various impurities. Chemists of the later eighteenth century used it to store and identify many 
gases. Renamed the hydraulic main, it eventually found use in gas lighting apparatus as the first purifying step, removing oils and heavy hydrocarbons from the gas and isolating the retorts from the rest of the gas plants.

Hales did not speak about the properties of different kinds of gases, nor did he break from the tradition of common air as the only kind of air. He was more interested in the volumes of gases produced than in their properties. For Hales, the trough served the purpose of washing the airs of foreign matter which somehow reduced its volume with time. As he recount in the Vegetable Staticks (1727), Hales initially used a device similar to Glauber's and Boyle's, where the storage receptacle was in direct communication with the retort where the gases were generated. The receiver contained water underneath the gases, but it served as a volume buffer, being forced out as the gas pressure above it increased. Hales had found to his dismay that the volume of air over the water decreased in days after the conclusion of his experiments. This was of course because the water absorbed some of gases, but Hales thought it was because some 'acid sulphureous fumes' produced with the air 'did resorb and fix the elastick particles'. In order to avoid this, he set up his trough 'so that as the air which was raised in distillation, passed thro' the water up to the top of the receiver [...] a good part of the acid spirit and sulphureous fumes were by this means intercepted and retained in the water'..$^{19}$ The hydraulic main of the later gasworks was then used for the very purpose the trough had been created to serve: washing gases.

\footnotetext{
19 Stephen Hales, Vegetable staticks: or, an account of some statical experiments on the sap in vegetables: being an essay towards a natural history of vegetation. Also, a specimen of an attempt to analyse the air (London: printed for W. and J. Innys, and T. Woodward, 1727), 183. For a complete discussion on Hales' use of the pneumatic trough and its subsequent history, see John Parascandola and Aaron J. Ihde, "History of the Pneumatic Trough," Isis 60, no. 3 (1969).
} 
Hales' second important contribution relevant to the history of gas lighting is his extensive work in producing airs from a wide range of materials. In the Vegetable Staticks and its later editions Hales observed that many materials contained what he called 'fixed air'. ${ }^{20}$ For Hales, fixed air was the air that was in some way fixed or ensconced in a solid, and that could be released by the action of heat or by fermentation. The term was later usually used by Joseph Black to refer to carbon dioxide, but for Hales all air was some sort of common air. Any kind of air released by the action of heat was fixed air. Although Hales was by no means the first to observe the phenomenon of the discharge of fixed airs, the vast number and the wide range of test materials of his experiments demonstrated its existence beyond doubt and brought attention to them in the broader scientific community. Hales is frequently cited by pneumatic chemists of the mid eighteenth century.

Hales also observed that some of these fixed airs were inflammable, such as that from peas:

Nine days after this Air was made, I lifted the inverted mouth of the receiver which contained it, out of the water, and put a lighted candle under it, upon which it instantly flashed: then I immediately immersed the mouth of the receiver in the water, to extinguish the flame. This I repeated 8 or 10 times, and it as often flashed, after which it ceased, all the sulphureous spirit being burnt. It was the same with Air of distilled Oystershell and Amber, and with new distilled Air of Pease and Bees-wax. I found it the same also with another like quantity of Air of Pease; notwithstanding I washed that Air no less than

20 See Hales, Vegetable staticks, 165. 
eleven times, by pouring it so often under water, upwards, out of the containing vessel, into another inverted receiver full of water. ${ }^{21}$

It is not clear whether Hales made this same experiment with air from coals, but he does refer to question 10 from Newton's Opticks (1704) where Newton describes how 'in distilling hot Spirits ... the Vapour which ascends out of the Still will take fire at the Flame of a Candle, and turn into Flame'22 and lists 'fossil Coals' among the materials which produce this inflammable smoke.

The term fixed air was redefined by Joseph Black (1728-1799), who used it to denote what is now known as carbon dioxide. ${ }^{23}$ Born in France to Irish émigrés, Black was a medical doctor who studied at the University of Glasgow and later Edinburgh before taking a teaching position there which he held to the end of his life. During his studies, Black became interested in the medicinal uses of alkaline substances such as lime (calcium carbonate $\mathrm{CaCO}_{3}$ ) and magnesia alba (magnesium bicarbonate $\mathrm{Mg}\left(\mathrm{HCO}_{3}\right)_{2}$ or carbonate $\left.\mathrm{MgCO}_{3}\right)$ for curing stones and other ailments. He pursued this interest during his doctoral studies and afterwards, during which he observed that the heating magnesia alba produced a solid he called magnesia usta (magnesium oxide $\mathrm{MgO})$. This new solid generated the same salts when mixed with acids as magnesia alba but without effervescence. He then observed that when he distilled magnesia alba

\footnotetext{
$21 \mathrm{lbid}$., 170-1. It is often stated that Hales produced inflammable air from coal, and it is very likely that he knew the airs he produced from coal were inflammable, but I have not been able to find a specific mention of this.

22 Isaac Newton, Opticks, or, A treatise of the reflexions, refractions, inflexions and colours of light also two treatises of the species and magnitude of curvilinear figures (London: Printed for S. Smith and B. Walford, 1704), 134. Hales, Vegetable staticks, 280-1.

23 See Henry Guerlac, "Joseph Black and Fixed Air: a bicentenary retrospective, with some new or little known material," Isis 48, no. 2 (1957). for a description of Black's discovery of fixed air.
} 
in a retort, it lost weight. This puzzled him until he made the connection with Hales' demonstration that many substances gave off fixed air when distilled. He then made the final link between the air lost in distillation and that given off in effervescence when magnesia alba was neutralized with acids, which he identified with the fixed air Hales had spoken of. He repeated his experiments on lime and showed that the phenomenon repeated itself: burnt lime or quicklime (calcium oxide $\mathrm{CaO}$ ) weighed less than lime but neutralized an equal quantity of acid without effervescence. Other experiments followed to explore the nature of causticity and alkalinity which was his primary interest.

Unlike Hales, Black identified fixed air as different in kind from common air. In the one experiment touching on this point, he created vacuums over lime water (aqueous calcium hydroxide $\mathrm{Ca}(\mathrm{OH})_{2}$ ) and ordinary water and observed the airs which formed above each. Both liquids produced seemingly equal quantities of gas, but since he knew that quicklime did not absorb ordinary air, he reasoned that the air it released into the vacuum had to be another kind of air:

Quick-lime therefore does not attract air when in its most ordinary form, but is capable of being joined to one particular species only, which is dispersed thro' the atmosphere, either in the shape of an exceedingly subtil powder, or more probably in that of an elastic fluid. To this I have given the name of fixed air, and perhaps very improperly; but I thought it better to use a word already familiar in philosophy, than to invent a new name, before we be more fully acquainted with the nature and properties of this substance which will probably be the subject of my further inquiry. ${ }^{24}$

\footnotetext{
24 Joseph Black, "Experiments upon Magnesia Alba, Quick-Lime, and other Alcaline Substances," Essays and observations, physical and literary of the Philosophical Society of Edinburgh (1756): 198-9., cited in Henry Guerlac, "Joseph Black and Fixed Air: Part II," Isis 48, no. 4 (1957): 451.
} 
He had also observed that this fixed air acted as a weak acid and did not sustain flame. Unfortunately for those who might want clarity in terminology, Black kept the name fixed air, but he was now using it in a different, more narrow sense than Hales. He had also broken with the Aristotelian tradition of air as a fundamental element by identifying fixed air as a different species altogether. He explored the nature of fixed air further and discovered its lethal effects on animals, and that it was identical to the gas produced during fermentation. He conclusively demonstrated that it had chemical properties distinct from common air and that it was derived from calcareous earth. He also noted, as the quote above indicates, that lime water reacts with fixed air by turning a milky white. ${ }^{25}$ This became the chemists' standard test for detecting the presence of fixed air in experimentation, and was used in the gaslight industry to purify coal-gas of carbon dioxide.

Although not the first to realize the importance of Black's work in identifying a chemically distinct kind of air, Henry Cavendish (1731-1810) was among those who built on Black's work by identifying other kinds of gases distinct from common air. Cavendish was the son of an English Lord and politician, Charles Cavendish, who had himself devoted his energies later on in life to experimentation in natural philosophy. Being reclusive and never married, Cavendish dedicated himself to natural philosophy, showing himself to be a master experimenter by, among many other feats, his determination of the value of the universal gravitational constant and his experiments in pneumatic chemistry. He studied at Cambridge, and carried out his research at his

\footnotetext{
${ }^{25}$ For a thorough history of Black's discoveries, see Guerlac, "Joseph Black and Fixed Air: a bicentenary retrospective, with some new or little known material." and Guerlac, "Joseph Black and Fixed Air: Part II."
} 
home laboratory in London and at another laboratory at his country estate. Although he published relatively few papers in his lifetime, he was a prolific and ingenious researcher. This came to light more fully after James Clerk Maxwell had some of his notebooks published in 1879 .

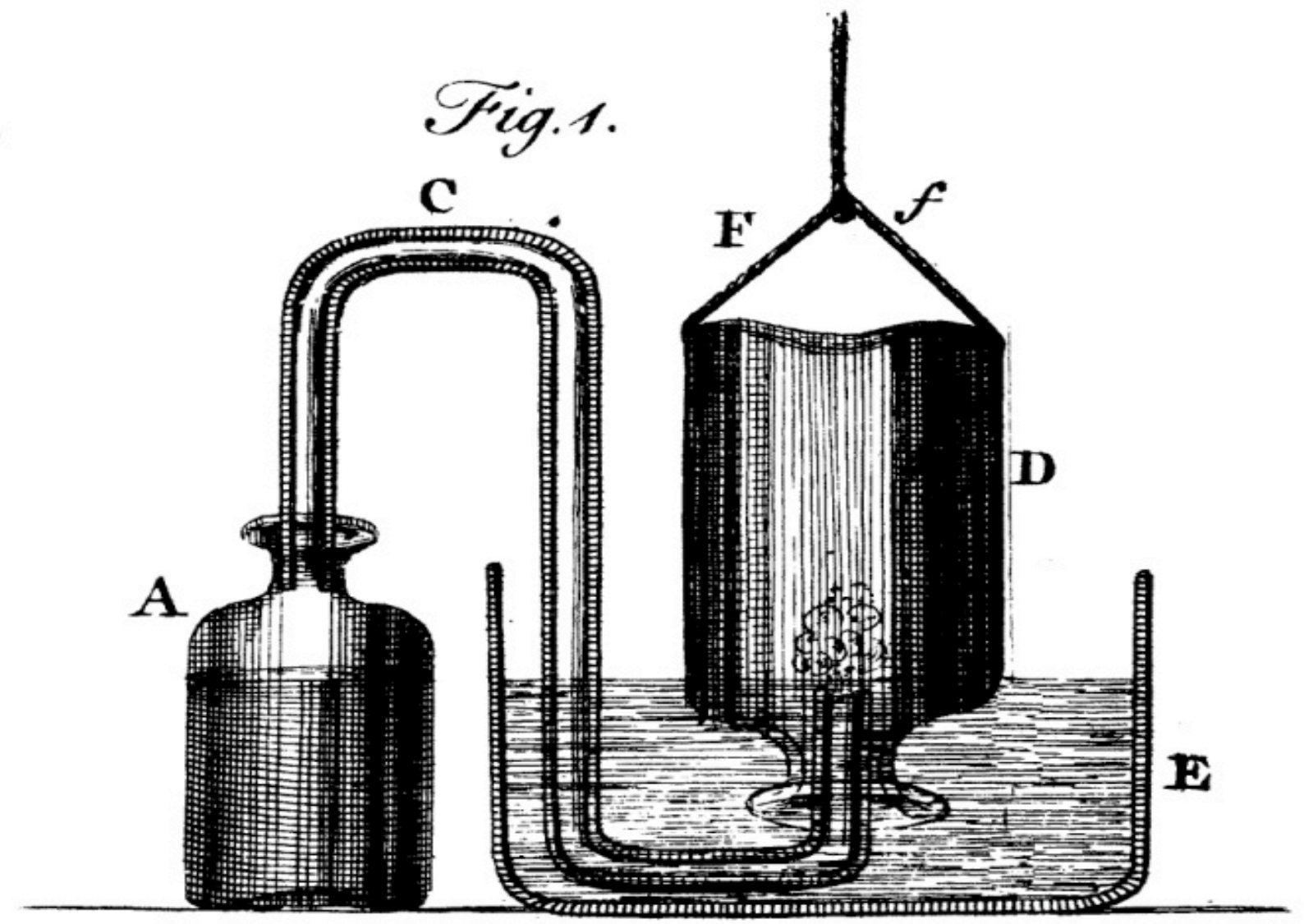

Figure 1.4 Pneumatic apparatus from Cavendish, "Three Papers on Factitious Air" Phil. Tran. 56 (1766): 141-84. 
Cavendish's key publications for the history of gaslight are his famous three 1766 papers in the Philosophical Transactions the Royal Society. ${ }^{26}$ In them Cavendish reintroduced the term factitious air ${ }^{27}$ originally coined by Boyle to designate any air which could be released from a given material, to replace the term fixed air which Black had co-opted for carbon dioxide. In the paper Cavendish relates his experiments in producing and identifying the properties of other airs distinct from common air, including inflammable air. He was not, however, the discoverer of inflammable exhalations of metals dissolved by acids. As early as 1672, Robert Boyle had dissolved iron in acid to produce an inflammable air. ${ }^{28}$ By the eighteenth century, natural philosophers were well acquainted with this occurrence as this quote from the Philosophical Transactions of 1735 reveals:

It is very well known to every one versed in Chemical Affairs, that most Metals emit great Quantities of sulphureous Vapours, during the Effervescence which they undergo in the Solutions in their respective Mensura, or Solvents. Of these Fumes Iron emits a great

\footnotetext{
26 Henry Cavendish, "Three Papers, Containing Experiments on Factitious Air, by the Hon. Henry Cavendish, F. R. S," Philosophical Transactions (1683-1775) 56 (1766).

27 The term 'factitious air' was used before Cavendish. See for example John Maud and James Luther, "A Chemical Experiment by Mr. John Maud, Serving to Illustrate the Phoenomenon of the Inflammable Air Shewn to the Royal Society by Sir James Lowther, Bart as Described in Philosoph. Transact. Numb. 429," Philosophical Transactions (1683-1775) 39 (1736): 283.

28 Robert Boyle, Tracts written by the Honourable Robert Boyle containing New experiments, touching the relation betwixt flame and air, and about explosions, an hydrostatical discourse occasion'd by some objections of Dr. Henry More against some explications of new experiments made by the author of these tracts : to which is annex't, An hydrostatical letter, dilucidating an experiment about a way of weighing water in water, new experiments, of the positive or relative levity of bodies under water, of the air's spring on bodies under water, about the differing pressure of heavy solids and fluids (London: Printed for Richard Davis, book-seller in Oxon, 1672), 63-66.
} 
Quantity whilst it is dissolving in Oil of Vitriol, which are very inflammable, and not easily to be condes'd. ${ }^{29}$

Cavendish produced inflammable air by dissolving zinc, iron, and tin in vitriolic acid (sulphuric acid) or spirit of salt (hydrochloric acid). He noticed that it was lighter than common air and that all three metals seemed to give the same air. He further observed that although nitrous acid readily dissolved these metals and produced air, the air was not the same as with vitriolic acid: it was Black's non-inflammable fixed air. ${ }^{30}$ Cavendish, in the third and final part of the paper looked at air from fermentation and putrefaction, and noted that the airs from the putrefaction of gravy broth and meat were inflammable. While he observed that this air was not as explosive as the inflammable air from zinc, ${ }^{31}$ he concluded that 'On the whole it seems that this sort of inflammable air is nearly of the same kind as that produced from metals. It should seem, however, either to be not exactly the same, or else to be mixed with some air heavier than it, and which has in some degree the property of extinguishing flame, like fixed air'. ${ }^{32}$

Cavendish undertook further investigations into inflammable gases from the distillation of organic substances after he published these papers. He wrote a fourth part, probably in 1767, which however he never published. ${ }^{33}$ In this fourth paper,

\footnotetext{
29 Maud and Luther, "A Chemical Experiment by Mr. John Maud," 283. Examples of similar experiments before Cavendish can be multiplied.

30 Cavendish, "Three Papers on Factitious Air," 145.

31 Ibid.: 182.

32 Ibid.: 183.

33 Henry Cavendish, "Experiments on Factitious Air Part IV: Containing experiments on the air produced from vegetable and animal substances by distillation," in The scientific papers of the Honourable Henry Cavendish vol 2, ed. James Clerk Maxwell, Joseph Larmor, and T. E. Thorpe (Cambridge: The University Press, 1921).
} 
Cavendish recounts how after passing airs made by distillation of wood, coal, and other animal and vegetable substances through 'sope leys' (lime water) ${ }^{34}$ to remove the fixed air, he obtained an inflammable air which had a specific density 6.5 times that of metallic inflammable air. He states that 'I fancy this air must really be of a different kind from that of metals' and that there is a 'considerable resemblance between the air produced by distillation from all animal and vegetable substances'. ${ }^{35}$ Why he never published this paper is not clear. The editors of his unpublished papers suggested he was not satisfied with his results and wanted to further refine his analysis, returning to the subject several times in his experiments. As these distillation gases include carbon monoxide, methane, hydrogen, ethylene and other hydrocarbons in various proportions, achieving consistent results was a serious challenge which he must have wrestled with. Cavendish also came close to identifying carbon monoxide by heating charcoal and separating the carbon dioxide from the carbon monoxide with lime water, but again, did not publish his results. ${ }^{36}$

Joseph Priestley (1733-1804) did more than anyone else to further pneumatic chemistry by identifying 22 new gases and exploring their properties in great detail. Priestley was a Nonconformist preacher who taught for some time at the Warrington Academy, before becoming a pastor in Leeds. He had already been interested in natural philosophy, publishing a book on the history and state of the study of electricity

\footnotetext{
34 See Caspar Lewis William Neumann, The chemical works of Caspar Neumann containing the later discoveries and improvements made in chemistry and the arts depending thereon by William Lewis (London: Printed for W. Johnston, G. Keith, A. Linde, P. Davey, B. Law, T. Field, T. Caslon, and E. Dilly, 1759), 473 footnote $i$.

35 Cavendish, "Experiments on Factitious Air Part IV," 311 and 13.

36 Ibid., 316.
} 
in 1769 , when his curiosity about gases was piqued by the bubbles of fixed air forming in the fermentation vats of a neighbouring brewery. He undertook researches on gases and became acquainted with Cavendish's and Hales' work on pneumatic chemistry. He went on to publish Observations on Different Kinds of Air, first in the Philosophical Transactions of 1772, and then as a book entitled Experiments and Observations on different kinds of Air running through numerous volumes and editions. He received immediate recognition for his work and was awarded the Copley medal by the Royal Society in 1773 . He was to have tremendous influence on chemists throughout Europe as is shown by the nearly ubiquitous citations to his works in texts of pneumatic and more general chemistry during these decades.

In 1772, Priestley took the post of librarian and private tutor in the household of the politically radical Lord Shelburne, a position which afford him greater leisure for his pneumatic researches and these proved to be his most productive years as a chemist. In 1780 he moved to Birmingham, resuming his work as a pastor, but now as a Unitarian. His own politically radical views - he was a supporter first of the American and then the French Revolutions - clashed with those of an increasingly conservative England, a dangerous situation which eventually exploded when a reactionary mob sacked his laboratory and home in 1791 . Fearing for his life, he first fled to London, and then on to the United States where he passed his last years in increasing isolation from contemporary science, fighting a rearguard action by defending phlogiston theory against Lavoisier's new chemistry. Priestley's work in pneumatic chemistry before his flight was the spark that set off a frenzy of interest in the subject of gases and was an inflection point in the development of pneumatic chemistry. He clearly captured the 
imaginations of the chemists of the period and it was this flurry of activity that led to further developments in the knowledge and apparatus of pneumatic chemistry.

Despite Priestley's interest in inflammable airs, he had not realized at this time as Cavendish had that there were different kinds of inflammable air, or if he had, he did not consider it in his first publications. In the 1772 edition of Observations Priestley makes no distinction between the different kinds of inflammable air, although he was clearly aware that metals dissolved in acids were not the only sources: 'There is not, I believe, any vegetable or animal substance whatever, nor any mineral substance, that is inflammable, but what will yield great plenty of inflammable air, when they are treated in this manner, and urged with a strong heat'. ${ }^{37}$ It is certain that Priestley found out about other kinds of inflammable air at the latest in 1776 from Alessandro Volta, who had hinted at it in a letter to Priestley, ${ }^{38}$ and later sent him a copy of his 1777 book on marsh gas. ${ }^{39}$ Priestley included Volta's 1776 letter in an appendix to the 1777 edition of Experiments and Observations. 40 It took some time for Priestley to be convinced that these really were distinct species of inflammable airs, and he continued to use the singular form of the noun in his writings, as he always believed it was phlogiston,

37 Joseph Priestley and William Hey, "Observations on Different Kinds of Air. By Joseph Priestley, L L. D. F. R. S," Philosophical Transactions (1683-1775) 62 (1772): 171.

38 Volta to Priestley 1776/12/10, Alessandro Volta, Epistolario di Alessandro Volta (Bologna: N. Zanichelli, 1949), vol 1, 139. and Lettera quinta al padre Carlo Giuseppe Campi 1777/01/08 Volta, Le opere di Alessandro Volta (Milano: Hoepli, 1918), vol 6, 61-2. Volta's letter to Priestley is dated December 10, 1776, before many of the letters to Campi. In the third letter to Campi, dated November 26, 1776, Volta is quite clear about the differences between metallic inflammable air and inflammable air from animal and vegetable sources.

39 Priestley acknowledges receipt in a letter dated July 6, 1777. Volta, Espistolario, vol 1, 170.

40 Priestley made no mention of differences among inflammable gases, other than flame colour. Volta informed Priestley in a letter dated 10 December 1776. See Joseph Priestley, Experiments and observations on different kinds of air Vol.III. By Joseph Priestley (printed for J. Johnson, 1777), 381-83. 
possibly combined with something else such as an acid. A 1779 volume of Observations does dwell on the different kinds of inflammable air such as from metals and acids, from oil of turpentine, and other sources. By that point, Priestley acknowledged that these air could have different properties, and might even have different composition, but made made no strong statements in this matter. ${ }^{41}$

Priestley's early silence on the matter reflects his suspicion that the kinds of inflammable air were merely a mixture of the inflammable air obtained from metals (hydrogen) - probably pure phlogiston-mixed with other airs, and he had good cause to be cautious like Cavendish before him. Hydrogen mixed with carbon dioxide burns blue, ${ }^{42}$ as do carbon monoxide and methane on their own to varying degrees. Besides, it would have been clear after a little experimentation to someone of Priestley's abilities that marsh gases and distillation gases were extremely variable cocktails, comprising of carbon dioxide, carbon monoxide, methane, hydrogen, as well as heavy hydrocarbons and probably hydrogen sulphide and perhaps ammonium compounds. The constituents varied with the substance distilled, the temperatures applied, the material of the retort, and the duration of the distillation. The same material, if heated slowly, would give more fixed air than when heated rapidly. In addition to this, the mixing of gases could also account for the increased specific density of marsh gas as compared to hydrogen. Priestley's hesitance in accepting the new kind of inflammable air can then be seen as caution in the face of what was clearly a difficult problem of isolating gases.

\footnotetext{
41 Priestley, Experiments and observations relating to various branches of natural philosophy with a continuation of the observations on air. By Joseph Priestley (peinted [sic] for J. Johnson, 1779), 360-83. See p. 377 in particular for Priestley's views on the nature of inflammable air.

42 Priestley, Experiments and observations on different kinds of air By Joseph Priestley, The third edition, correct ed. (printed for J. Johnson, no.72, St. Paul's Church-Yard, 1781), 337.
} 
The story of pneumatic chemistry now moves to the continent. Pneumatic chemistry had been an English phenomenon to this point, but when Joseph Black's work was translated into French in 1772, the Parisian chemists, and soon thereafter other chemists in the rest of Europe became caught up with pneumatic chemistry. ${ }^{43}$ In 1774 Lavoisier published his Opuscules physiques et chymiques which included a history of pneumatic chemistry, and Priestley's Experiments was partially translated into French in 1777 , and fully in 1780.44

\subsection{Alessandro Volta: Marsh gas and the Inflammable Air Lamps}

Alessandro Volta (1745-1827) was born in Como, Italy, and was raised in a devout Catholic family. Unlike most of his relatives, he did not want to enter orders and became interested in natural philosophy after reading Priestley's book on electricity at the age of 14 . In a daring move, he wrote Priestley in 1772 at the age of 18 about his interests and work in electricity, ${ }^{45}$ to which Priestley responded amiably and encouragingly. ${ }^{46}$ Volta pursued his love for natural philosophy and became a teacher of physics at the local school in 1774 , the same year he improved the electrophorus, a device for storing electricity and that earned him some renown. Volta continued his correspondence with Priestley, and was exposed to Priestley's Observations in 1774, a work that deeply impressed him and convinced him that a great future lay in store for

\footnotetext{
43 Mi Gyung Kim, "'Public' Science: Hydrogen Balloons and Lavoisier's Decomposition of Water," Annals of Science 63, no. 3 (2006): 296.

44 Ibid.: 297.

45 Volta to Priestley 1772/03/14, Volta, Espistolario, vol 1, 59.

46 Priestley to Volta 1772/03/14, Ibid., vol 1, 59-60.
} 
pneumatic chemistry: 'the chemistry of air will set a great revolution in Natural science', ${ }^{47}$ He decided to pursue the subject in earnest himself in $1776,{ }^{48}$ although he had already been interested in eudiometry as early as $1775^{49}$ and had experimented with airs in 1774.50

Volta's work in pneumatic chemistry at this time concentrated around a series of experiments on inflammable air, which included collecting gas arising from rotting plant matter at the bottom of stagnant marshes. The marsh airs had been suggested to him by a friend and fellow natural philosopher, Fr. Carlo Campi (1732-1799), who had observed inflammable gurglings (gorgoglia) in a spring near San Colombano al Lambro, near to Pavia, and had recommended that Volta investigate the spring himself. Volta did not manage to visit the spring, but in the meantime collected inflammable gases from the swamps of Lake Como and from damp ditches. Volta rowed out into the marshes and agitated the lake bed with a rod, releasing bubbles of gas from the mud which he then collected in an inverted jar. He described his discoveries and subsequent

\footnotetext{
47 'la Chimica dell'aria va a partorire un gran rivoluzione nella Scienza naturale' Volta, Proposizioni e sperienze di aerologia (1776) cited in Gli Strumenti di Alessandro Volta: II Gabinetto di fisica dell'Università di Pavia, (Milano, Pavia Università degli studi di Pavia, Editore Ulrico Hoepli, 2002), 56.

48 Roderick W. Home, "Volta's English Connections," in Nuova Voltiana : studies on Volta and his times, ed. Fabio Bevilacqua and Lucio Fregonese, Collana di storia della scienza (Milano, Pavia Università degli studi di Pavia, Editore Ulrico Hoepli, 2000), 121.

49 Gli Strumenti di Alessandro Volta, 60.

50 Volta to Priestley 1774/05/24, Volta, Espistolario, vol 1, 65., Appendix to Volta's article on Eudiometro in Pierre Joseph Macquer and Giovanni-Antonio Scopoli, Dizionario di chimica (Paria: Nella Stamperia del R.I. Monastero di S. Salvatore, per G. Bianchi, 1783), vol 4, 458., letter dated 1775/08/30, Volta, Opere, vol 7, 80 .
} 
analysis in a series of seven letters to Campi in late 1776 and early 1777 which he had published in the same year as Lettere sull'aria infiammabile nativa delle paludi.51

Volta's discovery was not that were inflammable airs from natural sources. It had long been known that marshes, swamps, and even rivers could produce inflammable exhalations. ${ }^{52}$ Spontaneous swamp flames were called ignis fatuus, Will-o'-the-Wisp, and many other names, but their nature remained mysterious. Natural philosophers also speculated that inflammable airs coming from coal or metals buried in the earth could even be the cause of earthquakes as they built up and ignited underground. 53

Similarly, miners had long been aware of the inflammability and explosivity of some airs in coal mines dubbed fire-damp by English miners. In a case that is frequently mentioned in English sources up to the 1770s, and again in the historiography of gaslight, a colliery owner named James Lowther who was concerned with mitigating the dangers associated with fire-damps collected gas from his mines in Whitehaven in bladders and showed that it retained its inflammability, even days afterwards. He presented his results - flaming bladders included - to the Royal Society

51 A first edition was published in 1776, with a larger edition in 1777 Alessandro Volta, Lettere del Signor Don Alessandro Volta ... sull'aria infiammabile nativa delle paludi (Milano: Nella stamperia di G. Marelli, 1777; reprint, Sampietro editore, Menaggio [Italy], [1998]). The date given in the introduction is January 15, 1777. See also Georgia Santangelo and Carla Garbarino, "General Bibliography on Alessandro Volta," in Nuova Voltiana : studies on Volta and his times, ed. Fabio Bevilacqua and Lucio Fregonese, Collana di storia della scienza (Milano, Pavia Università degli studi di Pavia, Editore Ulrico Hoepli, 2000), 120.

52 See, for example, "Lettres de M. Alexandre Volta," Le journal des sçavans (1778): 1068-9. Some specific reports come up frequently in the histories of gaslighting, such as Thomas Shirley, "The Description of a Well, and Earth in Lanchashire, Taking Fire by a Candle Approached to It," Philosophical Transactions (1665-1678) 2 (1666). and Jean Tardin, Histoire naturelle. De la fontaine qui brusle près de Grenoble. Avec la recherche de ses causes, \& principes, \& ample traicté des feux sousterrains (Tournon: G. Linocier, 1618).

53 Maud and Luther, "A Chemical Experiment by Mr. John Maud," 284. 
in 1733.54 This was the beginning of a research program undertaken by Lowther's steward Carlisle Spedding and William Brownrigg and which produced five papers read to the Royal Society on the nature of fire-damps. Gas from one of Lowther's mines was in fact piped into a laboratory for analysis by Brownrigg. As these papers were never published, they had a fairly limited influence outside the Royal Society. Had they been published, it is likely that Brownrigg's work would rank with Cavendish's and Priestley's in this history. I will return to Lowther's and Brownrigg's work in greater detail in chapter two.

In an another instance directly relevant to Volta's work, Benjamin Franklin had written Priestley a letter in 1774 describing the inflammable airs collected over a river in New Jersey. Franklin tried twice unsuccessfully to repeat the experiment himself in England, and 'ascribed an intermittent fever, which seized me a few days later, to breathing too much of the foul air which I stirred up from the bottom'. Priestley published the letter in 1775 edition of Observations, and Volta quoted it in a footnote in one of his letters to Campi.55

In the Lettere sull'aria infiammabile, Volta compared marsh gas with metallic inflammable air. He suggested that a new name be given to inflammable air from

\footnotetext{
54 James Lowther, "An Account of the Damp Air in a Coal-Pit of Sir James Lowther, Bart. Sunk within 20 Yards of the Sea; Communicated by Him to the Royal Society," Philosophical Transactions (1683-1775) 38 (1733). See p. 112 for demonstration before the RS. J. V. Beckett, Coal and tobacco : the Lowthers and the economic development of West Cumberland, 1660-1760 (New York, 1981), 73. states that the paper was written by Lowther's stewart, Carlisle Spedding.

55 Volta, Lettere sull'aria infiammabile, 22-25. Volta's letter is date 10 November, 1776. Priestley published the original text in Joseph Priestley, Experiments and observations on different kinds of air The second edition correct ed. (printed for J. Johnson, 1775), 321-23.
} 
marshes as they present characteristics clearly distinct from that of metallic inflammable air:

[Marsh gas] differs considerably from that generated from the dissolution of metals in acids, and somewhat less from that which arises from the distillation of animal and vegetable matter. It is distinguished not only through the elegant blue colour of the flame, but also the steadiness with which it slowly burns, lambent and flickering. ${ }^{56}$

In the only quantitative results given in the letters, Volta explained that it exploded in a ratio of between 8 and 10 to 1 of common air, as opposed to 2 to 1 for metallic inflammable air. ${ }^{57} \mathrm{He}$ also observed that metallic inflammable air 'arde piu prestammente e scopia con assai piu stentore e fracasso’58 than that from plant matter. Finally, Volta observed that the inflammable air produced by the distillation of plants was similar to that of marsh gas.

Volta's work did not extend to measuring the specific densities of marsh gas, as Cavendish's had, but unlike Cavendish, Volta published his work and staked his claim for the discovery of a new air forcefully. In fact, Volta's own claim of novelty was founded on the assertion that pneumatic chemists before him had missed the plant origin of this new kind of inflammable air. He states that they all thought inflammable air had mineral origin:

\footnotetext{
56 Se non altro pel colore della fiamma elegantemente azzurro e per la lentezza con cui s'avanza cheta cheta, lambendo e ondeggiando, differisce considerevolmente da quella che viene generata colle soluzioni metalliche negli acidi, e alcun poco da quella pure che cavasi dalle sostanze o vegetabili o animali per distillazione. Volta, Lettere sull'aria infiammabile, 26.

57 Ibid., 27.

58 Ibid., 29.
} 
Neither Mr. Pringle, nor Mr. Lavoisier, nor even Dr. Priestley have ever spoken about inflammable air generated from vegetable or animal matter rotting under water, and which can easily be driven out of the bed of every ditch or swamp. These authors, and other as well, have spoken about native inflammable airs, but have recognized the production of this gas only from mineral sources, because they found inflammable air usually in coal mines. ... In every case, it was assumed that inflammable air came from the vigourous action of flame, from acids and metals: in short, from mineral sources. In summary, all who have written about or discussed this subject have been far from attributing it to the rotting and putrefaction of animal or vegetable matter, and from the idea that such inflammable airs could be generated and collected from the bottoms of marshy waters. ${ }^{59}$

Volta, however, was clearly mistaken about the novelty of his claim. Hales, Priestley, and others had realized that inflammable gases could be obtained from vegetable and animal sources alike.

Volta was uncertain as to what his new marsh gas actually was, and his opinion evolved with time. He did not think it was the same as coal-gas: 'Non ho avuto mai occasione di metter a cimento l'aria infiammabile nativa delle miniere di carbon fossile, o di sal gemma; pure non dubito punto, che eziandio da queste differir possa la nostra'.60 On this point he was correct: marsh gas is not pure methane but usually contains other gases, including a good deal of nitrogen. Volta thought it was a mixture

\footnotetext{
59 nè il Sig. Pringle ... nè Mr. Lavoisier ... nè finalmente il Dr. Priestley ... hanno parlato mai d'aria infiammabile generata da vegetabili o da animali corrotti sott' acqua, e che si snida agevolmente dal letto di ogni fosso, o stagno. Questi autori, ed altri, a dir vero, hanno parlato delle arie infiammabili native, ... ma hanno riconosciuta la produzione di esse unicamente da' minerali, imperciocchè avevano rinvenuta l'aria infiammabile stanziante d'ordinario nelle cave di carbon fossile ... in ogni caso presumevasi l'aria infiammabile provenuta da vigorosa azione di fuoco, da acidi e metalli, insomma da minerali.lbid., 64-65. footnote

60 Ibid., 26-27.
} 
of gases including phlogisticated air and a new kind of inflammable air, which first thought was phlogiston combined with an 'aerial sulphur'. He later drop this term in favour of 'aerial salt'.61

Soon after the publication of these letters, Volta was widely regarded as being the discoverer of new species of inflammable air. Numerous French and German editions of his letter to Campi were available by 1778,62 and became well known among natural philosophers. He is cited in most works touching on inflammable airs in the years immediately after 1777 .

After his letters to Campi were finished, Volta devoted his attention to his inflammable air pistol and eudiometer, both of which used mostly metallic inflammable air. He did, however, revisit marsh gas in 1778 and developed his thought on the its composition further. In a couple of letters to Jean Senebier (1742-1809), a Swiss natural philosopher with whom Volta maintained an extensive correspondence, he described how he compared the combustion of inflammable airs from metals and marshes in his eudiometer. He confirmed what he had written to Campi, that inflammable air from marshes required approximately four times as much dephlogisticated air for combustion as metallic inflammable air, a fact Volta explained by relative abundance of phlogiston in marsh gas. He thought that this also explained why a flame of burning marsh gas was blue and generally larger than metallic inflammable

\footnotetext{
61 See Frederic Lawrence Holmes, "Phlogiston in the Air," in Nuova Voltiana : studies on Volta and his times, ed. Fabio Bevilacqua and Lucio Fregonese, Collana di storia della scienza (Milano, Pavia Università degli studi di Pavia, Editore Ulrico Hoepli, 2000), 91. for a discussion of Volta's views on the nature of inflammable air.

62 Santangelo and Garbarino, "General Bibliography on Alessandro Volta," 121. It was also mentioned in "Review: Lettres de M. Alexandre Volta," The Monthly review or Literary Journal 59, no. 4 (1778).
} 
air. ${ }^{63}$ Volta indicated to Senebier that all marsh gases were fundamentally the same, but were almost always mixed with putrid air and phlogisticated air when collected. Finally, although there were similarities between marsh inflammable air and that are produced by distilling plant and animal substances - 'the slowness and the colour of the flame'Volta did not assimilate them into the same gas. ${ }^{64}$ In this sense he had not characterized methane sufficiently to be always able to recognize it, and this suggests that caution should be used when stating the Volta discovered methane, as is frequently claimed.

After these letters, Volta lost interest in the subject of marsh gases. He indicated to Senebier in 1778 that he planned a third letter to Priestley in addition to two on the inflammation of inflammable air he was having published in Rozier's Observations sur la physique, with the focus on comparing inflammable airs, but he never did get around to it. 65

63 Volta to Senebier 1778/05/09, Volta, Opere, vol 6, 265., Volta to Senebier 1778/05/30, Volta, Opere, vol 6, 271-74.

64 'la lenteur et la couleur de la flamme' Volta to Senebier 1778/05/30, Volta, Opere, vol 6, 277-8.

65 Volta to Senebier 1778/06/20, Ibid., vol 6, 279. For a broader discussion about Volta's pneumatic chemistry during this period, see Holmes, "Phlogiston in the Air." 


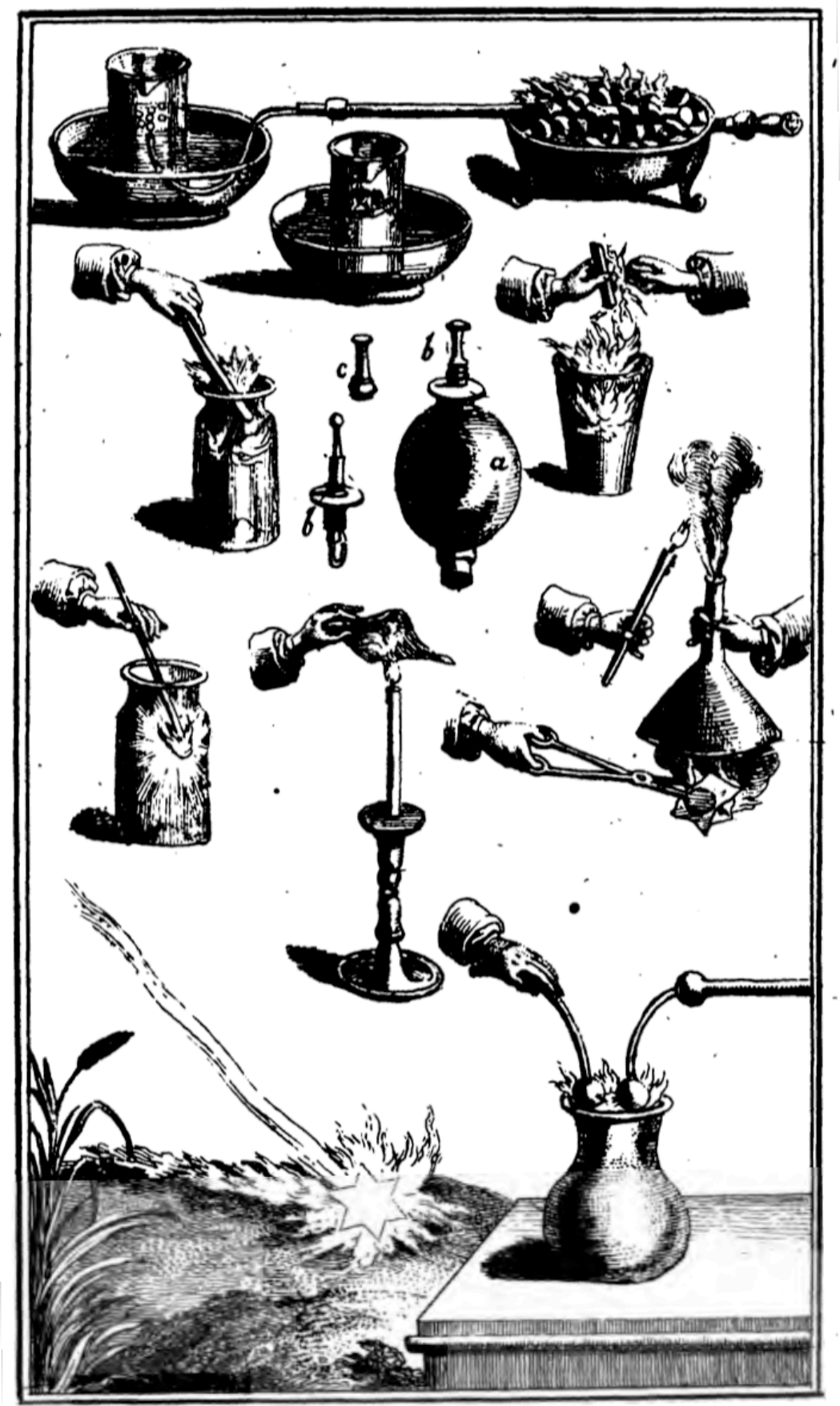

Figure 1.5 Plate from the 1778 German edition of Volta's letters on marsh gas. Briefe über die natürlich entstehende entzündbare Sumpfluft. 


\subsection{Volta's instruments}

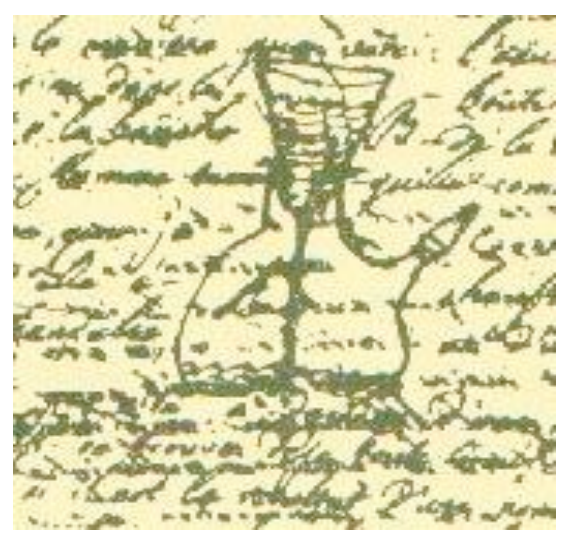

Figure 1.6 Sketch of an inflammable air lamp, drawn by Volta. "Due Lettere a Jean Senebier" (1778) in Opere Vol. 6 [1918], 256-68

Volta's part in this story is not limited to his discovery of marsh gas. Adept at inventing and making scientific instruments, Volta produced a series of inventions and technological improvements over the course of his life, the first of which was the aforementioned electrophorus and which culminated with the electric pile in the years 1797-1800. Combining his interests in electricity and inflammable airs, he concocted a number of electro-pneumatic inventions. The best known was the eudiometer, a device to measure the salubriousness of air, ${ }^{66}$ but also included in 1776, an inflammable air pistol, and, of the greatest importance in this history, an inflammable air lamp (Iucerna)

\footnotetext{
66 See Paolo Brenni, "Volta's electric lighter and its improvements: The birth, life and death of a peculiar scientific apparatus which became the first electric household appliance," in From the itinerant lecturers of the 18th century to popularizing physics in the 21st century-exploring the relationship between learning and entertainment (Pognana sul Lario, Italy 2003), 8.
} 
and later on a lighter (accendilume), which was often used as a lamp as well.67 I will, however, follow Volta's terminology, and refer to it as a 'lighter' to distinguish it from his earlier lamp.

Volta had briefly mentioned burning inflammable air in a lamp-like way in one of the letters to Campi,68 and he developed this idea into two devices, a lamp and a lighter. They were similar but the lamp used marsh gas while the lighter used metallic inflammable air.69 Volta described the lamp in an April 24, 1777 letter to Senebier:

It is better, and even more certain and straight-forward to leave aside bladders filled inflammable air which are squeezed to feed a flame from a tube attached to the bladder's mouth, and use a bottle and tube of the following design: water is held in an upper container $\mathrm{B}$, which then passes down as a jet into container $\mathrm{A}$, and displaces the inflammable air. The air exits as a jet from the mouth of the tube $C$, which can then be lit, and the flame holds steady, like a lamp. ${ }^{70}$

Volta's lamp had a short career and does not appear to have inspired direct imitators and even Volta abandoned the idea of gas lamps after two or three years. In a 1783 article on inflammable air for the Italian translation of Macquer's Dictionnaire de

${ }^{67}$ Alessandro Volta, "Memoria sopra i fuochi de terreni e delle fontane ardenti in generale, e sopra quelli di Pietra-Mala in particolare," Opuscoli scelti sulle scienze e sulle arti : tratti dagli atti delle accademie, $e$ dalle altre collezione filosofiche, e letterarie, dalle opere più recenti inglesi, tedesche, francesi, latine, e italiane, e da manoscritti originali, e inediti 7, no. 5 (1784): 331-2 footnote. makes this clear.

68 Volta, Lettere sull'aria infiammabile, 53-4.

69 Alessandro Volta, "Due lettere a Jean Senebier sopra esperienze e considerazioni sull'aria infiammabile," in Le opere di Alessandro Volta Vol. 6 [1918] (Milano: Hoepli, 1778), 235.

70 'Sans parler d'une vessie remplie d'air infl. qu'on presseroit pour soutenir la flamme sur la bouche d'un petit tuyau adapté, il suffit, et il est plus aisé même et plus sûr, de se servir d'une bouteille tubulée de la manière que voici : l'eau de l'entonnoir $B$ passant par un jet continu dans la bouteille $A$ en déplace l'air inf. et forme un jet à la bouche de la tubulure $\mathrm{C}$, qui si on l'allume entretient une flamme, tranquille comme celle d'une lampe.' Volta to Senebier 1777/04/24, Volta, Opere, vol 6, 258-9.. He is referring to the diagram shown above. 
Chimie, Volta explained that the lamp was not practical: the light was too weak and too many bottles of gas were needed for only a few hours of light. ${ }^{71}$

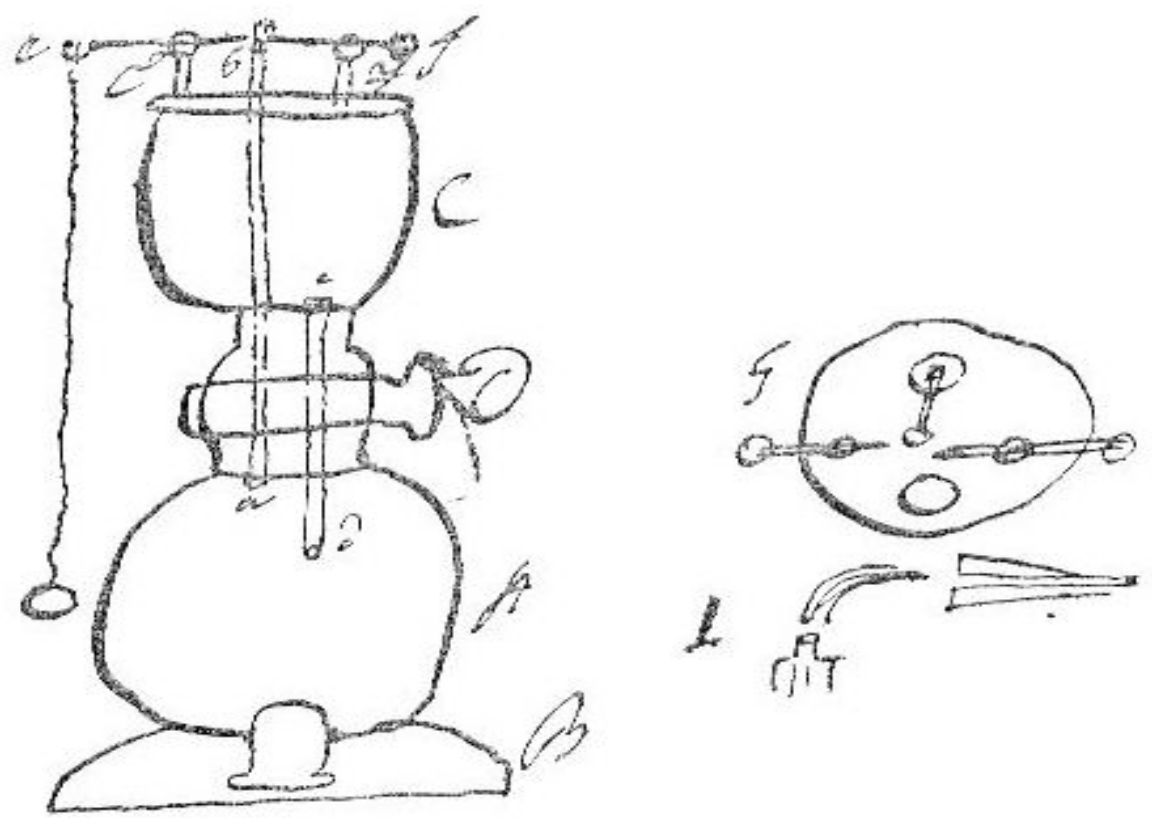

Figure 1.7 Sketch of an inflammable air lighter, from Volta "Descrizione ed uso di un accendilume ad aria infiammabile" (1778) in Opere Vol. 7 [1918], 153-57

In contrast to the lamp, the lighter was to enjoy much greater success - at least from the point of view of popularity, though it was never more than a curiosity - and inspired a host of imitators. Many of these instruments derived from Volta's lighter were also used as a lamp, and were frequently referred to as lamps. The lighter, like its ancestor the lamp, consisted of two reservoirs stacked vertically, the top one (C) filled

71 Nota di chiusa all'articolo "Aria infiammabile" in Macquer and Scopoli, Dizionario di chimica, vol 2, 286. Volta, Opere, vol 6, 409. 
with water, the bottom $(A)$ with metallic inflammable air. A tube connected the top reservoir with a bottom through a valve. A second valved tube led upwards out of the bottom reservoir and vented inflammable air to the outside. A sparking mechanism was located immediately adjacent to the mouth of the second tube. To produce a light, the operator let water from the top reservoir into the bottom one, increasing the pressure of the inflammable air. The second valve was then opened and a spark struck at the mouth of an egress, igniting the inflammable air now streaming out of the bottom reservoir. When used as a lighter, a candle was placed close to the exit jet and lit once the flame had been struck. The bottom reservoir had to be refilled carefully with metallic inflammable air using a pneumatic trough, a cumbersome and delicate procedure that could only be performed by someone with chemical laboratory at his disposal and sufficient skill not to mix any common air with the inflammable..$^{72}$ The figure reproduced above was drawn by Volta at an unknown date, but probably before 1778 . He continued working on the lighter for a few years, at least into 1779 when he wrote Senebier to say that he had perfected it. ${ }^{73}$

Mostly thanks to Volta's constant efforts to expand his base of contacts, the lighter achieved a wide diffusion in Europe and especially in Germany in geographical terms, though not in numbers. It must have been quite intriguing because many people either made copies of it or asked Volta for one or at least some basic plans. A number of

\footnotetext{
72 Johann Georg Krünitz, "Lampe," in Oekonomische-Technologische Encyclopädie; oder, Allgemeines System der Land-, Haus-, und Staats-Wirthschaft, in alphabetischer Ordnung; aus dem Französischen übersetzt und mit Anmerkungen und Zusätzen verhmehrt, auch nöthigen versehen Band 59, ed. Johann Georg Krünitz (Berlin: J. Pauli, 1793), 291.

73 Volta to Senebier 1779/07/10, Volta, Espistolario, vol 1, 355.
} 
works soon appeared in print either exclusively dedicated to it or describing it in some detail. ${ }^{74}$

In 1777 Volta went on his first trip across the Alps, visiting Switzerland and meeting with many natural philosophers, instrument makers, and others. He gave lectures and demonstrations about his discoveries, including marsh gases and also took the opportunity to show his inflammable air lighter to many people. Among them was a certain Fürstenberger in Basel. ${ }^{75}$ Fürstenberger was a collector of scientific instruments who described himself as an 'amateur'. ${ }^{76} \mathrm{He}$ made a lighter quite similar to Volta's, and may have tried to pass off the invention as his own, as some later German and French sources name Fürstenberger as its inventor. A German instrument maker from Augsburg, Georg Friedrich Brander (1713-1783), also made one within a year or two of Volta's trip to Swizterland and his was the first to be described in print in 1779 by Joseph Weber (1753-1831) a German priest and inventor with interest in electrical apparatus. ${ }^{77}$

\footnotetext{
74 The first was Joseph Weber, Beschreibung des Luftelektrophors nebst angehängten neuen Erfahrungen, neuen Instrumenten, einem Unterrichte von Zubereitung der brennbaren Luft, und verschiedener Versuche mit derselben ... Sammt drey Kupfertafeln, Neueste mit der Beschreibung der elektrischen Lampe verm. Aufl. ed. (Augsburg: Bey Eberhard Kletts sel. Wittwe und Franck, 1779)., which also had a 1778 edition, followed soon thereafter by Friedrich Ludwig Ehrmann, Déscription et usage de quelques lampes à air inflammable (A Strasbourg: J.H. Heitz, 1780). and Jan Ingenhousz, Vermischte Schriften phisisch-medizinischen Inhalts (Wien: Bei Johann Paul Krauss, 1782).. Krünitz, "Oeconomische Encyclopädie." contains quite an extended discussion. For a recent article on the lighter, see Brenni, "Volta's electric lighter and its improvements."

75 Alessandro Volta, "Memoria sopra i fuochi de' terreni e delle fontane ardenti in generale, e spora quelli di Pietra-Mala in particolare," Memorie di matematica e fisica della Società italiana 2, no. 2 (1784). in Volta, Opere, vol 7,118.

76 Johann Gottfried Ebel, Instructions pour un voyageur qui se propose de parcourir la Suisse de la maniere la plus utile et la plus propre à lui procurer toutes les jouissances dont cette contrée abonde (Vol 2) (Basle [Basel] J.J. Tourneisen, 1795), 26.

77 "Weber, Josef," in Allgemeine deutsche Biographie (Vol 41) (Leipzig: Historische Commission bei der Königl. Akademie der Wissenschaften, 1875).
} 


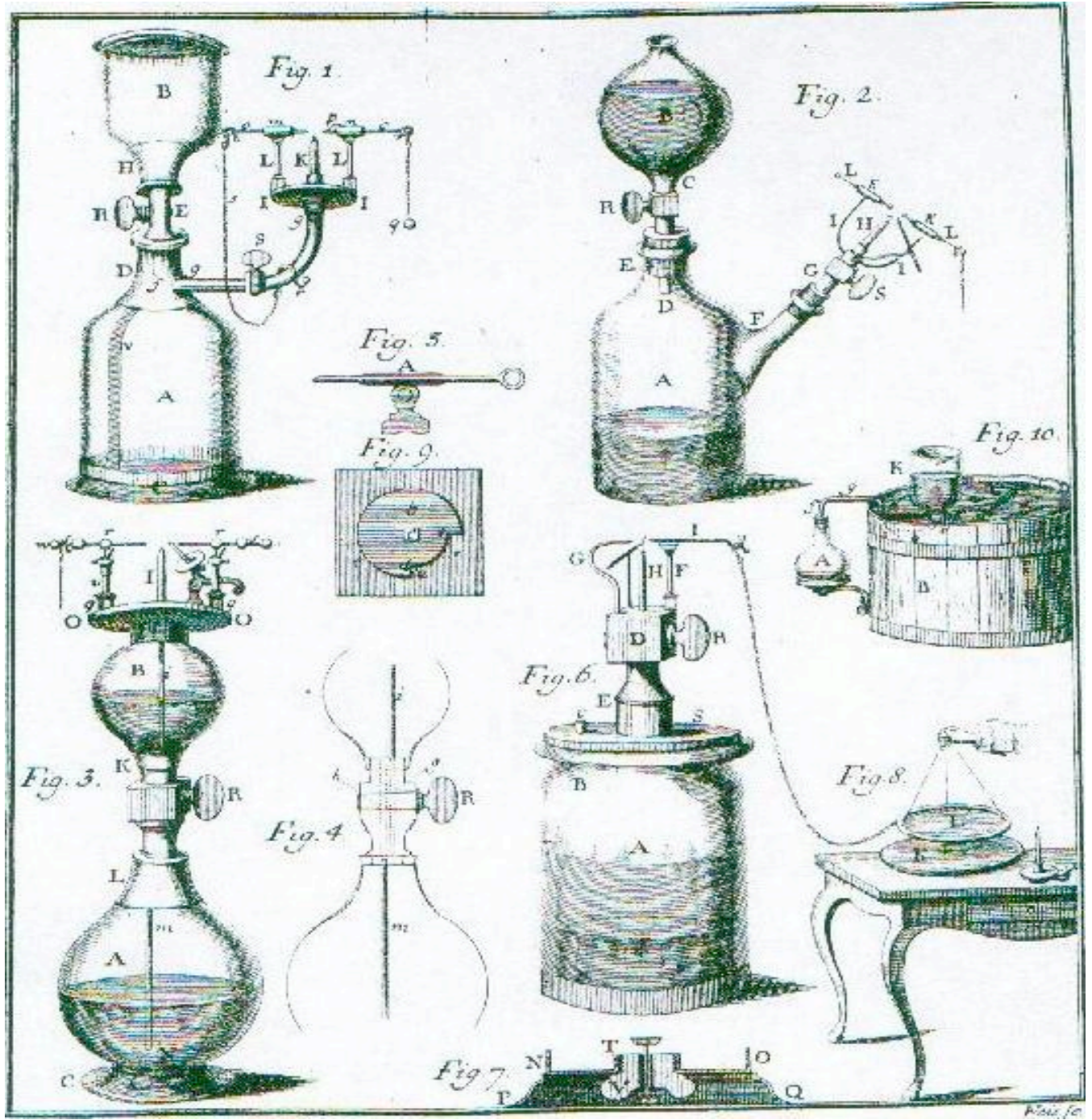

Figure 1.8 A series of inflammable air lamps, from Friedrich Ehrmann, Déscription et usage de quelques lampes à air inflammable (1780) 
Frédéric-Louis Ehrmann (1740-1800), a physics lecturer in Strasbourg, ${ }^{78}$ which Volta had also visited on his 1777 journey, published a lengthier treatise exclusively dedicated to the subject of the lighter. Ehrmann identifies Fürstenberger as the inventor, and describes versions of the lighter made by assorted instrument makers, including Brander, another one named Degabriel, as well as his own, all of which substantially follow Volta's design. ${ }^{79}$ All these lighters used inflammable air made from iron and vitriolic acid, with no mention of marsh gas or other sources of heavier inflammable airs. 80

Volta had shown his lighter to others on his Switzerland trip, including to the Swiss physicist Horace-Bénédict de Saussure (1740-1799), and to a Strasbourg physicist, Jean-Jacques Théodore Barbier de Tinan (?-1791).81 Barbier was a good friend of Volta's, and they corresponded frequently over the years. After Barbier saw the lighter,

78 "Ehrmann, Frédéric-Louis," in Nouvelle biographie générale depuis les temps les plus reculés jusqu'à nos jours, avec les renseignements bibliographiques et l'indication des sources à consulter (Vol 15), ed. M Hoefer (Paris: Firmin Didot fréres, fils et cie, 1858).

79 See also Johann Heinrich Moritz von Poppe, Geschichte der technologie seit der wiederherstellung der wissenschaften bis an das ende des achtzehnten jahrhunderts, vol. 3 (Göttingen: Bey J.F. Röwer, 1811), 16-18. and "Lampe, elektrische," in Physikalisches Wörterbuch; oder, Erklärung der vornehmsten zur Physik gehörigen Begriffe und Kunstwörter so wohl nach atomistischer als auch nach dynamischer Lehrart betrachtet mit kurzen beygefügten Nachrichten von der Geschichte der Erfindungen und Beschreibungen der Werkzeuge in alphabetischer Ordnung. Band 3, ed. Johann Carl Fischer (Göttingen: J.C. Dieterich, 1800). for a list of people who worked on the lighter and a bibliography.

80 Ehrmann, Déscription et usage de quelques lampes à air inflammable, 26-7.

${ }^{81}$ Alessandro Volta, "Seconds Partie du memoire de M. de Volta sur les Isolements Imparfaits," Observations sur la physique, sur l'histoire naturelle et sur les arts 23, no. 2 (1783): 10 footnote. Volta, "Memoria sopra i fuochi de terreni e delle fontane ardenti in generale, e sopra quelli di Pietra-Mala in particolare," 331-2 footnote. 
he subsequently made one for himself and, as he mentioned in succeeding letters to Volta, he used it frequently as a lighter and even a lamp. ${ }^{82}$

I would be very glad to see you inflammable air lamp which is certainly more handy than mine, since it is portable. Mine is, however, good for some experiments. When I add a curved appendage, it burns for an hour and l've had the time to try this flame on several substances, such as metals which melt more readily than with ordinary flames, even when enlivened with a blast of air directed at the metallic calxes being revived, the small glass tubes being melted, etc. ${ }^{83}$

Interestingly, Jan Ingenhousz (1730-1799), a Dutch natural philosopher who learned of the lighter from Barbier de Tinan on a trip to Strasbourg in 1780 also names Fürstenberger as its inventor. Ingenhousz, who was living in London at the time, had a lighter made in Vienna when he arrived there on this same trip. ${ }^{84}$ In his 1782 Vermischte Schriften phisisch-medizinischen Inhalts, he states that 'inflammable air from standing water can not be used in this lamp. The air does not easily take fire from a small electric spark, and even if a flame starts at the tube it is soon extinguished. At least, I have had

\footnotetext{
82 Barbier de Tinan to Volta, 1779/04/29, Volta, Espistolario, vol 1, 344. Ingenhousz, Vermischte Schriften phisisch-medizinischen Inhalts, 214.

83 'J'y verrai avec bien de plaisir votre lampe d'air inflammable que doit etre sans doute plus commode que la mienne, puisquelle est portative; la mienne l'est cependant fort pour de certaines experience. Lorsque j'y mets un très petit ajoutage recourbé elle brule pendant une heure et j'ai le temps d'essayer ce feu sur plusieurs substances, sur les metaux qu'il fond plus promptement que le feu ordinaire meme animé par un souffle sur les chaux métallique qu'il révivifie, sur des petits tubes de verre qu'il fond etc.' Barbier de Tinan to Volta, 1779/09/18, Volta, Espistolario, vol 1, 374-5.

84 Ingenhousz, Vermischte Schriften phisisch-medizinischen Inhalts, 214-5. Ingehousz visited with Barbier on his way to Vienna and they made experiments with Volta's inflammable air pistol, Barbier to Volta 1780/08/02, Volta, Espistolario, vol 1, 417-8.
} 
no success with air from marshy water.' 85 These sorts of problems would occur if the marsh gas was not purified of its carbon dioxide or nitrogen.

The lighter also found its way to England via George Nassau Clavering, the third Earl of Cowper (1738-1789) who lived in Florence and was an avid collector of scientific instruments. He heard about Volta's lamp, lighter, and other inventions and asked him for a collection of them in July of 1778 with a view to forwarding them on to the Royal Society. ${ }^{86}$ Volta agreed and Cowper mentions in a subsequent letter that he sent it on to Edward Nairne (1726-1806), a renowned London instrument maker and fellow of the Royal Society who was actively interested in electricity. ${ }^{87}$ Volta also gave a lighter to Cowper sometime in 1779,88 and Nairne afterwards presented it to the Royal Society. Nairne was deeply impressed by Volta's work and recommended to the president that Volta be given membership in the Royal Society in 1778, but was turned down on the grounds the no new foreign members were being admitted. ${ }^{89}$ Soon after Nairne presented the instruments to the Royal Society, Joseph Banks gave a series of public

\footnotetext{
85 'der brennbare Luft der stehenden Wässer kann zu dieser Lampe nicht dienen. Diese Luft fängt durch einen kleinen electrischen Funken nicht so leicht Feuer, und wenn auch eine aufsteigende Säule derselben Feuer gefangen hat, so verlöscht es wieder. [...] Wenigstens hat es mir mit der Luft sumpfichter Wässer noch nicht gelungen' Ingenhousz, Vermischte Schriften phisisch-medizinischen Inhalts, 221-2.

86 Cowper to Volta, 1778/07/09, Volta, Espistolario, vol 1, 261.

87 Cowper to Volta 1778/09/08, Ibid., vol 1, 281., Brenni, "Volta's electric lighter and its improvements," 10., E. G. R. Taylor, The mathematical practitioners of Hanoverian England, 1714-1840 (London: Cambridge U.P. for the Institute of Navigation, 1966), 214.

88 Volta, Opere, vol 7, 118. cited above, Volta to Cowper 1779/07/27, Volta, Espistolario, vol 1, p. 357. Volta, "Memoria sopra i fuochi de terreni e delle fontane ardenti in generale, e sopra quelli di Pietra-Mala in particolare," 331-2 footnote.

89 Nairne to Cowper 1778/11/13, Volta, Espistolario, vol 1, 300.
} 
lectures in London partly based on Volta's instruments, especially the pistol. .90 The lighter had some circulation in England as the royal instrument maker Sir George Adams junior (1750-1795)91 described it in his 1784 book An Essay on Electricity, attributing it to Volta.92 It is also described in subsequent editions.

With the confusion over the lighter's origin, Volta at a certain point felt the need to assert his priority in print over the lighter and did so in a footnote to a 1783 article he published in l'abbé Rozier's Observations sur la physique..$^{93}$ This was before he had even seen Ehrmann's book, and when he did do so and realized that there was no reference to him he asserted his claim again in Memorie di matematica e fisica della società italiana in $1784 .{ }^{94}$ On the whole his campaign was successful.

The lighter became fairly well-known: one German text referred to it in 1803 as the 'bekannten elektrischen Lampen'.95 There are references to Volta's lighter in many encyclopedias and texts, for example in the Encyclopaedia, or A Dictionary of Arts of

90 "Mr. Banks' Lectures," London Evening Post, Thursday, May 141778.

91 Taylor, The mathematical practitioners of Hanoverian England, 1714-1840, 277.

92 George Adams, An essay on electricity : in which the theory and practice of that useful science, are illustrated by a variety of experiments, arranged in a methodical manner. To which is added, An essay on magnetism (London: Printed for and sold by the author, at Tycho Brahe's Head ... 1784), 286-8. It is also in subsequent additions of this book. See also John R. Millburn, Adams of Fleet Street : instrument makers to King George III (Aldershot: Burlington, VT, 2000).

93 Volta, "Seconds Partie du memoire de M. de Volta sur les Isolements Imparfaits," 10 footnote.

94 Volta, Opere, vol 7, 118. Volta, "Memoria sopra i fuochi de terreni e delle fontane ardenti in generale, e sopra quelli di Pietra-Mala in particolare," 331-2 footnote.

95 Zacheus Andr Winzler, Die Thermolampe in Deutschland : oder, vollständige, sowohl theoretisch-als praktische Anleitung, den ursprunglich in Frankreich erfundenen, nun aber auch in Deutschland entdekten Universal- Leucht- Heiz- Koch- Sud- Destillir- und Sparoven zu errichten. Mit vier Kupfertafeln (Brünn: Gedruckt bei Franz Karl Siedler ... 1803), 20. 
1798, the New Encyclopaedia of 1807, or the 1810 Encyclopædia Britannica. ${ }^{96}$ The situation was similar in Germany. The lighter was described in a very long article under 'Lampe' in volume 59 of Johann Georg Krünitz's Oekonomische encyklopädie (1793),97 and subsequently in a number of early nineteenth century encyclopedias. ${ }^{98}$ It is also mentioned in a variety of French texts, such as Guyot's Nouvelles récréations physiques et mathématiques $(1786,1799)$ and the 1805 Encyclopédie méthodique.99

Although the lighter did not disappear until midway through the nineteenth century, it was never more than a scientific oddity. The difficulties in making hydrogen and the dangers inherent in storing it while preventing an admixture of atmospheric air, ${ }^{100}$ as well as its delicate construction and high cost, all meant that it could never achieve adoption outside of a limited group of enthusiasts or scientists. ${ }^{101}$ In addition, the limited

96 "Electricity: XLVI. The Inflammable Air-Lamp," in Encyclopaedia; or, A dictionary of arts, sciences, and miscellaneous literature, ed. James Akin (Philadelphia: Printed by Thomas Dobson, at the stone House, no 41, South Second Street., 1798)., "Lamp (Inflammable air)," in The new encyclopaedia, or, Universal dictionary of arts and sciences (London: Vernor, Hood, and Dharpe, 1807)., "Electricity," in Encyclopædia Britannica, or, A Dictionary of arts, sciences, and miscellaneous literature [Vol. 7], ed. James Millar (Edinburgh: Printed by A. Bell for A. Constable [et al.], 1810), 692.

97 Krünitz, "Oeconomische Encyclopädie."

98 Oekonomische-technologische Encyklopädie (1801) 2nd ed. vol 59, pp. 247-343

Johann Carl Fischer's Physikalisches Wörterbuch (1800) vol 3, pp. 215-220

Johann Gehler Physikalisches Wörterbuch (1831), vol. 6, part 1, pp. 75-86

all cited in Brenni, "Volta's electric lighter and its improvements."

See also Poppe, Geschichte der technologie, 16-18.

99 Edme-Gilles Guyot, Nouvelles récréations physiques et mathématiques, contenant ce qui a été imaginé de plus curieux dans ce genre et qui se découvre journellement; auxquelles on a joint les causes, leurs effets, la manière de les construire, et l'amusement qu'on en peut tirer pour étonner et surprendre agréablement, Nouv. éd. Par m. Guyot ed., 3 vols., vol. 2 (Paris, 1799), 330-1.. It is also in the first edition. Also in "Lampe a Gaz Inflammable," in Encyclopédie Méthodique: Chimie Et Métallurgie, ed. Antoine-François Fourcroy (Paris: Pancoucke, 1805).

100 Winzler, Die Thermolampe in Deutschland, 169. mentions criticisms of the 'elektrischen feuerzeuge' in regard to explosive accidents caused by the mixing of hydrogen and atmospheric air.

101 "Lampe a Gaz Inflammable." states: Ces machines, trop délicates \& trop chères pour être d'un usage habituel, ne sont presque que des objets de curiosité dans quelques cabinets précieux. 
volume of hydrogen storable in the lighter effectively excluded its use for lighting as Volta had very quickly realized, and although a few people used it as a night lamp, ${ }^{102}$ it could never have been used as such in extended applications. ${ }^{103}$

The lighter's relevance in the history of gaslight is fourfold. First, it shows that the invention of gaslight cannot be reduced to simply observing that inflammable airs exist and can be contained, and then trying to use them for lighting. Volta and the host of instrument makers who developed his invention were never able to make it more than a scientific curiosity.

Second, it reveals the not-insignificant challenges faced by those who did finally deploy gaslight: the need to ensure a constant and reliable supply of inflammable gas with a minimum of bother to its users. For this reason, hydrogen could never have been adequate as the inflammable gas of choice for light. As balloon enthusiasts found out, it was quite difficult to produce in industrial quantities. ${ }^{104}$ Large quantities of vitriolic acid and especially iron were never going to be feasible for large-scale production of gases. Iron was too bulky - both as raw material and as waste - and too expensive to

102 Krünitz, "Oeconomische Encyclopädie," 283., See also "Thermolampe," Der Verkündiger, oder, Wochenschrift zur Belehrung, Unterhaltung und Bekanntmachung für alle Stèande 6, no. 35 (1802): 273. footnote. It mentions that Georg Pickel lighted his laboratory with inflammable gas in 1786. See Brenni, "Volta's electric lighter and its improvements," 14. for a description of his instruments.

103 Richard Lorentz, took out a patent in England on a lamp that was fundamentally based on Volta's design, but it never went far. "Specification of the Patent granted to Richard Lorentz for certain inventions (communicated to him by Foreigners residing abroad), of different MAchines or Instruments, one of which will produced instantaneous Light, and the other instantaneous Fire," The repertory of arts, manufactures, and agriculture 2nd series 111, no. 64 (1807).

104 Janis Langins, "Hydrogen production for ballooning during the French Revolution: An early example of chemical process development," Annals of Science 40, no. 6 (1983). 
allow for any kind of scale in gas production. And so Volta's lighter was never to be more than a small scale instrument.

Third, it shows that using methane - or a mixture of gas predominated by methane - was not an obvious choice either. Volta, Ingenhousz, and others tried to use marsh gas but never succeeded. It was too difficult to light, went out too easily, and it needed purification before it could be used. It was only with larger flames of many candle power that methane-based gaslight was feasible, but this demanded a much larger supply than could ever be met with using Volta's lighter.

Finally, the lighter and hence the idea of using inflammable gases was fairly widespread in the late 1770s: the lighter became so well known in the 1790s that by the beginning of the nineteenth century, chemists writing to expert audiences felt they could mention it without describing it.

Volta's interest in pneumatic chemistry waned in the years after 1783. He had received a much-desired appointment in 1779 to a professorship in physics at the University of Pavia and increasingly turned his attention to electricity. He was elected to the Royal Society in London in 1791. Volta later became embroiled in a dispute with Luigi Galvani over animal electricity, and later designed and built his most famous invention, the electric battery. In 1801, Napoleon honoured Volta with the title of count in recognition for his achievements, and made him a senator of the kingdom of Lombardy. Volta retired to his family home of Como and died there in 1827. 


\subsection{Carbonated Hydrogen I 1777-1785}

Thus far, I have traced the development of pneumatic chemistry to first realizations that there might in fact be altogether different species of inflammable gases. Volta was a key to this development, but his intervention was not decisive. It was to take some work and discussion before chemists accepted that they were dealing with truly distinct types of inflammable air, and this discussion was not only about the composition of inflammable airs. It also concerned a more philosophical point about what constituted a distinct species of inflammable air. If fixed air was distinct from inflammable air because they had clearly distinct properties, how different do inflammable airs need to be before they rank as a separate species? Or is the property of inflammability the specific characteristic? Composition provided one possible avenue for the differentiation of species, but since methane was almost always procured mixed with other gases, chemists remained uncertain about the exact composition of non-hydrogen species of inflammable airs, if they even thought in terms of 'exact composition' at all. In addition, carbon had not yet been identified as an element. ${ }^{105}$ Even once it became clear that some inflammable gases were composed of hydrogen and carbon, separating methane from ethylene, to say nothing about other hydrocarbons, required some more work.

The synthesis of water was an important step that allowed chemist to clearly demarcate hydrogen from the other kinds of inflammable air because until this happened, it could be claimed - with some justification - that all inflammable airs were physical mixtures. Once water had been synthesized, however, hydrogen could be put into a separate class: only it produced exclusively water on combustion. The other

105 See T. A. Wertime, "The Discovery of the Element Carbon," Osiris 11 (1954). 
inflammable airs would take some time longer to sort out. The question about whether they were mixtures of hydrogen with other gases remained. In fact, confusion reigned among chemists about the nature of the other kinds of inflammable gases, and the nomenclature remained muddled and unclear. Priestley, Watt, and Lavoisier to take some prominent examples, did not distinguished between carbon monoxide and methane. Even as late as 1820 , William Thomas Brande managed to confuse the two. ${ }^{106}$ Hydrogen sulphide and ethylene were two other inflammable gases that added to the chaos. The jungle of interlocking terms referring to non-hydrogen inflammable gases demonstrates the degree of confusion. It is never clear in this period what a chemist meant (maybe not even in his own mind) when he spoke of heavy or dense inflammable air, other than that it was not pure hydrogen. Nevertheless, absolute clarity on the matter was not necessary for the development of lighting by coal-gas, as will be discussed below.

To take up the story again, we go back to 1777 before Volta's work was known in Paris, a premier centre of scientific activity of the period. In May of that year the unofficial record of the Académie Royale des Sciences, l'abbé Rozier's Observations sur la physique, issued a challenge to contemporary chemists to resolve whether there was in fact more than one kind of inflammable air. ${ }^{107}$ Most contemporary chemists

\footnotetext{
106 William Thomas Brande, "The Bakerian Lecture: On the Composition and Analysis of the Inflammable Gaseous Compounds Resulting from the Destructive Distillation of Coal and Oil, with Some Remarks on Their Relative Heating and Illuminating Powers," Philosophical Transactions of the Royal Society of London 110 (1820). See Partington, A History of Chemistry, vol 3, 825.

107 "Seconde problème de chymie a résoudre: déterminer s'il y a plusieurs espèces de Gas inflammable, ou s'il n'y en a que d'une seule espèce," Observations sur la physique, sur l'histoire naturelle et sur les arts 9 (1777).
} 
probably agreed with Pierre-Joseph Macquer (1718-1784) when, in October of 1776,108 while writing the article on inflammable gas for the second edition of his Dictionnaire de Chymie (1778) stated that there was only one kind: 'Relative to our current state of knowledge, I persist in thinking that there is only one species of inflammable gas'.109 Although Macquer realized that some kinds of inflammable air seemed different than others, he saw inflammability as the essential characteristic of the species, the other qualities being of secondary importance. ${ }^{110}$

Contrary opinions can be found in this time before the publication of Volta's work, such as that expressed by James Keir (1735-1820), the superintendent of Boulton \& Watt's works in Soho and the English translator of Macquer's Dictionnaire. ${ }^{111}$ Keir appended his own treatise on gases to his 1777 translation of the first edition (1766) of the Dictionnaire, in which he wrote that inflammable gases 'are procured from very different matters and by very different methods. Probably, therefore several kinds of inflammable Gas may exist'. ${ }^{112}$ By the time the translation of the second edition appeared in 1779, Keir included references to Volta's discovery. ${ }^{113}$

\footnotetext{
108 See Pierre Joseph Macquer, Dictionnaire de chymie, contenant la théorie \& la pratique de cette science, son application à la physique, à l'histoire naturelle, à la médecine \& aux arts dépendans de la chymie, Seconde éd., revue \& considérablement augmentée ed. (Paris: P. Fr. Didot, 1778), vol 2, 315. 109 'Mais relativement a l'état actuel de nos connoissances, je persiste a penser qu'il y a qu'une seule espece de gas inflammable' Ibid., vol 2, 318.

110 See Ibid., vol 2, 318-9.

111 Partington, A History of Chemistry, vol 3, 298.

112 James Keir, $A$ treatise on the various kinds of permanently elastic fluids or gases (London: Printed for T. Cadell, 1777), 64.

113 James Keir, $A$ treatise on the various kinds of permanently elastic fluids, or gases, The second edition, revised ed. (London: printed for T. Cadell, and P. Elmsley, 1779), 53.
} 
Like Keir, Rozier observed in his challenge that inflammable airs had been produced in many ways, such as heating combustible materials, dissolving them acids and even alkalis. Joseph-Marie de Lassone (1717-1788) had published in the Histoire de l'académie royale des sciences during the previous year a paper that showed that inflammable air could be obtained in precisely these ways, ${ }^{114}$ as well as by heating flower of zinc (zinc oxide) mixed with charcoal, which together evolved a non-detonating blue-burning gas (carbon monoxide). ${ }^{115}$ Lassone had not characterized his new gases and Rozier invited further research into the matter. Macquer had been in personal contact with Lassone when he wrote his article on inflammable air but was obviously not convinced that this constituted a separate species. ${ }^{116}$

Also in 1777, Antoine-Laurent Lavoisier (1743-1794) was conducting a series of experiments on combustion, and in September of that year, read a paper to the Académie on the formation of pyrophorus, an inflammable powder produced from heating alum and organic matter. For his experiments, he used charcoal and discovered that an inflammable air (carbon monoxide) evolved during the formation of the pyrophorus burned with a greater volume of common air than did inflammable air from metals, and that the product was fixed air, which he redubed aeriform chalky acid (acide crayeux aériforme). Lavoisier argued that this inflammable air was not the same as the inflammable air from metals, as it had different properties: it was less

\footnotetext{
114 Lassone also heated Prussian blue to give cyanogen, another inflammable gas, See Partington, $A$ History of Chemistry, vol 3, 95, 539. and Maurice P. Crosland, Gay-Lussac : scientist and bourgeois (Cambridge: New York, 2004; reprint, 2004), 129-31.

115 Joseph Marie de Lassone, "Sur les gas aériens," Histoire de l'Académie royale des sciences (1776 [1779]).

116 Macquer, Dictionnaire de chymie, vol 2, 314.
} 
inflammable, it was barely explosive, and most remarkable of all, it produced aeriform chalky acid when burned, unlike the inflammable air from metals: 'none of the other inflammable airs obtainable from the dissolution of metals, either with vitriolic acid or with marine acid, produce the same phenomenon, and, instead of converting into aeriform chalky acid during their inflammation, seem to give acids analogous to the substances from which they derived.' ${ }^{\prime 117}$ Lavoisier then asserted, perhaps in answer to Rozier's question but without reference to it, that there are in fact three kinds of inflammable airs: a vitriolic, a marine, and a chalky kind. He concluded the paper with the observation that since the last kind of inflammable air produces fixed air on combustion, as does charcoal, it must really be aeriform charcoal: 'is the substance of charcoal, in a vapourous state and in the form of air.'118

In the end it was Volta's discovery that set of a flurry of investigative work into other kinds of inflammable gases among the Parisian chemists. News of Volta's finding had not yet arrived in Paris in 1777, but it was on its way. In that same September 1777 when Lavoisier presented his work on pyrophorus, Volta was on his trip to Switzerland showing his lighter around. He also lectured in various cities on a number of subjects including his newly discovered marsh gas. One of the attendees at a Volta lecture in Strasbourg was Philippe-Frederic, Baron de Dietrich (1748-1793). Dietrich was a Strasbourg-based industrialist, amateur scientist, and correspondent of the Académie in

\footnotetext{
117 'aucun des autres airs inflammables qu'on obtient par la dissolution des métaux, soit dans l'acide vitriolique, soit dans l'acide marin, ne présente le même phénomène, et, au lieu de se convertir en acide crayeux aériforme, lors de leur inflammation, ils paraissent donner des acides analogues a ceux dont ils ont été tirés.' Antoine Laurent Lavoisier, "Expériences sur la combinaison de l'alun avec les matières charbonneuses," in Oeuvres Vol. 2 [1865] (Paris: Imprimerie Impériale, 1777), 207.

118 'la substance charbonneuse, même dans l'état de vapeurs et sous forme d'air' lbid., 207-8.
} 
Paris. ${ }^{119}$ He was struck by Volta's work and decided that it merited a report to the Académie in Paris, which he made in person in March of $1778 .{ }^{120}$ With help from Lavoisier and Antoine-François Fourcroy (1755-1809), Dietrich presented Volta's results to some members of Académie, complete with a demonstration using gases cultivated from the shores of the Seine that he burned in the presence of the assembled savants, employing equipment borrowed from Lavoisier. ${ }^{121}$ Dietrich gushingly wrote to Volta a few days later about the great success of these demonstrations. ${ }^{122}$

In an unpublished manuscript which was likely read to the Académie in 1778, Lavoisier described his work with Dietrich along with some subsequent work. Together with Fourcroy, they collected gas from the Seine and putrid ditches, which Lavoisier purified with lime to remove any fixed air. Once completely purified, he burned the gas over lime, noting with surprise-'très remarquable'-that the flame was blue. ${ }^{123}$ As inflammable air from metals burned blue only when mixed with fixed air, this was unexpected. Chalk also precipitated in the lime water during combustion indicating the reappearance of fixed air. This, claimed Lavoisier, demonstrated that fixed air was either formed in the combustion of marsh gas, or it was separated from it during combustion. Lavoisier finished the manuscript by equating the inflammable air from

119 C. E. Perrin, "A Lost Identity: Philippe Frederic, Baron de Dietrich (1748-1793)," Isis 73, no. 4 (1982): 549. Dietrich also knew Ehrmann.

120 See Dietrich to Volta 1778/03/23, Volta, Espistolario, vol 1, 229-30.

121 Perrin, "Baron de Dietrich," 548. Antoine Laurent Lavoisier, "Sur l'air inflammable," in Oeuvres Vol. 5 [1865] (Paris: Imprimerie Impériale, 1778). Dietrich to Volta 1778/03/23, Volta, Espistolario, vol 1, 229-30. Lavoisier, "Sur l'air inflammable," 250-1.

122 Dietrich to Volta 1778/03/23, Volta, Espistolario, vol 1, 229-30.

123 Lavoisier, "Sur l'air inflammable," 251. 
marshes with that produced when fixed air is decomposed by metals (carbon monoxide) since they both produce fixed air during combustion. He concluded as he did in his paper on pyrophorus that this native inflammable air is 'the substance of charcoal, in a vapourous state'.124

Lavoisier preferred the second of his two hypotheses about the nature of marsh gas, that it was a chemical compound of fixed air and inflammable air, not mechanical mixture. He was at this time developing his oxygen theory of acidity and was seeking support for it by analysing the composition of carbonic acid which included a good deal of burning things. ${ }^{125}$ In a paper read in $1781^{126}$ he stated that the sole components of carbonic acid were oxygen and carbon (substance charbonneuse). Throughout the paper, he referred to hydrogen as 'inflammable air from water', ${ }^{127}$ and also made reference to 'heavy inflammable air, weighing 0.128 a cubic inch'128 which he generated by dripping water onto coal heated in a gun barrel until the coal was consumed. He was of the opinion that this heavy inflammable air was inflammable air united to fixed air: 'it is probable that a quantity of acid of charcoal remains intimately united to the inflammable air'. ${ }^{29}$ Thus, while he had not identified the correct composition of

\footnotetext{
124 'matière charbonneuse dans l'état de vapeur' lbid., 255.

125 H. E. Le Grand, "Lavoisier's oxygen theory of acidity," Annals of Science 29, no. 1 (1972): 9.
}

${ }^{126}$ Antoine Laurent Lavoisier, "Mémoires sur la formation de l'acide nommé air fixe ou acide crayeux, et que je désignerai désormais sous le nom d'acide du charbon," in Oeuvres Vol. 2 [1865] (Paris: Imprimerie Impériale, 1781). Lavoisier, "Mémoires sur la formation de l'acide nommé air fixe ou acide crayeux, et que je désignerai désormais sous le nom d'acide du charbon," Histoire de l'Académie royale des sciences (1781 [1784]).

127 'air inflammable aqueux' or 'air inflammable de l'eau' Lavoisier, "L'acide nommé air fixe," 414.

128 'air inflammable lourd, c'est-a-dire pesant 0,128 le pouce cube' Ibid., 416.

129 'il est probable qu'[une quantité d'acide du charbon] est resté intimement unie a l'air inflammable' Ibid., 417. 
methane, he had narrowed down its constituents to three elements: oxygen (as he now called it), inflammable air, and carbon.

In the meantime, Volta's Lettere were translated into French, with extracts published in the Observation sur la physique ${ }^{130}$ and the Journal des sçavans, the latter of which misunderstood Volta, presenting him as not claiming the discovery of a new kind of inflammable air, but one that was 'essentially of the same nature as the inflammable air from the dissolution of metals; that is, combustible substances in form of air'. ${ }^{131}$ An obscure chemist named Neret (fils, for there are two) decided to follow up Volta's discovery and published a couple of memoirs in the Observations sur la physique in 1779.132 Neret thought that marsh gas, which he also identified with the gas from the distillation of animal and vegetable compounds, was a 3 to 1 mixture of fixed air and a different sort of inflammable air which was produced in its pure form by distilling oils. This oil gas is in fact a different mixture of gases. ${ }^{133} \mathrm{He}$ tried mixing his oily inflammable air with three times as much fixed air to see if could make marsh gas by artificial means, but he could not re-create it with the same properties: his mixture reacted heavily with lime water indicating the presence of fixed air, whereas marsh gas

\footnotetext{
130 Jean-Baptiste Le Roy, "Lettre de M. de Le Roy, de l'Académie des Sciences, adressée à l'auteur de ce recueil relative aux expériences sur l'air inflammable des marais découvert par M. Volta," Observations sur la physique, sur l'histoire naturelle et sur les arts 11 (1778). cites the places p. 152, 219 in same volume

131 'essentiellement de même nature que l'air inflammable des dissolutions métalliques; c'est-à-dire, que ce sont des matières combustibles sous forme d'air' "Lettres de M. Alexandre Volta," 1075.

132 Neret, "Sur une nouvelle espèce de Gas inflammable," Observations sur la physique, sur l'histoire naturelle et sur les arts 14 (1779). Neret, "Second Mémoire Sur le principe de l'Inflammabilité des corps combustible, ou Gas inflammable huileux " Observations sur la physique, sur I'histoire naturelle et sur les arts 14 (1779).

133 Neret, "Second Mémoire Sur le principe de I'Inflammabilité des corps combustible, ou Gas inflammable huileux ": 129.
} 
only weakly clouded lime water. He supposed that the fixed air and oily inflammable air in his artificial marsh gas were not strongly bound: 'perhaps there is only a weak link and adhesion between the fluid molecules of these two airs'. The stronger bonds in natural marsh gas had to do with details of its formation of which he was not aware. Neret's concept of chemical bonding seems to be on a continuum with mechanical mixing.

Neret also compared the explosivity of these three gases when mixed with dephlogisticated air in various proportions, and also noted that oily inflammable air was much denser than metallic inflammable air by setting two decanters of the gases on top of one another, and remarking that they mixed rapidly when the metallic inflammable air was below, but hardly at all in the reverse situation. ${ }^{134}$

Barbier de Tinan, the same Strasbourg physics professor who met Volta on his 1777 visit there and corresponded with him subsequently, had a public exchange with Neret. When he read Neret's reports, he and Neret published four letters in the Observations, two in 1780 , two in $1782 .{ }^{135}$ In the first missive, among other things, Barbier pointed out that using Magellan's eudiometer, he had shown that marsh gas vitiates common air much more than inflammable air from metals, and concurred with

\footnotetext{
134 'peut-être y a-t-il toujours peu de liaison \& adhérence entre les molécules fluids de ces deux airs' lbid.: 297.

135 Barbier de Tinan, "Lettre á M. Neret fils, sur les Airs inflammables," Observations sur la physique, sur I'histoire naturelle et sur les arts 15 (1780). Neret, "Réponse de M. Neret fils a la Lettre de M. Barbier de Tinan, sur l'Air des Marais \& les différents espèces de Gaz inflammable," Observations sur la physique, sur l'histoire naturelle et sur les arts 15 (1780). Barbier de Tinan, "Lettre á M. Neret fils, sur les Airs inflammables," Observations sur la physique, sur l'histoire naturelle et sur les arts 19 (1782). Neret, "Réponse de M. Neret fils a la seconde Lettre de M. Barbier de Tinan, sur l'Air des Marais \& les différents espèces de Gaz inflammable," Observations sur la physique, sur l'histoire naturelle et sur les arts 19 (1782).
} 
Neret's view that marsh gas was some sort of inflammable air mixed with another gas, which in his view was phlogisticated air. Neret replied stating that Fourcroy and his collaborator Jean Baptiste Michel Bucquet had managed to make metallic inflammable air from marsh gas, and insisted that fixed air was an essential constituent of marsh gas. When Barbier de Tinan got around to answering two years later, he said that Volta had read their original exchange, and had disagreed with Neret, specifically about the composition and detonating nature of marsh gas. ${ }^{136}$ Volta thought that marsh gas did not contain fixed air and had done experiments to prove it which he would send along. ${ }^{137}$ Barbier, on the other hand, thought with Volta that it did contain phlogisticated air, but unlike Volta, insisted it included fixed air, a point he tried to prove to Volta. ${ }^{138}$

As Neret had indicated to Barbier de Tinan, like Lavoisier, Fourcroy had also followed up the Dietrich demonstrations with experiments of his own. Unlike Lavoisier, for many years after Volta's work he sided with Macquer's view that there was only one kind of inflammable gas, with all others, including gas from the distillation of organic compounds and marsh gas, being merely mixtures of pure inflammable gas with chalky acid (carbon dioxide). As he wrote in his 1782 Leçons élémentaires, after summarizing Lassone's and Lavoisier's work: 'Chemists are not agreed about the species of inflammable gas. [...] It is true that an exact analysis has shown that they are composed of pure true detonating inflammable gas and chalky acid in various proportions. We can

\footnotetext{
136 Barbier to Volta 1780/11/13, Volta, Espistolario, vol 2, 11-14.

137 Barbier de Tinan, "Lettre á M. Neret fils, sur les Airs inflammables," 457.

138 Barbier to Volta 1780/11/13 Volta, Espistolario, vol 2, 13.
} 
bring these mixtures to pure inflammable gas using lime water and caustic alkalis'. ${ }^{139}$

This statement was based experiments he described in papers presented to the Académie in March 1780 and July $1782 .{ }^{140}$ In those papers, Fourcroy explained how he collected marsh gas, and after purifying it of all the chalky acid he could by passing it through lime water several times, its volume was diminished by a half. When burned, its flame was hardly blue anymore, and was now explosive and burned easily, unlike in its unpurified state. Volta had missed this, Fourcroy claimed with satisfaction, and he had demonstrated that marsh gas was not a new kind of inflammable gas, but a mixture of the pure kind with chalky acid and some odours. ${ }^{141}$ It is remarkable that Lavoisier had at this same time performed the exact same experiment, and had come to precisely the opposite conclusion, although as Fourcroy's second paper demonstrates, the divergence was not about the composition of marsh gas, but more philosophically over what is meant by a species of inflammable air. ${ }^{142}$

In the second paper, Fourcroy relates experiments he has made to confirm this opinion. Like Neret, he had tried to make artificial marsh gas by mixing chalky acid and pure inflammable gas (hydrogen). To his dismay, while he found that although his mixture possessed some of the properties of marsh gas, such as its slow blue flame,

\footnotetext{
139 'Les Chimistes ne sont point encore d'accord entr'eux sur les espèces de gaz inflammable [...] Une analyse exacte nous a prouvé, il est vrai, que ces derniers sont des composés de véritable gaz inflammable pur \& détonnant, avec de l'acide crayeux en différentes proportions, \& qu'on peut, par l'eau de chaux, \& les alkalis caustiques, l'amener à l'état de gaz inflammable pur' Antoine-François Fourcroy, Leçons élémentaires d'histoire naturelle et de chimie, 2 vols. (Paris: Sous le privilège de la Société Royale de Medicine, 1782), 404-5.

140 Both were published in Fourcroy, Mémoires et observations de chimie (Paris: Cuchet, 1784).

${ }^{141}$ Fourcroy, Leçons élémentaires d'histoire naturelle et de chimie, 155-6, 63.

142 Macquer has a disquisition on 'species' in his article on inflammable air in the Dictionnaire, and his reasons for stating that there is only one kind is quite a priori and philosophical.
} 
increased density, and decomposition into the same substances, his artificial marsh gas, in addition to lacking a smell, was more easily decomposed. He could separate the chalky acid out of his concocted gas very easily with lime water. This he attributed to stronger bonding of the natural sort of the gas: it was 'mieux bien combiné'.143 In this way, he reconciled himself to the second of Lavoisier's suggested possibilities, which was that carbon dioxide was released during the combustion of marsh gas, rather than being formed. For Fourcroy, marsh gas was then a firm combination of inflammable gas and fixed air, one which could not be broken up by lime water, but could be released in combustion. Fourcroy also pointed out in his second paper that marsh gas was a poor name as the same gas was also produced in many other ways, such as the distillation of organic compounds. ${ }^{144}$

The discovery that pure inflammable air from metals, hydrogen as it was soon to be called, forms only water when burned with pure oxygen made clear the demarcation between it and all the other kinds of inflammable airs. The story of the synthesis of water is too well known to be repeated here, but Lavoisier, Cavendish and Watt all synthesized water and published the results in 1783-4, even if giving different interpretations to the results. ${ }^{145}$ While this made clear that hydrogen did not form carbonic acid on combustion, it did not help to resolve the questions about what precisely was Volta's marsh gas. In addition, the majority opinion among chemists of this period seems to be that all species of inflammable airs are impure inflammable air

\footnotetext{
143 Fourcroy, Leçons élémentaires d'histoire naturelle et de chimie, 172-3.

144 lbid., 186.

145 Davide Philip Miller, Discovering Water: James Watt, Henry Cavendish, and the Nineteenth Century 'Water Controversy' (Ashgate Publishing, Ltd., 2004).
} 
(hydrogen), whether mixed with fixed air or any number of other substances.

Lavoisier's question remained unanswered: was carbonic acid formed or released in the combustion of marsh gas? Was this marsh gas a tightly bound compound of hydrogen and carbonic acid, or was carbonic acid formed by other means? Lavoisier's work on the composition of carbonic acid and water paved the way for the answer, but until methane could be purified effectively from other gases the answer remained elusive.

The muddle about the number of species of inflammable airs at this period is reflected in a couple of books on pneumatic chemistry published in 1784-5. Jean Senebier, Volta's Geneva-based friend, frequent correspondent, and French translator published the first book dedicated exclusively to inflammable air entitled Recherches analytiques sur la nature de l'air inflammable in 1784. The book did not help clarify the situation about the kinds of inflammable air, and Senebier seemed confused even about hydrogen, although he knew of Lavoisier's work. He dedicates separate chapters to inflammable air from iron and vitriolic acid (sulphuric acid), and from zinc and marine acid (hydrochloric acid), both of which are hydrogen, although they had different odours because of other substances released in the dissolution of the metals. For Senebier, then, RECHERCHES A N A L Y T I Q U E S $S U R$ LA NATURE

DE L'AIR INFLAMMABLE ; $P \cdot A R$ IEAN SENEBIER, Miniftre du Saint-Evangile \& Bibliothécaire de la République de Genève. species of inflammable air are just mixtures. Senebier's usage of the singular noun 'air' in the title and much of the book, combined with chapters dedicated to various characteristics of inflammable airs from different sources add to the confusion. ${ }^{146}$ 
Senebier, however, extensively enumerates modes of making inflammable air, and points out that coal produces it great quantities referring to it as a 'mine of inflammable air'. ${ }^{147}$ His opinion was that heavy inflammable air was a composed of water, acid or a salt, and phlogiston. ${ }^{148}$

In the following year, Jean-Claude de La Métherie (1743-1817) came out with his Essai analytique sur l'air pur et les différentes espèces d'air. De La Métherie was a doctor who become the editor of the Observations sur la physique in 1785. Like Senebier, he used the singular when referring to inflammable air, but spoke of different species from different sources, concluding on one hand that 'one could make as many species of inflammable air as there are agents which release it', but 'by washing the inflammable airs and removing from them all extraneous principles, they seem to constitute but a single species' which he equated to Stahl's phlogiston. ${ }^{149}$ Senebier and De La Métherie used the concept of species so broadly that almost any gaseous mixture that inflames would merit the title.

\footnotetext{
147 'mine d'air inflammable' Jean Senebier, Recherches analytiques sur la nature de l'air inflammable (A Geneve: Chez B. Chirol, 1784), 127, 46. refers to article Carra, "Lettre écrite le 8 du mois dernier a M. ${ }^{* * *}$, membre de plusieurs académies, par $\mathrm{M}$. Carra, pour réclamer la priorité de l'invention de deux ballons dans les expériences de nautique aérienne proposées à l'académie des sciences de Paris," Journal encyclopédique ou universel 2, no. 2 (1784).

148 Senebier, Recherches analytiques sur la nature de l'air inflammable, 145, 306.

149 'on en pourroit faire autant d'espèces qu'il y a d'agens qui le dégagent' but 'en lavant ces airs inflammables, \& les dépouillant autant que l'on peut des principes qui leur sont étrangers, ils paroissent ne constituer qu'une seule espèce' Jean-Claude de La Métherie, Essai analytique sur l'air pur et les différentes espèces d'air (Paris: [s.n.], 1785)., Partington, A History of Chemistry, vol 3, 494-5.
} 


\subsection{Ballooning}

The topic of inflammable air went from being a fairly mundane and secondary subject of discourse among a select group of chemists to a subject of everyday conversation throughout Europe in 1783 with the sensation created by the inaugural balloon flights of the Mongolfier brothers, followed soon thereafter by Jacques Charles and Louis Robert's flight in Paris. The ballooning episode provided an opportunity to secure credit for pneumatic chemistry in the eyes of the broader public. ${ }^{150}$ The Montgolfier brothers used hot air, although this was not immediately clear to anyone, even the Mongolfiers themselves, since they thought their fires were also producing new gases which contributed to the balloon's buoyancy. Their flights created a sensation, prompting government officials all over Europe to trip over themselves promoting research into balloons and inflammable gases, with the leading chemists of France, including Lavoisier and Berthollet, getting into the act. Charles' balloon was a product of this excitement, and he used hydrogen generated from metals and acids in his balloon.

While most of the interest in the ballooning craze was focused on hydrogen with its lower density, other inflammable gases did not escape attention. ${ }^{151}$ Producing hydrogen in large quantities was bound to be expensive and cumbersome, and so balloon enthusiasts 'discovered' that inflammable gas could also be produced by distilling coal and other materials, and for a fraction of the cost of hydrogen. A certain Lapostolle, who is frequently mentioned in histories of coal-gas, though without any real contribution to

150 Kim, "'Public' Science," 299.

151 lbid.: 305. 
the matter, described with almost breathless enthusiasm in the January 24,1784 edition of the Journal de Paris what he thought was a newly discovered source of inflammable gas: 'the learned are trying to find ways of making an inflammable gas which is both cheap and has the lightness of the gas taken from the dissolution of iron. I frequently read that we have finally found a way of procuring an inflammable gas at a hundredth the cost. This gas is found in coal, and is extracted by distillation'. ${ }^{152}$ He goes on to describe how to distil coal in a pneumatic apparatus and how to purify it of oils by washing it in water, an indispensable step because the oils would coalesce on the sides of the balloon quickly making a mess of the fabric. Lapostolle does not cite the source of his information, but whatever the source, the original article was reprinted in part a couple of months later in the Journal encyclopédique ou universel in another article on ballooning, which includes mention of experiments in Germany, Austria, and Italy. ${ }^{153}$

\footnotetext{
152 'les Savans s'occupoient des moyen ... à former un gaz inflammable qui pût réunir le bon marché à la légéreté qui caractérise le gaz tiré de la dissolution du fer [...] [je] relis fréquemment qu'on est enfin parvenu à se procurer une espèce de gaz inflammable à cent fois meilleur marché [...] Ce gaz inflammable se trouve dans le charbon de terre; on l'en extrait par la distillation' Lapostolle, "Lettre de M. Lapostolle aux Auteurs du Journal," Journal de Paris, 24 January 1784.

153 Carra, "Lettre écrite le 8 du mois dernier a M. ${ }^{* * *}$, membre de plusieurs académies, par M. Carra, pour réclamer la priorité de l'invention de deux ballons dans les expériences de nautique aérienne proposées à l'académie des sciences de Paris."
} 


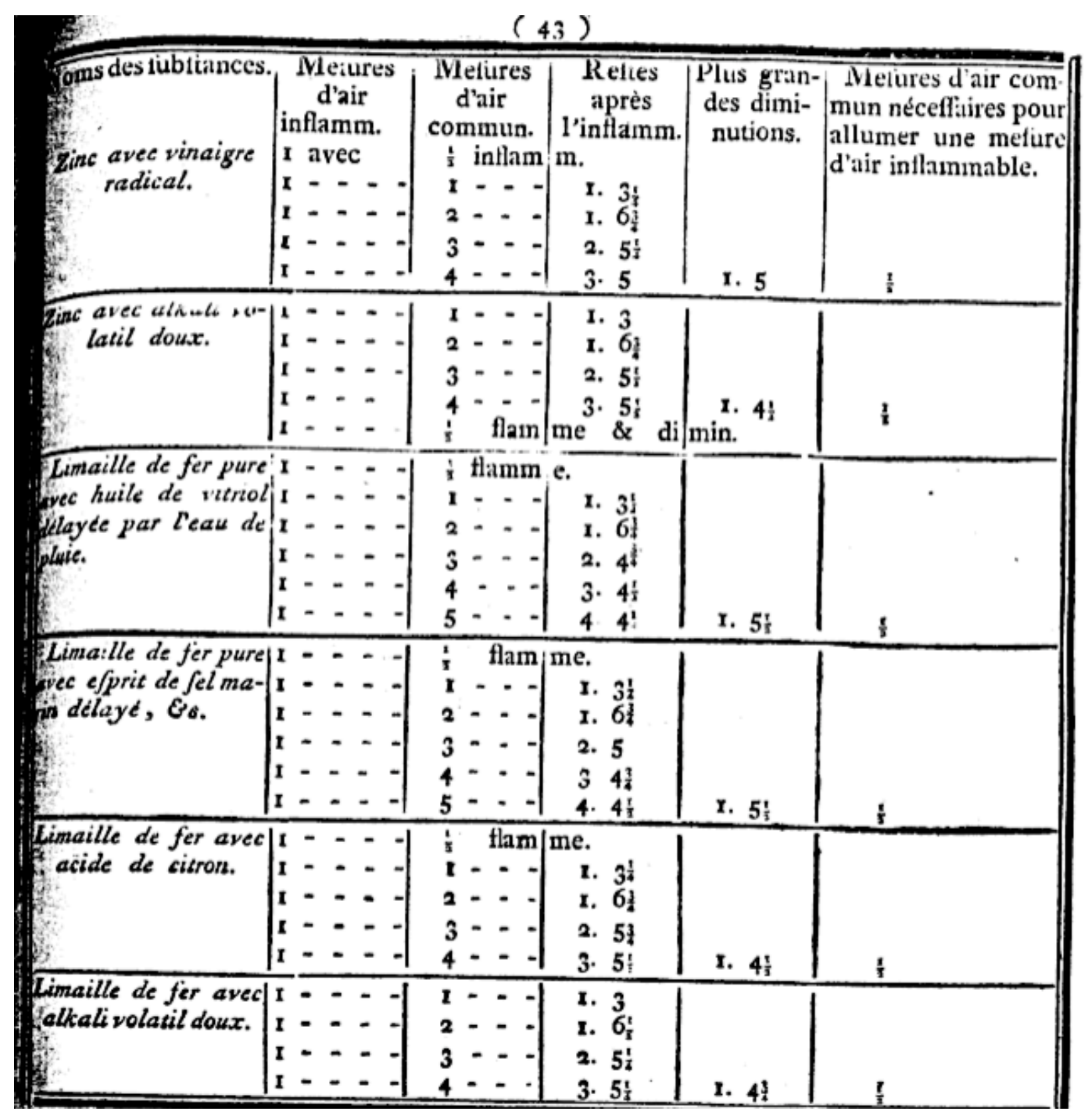

Figure 1.9 Table from J. P. Minckelers' Mémoire sur l'air inflammable tiré de différentes Substances (1784) 
The ballooning craze's most tangible impact on gaslight came about in Louvain at the hands of Jan Pieters Minckelers (1748-1824). ${ }^{154}$ Minckelers was a professor of natural history and lecturer of chemistry at the university of Leuven. He and two other natural philosophers at the university, Jan-Frans Thysbaert and Carolus Van Bochaute were commissioned in 1783 by their patron, the duc d'Arenberg to investigate ballooning, and specifically how to make inflammable air abundantly and cheaply. The three of them were well acquainted with pneumatic chemistry, as demonstrated by surviving engravings of the laboratory apparatus at the university, as well as the references in Minckelers eventual publication, the Mémoire sur l'air inflammable (1784). ${ }^{155}$ Minckelers and company worked intensely on their assigned task, doing many experiments and eventually floating balloons in the space of a few months. In an effort to find the best and cheapest inflammable air, they distilled all sorts of organic substances, from straw to wood to bones to nuts, and measured the densities of the evolved airs, which they listed in tables included in the Mémoire. Because of their narrow focus, the paper includes almost no other details about the gases. In the end, they decided to use coal-gas for their ballooning experiments because of how easy it was to produce in large quantities when light coal was subjected to high heat in closed retorts. ${ }^{156}$

\footnotetext{
154 The name is frequently misspelt 'Minkelers'. This is due to the printer's omission of the 'c' when his paper on inflammable airs was printed. See P. A. Th. M. Jaspers and J. Roegiers, "Le Mémoire sur l'air inflammable de J. P. Minckelers (1748-1824)," Lias 10, no. 2 (1983): 219. For more details about Minckelers in the context of the ballooning craze, see Peter J. Austerfield, "The development of largescale production and utilisation of lighter-than-air gases in France, Britain and the low countries from 1783 to 1821 with reference to aeronautics and the coal-gas industry" (Ph.D., University of London, 1981), 138-60. and Jaspers and Roegiers, "Le Mémoire sur l'air inflammable."

155 Jean Pierre Minckelers, Mémoire sur l'air inflammable tiré de différentes substances (Louvain, 1784). 156 P. A. Th. M. Jaspers, J.P. Minckelers, 1748-1824 (Maastricht: Stichting Historische Reeks, 1983), 42.
} 
Sometime in 1785 , Minckelers lighted his lecture hall with coal-gas, and this was later extended to some student bedrooms. Unfortunately, there seems to be no surviving contemporary evidence for Minckelers' gaslighting, other than remembrances of one or two of his students made almost 50 years after the fact. ${ }^{157}$ The earliest mention of his lighting are some reports written in 1832 and 1839, after Minckelers' death. ${ }^{158}$ Few details survive about Minckelers' apparatus and about the success (or lack thereof) of his lighting techniques. Minckelers had to flee Louvain in 1790 due to political turmoil there, and presumably left the gaslight apparatus behind, never to take it up again. Nor did his work influence any subsequent development of gaslight. It has been claimed that Minckelers' apparatus survived until the First World War when it was destroyed. ${ }^{159}$

From the point of view of possible inspirations for Minckelers' idea of using gas for lighting, it is known that Volta visited Louvain on at least two occasions, and gave lectures and demonstrations of his apparatus, certainly of his eudiometer, and possibly his lighter, to an audience including Minckelers. ${ }^{160}$ Was Volta's lighter the inspiration for Minckelers' gaslight? Lacking contemporary documents, it cannot said for certain, but

\footnotetext{
157 Charles Morren, "Notice sur la vie et les travaux de Jean Pierre Minkelers," Annuaire de l'Académie royale des sciences et belles-letres de Bruxelles 5 (1839): 82. Morren, "Invention de l'éclairage au gas," Bulletins de l'Académie royale des sciences, des lettres et des beaux-arts de Belgique 2 (1835).

158 Jaspers, J.P. Minckelers, 1748-1824, 47-8. Minckelers, Mémoire sur l'air inflammable tiré de différentes substances, 20-21.

159 Austerfield, "The development of large-scale production and utilisation of lighter-than-air gases", 395., citing Eg Adry, Un siècle d'éclairage, 1824-1924 (Anvers: Ratinckx frères, 1925).

160 Jaspers and Roegiers, "Le Mémoire sur l'air inflammable," 251, note 45. The eudiometer in paragraph 16 of the Mémoire.
} 
we do know that Volta had demonstrated his lighter at other times during voyages, and that it was copied on those occasions by members of his audience.

Despite the limited extent of the implementation and little subsequent influence of Minckeler's work, it is important for the history of gaslight. It demonstrates that by 1785 , pneumatic chemistry had progressed to the point where someone knowledgeable in pneumatic chemistry such as Minckelers had sufficient understanding about the manipulation and properties of gases to be able to put together coal-gas producing apparatus in less than a year. Minckelers was no neophyte in regard to chemistry. He had been steeped in the subject and was chosen for the ballooning research precisely for this reason. Minckelers and compatriots knew, for example, that fixed air could be removed from coal-gas using lime water. ${ }^{161}$ Nor was his work a triviality. He was exposed to all the leading chemical research of the period, and had even been in touch with Volta, from whom he may have heard of lighting by inflammable gas. If this was the case, the Minckelers' true achievement was not the invention of lighting by gas, nor the discovery of coal-gas, but of the first successful application of lighting by coal-gas in a scale larger than a desktop scientific instrument.

Ballooning did not otherwise directly influence gaslighting, as hydrogen proved to be the only feasible gas for balloons, ${ }^{162}$ and the apparatus used to make it, involving mixing acids and metal filings, was far removed from the distillation and purification

\footnotetext{
161 Barthélemy Faujas-de-Saint-Fond, Description des expériences de la machine aérostatique de MM. de Montgolfier, et de celles auxquelles cette découverte a donné lieu (Paris: Cuchet, 1783-4), vol 2, 244. Minckelers, Mémoire sur l'air inflammable tiré de différentes substances, 12.

162 See Austerfield, "The development of large-scale production and utilisation of lighter-than-air gases". for a detailed chronology. Austerfield dwells mostly on the production of gases for ballooning.
} 
apparatus of methane gas production. The Louvain university group was also not the only ones to investigate inflammable gases from many sources on a large scale. Louis Bernard Guyton de Morveau (1737-1816) and François Chaussier also made investigations much like Minckelers and company for the same reasons, and similarly published an account of many different sorts of gases and how to produce them. ${ }^{163}$

\subsection{Carbonated hydrogen II 1785-1800}

Claude-Louis Berthollet (1748-1822) made the most thorough and penetrating analysis of heavy inflammable air of anyone up to this date, and showed that it was composed of inflammable air from metals (hydrogen) and carbon. Before the ballooning episode, he had already been investigating inflammable airs by distilling many substances. ${ }^{164}$ He presented his completed research to the Académie in 1785 . He was primarily interested in analysing volatile alkali (ammonia) and 'mofette' (nitrogen) in various materials, including animal and plant matter. He found over the course of his work that he had to understand the nature of the evolved gases better in order complete his analysis. He was aware of Foucroy's opinion that heavy inflammable air was merely light inflammable air mixed with fixed air, Neret's and Barbier de Tinan's view that all heavy inflammable air was derived from inflammable air from oil, as well as Senebier's hypothesis that it was a combination of water, an acid, and phlogiston. He astutely

\footnotetext{
163 Louis Bernard Guyton de Morveau and Francois Chaussier, Description de l'aérostate l'Academie de Dijon : contenant le détail des procédés, la théorie des opérations, les dessins des machines \& les procès-verbaux d'expérieces (Dijon: Causse, 1784), 46-106.

164 Antoine Laurent Lavoisier, "Réflexions sur les points principaux qui doivent occuper les commissaires nommés pour les machines aérostatique," in Oeuvres Vol. 3 [1865] (Paris: Imprimerie Impériale, 1783), 744, 46., and Austerfield, "The development of large-scale production and utilisation of lighter-than-air gases", 225-6.
} 
rejected all these for a number of reasons. First, water had been shown to be a compound of inflammable air and vital air. Second, heavy inflammable air could not be a mixture of light inflammable air (hydrogen) with fixed air, because as Volta had observed, it required more vital air to burn than light inflammable air, not less as one would expect if it were a mixture of fixed and light inflammable air. Third, it could not be merely oily inflammable air, as dry coal -lacking almost any oil-could produce inflammable air, and this left unexplained what oily inflammable air was. Fourth, when light inflammable air and vital air burn, they give neutral water, with no evidence of acid. 165

Having rejected all earlier hypotheses, Berthollet tested inflammable air from charcoal, sugar, oil, marshes, and silk. ${ }^{166}$ After removing all the fixed air he could by lime water, he detonated it with vital air repeatedly until the residue was no longer combustible. He measured the resulting fixed air, and from there calculated the quantity of carbon contained in the original inflammable air using Lavoisier's calculations of the composition of fixed air. Berthollet, however, decided that it was best to work with inflammable air from charcoal as it seemed the purest, lacking the smell of acid. He judged all other heavy inflammable airs to be based on this one. He then tried to determine how much light inflammable air was combined with carbon in the heavy inflammable air by assuming the rest of the vital air had formed water. He concluded

165 Claude-Louis Berthollet, "Suite des recherches sur la nature des substances animales, et sur leurs rapports avec les substances végétables," Histoire de l'Académie royale des sciences (1785 [1788]): 340.

166 The French word used was 'soie', but contemporary dictionaries define this as silk or fur. "SOIE," in Dictionaire critique de la langue française, ed. Jean-François Féraud (A Marseille: Chez Jean Mossy Pere et Fils ..., Place: France; Marseille., 1787). 
that heavy inflammable air had in general twice the light inflammable air than an equal volume of light inflammable air, which of course is the correct value for methane. ${ }^{167} \mathrm{He}$ finished the paper by stating that heavy inflammable air was a compound of light inflammable air and carbon, although he did not think that the ratio between the two was fixed. ${ }^{168} \mathrm{He}$ recognized that airs from distillation could be quite variable, but he tried to mitigate this by not taking air produced right at the beginning of distillation.

Berthollet's work was presented to the Académie in December of 1785 , but was not otherwise made public at that time. It did appear in the Histoire de l'Académie royale des sciences but only in 1788 , as they were usually three years in arrears. In fact, Berthollet's work was not widely cited in the period and the influence of his research was more indirect, a result of the new nomenclature, as will be discussed below, than his research or this paper per se. It took almost a decade before his result for the ratio of carbon to hydrogen in methane was reproduced.

Outside of the French chemical circle who had access to Berthollet's work, the situation continued to be unclear, but some progress was being made. Joseph Priestley now makes a reappearance in this story. Although to the end of his life he remained unclear about the exact nature of the types of inflammable airs, ${ }^{169}$ he now acknowledged that ' $[\mathrm{t}] \mathrm{here}$ is an astonishing variety in the different kinds of inflammable

\footnotetext{
167 Berthollet, "Suite des recherches sur la nature des substances animales, et sur leurs rapports avec les substances végétables," 344-5.

168 Claude-Louis Berthollet, "Cinquante-deuxième séance: Chimie," Séances des écoles normales 5 (1800): 256.

169 Partington, A History of Chemistry, vol 3, $271 \mathrm{ff}$.
} 
air, the cause of which is very imperfectly known'. ${ }^{170}$ Confused as he was, Priestley in 1786 did the math on the combustion reaction and gave an answer to Lavoisier's question about whether fixed air was produced or released in the combustion of the 'heavier kinds of inflammable air'. It is interesting that despite Priestley's resistance to Lavoisier's anti-phlogistic chemistry, we see him here using another aspect Lavoisier's work: balancing products and reactants mathematically by weight. In repeated experiments, he purified heavy inflammable airs from many sources of fixed air by lime water, and burned it in dephlogisticated air to produce more fixed air which he then removed with lime water once again. By comparing how much fixed air was available after combustion, he demonstrated repeatedly that far more was present than could have been contained by weight in the heavy inflammable air, and that therefore it truly was produced in the reaction with dephlogisticated air and not released from the heavy inflammable air. ${ }^{171}$

In the same year (1786), Bryan Higgins (1737?-1818) in Experiments and Observations Relating to Acetous Acid ${ }^{172}$ was the first to state in print (as Berthollet's paper was published only in 1788) that the products of the combustion of dense inflammable air, as he called it, and oxygen were exclusively carbon dioxide and water, and to state that the composition of dense inflammable air was carbon and hydrogen,

\footnotetext{
170 Joseph Priestley, Experiments and observations, relating to various branches of natural philosophy with a continuation of the observations on air. Vol. III. By Joseph Priestley (printed by Pearson and Rollason, and sold by J. Johnson, London, 1786), 406-7.

171 Ibid., 171-73. See also p. 167-8 Priestley, Experiments and observations on different kinds of air and other branches of natural philosophy, connected with the subject. In three volumes; being the former six volumes abridged and methodized, with many additions. By Joseph Priestley (printed by Thomas Pearson; and sold by J. Johnson, London, 1790), vol 1, 311-12.

172 Acetous acid is acetic acid, which at the time were thought to be different. See Partington, A History of Chemistry, vol 3, 543, 643.
} 
although he did not use those terms. Higgins was a London based medical doctor who had eventually opened a School of Practical Chemistry in which he gave lectures and chemical demonstrations. ${ }^{173}$ In his work, Higgins proceeded using gravimetrically balanced products and reactants in various combustion reactions to arrive at his conclusions. ${ }^{174} \mathrm{He}$ tried to determine if other gases, such as phlogisticated air (nitrogen), ${ }^{175}$ are involved in these combustion reactions, and, by comparing the quantities present before and after combustion, concluded that they are not. Higgins believed from these experiments that dense inflammable air, which for him was any hydrocarbon denser than hydrogen, contained phlogiston (at this time, sometimes equated with hydrogen, as Higgins did $^{176}$ ) and the acid principle of fixable air (carbon, as Higgins seems to have agreed with Lavoisier's oxygen theory of acidity), ${ }^{177}$ arriving at the conclusion that '[t]herefore, the invariable products in the combustion of dense inflammable air, are fixable air, water, and fire, and nothing else'.178 This was in contrast to phlogiston, which yields no fixable air in combustion. ${ }^{179}$ Higgins also pointed out that

173 Ibid., vol 3, 727.

174 See, for example, Bryan Higgins, Experiments and observations relating to acetous acid, fixable air, dense inflammable air, oils and fuel, the matter of fire and light, metallic reductions, combustion, fermentation, putrefaction, respiration, and other subjects of chemical philosophy (London: Printed for T. Cadell, 1786), 26-30.

175 Ibid., 292-3.

176 Ibid., 290.

177 Ibid., 291. See also his William Higgins' interpretation, which is essentially the same. William Higgins, A comparative view of the phlogistic and antiphlogistic theories With inductions., The second ed. (printed for J. Murray, 1791), 249-50.

178 Higgins, Experiments and observations relating to acetous acid, 293.

179 lbid., 294. 
it 'is well known that charcoal continues to yield dense inflammable air, as long as it is urged with intense heat'. ${ }^{180}$

Neither Berthollet's nor Higgins' work, however, were sufficiently well known to dispel the general confusion over the heavier inflammable airs, nor lead to clarity about nomenclature. Bryan Higgins' nephew and assistant in these experiments, ${ }^{181}$ William Higgins complained three years later that 'neglecting to discriminate between the light and heavy inflammable airs, has been the chief cause of all the errors and confusion that at present prevail in the science of chemistry'. ${ }^{182}$ While he may have been putting the case too strongly, his gripe was apposite, and would be for some time yet.

A reform of chemical nomenclature, which encapsulated within it Berthollet's findings that heavy inflammable air was a compound of hydrogen and carbon was underway in France. In 1786, Guyton de Morveau, Lavoisier, Berthollet, and Fourcroy were forming a new chemical nomenclature, with the idea that chemical composition should be the basis of chemical names. The first edition of the new nomenclature, the Méthode de nomenclature chimique, was published in 1787. Within the list of gases, the former 'gaz inflammable charbonneux' became 'gaz hydrogène carboné'. ${ }^{183}$ This influential group of chemists had evidently been convinced by Berthollet that heavy

180 lbid., 293.

181 Higgins, A comparative view of the phlogistic and antiphlogistic theories With inductions., 249.

182 lbid., 250-1. and William Higgins, A comparative view of the phlogistic and antiphlogistic theories (London: J. Murray, 1789), 250., cited in Partington, A History of Chemistry, vol 3, 813.

183 Louis Bernard Guyton de Morveau et al., Méthode de nomenclature chimique (Paris: Cuchet, 1787), 123. 
inflammable air was a compound of hydrogen and carbon, and did not contain any fixed air, or carbonic acid as they now called it.

The new nomenclature was further expanded in Lavoisier's landmark Traité élémentaire de chimie (1789), and Lavoisier stated unambiguously that 'gaz hydrogène carboné' was a compound of hydrogen and carbon:

\begin{abstract}
When hydrogen and carbon are united without the hydrogen having been made into a gas by caloric, a particular combination is the result. It is known by the name of oil and this oil is either fixed or volatile according to the relative proportion of hydrogen and carbon. The two principles combine with caloric to form a gas, and it is to this form that oil changes during distillation. ${ }^{184}$
\end{abstract}

Lavoisier and company did not know of carbon monoxide, however, nor did they distinguish between hydrocarbon gases, except to acknowledge that carbon and hydrogen could mix in various ratios. In Lavoisier's chapter in the Traité on the separation of gases, the test for hydrogen and carbonated hydrogen was flame colour, white indicating hydrogen, and blue indicting a carbonated gas. ${ }^{185}$ All hydrocarbon gases continued to be lumped under carbonated hydrogen (or equivalent names) for the next ten years or so.

\footnotetext{
184 'Lorsque l'hydrogène et le carbone s'unissent ensemble sans que l'hydrogène ait été porté a l'état de gaz par le calorique, il en résulte une combinaison particulière, connue sous le nom d'huile, et cette huile est ou fixe ou volatile, suivant les proportions de l'hydrogène et du carbone. [...] Les deux principes ... se combinent avec la calorique pour former un gaz, et c'est dans cet état que les huiles passent dans la distillation.' Antoine Laurent Lavoisier and Marie-Anne-Pierrette Lavoisier, Traité élémentaire de chimie, présenté dans un ordre nouveau et d'après les découvertes modernes; avec figures (Paris: Cuchet, 1789; reprint, Oeuvres Vol. 1 [1865]), 88. Lavoisier cites research on oils published in 1784: Antoine Laurent Lavoisier, "Mémoires sur la combinaison du principe oxygine, avec l'esprit-de-vin, I'huile, \& differens corps combustilbes," Histoire de l'Académie royale des sciences (1784 [1787]).
}

185 Lavoisier and Lavoisier, Traité élémentaire, 272. 
The more philosophical question of what constituted a separate species of inflammable gas remained as viable as before. Fourcroy, even at this late date, persisted in the view that there was only one species of inflammable gas. Even in the fifth edition of his Leçons élémentaires (1793-4), he remained steadfast. After mentioning Lassone's gas (cyanogen), marsh gas, and gas from the distillation of organic compounds, he states: 'We agree with the illustrious Macquer that there is only one form of this inflammable species capable of modification by combining with different substances'. 186 Fourcroy regarded hydrogen as the principle of inflammability. In other inflammable compounds, the elements dissolved in hydrogen, whether carbon, sulphur, or otherwise, reduced its inflammability and increased its density. ${ }^{187}$ Fourcroy's view could be a transposition of older views about inflammable gases, such as Kirwan's or Guyton de Morveau's, into the new chemistry. According to this opinion hydrogen was pure phlogiston, combined with heat and hence the principle of inflammability in all substance. ${ }^{188}$

\footnotetext{
186 '[N]ous étions porté a croire, avec l'illustre Macquer ... qu'il n'y a qu'un être de cette espèce [inflammable] susceptible de plusieurs modifications par ses combinaisons avec différentes substances' Antoine-François Fourcroy, Elémens d'histoire naturelle et de chimie, Cinquième édition. ed. (A Paris: Chez Cuchet ... 1793), 327.

187 Ibid., 328.

188 Claude-Louis Berthollet, "Mémoire su l'Acde marin déphlogistiqué," Histoire de l'Académie royale des sciences (1785 [1788]): 281, 85 .
} 
When the new French nomenclature was imported into English, the term 'carbonated hydrogen' was coined. ${ }^{189}$ The new nomenclature was not universally accepted, however, and carbonated hydrogen continued to go by many names, such as carburetted hydrogen, hydro-carburet, carbonated hydrogenous gas, or hydrogenated carbon, as well as heavy or dense inflammable air, which continued to be frequent. The French chemists' opinion about the constitution of carbonated hydrogen became the most common view from this point (1790) forward, ${ }^{190}$ although it took some time for the stance to have been completed accepted in England, as William Nicholson observed in his 1795 Dictionary of Chemistry. In it he repeated Priestley's old view that heavy inflammable air could contain fixed air, but then comments that 'the French chemists, ... consider fixed air as an acid composed of vital air, united with a peculiar basis which forms the greatest part of the weight of charcoal, ... for they state, that [heavy inflammable air] consists of light inflammable air holding charcoal as the base of fixed air in solution'. ${ }^{191}$ Presumably, the difficulty in producing pure methane was a stumbling block.

189 Louis Bernard Guyton de Morveau et al., Method of chymical nomenclature proposed by Messrs. De Morveau, Lavoisier, ... To which is added, a new system of chymical characters, ... by Mess. Hassenfratz and Adet. Translated from the French, ... by James St. John, M.D. (printed for G. Kearsley, 1788), 90, 129. Antoine Laurent Lavoisier, Elements of chemistry in a new systematic order, containing all the modern discoveries, trans. Robert Kerr (printed for William Creech, and sold in London by G. G. and J. J. Robinsons, 1790), 198. The term carburetted hydrogen was coined later. In the 1793 translation of the Traité, the translator pointed out that the French 'carburé' was equivalent to the Latin 'carburettum', which could be translated as 'carburetted'. He continued to use 'carbonated', but it eventually became 'carburetted'. See p. 165.

190 See, for example, Richard Kirwan, Elements of mineralogy, 2nd with considerable improvements and additions ed. (London: Printed by J. Nichols, 1794), vol 2, 41.

191 William Nicholson, A dictionary of chemistry (London: printed for G. G. and J. Robinson, 1795), vol 1, 96. 
There are a couple of papers from the decade of the 1790s that looked at carbonated hydrogen, and specifically, whether hydrogen was a component of carbon or not. The first paper was by William Austin (1754-1793). Austin had lectured on chemistry at Oxford before becoming a physician at St. Bartholomew's Hospital in London, where he also taught chemistry. ${ }^{192}$ In a series of experiments, he decomposed heavy inflammable air by passing electric shocks through a small quantity of the gas over mercury. ${ }^{193} \mathrm{He}$ noted that the resulting gases contained over twice the original volume of light inflammable air, or hydrogen, mixed with 'pure charcoal', or carbon. Austin also claimed-erroneously - that the new gaseous mixture require more oxygen to burn than the original gas, indicating that hydrogen had somehow been formed in the electrification of the heavy inflammable air. He did not regard the carbon as being a constituent of the original gas, but rather copiously diffused throughout it in some way. ${ }^{194}$ Austin favoured the opinion that carbon itself was composed of hydrogen, and that the sparks decomposed it. He concluded that carbon is a compound of hydrogen and azote (nitrogen). Austin, however, was somewhat sloppy with his experiments, not always careful to ensure that combustion proceeded to completion, nor that he analysed the residues exactly, as William Henry was to point out.

192 Partington, A History of Chemistry, vol 3, 746.

193 William Austin and Charles Blagden, "Experiments on the Analysis of the Heavy Inflammable Air. By William Austin, M. D. Fellow of the College of Physicians; Communicated by Charles Blagden, M. D. Sec. R. S," Philosophical Transactions of the Royal Society of London 80 (1790).

194 William Henry and Thomas Henry, "Experiments on Carbonated Hydrogenous Gas; With a View to Determine Whether Carbon be a Simple or a Compound Substance. By Mr. William Henry. Communicated by Mr. Thomas Henry, F. R. S," Philosophical Transactions of the Royal Society of London 87 (1797): 403., Austin and Blagden, "Experiments on the Analysis of the Heavy Inflammable Air," 68-9. 
William Henry (1774-1836) examined one main question from Austin's paper seven years later: whether carbon was a compound and capable of decomposition by the sparks. ${ }^{195}$ William Henry was the son of Thomas Henry, a medical doctor and industrial chemist from Manchester. William had studied medicine and practised for five years, before actually earning an M.D. from Edinburgh in 1807. He maintained the family tradition by continuing research in chemical matters, including industrial chemistry. William Henry is best known for his eponymous gas law about the solubility of gases in liquids but he is important for the history of gaslight because of his extensive research and publications about coal-gas, which are unequalled in the period. Suffering ill health from a childhood accident which had been exacerbated by a failed surgical intervention, he had to give up chemical experimentation in the 1830 s and finally committed suicide.

In his experiments on the nature of carbon, Henry was careful in his experiments to remove any azotic gas he could, as he found it interfered with the decomposition of the gas by electricity, a measure not taken by Austin. ${ }^{196}$ Henry burned undecomposed carbonated hydrogen ${ }^{197}$ and compared the amount of carbonic acid produced with that of an equal measure of carbonated hydrogen, this time decomposed before combustion. By repeating the experiment many times, Henry concluded that no carbon was decomposed by the sparks. Whether carbon was compound or not, he could not

\footnotetext{
195 Henry and Henry, "Experiments on Carbonated Hydrogenous Gas." See also Farrar, Wilfred Vernon Brock W. H., and Richard Leslie Hills. Chemistry and the chemical industry in the 19th century : the Henrys of Manchester and other studies . Brookfield, Vt.: Variorum, 1997.

196 Henry and Henry, "Experiments on Carbonated Hydrogenous Gas," 406.

197 Henry uses the term carbonated hydrogen, which was synonymous with hydrocarburret, as a letter from his father Thomas to Watt demonstrates.
} 
say, but only that it was not decomposed by electricity, nor by combustion. He rejected Austin's conclusions and pointed out that in addition to Austin's measurement errors, he sometimes left his carbonated hydrogen sitting over water for a long time, with the result that azote would be mixed with gas. ${ }^{198}$ Neither Henry nor Austin were able to conclude that carbonated hydrogen was a two to one ratio compound of hydrogen and carbon (taking hydrogen as $\mathrm{H}_{2}$ ) as Berthollet had done, as they could not sufficiently purify the gas, nor indeed was it their purpose to determine this ratio. It was John Dalton who finally made this conclusion in 1808 , over twenty years after Berthollet had produced his results. ${ }^{199}$

Carbon monoxide would not be clearly distinguished for another ten years, until the independent work of William Cruikshank in England, and Charles-Bernard Desormes and Nicolas Clément in France in 1801.200 Ethylene $\left(\mathrm{C}_{2} \mathrm{H}_{4}\right)$ was the first gaseous hydrocarbon to be distinguished from methane because of its properties, decisively putting to an end the grouping of all carbonated hydrogen as a single kind of gas. Ethylene had been first reported by Ingenhousz in 1779,201 but it was only analysed in 1796 by the Dutch chemists (Johann Deiman, Adrien Paets Van Toostwijk, Peter Nieuland, Antoni Lauwerenburgh, and Nicolas Bondt) as a compound of hydrogen

\footnotetext{
198 Henry and Henry, "Experiments on Carbonated Hydrogenous Gas," 411.

199 John Dalton, A new system of chemical philosophy (Manchester: R. Bickerstaff, 1808), vol 1, part 2, 442. ff. Partington, A History of Chemistry, vol 3, 818-9.

200 See Partington, A History of Chemistry, vol 3, 816.

201 Jan Ingenhousz, "Account of a New Kind of Inflammable Air or Gass, Which Can Be Made in a Moment without Apparatus, and is as Fit for Explosion as Other Inflammable Gasses in Use for That Purpose; Together with a New Theory of Gun-Powder. By John Ingen-Housz, Body Physician to Their Imperial Majesties, and F. R. S," Philosophical Transactions of the Royal Society of London 69 (1779).
} 
and carbon. ${ }^{202}$ Fourcroy named it olifiant gas because it produced an oil (ethylene dichloride, $\mathrm{C}_{2} \mathrm{H}_{4} \mathrm{Cl}_{2}$ ) when reacted with chorine. ${ }^{203}$ These later developments were not, as will be seen, crucial to gaslight, and I will not go into them in detail here.204

\subsection{The Gasometer}

Nomenclature and composition were not the only elements of Lavoisier's Traité of direct influence on gaslight. The third section of his historic work was devoted to chemical laboratory techniques and apparatus: 'la description sommaire de tous les appareils et de toutes les opérations manuelles qui ont rapport a la chimie élémentaire'.205 This included a section dedicated to pneumatic chemistry. After describing the pneumatic trough as implemented by Priestley, Lavoisier explained his gasometer in detail. The gasometer, as the name implies, was an instrument used to store gas and measure its volume. The pressure on the enclosed gas was regulated by a counterweight sitting in a pan supported by a balance arm which raised the gasometer's holding tank as it filled with gas. The gasometer's origins go back to the years when Lavoisier first began investigating gases and their properties and regarding them as chemical agents. Lavoisier initially used a modified pneumatic trough that included spigots on the gas receptacle to let out gas in controllable quantities. This

\footnotetext{
202 See Antoine-François Fourcroy, "Extract of a Memoir concerning three different Species of Carbonated Hydrogenous Gas, obtained from Ether and Alcohol by different Processes," A Journal of natural philosophy, chemistry and the arts 1 (1797).

203 Partington, A History of Chemistry, vol 3, 584.

${ }^{204}$ For a summary of the current state of knowledge about inflammable gases see Berthollet, "Cinquantedeuxième séance: Chimie.", especially 255-259.

205 Lavoisier and Lavoisier, Traité élémentaire, 246.
} 
arrangement, however, was not adequate, because as Lavoisier started to use gravimetric measurements in his work, he had to find a way to include the mass of gases in his calculations. Weighing a given quantity of gas is not an easy matter, but volume, if the density of the gas is known, serves as an effective route to find the its mass. The gasometer, designed to measure the volume of a gas, was the solution. Lavoisier developed it in conjunction with an military engineer named Jean-Baptiste Meusnier (1754-1793) over the course of a number of years. ${ }^{206}$ It was built by the instrument maker Pierre Mégnié between 1785 and 1788, and was presented to the Académie in March of that year.207 The final version was a large and very expensive instrument-costing 636 livres - which could not have been reproduced by any except the best instrument makers, nor afforded by any except the best funded chemists of Europe.208

\footnotetext{
206 Jean Baptiste Meusnier, "Description d'un appareil propre a manoeuvrer différentes espèces d'airs," Histoire de l'Académie royale des sciences (1782 [1785]).

207 For more details, see Trevor Levere, "Lavoisier's Gasometer and others: Research, Control, and Dissemination," in Lavoisier in perspective, ed. Marco Beretta (Munich: Deutsches Museum, 2005). 208 Ibid. 9
} 


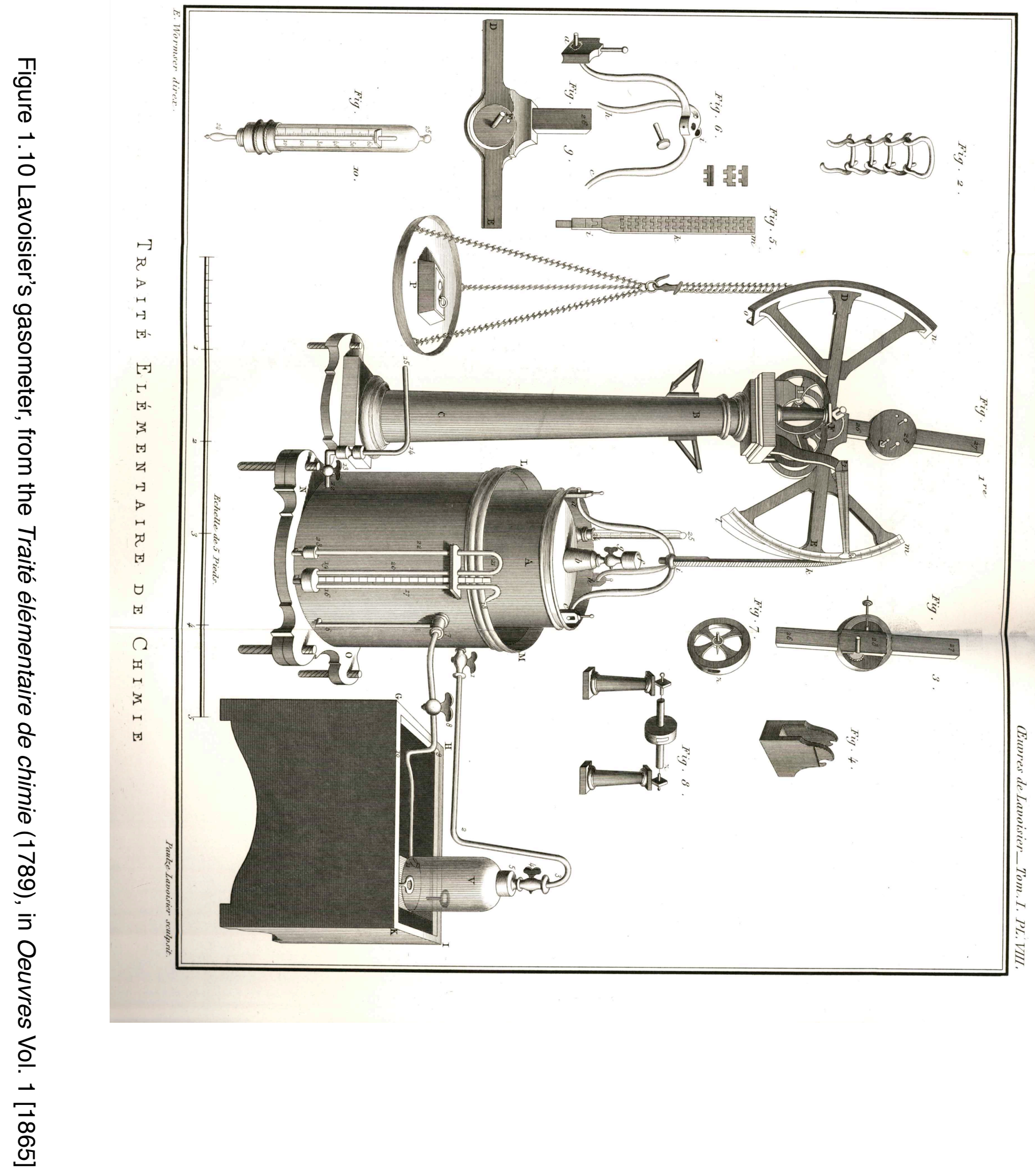




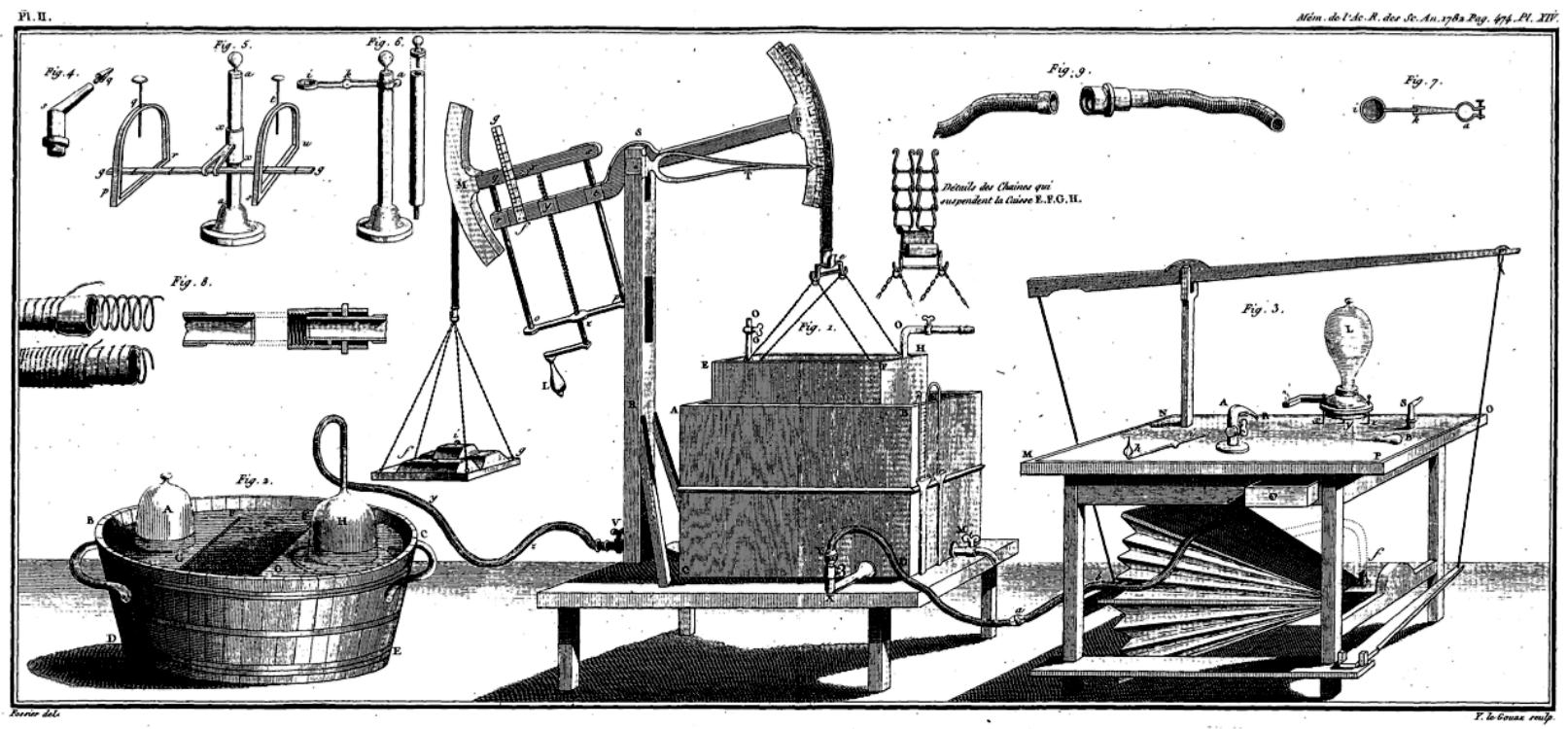

Figure 1.11 Meusnier's gasometer, from the Histoire de l'Académie royale des sciences (1782 [1785])

With the wide diffusion and extensive influence of Lavoisier's work, coupled with the ongoing interest in pneumatic chemistry, gasometers soon became a more common feature in chemical laboratories. Instrument makers throughout Europe started to make them. ${ }^{209}$ References to gasometers appear in chemical texts of the period, often referring the reader to the Traité. ${ }^{210}$ Lavoisier's gasometer, however, was not the model

209 The Dumotiez brothers advertised it in 1795. See also Frederick Christian Accum, "Description of an improved Gazometer," The repertory of arts, manufactures, and agriculture 2nd series, 5 (1804): 179. For a contemporary history of the gasometer see Ludwig Gilbert, "Von den veschiedenen Gasmessern, und Beschreibung des von Seguin erfundenen Gazometers," Annalen der Physik 2, no. 2 (1799). and Friedrich Parrot, Ueber Gasometrie nebst einigen Versuchen über die Verschiebbarkeit der Gase (Dorpat: 1811).

210 Jean-Antoine-Claude Chaptal, Elements of chemistry, trans. William Nicholson (London: Printed for G. G. J. and J. Robinson, 1791), vol 1, 200. "Chymistry," in The new encyclopædia; or, modern universal dictionary of arts and sciences. On a new and improved plan. In which all the respective sciences are arranged into complete systems, the arts digested into distinct treatises, and philosophical subjects introduced in separate dissertations, ed. William Henry Hall and Thomas Augustus Lloyd (London: Printed for C. Cooke, 1797). 
that proliferated, most especially because of its cost. ${ }^{211}$ Martinus Van Marum (17501837) was a Dutch chemist who had witnessed Lavoisier's demonstrations on the composition of water in Paris in 1785, and wanted to repeat these demonstrations, but owing the cost of the gasometers, could not do so until 1791, and then only with gasometers of his own design that used a number of containers to shift water around in order to maintain the gas under constant pressure. Van Marum published a description of a simplified version in $1792 .{ }^{212}$ Other variants soon appeared, including one designed by the well-known Parisian instrument makers the Dumotiez brothers, which included four separate counterweights supported by pulleys running over vertical supports. They were selling and advertising these by 1795 , but they were by no means the only ones. The Dumotiez gasometer was the model that became the most popular in chemists' laboratories, and a similar one was initially adopted by the gas industry through James Watt's choice of such a plan for his own pneumatic apparatus, which will be discussed in the third chapter.

\footnotetext{
211 Gilbert, "Von den veschiedenen Gasmessern, und Beschreibung des von Seguin erfundenen Gazometers," 186-7.

212 Levere, "Lavoisier's Gasometer and others: Research, Control, and Dissemination." 11-12 citing Blumenbach Johann Friedrich Van Marum, "Lettre à Berthollet, contentant la description d'un Gazomètre, construit d'une manière différente de celui de Lavoisier et de Meusnier, et d'un appareil pour faire très exactement l'expérience de la composition de l'eau, par combustion continuelle, avec plus de facilité et moins de frais," Annales de Chimie, ou, Recueil de mémoires concernant la chimie et les arts qui en dépendent 12 (1792).
} 
PI. V.

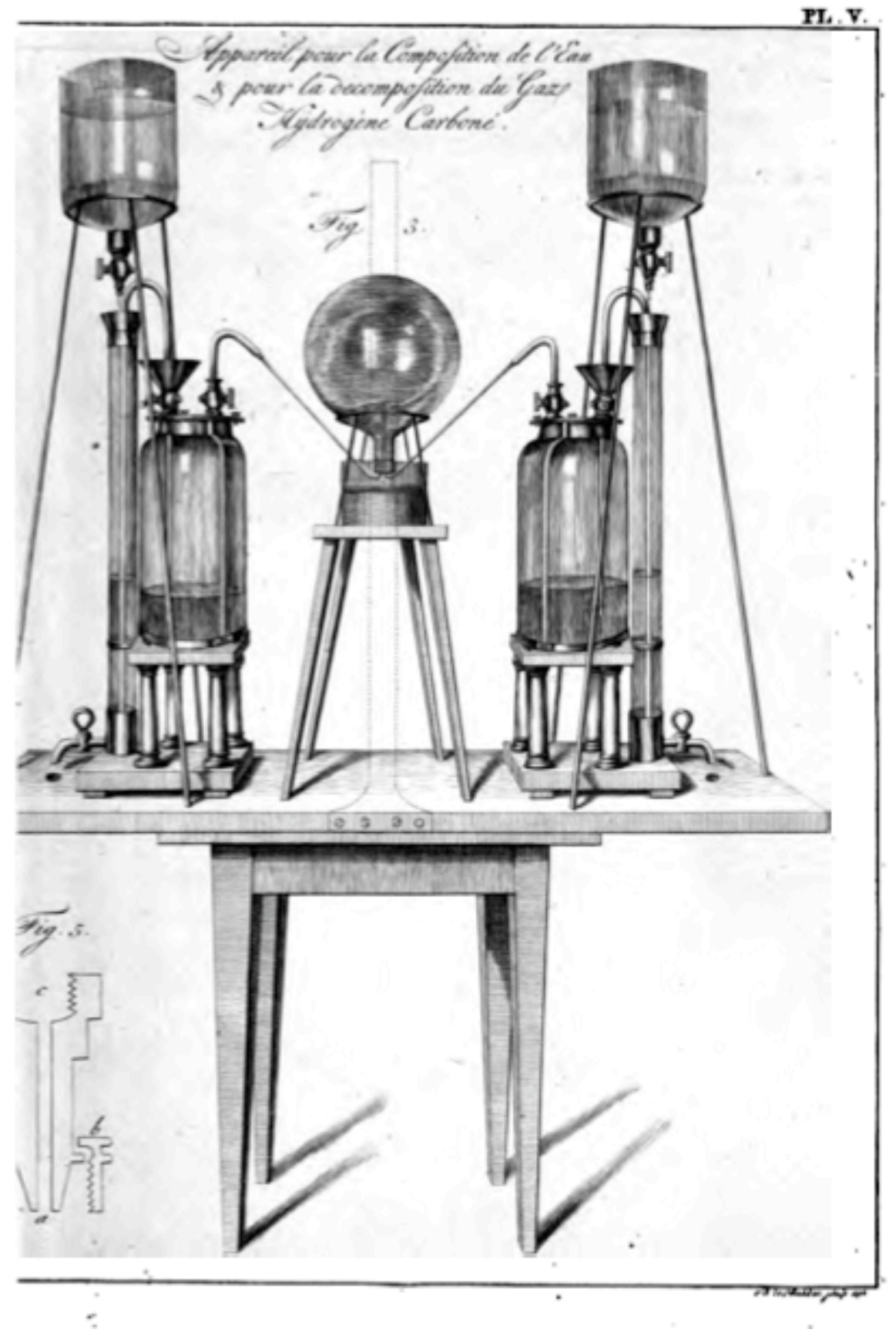

Figure 1.12 Van Marum's hydrostatic gasometer, taken from Description de quelques appareils chimiques nouveaux (1798) plate $\mathrm{V}$ 


\subsection{Sulphuretted Hydrogen}

Pneumatic chemistry had one other significant contribution to make to the technology of gaslight, and that was regarding the properties of hydrogen sulphide $\left(\mathrm{H}_{2} \mathrm{~S}\right)$. Because of its rancid odour - it is the olfactory agent produced by rotting eggsand its toxicity, hydrogen sulphide was a great obstacle to the use of gaslight, especially indoors. Most coal contains some amount of sulphur, and hydrogen sulphide is produced during distillation in proportion to the sulphur concentration in the coal. Lime water reacts with it, and so the same means used to purify coal-gas of carbon dioxide served also to remove most of the hydrogen sulphide. Its story is much simpler than that of heavy inflammable air, as Karl Scheele, the chemist who first characterized it, also observed that it reacted with lime water, and gave its correct composition, at least in his own terms.

Hydrogen sulphide was produced as early as the 1754 by Hilaire Martin Rouelle (1718-1779). After he became the demonstrator in the Jardin du Roi in Paris from 1768 he made a yearly demonstration of producing the gas from liver of sulphur (potassium polysulphide $\mathrm{K}_{2}\left(\mathrm{~S}_{\mathrm{x}}\right)$ ) and burning it, as reported by Macquer. ${ }^{213}$ It was, however, Karl Wilhelm Scheele (1742-1786) who first described the properties of what he called stinking or sometimes inflammable sulphureous air (stinkende or brennende Schwefelluft) in Chemische Abhandlung von der Luft und dem Feuer (1777). Scheele thought it was a combination of phlogiston (by which he referred to hydrogen), sulphur, and heat. He produced it, among other ways, by dissolving liver of sulphur with hydrochloric acid. He collected the gas and determined various of its characteristics, 
including that although it does not precipitate lime water, it is absorbed by it in significant quantities. ${ }^{214}$ Scheele's work was fairly well known and was translated into English (1780) and French (1781) in short order.

A number of other chemists produced some studies on sulphuretted or sulphurated hydrogen, as it became known in the new nomenclature in 1787.215 These include in 1792 the Dutch chemists, Johann Deiman et al, who also investigated ethylene. ${ }^{216}$ Claude-Louie Berthollet did a lengthy study into properties of sulphuretted hydrogen which he read to the Institut national on March 11, 1796, and published in the Annales de chimie two year later. ${ }^{217}$ Berthollet produced the gas by dissolving ferrous sulphide (iron(II) sulphide FeS) with sulphuric acid. He listed many of the reactions that hydrogen sulphide has alkalis, metals, metal oxides, and other chemicals include lime. ${ }^{218} \mathrm{He}$ also investigated ways it can be formed and decomposed. Many of the results of Berthollet's extensive study were incorporated into dictionaries and handbooks of chemistry, such as in Foucroy's Elémens d'histoire naturelle et de chimie (1793, English 1800).219

\footnotetext{
${ }^{214}$ Carl Wilhelm Scheele, Chemische abhandlung von der luft und dem feuer, Second ed. (Leipzig: W. Engelmann, 1782; reprint, 1894 ed. Wilhelm Ostwald, Ostwalds Klassiker der exakten Wissenschaften, nr. 58;), 102. Partington, A History of Chemistry, Vol. 3, 229.

215 Guyton de Morveau et al., Method of chymical nomenclature, 83, 90.

216 Memoires sur la nature des sulfures alkalins, our foies de soufre, Recherches physico-chimiques (1792) Vol. 1, 1-40, Partington, A History of Chemistry, Vol. 3, 585.

217 Claude-Louis Berthollet, "Observations sur l'hydrogène sulfuré," Annales de Chimie, ou, Recueil de mémoires concernant la chimie et les arts qui en dépendent 25 (1798).

218 Ibid.: 268.

${ }^{219}$ Antoine-François Fourcroy, Elements of chemistry and natural history To which is prefixed, the philosophy of chemistry. By A. F. Fourcroy, Fifth edition, with notes, by John Thomson ed. (printed by Mundell \& Son; for Longman \& Rees, and J. Johnson, London; and for Mundell \& Son, Edinburgh, 1800), vol. 2, 167. \# Fourcroy, Elémens d'histoire naturelle et de chimie, vol. 2, $352 \mathrm{ff}$.
} 


\subsection{Conclusion}

By 1790 , then, theoretical knowledge of carbonated hydrogen had advanced to the point that facts about its basic properties -its inflammability, composition, and ready availability from combustible substances - were easily accessible in the most readily available chemistry texts of the period.220 Many techniques for its manipulation had been developed: production, purification, and storage. The episode of Minckelers' gaslight demonstrates that someone with good knowledge of pneumatic chemistry could produce and deploy this gas on a larger-than-laboratory scale without years of effort in theoretical development, nor having to invent all the technology. In the years after Minckeler's work, and the new nomenclature of French origin combined with important and widely circulated chemical texts from Lavoisier and Fourcroy disseminated, expanded, and clarified the knowledge Minckelers had had access to when he developed his gaslight. In addition to theoretical progress, the development of pneumatic laboratory apparatus had advanced to the point where all of the basic elements of gaslight apparatus were present in the chemist's laboratory in seminal form. The retort had been present for a long time, the pneumatic trough was over sixty years old, and had undergone many refinements. Laboratory techniques for the purification and separation of gases had flourished, including those most important for the gas industry: the use of lime water to remove carbon dioxide and hydrogen sulphide, and washing gases with water in the pneumatic trough. The most recent addition to this list was Lavoisier's gasometer, which was further simplified by others after him. Like the

\footnotetext{
220 See Johann Friedrich Gmelin, Geschichte der Chemie seit dem Wiederaufleben der Wissenschaften bis an das Ende des achtzehnden Jahrhunderts, vol. 2 (Göttingen: J.G. Rosenbusch, 1798), 367-80. for an extensive bibliography summarizing contemporary knowledge of inflammable gases.
} 
theoretical knowledge of gases, these laboratory techniques and instruments were all appropriated by the gas industry. 


\section{Chapter 2: \\ The road to gaslight: coal mines, distillation processes, and natural philosophy}

2.1 Introduction

2.2 Coal mining

119

2.3 Diller's Philosophical Fireworks 126

2.4 Uses of inflammable gases before the thermolamp 143

2.5 Distillation

2.6 The thermolamp-Lebon and industrial distillation

2.7 Zachaeus Winzler and the thermolamp

2.8 Other German thermolamps

2.9 The failure of the thermolamp 189

2.10 Conclusion

196

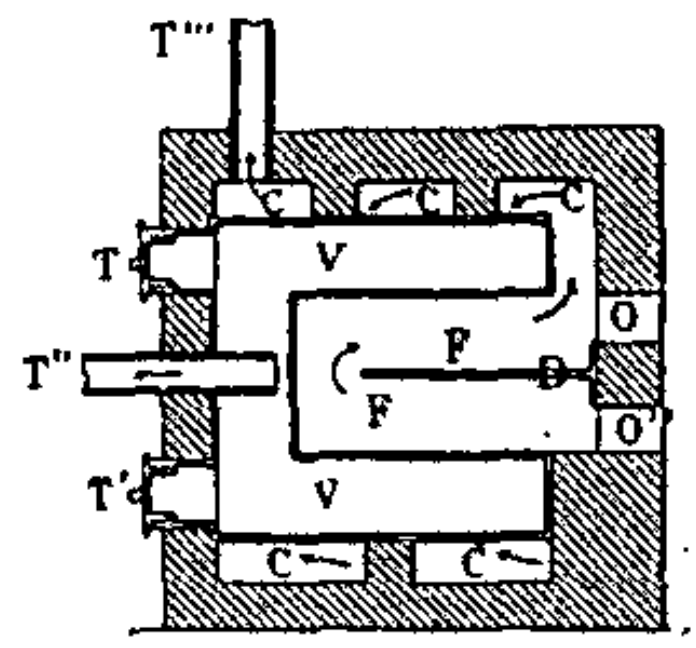

Figure 2.1 Lebon's themolamp, from Magnier, Nouveau manuel complet de l'éclairage et du chauffage au gaz Vol. 1 (1899) 


\title{
Chapter 2: \\ The road to gaslight: coal mines, distillation processes, and natural philosophy
}

\author{
Every man who receives a liberal education, at present considers Chemistry as one of \\ the most indispensable objects of his study. [...] It is now cultivated by almost every class \\ of society.
}

--Antoine Fourcroy, Systême des connaissances chimiques (1800) Vol. 1, p. xviii ${ }^{1}$

\subsection{Introduction}

The growing experience and knowledge of pneumatic chemistry and inflammable gases in particular in the second half of the eighteenth century created the conditions in which various pioneering attempts at gaslight could occur. The knowledge forged within the scientific community was codified in books and journals which circulated throughout Europe, as well as implicit in the various scientific instruments created to manipulate gases. Public lecturers of various sorts also propagated this new knowledge. Volta's lighter, although not a practicable technology, nevertheless was a materialization of the new knowledge of inflammable gases and the possibility of using them for lighting. As the knowledge of pneumatic chemistry spread, a growing number of people outside of the elite core of scientists such as Volta and Priestley became ever more familiar with the subject. This included instrument makers, engineers, and others with a semiprofessional interest in the developments in sciences. Most of these people were

\footnotetext{
1 Tout homme qui reçoit une éducation libérale, compte aujourd'hui la chimie parmi les objets les plus indispensable de ses études. [...] Elle est maintenant cultivée dans presque toutes les classes de la société. English: A General System of Chemical Knowledge (1804) vol. 1, p. 21
} 
primarily engaged in some sort of commercial activity, be it as instrument makers, technicians or engineers, chemical manufacturers, merchants, or public lecturers. Their practical interests were an important element in creating a new technology out the scientific knowledge of gases.

This dispersal of scientific knowledge away from the elite scientists towards people who were interested in application is part of the story of this chapter. A number of historians have discussed these connections, including Hilaire-Perez and Mokyr. ${ }^{2}$ Mokyr has insisted that it was these connections that made the eighteenth century enduringly fruitful in technological and industrial development. If the Industrial Revolution were driven only by technicians working on improving best-practices, it would have petered out once the epistimic base supporting these best-practices had been exhausted. That it did not do so in the long run is attributable to the constant input from the more abstract intellectual sphere where potentially useful knowledge was being generated. The manifold connections, which ran both ways, were constructed and strengthened by the Enlightenment. As Mokyr puts it, '[t]o construct pipelines through which those two groups could communicate was at the very heart of the movement.'3 Larry Stewart has refined Mokyr's vision of the Industrial Enlightenment by discussing how the spaces in which experimental philosophical inquiry were pursued and technological development occurred were frequently one and the same in this period. ${ }^{4}$

\footnotetext{
2 Joel Mokyr, "The Intellectual Origins of Modern Economic Growth," The Journal of Economic History 65, no. 2 (2005). Mokyr, "Knowledge, Enlightenment, and the Industrial Revolution: Reflections on The Gifts of Athena," History of Science 45 (2007). and

${ }^{3}$ Mokyr, "The Intellectual Origins of Modern Economic Growth."

${ }^{4}$ Larry Stewart, "Experimental Spaces and the Knowledge Economy," History of Science 45 (2007).
} 
This certainly emerges a number of times in this chapter, and most clearly in the case of Zachaeus Winzler, a German chemist and saltpetre manufacturer who described in great detail how he recreated Lebon's thermolamp from the apparatus of his chemical laboratory.

The people who thought of using inflammable gases for lighting were found in a number of places geographically and socially, with varying levels of exposure to pneumatic chemistry. In some cases, their exposure seemed to be minimal, while in others, it was extensive. These parties had quite different interests, but it was ultimately those who had better access to the knowledge generated in pneumatic chemistry who made it farther along the road to implementing gaslight in a viable way. There are three main sources or common interests from which early experiments with gaslight sprang: coal mining, distillation processes, and scientific societies, broadly understood. Each of these three sources produced forms of gaslight with distinctive characteristics, and in some cases, individual versions of gaslight show influence from more than one source.

As coal miners dug deeper and more extensive mines over the course of the eighteenth century, particularly in England, they became more acquainted with firedamps: concentrations of methane gas which could burn or explode with often tragic consequences. Fire-damps were one way through which gaslight was thought of, but the gulf to a viable implementation proved to be too great. Coal-gas required far more control and reliability than what the gas naturally volatilized in mines could afford.

Distillation processes proved to be the strongest impetus for gaslight, and ultimately the way though which gaslight became a large scale industry. Distillation 
refers to the process of heating some material-in this case wood or coal-in a low oxygen environment to inhibit combustion, with the goal of breaking down the subject matter into its constituent parts. Distillation had been used for many centuries by gunpowder manufacturers to make charcoal from wood by burying a burning pile of wood for several days, after which the pile was dug up again. All that was left of the wood was charcoal-mostly just elemental carbon. In the eighteenth century, distillation began to be used more frequently, partly as knowledge of its effects became better known through its use in the chemical laboratory. People began to experiment with large scale distillation with a view to making industrial chemicals, such as tar, acid, and coke. Perhaps the best known example of this is the production of coke for iron smelting, but this was by no means the only one. Ballooning also could require distillation, and as has been discussed in the previous chapter, produced at least one instance of gaslight. Since inflammable gas is one of the products of the distillation of wood and coal, many of those exploring distillation as an industrial mode of producing another product also thought of using the other products, and this included the gas if they understood pneumatic chemistry well enough. Using gas, however, is not as simple as using charcoal and coke, or acid and tar. The path from distillation processes to gaslight was difficult. If gaslight was to succeed commercially, it required moving from what is on the production side and inherently messy batch process to what is on the consumption side a simple and continuous process. Philippe Lebon's thermolamp and its progeny, together with William Murdock's work, fall into the category of attempts at gaslight originating from investigation into distillation processes. 
Gaslight also emerged among those whose primary concerns were theoretical research in the natural sciences and the development of associated scientific instruments. Volta's lighter is one example, but there are others. This more theoretical context is also found in the broad public science of the eighteenth century, including the public lecturers who, while not the research scientists of the form and stature of Lavoisier or Priestley, nevertheless engaged in research that was interesting to the more famous scientists. For the history of gaslight, the focus was the philosophical fireworks of Charles Diller, an instrument maker and science lecturer from Holland. Although his fireworks were not the technical ancestors of the nineteenth century gas plant, his demonstrations undoubtedly influenced Lebon, Frederick Winsor and possibly Murdock. Pneumatic instruments derived from Diller's spread throughout Europe and his own philosophical fireworks were also put on display into the first decade of the nineteenth century. Diller was one of the key channels through which knowledge about pneumatic chemistry flowed to a broader audience.

The thermolamp and Diller's philosophical fireworks figure most prominently in this chapter. The thermolamp is very important because it was simultaneous with Boulton \& Watt's production of William Murdock's apparatus. It is a distinct and ultimately abortive branch of gaslight technology. Its history reveals the difficulties and challenges facing any gaslight technology. Like Diller's fireworks, it directly influenced some key players in the eventual success of gaslight, notably Winsor and Murdock.

Previous histories of gaslight have tended to conflate or at least not sufficiently nuance the various kinds of early gaslight apparatus, from those derived from Volta's 
lighter, to those that seem to be independent from other technologies, to Lebon's thermolamp, and finally Murdock's apparatus. This has been the result of a reductive approach to gaslight which trivializes the technology, usually because details about the technologies were unknown, or because the one common thread of burning inflammable air used for light trumped all other considerations. In this chapter, I will first discuss the independent uses of inflammable gases for light, and then proceed to the thermolamp. Murdock's work will be the subject of the third chapter.

Volta's lighter and its imitations have already been discussed in chapter one. While they ultimately did not become useful or widespread, they did bring the idea of lighting with gas to the community of pneumatic chemists and instrument makers, especially in Germany.

\subsection{Coal mining}

Coal mining expanded in England in the eighteenth century. Coal miners had been long aware of the dangerous explosions possible in coal mines caused by gases, which were called fire-damps. As the volume of coal mining increased in the eighteenth century, fire-damps became more of a concern for colliery workers and owners.

As was mentioned in chapter one, Sir James Lowther (1673?-1755), a colliery owner from Whitehaven just south of Scotland, was concerned about explosions in mines and had observed that fire-damps could be collected in bladders and retained 
their inflammability for a long time. ${ }^{5}$ Apparently, workers in one of his mines opened an area where 'a vast quantity of corrupted air' was released. The air continued to flow and pipes were eventually installed by Carlisle Spedding (-1755), Lowther's colliery steward, in the mine to lead the fire-damp to the surface, where the emerging air could be lighted by a candle. ${ }^{6}$ In 1737 , four years after his paper was presented to the Royal Society, Lowther became the patron of William Brownrigg (1711/2-1800), a young medical doctor and chemist of some ability who had just returned from his studies in Leyden. ${ }^{7}$ That same year, there was a horrific explosion that killed twenty two miners in Whitehaven, and the incident seems to have affected Brownrigg. Lowther's concerns with fire-damp were evidently reinforced and he worked with Brownrigg and Spedding on experiments on fire-damps. The result of these experiments were five papers by Brownrigg presented to the Royal Society in $1741-2$, none of which were published, ${ }^{8}$ but whose manuscripts still exist in its archives. ${ }^{9}$ Brownrigg also found the time in 1741 to wed Mary Spedding, Carlisle's niece and the daughter of Lowther's principal estate steward, John Spedding.

\footnotetext{
5 James Lowther, "An Account of the Damp Air in a Coal-Pit of Sir James Lowther, Bart. Sunk within 20 Yards of the Sea; Communicated by Him to the Royal Society," Philosophical Transactions (1683-1775) 38 (1733). J. V. Beckett, "Dr William Brownrigg, F.R.S.: Physician, Chemist and Country Gentleman," Notes and Records of the Royal Society of London 31, no. 2 (1977): 258.

${ }^{6}$ William Jones, The theological, philosophical and miscellaneous works of the Rev. William Jones ... : to which is prefixed a short account of his life and writings. , 12 vols., vol. 10 (London: F. and C. Rivington, 1801), 425.

7 J. Russell-Wood, "The scientific work of William Brownrigg, M.D., F.R.S. (1711-1800) - I," Annals of Science 6, no. 4 (1950): 436. Beckett, "Dr William Brownrigg," 255-7.

8 Beckett, "Dr William Brownrigg," 258.

9 J. Russell-Wood, "A biographical note on William Brownrigg, M.D., F.R.S. (1711-1800)," Annals of Science 6, no. 2 (1949): 189-90. Beckett, "Dr William Brownrigg," 268, footnote 26. Royal Society Archives, L\&P/1/78 Of the quantity of Fire-damp produced from the Main Band coal at Hind Pitt 1740
} 
After the five papers had been presented, Brownrigg continued his research into fire-damps, and in 1743 requested funds from Lowther to set up a laboratory close to a mine pit so that lead pipes could be installed to bring gas from the mine into the laboratory for testing. ${ }^{10}$ The laboratory included furnaces where Brownrigg could burn the gas. Unfortunately for his experiments, the gas was of uneven quality and pressure. Brownrigg apparently described the laboratory in a letter to the Royal Society, but nothing of this letter survives. ${ }^{11}$ Brownrigg did, however, make a real contribution to the safety of mines by linking lower barometric pressure to higher concentrations of firedamps and hence heightened likelihood of explosions.

The pipes bringing fire-damp from mines to Brownrigg's laboratory were not unique. Miners had long sought ways to alleviate the dangers associated with explosive gases, and one such method was to improved air circulation in mines by venting dangerous fumes to the surface. Other Whitehaven mines had precisely these sorts of

\footnotetext{
10 Beckett, "Dr William Brownrigg," 257.

11 Ibid.: 268, footnote 21.
} 
ventilating pipes..$^{12}$ It was sometimes observed that the fumes from these pipes could be

flared, as this letter from 1747 demonstrates:

[S]ome of the Pits in one of the Coallieries near [Whitehaven] are, probably, the deepest of any in the World, and by that Means subject to Fire-damps so that, if a great deal of foul or inflammable Air, by any Neglect or Mischance, is collected together under Ground, and is set on Fire by a Candle, or any Flame, it goes off with a very great Explosion, and does great Damage to what it meets with in its Way to the Pit where it goes up to vent itself in the open Air. [...] Where the foul Air is very strong, as it is often at the sinking of new Pits, the Air brought up in Pipes along the Sides of the Pits into the open Air, and a Candle, or lighted Paper, being put to the End of the Pipe, it will break out into a Flame, one or two Feet in Breadth, and several Feet in Height, more or less, according to the Quantity of foul Air that is vented, and will burn Day and Night, for Months or Years. ${ }^{13}$

Some of these pipes installed in Whitehaven remained there for years. When Gabriel Jars, who was commissioned by the French government to investigate mining

\footnotetext{
12 For a description of ventilation in mines, see Gabriel Jars, Voyages metallurgiques; ou, Recherches et observations sur les mines \& forges de fer, la fabrication de l'acier, celle du fer-blanc, \& plusieurs mines de charbon de terre, faites depuis l'année 1757 jusques \& compris 1769, en Allemagne, Suéde [sic], Norvege, Angleterre \& Ecosse. Suivies d'un mémoire sur la circulation de l'air dans les mines, \& d'une notice de la jurisprudence des mines de charbon dans le pays de Liege, la province de Limbourg \& le Comté de Namur (Paris: L. Cellot [etc.], 1774), 248-9. Thomas White Benjamin Pennant, $A$ tour in Scotland, and voyage to the Hebrides, MDCCLXXII. Part I [-II], 2 vols., vol. 1 (London: Printed for Benj. White, 1790), 57. also mentions the old pipes in Whitehaven. Pennant visited there in 1772 . These sorts of pipes are also mentioned in J. H. H. Holmes, $A$ treatise on the coal mines of Durham and Northumberland : with information relative to the stratifications of the two counties: and containing accounts of the explosions from fire-damp, which have occurred therein for the last twenty years; their causes, and the means proposed for their remedy, and for the general improvements of the mining system, by new methods of ventilation, \&c (London: printed for Baldwin, Cradock, and Joy, 47, Paternoster Row, (C. Baldwin, Printer, New Bridge-street, London). 1816), 123. Carlisle Spedding was responsible for many of them. J. V. Beckett, Coal and tobacco : the Lowthers and the economic development of West Cumberland, 1660-1760 (New York, 1981), 70-74.

13 "As there is something curious in relation to Coal Pits, in the following extract of a Letter from Whitehaven, dated May 16, we have therefore given it our Readers," The British magazine: or, the London and Edinburgh intelligencer 1 (1747). Also in London Evening Post (London, England), Saturday, May 30, 1747; Issue 3054
} 
and metallurgical techniques in foreign countries for possible importation to France visited Whitehaven in 1765 , they had just been removed. Similar pipes were present at another mine in nearby Workington:

\begin{abstract}
The upper layer of the Workington mine is not currently exploited. It contains within the former works a great quantity of bad air. A small tube of no more than an inch and a half diameter has been installed from the time the mine was active up to the present day. Bad air continuously streams from the tube, and burns with a flame of around a foot in height. It is easily extinguished by a stoke with a hat, and one can then feel cool air exiting with one's fingers in the tube. I put a candle at least six inches above the opening and it took fire right away. The flame is blue, similar to that from spirit of wine. ${ }^{14}$
\end{abstract}

Jars mentions that the director of the mine in Whitehaven had suggested at some point to the city magistrates that gas be piped from the mine to the town and used for lighting the streets at night. His offer was refused, perhaps because the explosive nature of these gases was all too familiar to the local inhabitants and there would not have been sufficient confidence to test such an arrangement. The ultimate failure of Brownrigg's laboratory due to uneven gas supply also suggests that the attempt would have failed without significant apparatus to purify and pressurize the gas. Nor is it likely that the naturally produced gas would have been sufficient to light more than a few street lights. This sort of lighting was never tried to the best of my knowledge even in

\footnotetext{
${ }^{14} \mathrm{La}$ couche supérieure de la mine de Workington, n'est pas exploitée actuellement. Elle renferme dans ses anciens ouvrages, une très grande quantité de mauvais air. Depuis ses vieux travaux jusqu'au jour, on a conduit un petit tuyau, dont l'embouchure n'a pas plus d'un pouce $\&$ demi d'ouverture. II en sort continuellement du mauvais air, auquel on a mis le feu; il brûle perpétuellement \& fait un jet de flamme, au dessus de l'ouverture du tuyau, d'environ un pied de hauteur. On l'éteint aisément, en y donnant un coup de chapeau, \& en mettant ensuite le doigt dans l'embouchure, on sent un air frais qui en sort. J'ai présenté une chandelle, au moins à six pouces au dessus de l'ouverture, elle a pris feu tout de suite. La flamme en est bleuâtre \& de la couleur de celle que donne l'esprit de vin. Jars, Voyages metallurgiques, 284.
} 
the nineteenth century when it would not have been a daring move. It does, however, show that miners would have been acquainted with the inflammable and lighting capabilities of coal-gas, but this is still a long way from practical gaslight.

In sources mentioning this proposal to use coal-gas to light Whitehaven the identity of the mine director is usually given as a Spedding, either Carlisle or Stephen. Carlisle Spedding died in 1755 in a mine explosion, so it was likely his successor Stephen. I have not found the original reference to the director's name and Jars does not provided it. Brownrigg's work at Whitehaven and his marriage into the Spedding family provides a likely conduit for the inspiration for this proposal.

There is one remaining footnote to the Whitehaven story which only merits mention because its protagonist, Richard Watson (1737-1816), figures in just about every history of gaslight. He was first discussed in the priority debates between Winsor and Murdock and like most others in this category, his name continues to be repeated without much sense of what his real contribution was. Watson was a professor of chemistry at Cambridge who visited the Whitehaven mines at some point. ${ }^{15} \mathrm{He}$ had been appointed professor in chemistry in 1764 , knowing close to nothing about the subject, and by his own admission, never having read anything about chemistry. The appointment was in fact an unpaid sinecure, requiring no lectures on the part of the holder, but he decided to advance his career by making something of it and educated himself in various chemical subjects. Although not a brilliant research chemist, he published a five volume work, the Chemical Essays, between 1781 and 1787. In the

\footnotetext{
${ }^{15}$ Richard Watson, Chemical essays, 5 vols. (Cambridge: Printed by J. Archdeacon for T. \& J. Merrill, 1781), Vol. 2, 39.
} 
Essays, he describes how he produced inflammable gas from oak by distillation in closed retorts in his laboratories in Cambridge, and burned the gas in his lectures. ${ }^{16} \mathrm{He}$ remarked that the gas could be stored in bladders and retained its inflammability. He also added that 'it is now believed, that this kind of air may be separated from all vegetable, animal, and inflammable mineral substances by distillation'. ${ }^{17}$ In 1781 , this was old news for pneumatic chemists, and Watson was reporting the fact for students, rather than making a claim about a new discovery. Compare this to the following comment made in 1777: 'The processes for obtaining inflammable air are so numerous and well known that we have thought it useless to mention them'. ${ }^{18}$

Perhaps Watson had written this passage closer to the date given for the experiments, 1767, which would have made it approximately simultaneous with Cavendish's almost identical work on inflammable gases from organic substances. In fact, Watson had been aware of Cavendish's work on inflammable gases, as his plan for lectures submitted to the university in 1771 indicates. ${ }^{19}$ We do not know whether he was aware of Cavendish's unpublished work on inflammable air from coal, nor whether his visit to Whitehaven included viewing the flaring fire-damp pipes. Whatever the original inspiration of his experiments, his publishing them in 1781 would not have been a

\footnotetext{
16 Ibid., Vol. 2, 317-68., with a description of his 1767 lecture experiments on p. 329-331.

17 Ibid., Vol. 2, p. 330.

18 'Les procédés pour obtenir l'air inflammable, sont en si grand nombre, \& si connus que nous avons cru qu'il étoit inutile d'en faire mention' Francois Chaussier, "Mémoire de physique expérimentale, sur quelques propriétés de l'air inflammable, lu à la Séance publique de l'Académie des Sciences \& BellesLettres de Dijon 17 Aout 1777," Observations sur la physique, sur l'histoire naturelle et sur les arts, no. 10 (1777): 318.
}

19 Richard Watson, An essay on the subjects of chemistry, and their general division. By R. Watson (Cambridge: printed by J. Archdeacon, 1771), 43. 
ground-breaking announcement to the chemical world, as it is sometimes represented in gaslight histories.

\subsection{Diller's Philosophical Fireworks}

From around 1780 until the campaign for the incorporation of the first gas company in London in 1805, a mode of illumination with inflammable gases called the philosophical fireworks existed. The philosophical fireworks were initially conceived as a public display for the purpose of amusement but that also had pretensions of being scientific research put on display. Although the fireworks quickly lost their scientific novelty and were no longer relevant for the expert community, they persisted as a form of theatrical display and garden entertainment. They were to play an important rhetorical role in the battle between Boulton \& Watt on one hand, and Frederick Winsor's National Heat and Light Company on the other. ${ }^{20}$ Phillippe Lebon also fit his own demonstrations into the tradition of the philosophical fireworks.

The initiator of the fireworks was Charles Diller, a Dutch natural philosopher and instrument maker from the Hague, probably a student of Jean-Nicolas-Sébastien Allamand's, a Leiden professor and publisher. ${ }^{21}$ Diller was sometimes described as a

\footnotetext{
20 For a complete description of the history of the firework and its influence upon the rhetoric surrounding the political battle for the incorporation of the first London gas company, see Simon Werrett, "From the grand whim to the gasworks: 'philosophical fireworks' in Georgian England," in The mindful hand : inquiry and invention from the late Renaissance to early industrialisation, ed. Lissa Louise Roberts, Simon Schaffer, and Peter Robert Dear (Amsterdam : Edita: Bristol, 2007).

21 Ibid., 332.
} 
demonstrateur de physique ${ }^{22}$ or a physicien-mechanicien. ${ }^{23}$ Diller must have been an instrument maker of some note as the stadholder William $\mathrm{V}$ patronized him and purchased several of his instruments over the years. ${ }^{24}$ Diller also became a focus of the ballooning craze in the Netherlands in 1783 when he built a 30 foot diameter balloon in the Hague. ${ }^{25}$

Diller's philosophical fireworks used inflammable gases burning with different colours, and included moving parts, representing stars, dragons, snakes and other things which emitted flame in succession as they moved around. One source reports that he had 6000 flames in his display, presumably sequentially, not simultaneously. ${ }^{26}$ The actual form the fireworks took on varied, especially as imitators sprang up, but Diller himself also used different versions. ${ }^{27}$ The constant heart of the apparatus was the bladders of inflammable gas feeding flames of different colours.

Diller represents a remarkable case of the intersection of entertainment, public lecture, and scientific research in the eighteenth century, as his work was clearly aimed on one hand, at a broad audience for the purposes of entertainment, but also at the

\footnotetext{
22 Mathurin-Jacques Brisson, Traité élémentaire ou principes de physique; fondés sur les connoissances les plus certaines, tant anciennes que modernes, \& confirmés par l'expérience, 2nd ed., 3 vols., vol. 2 (Paris: Moutard, 1797), 62.

${ }^{23}$ Peter De Clercq, "Science at Court: the Eighteenth-century Cabinet of Scientific Instruments and Models of the Dutch Stadholders," Annals of Science 45 (1988): 124.

24 Ibid.: 124-5 and 38. give some details about Diller.

25 "Hague, Dec. 19," General Evening Post, Tuesday, December 23 1783. mentions Diller and the balloon.

26 "Philosophical Fire," The Scots magazine 50 (1788).

27 Diller sold at least two version in the Netherlands. The one for Stadholder's cost seven times as much as the one sold to the Renswoude Foundation. De Clercq, "Science at Court," 138.
} 
scientific community. His work involved original research and he presented his work to elite scientific audiences in Paris and London. As with other such public lecturers of science in the eighteenth century, Diller and his audience moved easily from entertainment to the technological research in this display, taking in the spectacle, but also seeing it as a presentation of new scientific work and a avenue for technological development, all combined into one. Diller represents a prominent case of the 'open science' and 'open technique' of the Industrial Enlightenment, as described by HilairePerez and others. ${ }^{28}$

The origins of Diller's fireworks are not known, but it likely drew from a number of sources. On one hand, there had been a tradition of fireworks displays and illuminations in public places in the second half of the eighteenth century. These included fireworks based on gunpowder, but also other sorts of stable illuminants such as lamps of various sorts. The promoters and creators of these displays vied to outdo one another to attract an audience to the pleasure gardens hosting the fireworks, and they increasingly turned to natural philosophy to inspire the greater variety that drew people to the display. ${ }^{29}$ Diller's displays of philosophical fireworks fit into this tradition, and on at least one occasion, it was suggested that his fireworks were much better than the 'ordinary ones'. ${ }^{30}$

\footnotetext{
28 Liliane Hilaire-Perez, "Technology as a Public Culture in the Eighteenth Century: The Artisans' Legacy," History of Science 45 (2007).

29 Werrett, "From the grand whim to the gasworks," 328-32.

30 "Divers articles d'inventions dans les arts, \& de découvertes dans les sciences, \&c," Journal encyclopédique ou universel 6, no. 3 (1787).
} 
On the other and, Diller may have taken some inspiration from a number of scientific instruments. It is probable that some were Alessandro Volta's, whose lighter and lamp have been described the previous chapter. As an instrument maker Diller would almost certainly have been aware of Volta's family of new instruments based on inflammable air. Indeed, Diller sold an inflammable air pistol and canon, two of Volta's creations, to the Stadholder. ${ }^{31}$ The lighter was contemporary with the pistol and canon, and was receiving attention in the period immediately before and during the fireworks' first appearance.

Another inspiration from the scientific side may have been François Chaussier whose gas bladders were quite similar to and appeared just prior to Diller's. Chaussier was medical doctor who was interested in pneumatic chemistry and electricity. He was familiar with Cavendish and Priestley's work on inflammable airs, as well other other related phenomena such as fire-damps observed in English mines and flaming springs such as the one Volta observed.

In 1777 Chaussier presented experiments on inflammable air to the Académie des Sciences et Belles-Lettres de Dijon. ${ }^{32}$ He filled bladders with the airs he generated from metals and lit them with a spark. He tested flame properties of inflammable gases, such as its heat, and observed that, for example, it burned with greater heat than an enameler's torch. Chaussier did not make suggestions about the practical possibilities of this arrangement. Chaussier's article was reprinted in the Observations sur la

31 De Clercq, "Science at Court," 124.

32 Chaussier, "Mémoire de physique expérimentale, sur quelques propriétés de l'air inflammable, lu à la Séance publique de l'Académie des Sciences \& Belles-Lettres de Dijon 17 Aout 1777." 
physique, meaning it would have reached a wide audience in the expert community. His work was known in England, as the paper is cited by Kirwan. ${ }^{33}$

${ }^{33}$ Richard Kirwan, "Continuation of the Experiments and Observations on the Specific Gravities and Attractive Powers of Various Saline Substances. By Richard Kirwan, Esq. F. R. S," Philosophical Transactions of the Royal Society of London 72 (1782): 199., also in James Keir, A treatise on the various kinds of permanently elastic fluids, or gases, The second edition, revised ed. (London: printed for T. Cadell, and P. Elmsley, 1779), 52-3. 


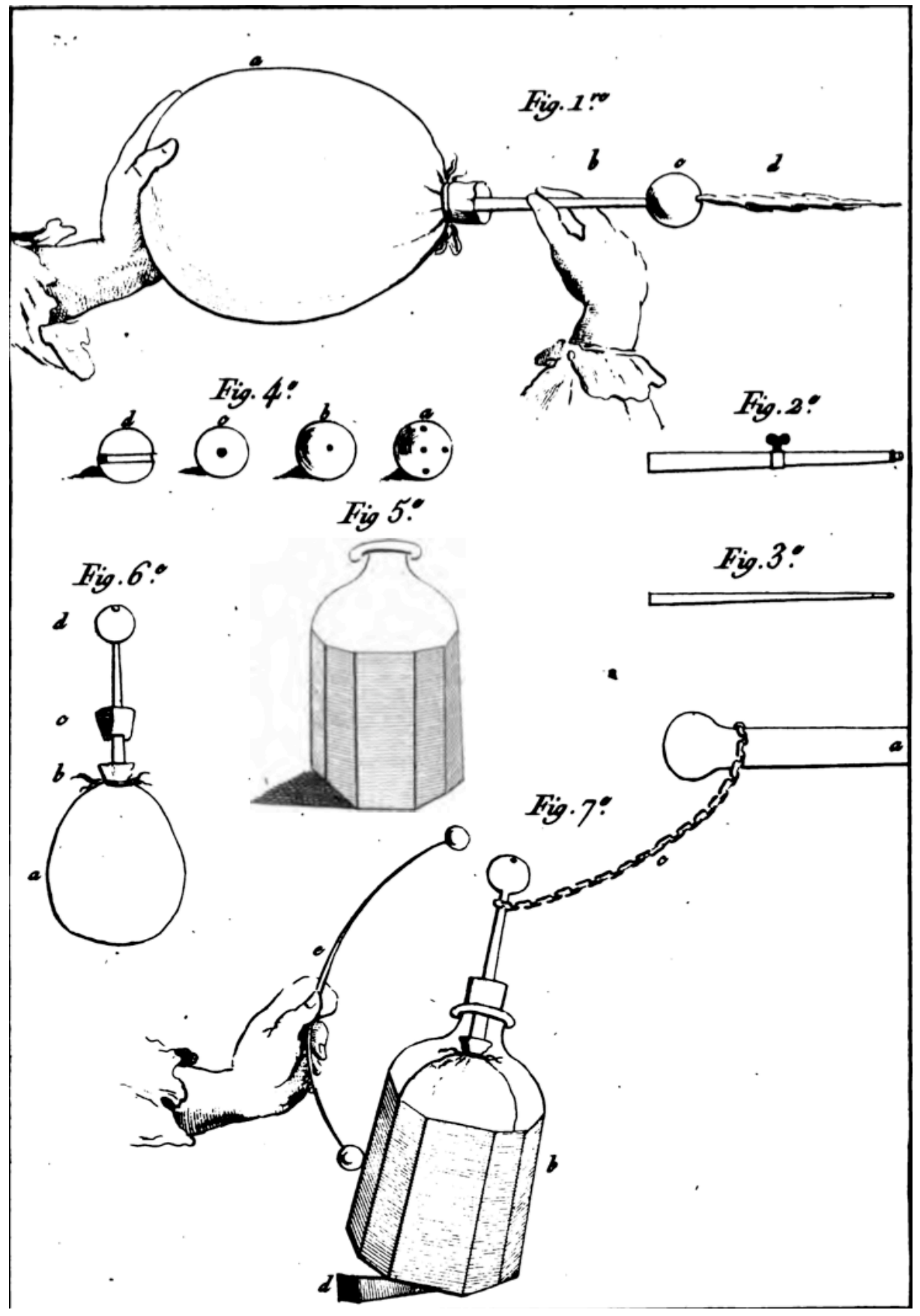

Figure 2.2 Plate from Chaussier "Mémoire de physique expérimentale, sur quelques propriétés de l'air inflammable" Observations sur la physique no. 10 (1777): 309-21 
Wherever Diller took his ideas from, by 1780 , he was making and selling the philosophical fireworks. In 1787 he set off on a grand tour that would take him to Paris and London. He arrived in Paris from the Hague in June of 1787, where he made a number of presentations, and on June 25 displayed his fireworks to the Académie. The audience was apparently impressed:

\author{
Mr. Diller last Monday the 25th put on a completely novel spectacle at the Panthéon: a \\ display of fireworks with inflammable air, without smoke, without odour, and which \\ surpasses all previous fireworks. The Académie des Sciences were invited to these \\ experiments, and this Body, though quite familiar with the phenomena of physics and \\ chemistry have singularly approved of the talents of the artist, the elegance of his \\ machines, and the perfection of his means. ${ }^{34}$
}

\footnotetext{
34 'Sr. Diller ... a donné lundi dernier 25 de ce mois, au Panthéon le spectacle tout-à-fait neuf, d'un feu d'artifice à air inflammable, sans fumée, sans odeur, \& qui efface l'éclat des feux d'artifice connus. L'Académie des Sciences avoit été invitée à ce nouveau genre d'expériences, \& cette Compagnie, quoique bien familiarisée avec les phénomènes de la physique \& de la chymie, a singulièrement applaudi au talent de l'artiste, à l'élégance de ses machines, \& à la perfection de ses moyens.' "Les expériences de M. Diller," in Mémoires secrets pour servir à l'histoire de la république des lettres en France, depuis MDCCLXII jusqu'à nos jours; ou, Journal d'un observateur v. 35, ed. Louis Petit de Bachaumont, Mathieu François Pidanzat de Mairobert, and d'Angerville Mouffle (A Londres: chez J. Adamson, 1789), 282. which is taken almost word for word from "Physique," Journal de Paris, 28 June 1787.

Thomas Paine witnessed one of Diller's demonstrations. He arrived in Paris on May 30, 1787, and was a friend of le Roy's. He described what he saw in a letter to Benjamin Franklin:

M. Le Roy has been most attentively kind to me. As he speaks English, there is scarcely a day passes without an interview. [...] In the evening he sent me an invitation to see an exhibition of fireworks of a new kind, made of inflammable air. It was done as an experiment. The exhibition was in a room. The performer had two large bladders of air, one under each arm, with pipes from them communicating with the figures to be represented, such as suns, moons, stars, flowers, architecture, and figures of moving machinery. By compressing the bladders and mixing the air, he produced the most beautiful and sudden transitions of light and colors, increased or diminished the motion, and exhibited the most pleasing scene of that kind that can be imagined.

From: Benjamin Franklin, The works of Benjamin Franklin, including the private as well as the official and scientific correspondence together with the unmutilated and correct version of the Autobiography, ed. John Bigelow, 12 vols., vol. 11 (New York: London, G.P. Putnam's Sons, the Knickerbocker Press, 1904), 338-9.
} 
He was invited to repeat the show before the royal family, which he did a few weeks later, ${ }^{35}$ and was awarded a pension by the king for his efforts. ${ }^{36}$ The demonstrations created such interest that the Académie commissioned a group to investigate Diller's 'feux d'artifice', consisting of le Roy, Brisson, Lavoisier, Monge, Berthollet, and Fourcroy. They made quick work of their charge, presenting their results on July 4 of the same year. ${ }^{37}$ Diller, however, did not reveal all the details of mechanism to the committee, and in particular, they could not say what the sources of his inflammable gases were, but the committee was certain that it was not inflammable gas taken from metals, as Diller's flames was clearly brighter than what their own experience with hydrogen indicated they would be. Diller even suggested to the committee that this gas could be used for lighting (il propose pour l'usage des phares), given its brilliance.

\footnotetext{
35 "Les expériences de M. Diller," 282, 334. "Divers articles d'inventions dans les arts, \& de découvertes dans les sciences, \&c."

36 Times, April 7, 1788

37 "Extrait des registres de l'Académie Royales des sciences," Observations sur la physique, sur I'histoire naturelle et sur les arts 31 (1787). "Mercredy 27 Juin 1787; Mercredy 4 Juillet 1787," in Procès-verbaux, volume 106 (Académie royale des sciences, 1787).
} 


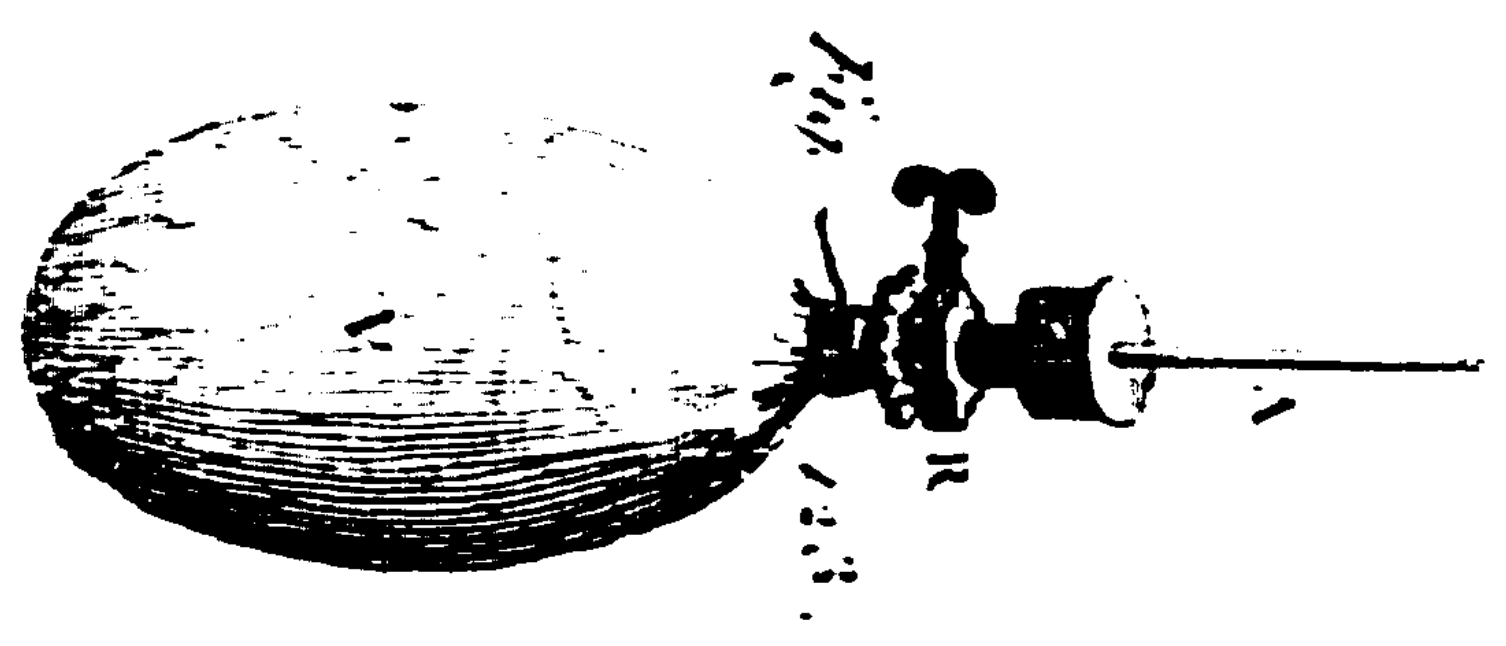

Figure 2.3 A bladder from Diller's apparatus, take from Brisson, Traité élémentaire ou principes de physique 2nd ed. Vol. 2. (1797), after p. 69

The committee provided a physical description of Diller's apparatus, the most complete available of the philosophical fireworks ${ }^{38}$ and Brisson, one of it members, later published a description of the interior of the apparatus. ${ }^{39}$ It consisted of bladders kept pressurized by screws and set in wooden boxes. Pipes connected the bladders to the flowers and suns serving as burners and visible to the audience. The displayed pieces were moved by the pressure of the gas, or by Diller or an assistant during the public spectacle. Finally, the committee was most impressed by the odour free nature and non-explosivity of the gas, in contrast to wood or coal-gas, which always had foul smells.

\footnotetext{
38 "Physique." also contains a more detailed description.

39 "Samedy 24 Mai 1788," in Procès-verbaux, volume 107 (Académie royale des sciences, 1788). Brisson, Traité élémentaire ou principes de physique; fondés sur les connoissances les plus certaines, tant anciennes que modernes, \& confirmés par l'expérience.. It was also in the first edition (1789) p. 71. The description was partly reprinted in English in George Gregory, The economy of nature explained and illustrated on the principles of modern philosophy (London: Printed for J. Johnson, 1796), Vol. 1, 400. On Bienvenu see Patrice Bret, "Un bateleur de la science : Le « machiniste-physicien » François Bienvenu et la diffusion de Franklin et Lavoisier," Annales historiques de la Révolution française, no. 338 (2004).
} 
The Dumotiez brothers, Louis-Joseph and Pierre-François, made trials of their own to ascertain the nature of Diller's gases, and within a year, reported to the Académie that it was probably ether (diethyl ether). Diller had produced ether gas by forcing atmospheric air through sponges soaked in the liquid. The brothers then began to make and sell simple devices at a low price based on this design. ${ }^{40}$ Another Parisian instrument maker, François Bienvenu, also made a 'Lampe à gaz inflammable' in imitation of Diller's, ${ }^{41}$ although what these were and how they differed from the other forms in not known. Bienvenu's inflammable air lamp spread outside of France and references to it known in the Netherlands, ${ }^{42}$ Germany, ${ }^{43}$ and England. ${ }^{44}$

40 "Des feux d'air inflammable," Observations sur la physique, sur l'histoire naturelle et sur les arts 33 (1788)., Dumotiez, "Les feux d'air inflammable de M. Diller," Observations sur la physique, sur I'histoire naturelle et sur les arts 34 (1789)., "Foreign literary intelligence," The Critical review, or, Annals of literature 66 (1788)., Zacheus Andr Winzler, Die Thermolampe in Deutschland : oder, vollständige, sowohl theoretisch- als praktische Anleitung, den ursprunglich in Frankreich erfundenen, nun aber auch in Deutschland entdekten Universal- Leucht- Heiz- Koch- Sud- Destillir- und Sparoven zu errichten. Mit vier Kupfertafeln (Brünn: Gedruckt bei Franz Karl Siedler ... 1803), 163.

41 "Académie," Journal de Paris, 4 July 1788.

42 Antoine-François Fourcroy, "Extract of a Memoir concerning three different Species of Carbonated Hydrogenous Gas, obtained from Ether and Alcohol by different Processes," A Journal of natural philosophy, chemistry and the arts 1 (1797): 44-5. The Dutch chemists state ethylene was preferred in 'lamps supported by inflammable air'.

43 "Nachrichten von einer Lampe für brennbare Luft des Hrn. Bienvenu," Magazin für das Neueste aus der Physik und Naturgeschichte 5, no. 4 (1788). Winzler, Die Thermolampe in Deutschland, 163.

44 World (1787) (London, England), Monday, July 14, 1788; Issue 481; A catalogue of optical, mathematical, and philosophical instruments, made and sold by Willm. and Saml. Jones, at their shop, No. 135, next Furnival's Inn, Holborn, London, (London, 1793), 8. An instrument described as 'A new perpetual inflammable air lamp, lighted by the electrophorus' is sold for $£ 4 \mathrm{~s} 4$. 
Diller's work was reported in Germany ${ }^{45}$ and England, ${ }^{46}$ and Diller went to England himself soon after his Parisian sojourn. After private showings to members of the Royal Society, Diller put on the his spectacle in the Lyceum theatre in London, beginning on April $11,1788,{ }^{47}$ and running until the middle of July. ${ }^{48}$ It generated excitement and interest there as it had in France. ${ }^{49}$ The Critical Review, reporting the Dumotiez's investigations when Diller's display was in England, describes them as the 'fire-works which have afforded so much entertainment in London'. The author of this article was hopeful about the future of Diller's invention: 'we have reason to think [the process] will be successful'.50

A spectator at the Lyceum theatre described the display as follows:

\begin{abstract}
We all went to Diller's philosophical fireworks, which is a most beautiful and most ingenious exhibition, as well as a very fashionable one at present. It is an imitation of fireworks, but without any noise or any smoke, and the figures and designs are infinitely more elegant and beautiful, with the additional advantage of a great variety of the richest and finest colours. He represents the growth of plants and flowers, showing first a little
\end{abstract}

\footnotetext{
45 "Herr Diller," Magazin für das Neueste aus der Physik und Naturgeschichte 5, no. 1 (1788).

46 "Report from the Royal Society on Diller's invention," The Critical review, or, Annals of literature 64 (1787). "Among the Nouvelles Literaires of this month, is a Notice des feux d'Air inflammable," The Analytical review, or History of literature, domestic and foreign, on an enlarged plan 2 (1788)., Public Advertiser (London, England), Tuesday, July 24, 1787; Issue 16592; St. James's Chronicle or the British Evening Post (London, England), Saturday, July 14, 1787; Issue 4125. Whitehall Evening Post (1770) (London, England), Tuesday, July 17, 1787; Issue 6268; World and Fashionable Advertiser (London, England), Thursday, July 19, 1787; Issue 172.
}

47 "At the Lyceum near Exeter Change near the Strand," The Times, Apr 71788.

48 The advertisements for his show appear in The Times during May, June, and July. The end date was announced to be July 18 th. See The Times on July 7 .

49 "Philosophical Fire."

50 "Foreign literary intelligence." 
stem, which grows gradually, and from which is shot out both leaves and foliage; then comes the flower budding, expanding by degrees, till you have the whole plant in its full growth, with the flowers in full bloom. The proper colours are observed, and the changes of colour take place in their proper order. He represents different insects and animals, and has a most curious chase of a viper after its prey, and of a little flying dragon after a butterfly. I cannot give you any just idea of the beauty and elegance of the show. There is a vast deal of ether employed, and the room smelt so strongly of Hoffman as to add very much to my pleasure and to that of Mrs. Johnston, who has the same affection for Hoffman that I have. Everybody else was loudly complaining of the stench, while we were whiffing it up and agreeing that it was a nosegay, and that it smelt of a good night. ${ }^{51}$

He then returned to London to the Royalty Theatre with a more elaborate show that included songs and dancing beginning on September 29, 1788, but the show did not attract as great an audience as it had during the summer. ${ }^{22}$ Advertising for it stopped in October after about four shows ${ }^{53}$. Diller soon fell seriously ill and died not long thereafter, with his apparatus inherited by a certain Victor Gonetti, who hoped to continue exhibiting the fireworks. ${ }^{54}$

Sir George Adams junior, the royal instrument maker in England, knew of Diller and provided some more details about the nature of the gases Diller used. After describing how a bladder can be filled with inflammable gas and used like a torch, he

\footnotetext{
51 Gilbert Elliot, Life and letters of Sir Gilbert Elliot, first earl of Minto, from 1751 to 1806, when his public life in Europe was closed by his appointment to the vice-royalty of India, vol. 1 (London: Longmans, Green and Co., 1874), 217-8. Another description can be found in Caroline Girle Mrs P. L. Powys Climenson Emily J. Powys and ed, Passages from the diaries of Mrs. Philip Lybbe Powys of Hardwick house, Oxon. A.D. 1756-1808 (London: New York, Bombay, Longmans, Green, and Co., 1899), 232-3.

52 See review of Diller's show: "Royalty Theatre," The Times, Oct 061788.

53 See The Times for Sep 29, Oct 1, 2, 4, 61788

54 "Signor Victor Gonetti," World (1787), Wednesday, March 111789.
} 
states 'Mr. Dillier [sic] exhibited some very beautiful fireworks of this kind, at London, of different figures and colours. The colour varying with the mixture, one third of the air of the lungs mixed with inflammable air of pit-coal, gives a blue coloured flame; inflammable mixed with nitrous air [sic], affords a green colour; the vapour of ether affords a white flame.'55

After Diller left the scene, his fireworks had a continued existence in England. The natural philosopher and avid collector of scientific instruments James Dinwiddie (17461815) purchased Diller's philosophical fireworks in 1788, although it is not clear if they were a copy or the original Diller used on tour. ${ }^{56}$ Diller had a partner who also perpetuated the performances. While he was still in France, Diller had teamed up with John Cartwright, a musician who was teaching the queen how to play 'musical glasses'. Diller and Cartwright had gone to London together, and Cartwright provided musical interludes to Diller's displays. ${ }^{57}$ After Diller's death, Cartwright used a version Diller's apparatus and improved it. ${ }^{58}$ Over the years, he occasionally put on demonstrations

55 George Adams, Lectures on natural and experimental philosophy : considered in it's [sic] present state of improvement : describing, in a familiar and easy manner, the principal phenomena of nature, and shewing, that they all co-operate in displaying thegoodness, wisdom, and power of God (London: Printed by R. Hindmarsh, 1794), Vol. 1, 496. G. S. Klügel, Encyclopädie, oder, zusammenhängender Vortrag der gemeinnützigsten, insbesondere aus der Betrachtung der Natur und des Menschen gesammelten Kenntnisse (Berlin: 1806), 460. also mentions that flame colour was produced by mixing gases in fireworks.

56 William Jardine Proudfoot and James Dinwiddie, Biographical memoir of James Dinwiddie, L.L.D., astronomer in the British Embassy to China, 1792, '3, '4, afterwards professor of natural philosophy in the College of Fort William, Bengal : embracing some account of his travels in China and residence in India (Liverpool: E. Howell, 1868), 25.

57 See for example, "At the Lyceum near Exeter Change near the Strand."

58 "Cartwright (John)," in The Thespian dictionary, or, Dramatic biography of the eighteenth century : containing sketches of the lives, productions, \&c., of all the principal managers, dramatists, composers, commentators, actors, and actresses, of the United Kingdom: interspersed with several original anecdotes; and forming a concise history of the English stage (London: Printed by J. Cundee for T. Hurst; [etc.], 1802). 
with the fireworks and musical glasses, even as late as 1811.59 He subsequently moved to the United States with his show and died there.60

Diller's apparatus also found widespread diffusion in Europe, probably through the Dumotiez' incarnation of his instruments, as well as Bienvenu's. A contemporary of Diller's from France, a Mr. Henry described as the 'Original Inventor of this New Phenomenon in Chemical Philosophy', ${ }^{61}$ toured with philosophical fireworks. ${ }^{62}$ In England, a 'specimen of the philosophical fireworks' were included in some of the lectures offered in 1800 at the Royal Institution. ${ }^{63}$ By the turn of the nineteenth century, the fireworks were sufficiently commonplace that the Sporting Magazine, when describing a new version suspended from a balloon, said it was 'a fine and expensive firework, differing in nothing from the usual wheels, stars, \&c. except in this, that the fire did not begin till it was elevated several hundred feet in the air. ${ }^{\prime} 4$ There was also a William Clarke who toured the country with the philosophical fireworks up to 1830 ,

\footnotetext{
59 Displays in theatres are advertised in "The Philosophical Fireworks," Morning Post and Daily Advertiser, Friday, March 27 1789. "Lyceum, Strand," The Morning Chronicle, Friday, June 12 1801. "New entertainment. Mr Cartwright's exhibition," The Times, May 17 1800. "Cartwright's musical glasses and philosophical fireworks," The Times, Apr 03 1809. "Patronised by Her Majesty," The Aberdeen Journal, Wednesday, November 271811.

60 R. S. Coffin, Oriental harp. Poems of the Boston bard (Providence: R.I., Printed and published by Smith \& Parmenter, agents for the sale of the Oriental harp, 1826), 16-7.

61 "Young Astley's Night," World (1787), Tuesday, September 161788.

62 "Royal Grove, Westminster Bridge," World (1787), Monday, October 6 1788. "Royal Grove. Astley's. Westminster Bridge.," World (1787), Thursday, April 221790.

63 Bence Jones, The Royal Institution, its founder and its first professors (London: Longmans, Green, and Co., 1871), 171.

64 "Full and Interesting Account of the Various Ascents of Messrs. Garnerin, Sowden, Locker, \&c. in Balloons," Sporting magazine; or, Monthly calendar, of the transactions of the turf, the chace, and every other diversion interesting to the man of pleasure, enterprize and spirit 20, no. 4 (1802).
} 
although by the end, he attracted only small audiences. ${ }^{65}$ Shows with the fireworks were reported in Cambridge, Oxford, Manchester and Birmingham, where it was advertised for possible use in lighthouses. ${ }^{66}$ In 1805 , an apparatus built by 'M. Dumutier' in Paris was used in a show called Pantascopia. ${ }^{67}$ In Italy, the inventory of Volta's instrument cabinet include a Diller device. ${ }^{68}$ It was also known in Austria, where an early worker on the thermolamp, in reference to 'fireworks with inflammable air' (Feuerwerken mit brennbarer Luft) stated: 'Messrs. Diller, Bienvenü and Dümoustier have done much work in this area with great success'. ${ }^{69}$ What exactly all these devices were and how they were interrelated is not known and requires further study.

Diller provides a remarkable case of the public science of the eighteenth century, one where an itinerant lecturer presents a device that incorporates on one hand, some of the latest findings of pneumatic chemistry as well as some original research in the field, and on the other, was intended to be entertaining. Diller's audiences were just as eclectic, socially and scientifically. He advertised broadly and attracted many people, up the social ladder to the nobility and gentry, 70 and even the king of France. The scientific audience could be just as elite, including the members of the Académie and

\footnotetext{
65 "Obituary: Mr. William Clarke," Gentlemen's Magazine 86 (1830).

66 Werrett, "From the grand whim to the gasworks," 334. John Alfred Langford, A century of Birmingham life: or, A chronicle of local events, from 1741 to 1841. Vol 2 (Birmingham: E.C. Osborne; London, Simpkin, Marshall \& Co., 1868), 388.

67 "Pantascopia and Ergascopia," The Times, Jan 011805.

68 Gli Strumenti di Alessandro Volta: Il Gabinetto di fisica dell'Università di Pavia, (Milano, Pavia Università degli studi di Pavia, Editore Ulrico Hoepli, 2002), 354.

69 'Die Herren Diller, Bienvenü und Dümoustier haben überhaupt hierinne mit vielem Erfolg vorgearbeitet.' Winzler, Die Thermolampe in Deutschland, 163.

70 "Royalty Theatre."
} 
the Royal Society. The result of his brief dash across the stage was that his instruments spread throughout Europe, beginning in England and France, but also as far as Italy and Austria. Subsequently, even if they did not copy Diller's device, Lebon, Winsor, and Bouton \& Watt all followed in the same tradition of public illuminations in which Diller was situated before them. 


\section{AIR ANALYZED; or,} A Syltem of Experiments to prove the nature Air, Mephetic, Acid, Fluor Acit, Alkaline, Phlogiftic and Dephlogenticated Airs, on a coirsplete apparatus ; fo as to give a minute exhibition of thofe interefting difio. veries, lately made by Dr. Priefley, Dr. Blick, Lavoifier, \&ec.

It is no compliment to thofe ufeful libourers in the vineyard of feience to fay, that their sifcoveries illuftrate not only the propertics of Air, but the ecconomy of the human conftitution; hew the finure of its modirn maladies, and hold out the moft rational fyftem ior its prefervation, of any that ever graced the annals of Philurophy.

In this Lecture, the mude of producing thofe various Airs, and their medical application, will b: made ocularly evident; fo that thofe who have not fo much as bettowed a thought upon philofophical fubjeds, may underftand, and be benefized by it.

The Lecture begins at Twelye, ant will continue at that hour every day for a tortnight, at Mr. Kennet's large room, nigh Air-ftrect, Piccadilly. Tickets 5 s. each. By $R$, W A L K E R, of Yok $x$.

"Air Analyzed." Morning Post and Daily Advertiser, Thursday, May 9, 1776.

Nor was Diller an isolated case of public demonstration of the properties of inflammable gases. In England, there were itinerant public lecturers who included pneumatic chemistry in their repertoire. There was, for example, a R. Walker of York 
who in 1776 gave lectures in London entitled 'Airs Analyzed'. ${ }^{71}$ Walker included inflammable air among his subjects, and demonstrated how to produce them. Such lecturers can also be found in the areas outside of London, such as in Leeds, where in 1784 Mr. J. Weavor delivered an 'entertaining course of lectures on natural and experimental philosophy'. He included a section on pneumatics that would examine, among other things, 'inflammable Gas, or Air, in the Construction of Balloons ... its Use in the in the Vegetable, Animal, and Fossil Kingdoms, when in a proper state, and its noxious Qualities and dire Effects when contaminated,-Exemplified by analyzing certain Bodies, and the blowing up Mines and artificial Earthquakes on a small and harmless Scale. ${ }^{72}$

\subsection{Uses of inflammable gases before the thermolamp}

There are few other miscellaneous episodes of people trying to find practical uses for inflammable air in the pre-history of gaslight. Neret, the same who had an exchange with Barbier de Tinan in the Obervations sur la physique about the nature of inflammable airs, printed in 1777 a short notice in same journal about a culinary heater that worked with inflammable air. ${ }^{73}$ It was simply a bladder stored in a metal cylinder and compressed from above by a plate that drove the gas out of the bladder. The gas

\footnotetext{
71 "Air Analyzed," Morning Post and Daily Advertiser, Thursday, May 9 1776. Also May 7.

72 "Philosophy," Leeds Mercury, Tuesday 13 April 1784.

${ }^{73}$ Neret, "Nouveau Réchaud d'un amateur de physique," Observations sur la physique, sur I'histoire naturelle et sur les arts 9 (1777).
} 
was burned as it came out, and lasted for a few minutes. The 'réchaud' did not have much success, although Krünitz describes it in his article on 'Brennluft Lampe'. ${ }^{74}$

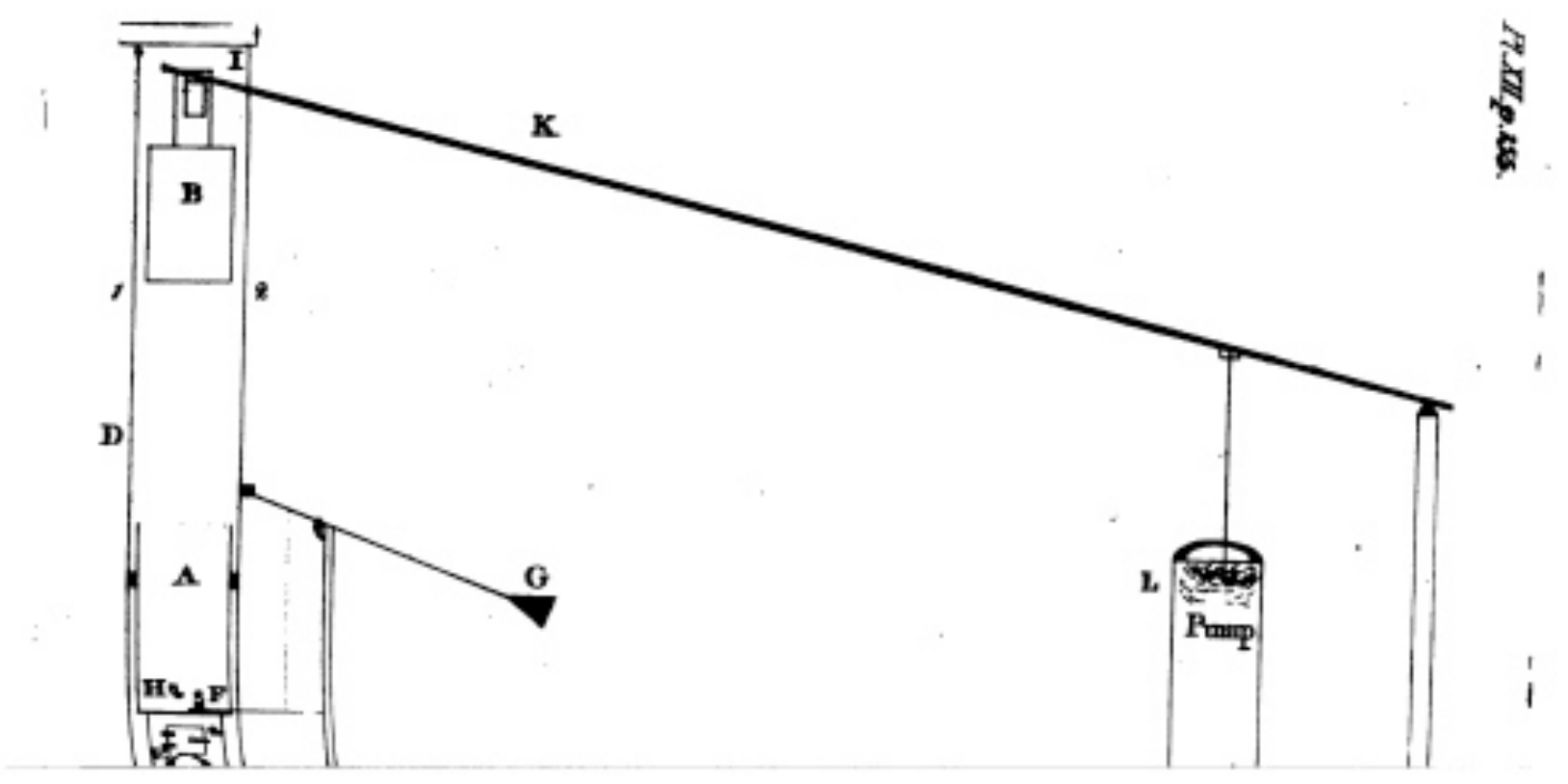

Figure 2.4 Inflammable air engine from "Specification of the Patent Granted to Mr. Robert Street" The repertory of arts and manufactures 1st series 1 (1794): 154-56.

There were at least two patents taken out in England in the early 1790 s for inflammable air engines: the first was by John Barber in 1791, the second by Robert Street in $1794 .{ }^{75}$ Barber's engine was supposed to work by combining streams of inflammable and common air with water, burning the airs in an 'exploder', with the flame

\footnotetext{
74 Johann Georg Krünitz, "Lampe," in Oekonomische-Technologische Encyclopädie; oder, Allgemeines System der Land-, Haus-, und Staats-Wirthschaft, in alphabetischer Ordnung; aus dem Französischen übersetzt und mit Anmerkungen und Zusätzen verhmehrt, auch nöthigen versehen Band 59, ed. Johann Georg Krünitz (Berlin: J. Pauli, 1793), 274-5.

75 "Specification of the Patent granted to Mr. John Barber, in the parish of Nuneaton," The repertory of arts and manufactures 1st series 8 (1798). "Specification of the Patent granted to Mr. Robert Street, Varnishmaker; for his Invention to produce an inflammable Vapour Force, for communicating Motion to Engines, Pumps, and Machinery," The repertory of arts and manufactures 1st series 1 (1794).
} 
mixed with steam subsequently driven out against a fly wheel. The specifications are a bit thin on detail. Street's machine was a basic internal combustion engine: inflammable air was generated inside a piston by dropping turpentine onto a heated surface, and subsequently sparked driving up the piston head which was attached to a lever. The lever could be used to do work of some form. Neither of these machines had any subsequent success.

By the early 1790 s then, there were many independent versions of gas lighting and even other uses of inflammable gases either attempted or suggested, and some of which, like the family of lighters and lamps derived from Volta's, were fairly widespread, at least among instrument makers, while others, such as Diller's were seen by many, copied extensively, and reported on in important publications. None of them, however, proved to be the seed of the gaslight technology which eventually became an industry. In fact, given the number of different attempts to make use of inflammable gases, the situation did not seem hopeful to Fourcroy, who wrote in the Leçons élémentaires that 'inflammable gas is not of much use. Some have, however, tried to replace other combustible material with it in various aspects of life, such as lighting, fire arms, etc. ${ }^{7} 6$ He goes on to mention Neret's heater, Volta's various instruments, as well as something that sounds like Diller's machine made by Jacques Bianchi (sometimes Bianchy), another Parisian instrument maker, although it antedates Diller's arrival in Paris, but not his work in the Hague. ${ }^{77}$ Fourcroy, probably because of the emergence of ballooning in

\footnotetext{
${ }^{76}$ Antoine-François Fourcroy, Leçons élémentaires d'histoire naturelle et de chimie, 2 vols. (Paris: Sous le privilège de la Société Royale de Medicine, 1782), 407.

77 As mentioned above with the Dumotiez brothers, instrument makers began making simple versions of Diller's apparatus.
} 
1783 , in later years softened his opinion on the futility of using inflammable gas, merely listing the inventions in subsequent editions without comment. ${ }^{78}$ Nevertheless, despite many attempts, neither gaslight nor any use of inflammable gas on a large scale was close to being a reality in 1790 .

\subsection{Distillation}

Distillation, such as for making coke or tar, is an industrial processes involving coal or wood where inflammable gases are generated in large quantities, and as with firedamps, it comes as no surprise that some of those involved flared the gases and thought of using them for lighting. The study of distillation as an industrial process intensified in the period $1770-1800$. This was partly driven by concerns over deforestation on the Continent leading to a search for an alternative to charcoal, but the increased use of coke in England as well as more general interest in developing a process to produce potentially useful chemicals also contributed to the attractiveness of distillation processes. Lebon and Murdock are among the people working on distillation more broadly before they hit upon gas lighting, but they are not the only ones. A number of others observed or even tried lighting with the distillation gases in some way. But it was one thing to think of the lighting potential of coal-gas, and another to develop it into a commercial product, and this is what truly separates Lebon and Murdock from the host of others who experimented with burning inflammable gases. Murdock himself

\footnotetext{
78 'le gaz inflammable est peu d'usage. On a cependant entrevenu qu'il pourroit suppléer à d'autres matières combustible dans plusieurs besoins de la vie, comme pour éclairer, pour charger quelques armes à feu, \&c.' Antoine-François Fourcroy, Elémens d'histoire naturelle et de chimie, Cinquième édition. ed. (A Paris: Chez Cuchet ... 1793), 332.
} 
explicitly recognized this to be the case when he wrote that 'the idea of applying [gas] as an economical substitute for oils and tallow, does not appear to have occurred to this gentleman, and I believe I may, without presuming too much, claim both the first idea of applying, and the first actual application of this gas to economical purposes. ${ }^{.79}$

Both tar and coke making processes were nascent in the eighteenth century. The use of coke for smelting iron was gradually increasing over the course of century after its first introduction by Abraham Darby at Coalbrookdale at the beginning of the century. Tar making was a less successful venture, and although there were a number of attempts during the century to make tar by heating coal in ovens, none succeeded commercially, at least in England.

The earliest known attempt at coal-gas lighting derived from distillation is a device put together by George Dixon II (1731-1785) of Durham sometime after 1779, although the date is uncertain. Dixon was a colliery owner and engineer who was had some knowledge of chemistry. ${ }^{80}$ The evidence for this case comes mostly from from one source: a book published by John Bailey, Dixon's nephew, in $1810 .{ }^{81}$ Bailey describes how Dixon made coal-gas as early as 1760 by heating coal in a kettle to which he attached a pipe and burned the gas flowing out of the end. These were never really

\footnotetext{
79 William Murdoch, "An Account of the Application of the Gas from Coal to Economical Purposes," Philosophical Transactions of the Royal Society of London 98 (1808): 132.

80 Henry Ecroyd Smith, Annals of Smith of Cantley, Balby, and Doncaster, County York : embracing elaborate pedigrees of the connected families and biographical notices of their more eminent members (Sunderland: Hills and Co., 1878), 197-8.

81 John Bailey, General view of the agriculture of the County of Durham with observations on the means of its improvement; drawn up for the consideration of the Board of agriculture and internal improvement (London: Richard Phillips (Printed by E. Walker), 1810), 290-2. J. Macfarlan, "George Dixon: Dicoverer of Gas Light from Coal," Transactions of the Newcomen Society 5 (1925). added a drawing by Dixon.
} 
taken to another level, but when Dixon decided to make tar by heating coal in ovens in 1779, he also thought to test his idea of gaslight further. Unhappily for him, he caused an explosion in the tar-making apparatus when trying to extinguish a gas flame, which cooled him to the idea permanently. He subsequently dropped tar making as well, due to the high cost of transportation to the ports where he sold the tar to ship builders.

Archibald Cochrane, the ninth Earl of Dundonald (1748-1831), is another famous instance of someone working with the distillation of coal in an industrial context who burned gas to a limited extent. Dundonald's work has been described on various occasions,,$^{82}$ and will not be repeated in detail here. Archibald Cochrane was a scion of a Scottish noble family, which, while not quite impoverished, had lost most of their estates and retained only their seat at Culross Abbey. After a career in the British Army and Royal Navy, Dundonald pursued coal mining on the estate as a source of revenue. He had some interest in chemistry, and engaged in limited experimentation in making tar from coal, perhaps because of his experiences on ships in the Royal Navy. Feeling that his work was promising, in 1781 patented his process. ${ }^{83}$ The tar works at Culross Abbey were functioning the following year, but, faced with the possibility of bankruptcy, he was forced to seek outside investors and incorporated the British Tar Company, which persisted into the nineteenth century. By the end of the year, he was able to sell some tar, but unfortunately, it was insufficient to relieve him completely of his financial burdens. He consulted with various people, including Joseph Black, about how to

\footnotetext{
82 Archibald Clow and Nan L. Clow, The Chemical Revolution; a Contribution to Social Technology (Freeport: N.Y., Books for Libraries Press, 1970), 389-423.

83 "Specification of the Patent granted to Earl of Dundonald," The repertory of arts and manufactures 1st series 1 , no. 3 (1794).
} 
derive more profit from his works, and decided with his partners to publish a pamphlet in 1784 describing his process and all the products he could make. Dundonald's list included coke, lamp black, ammonia, sal ammoniac, varnish, Glauber's salt, and fossil alkalis. ${ }^{84} \mathrm{He}$ appended to this description a long list of references from satisfied customers.

Dundonald placed a petition before

Parliament to extend his patent, which was granted in 1785 for twenty years. The British Tar Company expanded, setting up tar works close to some iron foundries. Unfortunately for Dundonld and the company, it became embroiled in lawsuits, including one with Macadam. In addition, the Royal Navy, which Dundonald had hoped would become his biggest customer, never obliged and the company began to struggle financially.

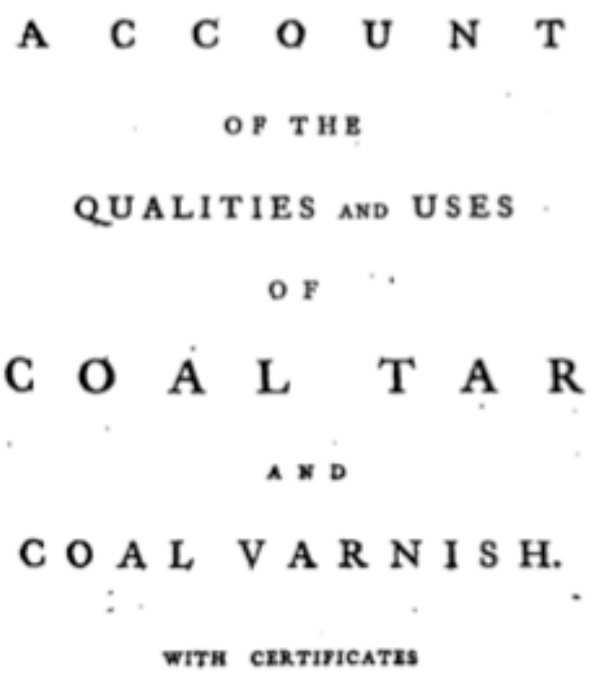

From SHIP-MASTERS and others.

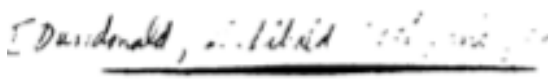

L $\bigcirc \mathrm{N}$ D $\mathrm{N}$ t

Printed for T. and G. Wrixiz, in St. Paul', Church-Yard. MDCCLXXXY.

to use some inflammable gas from his ovens to amuse guests, although there is no contemporary record for this. William Nicholson mentions Dundonald very briefly, in 1807.85 In any case, Dundonald does not seem to

\footnotetext{
${ }^{84}$ Archibald Cochrane Dundonald, Account of the qualities and uses of coal tar and coal varnish with certificates from ship-masters and others (W. Smellie, 1784).

85 William Nicholson, "Remarks on Mr. Winsor's projected Heat and Light Company," A Journal of natural philosophy, chemistry and the arts 16, no. 65 (1807)., Murdock also mentions it in Murdoch, "An Account of the Application of the Gas from Coal to Economical Purposes," 132.
} 
have piped the gas to his house, but gathered it in bladders, according to recollection from locals collected many years after the fact.

The tar was conducted by a pipe into similar cylinders of brick-work on the opposite side of the bank; each of these had a small opening in the top for the escape of the incondensible part of the products. To these openings the workmen were in the habit of attaching a cast-iron pipe by means of a lump of soft clay, and lighting the gas at the other end to give them light during the darkness. His Lordship, also, was in the habit of burning the gas in the Abbey as a curiosity; and for this purpose he had a vessel constructed resembling a large tea urn; this he frequently caused to be filled and carried up to the Abbey to light the hall with, especially when he had company with him. ${ }^{86}$

As with Dixon, an explosion made Dundonald and his employees far more reluctant to use the gas for amusement. Nothing more came of Dundonald's work, except that his son claimed at a much later date that he had discussed gaslight with Boulton. Murdock was later to deny that he had heard of any antecedents to his work, but this point is not that interesting because there were by the 1790s many people who used inflammable gas for light. In any case, Dudonald never took gaslight very seriously, as he neither patented it nor attempted a commercial venture based on it.

The episode of Dundonald, as that of Spedding at Whitehaven and even Dixon, shows that the observation of inflammability is not sufficient. Far more was needed, including a way to generate, purify, store, and distribute the gases in a large scale and

\footnotetext{
86 Thomas Thomson, "On Coal Gas," Proceedings of the Philosophical Society of Glasgow 1, no. 9 (1843): 173-4. John Hart, "Contribution to the history of gas lighting," The Mechanics' magazine, museum, register, journal, and gazette 40, no. 1088 (1844).
} 
safe way. The procedures and apparatus of the chemical laboratory were what ultimately allowed this happen.

\subsection{The thermolamp-Lebon and industrial distillation}

The thermolamp is the most important of the attempts at gaslight in this chapter, and like the Dixon and Dundonald episodes, also arose from an interest in distillation as a chemical and industrial process. Unlike Volta's lighter, the thermolamp had some possibility of becoming a more common and larger scale form of lighting, or at least was conceived as such by those who pursued it in a commercial way, something which never happened to the many versions of Volta's lighter. The thermolamp, however, had a relatively brief commercial existence, originating with Philippe Lebon's invention and patent in 1799 to its proliferation, mostly in Germany and France, but also in Russia and the US, in the few years afterwards. After a short burst of activity, interest in the thermolamp was waning by 1810 , although references to it can be found for many years afterwards.

I will not attempt a complete history of the thermolamp here, nor even of Lebon's work, neither of which has been written adequately. ${ }^{87}$ My primary concern will be to discuss its origins and what relevance it has to gaslight as it ultimately developed in England, and to contrast its failure with the successful implementation derived from the English model.

\footnotetext{
87 There are many biographies of Lebon and brief histories of the thermolamp, but unfortunately, the biographies do not give complete citations of the primary sources.
} 
Philippe Lebon (1767-1803) was born in Brachy, Champagne. After his early education in Châlons-sur-Marne close to his hometown, Lebon decided to pursue a career in the French civil engineering corps and enrolled in the École des ponts et chaussées in Paris. He moved to Paris in April of 1787,88 just before Diller arrived there with his philosophical fireworks. Although Lebon never mentions Diller or any other versions of lighting or heating with inflammable gas in his writings, the descriptions he gives of his own lighting follow in the tradition of Diller's philosophical fireworks. The fireworks certainly excited some interest in Paris, and they were known in various forms for years afterwards. Lebon, in his single published work, describes uses of gas very similar to Diller's:

We can produce the most magnificent illuminations. Ordered jets of fire change their colour, their duration, their form all at will, the movement of suns and spinning columns giving great effect. What an advantage over ordinary illuminations! Whoever has seen the flame in a lantern, has seen a flame as in all lanterns. But whoever sees a flame take

\footnotetext{
88 François Veillerette, Philippe Lebon, ou, L'homme aux mains de lumière : la vie et l'oeuvre de l'illustre inventeur français du gaz d'éclairage et du chauffage au gaz (Colombey-les-Deux-Eglises: N. Mourot, 1987), 95.
} 
the shape a palm, will find new pleasure on seeing it take the form of a wreath of

flowers. 89

This is by no means a proof that he had seen Diller's work, but it does make it a strong possibility. Wood-gas is not naturally multi-coloured. Diller achieved this effect with other kinds of gases not made by distillations and mixed in various proportions, and yet Lebon suggests multicoloured flames as a possibility. The mention of flowers and suns is also strikingly similar.

89 [O]n doit produire les illuminations les plus magnifiques. Des jets de feu bien filés, leur duré, leur couleur, leurs formes qui se carient à volonté, le mouvement de soleils, et de colonnes tournantes, doivent produire de grands effets. Que d'avantages sur les illumination ordinaires! qui a vu la flamme que forme un lampion, à vu celle de tous les lampions imaginables; mais celui qui a vu la flamme dessiner une palmette, la retrouve avec un nouveau plaisir sous la forme d'un calice de fleurs. Philippe Lebon, Thermolampes, ou poêles qui chauffent, eclairent avec economie, et offrent, avec plusiers produits precieux, une force motrice applicable à toute espèce de machines (Paris: Pougens, 1801), 7-8. Compare this with the following description of Diller's presentation:

'The apparatus begins and is directed in a circular motion. The flame communicates to a turning sun, then to a large cross of maeth [sic] of white and red fire, a sun fixed, four bouquets of yellow fire, five turning suns of different colours, four parasels [sic] of lilac flame, eight suns of two colours turning round eight grand bouquets sometimes red and sometimes white; 16 suns of different colours turning round, which while they move rapidly round their axis, revolve round another sun like planets, that act as their centre. These 16 suns in their revolutions light up eight candrilles [sic], each consisting of 18 flames, some white, some yellow. The next are eight grand flowers of yellow flame, which united with the former, compose altogether a very large volume of fire, consisting of 6000 flames of various colours.'

From "Philosophical Fire." 
In any case, Lebon was an excellent

engineering student. He graduated at the top of his class in $1792,{ }^{90}$ and in the same year submitted an entry to a national competition sponsored by his school for a design of a steam engine. His entry won first place, and he was granted 2000 francs to continue his research into steam engines. ${ }^{91} \mathrm{He}$ thereafter maintained an interest in research and invention, which he first directed towards the engines as well as distillation as an industrial process. There is evidence for his interest in these processes in $1791 .{ }^{92}$ Faujas-de-Saint-Fond

\section{E S S A I SUR LE GOUDRON D U} CHARBON DE TERRE;

Sur ta manière de l'employer pour caréner les Vaiffeaux, \& celle d'en faire ufage dans plufieurs arts;

Sur les différens produits de ce combuftible foffile, tels que le bitume folide, Phuile minérale, le naphte, Palkali volatil, l'eau ftyptique propre à la préparation des cuirs, le noir de fumée, le coaks ou charbon épuré:

Precidl de recherches fur Iorigine $\dot{\sigma}$ les diffírentes fortes de Charbons de terre.

Par M. B. F A U J A S.

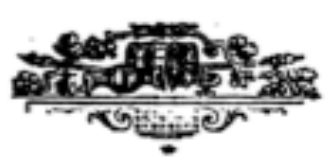

A P A R I S,

DE L'IMPRIMERIE ROYALE.

M. D C C. $\mathrm{x}$ C.

90 Veillerette, Philippe Lebon, 95.

91 Ibid., 103-4.

92 Ibid., 136. quoting a Lebon paper on "Disposition favorable à donner aux machine à feu" (1791), in the archives of the Ecole nationale supérieure des Ponts et Chaussés. Caution should be exercised in regard to Veilleret as his quotes from Lebon's patent indicate some unacknowledged editing and errors. $\mathrm{He}$ also misdates the diagram from Lebon's patent. 
had recently published a treatise devoted to products of the distillation of coal at its uses, at it may have been this work that stimulated Lebon's curiosity in that direction..$^{93}$

As a civil engineer in state service, Lebon was allocated a post, and his first assignment after graduation was in the town of Angoulême in the Charente district of western France. He had a rocky relationship with his superiors there, perhaps because of his continuing research, but also because of extended and sometimes unexplained absences from his post. 94

Lebon's ongoing research resulted in a patent for distillation processes (pour distiller au moyen du vuide [sic] et du froide) on September 11, 1796.95 He wrote in the preface to the patent that 'of all chemical operations, distillation is without a doubt the most precious and extensively used. ${ }^{96} \mathrm{He}$ thought he could use distillation as a technique for producing salts, for purifying oils, and for the separation of the fixed and volatile parts of any substance, all of which were well-known procedures from the chemical laboratory. An interesting and probably fruitful line of inquiry would be into

\footnotetext{
${ }_{93}$ Barthélemy Faujas-de-Saint-Fond, Essai sur le goudron du charbon de terre, sur la manière de l'employer pour caréner les Vaisseux, \& celle d'un faire usage dans plusieurs arts : sur les différens produits de ce combustible fossile tel que le bitume solide, l'huile minérale, le naphte, l'alkali volatil, l'eau styptique propre à la préparation des cuirs, le noir de fumée, le coaks ou charbon épuré : précédé de recherches sur l'origine \& les différentes sortes de charbons de terre (Paris: Imprimerie Royale, 1790). See also de Genssane, Traité de la fonte des mines par le feu du charbon de terre; ou, Traité de la construction \& usage des fourneaux propes à la fonte \& assinage des métaux \& des minéraux par le feu du charbon de terre, avec la manière de rendre ce charbon prope aux mêmes usages auxquels on emploie le charbon de bois (Paris: Vallat-la-Chapelle, 1770). Dundonald's treatise was also translated into French.

94 Jean-Pierre Williot, Naissance d'un service public : le gaz à Paris (Paris: Rive droite-Institut d'histoire de l'industrie, 1999), 16.

95 Veillerette, Philippe Lebon, 134.

96 'de toutes les opérations de chimie, la distillation est sans doute celle dont les usages sont les plus étendus et les plus précieux.' Quoted in Williot, Naissance d'un service public, 15. Veillerette, Philippe Lebon, 135.
} 
what the distillation processes and ovens were that he refers to in his patent of 1796.

He mentions that the government was seeking ways of improving them. Distillation was used to produce pyroligneous acid (a mixture of acetic acid and methanol) used in tanning, for making charcoal, coke, and tar. Lebon also refers to savants, presumably chemists such as Lavoisier, and their laboratories. Lebon had learned about pneumatic chemistry and its instruments from his exposure perhaps in public lectures and certainly in his subsequent research.

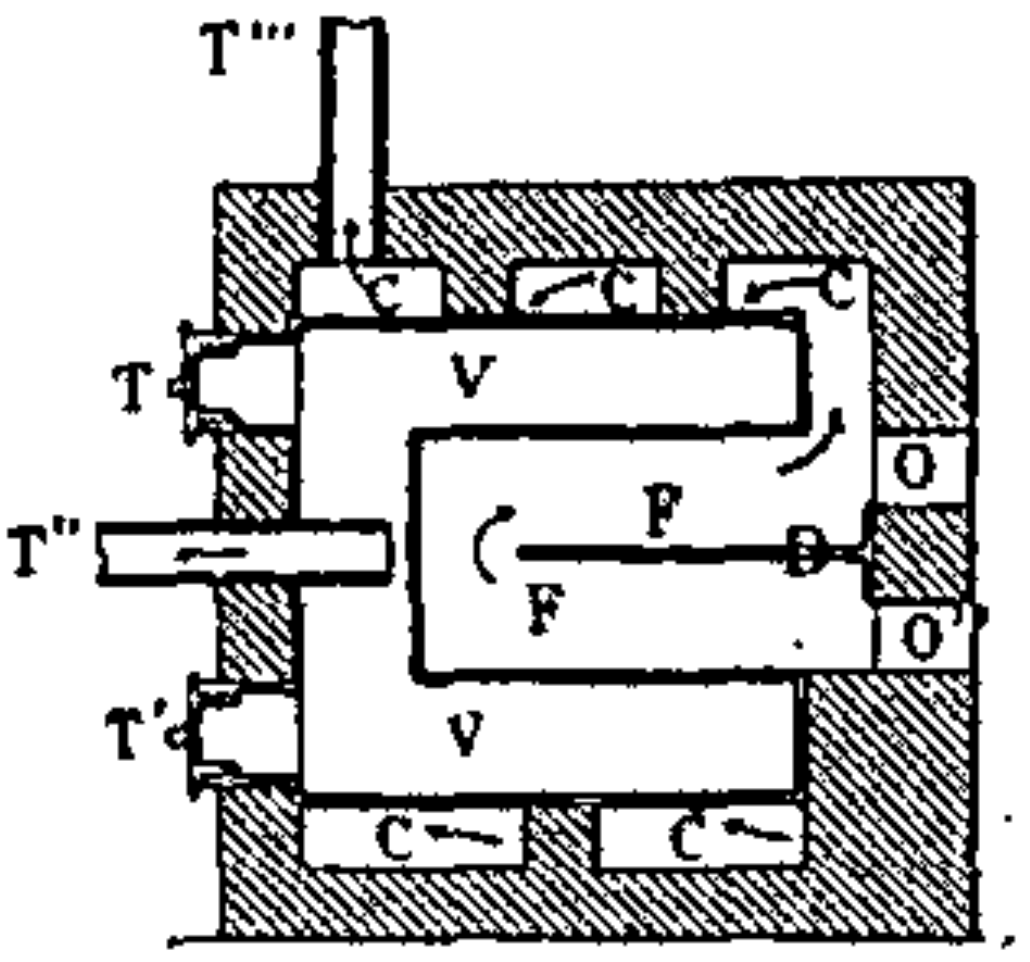

Figure 2.5 Lebon's furnace from his patent application (1799). From Magnier, Nouveau manuel complet de l'éclairage et du chauffage au gaz. (1899) Vol. 1, p. 5 
Lebon followed up this work on distillation by further investigating the possible uses of the products from combustible materials, including inflammable gases.

Sometime in the next year or two, he hit upon the idea of using these gases to heat and light, rather than having to rely on the source material burning with an open flame. In 1798 , he wrote a paper on 'New methods of using combustible more usefully for heat and light, and of collecting by-products thereby produced' which he presented to the Institut national, ${ }^{97}$ and also applied for patent with the same title on September 4, 1798.98 The paper and the patent application's title demonstrates that Lebon was thinking, as stated in the 1796 patent, along the lines of efficiency of separation processes. Lebon understood that distillation was used as an analytic process in the laboratory to resolve materials into their constituent parts, as well as being an industrial process for the production of material such as coke, tar, and pyroligneous acid. He had come up with a better distillation process, one that dissolved wood into its constituent principles more efficiently, of which inflammable gas was one. He specifically mentions in his patent that inflammable gases produced in this way can be used for balloons (aérostats) as well as for heating and lighting away from the open fireplace. ${ }^{99}$ The patent shows that Lebon was familiar with contemporary pneumatic chemistry. Although he treats the terms 'gas inflammable' and 'hidrogène' interchangeably in the

\footnotetext{
97 Lebon, Thermolampes, ou poêles qui chauffent, eclairent avec economie, et offrent, avec plusiers produits precieux, une force motrice applicable à toute espèce de machines, 1. title of paper given in Veillerette, Philippe Lebon, 138.

98 'Moyens nouveaux d'employer les combustibles plus utilement \& à la chaleur \& à la lumière, \& d'en recueillir leur sous-produits' Philippe Lebon, "Moyens nouveaux d'employer les combustibles plus utilement \& à la chaleur \& à la lumière, \& d'en recueillir leur sous-produits," in Masse: Le Gaz (1914) Annexe I, p. 234-247 (France: 1799).

99 Ibid., 234.
} 
first patent, 100 in the addition of 1801 , he spells out the composition of wood-gas more clearly. He follows Fourcroy's contemporary usage described in chapter one, that of classing all hydrocarbon gases as 'gas inflammable', with some of these gases being hydrogen with carbon held in solution. ${ }^{101}$ Lebon was familiar with Fourcroy and mentions him in his paper. ${ }^{102}$

Lebon did not use the word 'thermolampe' in the patent application, which was conceived as covering a distillation process. The subsequent use of the word projected by later historians back onto this first patent can obscure what Lebon actually thought he was doing. The French government granted Lebon his patent on September 28, 1799, over a year after he submitted it. These first public announcements of Lebon's in 1799 generated some interest, but more work was needed before he could think of commercializing it, something he clearly had in mind from the beginning. ${ }^{103}$

A couple of years later, on the 25th of August, 1801, Lebon submitted an extension to the original patent, where he tried to give more details about the invention proper, as the first patent had focused on a process, intentionally leaving vague the details of the apparatus. His thinking had clearly evolved over the intervening two years. The addition to the patent indicates that Lebon now concentrated more on heating and lighting: 'Since most applications of the thermolamp will have as object lighting and

\footnotetext{
100 Ibid.
}

101 Lebon, "Additions," in Masse: Le Gaz (1914) Annexe I, p. 234-247 (France: 1801), 240.

102 Lebon, Thermolampes, ou poêles qui chauffent, eclairent avec economie, et offrent, avec plusiers produits precieux, une force motrice applicable à toute espèce de machines, 3. 
heating, I will consider them particularly from this point of view'.104 Reflecting this new emphasis, the term 'thermolampe' had also been coined, but not by Lebon: 'this is how a number of people are content to call my apparatus'. ${ }^{105}$ Lebon had even tried to get the French government to adopt his scheme for lighting city streets, but apparently the financial pressures of France's wars made this sort of project a luxury it could not afford. ${ }^{106}$

The patent extension shows that Lebon was clearly aware of the difficulty in using wood-gas for heating and lighting because of the noxious and malodorous products of combustion. He proposed to have enclosed burners with chimneys that led the combustion products away from the flame without allowing them to mix with the room's air. ${ }^{107} \mathrm{He}$ also saw the need for purifying the gases by cooling them to remove suspended oils by passing the gas through water or other liquids. ${ }^{108}$ Finally, Lebon mentioned using inflammable gas in an internal combustion engine.

\footnotetext{
104 'Cependant le plus grand nombre des applications du thermolampes devrait avoir pour objet de chauffer et d'éclairer, je vais les considérer particulièrement sous ce point de vue' Lebon, "Additions," 244.

105 'c'est ainsi que plusieurs personnes se plaisent a nommer mon appareil' Ibid., 240.

106 Veillerette, Philippe Lebon, 164-5.

107 Lebon, "Additions," 246.

108 Ibid., 243.
} 


\section{Thermolampes.}

Ces Thermolampes sont des poēles qui chauffent, éclairent avec économie, et offrent avec plusieurs produits précieux, une force motrice applicable. a toute espèce de machines.

L'inventeur, le cit. Philippe Lebon, ingenieur des ponts et chausoces, vient d'en publier un Prospectus de 12 pag. in-4, dans lequel, apres avoir exposé l'utilité de son invention, il propose d'onvrir une souscription pour P'acquisition des Thermolampes. En stterdant cetie ouscription, il fera une foin par déeade, et dans sa maison, des expériences destinées a constater les effets qu'on peut attendre de ces lampes, pour le chauffage, la lumière, l'économie, la décoration intérieure des oppartemens, 'et l'embellissement des jardins. Le prix des billets d'entrée eat de 3 fr.. On s'adresse s l'auteur, roe Dousinique, no. 1517 , près celle de Bourgogne, F. G. et ehez Ch. Powgens, Debray, Henrichs, etc.
Lebon now felt he could try to bring his

thermolamp to the public in some way, and his next step was to market his invention and to raise funds by subscription. His experiments to date had cost him a good bit of his own funds and he was beginning to feel the pressure. His marketing efforts were remarkably successful, at least from the point of view of attracting international attention. He had presented his thermolamp at the Athénée des Arts on July 19, 1801 to an audience which included such prominent people as Fourcroy and GayLussac. ${ }^{109} \mathrm{He}$ published his pamphlet, and then

leased the Hôtel de Seignelay in a tony neighbourhood of Paris where he installed two thermolamps, using one to light five rooms, and the other to light the gardens and the building's facade. ${ }^{110} \mathrm{He}$ then advertised public demonstrations there in various newspapers and many people came paying three francs for the privilege. ${ }^{111}$

109 Williot, Naissance d'un service public, 18.

110 "Lebons Thermolampen. Absonderung und Waschung der brennbaren Luft. Flamme in der Krystallkugel. Uebrige Zurichtungen und Wirkungen. ," London und Paris 8 (1801). The footnote in Johan Wagner, "Versuche über Lebons Thermolampen, und deren Beschreibung," Annalen der Physik 10, no. 4 (1802). quotes at some length from German journals describing both Lebon's apparatus and his demonstrations. See also Williot, Naissance d'un service public, 21.

111 Philippe Lebon, "Thermolampes," Journal général de la littérature de France : ou répertoire méthodique des livres nouveaux, cartes géographiques, estampes et oeuvres de musique 4, no. 8 (1801). 
On October 23, 1801, an English traveller visited Lebon and wrote back a description of what he saw:

\begin{abstract}
In lieu of fire or candle, on the chimney stood a large crystal globe, in which appeared a bright and clear flame diffusing a very agreeable heat; and on different pieces of furniture were placed candlesticks with metal candles, from the top of each of which issued a steady light, like that of a lamp burning with spirits of wine. These different receptacles were supplied with inflammable gas by means of tubes communicating with an apparatus underneath. By this contrivance, in short, all the apartments were warmed very comfortably, and illuminated in a brilliant manner. ${ }^{112}$
\end{abstract}

The Treaty of Lunéville had been signed a few months earlier in February of 1801, ending the war on the Continent, at least temporarily. The peace allowed Lebon's invention and demonstrations to be reported more broadly, as well as for more foreign visitors to witness them. As it turns out, there were two visitors through whom these demonstrations were to have a lasting impact: a flamboyant German entrepreneur from Frankfurt, Friedrich Albrecht Winzer, and Gregory Watt, the son of James. Winzer, who had anglicized his name to Winsor after a stay in England, came to Paris in 1802 with the express purpose of seeing Lebon's invention, ${ }^{113}$ while Watt was in Paris for other reasons, and just happened to come across Lebon's work. For Winsor, who had

\footnotetext{
112 Francis William Blagdon, Paris as it was and as it is; or, A sketch of the French capital, illustrative of the effects of the revolution, with respect to sciences, literature, arts, religion, education, manners, and amusements; comprising also a correct account of the most remarkable national establishments and public buildings (London: C.and R. Baldwin, 1803), 23.

113 Frederick Albert Winsor, Account of the most ingenious and important National Discovery for some Ages. British Imperial Patent Light Ovens and Stoves, respectfully dedicated to both Houses of Parliament, and all Patriotic Societies; and recommended to all the learned in Physics and Chemistry (London: Printed for the author, and sold by Messrs. Richardsons, Royal Exchange; Mr. Miller; Principal Booksellers in Town and Country. T. Maiden, printer, 1804), 3.
} 
already had a burning interest in the thermolamp, it marked the beginning of a life-long series of gaslight projects. For Watt, it made him think of a similar scheme that an employee of his father's firm Boulton \& Watt had been thinking about and tinkering with, but not really pursuing in earnest. He fired off a letter back home, urging them move on William Murdock's project as they may be caught out by this Frenchman's aspirations. These two events set in motion the immediate chain of events leading to the birth of a new industry. Lebon was not to play a part in it, except as the spark that lit the flame.

Lebon's subscription failed to gain momentum, probably because of the smell, as reported in a German newspaper: 'The greatest inconvenience of this thermolamp, at least up till now, is the unpleasant odour which it produces'. ${ }^{114}$ He was now under greater financial pressure as the subscription failed. ${ }^{115}$ The experiments were expensive, as were the patent applications. He then tried to interest some individuals in the thermolamp, and sold at least one, but this strategy proved futile as well. ${ }^{116} \mathrm{He}$ was finally forced to return to his work as an engineer in the civil corps, which assigned him to the Vosges department on May 28, 1802.117

Lebon's failure in France has not yet been sufficiently explained. The most commonly cited reason is that the French government was preoccupied with the war,

\footnotetext{
114 'Die grösste Unbequemlichkeit dieser Thermolampen, wenigstens jetzt noch, ist der unangenehme Geruch, den sie verbreiten' Wagner, "Versuche über Lebons Thermolampen," 497. "Lebons Thermolampen. Absonderung und Waschung der brennbaren Luft. Flamme in der Krystallkugel. Uebrige Zurichtungen und Wirkungen. ." "Versuch mit der Thermo-Lampe," Magazin der Handels- und Gewerbskunde 1 (1803). Williot, Naissance d'un service public, 22, footnote 36.

115 Veillerette, Philippe Lebon, 182. Veillerette says that it was never even opened.

116 Winzler, Die Thermolampe in Deutschland, 34. For a specific sale, see p. 25

117 Veillerette, Philippe Lebon, 191.
} 
and even if France was generally at peace at that moment, England continued to be a threat and Napoleon was obsessed with Albion's defeat. While there is certainly truth to this evaluation, there is also more to Lebon's failure than official indifference, as private interest could also have led to larger projects. Perhaps Lebon simply failed to inspire, but contemporary commentators from Germany remarked on the lack of interest in the thermolamp in France as compared to Germany. Ludwig Gilbert, professor of physics in Halle and editor of the Annalen der Physik, ${ }^{118}$ for example, mentions on at least two occasions, once in 1802 during the first excitement, and again in 1806 after the thermolamp had lost its lustre, that no French chemical or physics journal carried reports on the thermolamp, and that it was ignored by the Parisian press. ${ }^{119}$ Gilbert was certainly overstating the case. The thermolamp was well known and five years after his demonstrations, a French commentator was able to write: 'Tout le monde se rappelle l'ingénieuse découverte du themolampe, et les expériences faites par M. Lebon'.120 In addition, there is at least one report in a French academic journal. ${ }^{121}$ Finally, and most significantly, there are examples of French chemists or engineers who took inspiration from Lebon, including Antoine Thillaye-Platel, who heard of Lebon while working as a

\footnotetext{
118 "Gilbert, Ludwig," in Allgemeine deutsche Biographie (Vol 9) (Leipzig: Historische Commission bei der Königl. Akademie der Wissenschaften, 1875).

119 Wagner, "Versuche über Lebons Thermolampen," 492, footnote. Ludwig Gilbert, "Ueber die sogenannten Thermolampen und den ersten Erfinder derselben," Annalen der Physik 22, no. 1 (1806): 52.

120 L. J. M. Gujon, "Sur la carbonisation du bois, et sur les produits de sa distillation en grand," in Mémorial forestier, ou recueil complet des lois, arrêtés et instructions relatifs à l'Administration forestière, ed. Goujon (Paris: Arthus-Bertrand, 1809), 234. Antoine-François Fourcroy, Claude-Louis Berthollet, and Louis-Nicolas Vauquelin, "Verkohlung und Erleuchtung im Grossen, mit Thermolampen - Oefen. Bericht über eine Abhandlung der Herren Mollerat, von der Verkohlung des Holzes in verschlossenen Gefässen, und den verschiedenen Produkten, die dabei gewonnen werden," Annalen der Physik 30, no. 12 (1808): 402. make similar remarks about how well known Lebon's thermolamp was.
}

121 Marchais, "Note sur la 1ere expérience du thermolampe." 
pharmacist in Rouen, and designed a thermolamp himself for carbonizing turf, ${ }^{122}$ as well as Mollerat, director of the Etablissement du Creusot, who did the same for the carbonization of wood on a large scale with a view selling the products. ${ }^{123}$ Maxime Ryss-Poncelet likewise tried to adapt the thermolamp to carbonize coal. ${ }^{124}$ But as an editor of a scientific journal that regularly reprinted articles from French and English journals, Gilbert was familiar with the situation in important foreign publications. In fact, the lone article I have found is not really a report, being mostly just a lengthy quotation from Lebon's publication. In contrast to both English journals, which seemed to have passed Lebon by with hardly any comment, ${ }^{125}$ and French journals, German language publications featured many reports on the thermolamp, written mostly by people who took an active interest in the subject. Moreover, by the 1820s French commentators were bemoaning the French failure to commercialized the thermolamp once gaslight had attained success in England. ${ }^{126}$

Gilbert, however, was no great admirer of Lebon or his invention. He abused it as 'more of a amusing science plaything than an invention of great use'-at least in its

\footnotetext{
122 Antoine Thillaye-Platel, "Carbonisation de la tourbe," Annales de Chimie, ou, Recueil de mémoires concernant la chimie et les arts qui en dépendent 58, no. 2 (1806): 128-9.

123 Gujon, "Sur la carbonisation du bois, et sur les produits de sa distillation en grand," 234-5. AntoineFrançois Fourcroy, Claude-Louis Berthollet, and Louis-Nicolas Vauquelin, "Rapport d'un mémoire de MM. Mollerat, concernant la carbonisation du bois en vaisseaux clos, et l'emploi de différens produits quelle fournit," Annales de Chimie, ou, Recueil de mémoires concernant la chimie et les arts qui en dépendent 58, no. 2 (1808). Fourcroy, Berthollet, and Vauquelin, "Verkohlung und Erleuchtung im Grossen, mit Thermolampen - Oefen. Bericht über eine Abhandlung der Herren Mollerat, von der Verkohlung des Holzes in verschlossenen Gefässen, und den verschiedenen Produkten, die dabei gewonnen werden."

124 "Sociétés savantes. Sociétés de Liége. Nouvel éclairage.," Bulletin de pharmacie 12, no. 6 (1811).

125 "Lebon's Thermolampe in Paris," The Anti-Jacobin review and magazine 16 (1803). is an exception.

126 "Eclairage par le Gaz Hydrogène," Bibliothèque physico-économique, instructive et amusante a l'usage des villes et des campagnes 8 (1810).
} 
current form. ${ }^{127} \mathrm{He}$ also thought little of Lebon's chemical knowledge, perhaps with some justification. Gilbert points out that Lebon did not purify the gas of its carbon dioxide (kohlensauer) which he could have done using lime water, although this is not a simple step for someone who was working with his first prototypes. ${ }^{128}$

After his failure, however, Lebon did not forget his thermolamp and tried to apply it some way that could draw the official support he had failed to garner thus far. He wrote to the ministry suggesting that he make tar for naval purposes from wood. He had more success with this tactic, and was given a forest concession in Rouen for this purpose in September of 1803. Lebon's untimely death in Paris in June of the following year, probably of natural causes, ended this project. Many years afterwards, the story of his murder began to circulate, but there is no evidence for this. ${ }^{129}$ His widow tried to carry on with the thermolamp, but was ultimately unsuccessful as well. ${ }^{130}$

There are various dates given for Lebon's 'discovery' of the inflammability of woodgas as well as stories of how he made the discovery, which are in a typical eureka style. There seems to be no contemporary evidence for dating the discovery nor to validate that this discovery incident ever occurred. In fact, Lebon never claimed in his patents or his later publication to have discovered that inflammable gas could be produced from wood. Even if he had made such a discovery, it would not have been an revelation for the scientific community, which had long been aware of this fact, but for him alone.

\footnotetext{
127 'mehr ... eine belustigende physikalische Spielerei, als ... eine Erfindung von grossem Nützen' Wagner, "Versuche über Lebons Thermolampen," 493, footnote.

128 Ibid.: 494, footnote.

129 Veillerette, Philippe Lebon, 206-9.

${ }^{130}$ An advertisement from Lebon's wife: "Avis - Thermolampe," Mercure de France 48, no. 74 (1811).
} 
Making an announcement of such a discovery in the mid 1790 s or even in 1787 when he entered the École would have been laughable, being really a statement of one's ignorance of the state of contemporary pneumatic chemistry. If Lebon had read anything about distillation in the chemical literature of the period, a certainty given his education and familiarity with Foucroy's, Chaptal's, and Vauquelin's writings, he would have found this knowledge there. Fourcroy mentions uses of inflammable gas, including lighting, in his writings, and Lebon probably knew of Diller's work. The story of his discovery of the inflammability of wood-gas is certainly a later invention on the part of those trying to strengthen Lebon's credentials as an inventor and in particular as the first inventor of gaslight, especially in the competing nationalistic claims of priority of invention that took place in the nineteenth century. The evolution of Lebon's thought, originating from the study of distillation as an industrial process also belies this discovery story, which places the emphasis on gaslight from the very beginning of Lebon's work, something which Lebon did not do in his first patent. I think it would be safe to discard the eureka version of his discovery. This story has distorted the understanding of Lebon's inventive process, prejudicing his study of distillation in order to strengthen his claim to be the inventor of gaslight.

What then is the significance of Lebon's work? Lebon's technical work was not tremendously original. The basic form of distillation oven he set up was similar to what Dundonald and Dixon had done before. Nor was it substantially different from what Minckelers had done, although they came to gaslight differently: Minckelers from the point of view of a chemist making inflammable gases for balloons, while Lebon's path was from distillation processes. Lebon, however, was commercially minded in regard to 
gaslight, something which neither Minckelers nor anyone else before him had ever been. No one had taken out a patent, advertised the invention, or tried to gain public and private support and funds as Lebon had. It was this difference that proved to be crucial, because, although Lebon's projects ended in failure, his publicity influenced Winsor, Watt, and a host of imitators in Germany and elsewhere, both technologically and commercially, whereas neither Minckelers, nor Dundonald, nor anyone else had such pretensions or influence. Lebon's successors would in turn spur each other on by their competition, with ultimately successful results coming in England.

\subsection{Zachaeus Winzler and the thermolamp}

Reference has already been made to the decisive impulse that Lebon gave to Frederick Winsor and Gregory Watt which were to result in, through separate paths that eventually collided, the ultimately successful version of gaslight that proliferated in the nineteenth century. Watt and Winsor were not the only ones, however, for whom news of the themolamp prompted action. It was in Germany in particular that inventors, instrument makers, scientists and others were fascinated by the thermolamp. The interest was such that Ludwig Gilbert, the editor of the Annalen der Physik, wrote: 'It is known how in Germany novelties receive the greatest eulogies. This was also true with 
the thermolamp, with more than one zealot wanting to tear down every oven and turn them all into thermolamps. ${ }^{131}$

The extent to which the thermolamp was reported on in Germany can be gleaned from a rambling book written by Zachaeus Andreas Winzler ${ }^{132}$ in 1803: Die Thermolampe in Deutschland. The book is valuable because Winzler wanted to explain everything related to the thermolamp, from basic scientific theory to its history, in great detail. It provides more information about the context of early gaslight than any other source from this time, being over 230 pages long. It was not until 1815 that another book of comparable length was written on the subject, and by then, the situation was very different.

Winzler (1750-? [1830]) was born in Unlingen in Moravia. ${ }^{133}$ He first studied philosophy in Constanz, and then theology and medicine in Marburg, when he became very interested in chemistry and metallurgy. He worked in various places including at mines and dye manufactures, and also travelled widely, visiting England, Holland and various places in Germany, which allowed him to expand his knowledge of chemistry.

131 'Dass in Deutchland, wie alles Neue, so auch die Thermolampe, gleich anfangs ihre grossen Lobpreiser und mehr als Einen Eiferer fand, der gern alle Oefen umgerissen und sie in Thermolampen verwandelt hätte, ist bekannt' Friedrich Kretschmar, "Zusatz des Herausbegers. Einige Erfahrungem enthaltend, über die Thermolampe, und deren Answendungen," Annalen der Physik 22, no. 1 (1806): 834.

132 One long standing source of confusion in the historiography of the early gas industry is the existence of three people with similar names, Zachäus (or Zachaeus) Andreas Winzler, Johannes Wenzler, who built a small thermolamp in 1802, and Friedrich Winzer, who went on to promote the first successful gas company on London and anglicized his name to Frederick Winsor.

133 Much of the following biographical information comes from "Winzler, Zachäus Andr.," in Oesterreichische National-Encyklopädie, oder, Alphabetische Darlegung der wissenswürdigsten Eigenthümlichkeiten des österreichischen Kaiserthumes, ed. Johann Jakob Heinricch Czikann and Franz Gräffer (Wien: Auf Kosten der beyden Herausgeber, in Commission der F. Beck'schen UniversitätsBuchhandlung, 1835). and Helma HalvaDenk, "Bedeutende Südmährer," Offizielle Homepage des Südmährischen Landschaftsrats (1991), www.suedmaehren.eu. 
He settled in Vienna in 1779 when he became the overseer of saltpetre production for all of Austria. In 1796, he established his own saltpetre works first in Hungary, and following a failure there, ${ }^{134}$ later in Znaim (Znojmo) back in Moravia. ${ }^{135}$

When Winzler read of Lebon's discovery in newspapers in 1801, he was intrigued, but not enough to pursue it himself. As reports continued to come in, and Lebon's small treatise was translated and published in 1802 in Regensburg, ${ }^{136}$ Winzler became convinced of the invention's advantages and decided to make one for himself, 137 without, however, ever having seen Lebon's lamp firsthand or plans of it (in fact, no surviving plans of Lebon's apparatus are known, although his patent has some sketches $\left.{ }^{138}\right)$.

Winzler was, in his own opinion, well-prepared for this task because of his lively interest in chemistry for professional and personal reasons: 'My grounding in physics and the new chemistry, which has recently been my favourite subject, proved to be very useful in this regard'.139 The knowledge he displays in the books shows that he was

\footnotetext{
134 "Winzler, Zachäus Andr.," 165.

135 Georg Christoph Hamberger, "Winzler (Zachäus Andreas)," in Das gelehrte Teutschland oder Lexikon der jetzt lebenden teutschen Schriftsteller, ed. Johann Samuel Ersch (Lemgo: Meyer, 1827). HalvaDenk, "Bedeutende Südmährer."

136 Winzler, Die Thermolampe in Deutschland, 13. The translation was done by Johann Michael Daisenberger, who made a thermolamp himself. See p. 4, 172.

137 Ibid., 12-3.
}

138 "Auszüge aus Briefen und ein Paar Zeitungsartikel," Annalen der Physik 10, no. 4 (1802): $496-7$. footnote contains a very brief description. "Lebons Thermolampen. Absonderung und Waschung der brennbaren Luft. Flamme in der Krystallkugel. Uebrige Zurichtungen und Wirkungen. ." has a plate with simple drawings.

139 'Meine Vorkenntniße in der Physik und neuern Chemie, welche letztere ganz vorzüglich mein Lieblingsfach ist, kamen mir hierbey sehr zu statten' Winzler, Die Thermolampe in Deutschland, 12-3. 
well-informed about much contemporary chemistry. He was certainly aware of who the most important chemists of the period as well as their works, citing them throughout the text. ${ }^{140} \mathrm{He}$ was also quite up to date on pneumatic chemistry as well. His conception of the composition of what he refers to as 'inflammable air' (brennbar Luft) in most of the book was, as Lebon, similar to what could be found in major chemical texts of the period. He thought the inflammability of this gas subsisted primarily with its hydrogen, but recognized that some elemental carbon (kohlenstoff) ${ }^{141}$ was chemically combined with it, and in his opinion, increased the lighting potential of the gas. On one occasion he uses the new nomenclature and calls the gas 'carbonated hydrogen' (gekohlten Wasserstoffgas), which he pointed out used to be called 'heavy inflammable air' (schweren brennbaren Luft). ${ }^{142}$ In contrast to when carbon was chemically combined with hydrogen, Winzler correctly argued that carbon, usually in the form of carbonic acid, when mechanically mixed with inflammable gas lowers its lighting potential. He knew that the carbonic acid could be removed a number of ways, including water, dry or wet lime, or alkali water, ${ }^{143}$ but preferred to use pure water as it was simpler to obtain and less messy. ${ }^{144}$

Winzler demonstrated knowledge and ability with chemical apparatus in the process of building his own thermolamp, both in what he chooses and rejects. This

\footnotetext{
140 He cites, for example, Lavoisier, Fourcroy, Guyton, Chaptal, Nicholson, Scheele, Priestley, Hales, Volta, as well as secondary figures like Minckelers(!), Leutmann, Göttling, Lampadius, Nordensciold, etc.

141 Winzler knew that pure carbon had resisted decomposition despite all the best efforts of chemists. See Winzler, Die Thermolampe in Deutschland, 131-2. and especially p. 122-3

142 lbid., 144.

143 lbid., 145.

144 Ibid., 84-5.
} 
process is of crucial importance because it reveals how much of the knowledge and apparatus used in constructing a thermolamp-the first commercially oriented gas plant - could be found in the laboratory of an educated and current chemist. When Winzler first decided to try his hand at making a demonstration thermolamp, he turned to the instruments he had available in his laboratory without making custom components. Winzler provides clear details about which pieces he used:

\begin{abstract}
I chose an ordinary ypfer Retort ${ }^{145}$; filled it with soft cut up wood, only as much as could it hold, and lay it in the free flame of a distillation oven; closed it with its top; stuck a pipe, which was bent downwards, into the mouth of the retort, and luted it there with strong metal; sunk this pipe a few inches into an empty Woulf flask; connected the flask via a glass pipe to a wooden receiver, which had been previous completely filled pure water; luted everything with fireproof clay; gradually increased the fire, and had the pleasure of seeing my theoretical plan confirmed by a complete success. ${ }^{146}$
\end{abstract}

145 'ypfer': A graphite crucible made in Passau. See Jöns Jacob Berzelius Lehrbuch der Chemie (1841) Vol. 10, p. 521

146 'Ich wählte eine gewöhnliche ypfer Retorte; füllte dieselbe mit würflicht geschnittenem weichen holze an, so viel sie nur fassen konnte legte sie dann in das freye Feuer eines Destillirofens; bedeckte solchen mit seiner Kuppel; steckte eine abwärts gebogene Röhre von gut gelötheten Metall an die Mündung der Retorte; senkte diese Röhre einige Zoll tief in eine leere Woulfische Flasche; verband solche durch eine Communicationsröhre von Glas mit einem hölzernen Fäßgen, welches zuvor ganz mit reinem Wasser gefüllte worden war; lutirte Alles mit feuerfestem Kütt; gab sodenn gradweise Feuer, und hatte das Vergnügen, meinen theoretischen Entwurf durch den Erfolg vollkommen bestätiget zu sehen.' Winzler, Die Thermolampe in Deutschland, 15-16. 


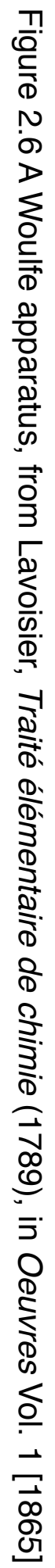

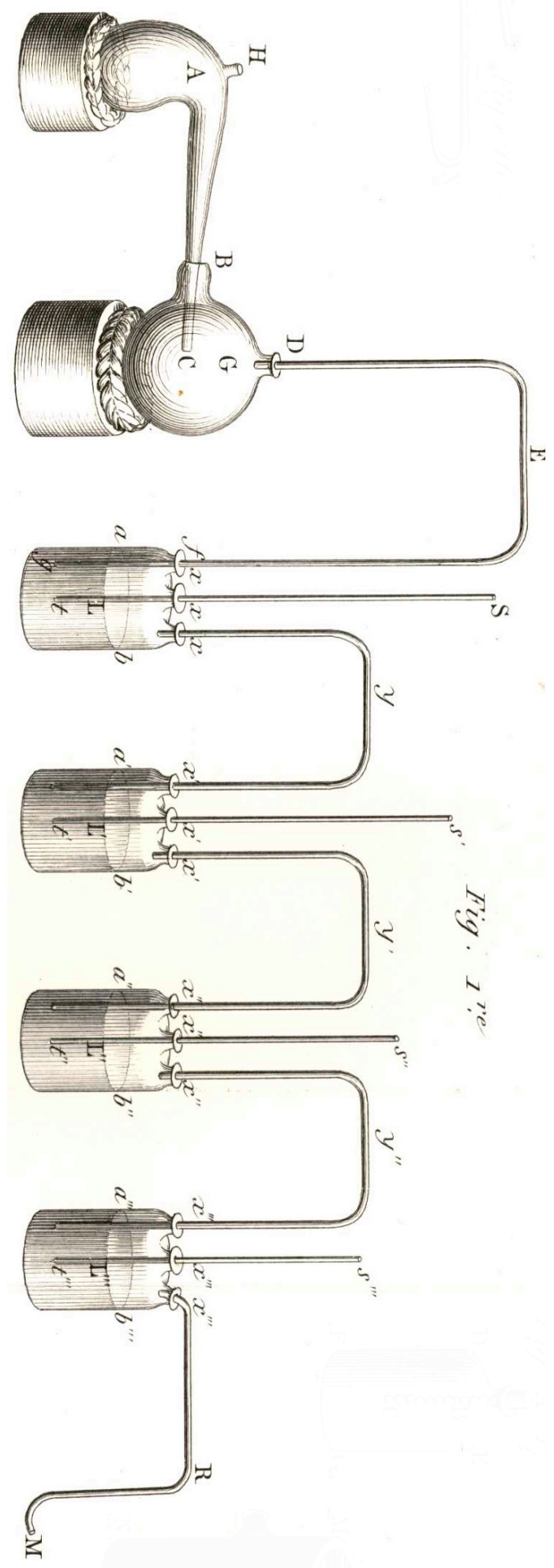




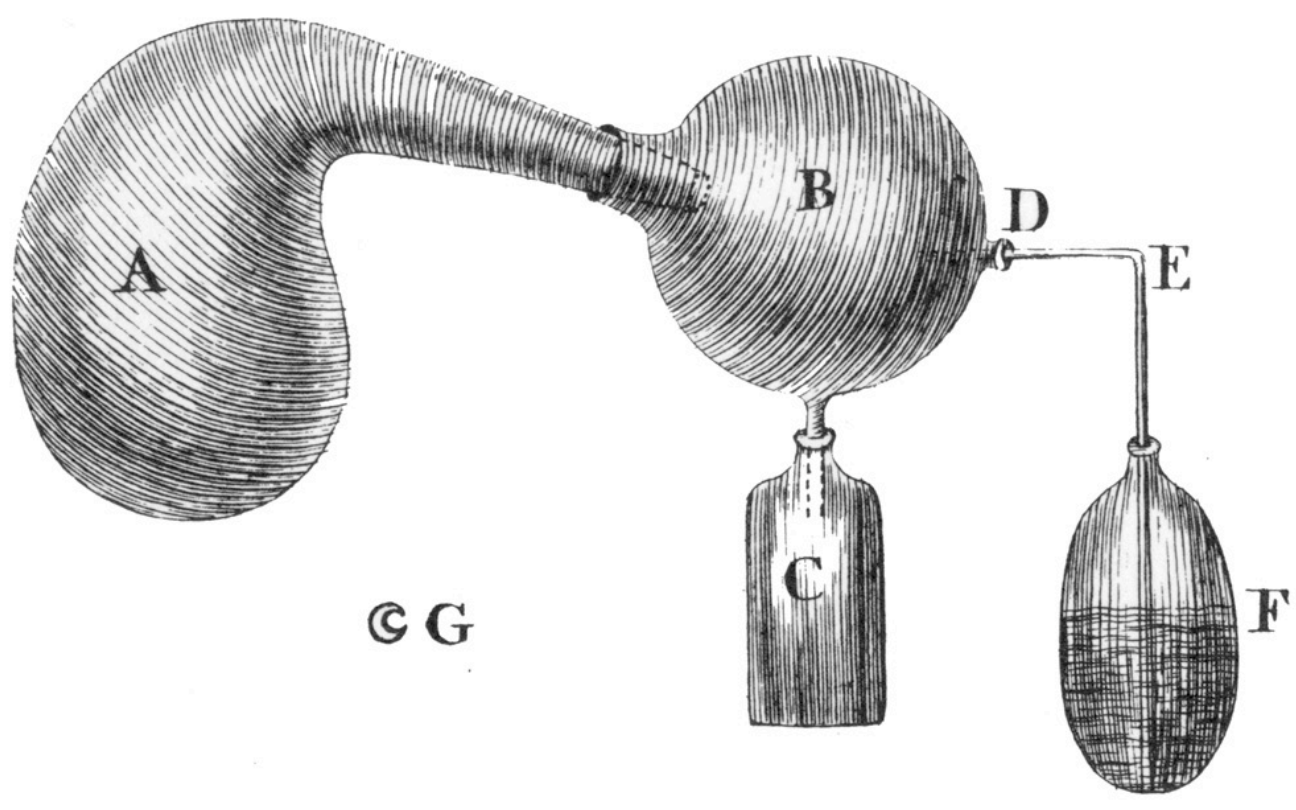

Figure 2.7 A Woulfe apparatus, from Woulfe, "Experiments on the Distillation of Acids" Philosophical Transactions 57 (1767): 517-36

The Woulfe apparatus ${ }^{147}$ Winzler mentions was invented in the 1760 s by Peter Woulfe (1727-1803?), a London chemist and instrument maker with some very eccentric habits. The apparatus' purpose was to facilitate the separation of vapours and gases produced in a retort $(A)$ through distillation by passing the products first through a cooled, empty globe (B), which condensed vapours and collected the newly formed liquids in a bottle $(C)$. The gases would continue on through the globe into another cooled bottle $(F)$, and there be bubbled through water which removed any remaining

\footnotetext{
147 Peter Woulfe, "Experiments on the Distillation of Acids, Volatile Alkalies, \&c. Shewing How They May be Condensed without Loss, and How Thereby We May Avoid Disagreeable and Noxious Fumes: In a Letter from Mr. Peter Woulfe, F. R. S. to John Ellis, Esq; F. R. S," Philosophical Transactions (1683-1775) 57 (1767).
} 
suspended solids and liquids. The water also acted as a seal to prevent the gases from returning into the retort. Other bottles could be added if further purifying steps were necessary. The Woulfe bottle proved to be tremendously useful and became an important part of the standard pneumatic apparatus. It is widely mentioned in chemical literature well into the nineteenth century. It was not, however, easy to put together correctly as all the connections between pipes and bottles had to be air-tight to maintain the purity of the gases. To achieve this, proper luting of joints was needed, and potential easier-to-use substitutes such as cork usually reacted with the gases and were thereby excluded..$^{148}$ Such an apparatus, of course, is a product of pneumatic chemistry, and could only be constructed with a knowledge and understanding of the properties of gases, as well as knowing that gases retain their form, in most cases, even after passing through water. ${ }^{149}$

After these first experiments using laboratory apparatus, Winzler was persuaded by friends, who were also to become partners in the resulting venture, to scale up the apparatus and make public demonstrations with a view to potentially commercializing the thermolamp. He then had to make his own equipment or procure larger versions of the pieces he had used. He was equal to the task, finishing the scaled-up thermolamp sometime in 1802 . Once again, he gives more details about the possible options available from the repertoire of laboratory of pneumatic chemistry. He now

\footnotetext{
148 Girard, "The Apparatus of Woulfe improved, so as not to require luting," A Journal of natural philosophy, chemistry and the arts 4 (1801). The original article was Girard, "Appareils à la manière de Wolf et sans luts, par le cit. Girard," Annales de Chimie, ou, Recueil de mémoires concernant la chimie et les arts qui en dépendent 32 (1798).

149 Many chemists used the Woulfe apparatus. To cite one example, Claude-Louis Berthollet, "Mémoire su l'Acde marin déphlogistiqué," Histoire de l'Académie royale des sciences (1785 [1788]): 278.
} 
recommended a retort with two openings to avoid having to re-lute the piping after every charge. For this, he suggests the pear-shaped retort of French origin, with sufficient capacity. ${ }^{150} \mathrm{~A}$ larger Woulfe bottle would do for purification. ${ }^{151}$ For an apparatus of this scale, Winzler recommended a gas-holder of some sort, which would provide the user with an even stream of gas when needed, rather than the hard to control streams generated directly by the retort. ${ }^{152}$ While Winzler knew of the gasometer, ${ }^{153}$ he decided to keep the gas-holder as simple as possible, and suggested using what are effectively large bags of leather or thick paper soaked in oil,154 with solid tops and bottoms to provide pressure. Only if the gas-holder is very large did he recommend using exterior guide rails, as found on some gasometers to provide stability. ${ }^{155} \mathrm{He}$ won some approbation for this simplification. ${ }^{156}$ Winzler was pleased to report that his apparatus was judged to be quite similar to Lebon's apparatus by Job von Schönfeld, who had seen one of Lebon's. Schönfeld had not actually been to Paris, but had met an unnamed gentleman who had purchased one and taken it from France, and he set it up in his home in Bohemia. Schönfeld had even had a meal 'á la thermolampe [sic]'.157

\footnotetext{
150 Winzler, Die Thermolampe in Deutschland, 77.

151 Ibid., 78.

152 Ibid., 80-1.

153 Ibid., 38. He also refers to Lavoisier's on p. 149.

154 Ibid., 81.

155 Ibid., 82.

156 Ibid., 38.

157 Ibid., 25.
} 
Winzler then sought a venue for his public demonstrations. Perhaps thinking of Diller style displays, he decided to eschew public halls and theatres to avoid having to give 'a coat of puffery' (einen Anstrich von Marktschreierei) to his demonstrations, and was granted permission to use a house with rooms to spare, belonging to a nobleman. ${ }^{158}$ Winzler then moved to Vienna from Znaim on April 13, 1802. ${ }^{159}$ The Oesterreichische National-Encyklopädie (1835) identifies the noble patron as Archduke Karl, third son of Emperor Leopold II, and brother of the reigning Emperor Franz II, and the lighted building as the k. k. Alsercaserne. ${ }^{160}$

158 Ibid., 20.

159 Ibid.

160 "Winzler, Zachäus Andr.." 


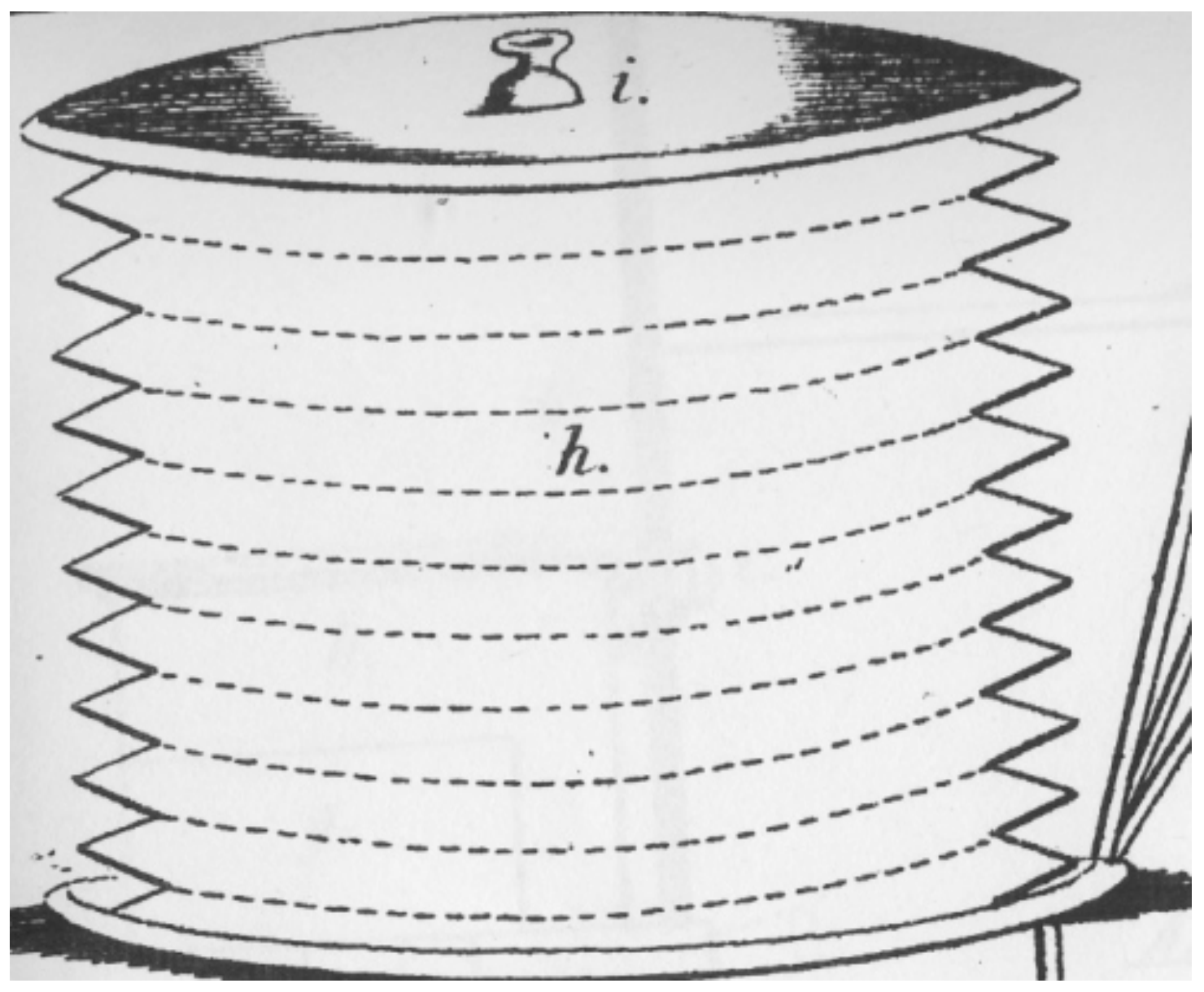

Figure 2.8 Gas-holder from Winzler Die Thermolampe in Deutschland (1803) 


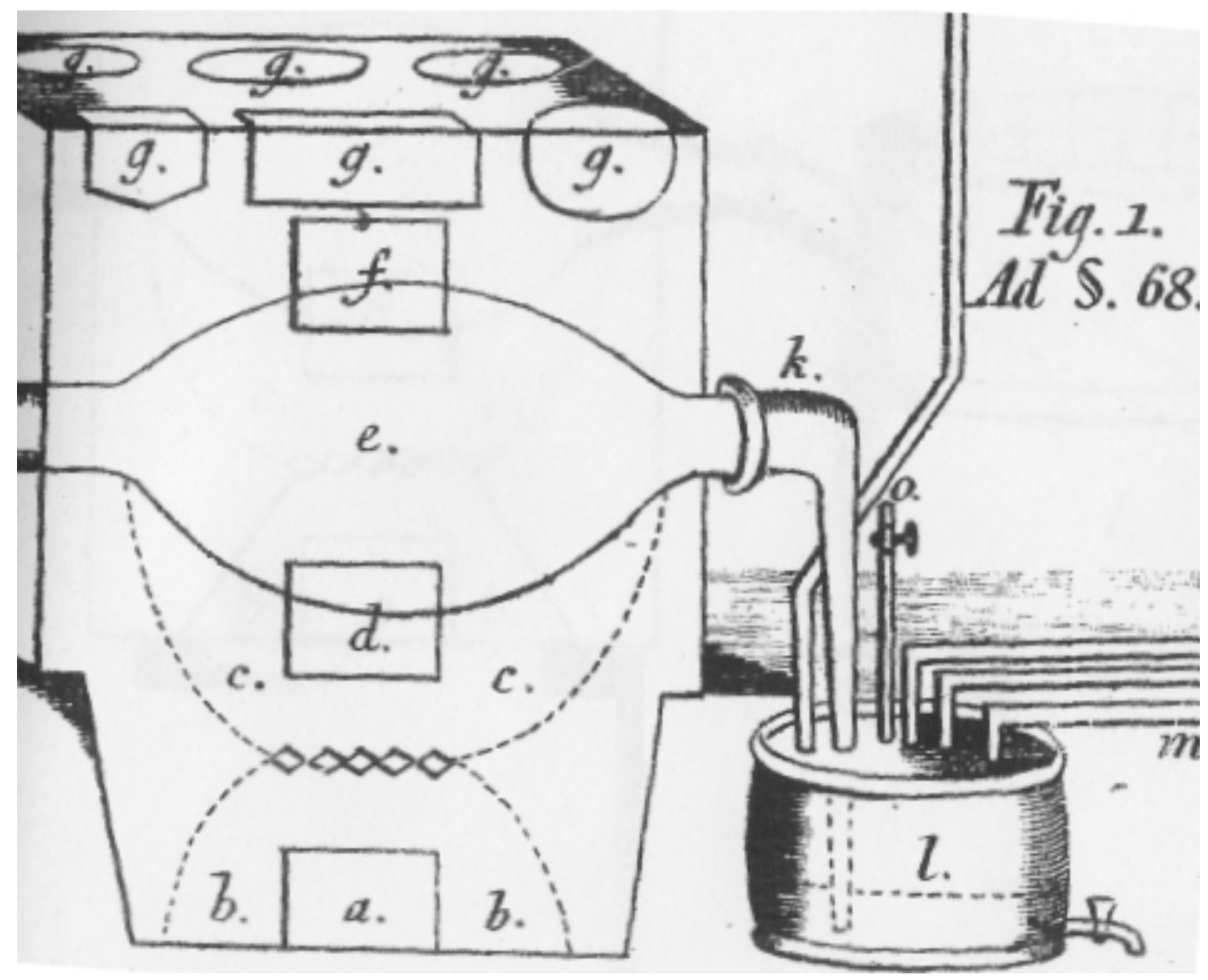

Figure 2.9 Retort oven from Winzler Die Thermolampe in Deutschland (1803)

Having erected the apparatus, the partners were ready for their public, but as yet undecided whether they should charge admission or not. They decided in the end that the more people saw their experiments, the better, and to raise funds for the publication of a book by a two florin subscription. ${ }^{161}$ The first public displays were then inaugurated in May, running almost daily for about three weeks. ${ }^{162}$ Winzler then had to return to his

161 Winzler, Die Thermolampe in Deutschland, 21.

162 Ibid., 38. 
post in Znaim, but his companions continued the demonstration for a few more weeks.

They finally gave the thermolamp to a Hungarian count, Theodor von Bathyan, who took it down the Danube to Pressburg (Bratislava). ${ }^{163}$

Both Winzler and others ${ }^{164}$ report that, on the whole, the demonstrations were well received, and his book was the outcome of the partners' resolution to pursue the project. They also thought of asking for an exclusive right over the thermolamp from the Emperor, but do not seem to have pursued it. ${ }^{165}$ They had their doubters, however, and someone wrote a pamphlet attacking the project, to which Winzler responded with another book, just as long-winded as the first, in the same year. ${ }^{166}$

Winzler did not conceive of the thermolamp simply as gas-making apparatus. His professional background in metallurgy and saltpetre production made him sensitive to the importance of charcoal and acids. As the full title of his book indicates, he thought in much broader terms by including coke and distillation in the title. He also poured scorn on Giersch, the author of a article on the thermolamp, who had neglected to mention that it could produce coke. ${ }^{167}$ Like Lebon and even Murdock, Winzler and others mentioned as gaslight pioneers were interested in distillation processes, more than gaslight per se.

163 lbid., 39.

164 "Winzler, Zachäus Andr.," 165.

165 Winzler, Die Thermolampe in Deutschland, 23.

166 Zacheus Andr Winzler, Berichtigungs-Magazin der Einwürfe, Zweifel und Bedenklichkeiten gegen den neu erfundenen Koch- Heiz- Leucht- und Sparofen, oder die deutsche Thermolampe (Wien: In der v. Schönfeldischen k. k. priv. Buchdruckerey, 1803).

167 Winzler, Die Thermolampe in Deutschland, 177-80. 
Once back in Moravia, Winzler wrote his book and laid out his research program. He had in his opinion demonstrated that the thermolamp was viable on a small scale. Now, however, he wanted to evaluate how it could work on a large scale, which was a very different thing. He thought this would require many experiments: 'the transition to the other extreme can only be made by means of many intermediary steps'. ${ }^{168} \mathrm{He}$ was as good as his word and erected a series of large scale thermolamps, the first of which was in the house of the local governor (Kreishauptmann) Vinzenz Edler von Rosenzweig as well as in the Znaim barracks. ${ }^{169}$ The experiment at the barracks did not go well. The thermolamp was abandoned by the army after one winter when they found it required too much attention. ${ }^{170}$ By 1806 Winzler had built another one at his saltpetre works in Znaim, but before the end of 1809 , it had fallen victim to the ravages of the Napoleonic wars. ${ }^{171}$

In 1807 Winzler built a much larger one at Blansko to the north of Brünn (Brno) $)^{172}$ through the patronage of Count Karl Joseph zu Salm ${ }^{173}(1750-1811)$ and his son Hugo

\footnotetext{
168 '[D]er Übergang auch zum zweyten Extrem, ... kann schlechterdings nur durch Mittelstuffen von mancherley Zwischenerfahrungen' Ibid., 41.

169 "Art. IX. Gemeinnüzige Anzeigen," Gnädigst-privilegirtes Leipziger intelligenz-blatt auf das jahr, no. 38 (1803). HalvaDenk, "Bedeutende Südmährer."

170 "Économie forestière: Améliorations, économie du combustible," in Annales forestières, faisant suite au Mémorial forestier, ou, Recueil complet des lois, arrêts et instructions relatifs à l'Administration forestière (A Paris: Chez Arthus.-Bertrand, 1808), 231.

171 "Correspondance. Suite de la correspondance de M. Boudet, Pharmacien en chef," Bulletin de pharmacie 2, no. 6 (1810): 284.

172 Hugo zu Salm-Reiferscheid, "Holzverkohlung im Grossen vermittelst der Thermolampe; geschrieben," Annalen der Physik 30, no. 12 (1808). "Anwendung der deutchen Thermolampe im Großsen," Vaterländische Blätter für den österreichischen Kaiserstaat, no. 97 (1812). describes the Blansko thermolamp as the first large one.

${ }^{173}$ For a history of the zu Salm family, see Heinrich Wankel, Bilder aus der mährischen Schweiz und ihrer Vergangenheit (Wien: Druck und Verlag von Adolph Holzhauser, 1882).
} 
Karl zu Salm (1776-1836). ${ }^{174}$ The two zu Salms had been interested in making charcoal from wood in enclosed ovens as a way to preserve the gas and other products which were simply exhausted during ordinary charcoaling and coking processes, and Hugo had apparently already presented a paper to the Berlin Akademie on the thermolamp in this context. ${ }^{175}$

Hugo Franz zu Salm was a serious chemist. He had been intrigued by the subject from a young age, but it was after his capture in Italy by Napoleon's troops and subsequent ransoming that he pursued it more closely. He developed a treatment for rabies (hundswut) and investigated the production of indigo dyes, among other things. In 1801 he travelled to England to garner further scientific knowledge and there became of member of the Jennerian Institution. He was very interested in industrialization and brought back with him drawings of textile machines, eventually having some built for his estates. He also wrote a number of books and articles on technical and scientific subjects. ${ }^{176}$

Hugo zu Salm worked with Winzler in Znaim but sometime in 1807, he may have set up a separate thermolamp in the Ernst valley, ${ }^{177}$ which soon thereafter, like Winzler's

\footnotetext{
174 Ibid., 112-3. The chronology of this source is hard to reconcile with Hugo zu Salm's article in the Annalen. I assume that the account in the Annalen is correct.

175 Ibid., 75, 112. Wankel's chronology, however, is not always sure.

176 "Salm, Hugo Franz Altgraf," in Oesterreichische National-Encyklopädie, oder, Alphabetische Darlegung der wissenswürdigsten Eigenthümlichkeiten des österreichischen Kaiserthumes, ed. Johann Jakob Heinricch Czikann and Franz Gräffer (Wien: Auf Kosten der beyden Herausgeber, in Commission der F. Beck'schen Universitäts-Buchhandlung, 1836).

177 Wankel, Bilder aus der mährischen Schweiz und ihrer Vergangenheit, 112. The source of Hugo zu Salm's thermolamp in the Ernst valley is exclusively Wankel. As mentioned in preceding footnotes, it is hard to reconcile Wankel's version of the events with other contemporary sources.
} 
own in Znaim, fell victim to the Napoleonic wars. ${ }^{178}$ Zu Salm then abandoned building thermolamps until 1822 , when he took it up again, ${ }^{179}$ by which time the technological situation had changed tremendously with the development of large scale gasworks in England.

The early reports at Blansko were not promising, however, and Hugo zu Salm reported in December of 1807 that 'the great gulf between the effective implementation of the process and its commercial success is still not crossed; patience and perseverance will, with the help of time, build the bridge'. ${ }^{180}$ The thermolamp there remained in operation for a few years, producing mostly tar, charcoal, and other products. Gaslight did not seem to be high on the list of uses for the thermolamp. Problems were still reported in 1810 , mostly with the large volume of gas produced towards the end of the distillation cycle, and which could become explosive and was hard to contain. ${ }^{181}$ These distillations would take days to complete, and only a few rounds were carried out every year. ${ }^{182}$

In 1808 Winzler's wife died in a tragic accident, falling into a vat filled with a liquid in one of his plants. ${ }^{183}$ Hugo zu Salm appointed him as his advisor (hofrath) and Winzler

\footnotetext{
178 Ibid., 117.

179 Ibid., 119.

180 'Die gewaltige Kluft zwischen der wirklichen Ausführung einer Unternehmung und ihrem Thermolampe; geschrieben." mährischen Schweiz und ihrer Vergangenheit, 113-4.

182 Wankel, Bilder aus der mährischen Schweiz und ihrer Vergangenheit, 117.

183 HalvaDenk, "Bedeutende Südmährer."
} kaufmännischen Gewinn ist noch nicht überschritten; Geduld und Beharrlichkeit werden mit Hülfe der Zeit schon noch die Brücke bauen.' zu Salm-Reiferscheid, "Holzverkohlung im Grossen vermittelst der

181 "Vermischte Schriften," Allgemeine Literatur-Zeitung 1811-4, no. 20 (1811). Wankel, Bilder aus der 
was posted to Vienna. ${ }^{184} \mathrm{He}$ may also have established an engineering consultancy of sorts, continuing to work on thermolamps. In 1811, Winzler built another large one in Klosterneuburg close to Vienna with the goal of using the gas to fire bricks. ${ }^{185}$ Winzler prepared and published construction and operating instructions as well as a material list for the construction of thermolamps based on the Klosterneuburg model. ${ }^{186}$ The operation of the thermolamp continued to be on the slow batch model, with a heating session lasting for six or seven days, ${ }^{187}$ followed by a few days for the oven and charcoal mass to cool. The charcoal then had to be broken up and the oven cleaned and prepared for a new load. ${ }^{188}$ In all, 20 cycles could be completed in one year. ${ }^{189}$ The initial hope was for the Klosterneubug thermolamp to cure 200,000 bricks in one year, ${ }^{190}$ although it proved to be a failure in the long run because the gas flame could not cure the bricks sufficiently. ${ }^{191}$

184 "Winzler, Zachäus Andr.," 165.

185 "Vermischte Schriften," Allgemeine Literatur-Zeitung 1817-4, no. 102 (1817). "Thermolampe," in Oekonomisch-technologische Encyklopädie, oder allgemeines System der Staats- Stadt- Haus- und Landwirthschaft und der Kunstgeschichte Vol 183, ed. Wilhelm David Korth (Berlin: Leopoeld Wilhelm Krause, 1844), 255. "Anwendung der deutchen Thermolampe im Großsen." "Dritte Classe der Kohlen. Die Thermolampen Kohlen," in Darstellung des fabriks- und gewerbswesens in seinem gegenwärtigen zustande, vorzüglich in technischer, mercantilischer und statistischer beziehung, ed. Stephan von Keess (Wien: M^rschner und Jasper, 1824), 61.

186 "Anwendung der deutchen Thermolampe im Großsen." contains information about where the instructions et al could be purchased.

187 "Thermolampe," 257. "Anwendung der deutchen Thermolampe im Großsen."

188 "Thermolampe," 258. "Anwendung der deutchen Thermolampe im Großsen."

189 "Thermolampe," 255. "Anwendung der deutchen Thermolampe im Großsen."

190 "Anwendung der deutchen Thermolampe im Großsen."

191 "Dritte Classe der Kohlen. Die Thermolampen Kohlen," 61. 
In these years, the thermolamp in Moravia continued to attract attention in the German newspapers and even abroad up to about $1814 .{ }^{192}$ The thermolamp in Blansko is undoubtedly his largest and the one that garnered the most notice. It shared the fate of its cousins and was destroyed, probably in 1814 during the last campaigns of the Napoleonic Wars. ${ }^{193}$ The latest record that survives of Winzler is from 1816, when he was working on yet another thermolamp in Slovenia, after which he disappears completely from the historical record. ${ }^{194}$

Winzler's themolamp was a rural industrial technology. From the beginning, Winzler thought of it as an oven for making charcoal, tar, and other products. Even if in the early days his rhetoric included the idea of domestic heating and lighting, once he left the small scale behind, the thermolamp implementations were always in rural and industrial contexts, associated with charcoal production, the firing of chalk, bricks and gypsum, the production of tar and acid, or any place that needed large ovens, such as forges. ${ }^{195}$ The lighting aspect, which for Lebon had been the centrepiece of the thermolamp's utility, declined in importance. By the time the article on the thermolamp in the Oekonomisch-technologische Encyklopädie was written in 1844, the thermolamp

\footnotetext{
192 Apparently, there was a book published in London in 1809 entitled Ackermann, first inventor of the Thermolamp, with a short account of the great Thermolamp in Moravia, written by Hugo zu Salm, but I have not been able to find it. See Wankel, Bilder aus der mährischen Schweiz und ihrer Vergangenheit, 82.

${ }^{193}$ Karl Freiherr Reichenbach, Caroline von Linsingen, die gattin eines englischen prinzen (Leipzig: Duncker \& Humblot, 1880), 12-13.

194 HalvaDenk, "Bedeutende Südmährer."

195 "Anwendung der deutchen Thermolampe im Großsen." is quite clear on this point.
} 
was described as being of great use in forest culture (Forst- und Waldkultur). ${ }^{196}$ The use of wood rather than coal, which was so abundant in England but less so in Austria, was a key difference. Some contemporary German commentators remarked on how useful the thermolamp could be in England given the enormous volume of coal present there. ${ }^{197}$

Although lighting by wood-gas was attempted, in the end, even the best wood produced between one sixth and one seventh the quantity of gas as coal, ${ }^{198}$ and woodgas gave a weak flame and smelled badly. ${ }^{199}$ Nor could wood ever be supplied in such quantities as to be a practical source of gas for the large scale gasworks feeding cities, at least not in Europe where there had been concerns about deforestation in the eighteenth century.

\subsection{Other German thermolamps}

Winzler was not the only German fired with enthusiasm by Lebon's thermolamp. Johann Michael Daisenberger, who translated Lebon's pamphlet into German, built two thermolamps, following the design of Johannes Wenzler, the Passau court treasurer.200 Wenzler and Daisenberger published a couple of books in 1802 describing these

\footnotetext{
196 "Thermolampe," 255. It was also described as such in "Anwendung der deutchen Thermolampe im Großsen."

197 "Anwendung der deutchen Thermolampe im Großsen."

198 "Thermolampe," 256.

199 lbid., 258.

200 Arthur Elton, "Gas for Light and Heat," in A History of Technology, Volume IV: The Industrial Revolution c. 1750 to c. 1850, ed. Charles Singer, et al. (Oxford, England: Oxford University Press, 1958), 263.
} 
lamps, ${ }^{201}$ and Wenzler claimed in his that there were 200 'scientists' (Physiker) working on it in some way in Germany.202 Many of them not doubt lost interest, such as a doctor named Johann Wagner who almost asphyxiated himself by inhaling distillation fumes from his experiments which left him groggy for three days.203 Like Winzler, Wagner made his first thermolamp quickly from the pneumatic apparatus of his laboratory.

A few other experimenters persevered with the thermolamp longer than Wagner. One of them was Karl Bünger, an apothecary from Leipzig who, after hearing of Lebon's work, thought it would be useful for a pharmacist's laboratory. He also wrote a book on thermolamp in 1802,204 and published a follow-up article in 1803. His initial attempts did not work well, but after getting some advice from Wilhelm Lampadius, he improved the device enough that he thought it was practicable. For Bünger, practicability meant that one could use ordinary wood without having to cut it into small pieces; that the thermolamp could be closed with an air-tight seal using a single screw; and that it should have no smell. ${ }^{205} \mathrm{He}$ intended to write another book on the subject, but never seems to have done so. This miniature thermolamp, however, might have had some popularity among apothecaries, but this needs further investigation. There is, for

\footnotetext{
201 Johann Michael Daisenberger, Beschreibung der Daisenberger'schen Thermolampe oder eines Sparofens, welcher alle Zimmer im ganzen Hause heitzen und beleuchten kann (Stadtamhof Selbstverl., 1802). Johannes Baptista Wenzler, Beschreibung einer Thermo-Lampe, oder eines Leucht- und SparOfens, welcher alle Zimmer im ganzen Hause heissen, und leleuchten kann. Mit einer Kupfer-Tafel (Passau: Gedruckt bei Ambrosi, 1802).

202 Cited in Winzler, Die Thermolampe in Deutschland, 191.

203 Wagner, "Versuche über Lebons Thermolampen."

${ }^{204}$ Carl Gottfried Bünger, Abbildung und Beschreibung einer Thermolampe : Nebst einem zweckmässigen Apparat zur Zimmerbeleuchtung (Pirna: Bei Friedrich G. Pinther, 1802).

205 Karl Bünger, "Neue Einrichtung der Thermolampe zum pharmaceutischen Gebrauche," Annalen der Physik 15, no. 2 (1803): 233.
} 
example, reference to an apothecary in London in 1805 who used a thermolamp of sorts. ${ }^{206}$

Wilhelm August Lampadius (1772-1842) was a chemist and metallurgist who had himself thought about using inflammable gases in 1796.207 Like Lebon, he was investigating the distillation of coal and remarked that a third of the weight of coal was lost in the form of an inflammable gas. He suggested in articles and in a metallurgical manual he published in 1801 that iron works could use the fire from these gases for some useful purpose. He did not go farther with this until Lebon's work spurred him to do so. He then built himself a thermolamp in the winter of 1799 , lighting some rooms in the palace of the king of Saxony, using wood-gas. He thought the smells from coal precluded its use for gaslight and dropped the subject until news came from London in 1810 that a company was proposed to light the streets with gas flames. He restarted his experiments and set up a few gaslight lamps during the winter of 1811-2.208

There are a few other, more minor attempts to use the thermolamp, such as at Baron von Fries' calico mill in Kettenhof close to Vienna, where he made acetic acid from wood. It was reported on by Dr. de Carro, a visiting physician from Geneva, in a letter sent to the Bibliothéque britannique, a journal published in his hometown. He

206 Benjamin Silliman, A journal of travels in England, Holland and Scotland, and of two passages over the Atlantic, in the years 1805 and 1806, 2nd Place: United States; Massachusetts; Boston.; United States; New York; New York. ed., 2 vols. (Boston : Howe and Deforest: New Haven [Conn.], 1812), 2368.

207 He mentions this in Wilhem August Lampadius, Handbuch der allgemeinen Hüttenkunde, 2 vols. (Göttingen: H. Dietrich, 1801). Vol. 1, as he states in W. Lampadius, "Ueber Strassenbeleuchtung mit Steinkohlen durch die Thermolampe vorzüglich in Hinsicht ihrer Anwendung in Grossen," Journal für Chemie und Physik 8, no. 1 (1813): 38.

208 Lampadius, "Ueber Strassenbeleuchtung mit Steinkohlen durch die Thermolampe vorzüglich in Hinsicht ihrer Anwendung in Grossen," 38-40. 
mentions that the thermolamp was not yet in use in use in Geneva. ${ }^{209}$ The Kettenhof thermolamp was used for a few years, even for lighting purposes, but the smells were too much, and finally it was put into abeyance..$^{210}$

Another minor figure who worked with thermolamps was Friedrich Kretschmar.211 Kretschmar lived in Sandersleben, a small town between Leipzig and Brunswick (Braunschweig) belonging to the principality of Anhalt. Kretschmar made a thermolamp after he heard of Lebon's and wrote a brief article about it in $1803 .{ }^{212}$ Although he had his doubts about the invention's viability, he pursued his experiments, and published a book in 1805 directed to a non-expert audience. ${ }^{213}$ By the time he wrote the book, Kretschmar had arrived at the conclusion that although the thermolamp was valuable for foundries, plumbers, apothecaries, and other such trades, its value for domestic lighting was insignificant. The gas flames were not bright enough to read by, extinguished too easily and then gave off odours that rapidly filled the room. He did not recommend using a gas-holder (Luftreservoir). Kretschmar's work lies at the opposite end of the scale spectrum as Winzler's, aimed at small scale thermolamps. Like Winzler, he also

\footnotetext{
209 de Carro, "Nachricht von einer in der Kattunfabrik des Barons von Fries zu Kettenhof eingerichteten Thermolampe. Zusatz des Herausgebers. Enigw Erfahrungen enthaltend, über die Thermolampe, und deren Anwendung, vom Dr. Kretschmar in Sandersleben," Annalen der Physik 22, no. 1 (1806).

210 "Dritte Classe der Kohlen. Die Thermolampen Kohlen," 62.

211 Kretchmar and a few others are also mentioned in Johann Heinrich Moritz von Poppe, Geschichte der technologie seit der wiederherstellung der wissenschaften bis an das ende des achtzehnten jahrhunderts, vol. 3 (Göttingen: Bey J.F. Röwer, 1811), 20-21.

212 Kretschmar, "Vervollkommung der sogenannten Thermolampe zum Gebrauche für das Haus-, Fabrikund Hüttenwesen," Annalen der Physik 13, no. 1 (1803). 
abandoned the idea of lighting, ${ }^{214}$ although he became interested again many years later and wrote to the Gas Light and Coke Company about his ideas in 1816, proposing a mode of making gas not requiring purification. ${ }^{215}$

\subsection{The failure of the thermolamp}

For all the interest in Germany surrounding the thermolamp, it was never made practicable enough for wide adoption. By 1806, Ludwig Gilbert passed a dour judgement on the device: 'the many attempt made in so many places in our fatherland have not in total lived up to expectations'. ${ }^{216}$ Gilbert himself was included among the many who had been studying the matter, so much so that he thought he should write something on the topic, but his negative mood prevailed, and he never did. Nor did many others after 1806. With a few exceptions, the rash of German language books and articles on thermolamps ended by 1808 . There was never to be another book on the subject. ${ }^{217}$

The root cause of the thermolamp's failure, especially as a mode of illumination, lay partly in the technology itself. It was too difficult and attention-needy for domestic or commercial use. People simply could not be bothered to clean and reload the ovens

\footnotetext{
214 Kretschmar, "Zusatz des Herausbegers. Einige Erfahrungem enthaltend, über die Thermolampe, und deren Answendungen."

215 Gas Light and Coke Company Minutes of the Court of Directors Book 3: London Metropolitan Archives B/GLCC/1/1 p. 48 1816/08/05, and p. 106 1816/11/01

216 'Die vielen Versuche, welche an so manchem Orte in unserm Vaterlande gemacht worden sind, ... haben allesamt ... den Erwartungen nicht entsprochen.' Gilbert, "Ueber die sogenannten Thermolampen und den ersten Erfinder derselben," 52.

217 Poppe, Geschichte der technologie, 18. also mentions how interest had waned in the last few years.
} 
regularly. ${ }^{218}$ The disposal of by-products was also a serious burden. In fireplaces and stoves, the only leftovers were ash, not tar, charcoal, and acid as with the thermolamp. The promoters of the thermolamp quickly confined themselves to industrial applications, such as charcoal and acid production. The thermolamp was more viable in this context -at least not stillborn-but gaslight was perforce moved down the list of benefits. Light from wood-gas was inherently poor: wood generated far less gas than coal, and seemed to be harder to purify, but lighting was never even seriously pursued. Moving from a batch process ideal for making charcoal and acid to a continuous process necessary for gaslight was too difficult, and simply not interesting when thermolamps were sited in saltpetre or textile factories. And so the thermolamp failed, almost from the very beginning, as a form of gaslight.

Could the French or German thermolamp have been a path to the gaslight industry instead of the British version of gaslight that was later transplanted to the Continent? This question touches on one of the key historiographic questions of the Industrial Revolution: why did it happen in England and not elsewhere? It is clear that the failure of the thermolamp to develop into something like the gas industry was not because of a lack of enthusiasm or desire to commercialize on the part of the participants. Perhaps there might be something to this reproach if directed at the French government, which was distracted by Napoleon's wars. But it was not true in Germany, where the Winzler episode shows clear interest from the technically proficient, and from patrons like the aristocracy, mostly in the form the of the zu Salm family. Nor was Winzler the only

\footnotetext{
218 For another reference see "Sur une nouvelle Manière d'éclairer les Rues et les Appartemens, à l'aide du Charbon de terre, inventée et mise à exécution en Angleterre par M. F. A. Winsor, de Londres," Annales des Arts et Manufactures 28, no. 3 (1808): 226.
} 
example of interest: it was widespread as a survey of the publications of the period, both popular and expert, reveals. The failure's cause needs to be found elsewhere.

It is certain that the Napoleonic wars did not help the situation. At least two major thermolamps succumbed during hostilities, as did Winzler's first one at Znaim, and the zu Salm's family's wealth was at least partially sequestered by Napoleon, hobbling whatever efforts they could direct towards the development of the technology.219 This sort of destruction and pillage was a serious drag to Winzler's work.

Another contributing cause was the emphasis on wood, rather than coal. While there are many references to coal, and although its marked advantage in producing gas was repeatedly recognized, it was not pursued for use in the thermolamp in general. Lebon never really looked at coal, and Winzler and the zu Salms were interested in charcoal from the beginning. While the interest lay with wood, charcoal would likely be considered the primary product of the thermolamp because of its value. Wood-Gas was not very good for lighting purposes because of it lower methane content. The converse is true for coal: coal-gas proved to be a good illuminant, even more valuable than coke. Whereas those using wood tended to emphasis charcoal in the long run, people using coal eventually thought coal-gas was the most valuable product. As will be seen in chapter four, even Winsor at first promoted coke as the primary product of his stoves, and only later did he switch to gas as the primary product. As long as the investigations centred on the distillation of wood then, gas would remain a secondary product, at least from an economic point of view.

219 "Salm, Hugo Franz Altgraf." 
It was only if gas was given importance that the problems of implementing of gaslight could be addressed. Producing gas from distillation is one thing, lighting with gas is something far more complicated. Most notable among the challenges to be met in implementing gaslight were, first of all, the impurity of the gas which caused odours and impinged on flame luminosity, ${ }^{220}$ and secondly the transition to a continuous process required for gaslight. Winzler and to a lesser extent Gilbert knew how to purify gas with lime water, and this step would have solved the odours problem and made the flames brighter. But because of lime water's messiness and complication they consciously decided not to use it. What is more, even if there had been a concerted effort at this point in time, it is unlikely that gaslight from wood-gas could have flourished. When in 1805 William Henry analysed gases from various sources, he noted that gas from wood contained between $25-30 \%$ carbon dioxide, as compared to $4-8 \%$ for coal. .21 With regard to a transition to a continuous process, the gasometer was one of the key tools. Winzler and Kretchmar also knew of the gasometer-one key component to transition from a batch to continuous process-but again did not recommend it because it was too complicated, too expensive if the emphasis was not on using a continuous stream of gas. And the emphasis was unlikely to shift while wood was distilled, not coal. As long as wood was the primary subject material of the thermolamp, overcoming these was not economically interesting. When Fourcroy, Berthollet, and Vauquelin reported on Mollerat's large thermolamp, gas was not even

\footnotetext{
220 "An account of Improvments made in Gas Light. By Messrs. Sobolewsky and Horrer, at Petersburgh," The repertory of arts, manufactures, and agriculture 2 nd series 24, no. 143 (1814).

221 William Henry, "Experiments on the gases obtained by the destructive distillation of pit coal, \&c., with a view to the theory of their combustion when employed as sources of artificial light," $A$ Journal of natural philosophy, chemistry and the arts 11 (1805): 69.
} 
mentioned among the products, despite mentioning two kinds of tar, four sorts of vinegar, and various species of acetates and carbonate. ${ }^{222}$

Why then did the Germans and the French not pursue coal, which would have made illumination a more achievable and profitable goal because of the greater volume and higher quality of gas generated? Certainly not because they were unaware of its advantages. It is likely because of its scarcity. As is well known, the abundance and accessibility of coal in England was much greater than on the Continent, especially in the eighteenth and early nineteenth century. Contemporary commentators in Germany pointed to the thermolamp's utility for the English who had such an abundance of coal. ${ }^{223}$ The contrary observation was also made in England: carbonizing turf or wood with a thermolamp may be useful for the continent, but at home, with such an abundance of coal, it was only of value in coal-poor places such as Ireland. ${ }^{224}$ In Austria, Winzler and others would have had to make a great effort to get coal in sufficient quantities for industrial use. There was, however, no reason evident and pressing enough for them to do this. The thermolamp worked with wood, and if coal was better at producing gas, charcoal was also very valuable, and the wood route seemed, at least at first, to have just as much potential as coal, albeit for different reasons.

\footnotetext{
222 Fourcroy, Berthollet, and Vauquelin, "Rapport d'un mémoire de MM. Mollerat, concernant la carbonisation du bois en vaisseaux clos, et l'emploi de différens produits quelle fournit," 176. 223 "Anwendung der deutchen Thermolampe im Großsen," 582. "Mr. Winsor's Thermolampen-Ofen in London," London und Paris 15 (1805). [sic]," The Athenaeum, a magazine of literary and miscellaneous information 2, no. 8 (1807).
} 
The presence of coal in large quantities in England has been presented by a number of historians, including John Nef, Davide Landes, J. R. Harris and more recently E. A. Wrigley and Christine MacLeod 225 as an important factor in Britain's process of industrialization. Many of these have described the craft skills related to the coal industry that benefited Britain, but that is best dealt with in the following chapters where the successful implementation of gaslight is described. The relative advantage of coal over wood as a source of gas discussed here fit in with comparisons historians have made between organic and mineral sources of power in the Industrial Revolution. Landes has connected the growth of coal mining and steam engines in a cycle of mutual reinforcement, of 'challenge and response', whereby mines benefited from the superior capacity of steam driven pumps, which were in turn fed by coal. Together, these two in turn propelled other industries forward with cheaper power, iron and coal. He does not of course reduce this dynamic to the sole cause of the Industrial Revolution, but he does claim that coal and steam 'permitted its extraordinary development and diffusion. ${ }^{2} 26$ The relative deforestation of Britain as compared to the Continent combined with the abundance of coal deposits led it in this direction. Landes

$225 \mathrm{~J}$. U. Nef, "The Progress of Technology and the Growth of Large-Scale Industry in Great Britain, 1540-1640," The Economic History Review 5, no. 1 (1934). David S. Landes, The unbound Prometheus : technological change and industrial development in Western Europe from 1750 to the present, 2nd ed. (Cambridge, New York: Cambridge University Press, 2003), 95-104. J. R. Harris, "Skills, Coal and British Industry in the eighteenth century," History 61, no. 202 (1976). Harris, Industrial espionage and technology transfer : Britain and France in the eighteenth century (Aldershort, Hants, England: Brookfield, VT, 1998), 238-61, 554-60. E. A. Wrigley, Continuity, chance and change : the character of the industrial revolution in England (New York, 1988), 8-33. Christine MacLeod, "The European Origins of British technological predominance," in Exceptionalism and industrialisation : Britain and its European rivals, 1688-1815, ed. Leandro Prados de la Escosura (New York: Cambridge University Press, 2004), 115-20.. For a general survey, see Chris Evans and Göran Rydén, eds., The industrial revolution in iron : the impact of British coal technology in nineteenth-century Europe (Burlington, VT, 2005)., especially the introduction.

226 Landes, The unbound Prometheus : technological change and industrial development in Western Europe from 1750 to the present, 95-104. 
speaks about how the move to coal allowed for energy use on a scale that would simply not have been possible had the power sources remained predominantly human and animal. There is no doubt that in comparing the various attempts at gaslight between Britain and the Continent that the English favoured coal while the rest generally favoured wood. Everyone, however, knew that gas could be had from both, and that coal was better for gas generation. Coal was used in Britain because it was simply more available there, and manufactured gas was viable only with coal.

The breaking away from organic sources of energy and the move to inorganic sources has also been an important theme for Wrigley. He describes how the eighteenth century witnessed a shift from an economy whose growth was based on organic sources of power, and hence limited in growth potential, to one where growth was founded on inorganic sources that allowed the economy to grow without the energy brake that held back the Continental economies. The two sources of energy overlapped for some time, but the new mineral basis provided much more potential and eventually came to dominate. The new regime featured heat and mechanical energy derived from mineral sources.227 To this I would add light as well. Before, light was primarily derived from organic sources (tallow and whale oil), but with the advent of gaslight, it came from coal, and Britain was well placed to host such a change. ${ }^{228}$

\footnotetext{
227 Wrigley, Continuity, chance and change : the character of the industrial revolution in England, 6. ${ }_{228}$ See also Wolfgang Schivelbusch, Disenchanted night : the industrialization of light in the nineteenth century (Berkeley: University of California Press, 1988), 16-18.
} 


\subsection{Conclusion}

In this chapter, I have surveyed various versions of gaslight other than the two that are the subject of the next chapters and whose collision led ultimately to the flourishing industry of the nineteenth century. A number of conclusions can be drawn from these early and failed attempts.

The first, one of the main points of this thesis, is that the pneumatic chemistry of the period was a foundation of gaslight technology in any form. This comes across most clearly in the case of the two important versions presented in this chapter: Diller's philosophical fireworks and the thermolamp. Diller's fireworks, while never losing aspiration for entertainment, were presented and accepted as a research project in pneumatic chemistry. The interest on the part of the Académie in Paris and the Royal Society alone demonstrate this. Diller's instruments were likely inspired by people like Volta. His demonstrations and instruments, or incarnations derived from his, made the idea of using inflammable gases for lighting well-known throughout Europe. In the case of the thermolamp, the ease and speed with which those acquainted with pneumatic chemistry recreated the thermolamp from laboratory apparatus show how much of the technology was found in the knowledge and apparatus of the pneumatic chemist's laboratory. Winzler is explicit about this in his book, but it can also be found in other accounts. The wide diffusion of the knowledge of pneumatic chemistry, both geographically and across professional boundaries, was as important as the knowledge itself for creating the condition in which inventors such as Lebon, Murdock, and Winzler 
Distillation processes, which were to be the most important impulse to the foundation of the gaslight industry, were themselves partly derived from the analytic chemistry of the eighteenth century. As mentioned in the previous chapter, Glauber introduced the retort which became an indispensable element of the chemist's tool kit. Although distillation, in the form of charcoal making, had been used for centuries, its use in the chemist's laboratory suggested its transmutation into a large scale process for the commercial production of various chemicals by breaking down a subject matter.

The second important conclusion of this chapter is that gaslight did not spring from a single source. The various versions of gaslight found up to the end of the eighteenth century arose from a number of sources, from pure chemistry to mining, and most importantly, distillation processes. All these different sources had their role to play, with distillation processes and academic chemistry being the most decisive. In most cases, various influences are evident.

The third conclusion is that histories that claim the discovery of inflammable gases as the origin of gaslight are reductive and simply wrong. These sorts of eureka stories may make good propaganda in nationalistic priority wars, hence their persistence, but are without foundation in the history. None of the players in the episodes mentioned here claimed originality for the discovery that inflammable gas could be had from wood or coal, and certainly not Lebon, for whom such a eureka story has been told since the early nineteenth century. As Gilbert wrote in 1806 when commenting on Lebon's invention: 
It has long been known that destructive distillation of vegetable matter produces a quantity of gas, and that a good part of this gas is inflammable. It required no great degree of inventive genius to to try burn this gas and use it for illumination. ${ }^{229}$

While Gilbert correctly identified the non-originality of the inflammability observation, he misjudged the value of Lebon's work. This points the fourth conclusion of this chapter, which is that the drive to commercialize an invention produces a very different dynamic than experimentation. No one before Lebon had made a serious attempt to commercialize such an apparatus, and in doing so, Lebon was a spark to the development of gaslight. It would have developed without him, but he was a key catalyst.

229 'Nun war es zwar längst bekannt, dass bei der zerstörenden Destillation vegetabilischer Theile eine Menge von Gas entweicht, und dass der grösste Theil dieses Gas brennbar sey, und es war daher kein grosser Grad von Erfindungsgeist zu dem Versuche nöthig, dieses Gas wirklich zu verbrennen und zu Illuminationen zu benutzen.' Gilbert, "Ueber die sogenannten Thermolampen und den ersten Erfinder derselben," 51. For another statement that Lebon's work rested on well-known chemical principles, see Poppe, Geschichte der technologie, 21.: 'Sind auch die Grundsätze der Chemie, auf welchen die Construction der Thermolampe beruht, nicht neu, sondern jedem Chemiker längst bekannt gewesen, so ist doch die Anwendung derselben auf die Verkohlung des Holzes in verschlossenen Cylindern, die Erzeugung einer brennbaren Lust daraus, und dessen Verwendung zur Heizung und Erleuchtung neu, und vor dem Lebon noch von Niemand versucht worden'. 


\section{Chapter 3: \\ Boulton \& Watt: a question of scale}

3.1 Introduction 2

3.2 William Murdock and distillation processes $\quad 8$

3.3 Development at Boulton \& Watt 1802-1805 14

3.3 Philips \& Lee and the first wave of commercial interest 29

3.3.1 The first installation at Philips \& Lee 1805

3.3.2 A flurry of new sales 1806

3.3.3 Design work at Philips \& Lee 1806

3.3.4 Other mills $1806 \quad 68$

$\begin{array}{ll}3.4 \text { A return to gaslight 1807-8 } & 71\end{array}$

3.4.1 Experimental work during $1807 \quad 72$

3.4.2 The review of December 1807-February 1808

3.5.1 New orders and deliveries 1808

3.5.2 McConnel \& Kennedy 92

3.5.3 Gillespie \& Co. 92

3.6 Other mills and denouement 1809-1812 92

$\begin{array}{ll}3.7 \text { Conclusion } & 92\end{array}$

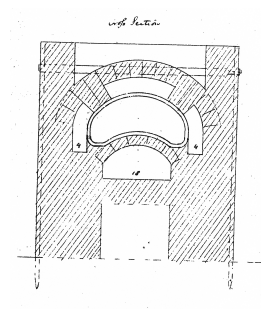

Figure 3.1 Retort cross section. From the Boulton \& Watt archives MS 3147/5/810 


\section{Chapter 3: Boulton \& Watt: a question of scale}

\subsection{Introduction}

The previous chapters have outlined how the first versions of gaslight were developed in a number of different places, and which influences were the most important to those first attempts. In the next two chapters, I will describe the process by which gaslight was transformed into a viable commercial technology and associated industry. This process took place in England, and had two main threads: the development of the first commercial versions of gaslight technology by William Murdock working at Boulton \& Watt, and the founding of the Gas Light and Coke Company in London at the instigation of Frederick Winsor. The present chapter will focus on the first of these threads: the development of gaslight as it took place within the firm of Boulton \& Watt.

The role of Boulton \& Watt in the history of gaslight has been presented in various ways. The most common version, and the one that goes back to nineteenth century histories of gaslight, is that Boulton \& Watt, as the employers of the brilliant engineer William Murdock, provided him with the support and encouragement he needed to bring Murdock's new invention from an idea to an industrial technology. The merit for the invention properly belongs to Murdock, but the resources which brought it into industrial use were provided by his employer. Even if Boulton \& Watt left the field not long after the founding of the first gas utilities after 1812 , they can be rightly assigned the merit of bringing this innovation to maturity. A contrary opinion was brought forward by Malcolm 
Falkus who argued that the role of Boulton \& Watt was exaggerated in the historiography of gaslight. He pointed to the fact that the sales of gaslight apparatus at Boulton \& Watt were in decline even as the first gas utilities were being founded. He also suggested that the ultimate industrial form that gaslight would take-the network utility - was conceived by Winsor and the National Light and Heat Company group. In this at least he was correct. Boulton \& Watt did not promote the corporate and industrial model that was to be the norm for the gaslight industry.

This chapter will show that Boulton \& Watt's true achievement was threefold. First, they took an idea-lighting with inflammable gases generated by distillation - that Murdock had conceived in a form similar to many others of the period-Lebon, Winzler, Minckelers, etc. - and transformed it into a functioning technology deployed in many mills, something no other gaslight pioneer even approached. This entailed recognizing and in most cases solving many non-trivial problems associated with scaling up gaslight apparatus, including how best to charge the retorts; extending apparatus life span and robustness; dealing with gas purification and supply; flame efficiency; assessment of economics, etc. Boulton \& Watt did not solve all the problem since they lost interest in gaslight around 1810 before the technology was mature, but they did address a good number of them.

Their second achievement was that they demonstrated the viability of the technology in the eyes of the public. A key element of this was the medal Watt junior had the Royal Society give William Murdock in 1808 to strike a blow against the Winsorites in Boulton \& Watt's battles with them. The paper and all the publicity 
surrounding the battle linked the prestige of the Royal Society and Boulton \& Watt to gaslight, effectively sanctioning it as a valuable technology in the public consciousness. Even if Boulton \& Watt left the field, they left the technology firmly rooted in public awareness.

Their third achievement was unintentional, but of vital importance. It was to train and give experience to many craftsman and engineers in the area of gaslight technology. Many Boulton \& Watt employees and contractors, as well as the employees of their customers such as Philips \& Lee gained knowledge of how to operate and build gaslight apparatus. The range of experience of their customers, especially Philips \& Lee, was extensive because they were not merely passive purchasers. They were actively involved in design decisions. Many of the people who gained experience in the through Boulton \& Watt's work went on to participate in the further development of the industry. The most important of these was Samuel Clegg, but there were also many unnamed craftsman who were hired from Manchester by the gaslight industry.

Boulton \& Watt did not, however, create these skills out of nowhere, and the prior existence of skills useful for the development of gas apparatus points to some of reasons for the success of gaslight in Britain. As Peter Mathias has described, an important element of the Industrial Revolution consisted in skills developed in one industry being transferred to another. ${ }^{1}$ The iron industry that was flourishing in Britain was particularly important for gaslight. The skilled iron workers at the Boulton \& Watt foundry and at their contractors enabled them to design and build iron gas apparatus

\footnotetext{
1 Peter Mathias, The first industrial nation : the economic history of Britain, 1700-1914 (London: New York, 2001), 129.
} 
fairly quickly, a vital aspect of scaling the apparatus. Boulton \& Watt and their suppliers forged a host of components, including wheels, chains, supports, valves, plates, pipes, rivets, and retorts from iron. Christine MacLeod has argued that the Industrial Revolution in Britain was the product of the combination of two streams, a panEuropean one of technological development and inventiveness, and a British stream centred on coal and related industries. ${ }^{2}$ This pattern is also evident in gaslight. The invention was not confined to a single country, but when it combined with Britain's advanced iron industry, it was scaled up into a viable technology. When Lebon and Winzler were trying to commercialize gaslight technology, they had the same access to pneumatic chemistry as Boulton \& Watt. They did not, however, have access to iron and coal as easily as Murdock did.

It was not, however, only experience with iron that Boulton \& Watt had to offer. Of similar importance was the work they had done in handling gases, whether steam, or much more importantly, medicinal gases. Working with Thomas Beddoes, Boulton \& Watt had been making pneumatic apparatus for medicinal purposes, and the pneumatic apparatus they had been making evolved naturally into gaslight apparatus. The gasometer in particular was the most important legacy of pneumatic medicine in gaslight.

If the first two chapters were about the circumstances surrounding the invention of gaslight, this chapter focuses on the first stage of development of the invention into an

\footnotetext{
2 Christine MacLeod, "The European Origins of British technological predominance," in Exceptionalism and industrialisation : Britain and its European rivals, 1688-1815, ed. Leandro Prados de la Escosura (New York: Cambridge University Press, 2004), 111-2.
} 
industrial technology. Boulton \& Watt with its host of engineers and craftsmen were responsible for this, together with their contractors and customers, mostly textile mill owners, and especially George Augustus Lee. Boulton \& Watt's interest in the technology was not undivided. Among the firm's partners, it was James Watt junior who the most interested, with Robinson Boulton being generally supportive, but not enthusiastic. Even Watt junior's support was not constant. The firm only sporadically devoted resources to the gaslight project, and development came in bursts, mostly when there was some threat of competition, at first from many smaller players trying out the technology for themselves, and later on from the Winsor group in London. When the competitive threat was less present, the firm tended its core steam engine business. The results of this was that development work came in fits and starts, with some low intensity work at other times. The periods of intense activity started in 1805, and lasted until mid 1806 when the first gasworks were prepared for Philips \& Lee. All then went quiet until late 1807 when the Winsorites frightened Boulton \& Watt into more development and providing additional gas plants to customers who had expressed interest in 1806, but whom they had neglected to serve. After a number of plants were installed between 1808 and 1810, the business was again neglected, despite the firm's victory over the Winsor group in Parliament. The business then petered out, although Boulton \& Watt expanded and built a few plants in the following years to 1812.

A comment about the sources used for this chapter is appropriate. Most of the citations are to the Boulton \& Watt archives in the Brimingham Reference Library, as reproduced on microfilm by Adam Matthew Publishers. There are no direct references to the gaslight project in these archives until 1805 , other than a few minor references in 
letters from 1801. There are, however, some printed sources that provide details of work from this period. Henry Creighton, an engineer working for Boulton \& Watt, later wrote an article entitled 'Gas-lights' for the 1824 supplement to the fifth edition of the Encyclopaedia Britannica. ${ }^{3}$ The article includes details about some of the experiments performed at Soho from 1802, including some plates detailing the retorts, which however, lack a scale. It may be that Creighton used some of the materials from Boulton \& Watt, but which were never returned. Samuel Clegg junior wrote a book on gaslight in 1841 entitled A Practical Treatise on the Manufacture and Distribution of Coal-gas in which he cites his father's notebooks from the era when he was still working at Boulton \& Watt. ${ }^{4}$ William Matthews, the first historian of gaslight, included some details from this period as well. ${ }^{5}$ William Henry gave a few more details in an article published in Nicholson's Journal in 1805 in which he cites a letter from Watt junior summarizing the early experiments from 1798-1802. Although Henry does not give the letter's source, it is Watt junior because in it he refers to a letter he received dated November 8, 1801 from Paris, which exists in the Boulton \& Watt archives. ${ }^{6}$ Finally, a

${ }^{3}$ William Matthews, An historical sketch of the origin, progress, \& present state of gas-lighting (London: R. Hunter, 1827), 24-5.

${ }^{4}$ Samuel Clegg, A practical treatise on the manufacture and distribution of coal-gas : its introduction and progressive improvement, illustrated by engravings from working drawings, with general estimates (London: J. Weale, 1841).

${ }^{5}$ Matthews, An historical sketch of the origin, progress, \& present state of gas-lighting. William Matthews, Compendium of gas-lighting, adapted for the use of those who are unacquainted with chemistry; containing an account of some new apparatus lately introduced (London: R. Hunter, 1827). Matthews, An historical sketch of the origin and progress of gas-lighting, 2nd ed. (London: Simpkin \& Marshall, 1832).

6 William Henry, "Experiments on the gases obtained by the destructive distillation of pit coal, \&c., with a view to the theory of their combustion when employed as sources of artificial light," A Journal of natural philosophy, chemistry and the arts 11 (1805). p.74\} 
Parliamentary committee gathered evidence in 1809 about the origins of the gaslight which contain some pertinent information. ${ }^{7}$

\subsection{William Murdock and distillation processes}

Murdoch (1754-1839) - he later anglicized his name to Murdock - was born in Old Cumnock, Ayrshire, in Scotland. His father was employed by the local Lairds, the Boswells, as a miller and millwright. He also did various engineering tasks, such as installing and repairing pumps at local coal mines and is known to have repaired a public bridge. In addition to whatever he learned at his father's side, William Murdock received what education the Scottish school of the eighteenth century had to offer, which was fairly good as compared to the English system. Through family connections, he was hired by Boulton \& Watt in August of 1777 at the age of 23. He must have showed some promise as an engineer for him to have been hired in this way. He was posted by Boulton \& Watt to Cornwall in the fall of 1779 to work as an engine erector and engineer. Cornwall was to be by-and-large his home base until 1798 when he moved to Birmingham to work at the Boulton \& Watt works. ${ }^{8}$

Murdock proved to be an able engineer and soon earned recognition from his employers. Matthew Boulton wrote to James Watt in 1778 that 'he is now a good

\footnotetext{
7 James Hall, "Select Committee on Gas-Light and Coke Company's Bill to incorporate Persons for procuring Coke, Oil, Tar, Pitch, Ammoniacal Liquor and Inflammable Air from Coal: Minutes of Evidence," in HOUSE OF COMMONS PAPERS; REPORTS OF COMMITTEES III.315 (1809).

8 John Charles Griffiths, The Third Man: the Life and Times of William Murdoch, 1754-1839, the Inventor of Gas Lighting (London: A. Deutsch, 1992), 4-11.
} 
engineer', ${ }^{9}$ and again in 1784 as the 'best engine erector I ever saw'. ${ }^{10}$ Murdock had an active interest in invention, sometimes tinkering and improving the steam engines he was responsible for erecting, much to Watt's annoyance. Murdock was responsible for a series of important inventions other than gaslight. In 1781 he invented the sun-andplanet gearing mechanism used to transform the reciprocal motion of a steam engine piston into rotary motion necessary to drive most factory machines. He also invented the D-slide valve for which he received a patent in 1799 . This valve was the most frequently used method to regulate steam flows in locomotive engines in the nineteenth century. He also experimented with and even built a number of steam carriages between 1783-5, an idea he dropped, but which was picked up by Murdock's neighbour in Cornwall, Richard Trevithick. In addition, Murdock was a competent inventor of machine tools as he showed once he had moved to Birmingham to set up the works at the Soho foundry. ${ }^{11}$

Murdock, like most of his contemporaries who worked on gaslight, came to the invention through the investigation of distillation processes. While his primary interests lay in mechanical engineering, Murdock also maintain some interest in chemistry which produced a couple of minor inventions. While in Redruth in Cornwall sometime before 1784, Murdock worked on improving the cement used to fuse the components of steam engines, and developed iron cement-a mixture of iron and sal ammoniac-as a

\footnotetext{
9 Boulton \& Watt Archives, hereafter BWA, MS 3147/3/2 \#11, from Adam Matthew publishers, Industrial Revolution Series, hereafter AM-IR Series 1, Part 12, Reel 198.

10 Griffiths, The Third Man: the Life and Times of William Murdoch, 1754-1839, the Inventor of Gas Lighting, 102.

11 For details see Ibid. and John C. Griffiths, 'Murdock, William (1754-1839)', Oxford Dictionary of National Biography, Oxford University Press, 2004
} 
consequence. ${ }^{12}$ In 1795 he also developed a new clarifying agent for beers based on codfish skins. ${ }^{13}$

In 1790, for reasons that are not clear, Murdock became interested chemical processes to produce all sorts of chemicals agents, dyes, paints, and so forth from materials containing sulphur-typically pyrites from the Cornwall mines-by distillation processes similar to some coking processes. No evidence remains of the motivations or the steps Murdock took, but the end result was a patent, granted in May 2, 1791, for 'a Method of Making (from the Same Materials, and by Processes Entirely New,) Copperas, ${ }^{14}$ Vitriol, and Different Sorts of Dye or Dying Stuff, Paints, and Colours ; and Also a Composition for Preserving the Bottoms of All Kinds of Vessels, and All Wood Required to Be Immersed in Water, from Worms, Weeds, Barnacles, and Every Other Foulness Which Usually Does or May Adhere Thereto'. ${ }^{15}$ Murdock's biographer, John Griffiths, suggests that local Cornwall mining interests collaborated with Murdock and probably funded his patent application, and it is likely that he had help on that score, given the high cost ( $₹ 100$ or so) of filing for a patent in England at this period. ${ }^{16}$ Griffiths also suggests, probably correctly, that these experiments were the first steps in what

\footnotetext{
12 Ibid., 221.

13 Ibid., 222.

14 Iron(II) sulfate, used for making dyes and as a mordant.

15 "Specification of the Patent granted to Mr. William Murdock, of Redruth, in the Country of Cornwall, Gentleman for a Method of making (from the same Materials, and by Processes entirely new,) Copperas, Vitriol, and different Sorts of Dye or dying Stuff, Paints, and Colours ; and also a Composition for preserving the Bottoms of all Kinds of Vessels, and all Wood required to be immersed in Water, from Worms, Weeds, Barnacles, and every other Foulness which usually does or may adhere thereto. Dated May 2, 1791," The repertory of arts and manufactures 1st series 9 (1798).

${ }^{16}$ Christine MacLeod, Inventing the Industrial Revolution : the English patent system, 1660-1800 (Cambridge: Cambridge University Press, 1988), 76.
} 
utimately led to Murdock's invention of gaslight sometime between 1792 and $1794 .{ }^{17}$ In his very brief patent, Murdock gives a high level description of the process, which was to 'put the [pyrites] into a kiln, house, oven, cone, or heap, covered nearly close, and then set the fame on fire, admitting no more air than is sufficient to cause the said pyrites, mundick, ${ }^{18}$ or other minerals or ores, to burn'. The smoke produced was collected in a receiver and condensed. Murdock provided other recipes such as mixing in ores of zinc with the pyrites before distilling them, burning the pyrite or dissolving them in water before heating. The patent does not cover any specific apparatus, being about the process of distilling pyrite generally.

There is no evidence that the patent was followed up with any significant commerical activity or further work in sulphur products, but it is likely that Murodock at some point chose to distill coal or wood in the stoves he was using for pyrite and, like so many other before and contemporaneous with him, remarked on the inflammable gases produced. ${ }^{19} \mathrm{He}$ would later claim that he was unaware that others had made this same observation, although that was many years after the fact and in the middle of a pitched battle over control of gaslight technology, one that involved priority claims. ${ }^{20}$ The chronology of the invention in Cornwall was investigated in great detail by Griffiths, and

\footnotetext{
17 Griffiths, The Third Man: the Life and Times of William Murdoch, 1754-1839, the Inventor of Gas Lighting, 224-5.

18 Cornish word for pyrite.

19 Henry, "Experiments on the gases obtained by the destructive distillation of pit coal, \&c., with a view to the theory of their combustion when employed as sources of artificial light," 73. basically corroborates this.

20 William Murdoch, "An Account of the Application of the Gas from Coal to Economical Purposes," Philosophical Transactions of the Royal Society of London 98 (1808): 132.
} 
from my own research his version of the events appears to be correct. ${ }^{21}$ Griffiths is quite concerned with the exact timing of the invention and the tired old debate about whether Lebon or Murdock can claim priority, a battle which has done much to obcure the actual origins of gaslight. What is important for this history, however, is that Murdock made a number of quite basic experiments with gaslight in the period 1794-1798, mostly while he was living in Cornwall. The apparatus he used was simple, as he described in his 1808 paper on the subject: 'My apparatus consisted of an iron retort, with tinned copper and iron tubes through which the gas was conducted to a considerable distance ; and there, as well as at intermediate points, was burned through apertures or varied forms and dimensions'. ${ }^{22}$

The experiments and apparatus were seen by James Watt junior ${ }^{23}$ and others in this period, but they generated no particular excitement. On the contrary: there are hardly any references to Murdock's gaslight in any archives before 1801. Despite the many surviving letters and journals, some directly concerning Murdock in Cornwall, references to gas light are fleeting. For example, when James Watt toured Cornwall and visited with Murdock in Redruth for several days, he did not record any hint of gaslight. ${ }^{24}$ There is, however, no doubting the basic chronology because of documentation from the period 1805 onwards, but it was simply not treated by anyone

\footnotetext{
21 See Griffiths, The Third Man: the Life and Times of William Murdoch, 1754-1839, the Inventor of Gas Lighting, 224-49. Griffiths does not properly cite the letters he uses. They are: Thomas Wilson to B+W 1808/01/27 and 29, BWA MS 3147/3/363 \#10 and 11, AM-IR series 1 part 13 reel 236.

22 Murdoch, "An Account of the Application of the Gas from Coal to Economical Purposes," 131.

${ }^{23}$ Hall, "Select Committee on Gas-Light," 51.

24 James Watt notebook 1795-1797, BWA MI/2/19 AM-IR series 1, part 2, reel 18.
} 
within the firm or by Murdock himself as an invention with such obvious advantages that it should be developed immediately. Although there was some discussion about commercializing the product, Watt junior discouraged Murdock from getting a patent because of the difficulties the firm was having over steam engine patents. Watt's awareness of prior use of inflammable gases, such as Lord Dundonald's, made him think a patent would be indefensible. ${ }^{25}$

In 1797, Murdock briefly repeated some tests while he was at Old Cumnock in Ayrshire in the north. ${ }^{26}$ After Murdock moved to Birmingham in 1798 to help with the foundry and manufactory there, a few more minor experiments were done. A retort was cast in December of $1798,{ }^{27}$ and various coals were tested. Watt junior stated that the apparatus 'was applied during many successive nights, to the lighting of the [Foundry] ... experiments on different apertures were repeated and extended upon a large scale. Various methods were also practised of washing and purifying the air, to get rid of the smoke and smell. ${ }^{28}$ In the end, however, they decided not to pursue the technology further for the moment because of ongoing steam engine work and litigation..$^{29}$ Watt junior specifically discourage Murdock from working on the invention, as he wrote to Robinson Boulton in 1799: 'With respect to Murdock's lamp, I am very doubtful whether it can be made to pay + have dissuaded him from thinking about it at

\footnotetext{
25 Hall, "Select Committee on Gas-Light," 51.

${ }^{26}$ Henry, "Experiments on the gases obtained by the destructive distillation of pit coal, \&c., with a view to the theory of their combustion when employed as sources of artificial light," 74.

27 BWA MS 3147/3/479 \#1, AM-IR series 1 part 14 reel 273.

${ }^{28}$ Henry, "Experiments on the gases obtained by the destructive distillation of pit coal, \&c., with a view to the theory of their combustion when employed as sources of artificial light," 74.

${ }^{29}$ Hall, "Select Committee on Gas-Light," 51.
} 
present. My father is to have the apparatus over to Heathfield + try some experiments with it'.30 Murdock then turned to steam engine design and took out a patent in August of 1799 for a new method of constructing steam engines.

\subsection{Development at Boulton \& Watt 1802-1805}

The spark that set off the serious development of gaslight technology at Boulton \& Watt, with a clear purpose of commercializing it, was Gregory Watt's visit to the continent in 1801-2. As mentioned in chapter two, Gregory was in Paris just when Lebon was publicly promoting his new thermolamp. Gregory thought of Murdock's work and in a letter written to his brother on November 8,1802 , he urged him to ' $[\mathrm{t}] \mathrm{ell}$ Murdock that a man here has not merely made a lamp with the gaz procured by heat from wood or coal but that he has lighted up his house and gardens with it and has it in contemplation to light up Paris'. ${ }^{31}$ The idea that they could be beaten to gaslight by this Frenchman who was actively promoting his scheme was sufficient motivation for them to begin work in earnest. Watt junior responded to Greg in December 1801: 'Murdock is going to Cornwall upon his own affairs. [...] [U]pon his return some decisive experiments are to be made which will determine whether we shall proceed upon his plan or not' ${ }^{32}$ Clearly, the work done up to the end of 1801 had not convinced anyone that the technology was viable. Ironically, Greg never learned of Lebon's failure, leaving Paris in the begining of 1802, and the competition which Watt and Murdock feared

\footnotetext{
30 James Watt jr to Matthew Robinson Boulton 1799/04/04, BWA MS 3147/47/3/48

31 Gregory Watt to James Watt jr, 1801/11/08, BWA JWP C2/10, AM-IR series 3 part 2 reel 40.

32 James Watt jr to Gregory Watt, date unclear, but it is located in the letter book before a letter dated 14 Dec 1801. BWA JWP LB/7, AM-IR series 3 part 2 reel 39.
} 
disappeared, but still drove them to develop gaslight until a host of real competitors emerged in 1804-5.

Murdock and Watt junior - the archives related to gaslight shows they were clearly at the forefront of development-determined that a propitious opportunity was at hand to demonstrate the new light in a public way. Napoleonic France and England had signed a ceasefire agreement and preliminary peace treaty in London in October of 1801 , with a view to finalizing the terms in upcoming negotiations. This marked the first time since 1793 that two countries were at peace, and the event was celebrated with fireworks and 'illuminations'. The final treaty was to be settled in Amiens, north of Paris. Boulton \& Watt determined in November 1801 to have illuminations of their own, and ordered '84 dozen illuminating lamps' of various colours, 6 dozen candles, and 14 gallons of oil from a local merchant Shakespeare, Johnson, \& Berry. ${ }^{33}$ Gaslights would make a small but nice addition, affording a demonstration of the new technology to a sizeable audience.

${ }^{33}$ BWA, Matthew Boulton Correspondence, Soho House MS 1682, series 1 part 4 reel 57. 


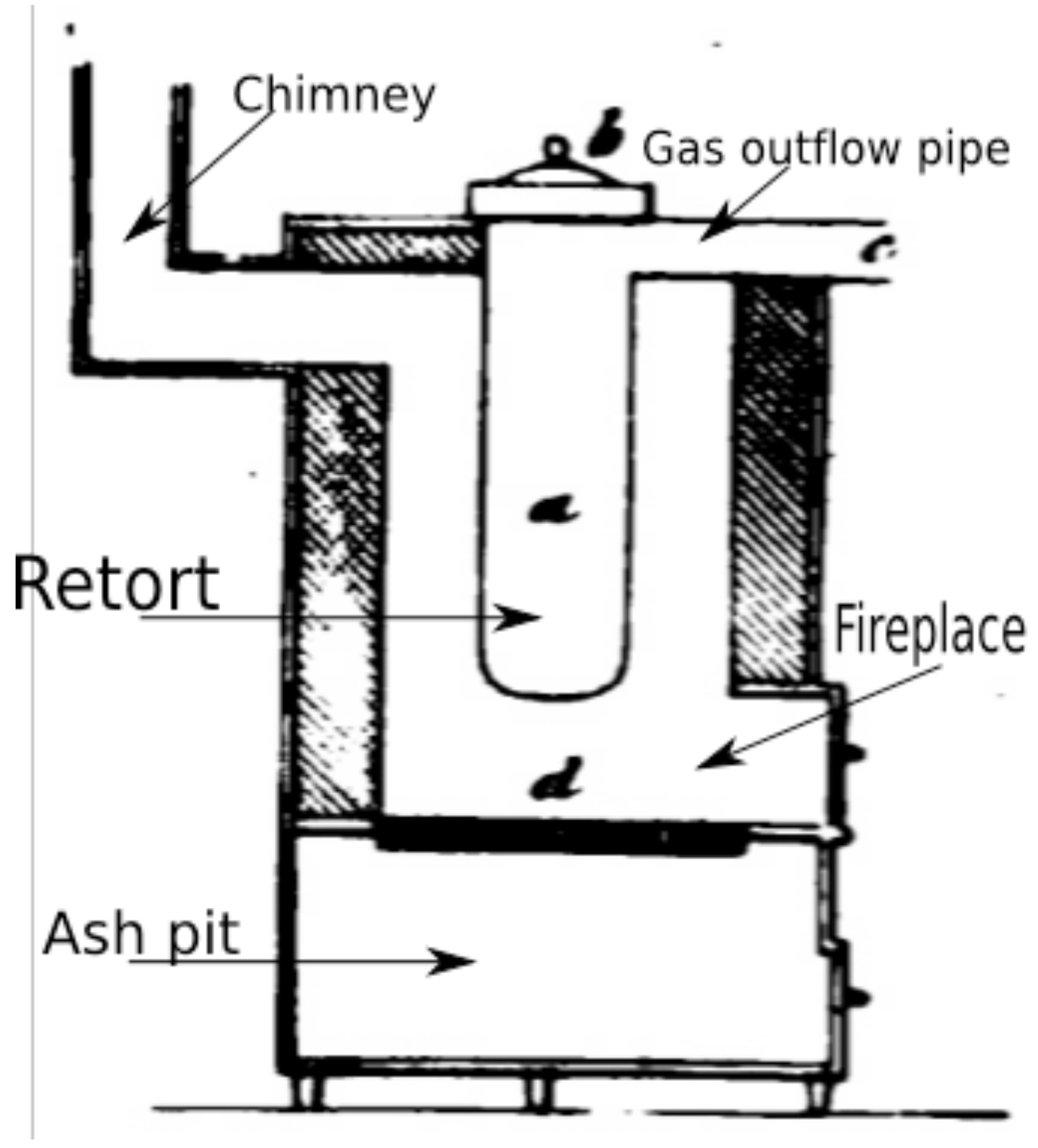

Figure 3.2 One of Murdock's first retorts, from Creighton "GasLights." in the Encyclopaedia Britannica (1824)

Murdock got to work early in 1802 and designed a new retort to be made of cast iron. The mould was prepared in February and the retort was cast soon thereafter. It 
was a vertical pot which could hold about $15 \mathrm{lb}$ of coal. ${ }^{34}$ No dimensions are available, but assuming an average density for the coal used, this corresponds to a $1 \mathrm{ft}$ depth and 3 inch radius. ${ }^{35}$ The foundry was first lit on February 20, 1802 with the retort placed in a stove. ${ }^{36}$ It is sometimes stated that the foundry or other buildings were lit earlier, and likely Murdock's 1798 work included some such lighting, but those first tests were limited in scope and clearly gaslights were not used on a regular basis after the tests were finished.

The Peace of Amiens was signed on March 25, 1802, and Boulton \& Watt set the date of the celebratory illuminations for March 31. They were busily preparing for the next few days. ${ }^{37}$ The personal correspondence surrounding the event is silent about gaslight, and it was a minor element of the display. James Watt senior, in the many letters he wrote before and afterwards, and although this was the first time he saw gaslights in use, ${ }^{38}$ never once mentioned it in his correspondence of the period despite referring to and describing the event many times. Samuel Clegg, who was later to become an important gas engineer, and was then employed by Boulton \& Watt,39 claimed that the gaslights were two copper vases, one at either end of the manufactory.

\footnotetext{
34 Henry Creighton, "Gas-Lights," in Encyclopaedia Britannica, or;: A dictionary of arts, sciences and miscellaneous literature. Supplement to the Fourth, Fifth, and Sixth Editions (Edinburgh: A. Constable, 1824), 449.

${ }^{35}$ Coal is about $70 \mathrm{lb} / \mathrm{ft}^{3}$, and $15 \mathrm{lb}$ has a volume of $0.2147 \mathrm{ft}^{3}$, or $7 \mathrm{in}^{3}$.

${ }^{36}$ Creighton, "Gas-Lights," 449., BWA MS 3147/3/479 \#1 AM-IR series 1 part 14 reel 273.

37 James Watt to Greg Watt 1802/03/31, BWA JWP LB/3 p. 214 AM-IR series 3 part 1 reel 8.

38 James Watt to Isaac Hawkins Browne 1809/04/26, BWA JWP LB/4 261, AM-IR series 3 part 1 reel 9.

39 Clegg, A practical treatise on the manufacture and distribution of coal-gas, 6. Clegg was on the payroll on 1801, see BWA MII /7/3, AM-IR series 1 part 6 reel 75 .
} 
These 'Bengal lights', as they were called, were fed from retorts placed in fireplaces. ${ }^{40}$ Clegg's presence at the firm at this period is crucial because he witnessed some of the important development work which he would then use after he went off on his own beginning in $1805,{ }^{41}$ and later when working for the Gas Light and Coke Company in 1813.

With this first modest but successful display behind them, Watt junior and Murdock were now determined that the next round of experiments should produce a viable technology, but obviously a good deal more work was needed to scale up the apparatus. Murdock and company would already have known from his earlier work that building an apparatus of usable dimensions would require some serious work. A retort the size of this first one could keep a single lamp burning for four hours or so, ${ }^{42}$ and as sizeable buildings such as the Soho foundry or manufactory could easily have had hundreds of candles and lamps lit on any given night, reaching a useful scale was their first challenge.

Recharging the retort was one element of the scaling problem Boulton \& Watt worked on from the beginning, and continued to do so for the next few years, even after the first apparatus was in use at Philips \& Lee's mill in Manchester. Coal expands with distillation as volatile materials are driven off leaving behind the pure carbon as coke that builds up as a heavy encrustation on the walls of the retort. This coke had to be

\footnotetext{
40 lbid.
}

${ }^{41}$ Matthews, An historical sketch of the origin, progress, \& present state of gas-lighting, 40. single candle brightness lamp consumed about $0.35-0.45 \mathrm{ft}^{3} /$ hour of gas. 
broken up and scraped out before the next load could be introduced. For scientific purposes, or for producing gas in small batches such as the Amiens illuminations, recharging the retort quickly was not a priority. The gas was simply not used on large scales or in a continuous way. With gaslight, however, downtime for recharging had to be minimized. If gaslight was to be used on a regular basis for several hours in a row on a daily basis, the question of how to recharge the retort becomes acute. As discussed in chapter two, Winzler's large thermolamps had lengthy recharge cycles: the thermolamps were allowed to cool for a few days and the charcoal be broken up with tools before the thermolamp was cleaned and reloaded. 


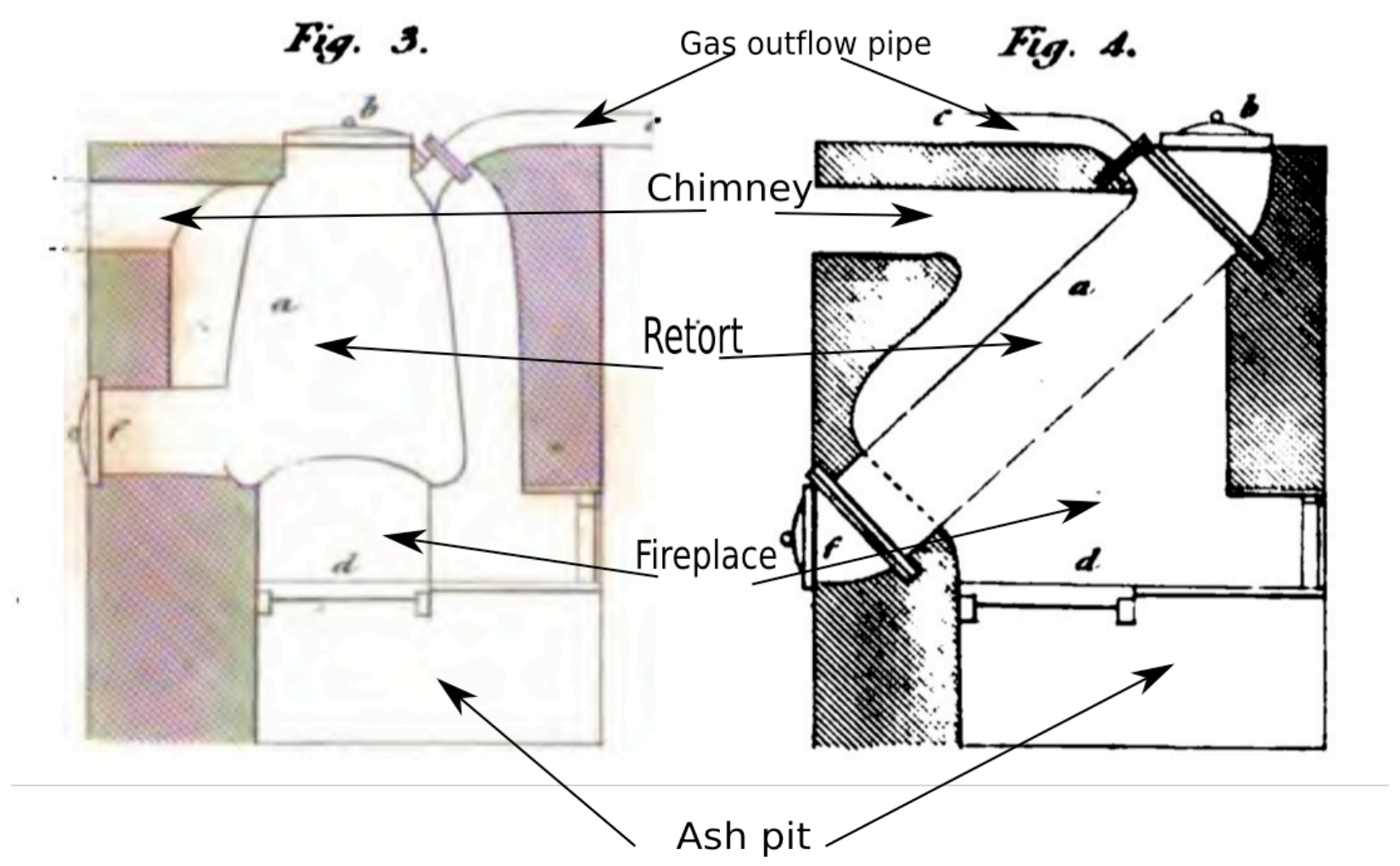

Figure 3.3 Early retort designs from Creighton "Gas-Lights." in the Encyclopaedia Britannica (1824)

The first attempted solutions involved retort designs that favoured simplified recharging by having two openings, one at the top and a second toward the bottom. Creighton reproduced two such retort designs from 1803-4. These models were quickly abandoned as the increased complexity and associated manufacturing costs proved to be too much of a barrier against the general adoption of these design. The associated problem and constraint was the relatively short service life that retorts had. Retorts burned out fairly quickly with constant heating cycles, either by cracking or 
oxidizing. Expensive and complicated retort designs were not possible as they would make the cost of renewing the apparatus prohibitive-both because of manufacturing costs and the difficulty and delays caused by replacing a burnt out retort. The experience Boulton \& Watt gained in $1802-5$ meant that by the time the first plant was installed at Philips \& Lee's, the retort design had reverted to a vertical pot much like the Amiens retort, although on a much larger scale. No complicated retorts such as those shown above were ever tried again.

The problem of rapid recharging was addressed through operating procedures and the adoption of the gasometer. As Winzler and the German gaslight pioneers realized, the gasometer made famous by Lavoisier would be an adequate means of guaranteeing an even supply of gas. They eschewed the solution because of the instrument's expense and their greater interest in the other products of distillation. At Boulton \& Watt, however, gasometers were familiar and available. James Watt had become very interested in pneumatic medicine after the untimely death of his daughter Jessie in 1794 to pulmonary tuberculosis. He was deeply affected by the event and resolved to seek remedies for the disease, especially since his second son, Gregory, also suffered from the illness. Watt was in contact with Thomas Beddoes, a medical doctor and lecturer who had recently left his post at Oxford University for Bristol because of his radical political sympathies. Beddoes had been thinking about the medicinal uses of gases when, in collaboration with Watt, he began to practice it in earnest. Watt designed and built a pneumatic apparatus whose purpose was to produce and deliver doses of gases to patients suffering various ailments. The apparatus consisted of an alembic or distilling apparatus where the gas, typically hydrocarbonate (a mixture of carbon 
monoxide and methane), was produced. ${ }^{43}$ In the case of hydrocarbonate, this was done by dropping water onto heated charcoal. The gas was then washed and cooled with water in a refrigeratory and stored in a gas-holder or gasometer until the patient was ready to inhale a dose of the air. ${ }^{44}$

43 Thomas Beddoes and James Watt, Considerations on the medicinal use, and on the production of factitious airs (Bristol: Printed by Bulgin and Rosser for J. Johnson, London, 1795), part 2, 27-35.

${ }^{44}$ For a brief summary of Beddoes and Watt's association over pneumatic medicine see F. F. Cartwright, "The Association of Thomas Beddoes, M.D. with James Watt, F.R.S," Notes and Records of the Royal Society of London 22, no. 1/2 (1967). 


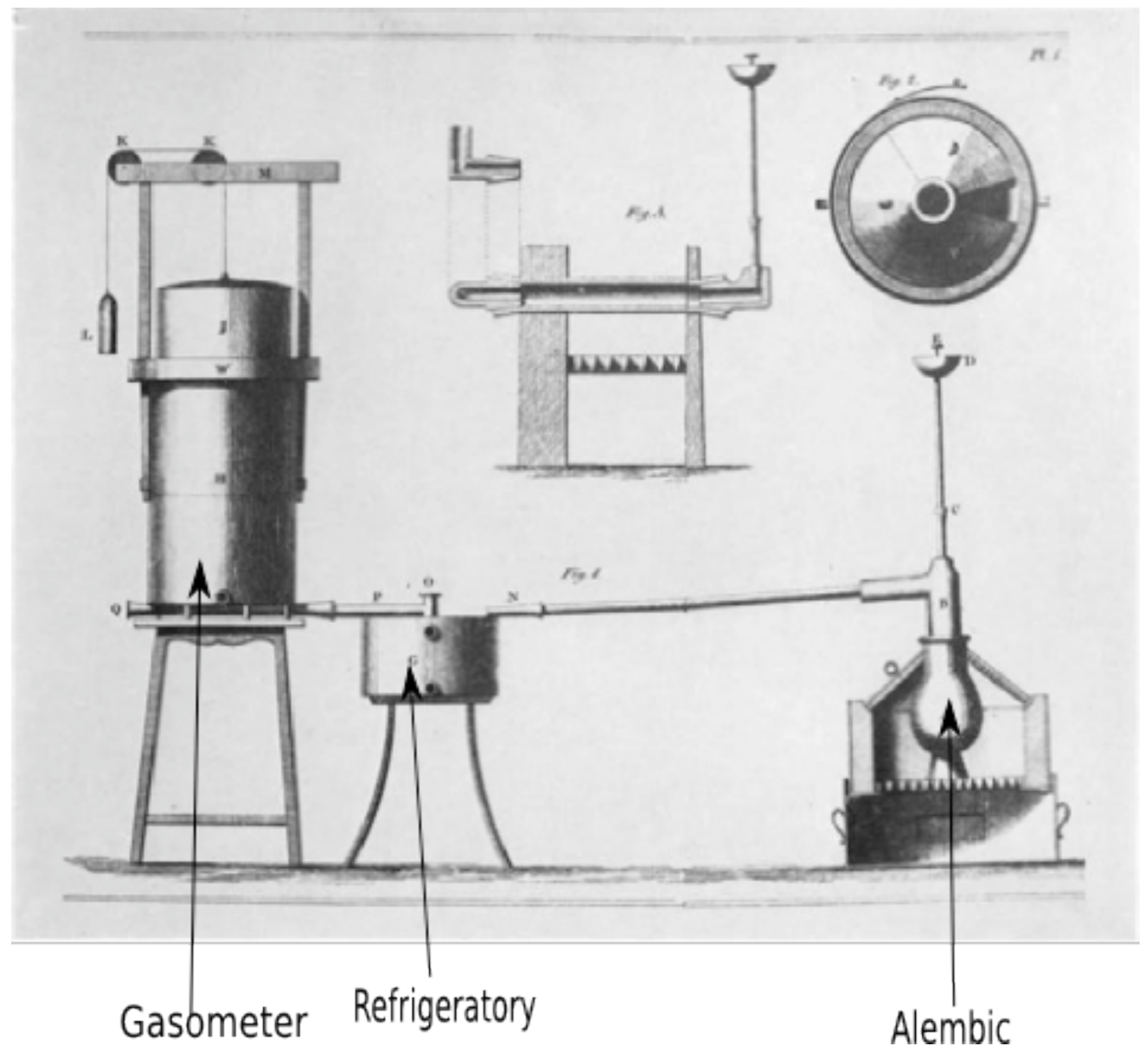

Figure 3.4 Pneumatic apparatus, from Beddoes Considerations on the medicinal use, and on the production of factitious airs. (1795)

Watt had heard of the gasometer from Lavoisier's Traité, and Beddoes later sent him a sketch of a gasometer in 1791.45 The design Watt used was a simple one with a

45 Trevor Levere, "The role of instruments in the dissemination of the Chemical Ravolution," Éndoxa: series filosóficas 19 (2005): 39. Levere, "Dr. Thomas Beddoes (1760-1808): Chemistry, Medicine, and Books in the French and Chemical Revolutions," in New narratives in eighteenth-century chemistry: contributions from the First Francis Bacon Workshop, 21-23 April 2005, California Institute of Technology, Pasadena, California, ed. Lawrence Principe (Dordrecht: Springer, 2007), 165-70. 
single counterweight to balance the weight of the gasometer's moveable upper section. This gasometer's design was less about measuring the volume of the air than about storing it for later use, but the name stuck. After 1794 Boulton \& Watt got into the business of manufacturing pneumatic apparatus of this kind for sale, either in a personal version, or a larger one for hospitals. The volume of the gasometer was quite small, being $1 / 2 \mathrm{ft}^{3}$ for the personal model and $1 \mathrm{ft}^{3}$ for the hospital edition. Sales of the pneumatic apparatus were never vibrant, but Boulton \& Watt had enough success with it over the year 1795-1803 that they made a profit from it a number of years in this period. 46

${ }^{46}$ See the various financial reports in BWA MII /7/3, AM-IR series 1 part 6 reel 75 . 


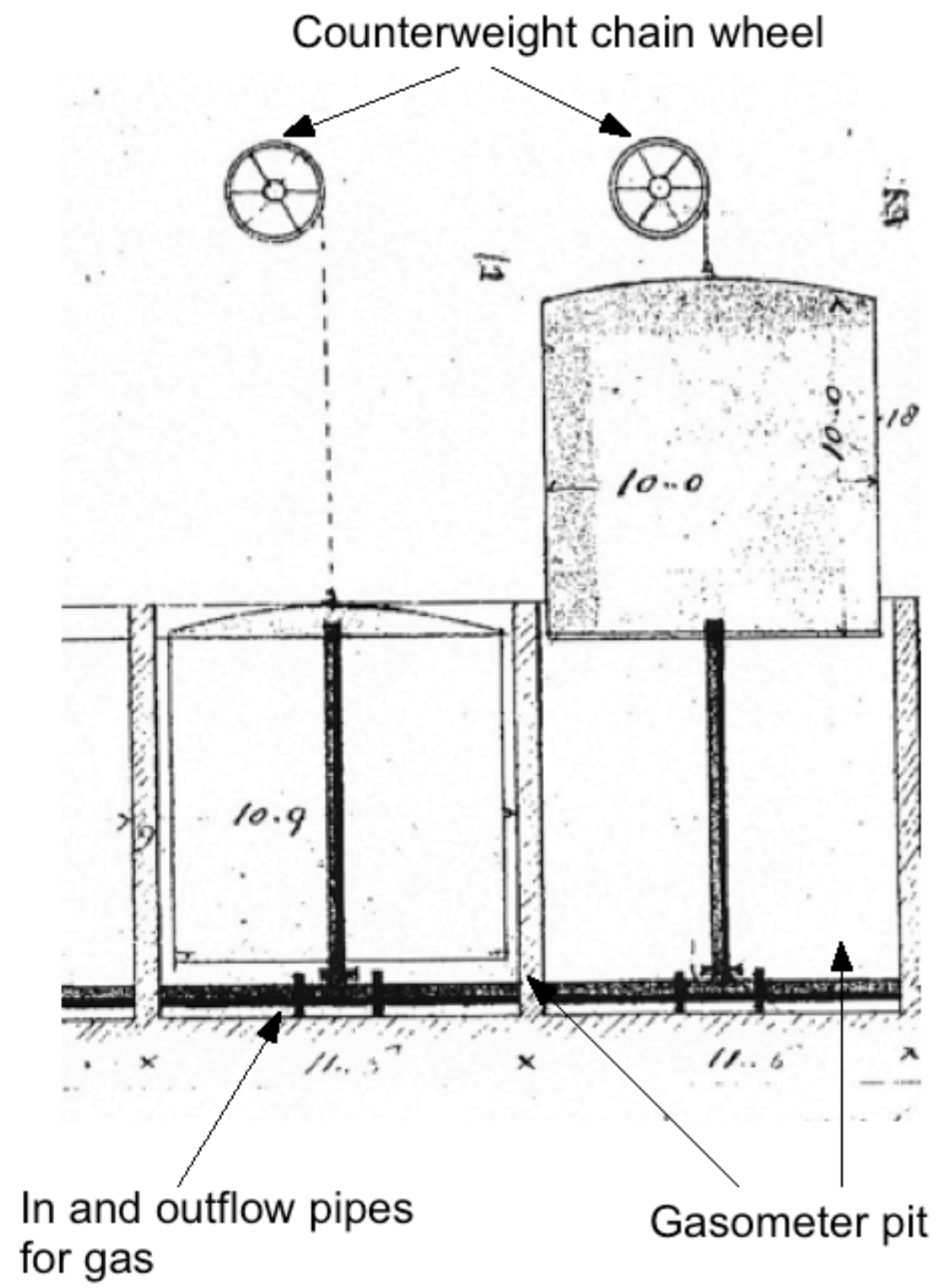

Figure 3.5 Sketches of gasometers for Philips \& Lee prepared in 1805 or 1806 . The basic design, including the counterweight mechanism and the location of the pipes follows the pneumatic apparatus closely. BWA MS 3147/5/804/5-7, AM-IR series 1 part 11 reel 184 
Pneumatic medicine ultimately proved to be a failure, as Beddoes despairingly admitted in one of his last letters before his death in 1808, but the legacy of pneumatic medicine was not lost as its apparatus was inherited by the fledgling gaslight technology within the firm. Experiments on gaslight began at just the time when pneumatic medicine started losing its currency. When research was conducted into how to scale up the gaslight apparatus, attention was naturally given to the gasometers that Boulton \& Watt had been manufacturing for almost a decade. The gasometers were far too small, of course, as a cubic foot of gas was sufficient for only one burner for one hour's light. According to Clegg, a larger model, one $8 \mathrm{ft}$ deep with a $6 \mathrm{ft}$ diameter and of 300 $\mathrm{ft}^{3}$ capacity, was built and in use by March of $1803 .{ }^{47}$ No sketch or design drawing of this gasometer survives, but it was likely similar to the earliest ones installed at first purchasers of the gaslight apparatus. These have a design almost identical to the one used in Watt's pneumatic apparatus: the single counter-weight is attached to the centre of the moveable section, with the chain passing over two wheels to the attached weights. The feed pipes enter from the bottom. With the exception of the feed pipes which proved to be problematic, this design was the prototype for pretty well all of the gasometers Boulton \& Watt manufactured from 1806-1815, and as Boulton \& Watt were the pioneer manufacturers of gaslight apparatus, they also served as an inspiration for many early gasometer designs. In fact, when the Royal Society was asked to report on the safety of gasworks in 1814 , they described the gasometers as being 'in effect the same thing as the receiver of the pneumatic apparatus'. ${ }^{48}$

\footnotetext{
47 Clegg, A practical treatise on the manufacture and distribution of coal-gas, 6.

48 Joseph Banks, "Report of Royal Society on Gas-Lights; Report of Inspectors on Gas-Light Establishments in the Metropolis," in HOUSE OF COMMONS PAPERS; ACCOUNTS AND PAPERS (London: House of Commons, 1823), 3.
} 
Watt designed and built another device that was sometimes referred to as 'Watt's air-holder', but this was quite different from the gasometer and should not be confused with it. Creighton mentions it his 1824 article as being wholly inadequate for gaslight purposes. ${ }^{49}$ It did not have a moveable upper section such as the ones described above, and the gas was stored under greater pressure. 50

Watt's pneumatic apparatus provided the bridge between the technology as it was implemented at Boulton \& Watt and then in the rest of Britain, and the scientific instruments derived from Lavoisier's gasometer. It is rarely possible in this period to find such a clear connection between an industrial technology and a scientific instrument, although the importance of the specific connection should not be exaggerated. It is likely that even if Boulton \& Watt had not been manufacturing apparatus for pneumatic medicine, they would still have been aware of Lavoisier's gasometer, as the German chemists had been. It was hardly a secret after all, being described in the Traité and other works. But the connection is nevertheless of some importance, since Boulton \& Watt's experience with manufacturing and using the gasometer certainly made it easier for them to absorb it into gaslight, a step other gaslight pioneers were more hesitant to take.

The matter of economics was judged to be of vital importance to the deployment, design, and scale of gaslight apparatus, and on this score, Boulton \& Watt remained inexperienced and ignorant of any specifics. Although they had been using gaslight in

\footnotetext{
49 Creighton, "Gas-Lights," 454.

50 Samuel Frederick Porter Arthur Livermore Gray, The chemistry of the arts; being a practical display of the arts and manufactures which depend on chemical principles (Philadelphia: Carey \& Lea, 1830), Vol. 1, 212. has a description.
} 
some way at the foundry, it was quite a different matter to try sell the lights to potential customers. They needed to know how bright gaslights were and therefore how many candles a gas flame could replace. To determine the luminosity of gaslights was a difficult task to accomplish satisfactorily, and it was revisited many times in following years, together with the associated economic and scaling calculations. The technology was not, however, to be as economical as Boulton \& Watt hoped it would be, despite their many attempts to show that it was. They were to spend a good deal of money on development before they finally reached the conclusion that were not interested in pursuing it further. For the moment, however, the financial calculations depended on comparing gaslight with oil and tallow, but calculating the luminosity of a flame was no easy matter. No one had as yet discovered an easy way to do it directly, but Count Rumford had suggested that a comparison of shadows cast was an effective proxy for the flames' brightness and Boulton \& Watt used this method, as did most others in the

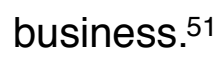

The experiments during most of 1805 had as their goal to come to some determination of the economic question based ultimately on the luminosity of a gas flame. In early March of 1805 , Boulton \& Watt tried to determine what the equivalent of one cubic foot of coal-gas was in terms of pounds of tallow, the most common mode of lighting used by the mills that were their customers. They concluded that $1 \mathrm{lb}$ of tallow

\footnotetext{
51 Frederick Christian Accum, A practical treatise on gas-light; exhibiting a summary description of the apparatus and machinery best calculated for illuminating streets, houses, and manufactories, with carburetted hydrogen, or coal-gas; with remarks on the utility, safety, and general nature of this new branch of civil economy (London: Printed by G. Hayden for R. Ackermann [etc.], 1815), 26. for a description of the method. See also Matthews, An historical sketch of the origin, progress, \& present state of gas-lighting, $86 \mathrm{ff}$.
} 
was equivalent to 17 cubic feet of gas. ${ }^{52}$ Tallow candles came in various sizes, usually given as being a certain number to the pound, typically 6,8 or 12 . Since $1 \mathrm{lb}$ of a tallow candle of 8 to the $\mathrm{lb}$ lasted for 31 hours, $17 \mathrm{ft}^{3}$ of gas would be needed to replace it. These experiments showed that $4 \mathrm{lb} 10 \mathrm{oz}$ of Wednesbury coal could produce that much gas, meaning $129 \mathrm{lb}$ of coal was equal to $28 \mathrm{lb}$ of tallow. ${ }^{53}$ The experiments broke off at this point, but they were revived after external factors and people, notably George Lee, intervened to restart them with greater urgency.

\subsection{Philips \& Lee and the first wave of commercial interest}

The period from mid 1805 to late 1806 marked the first time Boulton \& Watt turned outward and installed a full scale gas apparatus at a paying customer's mill. Up until now, the development work was mostly at Soho, but in 1805 , spurred on the emergence of possible competitors, they solicited orders, and built and installed their first apparatus at Philips \& Lee's textile mill in Salford near Manchester. The success of the first installation combined with Lee's enthusiasm for the technology produced interest and a series of orders from other industrial mill owners. Boulton \& Watt did not, however, feel that the technology was mature enough to build more quite yet, and so despite the many orders, no further apparatuses were built while analysis and development work on Philips \& Lee's installation continued during 1806. Boulton \& Watt were intent on filling their new orders, and even surveyed many mills, but by the end of 1806 , they were

\footnotetext{
52 1808/01/28, BWA MS 3147/3/479 \#12, AM-IR series 1 part 14 reel 273.

53 James Watt jr notebook 1805/07/13-15, BWA MS 3147/4/5 p. 55.
} 
distracted by other matters and stopped most work on gaslight until late 1807 . This section tells the story of this first wave of external work from mid 1805 to late 1806.

\subsubsection{The first installation at Philips \& Lee 1805}

George August Lee (1761-1826) was an important figure in the development of gaslight. He was the son of a theatre manager and actor, John Lee and his actress wife. He was well educated, and became particularly interested in commerce and the textile trade. He worked as the manager of the Salford Twist Mill from 1792 onwards, eventually becoming a partner in the concern, which, by 1807 , was known as Philips \& Lee. The Salford Mill was one of the largest in Manchester and was described in Murdock's 1808 Royal Society paper as possibly the largest in the country. It was a equally a travel destination for industrialists seeking inspiration and the curious looking for a landmark. Lee was always interested in improving the mill, including through the introduction of new technologies. He introduced fire resistant cast iron frames for his machines, as well as steam power and heating at the mill. ${ }^{54}$ Lee knew the elder and the younger James Watt and had been a customer of Boulton \& Watt's from the late 1790s. He had visited Soho on a number of occasions and would have seen the gaslight experiments going on there. His natural affinity for improvement and technological novelty undoubtedly drew him to thinking about using gaslight at the Salford Mill. He was seriously considering installing a gas apparatus is 1803 , and although he even sent a letter to Boulton \& Watt that year urging action, nothing seems to have come from

\footnotetext{
54 J. J. Mason, “Lee, George Augustus (1761-1826)," in Oxford Dictionary of National Biography, ed. H. C. G. Matthew and Brian Harrison (Oxford: Oxford University Press, 2004).
} 
this. ${ }^{55}$ In early 1805 he was again considering gas lighting and became convinced of the technology's viability. After a visit on the part of Murdock to Manchester where they discussed the subject, Lee was resolved. On March 27, 1805, he wrote Watt junior to encourage him to develop it into a saleable product and effectively ordered one for his mill:

I have intended every day since W. Murdocks Departure to write you upon the subject of the new Mode of lighting by inflammable gas. Is it not an object of attention for you to undertake to prepare the Retorts, Air-holders Pipes \& other Apparatus with Directions + Drawings for erecting them, which could afford you a profit + him a Recompense for the Invention? I am convinced it [will] be as generally introduced as your Engines here + that you will have the same pre-eminence + preference. In case you think it eligible to undertake it you will please to prepare the requisite apparatus for our Mills as early as possible. Other Modes might be devised of obtaining some Recompense for W. Murdocks but none so [elegant?] + reputable..$^{56}$

This letter set in the motion a new series of experiments and development work. Another experimental retort was design and cast in April of 1805,57 probably on the vertical model of 1802, but now on a much larger scale.

The importance of moving ahead in the near future was becoming increasingly evident as more and more engineers and inventors were also trying out the new mode of lighting and making it better known. Hints that others were working on gaslight had reached the firm by the end of 1804 , but in 1805 , it became a constant stream that

\footnotetext{
55 Philips \& Lee to B+W 1803/07/19, BWA MS 3147/5/804

56 George Augustus Lee to James Watt jr 1805/03/27 BWA MIV /L6, AM-IR series 1 part 8 reel 120.

57 BWA MS 3147/3/479 \#1AM-IR series 1 part 14 reel 273.
} 
created real pressure to commercialize it quickly or potentially risk losing any head start they had. Winsor had by now been on a very aggressive campaign for almost a year, and although he was based in London, he sent flyers all over the country, even to Boulton \& Watt, being in ignorance of their plans. ${ }^{58}$ Another Birmingham manufacturer, Josiah Pemberton, who may have been present the 1802 demonstrations, also had started to experiment with gaslight apparatus himself. ${ }^{59}$ Pemberton was a parts supplier to Boulton \& Watt, including for gaslight apparatus, and he learned about gaslight by making parts for apparatus sold by Boulton \& Watt.60 He was not, however, a threat since the apparatus he eventually produced was very small.61

In addition to the many advertisements Winsor had placed in London newspapers, there had been an exchange in the Monthly Magazine over gaslight. The periodical published a letter dated March 8, 1805 from John Northern of Leeds describing his own laboratory scale experiments. The descriptions provided in his letter make clear that he was using the standard laboratory apparatus of chemist, like many others before him, to produce gas in a small retort, which he then washed and stored with a pneumatic trough. He ended by stating that 'I have the great hope that some active mechanic or

\footnotetext{
58 BWA MS 3147/3/539 \#38, AM-IR series 1 part 15 reel 285.

59 Matthews, An historical sketch of the origin, progress, \& present state of gas-lighting, 40-42.

60 See, for example, Drawings for moveable water traps 1808/10/11, BWA MS 3147/5/817/4, AM-IR series 1 part 11 reel 184, which were sent to Pemberton for manufacturing. See also John Murdock to James Watt jr 1811/12/09, BWA MS 3147/3/288 \#4, AM-IR series 1 part 13 reel 221. Pemberton sold components to the GLCC. See 1812/12/4 GLCC Minutes of the Court of Directors, Book 1, p. 51.

61 Benjamin Cook, "On the advantages of employing coal gas for lighting small manufactories and other purposes," A Journal of natural philosophy, chemistry and the arts 21 (1808). Cook, "Second letter on the advantages of coal gas for lights," A Journal of natural philosophy, chemistry and the arts 22 (1809). Matthews, An historical sketch of the origin, progress, \& present state of gas-lighting, 43.
} 
chemist will, in the end, hit on a plan to produce light for large factories'. ${ }^{62}$ William Henry, who had visited Soho and was in the thick of a series of experiments to determine the composition of coal-gas, replied with a letter of his own on April 13, 1805 to assert Murdock's and Boulton \& Watt's priority claim. ${ }^{63}$ The following month's edition saw another letter, this one written on May 9th 1805 by G. J. Wright who described both Winsor's public demonstrations at the Lyceum theatre in London, as well as trotting out Lord Dundonald again. ${ }^{64}$ These sorts of priority claims were on one hand, of no consequence legally speaking as no patent was taken out and successfully enforced in gaslight technologies in the early years, and on the other, they were a constantly revisited topic as Boulton \& Watt's competition with Winsor and company took on epic proportions in the coming five years.

Other examples of gaslight cropped up from still closer quarters. Peter Ewart (1767-1842), another Manchester cotton spinner and former engineer of Boulton \& Watt's who still acted informally as their agent, wrote to Watt junior in June 1805 about a local shop that had already started using gaslight, albeit on a very small scale:

There is a reputable Ironmonger here (firm of Hutchinson \& [Nallatun?]) who have fitted up 5 or 6 lights in their shop with gas from coal. I asked them the other day what their intentions respecting it were. They said they had been much pressed by their friends to make the experiment, but they were sensible of Mr Murdocks merit in the discovery, and they were unwilling to go any farther without making some arrangement with Messr. B \&

62 J. Northern, "Experiments on Pit Coal," The Monthly magazine, or, British register 19, no. 127 (1805). 63 William Henry, "Response to Mr. Northern," The Monthly magazine, or, British register 19, no. 128 (1805).

${ }^{64}$ G. J. Wright, "Response to Mr. Northern and Mr. Henry," The Monthly magazine, or, British register 19 (1805). 
Watt. That Mr Lee had spoken to them upon the subject and that they expected some of your folks here soon. ${ }^{65}$

As more and more cases of gaslight came to their attention, Murdock became quite worried 'from having learnt that the new light is here [Glasgow] a subject of general enquiry + admiration, but that a competitor has started up to supply the public demand'. 66 The excitement and interest surrounding gaslight was such that by late 1805 when Watt junior visited Glasgow, he wrote back to Boulton:

The new lights are much in vogue here; many have attempted them, and some have succeeded tolerably in lighting their shops with them. I also hear that a cotton-mill in this neighbourhood is lighted up with gas. A long account of the new lights was published in the newspapers some time ago, in which they had the candour to ascribe the invention to Mr. Murdock. From what I have heard respecting these attempts, I think there is full room for the Soho improvements, though, when once they see one properly executed, it will have numerous imitations. ${ }^{67}$

One of these Glasgow gas pioneers soon came to ruin when his store burned down: 'I hear that poor Lumsden the bookseller who exhibited the new lights at Glasgow, has had the misfortune to set his shop on fire by the furnace in which he

\footnotetext{
65 Ewart to James Watt jr 1805/06/01, BWA MIV /E2, AM-IR series 1 part 8 reel 118.

66 James Watt jr to Matthew Robinson Boulton 1805/08/17, BWA MS 3147/3/54 \#5, AM-IR series 1 part 12 reel 206. See also "Einige Nachrichten aus England über Erleuchtung im Grossen mit Thermolampen," Annalen der Physik 30, no. 12 (1808)., p. 407 sates: 'Als ich im Sommer 1805 in Glasgow war, sollte ein Laden daselbst mit Gas erleuchtet werden; die ganze Stadt sprach davon', citing Nemnich, Neuester Reise durch England, Schottland und Irland, Tübingen, 1807 p. 127.

67 James Watt jr to Matthew Robinson Boulton, 1805/11/12, cited in Griffiths, The Third Man: the Life and Times of William Murdoch, 1754-1839, the Inventor of Gas Lighting, 268. The original letter is not known, but it was first cited in J. P. Muirhead, The Origins and Progress of the Mechanical Inventions of James Watt (1854), p. 303, and by Samuel Smiles after that.
} 
prepared it in his back shop. It is said he will be a great loser not being fully insured.' 68 The other shops using gas in Glasgow as well as in Edinburgh persisted only for a year or two before the heat, the smell and the constant maintenance forced most of them to abandon gaslight, demonstrating that the problems associated with scale were not easily solved.69 It took a good deal of development money and skill to achieve even the qualified success that Boulton \& Watt attained.

Although the pressure for development from competition was building from early 1805, the economic case has not yet been settled by anyone, and due to the difficulty in getting consistent experimental results, it would be some time yet before it was settled. In fact, it was not really until the Gas Light and Coke Company and other gas utilities had been functioning for a number of years and that enormous sums had been spent that the technology paid off and the matter settled. The willingness of so many different people to risk so much money for the new technology without any demonstration of economic viability is a remarkable testament to the faith in technology that existed among a good segment of the population with money to invest.

Boulton \& Watt's next experiments after the March 1805 ones took up where the former left off: determining how much light could be produced from gas, and how much coal was needed if the gaslight was to be used on a large scale. For this set of experiments, different sorts of coals were tried, especially Cannel coal of various sorts

\footnotetext{
68 James Watt to James Watt jr 1805/11/27, BWA MIV Box 16/14, AM-IR series 1 part 8 reel 135.

69 John Sinclair, Appendix to the General report of the agricultural state and political circumstances of Scotland (Edinburgh : Sold by A. Constable, (Edinburgh : D. Willison), 1814), 305. Malcolm E. Falkus, "The Early Development of the British Gas Industry, 1790-1815," The Economic History Review 35, no. 2 (1982): 230.
} 
on the recommendation of William Henry and through the encouragement of Lee. ${ }^{70}$ Cannel coal was a variety found in various parts Lancashire, which burned brightly and left relatively little ash. It was so dubbed because in the local accent 'candle' was pronounced as 'cannel'.

Using what was described as an 'old' retort of fair proportions $-7 \mathrm{ft}$ in length with $2 \mathrm{ft}$ diameter - that could hold $8 \mathrm{cwt}(112 \mathrm{lb} / \mathrm{cwt}$ or hundredweight) of coal, they conducted a test that last for three days. Beginning on July 13,1805 , they heated the coal until July 15 when it had become exhausted. More than one account of the experiment exists, but the coal produced approximately $2995 \mathrm{ft}^{3}$ of gas, or $375 \mathrm{ft}^{3} / \mathrm{cwt}$. This large scale experiment revealed, however, that not all the gas was adequate for lighting. Priestley, Minckelers and others had already noted that the gas given off by distilled coal varied according the heat to which the retort had been raised and the length of time from the start of the experiment, and Boulton \& Watt were no doubt aware of this as they did their experiments on the laboratory scale. Now, however, they were forced to confront it on a large scale and its resulting usability and economic consequences. The later portion of gas was discounted and the yield reduced to $360 \mathrm{ft}^{3}$ of good gas per cwt, coming at a rate of $160 \mathrm{ft}^{3}$ per hour. Combining this figure with the experiments of March 5, 1805, they determined that $1 \mathrm{cwt}$ of coal was equivalent to 21 $\mathrm{lb}$ of tallow, a lower figure than the $24.3 \mathrm{lb}$ of tallow the smaller experiment of March had given. ${ }^{71}$ It was still a hopeful result, as a single tallow candle of 6 to the $\mathrm{lb}$, equivalent to less than a cubic foot of gas, could last for 8 hours, meaning $1 \mathrm{cwt}$ of coal could provide

\footnotetext{
70 Eidingtoun Hutton to B+W 1805/07/01, BWA MS 3147/3/263 \#7, AM-IR series 1 part 12 reel 215.

71 The experiments are described in 1805/07/13-15 James Watt jr notebook, BWA MS 3147/4/5 p. 54-55 and 1808/01/28, BWA MS 3147/3/479 \#12, AM-IR series 1 part 14 reel 273.
} 
gas for the equivalent of 126 candles burning for eight hours, enough to light a small mill.

Boutlton \& Watt were by now actively soliciting orders, and stirred up some interest among manufacturers in the Manchester area and in Scotland, although they still did not have enough information to actually size an apparatus properly. In August 1805, a Boulton \& Watt engineer, Eidingtoun Smeaton Hutton wrote from Manchester that either Watt junior or Murdock were needed to close the various orders that were in process but had not yet been been finalized. ${ }^{72}$ Watt junior was in Scotland spreading the word there, and received expressions of interest, including one in Glasgow: 'Mr Dunlop has given me an order for an apparatus for the new light for his Cotton Mill. The particulars of the premises to be taken by Hutton when he comes and to be executed in succession to our present orders + charged similarly'. ${ }^{73}$ One of the first firms to place an order was the cotton spinner Wood, Daintry \& Wood in Macclesfield, which had been created that same year by the merger of two other firms. ${ }^{74}$ Their mill was surveyed in late July 1805 , probably by Hutton. The drawings indicate only the locations of the pipes. ${ }^{75}$ It is probable that this order was never executed because no further drawings or references to the firm can be found, and they are not listed among a summary of gaslight customers made in 1812.

\footnotetext{
72 Eidingtoun Hutton to B+W 1805/08/24, BWA MS 3147/3/263 \#10, AM-IR series 1 part 12 reel 215.

73 James Watt jr to B+W 1805/08/30, BWA MS 3147/3/54 \#7, AM-IR series 1 part 12 reel 206.

74 See Stanley D. Chapman, The early factory masters: the transition to the factory system in the Midlands textile industry (Newton Abbot (Devon): David \& Charles, 1967), 89.

75 Wood Daintry \& Wood 1805/07/28, BWA MS 3147/3/478 \#46 series 1 part 14 reel 273.
} 


$$
\begin{aligned}
& 478 \text { at } 46 \text { का } 18,3 \\
& \text { Manchester } 28 \text { fuly } 1805
\end{aligned}
$$

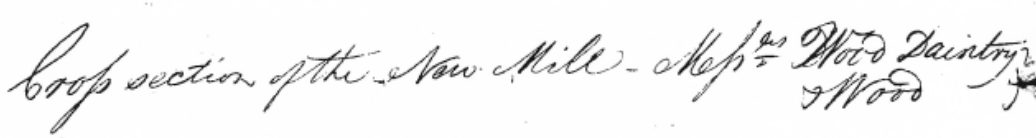

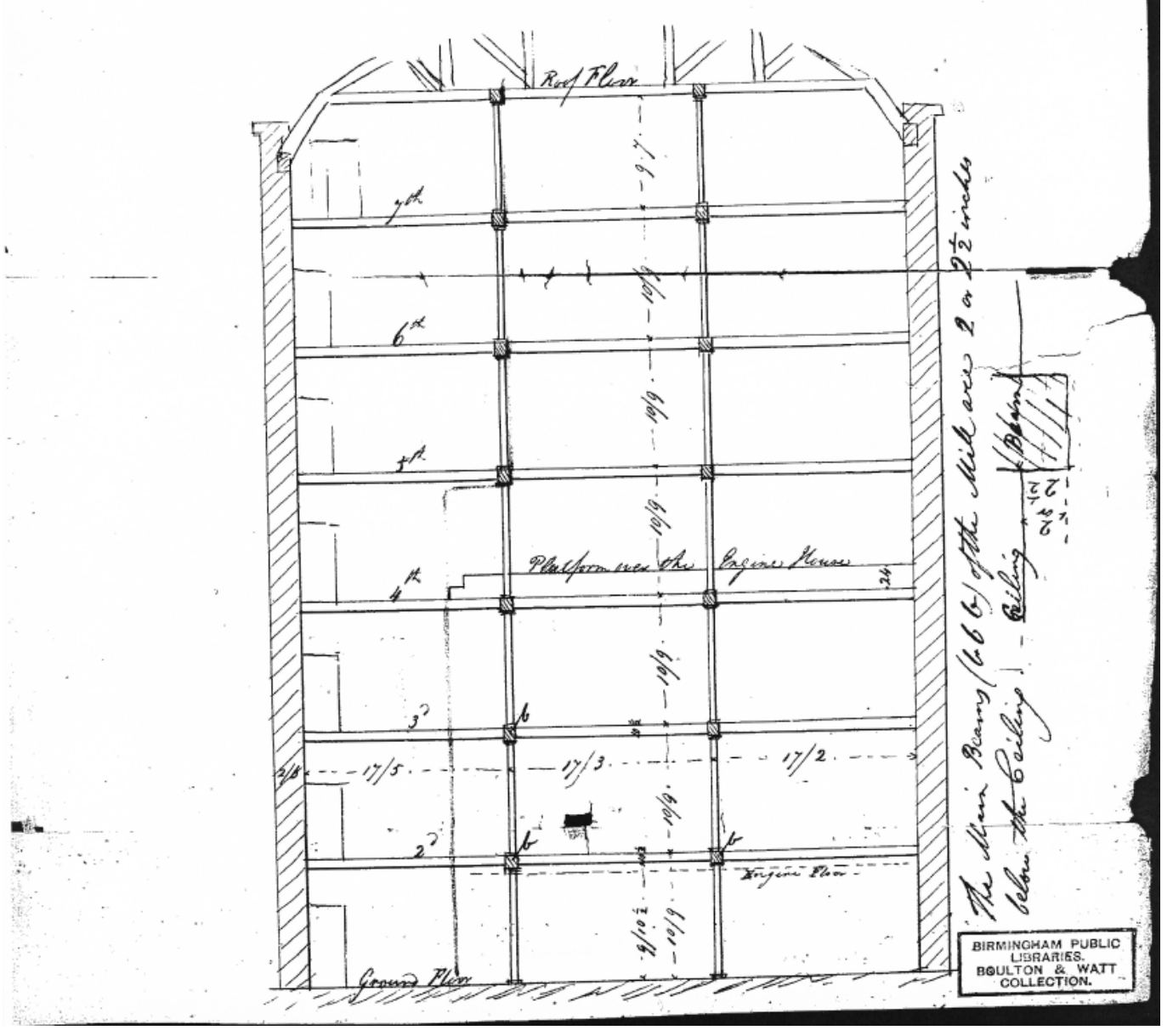

Figure 3.6 Cross section of Wood, Daintry \& Wood's New Mill, from July 1805, showing beams in the building. BWA MS 3147/3/478 \#46, AM-IR series 1 part 14 


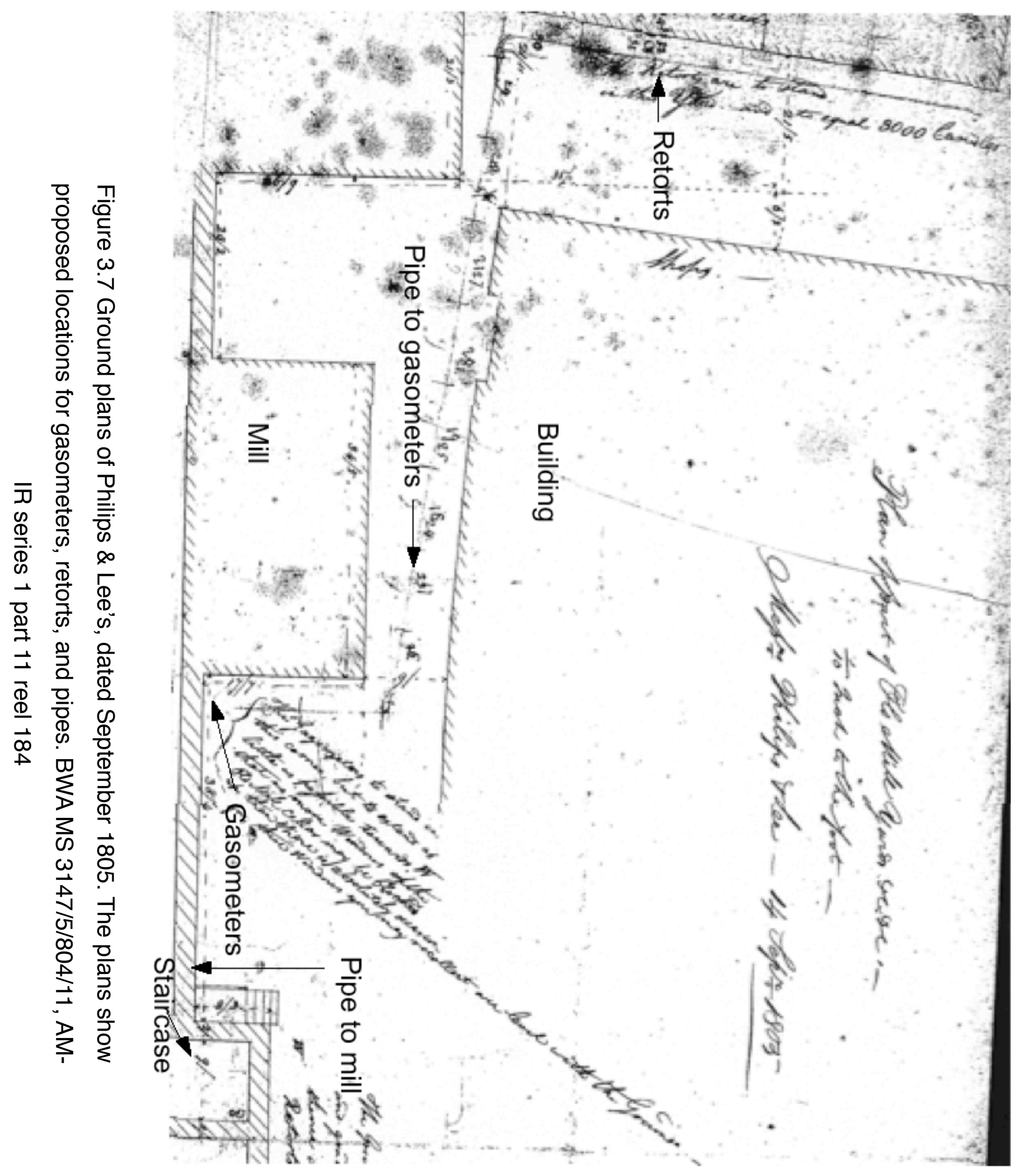


All the while new orders were being collected, the preparations for installing an apparatus at Lee's mill were proceeding apace. Hutton was still working in the Manchester area and was asked in September 1805 to survey the six storey Old Mill76 and lay out plans for the apparatus with a capacity of 3000 candles. ${ }^{77}$ The entire apparatus was to be nestled in among a number of building within Lee's yard, with the retorts set against some old sheds and the gasometers next to the wall of the Old Mill close to an interior staircase, around $100 \mathrm{ft}$ from the retorts. The pipes were to go from the gasometers into the stairwell and up to the many floors the mill had. A further complication, common to all their gaslight installations, was that the gasometers and retorts had to be located at a level below the lowest lamps. All the important constituents of coal-gas - methane, hydrogen, ethylene-were lighter than air, and could not be pumped downhill, except under pressure, which Boulton \& Watt were not prepared to do. The only solution was to locate the apparatus below the burners and allow the gas to rise. All of Boulton \& Watt's installation required gasometer pits to be dug out, which sometimes created water problems as most mills were located next to rivers. It also made accessing the lower part of the gasometer challenging, a serious problem if the pipes leading gas into or out of the gasometer became clogged. Boulton \& Watt had to abandon the idea of having the gas pipes enter the gasometer from underneath for this reason. The solution they came up with, described below, was a complicated mechanism involving moveable pipe joints.

\footnotetext{
76 The floors were called K, Twist, L, M, N and O. Notes 1806/06/28, BWA MS 3147/3/478 \#13 AM-IR series 1 part 14 reel 273.

77 Eidingtoun Hutton to B+W 1805/09/09, BWA MS 3147/3/263 \#12, AM-IR series 1 part 12 reel 215; Eidingtoun Hutton to B+W 1805/09/12, BWA MS 3147/3/263 \#13, AM-IR series 1 part 12 reel 215; Ground plans dated 1805/09/14, BWA MS 3147/5/804/11, AM-IR series 1 part 11 reel 184.
} 
With the Philips \& Lee survey complete, the apparatus had to be scaled and built, but this required more trials. Creighton did another series of experiments and calculations over September 23-27, 1805, much like the ones of July 1805 , to establish some of the figures to be used in this sizing calculation. Starting once again with $12 \mathrm{cwt}$ of Wednesbury coal, Creighton found he could make $330 \mathrm{ft}^{3}$ of gas per cwt, at an average rate of $250 \mathrm{ft}^{3}$ per hour, which 'does not at all coincide with that of 13 th July'. ${ }^{78}$ The difference is actually reconcilable because although the hourly production rates were different ( $160 \mathrm{ft}^{3}$ versus $250 \mathrm{ft}^{3}$ ), the yield per cwt agree fairly well ( $330 \mathrm{ft}^{3}$ to 360 $\mathrm{ft}^{3}$ ), and indeed, Creighton reported this very range in his 1824 Britannica article. The hourly production rate depends a great deal on the heat applied and the retort configuration used, whereas the total yield, if the distillation is continued until the coal is exhausted, is relatively indifferent to these factors. Creighton next calculated how long Lee's candles (6 to the Ib, or 1150 grains each) lasted, and found they burnt from $81 / 3$ hours, or 49 to 50 hours for the whole pound, corresponding to 140 grains per hour. The final step was to find that one of the gas burners to be installed at the mill was equivalent to 4 candles, meaning they would need 750 burners if the 3000 candle estimate was used.

78 1808/01/28, BWA MS 3147/3/479 \#12, AM-IR series 1 part 14 reel 273. 


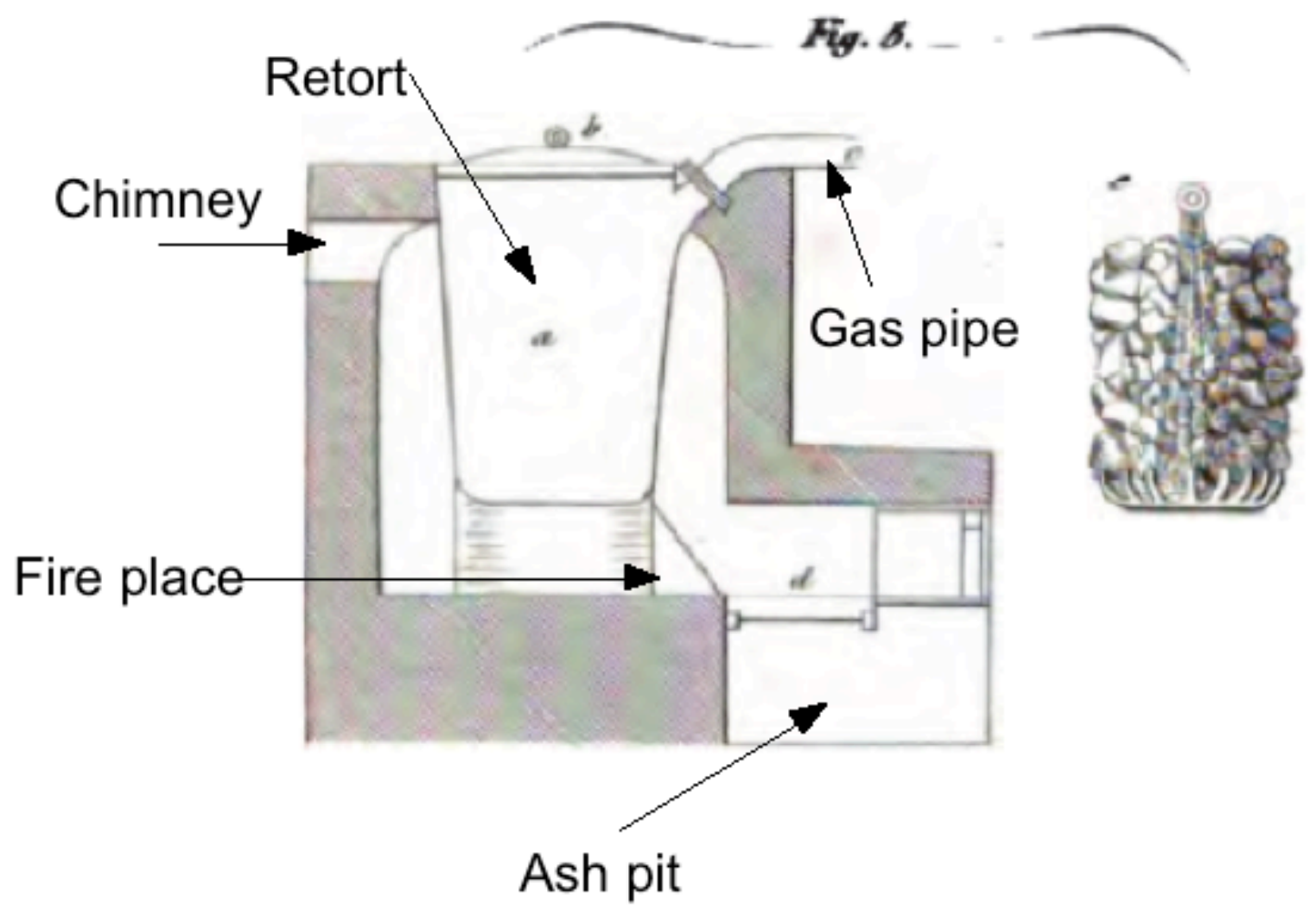

Figure 3.8 Vertical retorts used at Philips \& Lee, from Creighton "Gas-Lights." in the Encyclopaedia Britannica (1824) 


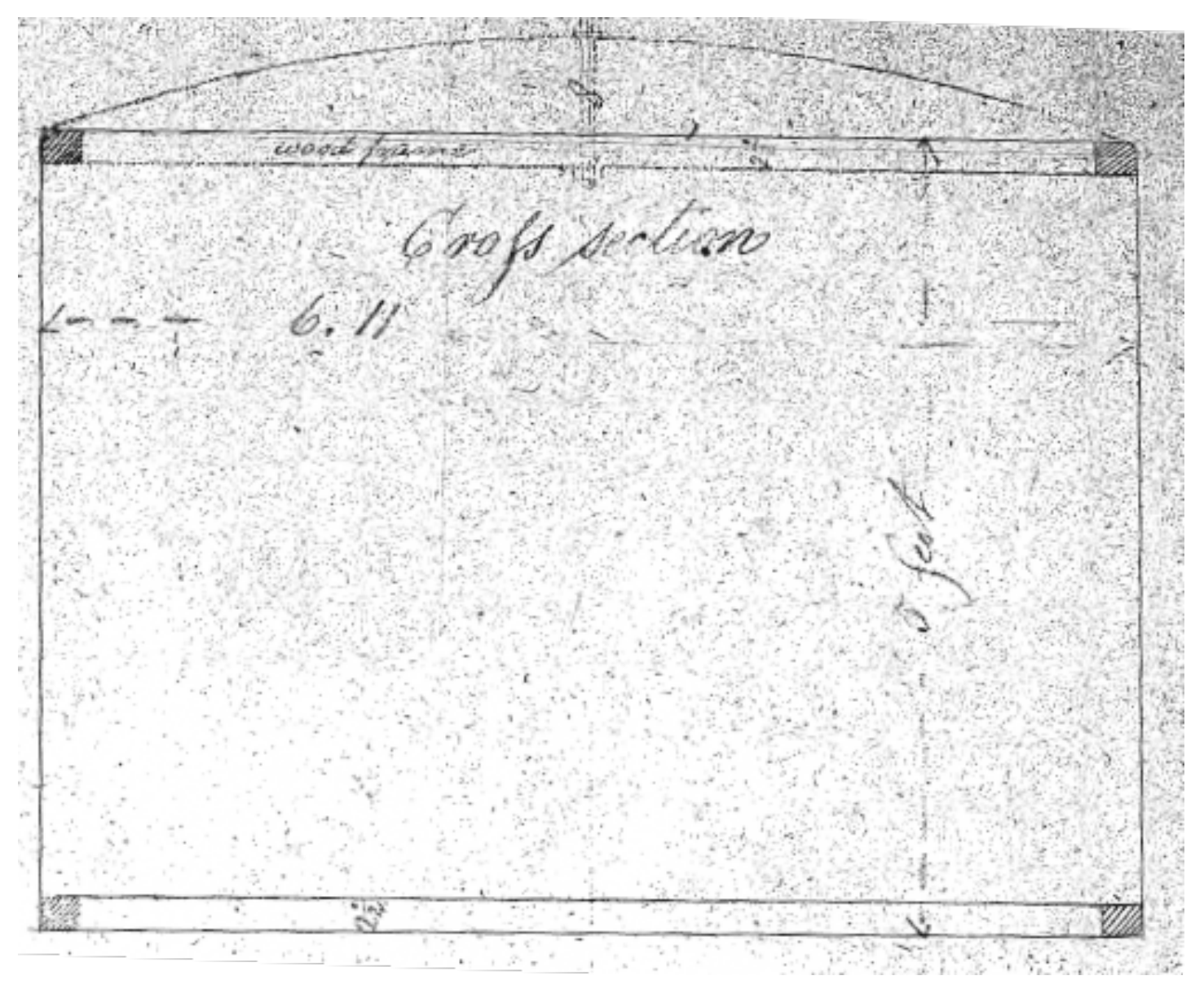

Figure 3.9 Gasometer cross section from March 1806. This is one of the earliest surviving plans for a gasometer. BWA MS 3147/5/821/24, AM-IR series 1 part 11 reel 184

No information survives of how the apparatus was sized based on these calculations, nor how the relative size and number of the retorts and gasometers was determined, but a few hints are available. Some letters as well as engineering drawings of the pipes dated November 3, 1806 exist which incidentally give some dimensions and other specifications. The initial plans called for four gasometers sitting in pits of 
approximately $8.75 \mathrm{ft}$ outer diameter. The actual size of the first gasometer is not exactly stated, but it had an inner diameter $7 \mathrm{ft}$ in diameter and was between 4.5 and 5 $\mathrm{ft}$ deep for a volume of $170-200 \mathrm{ft}^{3} .^{.79}$ There were three retorts of $3.6 \mathrm{ft}$ outer diameter, and about $5 \mathrm{ft}$ high, if Creighton's Britannica diagram represents the correct proportions. ${ }^{80}$ They stood $100 \mathrm{ft}$ from the gasometers with the pipes running between the buildings. Assuming the retort walls were about 6 inches thick, the retorts would have had a capacity of about $25 \mathrm{ft}^{3}$, and could hold $16 \mathrm{cwt}$ of coal, which agrees well with the $15 \mathrm{cwt}$ figure Creighton provides ${ }^{81}$ and figures given later on by Watt junior. ${ }^{82}$ In this case, the recharging problem was addressed with wire baskets, grapplers and a crane. This solution proved cumbersome in the long run because of the expense of the crane as well the grapplers. No purification device is present in the drawings at all.

The manufacturing began soon thereafter, but this was a large order. One retort and gasometer were ready in early December 1805, and Murdock went to Manchester to oversee the assembly of the apparatus personally. When the rest of the apparatus did not arrive promptly, both he and Lee grew impatient and started pushing to have it shipped. They hoped to have it on the site to be able to start lighting by Christmas time:

\footnotetext{
79 James Watt jr to John Southern 1806/03/01, BWA MS 3147/3/60 \#9, AM-IR series 1 part 12 reel 206 gives $7 \mathrm{ft}$ as the diameter, as does James Watt jr notebook 1806/03, BWA MS 3147/4/5 p. 54 and 52. Southern to James Watt jr 1806/03/09, BWA MS 3147/3/479 \#1 AM-IR series 1 part 14 reel 273 gives the surface area as $140 \mathrm{ft}^{2}$ which corresponds to a height of $5.25 \mathrm{ft}$. In another places the first gasometer is listed with a $7 \mathrm{ft}$ diameter and $4.5 \mathrm{ft}$ depth. See Memo 1806/03, BWA MS 3147/3/479 \#4 AM-IR series 1 part 14 reel 273.

80 Corroborated by Soho foundry order book, order for Philips \& Lee 1805/10/27 BWA MS 3147/4/115 81 Creighton, "Gas-Lights," 449.

82 James Watt jr to John Southern 1806/03/01, BWA MS 3147/3/60 \#9, AM-IR series 1 part 12 reel 206.
} 
I was informed by Mr Greeve 2 or 3 days ago that the second receiver was not shipped; if it is not yet sent off Please to send it that way you think quickest \& safest as I am resolved not to light with less than 2 and I have got but one retort. Mr Lee enters into the spirit of the project and wishes much to have it lighted before Christmas but I think it impossible however we may get it accomplished by New Years day if we get not hindrance from the Foundry. ${ }^{83}$

Murdock's anxiety was increased by his discovery that Samuel Clegg, his former co-worker at Boulton \& Watt who had apprenticed just as he was developing gaslight, was well advanced in his own operations at another mill. He wrote plaintively back to headquarters that: 'none of Mr Lees lighting apparatus is yet arrived. [...] It is of no use to thinking of taking orders here for your old servant Clegg is manufacturing them in a more speedy manner than it appears can be done at Soho.' 84 Clegg bested his former employers by a couple of weeks, at least according to his son, when he managed to start the lighting of Henry Lodge's mill in Halifax, about 50 km north-east of Manchester. ${ }^{85}$ The components that had arrived were installed, and despite Murdock's initial resolution not to do, he began using it without a second gasometer or another retort, so that on New Year's Day 1806, he was able to write back to Boulton \& Watt that:

We were obliged to set to work with the light without the second receiver as Mr Lee was very anxious to determine which of the burners should become general an order for them

\footnotetext{
83 Murdock to B+W 1805/12/20, BWA MS 3147/3/289 \#16, AM-IR series 1 part 13 reel 221.

${ }^{84}$ Murdock to B+W 1805/12/23, BWA MS 3147/3/289 \#17, AM-IR series 1 part 13 reel 221.

85 Clegg, A practical treatise on the manufacture and distribution of coal-gas, 13. "Materials for a memoir of Mr. Samuel Clegg, and Authentic History of the Art of Gas-Lighting," Mechanics' magazine and journal of science, arts, and manufactures 22, no. 607 (1835).
} 
and many other material will be forwarded by next [post?] [...] We have lighted 50 lamps of the different kinds this night which have given the greatest satisfaction to $\mathrm{Mr}$ Lee + the spinners. There is no Soho stink has yet offended them. Mrs and Misses Lees have visited it this night + their delicate noses have not been offended. ${ }^{86}$

Although Philips \& Lee were not the only firm to place orders before 1806, they were by far the largest and the focus of Boulton \& Watt's efforts and would serve as display and research prototype before other sale were confirmed. In fact, no other firm received any apparatus before 1808 . In addition to Greg \& Ewart and Daintry \& Wood mentioned above, the other firms with interest in gaslight in 1805 were Radcliffe \& Ross of Stockport, who inquired in early November with Hutton. Hutton was not able to provide much information and referred the matter to Murdock. ${ }^{87}$ Hutton then went to Scotland in December 1805 and received a strong expression of interest from John Grieve in Edinburgh. Grieve wanted his apparatus within three months, but it would take some time more before Boulton \& Watt were able to give him their attention. Messrs. G. Dunlop \& Co. of Glasgow had also expressed interest, but like Grieve and everyone else, had to wait. 88

\subsubsection{A flurry of new sales 1806}

The torrid pace of work took its toll on Murdock who had a tendency to overwork, and he fell ill not long after his new year's letter was sent, recovering after a week or

\footnotetext{
86 Murdock to B+W 1806/01/01, BWA MS 3147/3/289 \#18, AM-IR series 1 part 13 reel 221.

87 Eidingtoun Hutton to B+W 1805/11/03, MS 3147/3/263 \#19, AM-IR series 1 part 12 reel 215.

88 Eidingtoun Hutton to B+W 1805/12/05, BWA MS 3147/3/263 \#26, AM-IR series 1 part 12 reel 215.
} 
so. ${ }^{89}$ Robinson Boulton, Watt junior's co-heir to the firm, travelled to Manchester to survey the situation and spend time with Lee. Lee was ebullient and wanted to show off his new technological wonder to his manufacturing friends. He was to play an important role is securing most of Boulton \& Watt's orders for gaslight apparatus. Although Ewart and others had expressed interest in gaslight in 1805, ${ }^{90}$ Lee's ostentatious nature helped many more potential customers see the lights in operation. In fact, Lee's enthusiasm for the technology was deeper than even Boulton \& Watt's, and he continued to press them on the technology long after they had lost interest in it themselves after 1810.

Lee's personal enthusiasm for gaslight from the beginning was also domestic, and his house was as much part of the gaslight trial as his factory. His very first tests in 1804 had been with lighting his house. ${ }^{91}$ Now with the permanent apparatus just running, he had installed some of the first lamps in his own house, and he organized a series of showings for the elite of Manchester and his industrialist friends, which Boulton described to Watt junior: 'Lee + [Co?] are entertaining all the cognoscenti of Manchester with the wonders of the new lights which is displayed in the mansion as well as the factory. ${ }^{\prime 2}$ Lee had had pipes laid under the street to his house $300 \mathrm{ft}$ from the factory.

\footnotetext{
89 James Watt jr to Matthew Robinson Boulton 1806/01/11, BWA MS 3147/3/55 \#1, AM-IR series 1 part 12 reel 206;

Henry Creighton to B+W 1806/01/13, BWA MS 3147/3/247 \#6, AM-IR series 1 part 12 reel 212.

Matthew Robinson Boulton to James Watt jr 1806/01/14, BWA MS 3147/3/42 \#16, AM-IR series 1 part 12 reel 203.

90 Eidingtoun Hutton to B+W 1805/11/03, BWA MS 3147/3/263 \#19, AM-IR series 1 part 12 reel 215.

91 Lee testimony on May 12, 1809 Hall, "Select Committee on Gas-Light," 38.

92 Matthew Robinson Boulton to James Watt jr 1806/01/14, BWA MS 3147/3/42 \#16, AM-IR series 1 part 12 reel 203.
} 
The lighting in his house would be a constant feature over the years, and Lee would tinker with it regularly. ${ }^{93}$ In 1808 he added street lamps. ${ }^{94}$ When he moved to a house two miles from the mills, the gas could no longer be piped in, and William Henry described Lee's new arrangements in this regard:

A small carriage upon springs conveys two square close gazometers made of wrought iron plates, and each containing 50 cubic feet of perfectly purified pas, equivalent together to about $6 \mathrm{lb}$. of tallow. Each gazometer weighs about 160 pounds ; and has a valve at the bottom, which is opened by the upright main pipe, the moment the gazometer is immersed in the pit. The strength of one man is found to be sufficient for the labour of removing the gazometer from the carriage to its place. ${ }^{95}$

93 Henry Creighton to B+W 1806/11/08, BWA MS 3147/3/247 \#31, AM-IR series 1 part 12 reel 212.

94 Lee testimony on May 12, 1809 Hall, "Select Committee on Gas-Light," 42-3.

95 William Henry, "Experiments on the Gas from Coal, Chiefly with a View to its Practical Application," Memoirs of the Literary and Philosophical Society of Manchester 2nd series, 3 (1819): 418. 


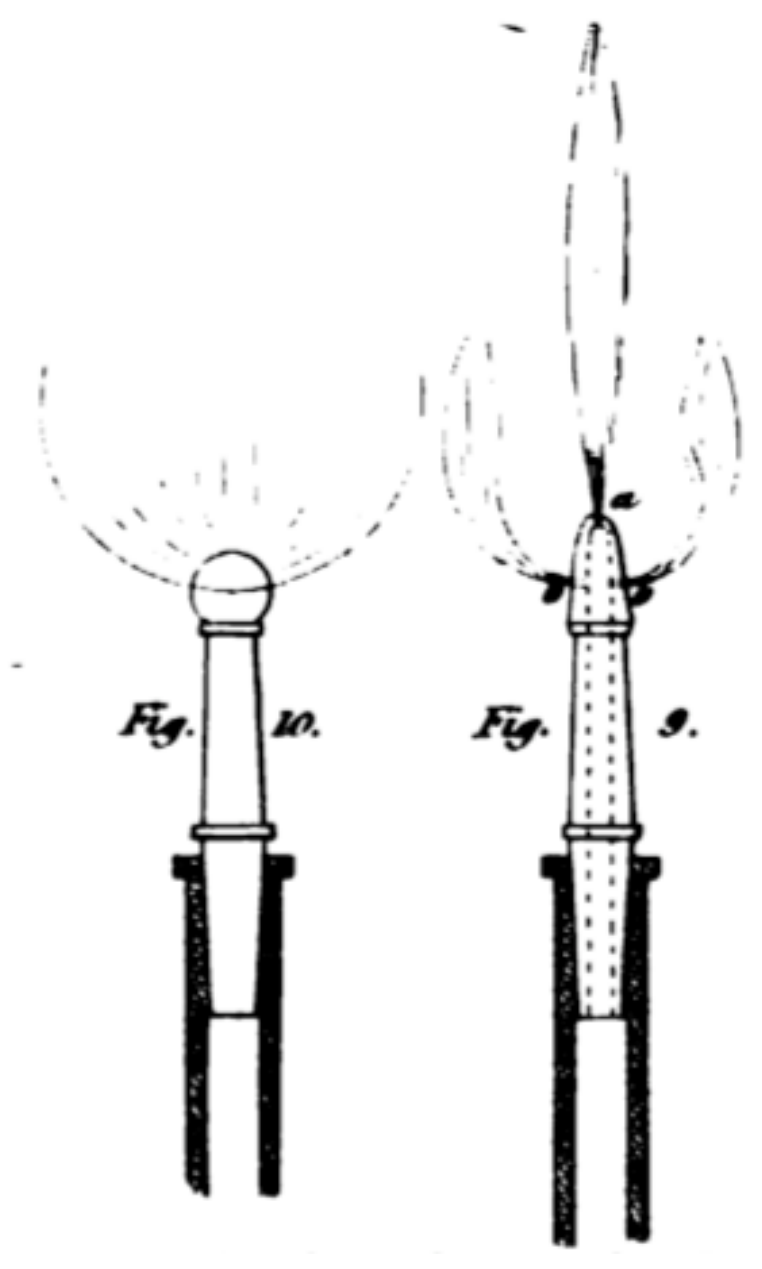

Figure 3.10 Cockspur burners from Creighton "Gas-Lights"

Work continued to bring the installation up to the planned for 3000 or so candle equivalents. The second gasometer arrived, followed shortly thereafter by a second retort, ${ }^{96}$ and Lee ordered a further 60 cockspur lamps. ${ }^{97}$ The lights were being installed

96 James Watt jr to Southern 1806/03/01, BWA MS 3147/3/60 \#9, AM-IR series 1 part 12 reel 206.

97 Murdock to B+W 1806/02/05, BWA MS 3147/3/289 \#19, AM-IR series 1 part 13 reel 221. 
in two rooms in the Old Mill (probably the first two floors) and were almost complete when, in early February 1806 Murdock thought that Lee's effusive talk and demonstrations were creating a real opportunity, and that one of the partners were needed on site to capitalize on it and close the sales: 'It appears a great deal may be done in the lighting way here which will require the assistance of one of you'.98 Watt junior, who was more of the promoter of the gaslight project than Boulton, was soon on his way to Manchester and arrived by the 11 th.

Once on site, Lee and Watt junior arranged for a grand meeting of potential customers to take place on the night of Tuesday, February 18, 1806. Watt junior described the preparations to Boulton:

There is to be a grand meeting of the Illuminandi at Lee's tonight, to see the wonders in his house and to have this general distribution of the apparatus explained to them, but whether the whole, or any of them are to be admitted into the mill, seems not yet determined. I had a glimpse of it last night; one room with the cock[spur] burners all lighted was nearly free from smell; the other room, in which part of the people had left works and perhaps had not turned their cocks very accurately was somewhat unsavoury. The parties have however seem to make nothing of it and I suppose there will be several orders. ${ }^{99}$

The big night proved to be a success, with two major order placed on the spot. Most of the people present at the event became Boulton \& Watt's customers for gaslight apparatus:

\footnotetext{
98 Murdock to B+W 1806/02/07, BWA MS 3147/3/289 \#20, AM-IR series 1 part 13 reel 221.

99 James Watt jr to Matthew Robinson Boulton 1806/02/18, BWA MS 3147/3/55 \#2, AM-IR series 1 part 12 reel 206.
} 
The exhibition upon Tuesday night was completely successfful. Messr McConnel + Kennedy, Mr Jas. Kennedy, Mr George Murray, + Mr Wilkinson of the Chorlton Twist Co. were abundantly gratified. The former has given a positive order for a photogenous apparatus, and the others seem all determined to have it. Peter Marsland has also given an order for the whole of his mills which will take some miles of small pipe and some half dozen retorts + gazometers. Radcliffe + Ross seem also strongly inclined, as indeed seems to be the case with numbers of others. H. Creighton will have full employment for sometime in preparing plans of the mills to show the situation of the retorts + the disposition of the pipes. ${ }^{100}$

The expressions of interest became confirmed orders within days, and Watt junior wrote to Boulton five days later with five more firm orders. ${ }^{101}$ With this volume of orders coming at a single stroke, Watt junior surmised the works at Soho would have to be rethought to handle the expansion: 'As soon as I can get a little leisure I shall write what occurs respecting the arrangements which it may be necessary to adopt at the foundry + Soho for meeting these orders'. ${ }^{102}$ Murdock was sent back to Soho to begin making preparations to manufacture this flood of orders, but Watt junior wanted him back with him as soon as possible to consolidate further possible orders in Leeds and Derby. The hectic pace and sustained salesmanship was not to Watt junior's liking, but he thought he had to do it to seize the opportunity before it slipped from their grasp: 'It is very

\footnotetext{
100 James Watt jr to Matthew Robinson Boulton 1806/02/21, BWA MS 3147/3/55 \#3, AM-IR series 1 part 12 reel 206.

101 James Watt jr to Matthew Robinson Boulton 1806/02/26, BWA MS 3147/3/55 \#4, AM-IR series 1 part 12 reel 206;

Greg \& Ewart, Radcliffe \& Ross, James Kennedy, A \& G Murray, Atkinson.

102. James Watt jr to Matthew Robinson Boulton 1806/02/26, BWA MS 3147/3/55 \#4, AM-IR series 1 part 12 reel 206.
} 
evident that whatever is to be done, must be done now, as the whole tribe of Engineers, founders, braziers $+\mathrm{C}$ will become our competitors as soon as they know how'.103

In a filial letter to his father written the next day, where he explained the progress of his affairs, he observed that 'the Photogenous business ... goes on very prosperously most of the large mills having given their orders, to which however for the most part, I have been obliged to eat my way; a mode of solicitation which is not very congenial either to my habits or obligations. ${ }^{1} 104$ Watt senior responded briefly the very next day in encouraging tones, but, as usual, he was not much enthused about the lighting project: 'I am glad to hear of your success in the new light way. I doubt your circuit will [?] and wish you soon home however business must be looked after.' 105

Murdock arrived at Soho on March 1, 1806 and worked with Southern to make preparations for the new orders. Before heading off to Leeds, Watt junior worked with Lee at Soho doing experiments (described below) to better refine the design of the apparatus. It was then that he received confirmation that Samuel Clegg had indeed set himself up as a competitor and had lit Lodge's mill. Clegg's father had been a customer of Boulton \& Watt's for many years, but had run into some financial difficulties recently with slowing trade, with the result that he had not been able to make timely payments on his accounts. Watt junior reacted to the gaslight news by shutting down the senior Clegg's credit with the firm: 'As I find the report is true that Lodge of Halifax has had a

\footnotetext{
103 James Watt jr to Matthew Robinson Boulton 1806/02/26, BWA MS 3147/3/55 \#4, AM-IR series 1 part 12 reel 206.

104 James Watt jr to James Watt 1806/02/27, BWA MII /13/1, AM-IR series 1 part 6 reel 82.

105 James Watt to James Watt jr 1806/02/28, BWA JWP LB/4 p. 134, AM-IR series 3 part 1 reel 9.
} 
photogenous apps. erected by Clegg, I think it would be but reasonable that the should no longer be a trespasser upon our liberality, and therefore propose that his acct. should be sent in immediately with a letter from Soho urging payment. ${ }^{106}$ It was not long before the older Clegg was having serious financial problems. ${ }^{107}$

Creighton arrived in Manchester at the end of February 1806, and began work preparing many drawings, beginning with McConnel and Kennedy's cotton mill at Manchester, and many others following in short order. ${ }^{108}$ Almost all this work done in 1806 for mills other than Philips \& Lee were preparatory work that had no design component. It was usually only drawing ground plans with some basic estimation of requirements. But even this work was so voluminous that Creighton was overwhelmed, and Watt junior had to call in Hutton from Scotland to help, as well as to learn more

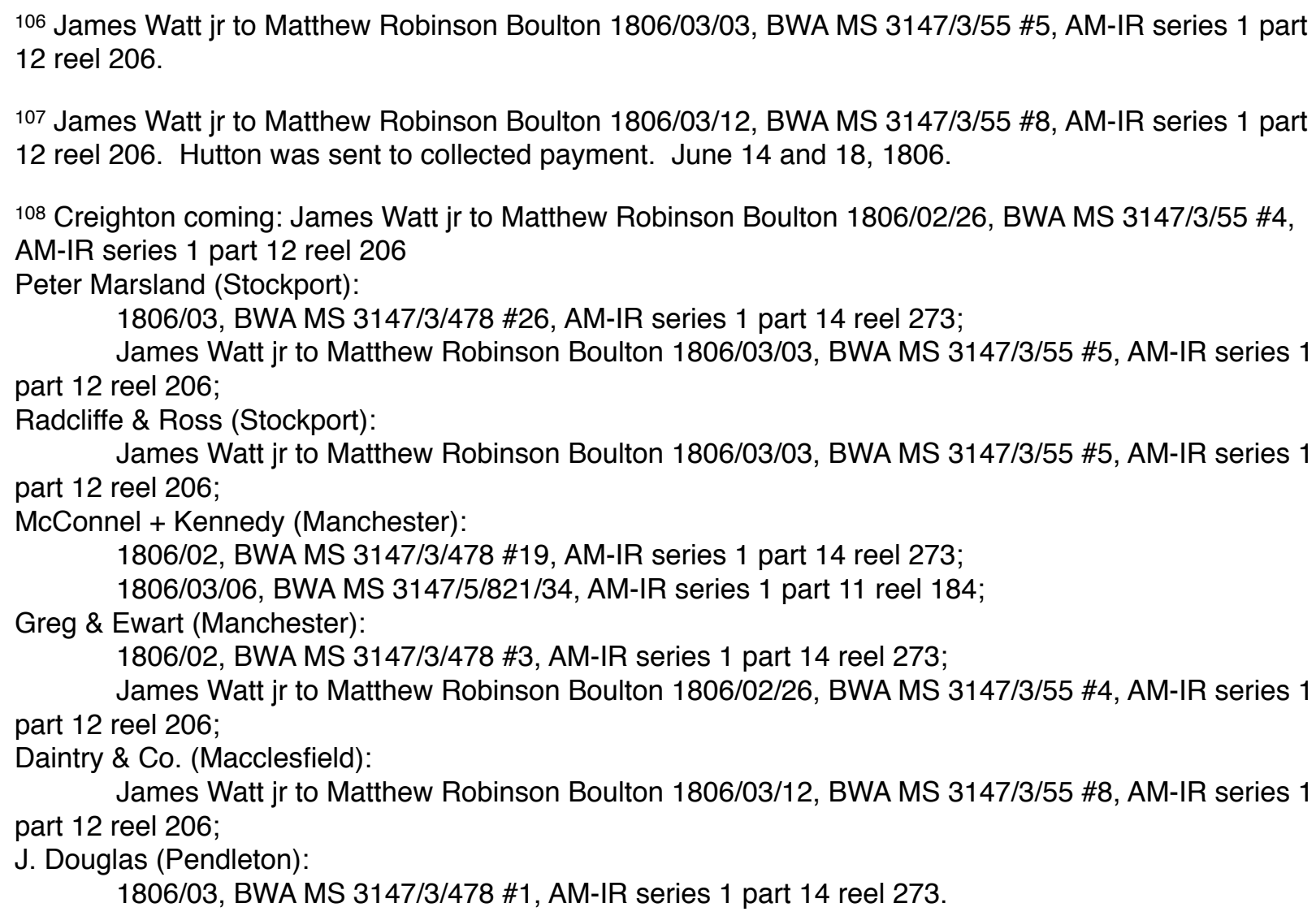


about gaslight so as to be able to do engineering work himself. ${ }^{109}$ Hutton at this point had had no experience with gaslight, although in late 1805 he had relayed expressions of interest from some of the Manchester firms now placing orders, and had even prepared property surveys before he was sent to Scotland by Boulton \& Watt. ${ }^{110}$

In the first two weeks of March 1806 Watt junior continued his sales tour, and confirmed more orders as he travelled around the mills in the vicinity of Manchester at a frenetic pace. ${ }^{111}$ With the large number of orders and consequent preparations to fill them going on at Soho led by Southern and Murdock, Watt junior was enthusiastic, but Boulton, emotionally and physically more distant from Watt's marketing campaign, wrote back to him a letter with a more sober assessment of their prospects: 'My expectations of profits from the photogenous orders are very moderate compared with your prospective statement; so much so that if the results should not fall short of one half of the anticipated profits they will not be disappointed.' $112 \mathrm{He}$ also feared what effect the large volume of orders would have on their business. The steam engine line was their

\footnotetext{
109 James Watt jr to Matthew Robinson Boulton 1806/03/14, BWA MS 3147/3/55 \#9, AM-IR series 1 part 12 reel 206.

110 Eidingtoun Hutton to B+W 1805/11/03, BWA MS 3147/3/263 \#19, AM-IR series 1 part 12 reel 215. Eidingtoun Hutton to B+W 1805/12/05, BWA MS 3147/3/263 \#26, AM-IR series 1 part 12 reel 215.

111 Pooley: James Watt jr to Matthew Robinson Boulton 1806/03/03, BWA MS 3147/3/55 \#5, AM-IR series 1 part 12 reel 206.

J. Douglas \& Co. (Holywell): James Watt jr to Matthew Robinson Boulton 1806/03/08, BWA MS 3147/3/55 \#7, AM-IR series 1 part 12 reel 206.

Daintry \& Co.: James Watt jr to Matthew Robinson Boulton 1806/03/12, BWA MS 3147/3/55 \#8, AM-IR series 1 part 12 reel 206.
}

See also James Watt jr notebook, BWA MS 3147/4/5, which has sizing calculations from late February and early March 1806 for Oldham, Birley \& Marsland, James Kennedy, Greg \& Ewart, McConnel \& Kennedy, Pooley, Wood \& Daintry, Douglas (Pendleton and Holywell), Garside \& Butterfield, Horrocks, Strutt, Peel, Wormald \& Gott (several mills), Radcliffe \& Ross, and a few illegible ones.

112 Matthew Robinson Boulton to James Watt jr 1806/03/09, BWA MIV /B6, AM-IR series 1 part 8 reel 116. 
profit-maker of long standing, and he did not want to divert many resources away from it as this new business was threatening to do, and indeed had done so in the last few weeks. Watt junior and Boulton had discussed how to handle the manufacturing of all the parts, agreeing that they should be farmed out to other manufacturing firms to the extent possible. In this letter, Boulton recognized that they would effectively transfer knowledge and skills to these other firms who would be their competitors after two years or so, but he thought this price was worth paying to protect their existing steam engine business and would not hurt them in the short term. He prediction did come true, as at least one of these subcontractors, Josiah Pemberton, turned out to be among the early manufacturers of gaslight apparatus. Many of the workers the Gas Light and Coke Company hired came from Manchester and area, and it also purchased parts from companies in Birmingham and Manchester.

On March 14, 1806, Watt junior set out with Lee and Murdock, who had come up from Soho five days before, ${ }^{113}$ to visit Leeds and Preston and collect what orders they could among mill owners there, including Benjamin Gott. They return to Manchester four days later, and Watt junior was finally satisfied. He had secured three more orders meaning he had commitments from almost all the large mills worth having as customers. ${ }^{114} \mathrm{He}$ wrote to his father the day after his return satisfied with the fruits of his

\footnotetext{
113 Matthew Robinson Boulton to James Watt jr 1806/03/09, BWA MIV /B6, AM-IR series 1 part 8 reel 116. 114 These were Wormald, Gott, \& Wormald (Leeds), Watson Ainsworth \& Co. (Preston), and S. Horrocks (Preston). James Watt jr to James Watt 1806/03/19, BWA MII /13/1, AM-IR series 1 part 6 reel 82. The firm of William Strutt \& Co. (Derby) also placed in order at this time see drawing dated 1806/04/26, BWA MS 3147/3/478 \#34, AM-IR series 1 part 14 reel 273. One of the Strutts lit his house with gas. See John Farey, "General view of the agriculture of the county of Derbyshire drawn up for the consideration of the Board of Agriculture and Internal Improvement," ed. Board of Agriculture and Internal Improvement, Agricultural surveys (London, 1817), 197.
} 
efforts of the last three weeks: 'This concludes my labours in this vocation for the present, as the orders for all the large mills, which are thought tolerably safe, are now secured. Many of the smaller ones will necessarily drop in in the course of another year + the remainder will fall to the lot of our competitors, unregretted by us. ${ }^{1115}$ Watt junior now turned his attention to other matters, leaving Manchester the next day ${ }^{116}$ and the work of gaslight to Murdock, Southern, Creighton and Hutton. He did not mention the business much in any surviving letters from this point until 1807, when Winsor and the National Light and Heat Company burst on the scene and threatened to completely upset the status quo, and forced Watt junior to pay a great deal of attention to gaslight once again.

A few other orders from other mills were collected by Southern and Hutton. Hutton was still in the Scotland when John Grieve of Edinburgh, who had been musing about an apparatus since 1805 , ordered a small one on March 15,1806 , followed by James Finlay. ${ }^{117}$ Finlay was quite excited by the prospect of lighting with gas, and wanted his apparatus as soon as possible. ${ }^{118}$ In letters from Hutton coming from Scotland for the rest of year, he frequently refers to Finlay's anxiety over the state of his order and his hope of having it in place by the end of the year. In Southern's case, he was based back at Soho, and was keeping Watt junior abreast of incoming correspondence by forwarding letters to Philips \& Lee in Manchester. Watt junior was not at Salford, having

\footnotetext{
115 James Watt jr to James Watt 1806/03/19, BWA MII /13/1, AM-IR series 1 part 6 reel 82. 116 Henry Creighton to B+W 1806/03/25, BWA MS 3147/3/247 \#7, AM-IR series 1 part 12 reel 212. 117 Eidingtoun Hutton to B+W 1806/03/15, BWA MS 3147/3/264 \#13, AM-IR series 1 part 12 reel 216. 118 Eidingtoun Hutton to B+W 1806/03/28, BWA MS 3147/3/264 \#14, AM-IR series 1 part 12 reel 216.
} 
moved on to Derby to visit William Strutt \& Co., when Southern's letters reached him informing him about Finlay's order and another from Dunlop, a mill that had shown interest in $1805 .{ }^{119}$ The next day he wrote again to say that 'Mr Peel of Burton is in want of a lighting apparatus immediately, as they constantly work night + day.' ${ }^{120} \mathrm{~A}$ few other orders were also collected before the end of May 1806. ${ }^{121}$

Having spent most of late March 1806 preparing sketches of the mills in the Manchester area, Creighton moved on to work with the mills that had placed orders in the Leeds area, starting with Benjamin Gott \& Co. and the related firm of Wormald, Gott, \& Wormald. This order was a large one that included their three mills, Park, Burley, Armley. ${ }^{122}$ The drawings were prepared by April 7, $1806^{123}$ and Creighton forwarded the packet on the 12th. ${ }^{124}$ Hutton arrived a couple of days later from Scotland to aid with the remaining drawings and other work for Boulton \& Watt, ${ }^{125}$ and was to remain there until the end of June 1806. ${ }^{126}$ On April 26, 1806, drawings were made of Samuel Oldknow's

\footnotetext{
119 Southern to James Watt jr 1806/03/19, BWA MS 3147/3/331 \#34, AM-IR series 1 part 13 reel 230. 120 Southern to James Watt jr 1806/03/20, BWA MS 3147/3/331 \#35, AM-IR series 1 part 13 reel 230. 121 These include Samuel Oldknow (Stockport), see drawing dated 1806/04/26, BWA MS 3147/3/478 \#30 series 1 part 14 reel 273, and possibly Sheppard, see drawing dated 1806/07/26, BWA MS 3147/3/478 \#32 series 1 part 14 reel 273.

122 For drawings and notes see 1806/04/ MS 3147/5/812/14 and 16, AM-IR series 1 part 11 reel 184, and 1806/04/, BWA MS 3147/3/478 \#47 and 48a series 1 part 14 reel 273.

${ }^{123}$ Henry Creighton to B+W 1806/04/07, BWA MS 3147/3/247 \#8, AM-IR series 1 part 12 reel 212.

${ }^{124}$ Henry Creighton to B+W 1806/04/12, BWA MS 3147/3/247 \#9, AM-IR series 1 part 12 reel 212.

125 Henry Creighton to B+W 1806/04/14, BWA MS 3147/3/247 \#11, AM-IR series 1 part 12 reel 212;

Eidingtoun Hutton to B+W 1806/04/14, BWA MS 3147/3/264 \#17, AM-IR series 1 part 12 reel 216.

126 Eidingtoun Hutton to B+W 1806/06/27, BWA MS 3147/3/264 \#22, AM-IR series 1 part 12 reel 216.
} 
Mellor Mill near Stockport, ${ }^{127}$ and of W. G. J. Strutt's mills at Milford near Derby ${ }^{128 ;}$ on May 24 and 27, 1806 of Douglas \& Co. at Holywell'129 and probably Penson at Wigan as well130; June 2, 1806 saw another of Strutt's mills in Derby surveyed ${ }^{131}$; June 27, 1806 included Horrocks ${ }^{132}$ and Watson Ainsworth, both in Preston, completed by Hutton. ${ }^{133}$

This batch of drawings represents the densest cluster of order taking by Boulton \& Watt in their entire history as a gaslight manufacturer. At no other time were preparations made for such a number of installations, and even despite this, letters from Creighton and Hutton from May and June of 1806 indicate that they were more taken up with steam engine work than with gaslight. Boulton's desire to maintain the firm's emphasis on steam engines was effective even in this period. At the beginning of July 1806, Watt junior instructed Creighton and Hutton to send no more drawings for gaslight apparatus, ${ }^{134}$ although a few more trickled in, especially James Finlay's who was by now 'extremely anxious about the lighting appt for the Catrine Mill'. ${ }^{135}$ Hutton reported that they even 'consider the order as given and do not wait for an estimate'.136 A long

\footnotetext{
127 1806/04/26, BWA MS 3147/3/478 \#30 series 1 part 14 reel 273.

128 1806/04/26, BWA MS 3147/3/478 \#34 series 1 part 14 reel 273.

129 1806/05/24, BWA MS 3147/3/478 \#2 series 1 part 14 reel 273.

130 Henry Creighton to B+W 1806/05/09, BWA MS 3147/3/247 \#12, AM-IR series 1 part 12 reel 212; 1806/05/24, BWA MS 3147/3/478 \#31 series 1 part 14 reel 273.

131 1806/06/02, BWA MS 3147/3/478 \#35 series 1 part 14 reel 273.

132 1806/06/27, BWA MS 3147/3/478 \#5 series 1 part 14 reel 273.

133 Henry Creighton to B+W 1806/06/29, BWA MS 3147/3/247 \#17, AM-IR series 1 part 12 reel 212. drawings 1806/06, BWA MS 3147/3/478 \#44 series 1 part 14 reel 273.

134 Eidingtoun Hutton to B+W 1806/07/12, BWA MS 3147/3/264 \#27, AM-IR series 1 part 12 reel 216. 135 Eidingtoun Hutton to B+W 1806/07/12, BWA MS 3147/3/264 \#27, AM-IR series 1 part 12 reel 216. 136 Eidingtoun Hutton to B+W 1806/07/26, BWA MS 3147/3/264 \#29, AM-IR series 1 part 12 reel 216.
} 
pause in collecting new orders now set in, and there was not to be preparations for another until May of 1807 , and even that was a small one. ${ }^{137}$ The next major order after this initial batch was prepared in May of 1808 , for James Kennedy. ${ }^{138}$ In any case, Watt junior's reticence to accept any new orders was well founded, because other than some experimental work for McConnel \& Kennedy and Douglas in 1806, ${ }^{139}$ Boulton \& Watt would not begin manufacturing any sizeable order other than Lee's until 1808.

\subsubsection{Design work at Philips \& Lee 1806}

Simultaneous with the marketing and sales campaign of February to June 1806, Boulton \& Watt engaged in further research and development work at Philips \& Lee and at Soho to better determine what all these new apparatuses should look like. Philips \& Lee's apparatus was a working prototype and more study was needed before they had sufficient knowledge to be able to design a new apparatus for a particular site. Hutton, before he left Scotland to help out in Manchester requested guidance in the matter of sizing and designing apparatus, which is indicative of the sort of knowledge the firm needed to acquire and consolidate internally:

At your leisure I shall be obliged by some information of what has been done at Mr Lees with this light, and also of two or three particulars on the subject for my government-say -the size of a Retort + Gazometer for furnishing light equal to 500 candles? About what

\footnotetext{
137 drawing for Joyce Cooper (Staverton) 1807/05/02, BWA MS 3147/3/478 \#6 series 1 part 14 reel 273.

138 James Kennedy (Manchester) 1808/05/14, BWA MS 3147/3/478 \#8 series 1 part 14 reel 273.

139 1806/03/ James Watt jr notebook, BWA MS 3147/4/5 p. 18, 49-50.
} 
the saving may be between using this light + candles including the first cost of an appts?

Murdock and Watt junior wanted to evaluate how Lee's apparatus was performing, but the first part of his apparatus, that serving the first two floors was not complete until the beginning of February $1806 .{ }^{141}$ The definitive size of Lee's apparatus had not yet been set, and the February and March 1806 tests were done partly to come to some agreement about Lee's own apparatus. In fact, it would take until the end of the year for the initial phase including three gasometers and four retorts - the apparatus for the first floors of the Old Mill and the New Mill-to be completed and in use. ${ }^{142}$ Even this was not large enough for the entirety of the two mills, and equipment for the remaining floors and then the other mills took a couple more years to finish.

Let us return to the conditions at Lee's at the beginning of February 1806. With a part of Lee's installation complete, Watt junior was feeling confident about the project. He described how gaslight fared at the mill to his father in optimistic tones:
Mr. Lee's answers extremely well in the mills, when the upper part of the windows are generally a little open, which gives it a complete ventilation. Indeed the pipes seem so tight, and the people manage the lighting + putting out so well in general, that this precaution scarcely appears necessary, and in fact had always been practised when candles were used. The Argand lamps are all discarded + cockspur burners only are in use. [...] This will be universally adopted in the mills, which have hitherto been all

\footnotetext{
140 Eidingtoun Hutton to B+W 1806/02/11, BWA MS 3147/3/264 \#8, AM-IR series 1 part 12 reel 216. He asked again a month later Eidingtoun Hutton to B+W 1806/03/15, BWA MS 3147/3/264 \#13, AM-IR series 1 part 12 reel 216.

141 Murdock to B+W 1806/02/05, BWA MS 3147/3/289 \#19, AM-IR series 1 part 13 reel 221. 142 Henry Creighton to B+W 1806/11/08, BWA MS 3147/3/247 \#31, AM-IR series 1 part 12 reel 212.
} 
underlighted. [...] the air which first comes over has a bad smell in burning, but this does not last long, and that which [subsequently?] succeeds is the most brilliant. Towards the end of the operation they are obliged to open the cocks much wider to obtain the same portion of light, which occasions the variation I have mentioned in the consumption of gas.

Chimnies are put over the burners in Mr Lee's house to carry off the consumed air + effluvia, which now answers very well, but have not been brought to bear without some alterations and occasional offense to the olfactory organs of the Gentleman + Lady + of their visitors. ${ }^{143}$

As the days passed and they could work out the wrinkles in the system, Lee and Watt junior felt they could start testing how the apparatus was performing and in particular better quantify the various gas production and consumption rates. They could then use these figures to validate the results from the experiments of March and July of 1805 done at Soho. Murdock and Creighton ran the new experiments. ${ }^{144}$ Using Clifton coal in the retorts, ${ }^{145}$ the gasometers were allowed to fill to close to capacity, and then they were isolated from the retorts. By this point, 203 burners were installed in the mill, and for this test, each was set to the same aperture, corresponding by their estimates to the light of 3.5 tallow candles of 6 to the $\mathrm{lb}$. The gas consumed over the course of one

\footnotetext{
143 James Watt jr to James Watt 1806/02/27, BWA MII /13/1, AM-IR series 1 part 6 reel 82.

144 James Watt jr to George Augustus Lee 1808/01/23, BWA MS 3147/3/478 \#17, AM-IR series 1 part 14 reel 273.

145 1808/01/28, BWA MS 3147/3/479 \#12, AM-IR series 1 part 14 reel 273.
} 
hour by these 203 burners was $256 \mathrm{ft}^{3}$, or $1.26 \mathrm{ft}^{3}$ per burner per hour. ${ }^{146}$ The conclusion was that $1 \mathrm{lb}$ of tallow was equivalent to $16 \mathrm{ft}^{3}$ of gas, which was within the range of 14$17 \mathrm{ft}^{3} / \mathrm{lb}$ tallow that the Soho experiments of 1805 gave.

Watt junior wrote a long letter to Southern back at Soho on March 1, 1806, summarizing all these experiments, and giving his opinion as what they meant for design and sizing of the retorts and gasometers. He was still very upbeat about gaslight, describing the 'auspicious commencement and rapid progress of our photogenous orders'. He acknowledged that the experiments were limited in scope to the extent that the gasometers were of insufficient capacity to hold the entire daily production of the two retorts, and hence complete production figures could not be obtained directly. After giving the results of the previous paragraph, Watt junior observed that

the proportion to be observed between the contents of the gasometer and the number of Retorts is difficult to determine, and I do not suppose that any general rules can be adopted. [...] It is probable that 3 hours Gazometer supply will be generally adopted. You see it is a combined question of first cost; conveniency of room + comparative wear + tear. I shall thank you for any remarks that occur upon it. - The Retorts are left with a fire under them when [?] work at night so as to raise a sufficient supply of gas for an hour or

\footnotetext{
146 These experiments are described in many places, including: James Watt jr to John Southern 1806/03/01, BWA MS 3147/3/60 \#9, AM-IR series 1 part 12 reel 206; James Watt jr to Lee 1808/01/23, BWA MS 3147/3/478 \#17, AM-IR series 1 part 14 reel 273; 1808/01/28, BWA MS 3147/3/479 \#12, AM-IR series 1 part 14 reel 273; James Watt jr notebook 1806/03/, BWA MS 3147/4/5 p. 52, 54-55;

See also Peter J. Austerfield, "The development of large-scale production and utilisation of lighter-than-air gases in France, Britain and the low countries from 1783 to 1821 with reference to aeronautics and the coal-gas industry" (Ph.D., University of London, 1981), 414-15.
} 
two's consumption in the morning. The fire will have to be [lighted?] in the course of the day in time to fill the Gazometers before the hour of lighting the burners in the evening.

Watt junior added some more results that Lee had given him from his own experience with using the apparatus, being that Philips \& Lee typically charged the retorts with 14 to $16 \mathrm{cwt}$ of coal, with each cwt giving about $370 \mathrm{ft}^{3}$ of gas at a rate of $150-200 \mathrm{ft}^{3} / \mathrm{hr}$ per retort. Watt junior suggested using a conservative figure of $160 \mathrm{ft}^{3} / \mathrm{hr}$ for their future calculations. ${ }^{147}$ All these figures are close to the 1805 experiments.

Southern responded to Watt junior in two letters, one of which is lost. ${ }^{148}$ In the second letter, written on March 9, 1806, Southern identified what was to become the determining issue for the relative size of the retorts and gasometers: the added cost of every heating and cooling cycle. Southern laid out this logic, together with a simple rule for determining the relative size of retorts to gasometers:

The most economical establishment appears to me to be, generally speaking, to have such a number of retorts as constantly being at work would supply the gas necessary for the day and one or two more, according to the magnitude of the apparatus, to supply defects from repairs $+c+c$. My reason for being of this opinion is that the brick-work, retorts, $+c$, would not get cool + thereby require an extra quantity of fuel to heat them. For it appears to me in Mr Lee's [apatt?], that to heat 4 or 5 of these retorts $+c$ twice per diem will take a considerable quantity of coals. Against this is to be set the expence of an extra man, to attend in the night, which in some cases may over balance the saving of coals. [...] The least necessary space for gazometer is the difference between the

\footnotetext{
147 James Watt jr to Southern 1806/03/01, BWA MS 3147/3/60 \#9, AM-IR series 1 part 12 reel 206. 148 Watt junior mentions the two letters in James Watt jr to Matthew Robinson Boulton 1806/03/12, BWA MS 3147/3/55 \#8, AM-IR series 1 part 12 reel 206.
} 
consumption of gas for the longest period of working it + the quantity raised in the same period by the retorts. ${ }^{149}$

His argument was based on the economy of coal alone but as it turned out over the long run, there was even more cost associated with each heating and cooling cycle that anyone had yet realized. A retort would last longer if it were keep under heat constantly and not allowed to cool. The more frequently a retort when through a heating and cooling cycle, the more quickly it burned out, and the more liable it was to developing a crack. As the gaslight industry matured, retorts which at first were replaced on the average every nine months in the early years, had extended life spans of twelve or fifteen months by mid century. It was soon standard practice to keep them under constant heat. If a retort had to be taken out of operation, it was allowed to cool slowly, over the course of a week. ${ }^{150}$ Obviously Boulton \& Watt had not yet come to this understanding, but Southern's thought went some way in this direction. Gasometers, on the other hand, were not subject to any such operational strains, and therefore gasometers would be less liable to future replacement costs. In general, the larger the gasometer was, the smaller the retorts could be, with the limit determined by the condition of retorts producing gas 24 hours per day.

Later in the same month, Watt junior concluded the work by doing some calculations about the size of the rest of the apparatus which he recorded a notebook. It is not evident whether these were made before or after he received Southern's letter, but his calculations show that he was not following the method Southern proposed. By

\footnotetext{
149 Southern to James Watt jr 1806/03/09, BWA MS 3147/3/479 \#2 AM-IR series 1 part 14 reel 273. 150 Clegg, A practical treatise on the manufacture and distribution of coal-gas, 70.
} 
now, the number of candles needed at Philips \& Lee had been reduced to 2800 from the 3000 of September 1805. Since each burner was equal to 3.5 candles, 800 burners would be needed, consuming $1.26 \mathrm{ft}^{3} / \mathrm{hr}$ each, or $1000 \mathrm{ft}^{3} / \mathrm{hr}$ in total, and $9000 \mathrm{ft}^{3}$ for the nine hours Lee needed for the mills during wintertime. Watt junior then figured they would need five retorts (with a spare) making $160 \mathrm{ft} 3 / \mathrm{hr}$ each. It is not clear how he came up with the number of retorts other than by somewhat arbitrary choice. The retorts as he designed them would not need be in operation 24 hours per day to supply the gas. ${ }^{151}$

He shortly thereafter revisited the calculations with more pessimistic values for the burners, using 3 candle power per burner, instead of 3.5 , and $1.5 \mathrm{ft} 3 / \mathrm{hr}$ each, rather than the $1.26 \mathrm{ft}^{3} / \mathrm{hr}$ from before. These figures meant they needed 930 burners using $1400 \mathrm{ft} 3 / \mathrm{hr}, 40 \%$ more than his earlier figure. This also meant that the gasometers would have to have a capacity of $3,600 \mathrm{ft}^{3}$. In fact, these figures were not adopted for Philips \& Lee's next phase. 152

The drawings Southern prepared for the final configuration of the Philips \& Lee apparatus show that a different basis for sizing was used altogether, closer to the mode of calculation he had suggested to Watt junior in his letter. ${ }^{153}$ The drawings propose eight gasometers with approximately $8000 \mathrm{ft}^{3}$ capacity in total, supplied by 6 retorts,

\footnotetext{
151 1806/03/ James Watt jr notebook, BWA MS 3147/4/5 p. 52; Austerfield, "The development of largescale production and utilisation of lighter-than-air gases", 414.

152 1806/03/ James Watt jr notebook, BWA MS 3147/4/5 p. 54; Ibid.

153 The drawings are: BWA MS 3147/5/804/5-7, AM-IR series 1 part 11 reel 184 . The drawings are not dated, but Lee refers to the eight gasometers represented there in another letter: George Augustus Lee to John Southern 1806/08/11, BWA MS 3147/3/478 \#14, AM-IR series 1 part 14 reel 273.
} 
approximately twice that required if they were run 24 hours a day. ${ }^{154}$ In fact, Southern's idea of running them constantly had not yet been adopted at Lee's and the plan was to run them 12 hours a day. ${ }^{155}$

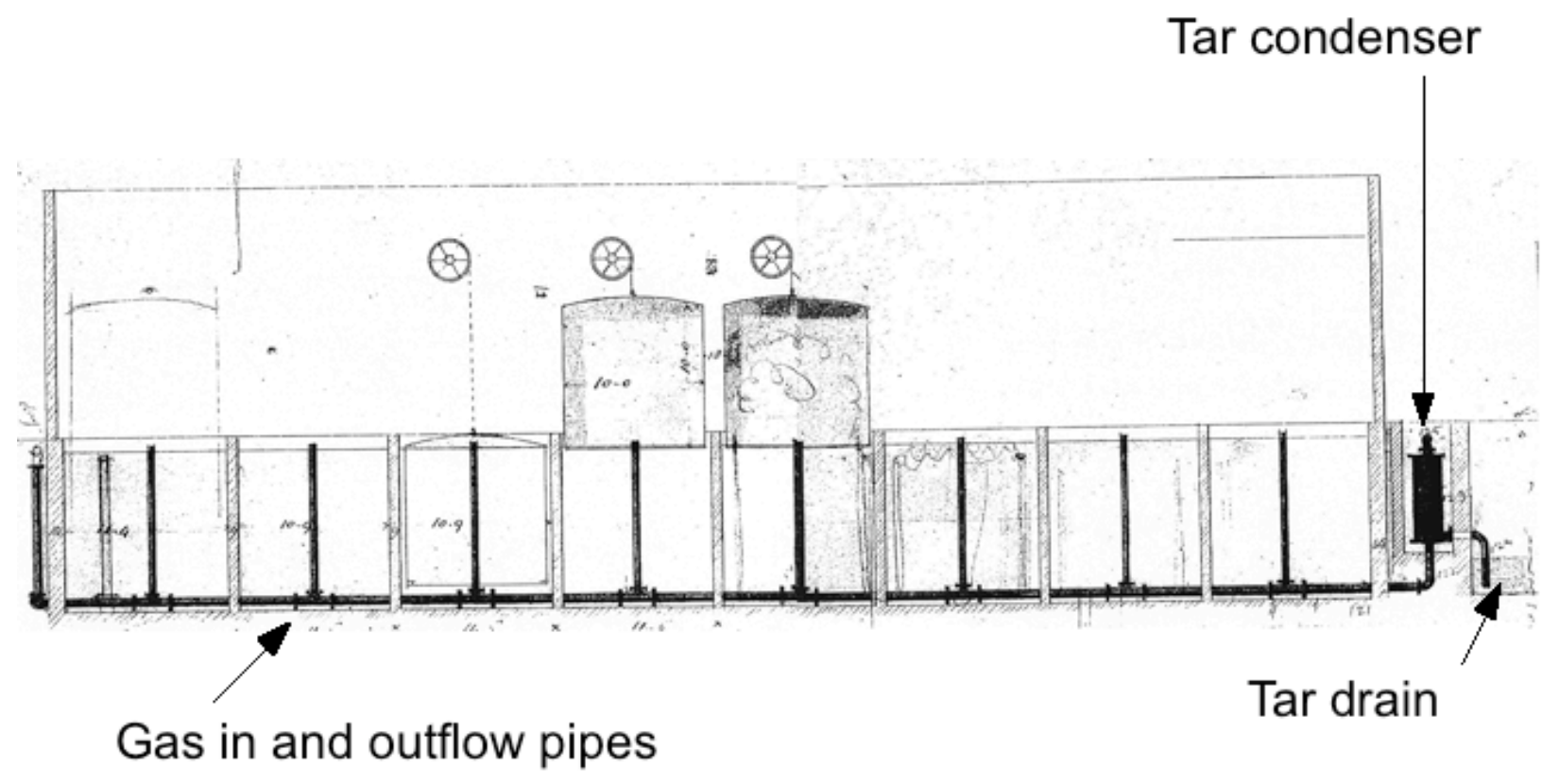

154 George Augustus Lee to Southern 1806/08/11, BWA MS 3147/3/478 \#14, AM-IR series 1 part 14 reel 273.

155 Memo about McConnel \& Kennedy's apparatus, 1806/09/29, BWA MS 3147/3/478 \#20, AM-IR series 1 part 14 reel 273. 


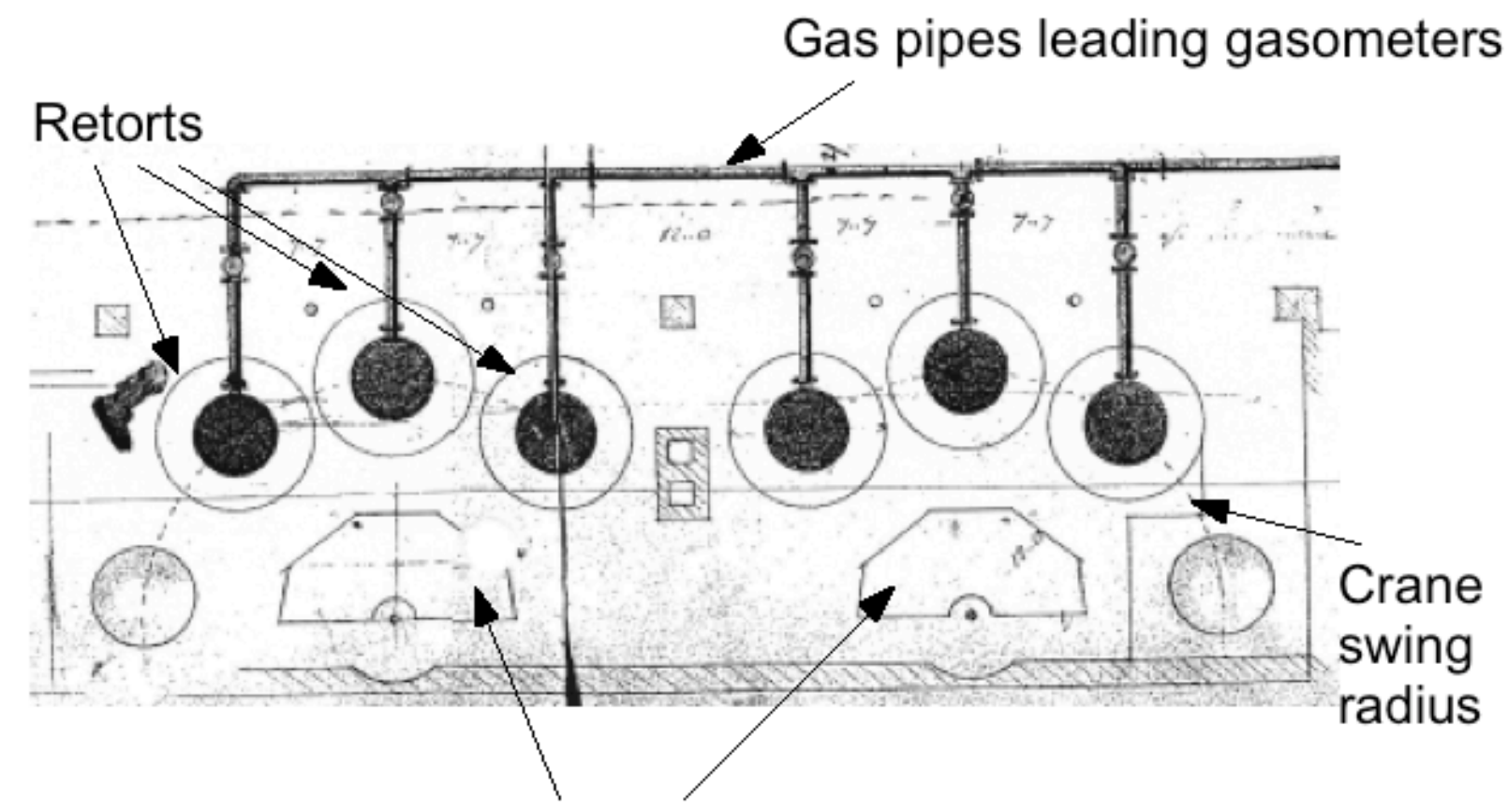

\section{Cranes for loading coal into retorts}

Figure 3.11 Above: side view of the gasometers at Philips \& Lee.

Figure 3.12 Below: Top view of the retorts with crane bases and swing arm radius.

Many of the remaining parts for Philips \& Lee's Old and New Mill apparatus were prepared at Soho largely in June of 1806 and shipped off to Manchester for assembly. ${ }^{156}$ At this point, the complement installed at the Old Mill consisted of 212 Argand burners and 117 tri-flame or cockspur burners. ${ }^{157}$ Some work remained, however, before the full contingent of eight gasometers was in place. Lee wrote to

\footnotetext{
156 Murdock memo 1806/06, BWA MS 3147/3/478 \#12 series 1 part 14 reel 273.

157 Notes 1806/06/28, BWA MS 3147/3/478 \#13 AM-IR series 1 part 14 reel 273.
} 
Southern at Soho in August 1806 explaining that he was now excavating the gasometer pits to make way for the rest of the gasometers, with sketches showing the pit dimensions. ${ }^{158}$ The pipes and burners were prepared more rapidly than the remaining retorts and gasometers, so that towards the end of the year, although the entire New Mill and four floors of the Old Mill were supplied with pipes and burners, many were not in use, as only three retorts were working, and even one of the three gasometers on site was still not in service. ${ }^{159}$ Other problems were also encountered. The grapplers used to lower and raise the coal into the retorts were not handling the heat well and were breaking. New ones needed to be made that were stronger and more resilient. 160

\subsubsection{Other mills 1806}

Some sizing and a very little manufacturing work was done for apparatuses at other customers in mid 1806, but it was generally sporadic, haphazard, and unfinished. One of the first set of drawings and written notes were prepared by Creighton for the apparatus for J. Douglas \& Co.'s mills at Holywell and at Pendleton. ${ }^{161}$ Douglas had four mills at Holywell, three of which were to be supplied by a single apparatus, with the last one independent of the others, while the Pendleton site had two mills. The Holywell notes are dated May 24-27, 1806 and those from Pendleton slightly later in June 1806.

\footnotetext{
158 George Augustus Lee to John Southern 1806/08/11, BWA MS 3147/3/478 \#14 series 1 part 14 reel 273.

159 Henry Creighton to B+W 1806/11/08, BWA MS 3147/3/247 \#31, AM-IR series 1 part 12 reel 212.

160 drawing 1806/12/19, BWA MS 3147/3/478 \#15b series 1 part 14 reel 273.

$161 \mathrm{~J}$. Douglas + Co, 1806/05/24-7, BWA MS 3147/3/478 \#1-2, AM-IR series 1 part 14 reel 273;

Notes 1806/06/28, BWA MS 3147/3/478 \#13 series 1 part 14 reel 273 also refer to Old and New Mill at Pendleton.
} 
They would therefore reflect-to some extent-how the experiments and calculations from March 1806 were assimilated and interpreted by the firm. For Holywell, the assumption was that the retorts would be working 'constantly', but this was because work at the mill went on 24 hours a day, rather than for the sake of retort life. In the middle of winter, this corresponded to 16 hours of lighting per day. The notes indicate that the total gasometer size was set independent of the actual number of gasometers.

The apparatus for Douglas \& Co.'s two mills at Pendleton was sized by Southern. ${ }^{162}$ In this particular case, the calculations were done with the goal of generally maximizing gasometer size in order to minimize retort size, although it was not a definite target. The retorts, for example, would be worked 18 hours a day rather than constantly as at Holywell. The sizing done by finding the gas needed per hour based on burner count, translating into 296 burners using $1.5 \mathrm{ft}^{3} /$ hour to give $444 \mathrm{ft}^{3} /$ hour total for daily gas consumption of $4972 \mathrm{ft}^{3}$. Most of these lamps were to be used 9 hours per day, with 81 of them lit for an additional 8 hours as they would stay on overnight. Southern figured the retorts would need to produce $4972 \mathrm{ft} 3 / 18 \mathrm{hr}=276 \mathrm{ft} 3 / \mathrm{hr}$ (incorrectly calculated as $265 \mathrm{ft} / \mathrm{hr}$ ). The longest continuous run of gas usage was not 9 hours but 6 , as the lights were on for 3 hours in the morning with the remaining 6 hour stretch at night. In these 6 hours, the retorts made $265 \mathrm{ft}^{3 *} 6$ hours $=1590 \mathrm{ft}^{3}$, and gas used in that interval was $444^{*} 6=2664 \mathrm{ft}^{3}$. Therefore gasometer capacity was the difference between consumption and production, or $1074 \mathrm{ft}^{3}$. Southern split the required volume between two gasometers: a cylindrical one of $7 \mathrm{ft}$ diameter and $4.5 \mathrm{ft}$ depth with a

\footnotetext{
162 The second gasometer was oblong, see Notes 1806/06/28, BWA MS 3147/3/478 \#13 AM-IR series 1 part 14 reel 273.

The notes refer to the Old and New Mill at Pendleton, which is clearly Douglas'.
} 
volume of $174 \mathrm{ft}^{3}$ and an oblong one $17.5 \mathrm{ft}$ long, $7 \mathrm{ft}$ wide, and $4.5 \mathrm{ft}$ deep for a volume of $550 \mathrm{ft}^{3}$, for a total volume of slightly less than his calculations would suggest.

Progress for other customers was slow to non-existent. Although some gaslight apparatus for at least one other customer, Ridgeway, was now under construction, ${ }^{163}$ Boulton \& Watt had not even managed to get estimates out to most of the mill owners that had placed orders. Even Ridgeway's apparatus was an experimental model, rather than a production apparatus: Ridgeway does not turn up anywhere in Boulton \& Watt's accounts as a gaslight customer. Their customers, however, were anxious to move ahead despite the delays in receiving quotes, and in June 1806 Creighton wrote in to head office communicating the desire of some of these (Oldknow, Marsland, and James Kennedy) to begin work at least on the gasometer pits while the summer days were still long. ${ }^{164} \mathrm{He}$ wrote again a month later with a similar request, this time from McConnel \& Kennedy. ${ }^{165}$ Perhaps as a way to prepare estimates for their other potential customers, Boulton \& Watt tried to calculate how much the apparatus for Philips \& Lee cost in order prepare these estimate, and drew up a long parts list for everything they sent to Philips \& Lee. ${ }^{166}$ These other customers had to wait some more, however, before their desires

\footnotetext{
163 Henry Creighton to B+W 1806/06/14, BWA MS 3147/3/247 \#16, AM-IR series 1 part 12 reel 212; Henry Creighton to B+W 1806/09/18, BWA MS 3147/3/247 \#24, AM-IR series 1 part 12 reel 212. 164 Henry Creighton to B+W 1806/06/29, BWA MS 3147/3/247 \#17, AM-IR series 1 part 12 reel 212. 165 Henry Creighton to B+W 1806/07/22, BWA MS 3147/3/247 \#21, AM-IR series 1 part 12 reel 212. 166 Estimate 1806/06/28, BWA MS 3147/3/479 \#4, AM-IR series 1 part 14 reel 273; Estimate 1806/06/28, BWA MS 3147/3/479 \#5, AM-IR series 1 part 14 reel 273; Estimate 1806/09/23, BWA MS 3147/3/479 \#7, AM-IR series 1 part 14 reel 273.
} 
for gaslight was satisfied. Philips \& Lee's apparatus was the only one Boulton \& Watt sold before $1808 .{ }^{167}$

\subsection{A return to gaslight $1807-8$}

After James Watt junior became distracted with other matters in later 1806, gaslight faded in importance for the whole firm. Philips \& Lee's apparatus was functioning and even being expanded, but no effort was put into developing the technology or even in filling the many orders Boulton \& Watt had collected in 1806. technology. With the exception of some sporadic experiments performed at the Soho Foundry in February, March and June of 1807 on different types of coal, the year was mostly quiet. All this changed in December 1807 when, prodded into action by the Winsorite storm brewing in London, Watt junior got the firm back into development work. He had first heard of their activities in June 1807, but when it became clear that he could not do much in terms of publishing a paper on gaslight, he dropped the subject again until December, when the Winsor threat loomed larger again.

The December 1807 experiments consisted of a large set done at the Soho foundry using a newly cast experimental retort, followed by many more at Philips \& Lee. The later set of experiments formed an important basis for a paper Murdock and Watt junior eventually did write for the Royal Society, but also served to get a better sense of the economics of the technology based on figures derived from Philips \& Lee's experience. The result of all this work was some new designs, including abandoning

${ }_{167}$ Extras per Agreement 30 Sep 1806-30 Sep 1807, BWA MII /7/4, AM-IR series 1 part 6 reel 82. 
the vertical retorts in favour of horizontal ones, as well finally installing more orders in 1808. It also showed that the economics of the technology were not as good as had been initially conceived.

\subsubsection{Experimental work during 1807}

Beginning on February 26, 1807 at Soho, Creighton with some collaboration from Murdock did a series of experiments that lasted through March 1807. These experiments were intended to explore which sorts of coal would be the best and especially what operating procedures could be adopted to maximize gas output. These questions that already been looked into on several occasions, even going back to the first experiments at Soho in 1798. They had been reopened in 1805 when Lee had provided Murdock with different kinds of coal, but now in 1807, having gained some real production experience, Boulton \& Watt wanted to 'ascertain the time each took to distil, the quantity of gas produced, per hour + the coal consumed under the retort'. ${ }^{168}$

The apparatus used was a 'small' one consisting of a vertical retort and a gasometer. The results are far too extensive to be repeated in detail here, but they can be summarized. Creighton first gasified Wednesbury coal and found that $1 \mathrm{lb}$ of tallow was equal to around $20.25 \mathrm{ft}^{3}$ of its gas, a worse result than had been found in 1805 and March of 1806 . By storing the coal for six days prior to distillation, Creighton increased the equivalency to $29.25 \mathrm{ft}^{3} / \mathrm{lb}$ of tallow. The fourth experiment involved heating the retort prior to loading in the coal, and the result was that $1 \mathrm{lb}$ of tallow was

168 Notebook 1808/01/28, BWA MS 3147/3/479 \#12, AM-IR series 1 part 14 reel 273 p. 1. 
equal to $25.5 \mathrm{ft}^{3}$ of gas, again a worse result than the first experiment. It is unusual that this should have produced a worse result than the first experiment, because it was had been observed, even going back to the scientific work of pneumatic chemists such as Priestley, that coal gave off better gas when the retort was heated rapidly.

Moving on to Wigan Cannel coal, which was to be one of the favourites of the gas industry, Creighton modified the experiment by 'returning the tar to the retort' in order to produce more gas, and here found that $1 \mathrm{lb}$ of tallow was equal to $14.5 \mathrm{ft}^{3}$ of gas, a very good result. The experiment was repeated and the new equivalence was found to be 13.2 $\mathrm{ft}^{3}$ of gas, an even better result. A third run of the experiment, this time interrupting the distillation occasionally, returned $14 \mathrm{ft}^{3}$ of gas as the result. 169 These findings were obviously very promising for Wigan Cannel coal, and Boulton \& Watt must have communicated the result to Lee because James Lawson informed Watt junior at the end of March 1807 that Lee had ordered 'Wygan' coal and was going to try it out. ${ }^{170}$

There were a few follow-up experiments done in June of 1807 to compare how much gas could be had from three different types of coal-Wednesbury, Wigan Cannel, and 'Mr. Fenton's coal'-and to ascertain how much coal was required to heat the retort in order. The results showed that once again the Wigan produced the most, although Wednesbury required less coal to gasify. ${ }^{171}$

\footnotetext{
169 All experiments lists in Notebook 1808/01/28, BWA MS 3147/3/479 \#12, AM-IR series 1 part 14 reel 273.

170 James Lawson to James Watt jr 1807/03/30, BWA MIV /L3, AM-IR series 1 part 8 reel 120.

171 1808/01/28, BWA MS 3147/3/479 \#12, AM-IR series 1 part 14 reel 273 p. 5.
} 
The economic side of the technology was revisited once again after Lee's apparatus with eight gasometers and six retorts was completed and had been in operation for some time. This was the first time real figures were available, and that Boulton \& Watt did not have to rely on estimates based on smaller scale experiments. The interest now was not only to see how the apparatus was functioning. Watt junior had become aware in the first months of 1807 that Winsor and company in London had gaslight plans of their own, and Watt junior wanted to write a paper on their work with gaslight. For this, however, he needed some economical analysis, which is what he now did. ${ }^{172}$ In June of 1807, he estimated the total cost of Lee's apparatus, arriving at the figure of $£ 5000$, including all pipes and burners, Lee’s excavation work and new buildings. Assuming a depreciation cost at $12.5 \%$ on the apparatus, the yearly expense for gaslight apparatus at Philips \& Lee came to $£ 625$. He estimated Philips \& Lee were burning about $£ 104$ worth of coal a year, meaning a net yearly expense of $£ 729$. The cost of labour was not included in the calculation because it was 'certain that the cost of attendance upon the Candles would be more than upon the apps'. Watt junior reckoned that Lee would have had to spend $£ 2600$ to light his mills with tallow, an enormous expense. This meant that Philips \& Lee were saving £1871 per year with gaslight. In fact, these calculations proved to be optimistic, not least because the retorts were assumed to last for several years. ${ }^{173}$

At this point, the Winsor affair was absorbing more of Watt junior's attention's in gaslight matters, and Murdock became seriously ill towards the end of August 1807,

\footnotetext{
172 See chapter 4.
}

173 Memorandum respecting Mr. Lee's Photogenous Apparatus 1807/06/02, BWA MS 3147/3/478 \#16, AM-IR series 1 part 14 reel 273. 
probably due to overwork again, coupled with the Winsor affair adding a further cause for anxiety. ${ }^{174} \mathrm{He}$ was sent down to Bristol to visit with Dr. Thomas Beddoes, but Beddoes wrote back to Watt that Murdock never showed up, although someone matching his description dropped by without leaving his name. ${ }^{175}$ Whatever the nature of his complaint, he improved over the next days, and Thomas Wilson, another employee of Boulton \& Watt, wrote from Truro in Cornwall that Murdock was feeling well enough that he 'had taken no physic from Doctor Beddoes' and had passed by there on his way to his old haunts at Redruth. ${ }^{176}$ Murdock kept a low profile as he convalesced, and slowly got back to work. Watt junior informed his father in October 1807 that Murdock had written him regarding his improving health, and was working again for them in Portsmouth. ${ }^{177}$

As in 1806, work for customers other than Philips \& Lee hardly moved, and some started to express their unease. Benjamin Gott wrote in July 1807 to chide Watt junior a little over the lack of activity in matters gaslight: 'Perhaps Mr. Winsor has eclipsed your new lights - or perhaps you do not wish to give him any insight into the way present process with your new works. We shall wait patiently until you find it convenient.'178 Hutton wrote in October 1807 to say that the ever anxious Finlay was 'much disappointed in not having the Catrine appt this season'. Hutton added that he was

\footnotetext{
174 James Watt jr to Matthew Robinson Boulton 1807/08/23, BWA Lunar Society \#102, AM-IR series 1 part 1 reel 6.

175 Beddoes to James Watt 1807/08/26, BWA MIV /B3, AM-IR series 1 part 8 reel 116.

176 Thomas Wilson to James Watt jr 1807/09/14, BWA MS 3147/3/363 \#9, AM-IR series 1 part 13 reel 236.

177 James Watt jr to James Watt 1807/10/04, BWA MII /13/1, AM-IR series 1 part 6 reel 82.

178 Benjamin Gott to James Watt jr 1807/07/06, BWA MIV /G2, AM-IR series 1 part 8 reel 119.
} 
unwilling to take any more details about mills until he had received any definitive news about timing. ${ }^{179}$

\subsubsection{The review of December 1807-February 1808}

A cluster of analysis, experimentation and design work took place at at the end of 1807 and the beginning of 1808 , just as Boulton \& Watt were about to manufacture more apparatus for other mills. Most of the work was done, as usual, at Philips \& Lee, but some experiments were done at Soho as well. Creighton, after finishing work at Soho, moved on to Manchester where he worked with Lee at his mills, while Watt junior and Murdock remained at Soho, and a series of letters, some quite lengthy, were exchanged during December 1807 and January 1808. Murdock and Watt junior were at this time also writing Murdock's paper for the Royal Society on the invention of gaslight, and Creighton's experiments here formed the basis of that paper's experimental results. The experiments, however, were far more extensive than the paper's scope, which was in fact a priority claim intended to deal a blow to the Winsorites. The experiments began with luminosity, but soon expanded to include a wide range of other points. They covered much ground, such as flame efficiency, economics, byproducts, operating procedures, etc. and provide insight into the problems with scaling up gaslight apparatus. With two years experience using the technology, Lee and Creighton were able to give more details about how gaslight was functioning, what was working, and what needed to be changed. The economics of gaslight were revisited once more,

179 Eidingtoun Hutton to B+W 1807/10/08, BWA MS 3147/3/265 \#26, AM-IR series 1 part 12 reel 216. 
probably because the results from mid 1807 rested on dubious assumptions rather than the actual production situation at Philips \& Lee. Lee provided a more negative assessment than had hitherto been the case, while Watt junior struggled to reconcile himself to the new reality. In short the discussion reveals that many results and conclusions made with small apparatus did not hold for larger ones.

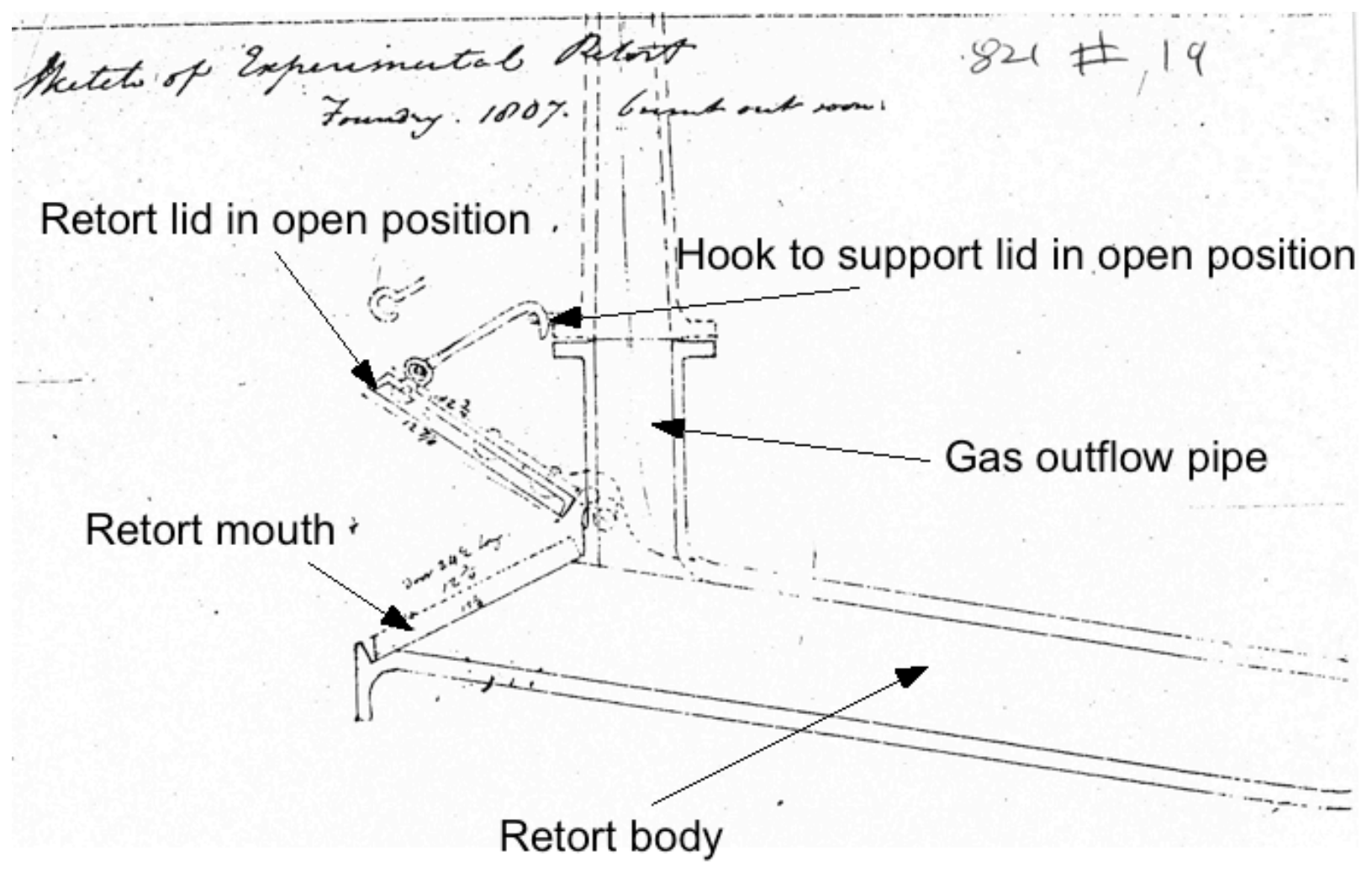

Figure 3.13 The small experimental retort. Side view. 1807, BWA MS 3147/5/821/19, AM-IR series 1 part 11 reel 184

The tests were started by Creighton using a small experimental apparatus at the Soho Foundry towards the end of year, probably before December 1807. The apparatus 
included a new retort design, 180 which held about $14 \mathrm{lb}$ of coal. The experiments were summarized in a table in Creighton's handwriting entitled 'Synopsis of Photogenous Experiments with the Small Retort' that lists various types of coal with their gas yields. ${ }^{181}$ The experiments have no conclusions, but the results are broadly in line with prior results are would not have generated any concern for Boulton \& Watt. For example, the gas needed to produce one candle for one hour was $0.25-0.5 \mathrm{ft}^{3}$, which was within or better than the $0.36-0.5 \mathrm{ft}^{3} /$ candle of 1805 and $1806 .{ }^{182}$

180 James Watt jr to Henry Creighton 1808/01/19, BWA MS 3147/3/478 \#17, AM-IR series 1 part 14 reel 273 mentions that the small oven he used at Soho had already burned out. See also 1807, BWA MS 3147/5/821/19, AM-IR series 1 part 11 reel 184. The notes here state it 'burnt out soon'. It is filed with McConnel + Kennedy, but this is clearly the experimental retort for the Soho Foundry The Soho Foundry account sheet lists 50\% of the cost of an experimental retort expense on Dec 311807 for $£ 48.12 .6$. See Soho Foundry Amounts of Sales of Goods manufactured 30 Sep 1807 to 30 Sep 1808, BWA MII /7/4, AM-IR series 1 part 6 reel 75.

181 Synopsis of Photogenous Experiments with the Small Retort 1807, BWA MS 3147/3/479 \#10, AM-IR series 1 part 14 reel 273.

182 This is derived from $1.26 \mathrm{ft}^{3}$ for 3.5 candles (1805), and $1.5 \mathrm{ft}^{3}$ for 3 candles (1806). 


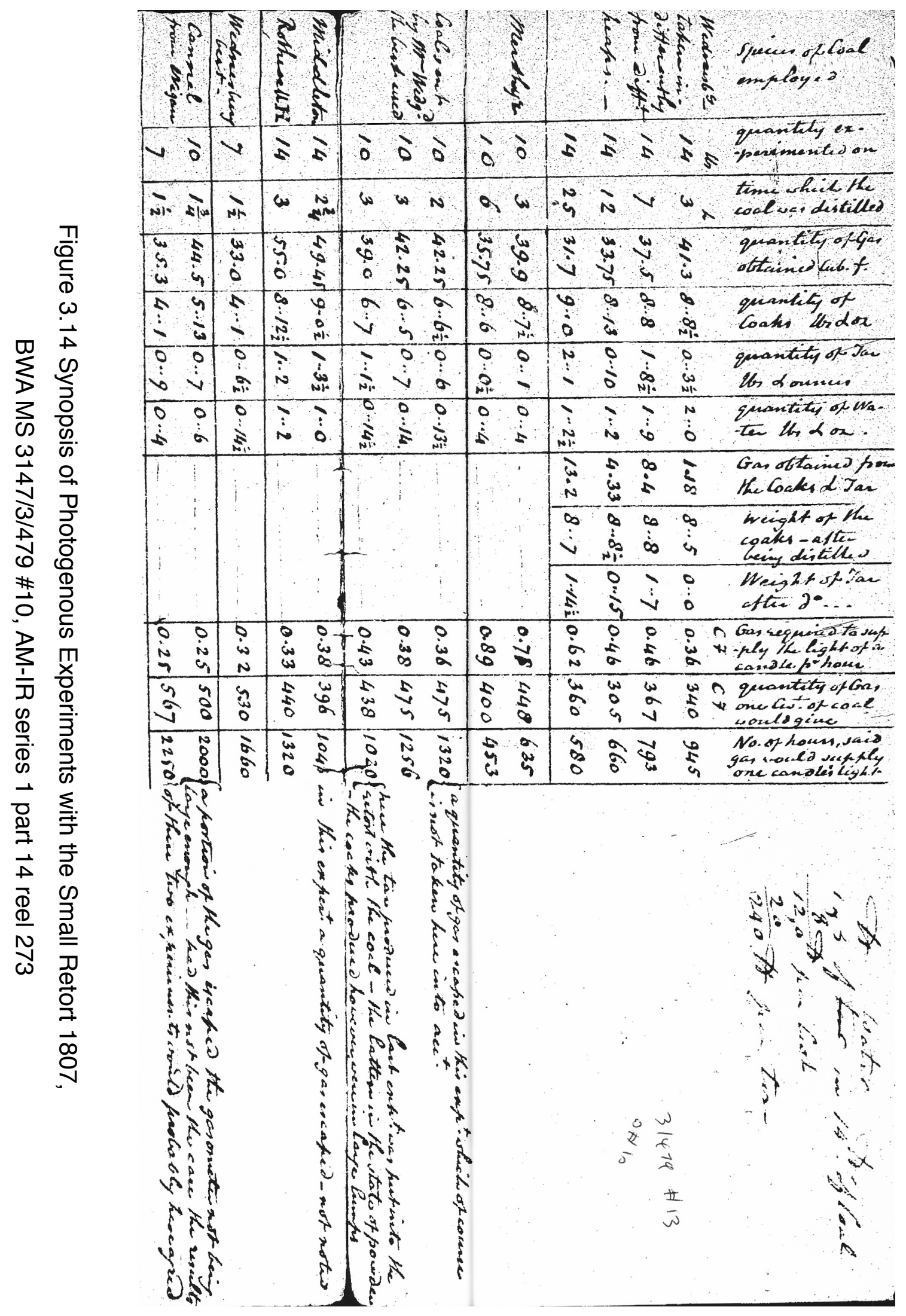


Creighton then moved on to Philips \& Lee and started experiments there on December 5, 1807.183 These continued throughout the month. Creighton sent a preliminary report to Boulton \& Watt on the 28th, running to three pages, to which Lee added a page of his own comments. ${ }^{184}$ The experiments consisted of gasifying a certain quantity of various types of coal in Lee's main apparatus, and measuring how much was produced and was needed to feed burners of various luminosities, all with a view of determining how economical gaslight actually was. The coals tried were Clifton, Wigan Cannel, and Blackrod Cannel, and the burners were the ones already installed at Philips \& Lee, being 2 candle power cockspurs and 4 candle power Argands.

183 Henry Creighton to B+W 1808/01/25, BWA MS 3147/3/247 \#43, AM-IR series 1 part 12 reel 212 p. 3 Experiments on the new light 1808/01, BWA MS 3147/3/479 \#11, AM-IR series 1 part 14 reel 273. These are press copies of notes taken during the experiments. They are almost completely illegible.

${ }^{184}$ Henry Creighton to B+W 1807/12/28, BWA MS 3147/3/247 \#40a, AM-IR series 1 part 12 reel 212. 


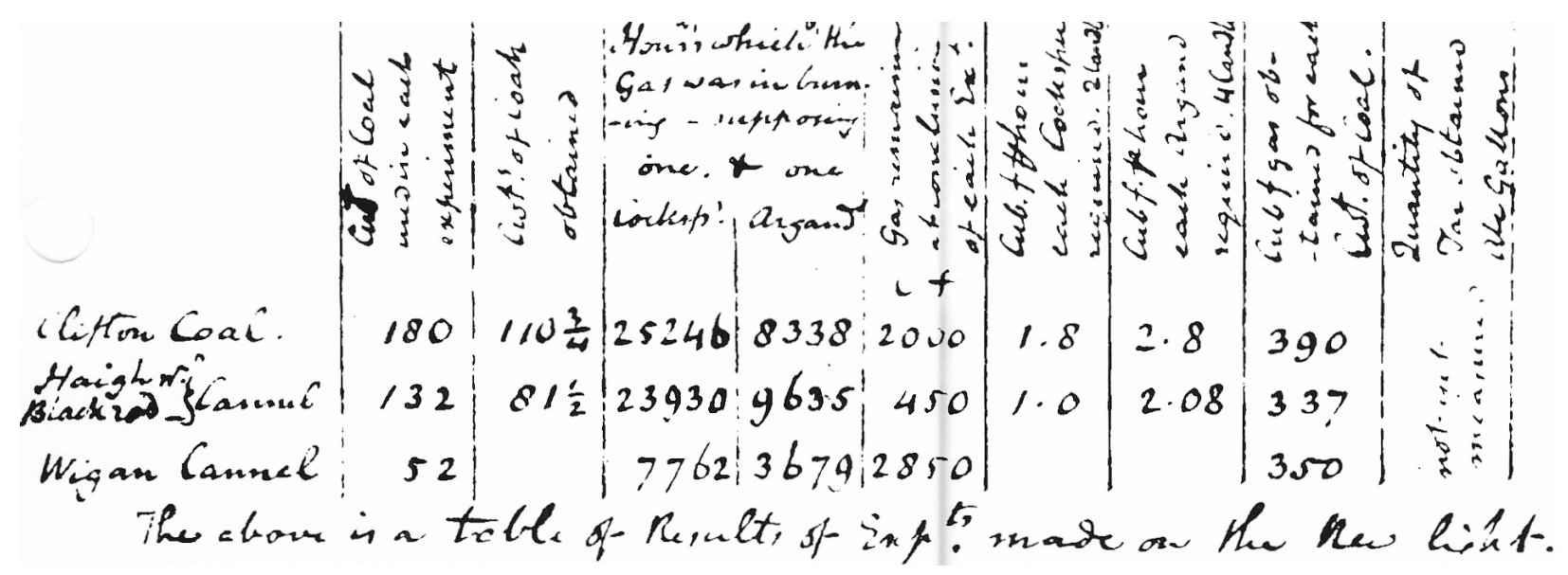

Figure 3.15 Results from coal carbonization experiments, sent by Henry Creighton to B+W 1807/12/28, BWA MS 3147/3/247 \#40a, AM-IR series 1 part 12 reel 212

The results of the experiments were that the figure hitherto used for the gas yield of coal ( $\left.160 \mathrm{ft}^{3} / \mathrm{cwt}\right)$ was approximately correct, and perhaps even a little optimistic. The Cannel coals were judged roughly equivalent, but Creighton thought their value had been overestimated in the past. His value for the candle power equivalent of cannel coal-gas was $0.5-1 \mathrm{ft}^{3} /$ candle, depending on the burner used. The range barely overlapped with the $0.36-0.5 \mathrm{ft}^{3} / \mathrm{candle}$ from the just completed Soho experiments and those of 1805 and 1806.185 When Watt junior received these results, he questioned their calculations, as will be discussed below.

Lee gave his opinion in a couple of paragraphs appended to Creighton's letter. He thought that Creighton's experiments 'afford no flattering Prospect of extending the

185 This is derived from $1.26 \mathrm{ft}^{3}$ for 3.5 candles (1805), and $1.5 \mathrm{ft}^{3}$ for 3 candles (1806). 
oeconomical Principle beyond our former Practice + Expectations'. ${ }^{186}$ He also surmised that this could be because the present experiments had been done with a retortpresumably the vertical retort at his mill-rather than an oven-the horizontal retort at the Soho Foundry. Lee would suggest the next month that Boulton \& Watt redesign the retort, and in short order the vertical retorts would be abandoned in favour of the horizontal one. It seems likely that these experiments prompted the change.

Lee also thought that they were over-distilling the coal since the gas given off at the end of the cycle was of lower quality. He proposed to do further tests on gas quality at a number of points during distillation, this time with a portable gasometer so as to be independent of the main apparatus. He hoped 'to obtain the precise Products after Combustion, by admitting the Gas ... into a close receiver united with a stream of Oxygen Gas to determine the quantity of Hydrogen, Sulphur + of Carbon by the electric Shock'. ${ }^{187}$ This was done by putting the gas 'under a Glass Jar immersed with Quick lime and fired the electric spark under Dr Henry's superintendence'. ${ }^{188}$ William Henry had already done some work on the nature of inflammable gases, and had already published a couple of papers on the subject, the second of which was based on experiments performed in close collaboration with Lee and with equipment from Boulton

\footnotetext{
186 George Augustus Lee to B+W 1807/12/28, BWA MS 3147/3/247 \#40b, AM-IR series 1 part 12 reel 212.

187 George Augustus Lee to B+W 1807/12/28, BWA MS 3147/3/247 \#40b, AM-IR series 1 part 12 reel 212.

188 George Augustus Lee to James Watt jr 1808/01/20, BWA MS 3147/3/478 \#18, AM-IR series 1 part 14 reel 273.
} 
\& Watt. ${ }^{189} \mathrm{~A}$ little later, Creighton described the how Henry's experiments were proceeding:

Dr Henry has in hand some expts on the component parts of coal gas which Mr Lee thinks it very desirous to be acquainted with. By comparing the analysis of the gas in its best state for illuminating, with that from coal nearly exhausted some hopes are entertained that a mode may be pointed out of restoring to the exhausted gas, in its formation, or otherwise that component part which it may be found deficient in. Any method $\mathrm{Dr} \mathrm{H}$ may think of for the purpose of converting the tar into gas will likewise be tried. I have been assisting in preparation for these experiments + it is probable some results will be obtained in a day or two. ${ }^{190}$

Watt junior was very happy to hear that Henry was investigating in this way but added that 'the subject is ... in much obscurity, but we do not feel ourselves chemists enough to assist him in his researches into constituent principles'. ${ }^{191}$ The final results however were not conclusive:

[T]he conclusions are far from being sufficiently uniform to be satisfactory; in the general outline they are as was expected. The Best contains three times the carbon compound with the exhausted or inferior + is about double the specific gravity. It does not yet

189 William Henry and Thomas Henry, "Experiments on Carbonated Hydrogenous Gas; With a View to Determine Whether Carbon be a Simple or a Compound Substance. By Mr. William Henry. Communicated by Mr. Thomas Henry, F. R. S," Philosophical Transactions of the Royal Society of London 87 (1797)., Henry, "Experiments on the gases obtained by the destructive distillation of pit coal, \&c., with a view to the theory of their combustion when employed as sources of artificial light."

190 Henry Henry Creighton to B+W 1808/01/10, BWA MS 3147/3/247 \#41, AM-IR series 1 part 12 reel 212.

191 James Watt jr to Henry Creighton 1808/01/19, BWA MS 3147/3/478 \#17, AM-IR series 1 part 14 reel 273. 
appear to be entitled to the denomination of Oxy, if it should be found to contain any in its blood, doubtless we should assert its claim. ${ }^{192}$

Henry published a paper, dated May 18, 1808 based on these experiments. ${ }^{193}$

192 George Augustus Lee to James Watt jr 1808/02/04, BWA MS 3147/3/478 \#18, AM-IR series 1 part 14 reel 273.

193 William Henry, "Description of an Apparatus for the Analysis of the Compound Inflammable Gases by Slow Combustion; With Experiments on the Gas from Coal, Explaining Its Application," Philosophical Transactions of the Royal Society of London 98 (1808). 


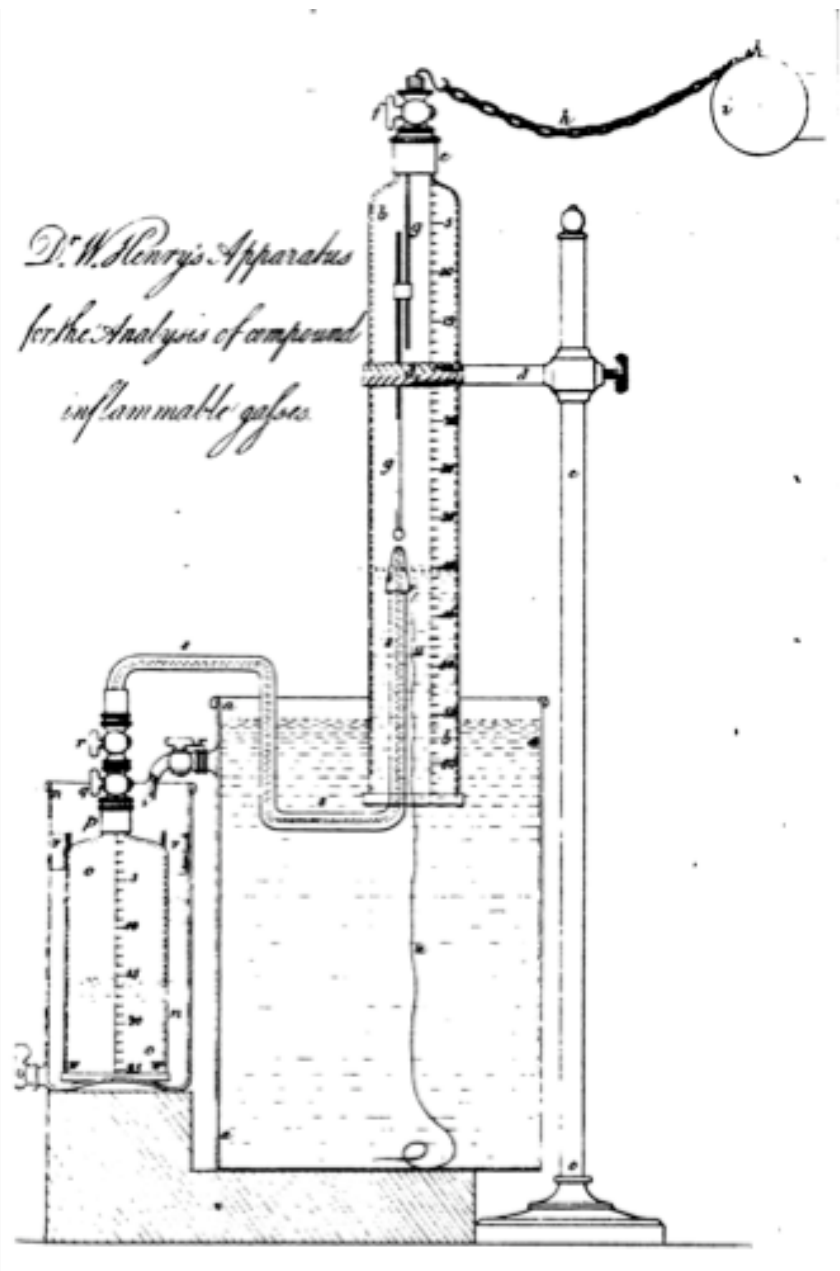

Figure 3.16 Henry. "Description of an Apparatus for the Analysis of the Compound Inflammable Gases by Slow Combustion" A Journal of natural philosophy, chemistry and the arts 22, no. 97 (1809): 83-100.

Beyond these luminosity investigations, the experiments and observations reveal that there were some concerns and questions about gaslight that had become more pressing with time. The first among these was odours, which had been one of the most 
evident objections to gaslight from the outset, but that had never really been addressed. Peter Ewart had written to Boulton \& Watt in 1805 warning them of this problem:

\begin{abstract}
When I was at Hutchinson $+\mathrm{C}$ as I mentioned to you in my last I had occasion to go up to the [garvat?] to look out some material I wanted and there I met the most damnable hogoo ${ }^{194}$ that ever assailed my olfactory nerves. I hope you will engineer better, otherwise we shall be forced speedily to withdraw the new light. ${ }^{195}$
\end{abstract}

Boulton \& Watt had been aware of the smells gaslights could produce from their own experiments at Soho even before Ewart had warned them about it. They had been hopeful that these would not be a problem on a larger scale and in their first comments from Philips \& Lee they dismissed them as not being strong enough to be a true concern. Now, however, Creighton addressed the matter for the first time in a systematic way since the apparatus had been installed at the mill. He mentioned that the Cannel coal was less malodorous than other types of coal, such as Oldham (which contained much pyrite i.e. iron sulphide), Ashton, Duckinfield, and Newton's Moor, which was 'very bad in smell after burning-yet the sulphur was not apparent in the coal'. Lee was also trying to purify the gas by washing it with running water. This worked to some extent, but since the water had to be pumped into the mill from the river, it could only be done when the steam engines were running. ${ }^{196}$ In Lee's opinion, the purification problem was the most pressing one, and would be for sometime. At the end of 1808 he

\footnotetext{
194 An antiquated word meaning an offensive taste or smell. OED.

195 Ewart to James Watt jr 1805/07/05, BWA MIV /E2, AM-IR series 1 part 8 reel 118.

196 Henry Creighton to B+W 1807/12/28, BWA MS 3147/3/247 \#40a, AM-IR series 1 part 12 reel 212.
} 
wrote to Watt junior to ask '[h]ave you consulted Murdock about forcing the Gas thro' a head of water or other Means of purifying it? It is the great Desideratum remaining'. ${ }^{197}$

Another factor affecting the odours was flame efficiency. Uncombusted gases smelled worse than those completely consumed in the flame, and so it was paramount to ensure that the burners apertures were set correctly. Unfortunately, this solution depended on constant gas pressure, which was in turn a function of the gasometers' predictability, but as gas engineers found with time, the desired constancy was hard to achieve, and the counterweight system was abandoned in favour of pressure regulators. Creighton wrote, 'The friction of the Gasometer pulleys, shafts $+\mathrm{c}$ occasion a considerable difference at times but the gasometer being loaded when the lights are running is a principal cause of this variation'.198 In fact, the counterbalance weights were being shifted every day. When the gasometers were being emptied, an extra 70 pounds was lowered onto the gasometer to drive out the gas, a procedure that completely negated the purpose of the counterweights. ${ }^{199}$

When Watt junior and Murdock received the letter, they were disappointed by the results and Lee's opinion of the financial and business prospects of gaslight. The question of how flame size affected the illuminating efficiency of gaslight was become a central question in these discussions, and experiments were taken up again at Philips \&

\footnotetext{
197 George Augustus Lee to James Watt jr 1808/12/07, BWA MIV /L6, AM-IR series 1 part 8 reel 120. 198 Henry Creighton to B+W 1807/12/28, BWA MS 3147/3/247 \#40a, AM-IR series 1 part 12 reel 212. 199 Henry Creighton to B+W 1808/01/25, BWA MS 3147/3/247 \#43, AM-IR series 1 part 12 reel 212, Answer \#11.
} 
Lee starting January 1,1808 to complete the analyses of the previous month. ${ }^{200}$

Creighton tried burners of 1,4 , and 6 candle power and found that larger flames were markedly more efficient than smaller ones. The tallow equivalent of the small flames were much higher than large flame:

\begin{tabular}{|l|c|c|}
\hline $\begin{array}{c}\text { Flame } \\
\text { (luminosity) }\end{array}$ & $\begin{array}{c}\text { Gas from Cannel coal } \\
\text { (volume equivalent to } \\
1 \mathrm{lb} \text { of tallow) }\end{array}$ & $\begin{array}{c}\text { Gas from Clifton coal } \\
\text { (volume equivalent to } \\
1 \mathrm{lb} \text { of tallow) }\end{array}$ \\
\hline 1 candle & $57 \mathrm{ft}^{3}$ & -- \\
\hline 4 candle & $20 \mathrm{ft}^{3}$ & $28 \mathrm{ft}^{3}$ \\
\hline 6 candle & $16 \mathrm{ft}^{3}$ & $24 \mathrm{ft}^{3}$ \\
\hline
\end{tabular}

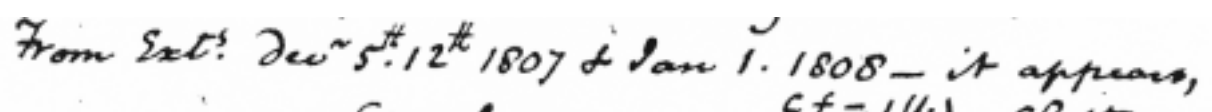

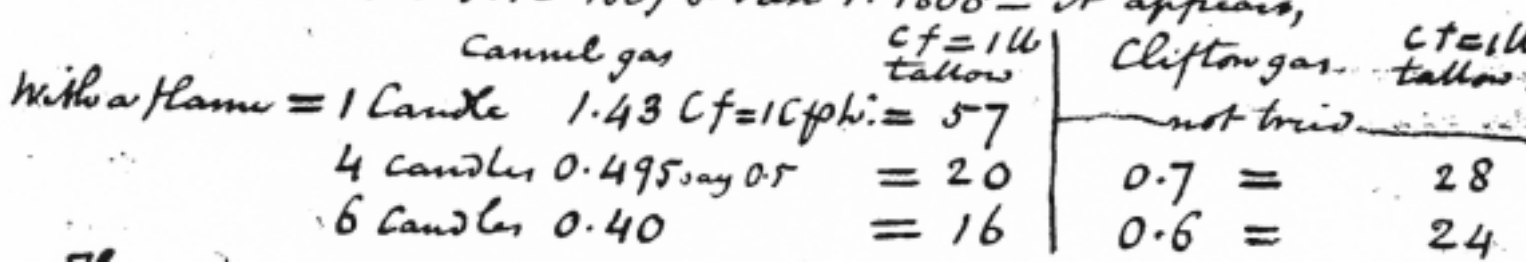

Figure 3.17 Calculation of candle equivalencies, from Henry Creighton to $B+W$ 1808/01/25, BWA MS 3147/3/247 \#43, AM-IR series 1 part 12 reel 212 p. 3

This meant that the previous figures of $14-17 \mathrm{ft}^{3}$ were only correct for the large Argand burners. There had been a tendency to favour the cockspur burners over the Argands because they were simpler and cheaper to manufacture and much easier to

200 The experiments are mentioned in Henry Creighton to B+W 1808/01/25, BWA MS 3147/3/247 \#43, AM-IR series 1 part 12 reel 212 p. 3 and Henry Creighton to B+W 1808/01/10, BWA MS 3147/3/247 \#41, AM-IR series 1 part 12 reel 212. 
keep clean. The Argands had cylindrical glass chimneys and corresponding mounts, while the cockspurs were effectively tubes. As Creighton wrote in a letter of January 10, 1808:

There are some, particularly an Ext. on the quantity of gas consumed by flames of different sizes from the same burners, that may be worth attending to-as this last (page 7) proves the oeconomy of large flames. ${ }^{201}$ A desirable thing seems to be a species of burner less complex than the Argand as now made + capable of giving the same light. As well as of burning the gas to the same (or greater) advantage. The present construction of these burners besides being expensive makes them troublesome to clean which is a thing often necessary to be done from the tar which collects in them + this tar getting hard renders it very difficult to get them in pieces. If the Glasses could be dispensed with? At any rate they should have some supports more substantial than what are used at present. ${ }^{202}$

The reports Creighton sent to Soho prompted some more serious reflection on the part of Murdock and Watt junior, who were then in the process of writing Murdock's paper for the Royal Society. They composed an extensive list of 27 questions for Creighton and Lee which they forwarded on January $19,1808.203$ The questions show that Murdock and Watt junior were not intimately familiar with how the gaslight apparatus was functioning at Philips \& Lee or even details about its physical arrangement, as the list included questions such as 'How long do the grapplers last?'; 'What number of Men are employ'd in attending to the retorts + c?', 'Is there any use

\footnotetext{
201 The press copy of these note is Experiments on the new light 1808/01, BWA MS 3147/3/479 \#11, AMIR series 1 part 14 reel 273.

202 Henry Creighton to B+W 1808/01/10, BWA MS 3147/3/247 \#41, AM-IR series 1 part 12 reel 212. 203 James Watt jr to Creighton 1808/01/19, BWA MS 3147/3/478 \#17, AM-IR series 1 part 14 reel 273.
} 
made of the tar?' and 'Are there any of the retorts worked with separate chimnies?'. The nature of these questions indicates that Philips \& Lee were doing considerable design and maintenance work, probably the great majority, in keeping gaslight going at their mill. They were not mere users whose employees were only involved as far as day to day operation of the apparatus were concerned. Rather, they maintained and repaired the apparatus, and made decisions about matters of design and implemented them. The question about the chimneys in particular demonstrates that Murdock and Watt junior had not even seen nor had access to schematics of the final configuration of the apparatus. Philips \& Lee employees had to be as familiar with the construction and operation of gaslight apparatus as anyone at Soho. Murdock does not even seem to have been at Philips \& Lee since the spring of 1806.204

Murdock's questions - the first 16-were mostly regarding the operation of the apparatus, while Watt junior was concerned primarily with the economics and reconciling Creighton's new results with the previous tests at Philips \& Lee's from March 1806 and at Soho in 1805. The picture that emerges about the operations from Creighton's answers to Murdock's queries indicate that many changes had been made since the beginning of 1806 , mostly in order to minimize the effects of the wear and tear on the apparatus and the intense heat. The retorts were now always under heat, except on Sundays when the mills shut down. Whereas in the past the retorts were allowed to cool at the end of each cycle, they were now charged under heat. The lessons of

\footnotetext{
${ }^{204}$ Henry Creighton to B+W 1808/01/25, BWA MS 3147/3/247 \#43, AM-IR series 1 part 12 reel 212, [hereafter CA] Answer \#11.
} 
extending retort life had been learned. ${ }^{205}$ Two men ran the apparatus, each working a 14 hour shift. They recharged the retorts in the two hours they were at work together. For this they received $£ 3$ a week ( $£ 100$ today). 206

The pipes immediately connected to the retorts were luted with lead to prevent the gas from leaking, but the soft lead melted easily and the joints needed to be resoldered every second charge, no easy matter considering the heat. Philips \& Lee were going through 2 cwt of lead a month. 207 The heat was also affecting the grapplers used to raise and lower the coal since they bent or broke frequently. The cranes were showing signs of heat strain. ${ }^{208}$ The original plan called for tar traps to separate the tar from the gas. These were large diameter pipes filled with water through which the gas was passed. The tar and spoiled water was removed and the water refreshed via valves, but in some cases these traps were too close to the furnace flues and the water evaporated away rapidly. The tar within the traps became thick and the valves difficult to move. The only solution was to replace the water every half hour. 209

The byproducts, especially the tar, were becoming a serious issue. Creighton had already mentioned in his letter of January 10, 1808 that the burners were becoming encrusted with tar, 210 and now he explained that the pipes closest to the retort mouth

205 CA Answer \#1 and 2, \#20. See also Lee's testimony May 12, 1809, Hall, "Select Committee on GasLight," 44., and Watt junior May 13, 1809 p. 53.

206 CA Answer \#10.

207 CA Answer \#1 and 2.

208 CA Answer \#6 and 7.

209 CA Answer \#8 and 9. It is frequently stated that Samuel Clegg invented the hydraulic main, but these traps were hydraulic mains.

210 Henry Creighton to B+W 1808/01/10, BWA MS 3147/3/247 \#41, AM-IR series 1 part 12 reel 212. 
needed to be cleaned out regularly, which entailed similar challenges from the intense heat as the reluting. Despite the tar traps, tar was getting into the pipes leading to the burners and the main pipe from the gasometers was almost choked up with 'a matter resembling hardened coak mixed with tar'. ${ }^{211}$ If the tar or other liquids accumulated in the pipes closer to the burners, the flames were liable to be extinguished or to vibrate greatly'.212 The burners were 'apt to get partially or wholly stopt with a hard substance which is probably occasioned by the iron's oxidating in some degree + the tar there growing thick + mixing with it'.213 This could only be removed by 'hammering or other considerable force which may endanger the soldering' and Creighton recommended redesigning the burners to make them easier to disassemble. ${ }^{214}$ The tar collected in the traps was allowed to pool in an excavated cistern which was not sealed in any way, with the idea of finding a buyer for it at some point. ${ }^{215}$ The tar was obviously leaching into the soil as Creighton observed that ground water was mixing with it.

211 CA Answer \#12 and 13.

212 CA Answer \#12 and 13.

213 CA Answer \#14.

214 CA Answer \#15.

215 CA Answer \#8 and 9. 


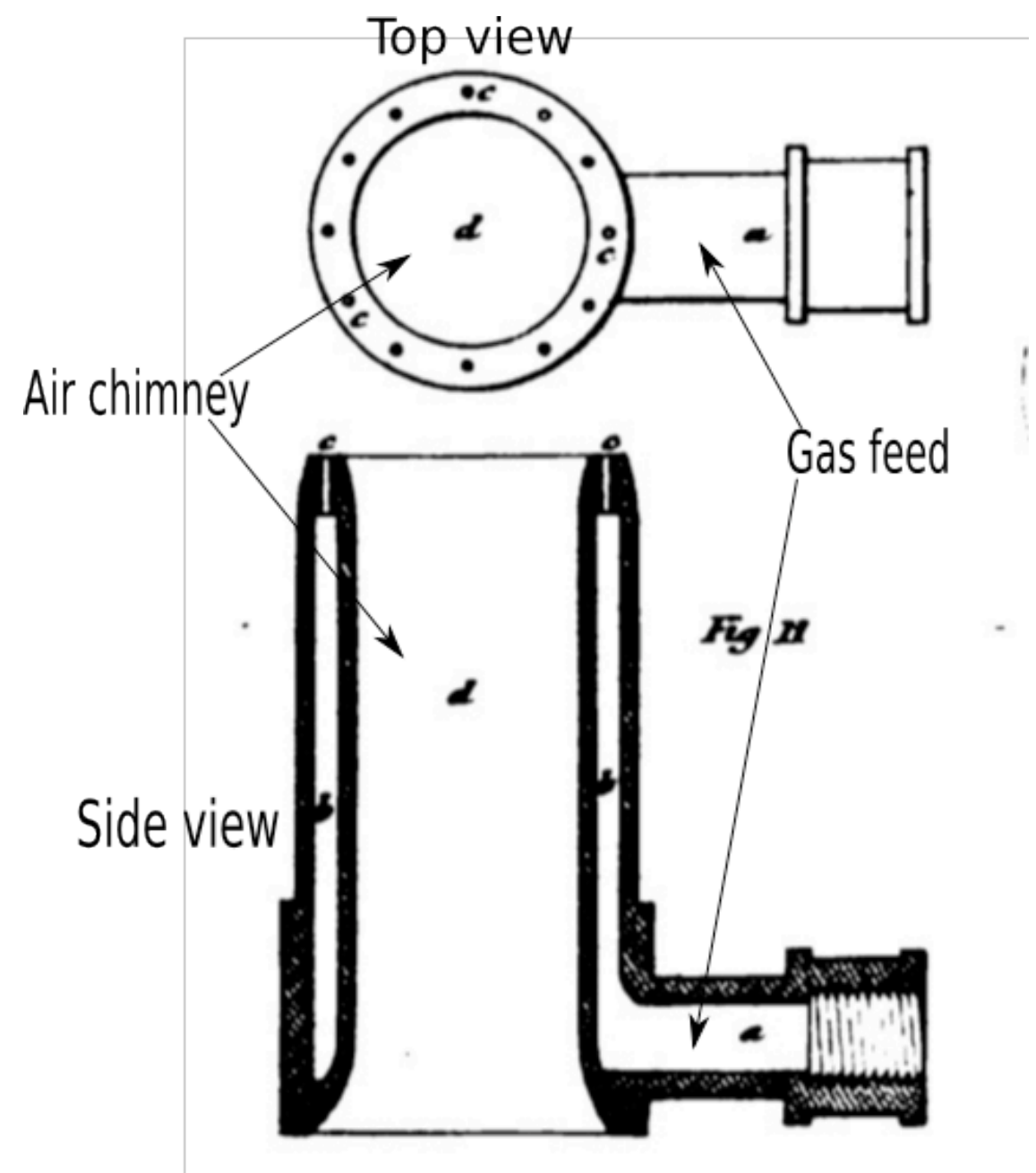

Figure 3.18 Argand burner from Creighton "Gas-Lights." in the Encyclopaedia Britannica (1824)

Watt junior's eleven questions to Creighton centred on reconciling the results from previous years in regard to luminosity and gas efficiency with Creighton's new figures. He first wanted to know why there was difference in flame efficiency for the Clifton coal- 
gas between cockspur and Argand burners, whereas this was not the case with Cannel coal. Creighton responded that that it may be because higher quality gas was less affected by flame size, but he could not provide any further reasons. To the question of why Creighton's flame efficiencies were so different than the 1806 of results, Creighton attributed most of the difference to flame sizes. The rest of the difference he put down to the quality of the gas, surmising that the 1806 gas had been taken from the optimal point in the distillation process, rather than averaged over a long period as he had done now. As he put it, 'the coal at that time was very imperfectly coaked + most of the inferior gas consequently remaining in it'.216

With regard to the 1805 Soho experiments in particular, the 'great differences' with which Watt Junior found 'extraordinary', both in terms of quality (illuminating power) and quantity produced, 217 Creighton pointed to a number of other differences that would go further to explain the puzzle. At Soho, they had used even larger flames than the 4 candle Argands, typically 10,12 , or 14 candles, and extrapolating his results to flames of that size accounted for most of the difference in gas quality. In terms of quantity of gas generated, Creighton thought that scale of the experiments accounted for the divergence. At Philips \& Lee they never got more than $350 \mathrm{ft}^{3} / \mathrm{cwt}$ compared to the 560 $\mathrm{ft}^{3} / \mathrm{cwt}$ recorded at Soho, but whereas at Soho they had used a small retort containing $10 \mathrm{lb}$ of coal, heated very rapidly, at Philips \& Lee they heated $1700 \mathrm{lb}$ of coal over

216 CA Answer \#17.

217 James Watt jr to Creighton 1808/01/19, BWA MS 3147/3/478 \#17, AM-IR series 1 part 14 reel 273: question \# 19. 
hours to the point of exhaustion. The circumstances were simply too different to achieve identical results, and the Soho results were based on invalid extrapolations. ${ }^{218}$

Creighton finished his letter by answering the rest of Watt junior's questions briefly, and then he proposed a new mode of setting the experimental retort which did not expose to such direct heat by protecting it with more firebricks. A number of years later, in 1817, the gas industry started using this sort of arrangement in retorts ovens. This is described in chapter five.

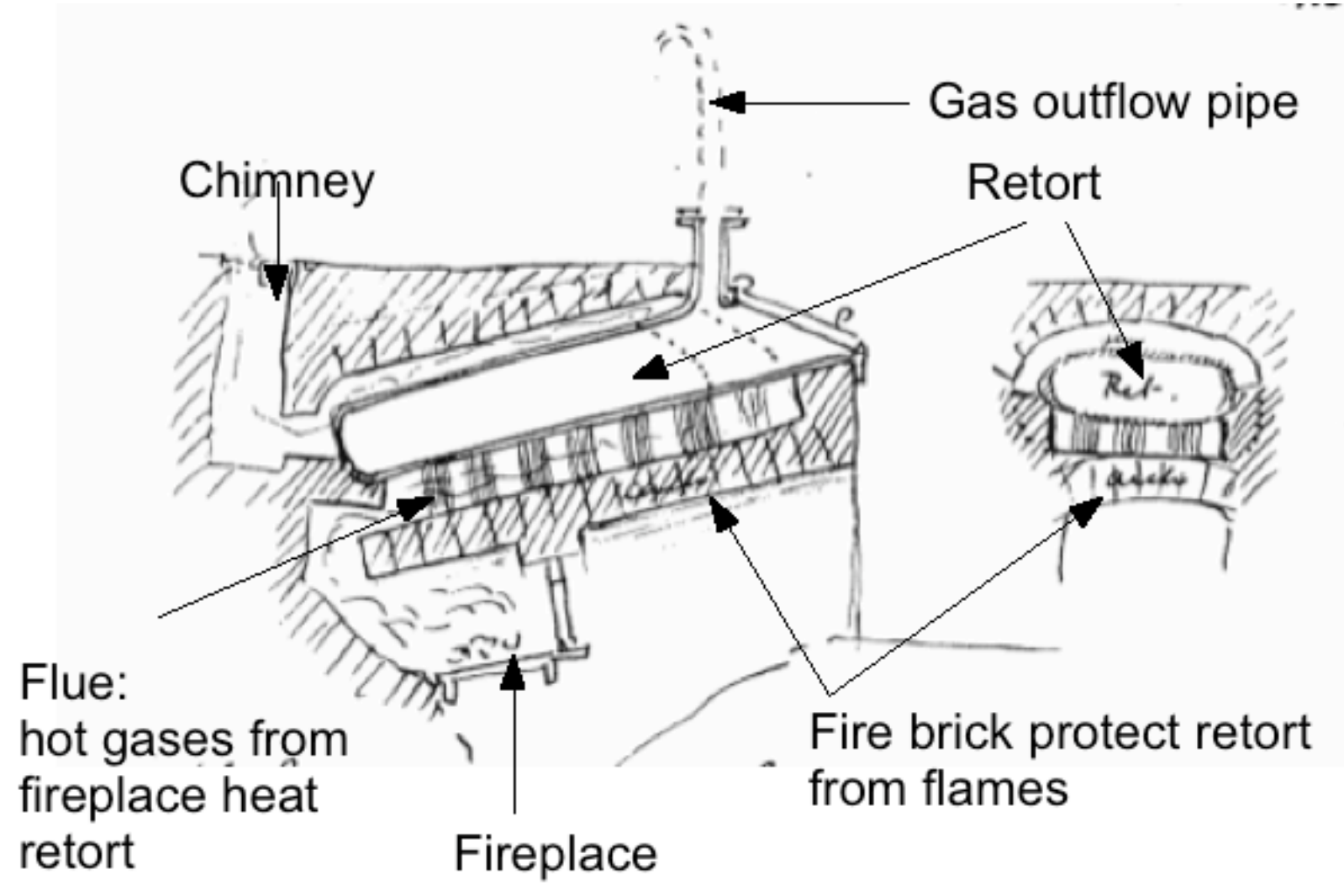

Figure 3.19 Suggestion for a new retort design, from Henry Creighton to $B$ +W 1808/01/25, BWA MS 3147/3/247 \#43, AM-IR series 1 part 12 reel 212

218 CA Answer \#19. 
With regard to the economics, Creighton went over the analyses and figures of June 1807 which had determined that gaslight saved Philips \& Lee £1871 per year. ${ }^{219}$ He sent in a new report which formed the basis of the Murdock's 1808 Royal Society. Almost all the figures in the Royal Society paper are identical to those found in this letter of Creighton's. Creighton reported that at this point there were 633 cockspur and 271 Argand burners in the Old and New Mill, counting houses, and Lee's home for a total of 2500 candles. $^{220}$ These consumed $2500 \mathrm{ft}^{3}$ of gas per day, requiring $7 \mathrm{cwt}$ of cannel coal. The yearly cost of distillation coal was $£ 125$, plus $£ 20$ more for fuel, less $£ 93$ for coke sold for a net coal expense of $£ 52$. The depreciation on $£ 5000$ for the apparatus at $12.5 \%$ was $£ 625$ (the same figures as Watt junior’s in 1807), for a total yearly cost for gaslight of $£ 677$. This replaced the equivalent of $£ 2000$ of tallow per year, for a net savings of $£ 1200$, or $35 \%$ less than what Watt junior had reckoned in 1807 . When the Royal Society paper was published on February 25, 1808, the depreciation expense was lowered to $£ 550$ with no justification provided for the new figure. ${ }^{221}$ Considering that the original depreciation figure was too low because it did not properly account for retort replacement frequency, the new lower figure had even less validity. The revision brought the net advantage of gaslight back to $£ 1800$.

\footnotetext{
219 Memorandum respecting Mr. Lee's Photogenous Apparatus 1807/06/02, BWA MS 3147/3/478 \#16, AM-IR series 1 part 14 reel 273. Creighton's new figures are in Henry Creighton to B+W 1808/01/25, BWA MS 3147/3/478 \#18, AM-IR series 1 part 14 reel 273 p. 4-5.

220 Memorandum respecting Mr. Lee's Photogenous Apparatus 1808/01/19, BWA MS 3147/3/478 \#18, AM-IR series 1 part 14 reel 273. This letter gives 629 cockspur and 275 Argand, but Creighton correct himself in Henry Creighton to B+W 1808/01/25, BWA MS 3147/3/478 \#18, AM-IR series 1 part 14 reel 273 p. 4-5. The correct values were used in Murdock's 1808 Royal Society paper.

${ }^{221}$ Murdoch, "An Account of the Application of the Gas from Coal to Economical Purposes," 128.
} 
Lee added his comments to Creighton's calculation:

Dear Sir,

Mr Creighton has communicated to you in course, the progress of our Photogenous Researches. The inclosed statement of the comparative oeconomy is the result of them. Your Experiments warranted more favourable conclusions because small Retorts appear to disengage more Gas, and large Argand Burners more light. Upon a large scale, the advantage of the former is yet dubious, and the latter would lose more in convenience than it saves in expence. Our successive weekly Results correspond + confirm their accuracy, and average 350 cubic feet per $112 \mathrm{lbs}$. Cannel Coal, and 20 cubic $\mathrm{ft}$ [which is?] a quantity of light equal to that from a pound of tallow. ${ }^{222}$

Gaslight was clearly not easily moved from the laboratory scale or even small industrial scale to the a production industrial context.

Watt junior received Creighton's and Lee's letters and wrote back on January 23, 1808 , saying 'I confess myself somewhat disappointed by the oeconomical statement for although I did conceive we had rather overdone it before, I did not expect so great a difference as appears, and I think the causes are not yet fully explained'. ${ }^{223} \mathrm{He}$ acknowledged that the 1805 Soho experiments had used large Argands, but insisted that the March 1806 experiments at Philips \& Lee had been performed with 3.5 candle cockspurs. He added:

222 George Augustus Lee to James Watt jr 1808/01/20, BWA MS 3147/3/478 \#18, AM-IR series 1 part 14 reel 273.

223 James Watt jr to George Augustus Lee 1808/01/23, BWA MS 3147/3/478 \#17, AM-IR series 1 part 14 reel 273. 
This deduction you see is made from cockspurs, + I am not aware of any other objection to it, than what may arise from the gas having been taken in its most perfect state. [...] Have you reduced the light of your cockspurs? Mr Murdock never estimated it at less than 3 to $31 / 2$ candles, and he assured me he made repeated trials. You will readily see from the above, that a further expt to determine the comparative quantity of light + consumption of Tallow, may be of service towards clearing up our difficulties. ${ }^{224}$

Watt junior also questioned whether Creighton had correctly estimate the tallow equivalents of Cannel coal-gas.

Creighton and Lee responded on January 25,1808 , standing by their results and analysis. Most of Creighton's answers were contained in the list of 27 answers described above, to which he appended another economic analysis, this time assuming gaslight was used for 3 hours a day rather than the 2 actually used at Philips \& Lee.225 Watt junior had requested this in his letter of the 23rd because it would strengthen the economic case for gaslight, although it did not correspond to the situation at Philips \& Lee. ${ }^{226}$

Lee wrote a separate letter to Creighton's and was unwavering in his opinion:

Mr H. Creighton's Answers to your Questions which accompany this letter, render it unnecessary for me to reply to yours of 23rd Inst upon these points. With our present

\footnotetext{
224 James Watt jr to Lee 1808/01/23, BWA MS 3147/3/478 \#17, AM-IR series 1 part 14 reel 273.

225 Henry Creighton to B+W 1808/01/25, BWA MS 3147/3/247 \#43, AM-IR series 1 part 12 reel 212 $3750 \mathrm{ft}^{3}$ of gas per day, requiring $10.75 \mathrm{cwt}$. The total yearly cost of coal was $£ 78$, and the depreciation on $£ 5000$ at $12.5 \%$ was $£ 625$, for a total yearly cost of $£ 703$. Tallow cost was $£ 3000$, oil $£ 1800$. Net gain $£ 2297$.

226 James Watt jr to George Augustus Lee 1808/01/23, BWA MS 3147/3/478 \#17, AM-IR series 1 part 14 reel 273.
} 
apparatus and knowledge of the subject, I feel fully confirmed in the correctness of our oeconomical statement, and as it is founded upon extensive and correct Experiments, which agree in their [confronted?] weekly results with each other, as well as with trials previously made upon a smaller scale. ${ }^{227}$

Lee was uncertain whether the shadows method of estimating luminosities was correct, but thought it would do. He did, however, suggest that Boulton \& Watt reconsider how the shape and size of the retorts. This was indeed done and new retorts made by Boulton \& Watt were horizontal.

Watt junior was still not satisfied. He considered that 'the difference between the present + former Expts is not sufficiently accounted for'.228 The only possibility he could see was that somehow the cockspurs at Philips \& Lee were dimmer now, being around 2.5 candles, than they had been in March 1806, when Murdock had estimated 3.5 candles. It was clear what he was driving at:

\footnotetext{
If indeed, both the Expts made in 1806 and those now made, are to be assumed correct, such reduction must have taken place; but I wish to be informed, whether any direction to that effect has been given, or whether Mr Lee or his managers are sensible of any in reduction of the Light.
}

227 George Augustus Lee to James Watt jr 1808/01/25, BWA MS 3147/3/478 \#18, AM-IR series 1 part 14 reel 273.

228 James Watt jr to Henry Creighton 1808/01/27, BWA MS 3147/3/478 \#18, AM-IR series 1 part 14 reel 273. 
It follows necessarily from your Expts that if the average light in the common course of working is greater than in your statement, the comparative oeconomy will likewise be greater, and this may materially affect the annual statement. ${ }^{229}$

To this question, Lee responded through Creighton that he did think the lights were dimmer now than in the past, but in that case the assumption about how many tallow candles they were replacing would also need to be modified, and so the economics would not be much improved. 230 He wrote personally at the beginning of February 1808: 'Our Photogenous Apparatus produces nearly uniform results + confirms most completely our statement'. ${ }^{231}$ This missive put an end to the discussion and Murdock and Watt junior went with Creighton's figures in the Royal Society paper, but as mentioned earlier, they found new economies by arbitrarily changing the depreciation expense. ${ }^{232}$

With the recent design work completed, Lee was of the opinion that the gaslight business was at an inflection point: 'Depen'd the Demand for the apparatus will one day be as great as sudden, + you have now an oppt. of more leisure to determine all difficult or dubious points', 233 of which the most pressing was purification. This was not a problem that Boulton \& Watt ever solved.

\footnotetext{
229 James Watt jr to Henry Creighton 1808/01/27, BWA MS 3147/3/478 \#18, AM-IR series 1 part 14 reel 273.

230 Henry Creighton to B+W 1808/01/29, BWA MS 3147/3/247 \#44, AM-IR series 1 part 12 reel 212, also mentioned in BWA MS 3147/3/478 \#18, AM-IR series 1 part 14 reel 273.

231 George Augustus Lee to James Watt jr 1808/02/04, BWA MS 3147/3/478 \#18, AM-IR series 1 part 14 reel 273.

232 Murdoch, "An Account of the Application of the Gas from Coal to Economical Purposes." p. 126.

233 George Augustus Lee to James Watt jr 1808/12/07, BWA MIV /L6, AM-IR series 1 part 8 reel 120.
} 


\subsubsection{New orders and deliveries 1808}

Boulton \& Watt did not deliver a second gaslight installation to a manufacturing mill until late in $1808,{ }^{234}$ but they then began to build and install new apparatus in earnest. When the orders were taken in 1806, they had believed they could get some of the apparatus done that year, but were frustrated in their ambition, probably because they wanted more experience with Philips \& Lee's apparatus before they made more. The sincerity of their belief in their ability to supply further apparatus that year is shown by the drawings they prepared for other mills, such as Wormald, Gott, \& Wormald in April $1806,{ }^{235}$ and for McConnel \& Kennedy in July of 1806.236 The number of light and the apparatus' size for McConnel \& Kennedy was finalized in September 1806,237 and the plans called for 110 lamps of two candles each, two $1500 \mathrm{ft}^{3}$ gasometers, and four retorts. There is no further word about this apparatus or any other apparatus until January 1808 and some of their customers, such as Finlay \& Co., were doubtless disappointed. Despite Finlay's great initial enthusiasm, they lost interest and do not list among Boulton \& Watt's purchasers of lighting apparatus at any time. The reversal happened when towards the end of 1807, one of the Finlay's associates, Robertson Buchanan, went to Manchester to evaluate how Lee's apparatus was running. His report must have been negative, because Finlay was not heard from again. ${ }^{238}$ Peter

\footnotetext{
234 Watt junior's testimony on May 13, 1809. Hall, "Select Committee on Gas-Light," 51.

235 Drawings and notes 1806/04/ MS 3147/5/812/14 and 16, AM-IR series 1 part 11 reel 184, and 1806/04/, BWA MS 3147/3/478 \#47 and 48a series 1 part 14 reel 273.

236 Henry Creighton to B+W 1806/07/22, BWA MS 3147/3/247 \#21, AM-IR series 1 part 12 reel 212.

237 McConnel \& Kennedy's Photogenous Apparatus 1806/09/29, BWA MS 3147/3/478 \#20, AM-IR series 1 part 14 reel 273.

238 Eidingtoun Hutton to B+W 1807/12/10, BWA MS 3147/3/265 \#36, AM-IR series 1 part 12 reel 216.
} 
Marsland is another case of a potential customer withdrawing. He was interested enough in 1806 to have drawings prepared, and asked for another estimate in 1809, but never ordered. ${ }^{239}$ Others such as Horrocks \& Co. in Stockport went bankrupt in the meantime. 240 In the quiet year of 1807 some other mills expressed interest but they were met with silence or vague assurances. One mill owner asked: 'Might I without being deemed too troublesome again ask what would be the expence of the apparatus'?241 Boulton \& Watt even had enquires about home gaslight apparatus, such as from Josiah Wedgewood who wrote to Watt junior in 1807 asking to get a quote for his house which he was about to renovate. ${ }^{242}$

The hesitations and delays stopped in 1808 , when Boulton \& Watt felt ready to supply other installations. When Creighton was at work at Philips \& Lee in early 1808 , he met with McConnel \& Kennedy and James Kennedy, both of whom had begun making preparations for their installations. He wrote that ' $M$ [cConnel] $\mathrm{K}$ [ennedy] is resolved to proceed with immediately. [...] I will endeavour to get the whole finally settled as well these as at Mr Jas Kennedys who is now digging the pits for his gasom. as he means to have part of the apparatus ready for next winter'. One challenge at James Kennedy's was that the ground was quite damp and so the gasometer pits could not be sunk very deeply, with the result that Creighton worried about whether 'the lower rooms of the mill would be deprived of much of their light'. Creighton also reported that the

\footnotetext{
239 Henry Creighton to B+W 1809/02/23, BWA MS 3147/3/247 \#66, AM-IR series 1 part 12 reel 212. 240 Henry Creighton to B+W 1808/01/10, BWA MS 3147/3/247 \#41, AM-IR series 1 part 12 reel 212. 241 William Balston to B+W 1807/01/23, BWA MS 3147/3/42 \#24, AM-IR series 1 part 12 reel 203. 242 Wedgewood to James Watt jr 1807/06/03, BWA MS 3147/3/529 \#64, AM-IR series 1 part 15 reel 275.
} 
apparatus for McConnel \& Kennedy was much altered from the plans originally prepared in 1806.243

The apparatus began to be manufactured in January 1808 , and Creighton acknowledged receipt of some retorts for McConnel \& Kennedy on the 29th. He also described that James Kennedy hoped to purify his gas much the same way as Philips \& Lee. Kennedy wanted to draw water for the neighbouring canal continuously and pass it through a tar trap where the gas could be washed before it reached the gasometer. ${ }^{244}$ The tar and waste water would be drawn off and washed down a drain back into the canal. ${ }^{245}$ Creighton also mentioned that Birley \& Co. of Oxford street in Manchester were also desirous of finalizing their purchase. ${ }^{246}$ Unfortunately for Birley, he received no faster service than Boulton \& Watt's earlier customers and Creighton wrote four months later than 'Mr Birley has made repeated enquiries respecting his estimate for lighting apps. + seems very anxious about it-you probably could furnish him with it soon'.247 Nor was James Kennedy getting his apparatus more expeditiously. Creighton prepared an estimate for the number of burners (555) and pipe lengths in May 1808, but no drawings were yet finished 248 . It was only in September and October 1808 that the

\footnotetext{
243 Henry Creighton to B+W 1808/01/10, BWA MS 3147/3/247 \#41, AM-IR series 1 part 12 reel 212. 244 Henry Creighton to B+W 1808/01/29, BWA MS 3147/3/247 \#44, AM-IR series 1 part 12 reel 212. 245 Gasometer pit 1808/10/17, BWA MS 3147/5/817/2, AM-IR series 1 part 11 reel 184. 246 Henry Creighton to B+W 1808/01/29, BWA MS 3147/3/247 \#44, AM-IR series 1 part 12 reel 212. 247 Henry Creighton to B+W 1808/04/16, BWA MS 3147/3/247 \#49, AM-IR series 1 part 12 reel 212. 248 James Kennedy Esq Photogenous Apps 1808/05/14, BWA MS 3147/3/478 \#8 series 1 part 14 reel 273 mentioned in James Watt jr to Matthew Robinson Boulton 1808/09/20, BWA MS 3147/3/57 \#2, AM-IR series 1 part 12 reel 206.
} 
drawings were finished for Kennedy ${ }^{249}$ and Birley, ${ }^{250}$ as well as additional ones for McConnel \& Kennedy. ${ }^{251}$ Watt junior made a trip to Manchester to visit the mills and scrutinize the situation. He wrote to Boulton about their customers:

[I] have now seen Messrs. H Birley + Co who are anxious to receive the drawings of the gazometer parts $+c$, that they may proceed with the brickwork. M. James Kennedy has built a pit for his gazometer which is proposed to be $20 \mathrm{ft}$ long 10 wide and [10?] deep, and he wishes it, as well as the other articles innumerated in the memorandum of which Mr Creighton gave me a copy, to be proceeded with immediately.252

The components were manufactured quite quickly in this case. The drawings indicate that Boulton \& Watt had heeded Lee's advice about rethinking the retorts, and they were now all on the horizontal plan. The retort cross section was made taller than the experimental retort used at the foundry in 1807 , and now resembled a D-form that became quite common in later history of the gaslight industry. Boulton \& Watt were now using a complicated set of pipes to get the gas into and out of the gasometers.

Previously, the pipes had entered from the bottom, but this made them difficult to access in case of blockage, a not infrequent event. Their new design called for pipes that entered the gasometers at the top, and that had moveable joints immersed in water

249 Gasometer pit, Moveable water traps, Retort section 1808/10/17, BWA MS 3147/5/817/2, 4 and 6, AMIR series 1 part 11 reel 184 1808, BWA MS 3147/5/817/10, AM-IR series 1 part 11 reel 184.

250 Retort and gasometer pit 1808/09/19, BWA MS 3147/5/817/5, AM-IR series 1 part 11 reel 184 Gasometer 1808/10/03, BWA MS 3147/5/817/2, 9, AM-IR series 1 part 11 reel 184 1808, BWA MS 3147/5/817/1, 9, AM-IR series 1 part 11 reel 184.

251 Gasometer suspending apparatus 1808/09/28, BWA MS 3147/5/821/12, AM-IR series 1 part 11 reel 184 Gasometer suspending apparatus 1808/10/05, BWA MS 3147/5/821/10, AM-IR series 1 part 11 reel 184. 252 James Watt jr to Matthew Robinson Boulton 1808/09/20, BWA MS 3147/3/57 \#2, AM-IR series 1 part 12 reel 206. 
to make the airtight. The assembly consisted of two pipes and three moveable water joints to allow for the gasometer's rise and fall during operation. This design was ingenious, but proved to be impractical. It was little used outside of Boulton \& Watt. 


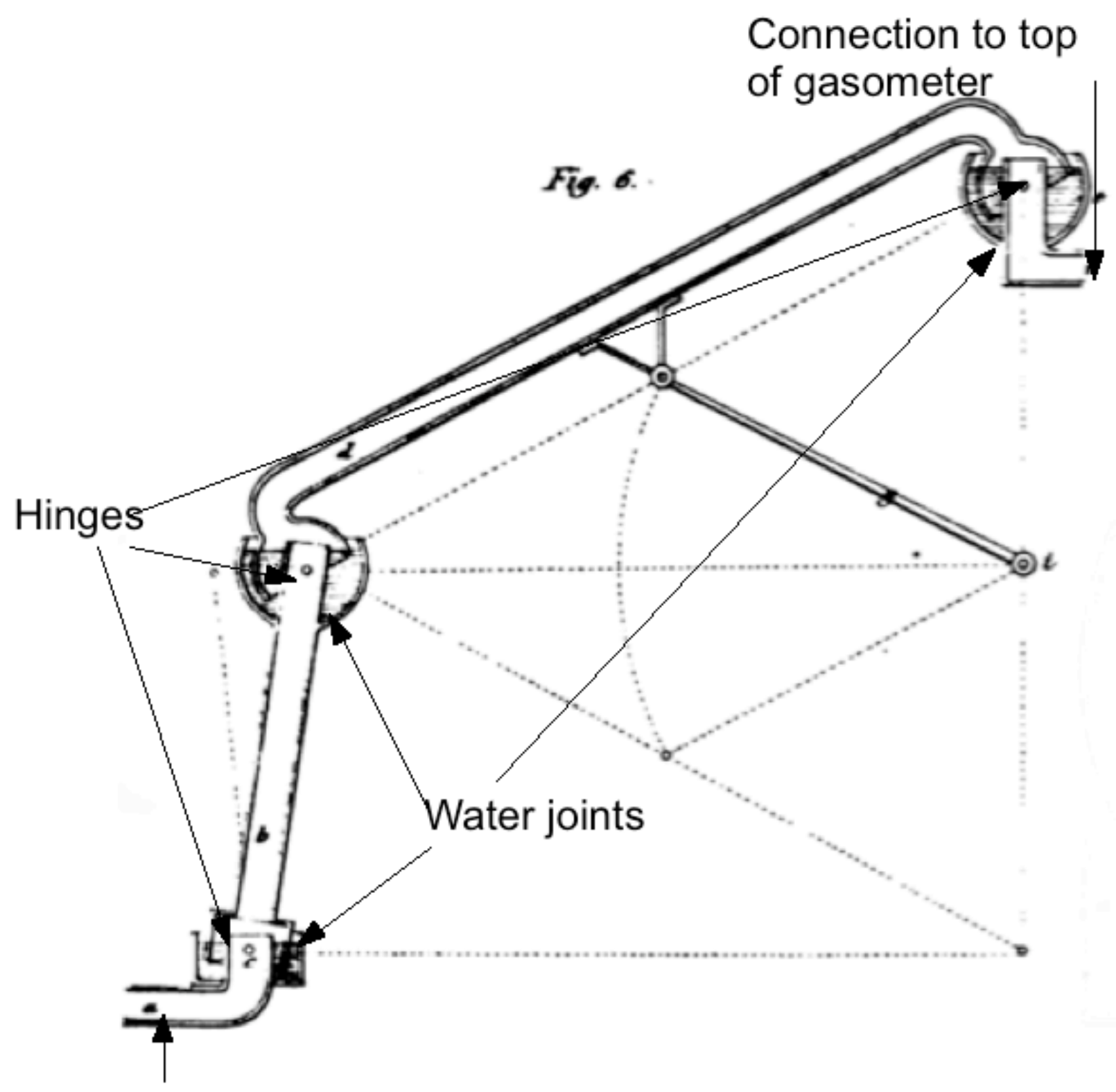

Gas inflow from retorts

Figure 3.20 Gasometer pipe, from Creighton (1824), showing water luted joints. 
Hook to support retort mouth when open

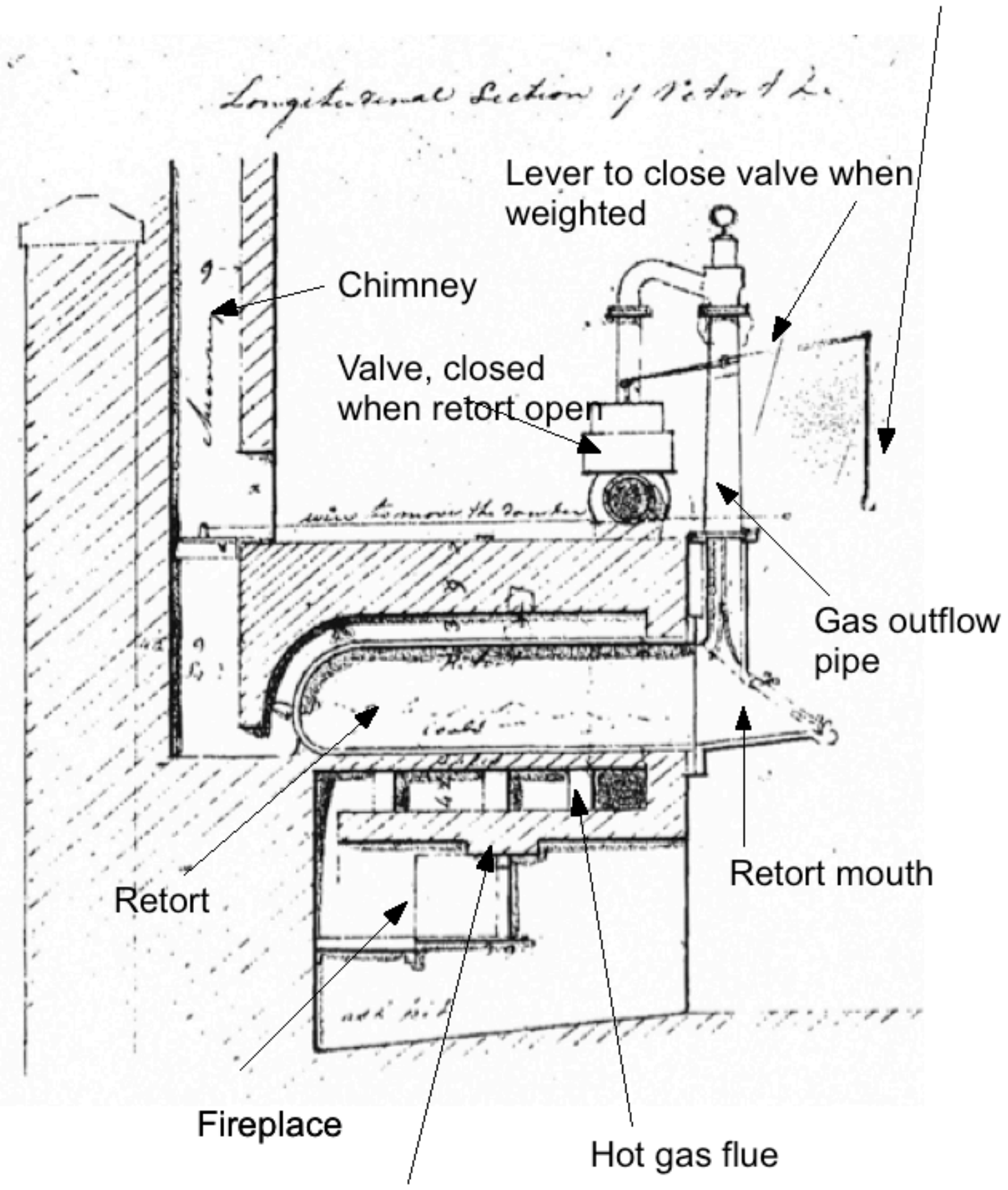

Fire bricks to protect retort from flames

Figure 3.21 Retorts at James Kennedy, side view.

Note the use of fire brick to protect the retorts. 


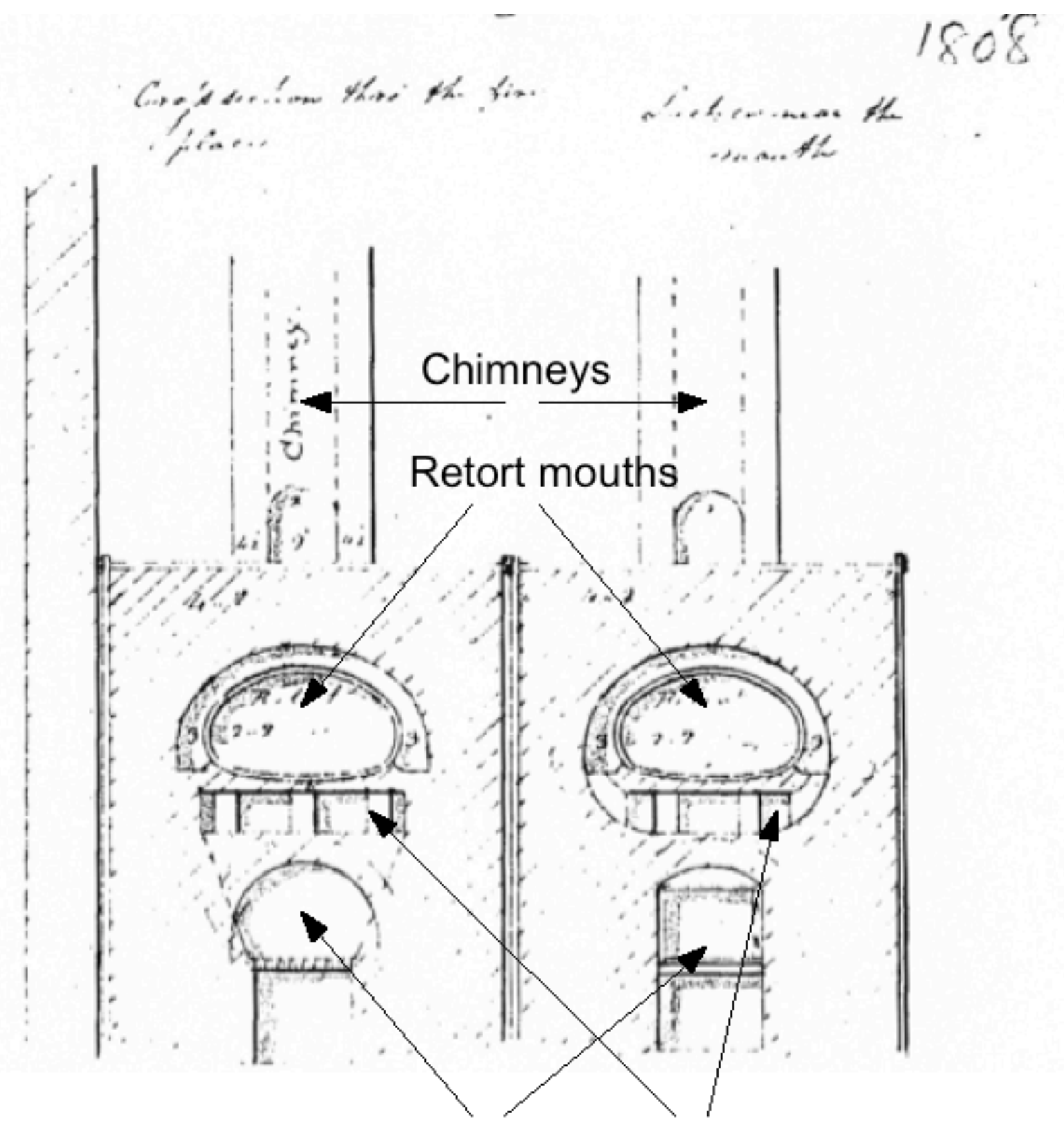

\section{Fireplaces Flues for hot gas from fireplace}

Figure 3.22 Retorts at James Kennedy front view.

Note the use of fire brick to protect the retorts. 


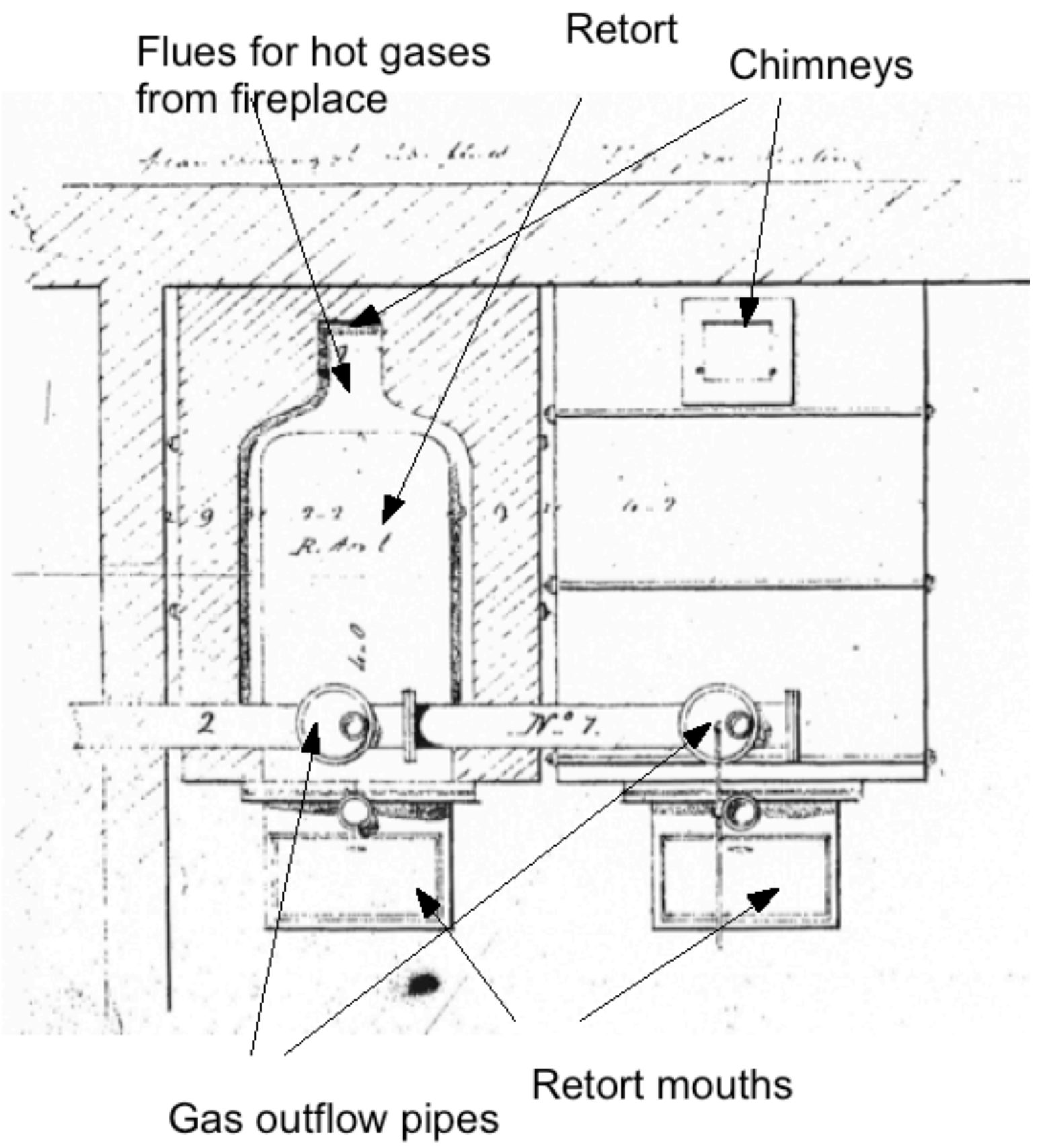

Figure 3.23 Retorts at James Kennedy, top view. 


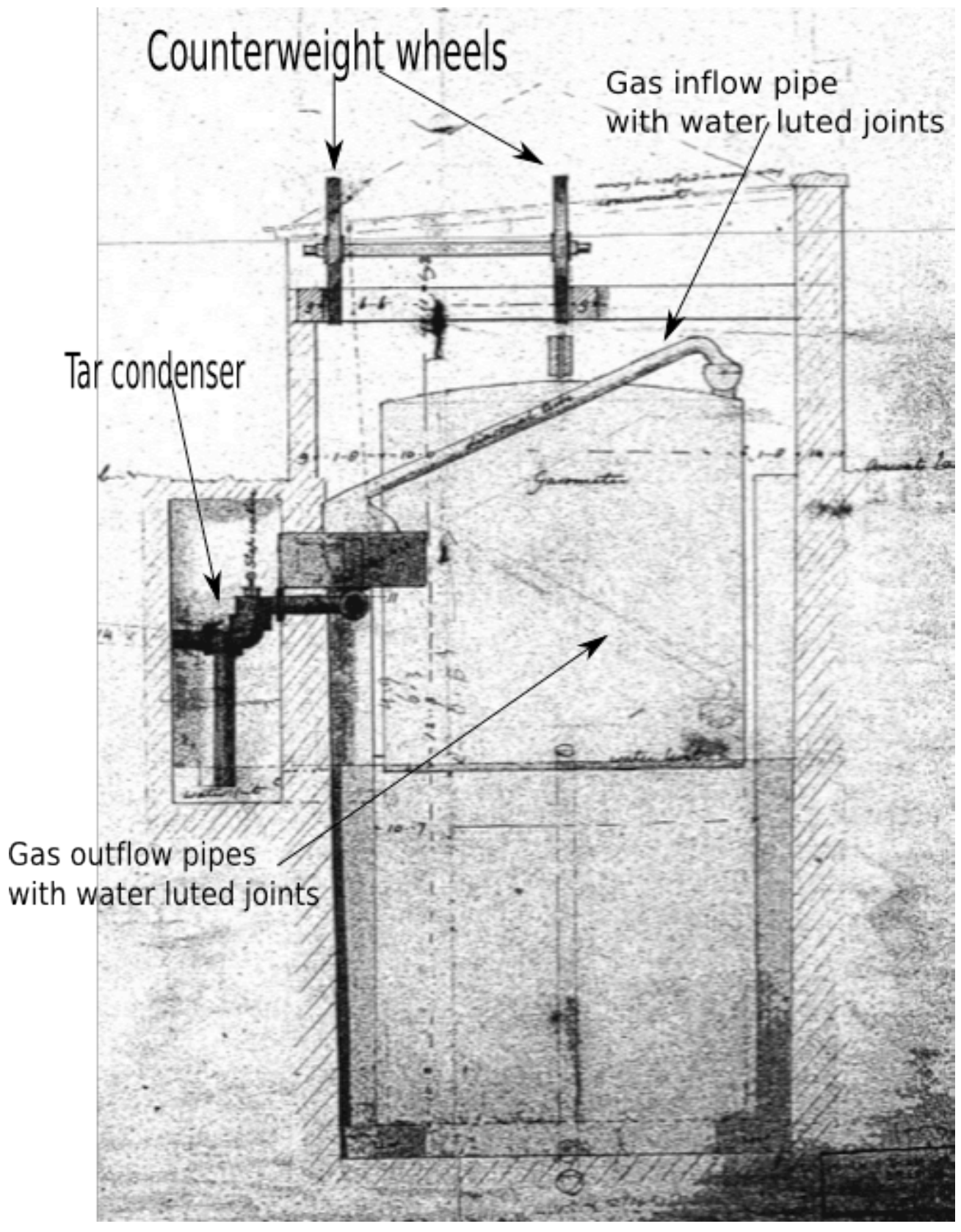

Figure 3.24 Side of gasometer at James Kennedy, all from 1808, BWA MS 3147/5/817/8, 10, AM-IR series 1 part 11 reel 184 


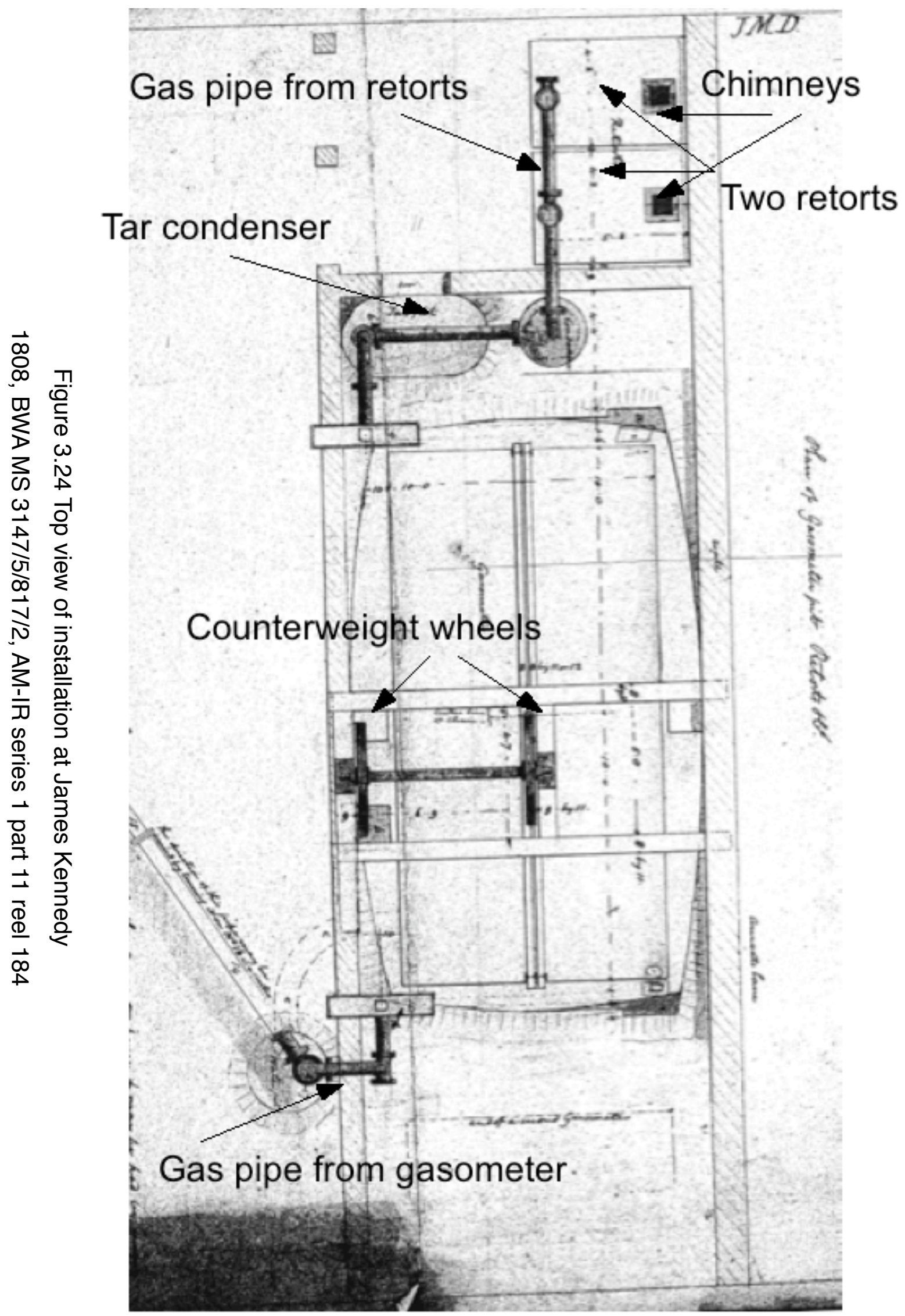


They were shipped off to the three mills before the end of the year, and payments are recorded from Birley (£779) and James Kennedy (£537) before the year was done. ${ }^{253}$ Gillespie \& Co. in Glasgow were also now interested, ${ }^{254}$ and Wormald, Gott \& Wormald of Leeds, who had been among the 1806 orders, restarted their order255 and fresh drawings prepared before the end of $1808 .{ }^{256}$ Birley \& Co.'s apparatus was running during the winter of 1808-1809 although they had some initial problems such as a poorly seated retort which subsequently cracked, ${ }^{257}$ lead accumulating in pipes, and burners made of thin material. ${ }^{258}$ They were to be minor customers of Boulton \& Watt for a few more years. ${ }^{259}$ James Kennedy's excavations were completed in February 1809 and he had his apparatus running that year. ${ }^{260} \mathrm{He}$ also made additions, such as one at the end of 1809,261 and in 1810.262

\footnotetext{
253 Lighting apparatuses per agreement 30 Sep 1808 to 30 Sep 1809, BWA MII /7/4, AM-IR series 1 part 6 reel 75: Birley 1808/11/28 for $£ 700$ and 1808/12/31 for $£ 79$; Kennedy 1808/12/30.

254 Matthew Robinson Boulton to James Watt jr 1808/11/21, BWA MIV /B6, AM-IR series 1 part 8 reel 116. 255 James Watt jr to John Southern 1808/12/09, BWA MS 3147/3/60 \#15, AM-IR series 1 part 12 reel 206. 256 Retorts 1808/12/16, BWA MS 3147/5/813/9, AM-IR series 1 part 11 reel 184; Gasometer and plans 1808/12/20, BWA MS 3147/5/812/1 and 6, AM-IR series 1 part 11 reel 184; Plan of Burley mill 1808/12/21, BWA MS 3147/3/478 \#48 series 1 part 14 reel 273.

257 Henry Creighton to B+W 1809/02/10, BWA MS 3147/3/247 \#64, AM-IR series 1 part 12 reel 212. 258 Henry Creighton to B+W 1809/02/14, BWA MS 3147/3/247 \#65, AM-IR series 1 part 12 reel 212. 259 Three retort bodies 1810/10/10, BWA MS 3147/5/816/11, AM-IR series 1 part 11 reel 184; Lighting apparatuses per agreement 30 Sep 1810 to 30 Sep 1811 BWA MII /7/5, AM-IR series 1 part 6 reel 76A: retort 1810/10/18 for £38.16; Lighting apparatuses per agreement 30 Sep 1811 to 30 Sep 1812 BWA MII /7/5, AM-IR series 1 part 6 reel $76 \mathrm{~A}: 1811 / 12 / 07$ for £26.

260 Henry Creighton to B+W 1809/02/23, BWA MS 3147/3/247 \#66, AM-IR series 1 part 12 reel 212.

261 Lighting apparatuses per agreement 30 Sep 1809 to 30 Sep 1810, BWA MII /7/4, AM-IR series 1 part 6 reel 75 : addition 1809/12/30 for £93.

262 Bill for three retorts 1810/08/11, BWA MS 3147/5/817/14, AM-IR series 1 part 11 reel 184; Lighting apparatuses per agreement 30 Sep 1809 to 30 Sep 1810, BWA MII /7/4, AM-IR series 1 part 6 reel 75: two retorts $1810 / 08 / 17$ for $£ 25.17$, retort and additional apparatus 1810/09/18 for $£ 61.2$.
} 
Philips \& Lee's mills continued to expand their gaslight over these years, and became well known for the sheer scales of their works. In 1815, two Austrian Archdukes went on a tour of England, which included a stop at Philips \& Lee when they were in Manchester. The Archdukes kept a journal and described what they saw as Lee ('you would take him for a Swiss of the first distinction, if his way of thinking did not shew the British merchant') showed them around his mill:

We were invited to visit the manufactory of Mr. Lee, one of the greatest in Manchester: and the evening was chosen for the purpose, that we might at the same time see the building lighted with gas. On entering the court-yard, we saw the first gas lamp which thoroughly lights it. The buildings make a very handsome appearance : one of them is seven stories high, and has forty-six windows in a row ; an adjoining building is a story lower, but of the same length. This brilliant illumination, and the noise of the machines, which resembles that of a considerable waterfall, all together makes, as you enter the court-yard, a new and extraordinary impression. [...] The apartment in which we were received, was lighted by a chandelier, in which gas burnt ; it is conveyed through several pipes, from the ends of which it issues, generally by three openings ; the flame from the middle one burns perpendicularly, and from the two lateral ones in an oblique direction. These lights, which do not at all offend the eye by their brilliancy, seemed to us rather unsteady. Mr. Lee then shewed us a plan of the building which contains the great spinning manufactory. [...] The counting houses are also lighted with gas; and, as we wished to see how it was prepared, we were conducted into the laboratory : ten stoves stand in it, in a semicircle; each of them contains a retort of thick iron, in the form of a chest, about five feet long, a foot and a half broad, and a foot high; from these proceed pipes which all unite in one large common pipe, through which the gas is conveyed into the receivers, of which there are ten or twelve. No coal is used for the preparation of gas, except Cannel coal, from the mines of Wigan. The receivers are large gasometers, the 
wooden balls of which are mostly borne by counter-weights, which produce a pressure that may be changed at pleasure. The establishment was [sic] one hundred tons, or 2000 cwt. of coal per week. ${ }^{263}$

\subsubsection{McConnel \& Kennedy}

Other than Philips \& Lee, there are two customers who figure with sufficient prominence in the surviving documentation to merit further comment: McConnel \& Kennedy, who was an important customer, and Gillespie \& Co., whose order was a rather minor one. Each of these will be treated separately. McConnel \& Kennedy had seriously pushed to have gaslight in their mills in 1806 when they resolved in September of that year that the size of the installation was to be 1100 lamps requiring $5500 \mathrm{ft}^{3}$ of gas every day, and this only for the Old Mill which was a seven storey building. The rest of the mills would have to wait for the future.264 As with other possible customers, nothing was done in $1806-7$. There is no accounting record showing that any business was done with McConnel \& Kennedy before 1808. In that year, they received some components of their apparatus from early on, but new plans for the Old Mill were prepared in March of $1809^{265}$ and a payment was then received. Several other payments were made during the year totalling £862.266 The Old Mill was supplied

\footnotetext{
263 "The Imperial Tourists," The Literary gazette and journal of belles lettres, arts, sciences, etc for the year 18182 , no. 57 (1818).

264 1806/09/29, BWA MS 3147/3/478 \#20, AM-IR series 1 part 14 reel 273.

265 Cross section of the Old Mill 1809/03/25, BWA MS 3147/3/478 \#21, AM-IR series 1 part 14 reel 273.

266 Lighting apparatuses per agreement 30 Sep 1808 to 30 Sep 1809, BWA MII /7/4, AM-IR series 1 part 6 reel 75: 1809/03/29, 1809/06/21, 1809/07/20, 1809/08/11, 1809/09/27.
} 
by three retorts and one large gasometer of over $1000 \mathrm{ft}^{3}$, supplying about 1000 candle worth of light, or around 400 burners. ${ }^{267}$

Further design work was done by Creighton throughout 1809. He sent drawings in August,, 268 in part intended to address a problem with inadequate burner luminosity. The only solution Creighton could find was to lengthen the vertical pipes which supported the burners to bring them closer to the floor. ${ }^{269}$ The apparatus continued to be assembled, and Creighton was finally able to report on October 13, 1809 that 'last night six stories of the old mill, staircase $+c c$ were lighted + did very well'. ${ }^{270}$

Late in 1809 McConnel \& Kennedy started a second, larger phase to their gaslight scheme, this one costing $£ 1038$ by the time it was paid for in February of $1810 .{ }^{271}$ Over the next few years, McConnel \& Kennedy did maintenance work for their system ${ }^{272}$ as well as another major expansion beginning in October 1810 that ended in the summer of 1811.273 It cost $£ 2507$ when all the bills were paid in February 1811.274

\footnotetext{
267 1809/03/25, BWA MS 3147/3/478 \#21, AM-IR series 1 part 14 reel 273.

268 Henry Creighton to B+W 1809/08/02, BWA MS 3147/3/247 \#72, AM-IR series 1 part 12 reel 212.

269 Henry Creighton to B+W 1809/08/09, BWA MS 3147/3/478 \#24, AM-IR series 1 part 14 reel 273.

270 Henry Creighton to B+W 1809/10/13, BWA MS 3147/3/247 \#73, AM-IR series 1 part 12 reel 212.

271 Lighting apparatuses per agreement 30 Sep 1809 to 30 Sep 1810, BWA MII /7/4, AM-IR series 1 part 6 reel 75: 1809/12/09 £275, 1810/02/13 £544, 1810/02/15£13;

Retort 1810/02/13, BWA MS 3147/5/821/6, AM-IR series 1 part 11 reel 184.

272 Bill for three retorts 1810/08/11, BWA MS 3147/5/821/1, AM-IR series 1 part 11 reel 184; Lighting apparatuses per agreement 30 Sep 1809 to 30 Sep 1810, BWA MII /7/4, AM-IR series 1 part 6 reel 75: Three retort bodies $1810 / 08 / 17$ for $£ 38.11$; Three retort bodies $1810 / 09 / 18$ for $£ 38.12$.

273 Retort sections 1810/12/10, BWA MS 3147/5/821/17 and 36; Retort sections 1810/12/13, BWA MS 3147/5/821/14; Descending tube 1810/12/14, BWA MS 3147/5/821/41; Gasometer 1811/01/14, BWA MS 3147/5/821/7; 1811/07/18, BWA MS 3147/5/821/4; all AM-IR series 1 part 11 reel 184.

274 Lighting apparatuses per agreement 30 Sep 1810 to 30 Sep 1811 BWA MII /7/5, AM-IR series 1 part 6 reel 76A: $1810 / 09 / 30$ for $£ 1900,1810 / 10 / 12$ to $1811 / 02 / 08$ for $£ 607$.
} 


\subsubsection{Gillespie \& Co.}

Hutton from his home base in Scotland took care of gathering the particulars for Gillespie \& Co.'s mill. It was to be a smaller apparatus, with only one retort (soon expanded to two) and a gasometer of $500 \mathrm{ft}^{3}$ providing the light of 100 candles in the dye house. Hutton added that Gillespie was 'perfectly aware that the expence of an appt for this purpose may be considerable' but wanted it anyway because 'he suffers considerable inconvenience from his present method of lighting by candles'. ${ }^{275}$ When the estimate arrived at the end of the month, Gillespie was surprised as '[t]he estimate was much above what he expected but he still thinks of adopting the plan'.276 After ruminating about it, Gillespie \& Co. placed a slightly modified order at the end of the month, expecting delivery for the beginning of July 1809.277 Hutton received sketches from Soho which he modified to fit the actual situation at Gillespie \& Co. in April 1809.278 Gillespie paid his $£ 378^{279}$ and received the apparatus a little later than expected in August 1809. Murdock travelled north to Glasgow to supervise the installation personally before moving on to Kirkland to work on steam engines in the area as well as Nielson \& Co's gaslight apparatus. ${ }^{280}$ As Gillespie's apparatus was being erected,

275 Eidingtoun Hutton to B+W 1809/01/03, BWA MS 3147/3/267 \#1, AM-IR series 1 part 12 reel 216. 276 Eidingtoun Hutton to B+W 1809/02/08, BWA MS 3147/3/267 \#4, AM-IR series 1 part 12 reel 216. 277 Eidingtoun Hutton to B+W 1809/02/25, BWA MS 3147/3/267 \#8, AM-IR series 1 part 12 reel 216. 278 Eidingtoun Hutton to B+W 1809/04/01, BWA MS 3147/3/267 \#9, AM-IR series 1 part 12 reel 216; Retort section 1809/04/24, BWA MS 3147/5/819/4 and 6, AM-IR series 1 part 11 reel 184.

279 Lighting apparatuses per agreement 30 Sep 1808 to 30 Sep 1809, BWA MII /7/4, AM-IR series 1 part 6 reel 75: 1809/06/15.

280 Eidingtoun Hutton to B+W 1809/12/19, BWA MS 3147/3/267 \#26, AM-IR series 1 part 12 reel 216. 
Gillespie started to consider extending the lights to other rooms and buildings on his grounds. ${ }^{281} \mathrm{He}$ ordered a minor change right away. ${ }^{282}$ The apparatus was completed, but it become clear after trial runs that not all was well with the installation. Gillespie was suspicious of Hutton's experience in gaslight, and thought a more experienced engineer would be required. He wrote to Boulton \& Watt with his request and asked Hutton to corroborate his account of the status of the apparatus. Hutton was much surprised at this, and wrote back to Birmingham to say Gillespie had run tests on his own without waiting for Hutton to finish the apparatus. He requested that no help be sent until he had had sufficient time to complete his work. ${ }^{283}$

As it happened, Gillespie did have legitimate cause for complaint. Atmospheric air was leaking into the system through a hole in the gasometer and the flames were quite poor, much to the Gillespie's irritation:

$$
\begin{aligned}
& \text { I feel extremely vexed at this circumstance on many accounts particularly as it will cause } \\
& \text { a delay of three or four days on coming to a result + Mr Richd Gillespie's impatience } \\
& \text { thereby be in full action again from which I have already experienced a good deal of } \\
& \text { interruption + insulting annoyance. }{ }^{284}
\end{aligned}
$$

The water was drained from the pits and the gasometer repaired. On December 12,1809 , Hutton reported that Gillespie was ready to try again. 285 The water was let

\footnotetext{
281 Eidingtoun Hutton to B+W 1809/08/19, BWA MS 3147/3/267 \#19, AM-IR series 1 part 12 reel 216. 282 Eidingtoun Hutton to B+W 1809/09/06, BWA MS 3147/3/267 \#20, AM-IR series 1 part 12 reel 216; Lighting apparatuses per agreement 30 Sep 1808 to 30 Sep 1809, BWA MII /7/4, AM-IR series 1 part 6 reel 75: 1809/10/28 for £2.19.

${ }^{283}$ Eidingtoun Hutton to B+W 1809/10/27, BWA MS 3147/3/267 \#22, AM-IR series 1 part 12 reel 216. ${ }^{284}$ Eidingtoun Hutton to B+W 1809/11/11, BWA MS 3147/3/267 \#23, AM-IR series 1 part 12 reel 216. 285 Eidingtoun Hutton to B+W 1809/12/15, BWA MS 3147/3/267 \#25, AM-IR series 1 part 12 reel 216.
} 
back into the gasometer pit, ${ }^{286}$ and the apparatus worked much better, although Hutton wrote that they were not yet able to 'produce that rapid distillation you mention as being necessary in obtaining a pure gas, tho' the gas we have obtained appears tolerably pure + furnishes a very good light.' ${ }^{287}$ With a little more tweaking, the system was functioning better, and Gillespie was now 'as much delighted with it now, as he was apprehensive about its success before it was complete'.288

Gillespie \& Co. were not running the retorts constantly. Rather, heating began sometime around breakfast time, but it was only around noon that the gas finally started streaming from the retorts. Gillespie was sufficiently satisfied that he extended the pipes to the other buildings and began using gaslight there as well. ${ }^{289} \mathrm{He}$ also started to 'light up a grand crown he has stuck at the front of his counting house in which there are abt $\underline{80}$ lights'. This was in fact where most of the gas was burnt, but Hutton prudently chose 'not to interfere in the least'. Otherwise, the light in the buildings were on between 6 and 7 in the morning, and then again from 3 or 4 in the afternoon to around 10 at night. Gillespie was now 'in such high spirits' that Hutton 'wished to his feelings subside a little ... before I made any particular trial to increase the [yield?] of the Distilling operation'.290 Gillespie was sufficiently happy with the apparatus that in 1810

\footnotetext{
286 Eidingtoun Hutton to B+W 1809/12/19, BWA MS 3147/3/267 \#26, AM-IR series 1 part 12 reel 216. 287 Eidingtoun Hutton to B+W 1809/12/21, BWA MS 3147/3/267 \#27, AM-IR series 1 part 12 reel 216. 288 Eidingtoun Hutton to B+W 1809/12/29, BWA MS 3147/3/267 \#28, AM-IR series 1 part 12 reel 216. 289 Eidingtoun Hutton to B+W 1809/12/29, BWA MS 3147/3/267 \#28, AM-IR series 1 part 12 reel 216. 290 Eidingtoun Hutton to B+W 1809/12/31, BWA MS 3147/3/267 \#29, AM-IR series 1 part 12 reel 216.
} 
he presented a memoir to the philosophical society of Glasgow praising it in glowing terms. ${ }^{291}$

At the very end of the year, Hutton received a harsh letter from Boulton \& Watt regarding his work at Gillespie \& Co. because of a letter of complaint from Gillespie. Hutton was much surprised, expecting that he 'would have written to you in a style of panegyrick rather of complaint', but this was probably an old letter reflecting the porous state of the apparatus before it was repaired, or perhaps Gillespie had written in a bad mood. Hutton then mentioned that he was trying to run the retorts constantly now, as they were producing little gas, about $100 \mathrm{ft} /$ hour in total, and he thought correctly that he could increase his yield by not allowing the retorts to cool. In any case he asked that Creighton come north so as to procure his 'cunning' in tackling the problem. ${ }^{292}$ The subsequent correspondence is missing, so the story must remain without a conclusion.

291 Richard Gillespie, "Gas light at Richard Gillespie's," The Edinburgh Monthly Magazine and Review 1, no. 1 (1810).

292 Eidingtoun Hutton to B+W 1809/12/31, BWA MS 3147/3/267 \#29, AM-IR series 1 part 12 reel 216. 


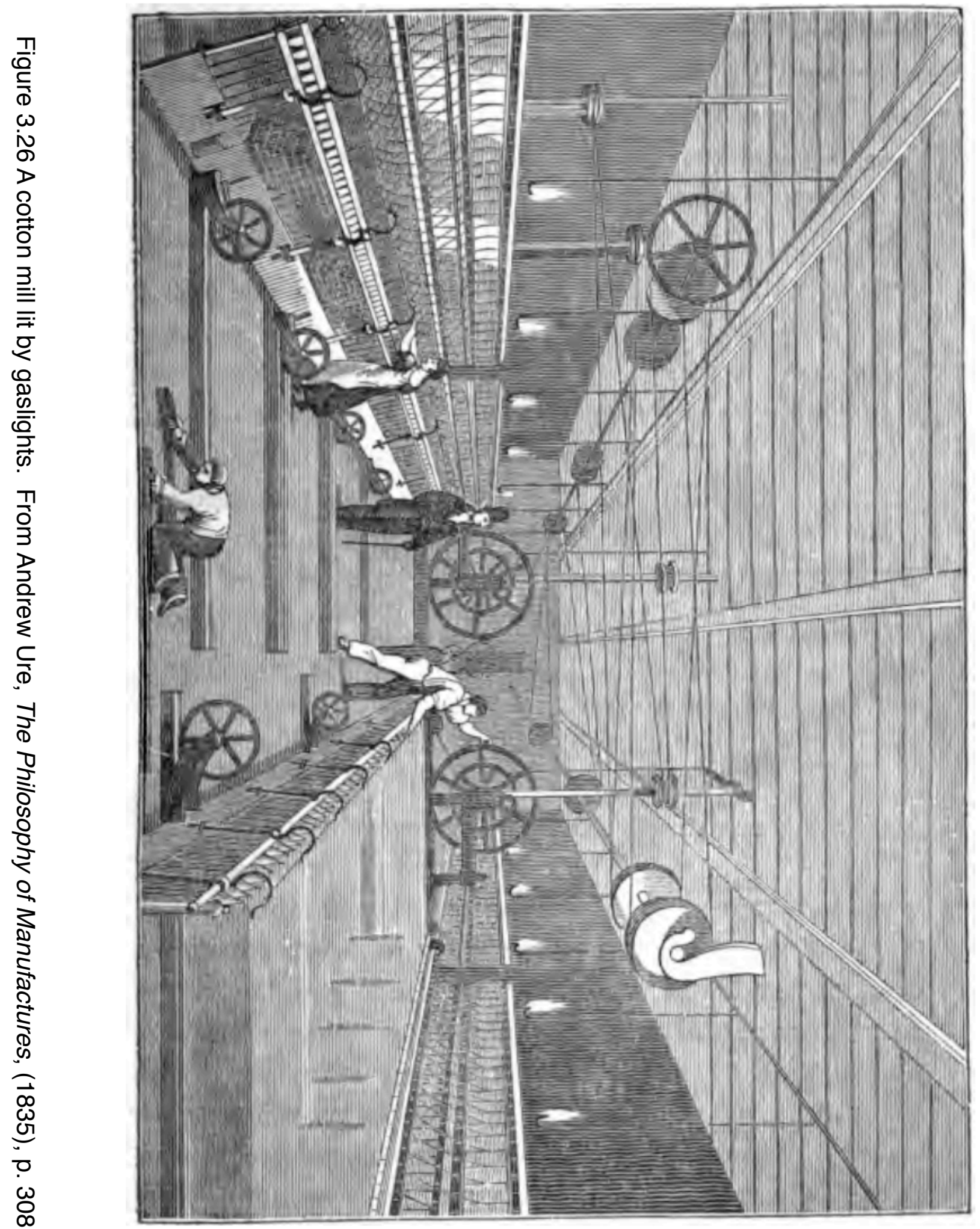




\subsection{Other mills and denouement 1809-1812}

After Boulton \& Watt took on new customers at the end of 1808 , they picked up a number of new ones in 1809-1811, but the business peaked very quickly. In 1809, they signed up four new customers, in 1810 another four, and only two in 1811. They had no new customers at all after that. Their income peak lagged their customers by a year as the equipment took time to manufacture and deliver, and existing apparatus was expanded and repaired. In 1812, they got no new customers, and had total sales of $£ 250$, a pittance in comparison to the 6 previous years. The last of the 1812 sales is recorded in February of that year. Boulton \& Watt had clearly lost interest in the manufactured gas business.

The largest among the other customers of gaslight was Worlmald, Gott \& Wormald and the associated firm of Benjamin Gott \& Co. Worlmald, Gott \& Wormald's gaslight apparatus for the Burley Mill was first prepared at the end of 1808 for which they paid $£ 650.293$ Benjamin Gott \& Co.'s Armley Mill followed that summer when Creighton prepared drawings in July 1809.294 The apparatus cost $£ 496.295$ Gott was very happy with his new lights, writing that they were 'excellent' in a letter to Watt junior. ${ }^{296}$ The Park

\footnotetext{
293 Lighting apparatuses per agreement 30 Sep 1808 to 30 Sep 1809, BWA MII /7/4, AM-IR series 1 part 6 reel $75,1809 / 03 / 02$.

294 Henry Creighton to B+W 1809/07/07, BWA MS 3147/3/247 \#70, AM-IR series 1 part 12 reel 212; Cross section 1809/07/08, BWA MS 3147/5/820/1, AM-IR series 1 part 11 reel 184

Wormald, Gott \& c. to B+W 1809/03/31, BWA MS 3147/3/439 \#124, AM-IR series 1 part 14 reel 261.

295 Soho Foundry Amounts of Sales of Goods manufactured 30 Sep 1808 to 30 Sep 1809, BWA MII /7/4, AM-IR series 1 part 6 reel 75, 1809/08/31.

296 Gott to James Watt jr 1809/09/01, BWA MIV /G2, AM-IR series 1 part 8 reel 119.
} 
Mill, the third of his big three mills, came next in $1810^{297}$ for $£ 490.298$ This was expanded in 1811 for $£ 224,299$ but other than a few replacement components, ${ }^{300}$ no more major work was done for any of Gott's mills.

The other 1809 customers were Nielson \& Co. of Kirland in Scotland, an order for $£ 503$, later expanded by $£ 205^{301}$ which Hutton took care of initially 302 and Murdock completed at the end of 1809303; Marshall Hives \& Co. of Leeds ${ }^{304}$ which cost $£ 890^{305}$; and Birley \& Hornby of Chorlton 306 for $£ 1006.307$ The 1810 customers were Lister Ellis \&

297 Gasometer 1810/07/02, BWA MS 3147/5/812/3, AM-IR series 1 part 11 reel 184; Bill 1810/07/20, BWA MS 3147/5/812/3.

298 Lighting apparatuses per agreement 30 Sep 1809 to 30 Sep 1810, BWA MII /7/4, AM-IR series 1 part 6 reel 75 1810/09/29.

299 Lighting apparatuses per agreement 30 Sep 1810 to 30 Sep 1811 BWA MII /7/5, AM-IR series 1 part 6 reel 76A: 1811/03/09.

300 Four retorts 1811/10/22, BWA MS 3147/5/812/5; Gasometer 1811/12/02, BWA MS 3147/5/812/5, both AM-IR series 1 part 11 reel 184.

301 Lighting apparatuses per agreement 30 Sep 1809 to 30 Sep 1810, BWA MII /7/4, AM-IR series 1 part 6 reel 75: 1809/08/16; Lighting apparatuses per agreement 30 Sep 1810 to 30 Sep 1811 BWA MII /7/5, AMIR series 1 part 6 reel 76A: 1811/01/21; "Gas lights used in the manufactories in Scotland," The Tradesman, or, Commercial magazine 4, no. 24 (1810)..

302 Retort 1809/05/04, BWA MS 3147/5/809/1, AM-IR series 1 part 11 reel 184; Southern to James Watt jr 1809/05/05, BWA MS 3147/3/332 \#9, AM-IR series 1 part 13 reel 230; Eidingtoun Hutton to B+W 1809/08/06, BWA MS 3147/3/267 \#17, AM-IR series 1 part 12 reel 216.

${ }^{303}$ Eidingtoun Hutton to B+W 1809/12/19, BWA MS 3147/3/267 \#26, AM-IR series 1 part 12 reel 216.

304 Drawing 1809/07/29, BWA MS 3147/3/478 \#25, AM-IR series 1 part 14 reel 273; Henry Creighton to B +W 1809/08/02, BWA MS 3147/3/247 \#72, AM-IR series 1 part 12 reel 212; 1809/08/29, BWA MS 3147/5/811/9, AM-IR series 1 part 11 reel 184.

305 Lighting apparatuses per agreement 30 Sep 1809 to 30 Sep 1810, BWA MII /7/4, AM-IR series 1 part 6 reel 75: 1809/12/14, 1810/02/09, 1810/02/19.

306 1809/09/07, BWA MS 3147/5/821/50; all AM-IR series 1 part 11 reel 184.

307 Lighting apparatuses per agreement 30 Sep 1809 to 30 Sep 1810, BWA MII /7/4, AM-IR series 1 part 6 reel 75: 1810/04/27 for £690; Lighting apparatuses per agreement 30 Sep 1810 to 30 Sep 1811 BWA MII /7/5, AM-IR series 1 part 6 reel 76A: 1811/08/29 for $£ 316$. 
Co. from near Otley 308 for $£ 610^{309}$; Thomas Coupland \& Sons of Leeds ${ }^{310}$ for $£ 500^{311}$; and J. Thomas \& E. Lewis of Manchester 312 for $£ 620.313$

The 1811 customers were Benyon, Benyon \& Bage near Shewsbury ${ }^{314}$ for $£ 970^{315}$; Marshall Hutton \& Co. of Shrewsbury ${ }^{316}$ for $£ 1150^{317}$; Huddart \& Co..$^{318}$ of Limehouse, London for $£ 487.319$

After 1812 there are a few minor signs that the gaslight business was still barely alive, such as a record of the total expense of gaslight apparatus sold in 1814 of

308 Bill 1810/04/06 and drawings 1810/04/24, BWA MS 3147/5/813/10, 1, and 7, AM-IR series 1 part 11 reel 184.

309 Lighting apparatuses per agreement 30 Sep 1809 to 30 Sep 1810, BWA MII /7/4, AM-IR series 1 part 6 reel 75: 1810/07/26, 1810/09/29; Lighting apparatuses per agreement 30 Sep 1810 to 30 Sep 1811 BWA MII /7/5, AM-IR series 1 part 6 reel 76A: 1811/01/16.

310 Gasometer 1810/06/01, BWA MS 3147/5/814/1, 1, and 7, AM-IR series 1 part 11 reel 184.

311 Lighting apparatuses per agreement 30 Sep 1810 to 30 Sep 1811 BWA MII /7/5, AM-IR series 1 part 6 reel 76A: 1810/10/21, 1810/10/30 and 1810/11/26.

312 Gasometer 1810/06/20, BWA MS 3147/5/815/1, 3, and 4; and Order summary 1810/08/ BWA MS 3147/5/815/6, both AM-IR series 1 part 11 reel 184 .

313 Lighting apparatuses per agreement 30 Sep 1809 to 30 Sep 1810, BWA MII /7/4, AM-IR series 1 part 6 reel 75: 1810/08/24, 1810/09/29, 1810/11/30, and 1810/12/24.

314 Ground plans 1811/04/07, BWA MS 3147/5/805/3; Bill for retort 1811/09/09, BWA MS 3147/5/805/3, both AM-IR series 1 part 11 reel 184.

315 Lighting apparatuses per agreement 30 Sep 1810 to 30 Sep 1811 BWA MII /7/5, AM-IR series 1 part 6 reel 76A: 1811/09/24. There was a fire in Benyon and Bage's factory in 1814. See "To the Editor of the Times, from A Chemist," The Times, Dec 291814.

316 Pipe design 1811/07/09, BWA MS 3147/5/805/3, AM-IR series 1 part 11 reel 184.

317 Lighting apparatuses per agreement 30 Sep 1810 to 30 Sep 1811 BWA MII /7/5, AM-IR series 1 part 6 reel 76A: 1811/07/26.

318 James Watt jr to B+W 1812/12/30, BWA MS 3147/3/61 \#18, AM-IR series 1 part 12 reel 206; Order details 1811/03/01, BWA MS 3147/5/806/3; Ground plan 1812/03/19, BWA MS 3147/5/806/3, both AM-IR series 1 part 11 reel 184.

319 Lighting apparatuses per agreement 30 Sep 1810 to 30 Sep 1811 BWA MII /7/5, AM-IR series 1 part 6 reel 76A: 1811/09/10 for £195; Lighting apparatuses per agreement 30 Sep 1811 to 30 Sep 1812 BWA MII /7/5, AM-IR series 1 part 6 reel 76A: 1812/02/13 for $£ 292$. 
$£ 219,320$ probably to William Jones, ${ }^{321}$ and a survey prepared by Creighton for John Maberly \& Co. in Aberdeen in late 1814 and early 1815,322 but it was clearly moribund. Gaslight was hardly mentioned in any letter sent within the firm after 1809 . There is no mention of any article related to gaslight in the accounts of Soho Foundry 18161820.323

The drawings and plans in the period 1810-1812 show that development work on gaslight at Boulton \& Watt had effectively ground to a halt. The retorts did not change in design, and drawings prepared in 1812 are almost identical to those of 1808 . The gasometers from the later period were somewhat larger than the earlier one, reaching $5000 \mathrm{ft}^{3}$, but this was not a giant step. 324 The lack of development was not only because the technology was mature enough. Boulton \& Watt were simply not developing this line of their business. Watt junior had even written in April 1809 that he felt unacquainted with it. ${ }^{325}$ Lee's last remaining desideratum, the more effective purification of the gas, had been solved by Samuel Clegg (among others ${ }^{326}$ ) during work done

320 Goods sold from 30 Sep 1813 to 30 Sep 1814, BWA MII /7/5, AM-IR series 1 part 6 reel 76A.

321 Drawing 1814/08/14, BWA MS 3147/3/478 \#45, AM-IR series 1 part 14 reel 273; Pipes, BWA MS 3147/5/807/4, AM-IR series 1 part 11 reel 184.

322 Notes 1815/02/14, BWA MS 3147/5/808/1, AM-IR series 1 part 11 reel 184;

Ground plans 1814/11/18, BWA MS 3147/5/808/2 and 3, AM-IR series 1 part 11 reel 184.

${ }^{323}$ BWA MII /7/6, AM-IR series 1 part 6 reel $76 \mathrm{~A}$.

${ }^{324}$ Ground plans 1815/03/15, BWA MS 3147/5/808/2 and 3, AM-IR series 1 part 11 reel 184.

325 James Watt jr to Matthew Robinson Boulton 1809/04/20, BWA Lunar Society \#118, AM-IR series 1 part 1 reel 6.

326 "Specification of the Patent granted to Edward Heard, of London, Chemist, for a Discovery of certain Means of obtaining inflammable Gas from Pit-Coal in such a State that it may be burned wihtout producing any offensive Smell," The repertory of arts, manufactures, and agriculture 2nd series 10, no. 56 (1807). "Mr. Edward Heard's Discovery," The Monthly magazine, or, British register 23, no. 1 (1807). 
1805-8 when he used cream of lime to remove the hydrogen sulphide. Lime was, however, never used successfully by the Boulton \& Watt. ${ }^{327}$ Perhaps they were unaware of this in 1808, but they could not have remained ignorant over the next seven years. They were not interested enough in the technology after 1809 to put much effort into it.

George Augustus Lee had always been a major driving force behind Boulton \& Watt's development of gaslight. He was certainly not the only one: both Murdock and Watt junior had been very much taken with the project for some time. But both lost interest over time. Boulton had never been enthused with the technology, and his coolness affected how many resources the firm was willing to dedicate to gaslight. It might even have rubbed off on Watt junior over time. Watt junior certainly developed a case of gaslight fatigue after the battles of 1807-1809 with the Winsorites, and even if he never consciously gave up the business, he conceded that he could not keep out serious competitors and lost interest afterwards.

Lee, however, remained as enthused as at the outset. In 1813, after the Gas Light and Coke Company had been established and was operating, Lee received a visitor from London. He was the architect for the General Post Office, and was investigating using gaslight for their buildings. Having heard of the famous gaslights at Philips \& Lee, he made a trip to Manchester with the purpose of dropping by the mill to see the lights in action. After the visit, Lee wrote to Watt junior:

327 Clegg, A practical treatise on the manufacture and distribution of coal-gas, 13. claimed they never used it, but he is partial to his father. Matthews, An historical sketch of the origin, progress, \& present state of gas-lighting, 25. claim Boulton \& Watt used quick-lime at some point, but 'very imperfectly'. I have found no mention of lime purification in the archives. 
[l]t appears to me that with a little exertion there is a very extensive field opening for the Extension of the Gas Lights and that after expending so much money + brains you will let the Quacks in + out of the Metropolis derive all the Advantage of the Dyscovery and our Experience.

Being satisfied that Coal gas can be effectually purified by agitation in the Cream of Lime, the time is near at Hand for its more general Introduction. A Gentleman from the General Post office in London who is their Architect came expressly for the Purpose + by their Directions to inquire about it and I am since informed means actually to introduce it there. He says the present Expense of Oil + Candles is no less than $£ 3000$ pannum. I have endeavoured to guard him against the quacks in London. This + more general but important Considerations induce me to press the Subject upon your early Attention, + if you can give it the due Exertions I shall either hear or see you about it. 328

But Watt junior did let the quacks derive all the advantage of their discovery. 


\begin{tabular}{|c|c|c|c|}
\hline Year ended Sept. 30 & Name of Firm & $\begin{array}{l}\text { Cost of Apparatus } \\
£ \text { s. d. }\end{array}$ & $\begin{array}{l}\text { Profit } \\
£ \text { s. d. }\end{array}$ \\
\hline I806 & Phillips \& Lee, Salford & 2137170 & - \\
\hline I807 & Phillips \& Lee & 92382 & $6 \mathrm{I}_{2} \mathrm{I}_{4} \mathrm{IO}$ \\
\hline I808 & Phillips \& Lee $\quad$.. & 445 I0 & $4 \mathrm{I} 4 \quad 2$ \\
\hline 1809 & H. H. Birley \& Co., Manchester & 62556 & I54 46 \\
\hline & J. Kennedy, Manchester & 447 I9 I & 89 O II \\
\hline & Wormald, Gott \& Co., nr. Leeds & 57205 & II2 I9 7 \\
\hline & McConnel \& Kennedy, Manchester & $71817 \quad 7^{\frac{1}{2}}$ & I43 $244^{\frac{1}{2}}$ \\
\hline & R. Gillespie \& Co., Glasgow & 30700 & $\begin{array}{lll}71 & 0 & 0\end{array}$ \\
\hline & Nielson \& Co., Kirkland, Fife & $420 \mathrm{I} 47$ & $82 \quad 5 \quad 5$ \\
\hline & Benjamin Gott, nr. Leeds & 42156 & 98 I4 6 \\
\hline & Total for year & $351328 \frac{1}{2}$ & $75173^{\frac{1}{2}}$ \\
\hline I810 & McConnel \& Kennedy & 933 I IO & I82 I 7 \\
\hline & R. Gillespie \& Co. & 53 10 0 & 0174 \\
\hline & Nielson \& Co. & 24 IO II & 3 I9 I \\
\hline & Marshall Hives \& Co., Leeds & 7171810 & I72 I 2 \\
\hline & J. Kennedy & I 50 II $9 \frac{1}{2}$ & $298 \quad 2 \frac{1}{2}$ \\
\hline & Wormald, Gott \& Co. & 4 II 126 & 82176 \\
\hline & Birley \& Hornby, Chorlton & 567997 & I22 I0 5 \\
\hline & Lister Ellis \& Co., nr. Otley & 521 I6 II & $883 \mathrm{I}$ \\
\hline & Phillips \& Lee & $317 \quad 12 \quad 4 \frac{1}{2}$ & $\begin{array}{lll}63 & 7 & 7 \frac{1}{2}\end{array}$ \\
\hline & J. Thomas \& E. Lewis, Manchester & 66 I I0 II & $4 \mathrm{I}$ IO II \\
\hline & T. Coupland \& Sons, Leeds & 448 I4 7 & 5155 \\
\hline & Total for Year & 4808 10 2 & $755 \circ 7$ \\
\hline I8I I & McConnel \& Kennedy & & 98 I2 3 \\
\hline & H. H. Birley \& Co. & $38 \mathrm{I} 6 \quad 0$ & ${ }^{90}-3$ \\
\hline & T. Coupland \& Sons & 48 I 0 & II I9 0 \\
\hline & Nielson \& Co. & $2072 \mathrm{IO}_{2}^{\frac{1}{2}}$ & $4 \mathrm{I} I 7 \quad \mathrm{I} \frac{1}{2}$ \\
\hline & R. Gillespie \& Co. & 3270 & $\begin{array}{lll}4 & 3 & 0\end{array}$ \\
\hline & Birley \& Hornby & 28066 & 5536 \\
\hline & Wormald, Gott \& Co. & I86 I2 6 & $37 \quad 7 \quad 6$ \\
\hline & Marshall, Hutton \& Co., Shrewsbury & $844 \quad 6 \quad 9$ & $30513 \quad 3$ \\
\hline & Huddart \& Co., Limehouse & 16253 & 33 I4 9 \\
\hline & Benyon, Benyon \& Bage, nr. Shrewsbury & $758 \quad 4 \mathrm{II}_{2}^{\frac{1}{2}}$ & $262 \quad 5 \quad 0 \frac{1}{2}$ \\
\hline & Total for Year & 3126 10 7 & 850 I5 5 \\
\hline
\end{tabular}

Figure 3.27 Table of Boulton \& Watt profits and costs of gas apparatus, from Falkus. "The Early Development of the British Gas Industry, 1790-1815." The Economic History Review 35, no. 2 (1982): 217-34. 


\subsection{Conclusion}

William Murdock and Boulton \& Watt had a central role to play in the development of gaslight technology. When Murdock first started using coal-gas for lighting purposes sometime before 1794, his apparatus was much like Minckelers' before him, or Lebon's after him: a good proof of concept, but small scale and of unproven viability on an industrial scale. When Boulton \& Watt lost interest in the technology sometime in 1810 , the technology had been implemented in many of the largest mills in England, and in the case of Philips \& Lee, for a few years. There was no questioning whether gaslight could be used in a large scale. Many scaling issues had been solved by solutions proposed by Boulton \& Watt, solutions which endured through most of the history of the gas industry. These include using gasometers for even flow; maximizing gasometer volume to save on retort capacity; running retorts as nearly constantly as possible; horizontal retort configurations with D-shaped profiles; condensing and washing gases with water. Other issues had been identified, but had not yet been solved. The most important of these was the purification of the hydrogen sulphide in the gas, but also included regulating pressure and mitigating the tar that resisted all attempts at purification. These would be solved by others.

Boulton \& Watt then had three important achievements in regard to gaslight: they demonstrated in a very public way that gaslight was a viable lighting technology which allowed the Winsorites to gather broad based support. Winsor may have been a quack, but Boulton \& Watt had proven that gaslight was viable, and the Royal Society had given it their blessing in 1808 . Their second achievement was that they had scaled it up 
from laboratory to industrial proportions, though without necessarily having solved all the concomitant problems. The third achievement was just as important. Leveraging the skills they had access to as steam engine and pneumatic apparatus manufacturers, they had trained and familiarized many people with gaslight technology. Samuel Clegg is the most important example, but he was not the only one. Josiah Pemberton, another Birmingham manufacturer of gaslight apparatus, made parts for Boulton \& Watt. ${ }^{329}$ Many of Philips \& Lee's workers also became familiar and proficient with the technology. It is no surprise then that when the Gas Light and Coke Company was looking for workers, they recruited in Manchester. Boulton \& Watt was then the seedbed of most of the first gas engineers and workers of England.

Finally, the scaling of gaslight apparatus at Boulton \& Watt was made possible by the extensive iron working skills they could bring to bear on the problem. While their Continental rivals had access to the same pneumatic chemistry, it was at Boulton \& Watt that the technology could be scaled up into the iron apparatus that it became. This suggests that the arguments of Harris, Wrigley, MacLeod and others that iron working skills, ultimately derived from the exploitation of Britain's coal deposits, was an important factor in Britain's technological success holds true in the case of gaslight. 330 This same factor will make a reappearance in chapter five, where the Gas Light and Coke Company also relied heavily on Britain's iron industry for most of its apparatus.

\footnotetext{
${ }^{329}$ Another Birmingham supplier to the GLCC of gaslight components was Ormond. See 1812/12/18 Minutes of the Court of Directors Book 1 p. 60: London Metropolitan Archives B/GLCC/1/1.

330 See J. R. Harris, "Skills, Coal and British Industry in the eighteenth century," History 61, no. 202 (1976). and Harris, Industrial espionage and technology transfer : Britain and France in the eighteenth century (Aldershort, Hants, England: Brookfield, VT, 1998), 554-60.. Harris also mentions firebricks in this context.
} 


\section{Chapter 4: \\ Frederick Winsor, Boulton \& Watt, and the National Heat and Light Company}

4.1 Introduction

4.2 Frederick Winsor and the thermolamp 1802-1804

4.3 The campaign of 1806-1807 and the first general meeting of 1807349

4.4 Boulton \& Watt and the Royal Society 1808

383

4.5 The Parliamentary Battle of 1809

397

4.6 Despair, Recovery, and Final Success 1809-1812

417

4.7 Conclusion

425

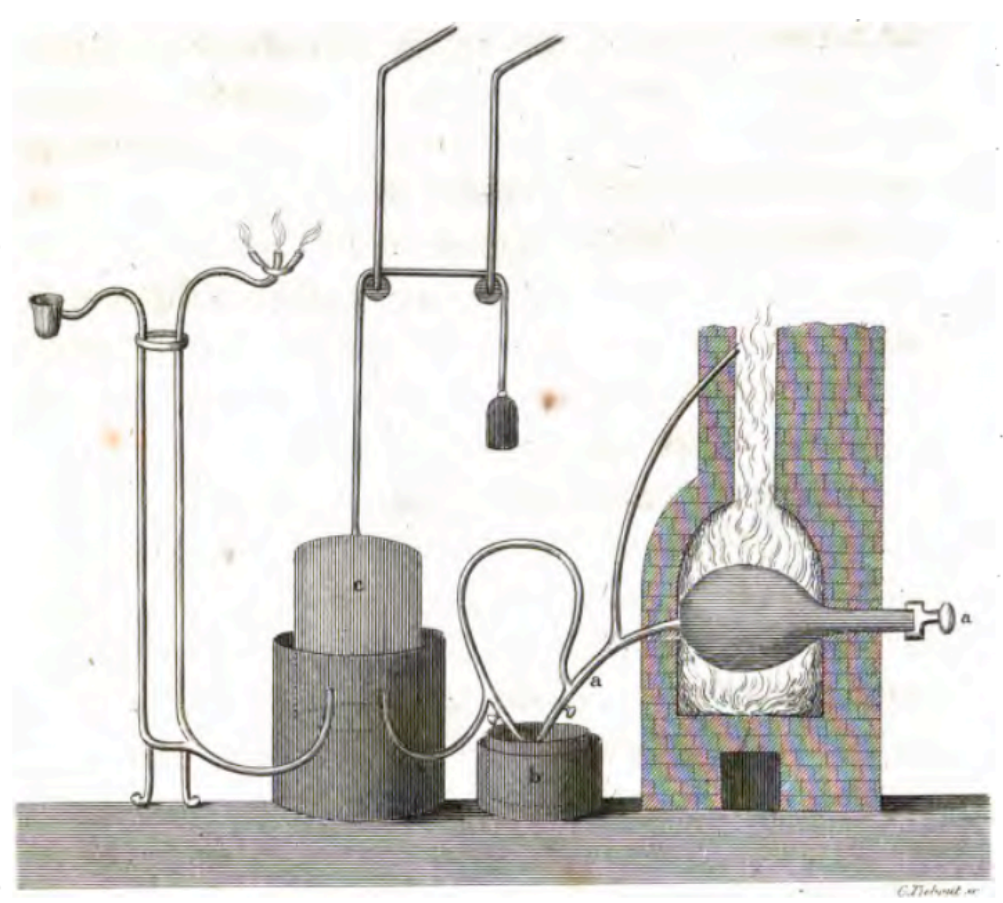

Figure 4.1 A demonstration gas apparatus, from Thomas Cooper, Some information concerning gas lights (1816) 


\section{Chapter 4: \\ Frederick Winsor, Boulton \& Watt, and the National Heat and Light Company}

\subsection{Introduction}

The next episode in the story of gaslight is the founding of the Gas Light and Coke Company (GLCC ) in London in 1812 as a gas utility. The central figure in the company's foundation was Frederick Winsor, a somewhat eccentric figure who gained notoriety with his extravagant claims and omnipresent marketing campaign in gathering investors for the company. It was through Winsor's efforts and the ensuing fracas that gaslight was brought so firmly and rapidly into the public eye in England. Despite his numerous patents and pretensions, Winsor had no real contribution to the development of the technology itself, nor was gaslight initially his most important aspiration. Nevertheless, the process he initiated in 1802 without ever really having a clear idea what the final goal was or being able to control it resulted by 1812 in the accumulation of a large amount of capital in a joint-stock company created by act of Parliament for the purpose of providing light by coal-gas in London. This chapter tells the story of the process that unfolded in that decade 1802-1812 centred on this one man as he brewed a storm that created the GLCC but that was ultimately to claim Winsor as a victim.

Winsor was not of course the only player in this story. Even if Winsor's financial prognostications were implausible and impossible, the sums of money involved were large. Winsor raised tens of thousands of pounds for the company which inevitably meant that his financiers would no longer leave him in control of the project, not the 
least because many, if not most, never really trusted him: they only believed in the viability of the technology. Nor were Winsor's collaborators the only ones concerned with his plans. His proposed business model would have brought him into direct competition with Boulton \& Watt as manufacturers of gaslight apparatus, and once they learned of Winsor's aspirations, they did all in their power to prevent him and his group from getting the act of Parliament they so craved to incorporate their company. They did so by undermining Winsor's claims to originality, by painting him as a quack, and probably most successfully, by tarring the company with the charge of establishing a monopoly. The promoters of the new company fought back, lost, but finally won their act of Parliament through a negotiated compromise with Boulton \& Watt that renounced any intention of manufacturing gaslight apparatus for sale in favour of being solely a gas utility without exclusion of other companies. The Gas Light and Coke Company's final form as a gas utility was the result of a political process, and it was this form that became the prototype of the other gas companies that were founded in quick succession in the England and then on the Continent.

This formative political process, with all its rhetoric and bombast, is the story of this chapter. Whereas natural philosophy and technology were central to the first, second and third chapters of this thesis, politics and societal forces take the centre stage here. These forces were what gave shape to the Gas Light and Coke Company. The technology itself fell into the background. It was never absent of course, as the battle was over the control and the form of the technology, but the specifics of the technology were not what the debates were ever about. They were about who controlled gaslight and in what form. 
Natural philosophy and technological issues did not, however, disappear in this part of the gaslight story. On the contrary, they feature very prominently, but were used for political ends. Patents are important example of this. Christine MacLeod has described how patents were taken out during the Industrial Revolution for a variety of motivations, including for the sake of marketing to consumers, attracting potential investors, and gaining prestige. ${ }^{1}$ Winsor took out a number of patents for these reasons, and used them extensively in his publicity, frequently using the moniker 'the patentee' to sign his pamphlets and notices. He almost always referred to his devices as 'the patent stove'; which produced 'patent coke'; he at first wanted to found the 'New Imperial Patent Company'; he threatened competitors with infringement lawsuits; he tried to use patent rights to keep himself at the centre of the gaslight project. While Winsor probably thought that his various patents were also ways to protect his technology, he never in fact tried to use his patent rights in an legal process. By the time the Gas Light and Coke Company received his charter, the question of patents had disappeared.

Winsor was not, however, the only one who marshalled the cultural value of science and technology for his business purposes. Boulton \& Watt, through their close connections with Sir Joseph Banks, the president of the Royal Society, used the Society's prestige to wipe away Winsor's claims to priority based on his patents. By having a paper putatively written by Murdock read to the Royal Society and printed in the Philosophical Transactions, and then by having the Royal Society give Murdock a medal for his invention (as described below), Winsor was painted as a fraud and

\footnotetext{
${ }^{1}$ Christine MacLeod, Inventing the Industrial Revolution : the English patent system, 1660-1800
} (Cambridge: Cambridge University Press, 1988), 78-88.] 
impostor seeking to steal credit from the true inventor. The battle then moved to Parliament, and here too scientists were called in by both sides to defend rival claims on very narrow bases. Humphry Davy was even courted by both sides before finally choosing to defend Boulton \& Watt. The whole process, however, was at its core political but fought with the symbols and institutions of science. In the end, it was settled in a political way: through a negotiated compromise. Once both sides came to agree on a demarcation separating their two businesses, all the scientific arguments and priority claims disappeared.

\subsection{Frederick Winsor and the thermolamp 1802-1804}

Very little is know about Winsor's early life. He was born Friedrich Albrecht Winzer in Brunswick (Braunschweig) in 1763. He worked as a merchant and lived in London for some time before 1796, having been granted English citizenship in $1795 .^{2} \mathrm{He}$ then left England for the continent when his possessions there were threatened and eventually lost during the revolutionary wars, after which he returned to England in 1799, now a widower and somewhat poorer. ${ }^{3} 1802$ found him again in Germany, living

2 Danby Pickering, The statutes at large from the Magna Charta, to the end of the eleventh Parliament of Great Britain, anno 1761 [continued to 1806] Anno tricesimo quinto Georgii III. Regis, being the fifth session of the Seventeenth Parliament of Great Britain (1795), vol. 40, part 1 (Cambridge: Printed by J. Bentham, 1795). Private Acts \#10, "An Act for naturalizing Frederick Albert Winzer"

${ }^{3}$ Frederick Albert Winsor, Prosperity of England midst the clamors of ruin ([England?] : Printed for the author, 1799), Dedication. 
in Frankfurt, when he read of Lebon's thermolamp in journals. ${ }^{4}$ He travelled to Paris to see Lebon and visited his demonstrations a number of times, but Lebon would not show him (or anyone else) the details of his thermolamp. ${ }^{5}$ Winsor, however, was nothing if not a determined person and tried repeatedly to learn more about the thermolamp from Lebon, as well as trying to negotiate a purchase of one by exchange of letters. ${ }^{6} \mathrm{He}$ was turned down, but his enthusiasm was not dimmed (nor would it be for the next thirty years). He left Paris in April of 1802, and by September, he had moved back to his hometown of Brunswick and was making many trials with a thermolamp of his own construction. ${ }^{7} \mathrm{He}$ also published a short memoir containing a trilingual edition of Lebon's 1801 thermolamp pamphlet and an account of his attempt to purchase one. ${ }^{8}$ In this publication, Winsor describes himself as being 'of London'.

For reasons unknown, Winsor decided that he had better chances with the thermolamp in England and moved there, probably in 1803. His activities at this point are obscure, but he may have resided in Shrewsbury House at Shooter's Hill in Dover,

\footnotetext{
4 Winsor, Account of the most ingenious and important National Discovery for some Ages. British Imperial Patent Light Ovens and Stoves, respectfully dedicated to both Houses of Parliament, and all Patriotic Societies; and recommended to all the learned in Physics and Chemistry (London: Printed for the author, and sold by Messrs. Richardsons, Royal Exchange; Mr. Miller; Principal Booksellers in Town and Country. T. Maiden, printer, 1804), 3.

5 Ibid., Johann Heinrich Moritz von Poppe, Geschichte der technologie seit der wiederherstellung der wissenschaften bis an das ende des achtzehnten jahrhunderts, vol. 3 (Göttingen: Bey J.F. Röwer, 1811), 20.

${ }^{6}$ Winsor, Account of the most ingenious and important National Discovery, 5.

7 Ibid., 11., Frederick Christian Accum and Frederick Albert Winsor, Traité pratique de l'éclairage par le gaz inflammable contenant une description sommaire de l'appareil et du mécanisme employés pour I'illumination des rues, des maisons, et des manufactures à l'aide du gaz hydrogène carburé, tiré du charbon de terre (Paris: Chez L'Auteur, 1816), 63.

${ }^{8}$ Frederick Albert Winsor, Description of the Thermolamp invented by Lebon, of Paris, published with remarks by F. A. W. (Braunschweig: Friedrik Vieweg, 1802).
} 
Kent. When he later filed a patent he listed himself as being from Shooter's Hill, ${ }^{9}$ as was his son in his wedding notice..$^{10}$ Chandler and Lacey surmised that Winsor was living under the patronage of Princess Charlotte of Brunswick who occupied Shrewsbury house at the time, ${ }^{11}$ and that Winsor's silence on this point was due to the Queen Caroline affair. Caroline was Charlotte's sister, and Winsor was keen to avoid associations that might have raised the ire of the Prince Regent, especially as Winsor was seeking his patronage.

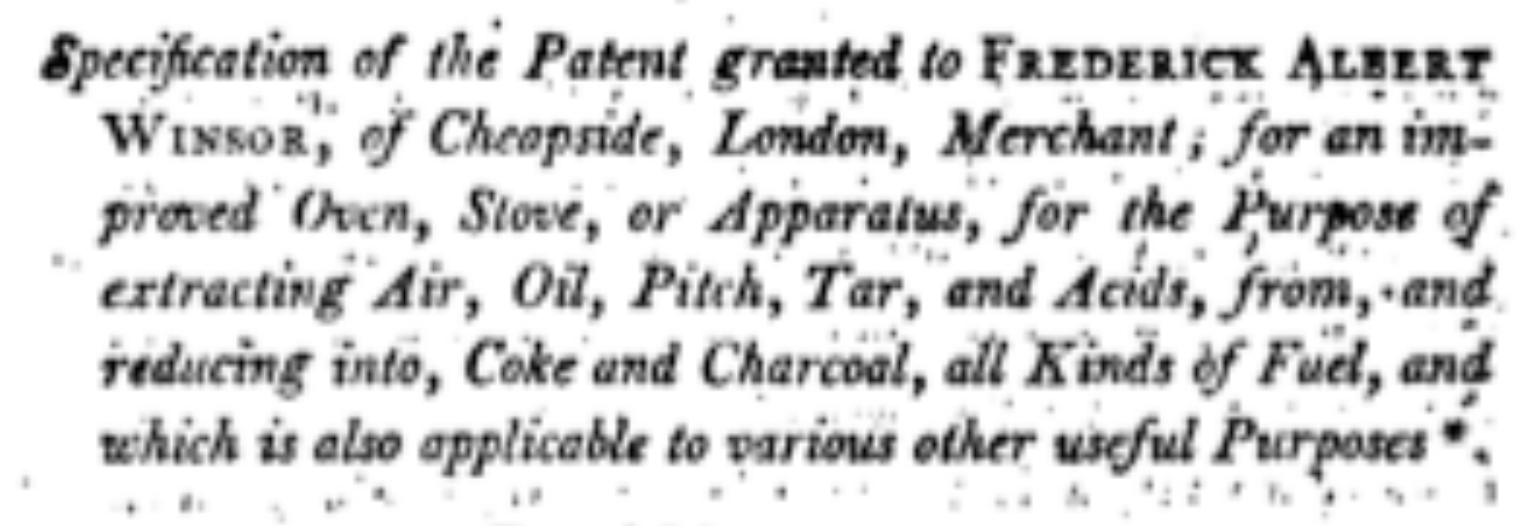

\section{Dated May 18, 1804.}

The repertory of arts, manufactures, and agriculture 2 nd series 5, No.

Whatever else he may have been doing, Winsor spent a good deal of time and money of developing his version of the thermolamp. Once he felt ready either late in

\footnotetext{
9 "List of patents for 1812," The Edinburgh annual register 5, pt 2 (1814).

10 New Monthly Magazine 12, (1819), 119

11 Dean Chandler and A. Douglas Lacey, The rise of the gas industry in Britain (London: British Gas Council, 1949), 25-27. citing William Thomas Vincent, The records of the Woolwich district (Woolwich, England J.P. Jackson, 1888).
} 
1803 or early 1804 to commercialize his invention, he moved to Cheapside in London. William Matthews reported in 1827 that Winsor convinced a wealthy coach manufacturer named Mr. Kenzie to fund his experiments once he settled in London. ${ }^{12}$ These led to Winsor filing for a patent on his new stove, which was granted on May 18, 1804. ${ }^{13}$ The patent and Winsor's first advertising make clear the gaslight was not Winsor's only priority at this point. The patent included inflammable gases among a long list of other useful products, including wood acid, ammonia, and coke, all of which the 'improved Oven, Stove, or Apparatus' was able to produce from either coal or wood. Winsor was clearly trying to make the patent as broad as possible in terms of uses, but it is difficult to see how he could ever have successfully defended it against Lord Dundonald's prior patent, as others would later point out. ${ }^{14}$ The patent also included the notion of conducting gas under city streets through pipes of 'silk, paper, earth, wood, or metal' for the purposes of light and heat.

At about this time Winsor printed the first of what turned out to be quite a lengthy series of verbose pamphlets: Account of the most ingenious and important National Discovery for some Ages. British Imperial Patent Light Ovens and Stoves, respectfully dedicated to both Houses of Parliament, and all Patriotic Societies; and recommended

\footnotetext{
12 William Matthews, An historical sketch of the origin, progress, \& present state of gas-lighting (London: R. Hunter, 1827), 29.

13 "Specification of the Patent granted to Frederick Albert Winsor for an improved Oven, Stove, or Apparatus, for the Purpose of extracting Air, Oil, Pitch, Tar, and Acids, from, and reducing into, Coke and Charcoal, all Kinds of Fuel," The repertory of arts, manufactures, and agriculture 2nd series 5, no. 27 (1804). The specification is in the National Archives, C210/101

${ }^{14}$ William Nicholson, "Remarks on Mr. Winsor's projected Heat and Light Company," The Athenaeum, a magazine of literary and miscellaneous information 1, no. 2 (1807): 187.
} 
to all the learned in Physics and Chemistry. ${ }^{15}$ The 47 page pamphlet provides a brief history of Winsor's dealings with Lebon, and then goes on to describe in prolix terms the theory and uses of his patent stove in his characteristically bizarre manner of thinking. His arguments in favour of adopting the stove included a humanitarian claim that his stoves would improve the lot of 'the most miserable and unhealthiest profession among the human race, that of the poor chimney sweepers' because of the diminution in the quantity of soot produced would obviate the need for this trade. ${ }^{16}$ The stove, in addition to bringing 'great œconomy, utility, convenience, cleanliness, and delight, in human life', would also provide great security and lower fire insurance premiums because no sparks would be emitted, and would improve health by doing away with 'the great blackening soot and dust continually inhaled by our lungs'. ${ }^{17}$

He claimed that inflammable air from his stove could supersede the 'dangerous and expensive steam-engines' because of 'the azot [by this, Winsor meant inflammable air, not nitrogen] produces by a mixture with the atmospheric air, is capable of tenfold powers, if employed in the freezing point only'.18 The list of useful products from the stove included tar, a product he hoped to outdo Dundonald and everyone else in producing, and 'pyrolignous and coal acidities', which could be used to tan skins; cure meat; produce whitelead, verdigrease, copperas, and alum; resolve metals; and fixes dyes so that they 'would never wash out again'.19 He marshalled the work of all the

\footnotetext{
15 Winsor, Account of the most ingenious and important National Discovery.

16 lbid., 17.

17 Ibid., 23-6.

18 Ibid., 14.

19 Ibid., 21.
} 
famous chemists he could-Lavoisier, Count Rumford, Fourcroy, Neuman-to

demonstrate how the stove was based on solid principles, all the while presenting a quasi-Aristotelean diagram of the four elements. ${ }^{20}$

Winsor finished with some of the fantastic and wildly exaggerated financial statements that would earn him much ridicule in the years to come. He suggested that, according to his estimates, the stove represented a $1000 \%$ savings over conventional stoves, and that even with this figure, it 'appears still undervalued'. ${ }^{21}$

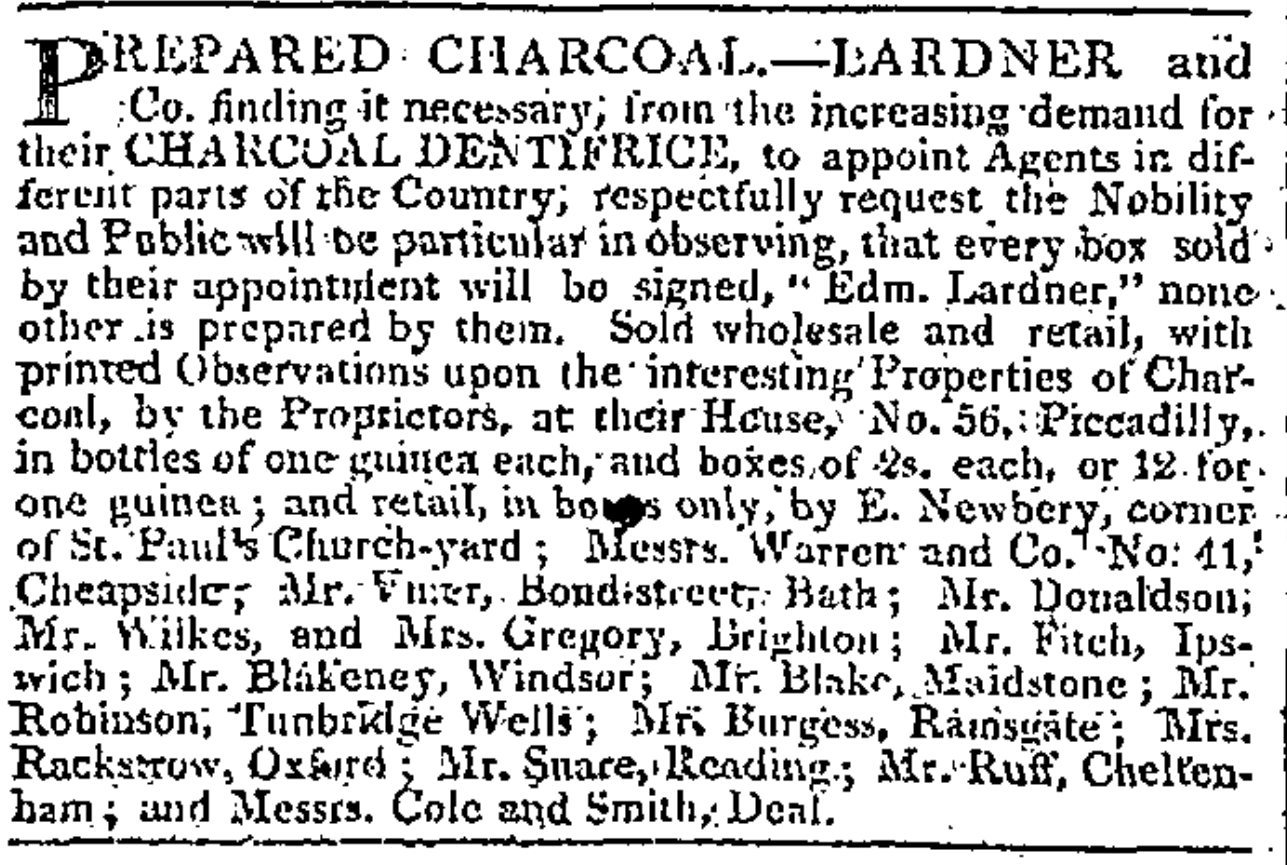

The Times, November 2, 1805. Classified

\footnotetext{
20 lbid., 16.

21 Ibid., 47.
} 
With his pamphlet ready, Winsor started making arrangements for public lectures and further development work on his patent stove. He hired some assistants, including Edward Heard who had advertised for a place as a chemist's assistant, having formerly been working at Lardner \& Co. of Picadilly Street, a London merchant and chemist. ${ }^{22}$ The connection with Lardner is intriguing because Lardner \& Co. had been using some sort of gaslight at their building. ${ }^{23}$ No details of Lardner's apparatus survive, although it likely used wood-gas. Lardner \& Co. advertised 'Charcoal Dentrifice' which they sold throughout the country. It is possible that they made the charcoal in their warehouses in London by distilling wood in ovens and at some point, perhaps because they heard of Lebon's work, they tried to make use of the gas for lighting purposes as well. ${ }^{24}$ Winsor later presented his hiring of Heard as a great act of charity on his part, almost as if he was taking in a vagrant, ${ }^{25}$ but Heard clearly had some chemical abilities because he was the first to take out a patent on lime purification on June 12, 1806.26 Winsor, in fact, rushed out and got a patent that included purification a month after Heard's patent was

\footnotetext{
22 Frederick Albert Winsor, Mr. W. Nicholson's attack, in his Philosophical Journal, on Mr. Winsor and the National Light and Heat Company: with Mr. Winsor's defence (London: 1807; reprint, Matthews' Historical Sketch (1827), p 246-65), 264.

23 "Comments on Mr. Wm. Henry's Experiments on the Gases obtained from the Distillation of Wood, Peat, and Pit-Coal," Retrospect of philosophical, mechanical, chemical and agricultural discoveries 1, no. 2 (1805): 133. John Ashton, The dawn of the XIXth century in England, a social sketch of the times, 5th ed. (London: T.F. Unwin, 1906), 206., the Morning Post of June 15, 1805. p. 4. Winsor accused Lardner of theft via humpheries N's attack p. 42

24 There were also reports made in 1807 of John Lardner of Oxford street selling gas lamps, but it is not clear what the relation is with the Edmond Lardner mentioned here. "Einige Nachrichten aus England über Erleuchtung im Grossen mit Thermolampen," Annalen der Physik 30, no. 12 (1808): 407.

25 Winsor, Mr. W. Nicholson's attack, 264.

26 "Specification of the Patent granted to Edward Heard, of London, Chemist, for a Discovery of certain Means of obtaining inflammable Gas from Pit-Coal in such a State that it may be burned wihtout producing any offensive Smell," The repertory of arts, manufactures, and agriculture 2nd series 10, no. 56 (1807). "Mr. Edward Heard's Discovery," The Monthly magazine, or, British register 23, no. 1 (1807).
} 
published in The Repertory of Arts,,$^{27}$ and later claimed Heard had stolen this idea from his use of lime 'many years before'. ${ }^{28}$

Heard and Winsor got to work in early 1804 by buying supplies and but within six weeks had a falling out which turned acrimonious, a course of events which seemed to happen to Winsor with some frequency. Winsor later claimed that Heard, whom he relied on to read his lectures while he demonstrated his apparatus, one day did not show up for his duties, apparently claiming to have mislaid the lecture notes. Winsor summarily dismissed Heard. Heard went off on his own trying to develop gaslight apparatus and embarked on a promotional lecture tour outside of London, finally settling in Bristol in 1805 where he tried to incorporate a gaslight company. ${ }^{29}$ Winsor later accused Heard of using the notes he claimed to have mislaid for Heard's own lectures and of otherwise having appropriated his ideas. ${ }^{30}$ Winsor had a similar disagreement at the same time with a smith named John Humphries who lasted a very short time working for Winsor. ${ }^{31}$

\footnotetext{
27 "Patent granted to Frederick Albert Winsor for an improved oven, stove, furnace, or apparatus for the extracting of inflammable air or gas and oil-tar from different kinds of fuel," The repertory of arts, manufactures, and agriculture 2nd series 10 (1807).

28 Winsor, Mr. W. Nicholson's attack, 45. - non-reprint

29 Edward Heard, Summary account of an improved method for illuminating theatres, assembly-rooms, public gardens, streets, light-houses, public offices, dwelling-houses, \&c, \&c, \&c with the philosophical lights, produced without candles!!! spirits!!! or oil!!! : a new and valuable application of a known principle, to which is annexed a proposal for carrying the same into effect respectfully submitted to the consideration of the inhabitants of Bristol by Edward Heard. (Bristol: Printed by R. Jenkins, 1805).

30 Winsor, Mr. W. Nicholson's attack, 262 ff.. See also "Truth was deemed a libel," The Times, Dec 27 1806.

31 Winsor, Mr. W. Nicholson's attack, 263.
} 


\begin{tabular}{|c|}
\hline 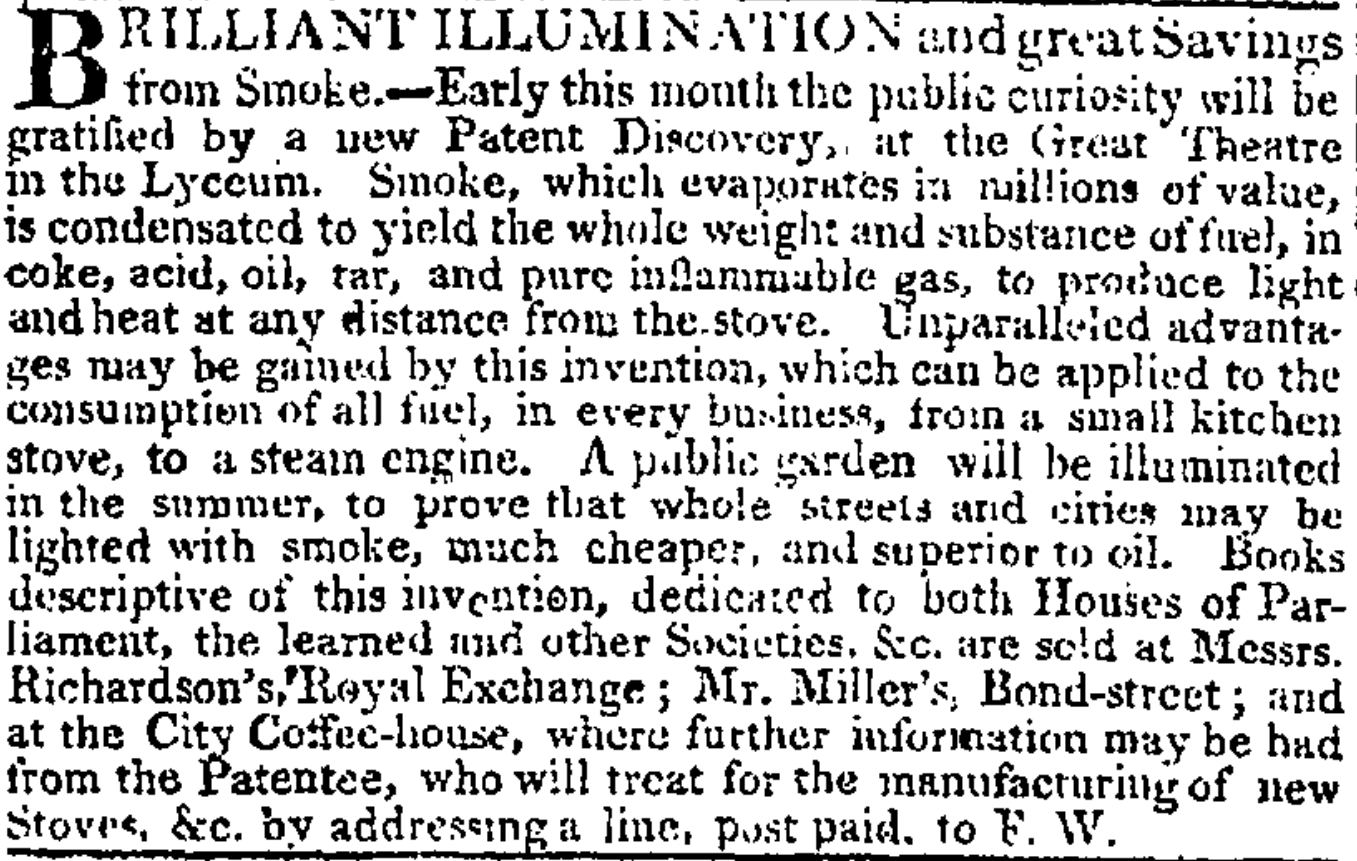 \\
\hline
\end{tabular}

The Times, May 7, 1804. Classified

Winsor's promotional campaign now began in earnest. In May of 1804, he started advertising his Lyceum lectures in newspapers, promising to light a local garden come summer. The lectures at the Lyceum included 'a chandelier in the form of a long, flexible tube suspended from the ceiling, communicating at the end with a burner, designed with much taste, being a cupid grasping a torch with one hand and holding the tube with the other' ${ }^{32}$ He established his office at the City Coffee House in Cheapside, ${ }^{33}$ and his Account pamphlet was now on sale.

\footnotetext{
32 Austin Brereton, The Lyceum and Henry Irving (London : Lawrence \& Bullen: New York, 1903), 28.

${ }^{33}$ Frederick Albert Winsor, The superiority of the new patent coke over the use of coals (London: Richardson, 1804), 3.
} 
Over the course of the summer, his ambitions had grown and he now hoped to establish an 'New Imperial Patent Company' by finding investors to sign up for 100 shares in a Coke Company. ${ }^{34}$ Winsor did not specify the price, and claimed that 100 was the legal limit for the number of shares without an act of Parliament. ${ }^{35} \mathrm{He}$ retained the joint-stock bank of Matthew Bloxam \& Co. to run the share subscription, and Bloxam himself eventually became an investor and leading backer of Winsor's efforts. Winsor printed posters and notices which he mailed out in large numbers to all the prominent people he could. He must have had substantial financial backing for the expenditures he had incurred so far, although it is not clear who his backers were. The most likely candidate is the Duke of Brunswick's family. By September, Winsor was claiming on his posters that he had had $£ 2000$ in expenses over the last three years, not an unbelievable sum considering the scale of the promotional campaign and his experiments. ${ }^{36}$ On the advice of the patent office, Winsor generally did not publish the details of his stoves nor show them off in public. ${ }^{37}$

Winsor was always sensitive to establishing the prestige of his projects, and his posters claimed that Sir Joseph Banks of the Royal Society as well as the Duke of

\footnotetext{
34 1812/08/05 GLCC Minutes of the Court of Directors Book 1 p. 18: London Metropolitan Archives B/ GLCC/1/1. providing our streets and houses with light and heat, on similar principles, as they are now supplied with water, demonstrated with the patentee's authority and instructions, by Professor Hardie, at the Theatre of Sciences, No. 98, Pall Mall, where it is proved by positive experiments and decisive calculation, that the destruction of smoke would open unto the empire of Great Britain new and unparalelled sources of inexhaustible national wealth, at this most portentous crisis of Europe, worth the whole century of inventions of the celebrated Marquis of Worcester, first ed. (London: Printed, for the patentee, by Watts \& Bridgewater, 1806), viii.
} 
Richmond had been to see his demonstrations and had been much impressed. ${ }^{38}$ Winsor had not taken sufficient care (if he took any care at all) to consult with people he named in his notices like this, and some of them would take exception to his public use of their names. ${ }^{39}$ In September, Winsor tried to interest Trinity House, the trust responsible for the lighthouses along the English coast, in using his stoves for light. The Deputy Master and some other 'brethren' went to visit Winsor at the Lyceum, and were apparently impressed with the technology. Nothing came of it in the short run, but the visit was reported in the local newspapers. 40

\footnotetext{
38 Poster sent with Winsor to B+W 1804/08/20, BWA MS 3147/3/539 \#38, AM-IR series 1 part 15 reel 285 39 Lord Stanhope. See "Gas Light Bill 3rd reading," The Times, Saturday, Jun 21810. 40 "Mr. Winsor's new discovery," The Times, Thursday, Sep 201804.
} 


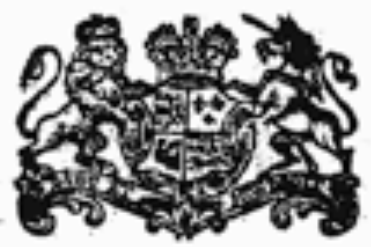

Profit! Information! Amufement! NOW EXHIBITING, Moft Brilliant Illuminations FROM

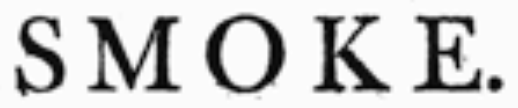

A NEW PATENT DISCOVERY, AT THE

LARGE THEATRE in the LYCEUM. EXAMINED AND SANCTIONED BY The DUKE of RICHMOND, SIR JOSEPH BANKS, And a numerous Parly of their noble and fcientific Friends.

S

MOKE, which evaporates in Millions of Value, is condenfated fo as to yield the whole Weight and Subftance of Fuel in Coke, Tar, Oil, Acid, and pure Gas; to produce Heat and Light at any Diftance from the Stove; whereby unprecedented. Advantages are gained, becaufe this Invention is applicable to every Confumption of Fuel in all Bufinefs, from a Kitchen-Grate to a Steam-Engine.

Books defcriptive of this Difcovery, dedicated to both Houfes of Parliament, and all the learned Societies, are fold at Meffrs. Richardsons', Royal Exchange; and at the Lyceum.

The LARGE THEATRE is open every Day from

ELEVEN till FOUR a'Clock. Admittance Two Shillings.

LECTURES, illuftrated by Experiments, are given every Evening from EIGHT till TEN o'Clock.

Boxes $4^{\text {s. Pit }} 3^{\text {s. G Gallery } 2 s .}$

* Society and Family Tickets of Admittance, to be had at

lower Prices, in proportion to the Nunber of Perfons. of. Subscription Books are opened at the Lyceum for Patent Stoves and Apparatus. 


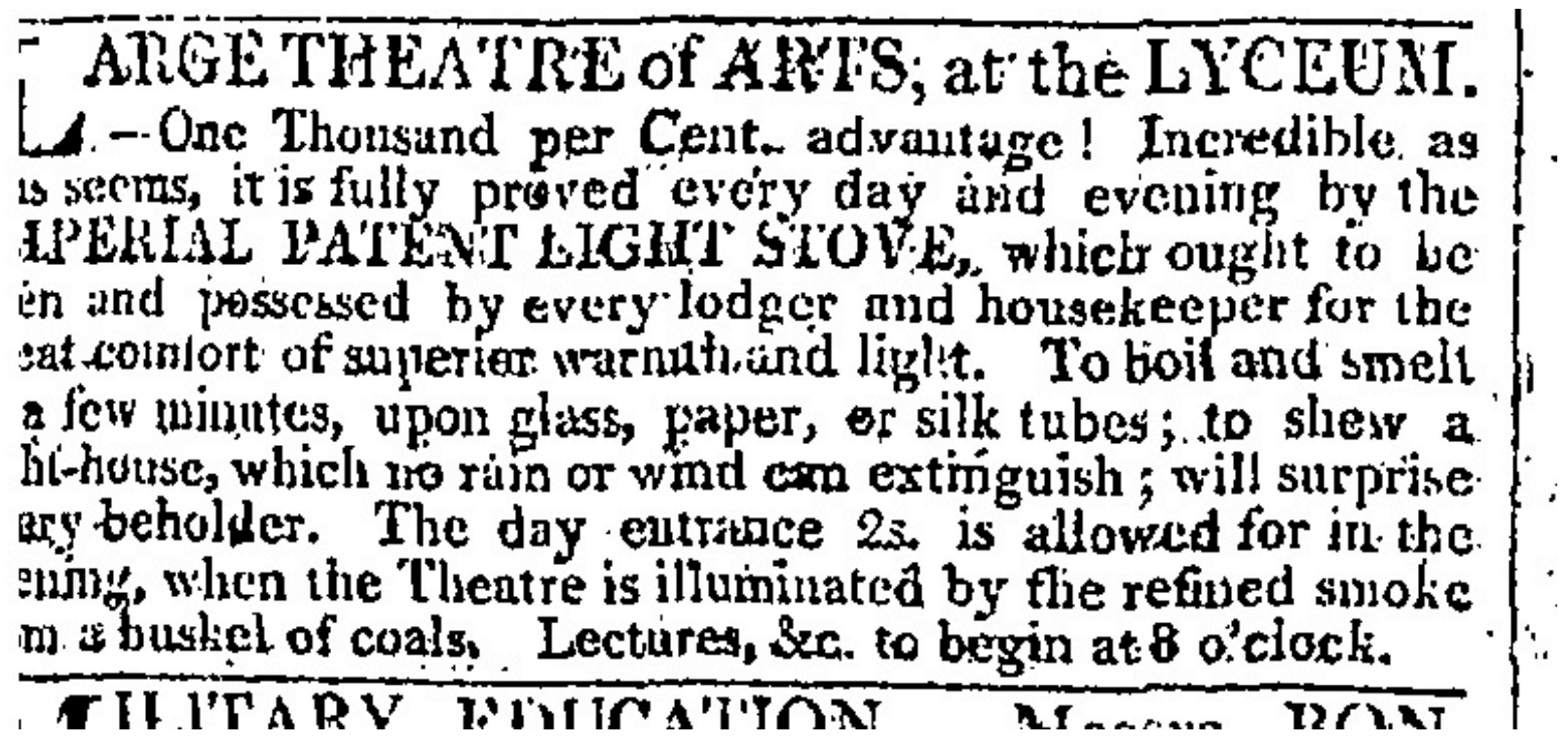

The Times, September 4, 1804. Classified

The last four months of the year saw Winsor push his campaign to a new level. He wrote and had printed a second pamphlet, The Superiority of the New Patent Coke over the Use of Coals, in which he argued that the coke produced in his stoves was far superior to ordinary coal. He listed many of the same arguments he had used in his earlier pamphlet, such as humanitarian treatment of chimney sweeps and the greater efficiency of his flames. He made no mention of gaslight in this pamphlet. This was not, however, because he has given up on the possibility, but because he thought he could attract more investors by emphasizing the coke aspect of his work, rather than the unproven lighting side of it. He continued to speak about the lighting uses of his stove in his lectures and newspaper advertisements. He also now lit the front of the Lyceum 
with gas lights. ${ }^{41}$ An account of the impression made by Winsor's demonstrations was printed in Kirby's Wonderful and Eccentric Museum soon thereafter:

The numerous discoveries resulting from the spirit of philosophic research, so generally diffused within these few years, throughout the most civilized nations of Europe, have undeniably contributed to promote in a high degree, the comfort and conveniencies of society. None however promises to be more beneficial, or of more general utility, than a discovery first exhibited at Paris, in 1802, and lately introduced into this country by an ingenious artist who obtained a knowledge of the secret, and who has for several months exhibited it to the curiosity of the public at the Lyceum in the Strand. The object of this discovery, which will doubtless form an important epoch in the annals of domestic œconomy, is to produce light without the aid of wax, oil, tallow, or any combustible now employed for that purpose. The expence of illumination both to the community in general, and to individuals in particular, is most sensibly felt at the present moment, when the materials employed for that purpose have attained to an unprecedented price. The public must therefore feel more deeply interested in a discovery which tends to reduce that expence to a mere trifle, and to supply them with a light infinitely superior to that to which they have hitherto been accustomed. [...] The extraordinary advantages of this method of producing light must be obvious to the most superficial observer. ${ }^{42}$

\footnotetext{
41 "Mondays, Wednesdays, and Fridays only," The Times, Oct 101804.

42 R. S. Kirby, Kirby's wonderful and eccentric museum; or, Magazine of remarkable characters. Including all the curiosities of nature and art, from the remotest period to the present time. Drawn from every authentic source; ... illustrated with elegant engravings, vol. 3 (London: R.S. Kirby, 1805), 38-40. See also "Mr. Winsor's Thermolampen-Ofen in London," London und Paris 15 (1805).
} 


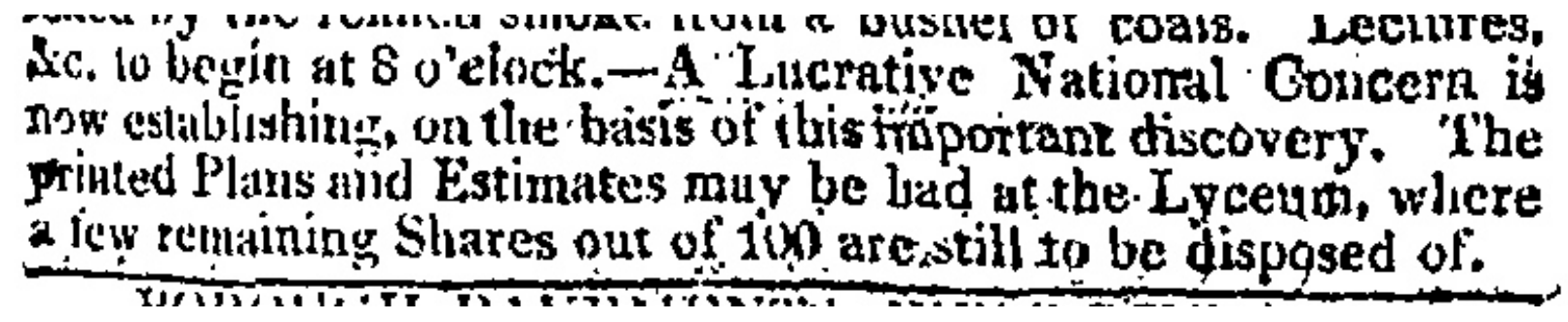

The Times, September 19, 1804. Classified

The share subscriptions was apparently going well. By late September, Winsor was claiming that only a few of the 100 shares originally available were left. Some time before the end of the year, all the 100 shares had been sold, and a committee of five shareholders was established to validate Winsor's claims. ${ }^{43}$ They met in November, and, at least according to Winsor, were satisfied that Winsor's stoves were sound and his claims valid. ${ }^{44}$ With the positive report of this committee, the subscribers voted to proceed with applying for a royal charter via an act of Parliament, and for this purpose, to build a large demonstration furnace that could carbonize a chaldron (32 bushels) of coal. The charter was necessary because a 1719 law required it for the formation of all joint-stock companies. They also voted to award Winsor five guineas each for his expenses to date. 45 Winsor now wound down his lectures and demonstrations at the Lyceum, closing the show off towards the end of December 1804.46

\footnotetext{
43 "Large theatre of arts, Lyceum." See also "Useful improvements and discoveries," The Literary magazine, and American register 3, no. 19 (1805).

44 "Large theatre of arts, Lyceum." Winsor, To be sanctioned by act of parliament [1806], 13.

45 Winsor, To be sanctioned by act of parliament [1806], viii-ix.

46 "Large theatre of the Arts, Lyceum: two last nights," The Times, Dec 191804.
} 
The subscribers constituted another committee of five who would act as trustees for the larger group of subscribers, and with whom Winsor legally entered into a partnership and licensed his patent in some way in order to proceed with the design and construction of the large furnace. Among the five was a Doctor Clarke who, as Winsor put it few years later, 'seemed to be a Newton in theory'. Clarke persuaded the group to allow him to build the large scale coking stove, and Winsor later claimed that he spent much of the firm's capital without producing a working model. Winsor put the figure at various points between $£ 300$ and $£ 1000$. Winsor and Clarke were soon in a dispute over the direction of the Coke Company and the possibility of seeking a new patent, with Winsor resisting Clarke's plan to be a co-patentee with Winsor. They reached an impasse and Winsor felt compelled to dissolve the partnership some time in 1805 . The entire venture then disintegrated. ${ }^{47}$

Winsor now returned to his developmental work, focusing this time on gaslight, and spent the greater part of the next two years doing this research work. Although the committee had disintegrated, Winsor seems to have retained the backing of some important shareholders who were willing to fund further work, but he also needed to supplement this, and started running up personal debts, owing $£ 4000$ by the beginning of 1806.48 Winsor had completely halted his public activity in 1804 , and he did not take up again immediately. He placed no advertisements nor wrote any pamphlets from

\footnotetext{
47 For details about this period see Winsor, To be sanctioned by act of parliament [1806], vii-x. and 1812/08/05 GLCC Minutes of the Court of Directors Book 1 p. 18: London Metropolitan Archives B/GLCC/ $1 / 1$.

48 James Ludovic Grant and Frederick Christian Accum, The report of James Ludovic Grant, Esq. Chairman, and the other acting trustees of the fund for assisting Mr. Winsor in his experiments to the subscribers of that fund, at a meeting convened ... on the 26th of May, 1808 (London: Printed by G. Sidney, 1808), 14.
} 
1805 until mid 1806. Chandler and Lacey claim that he became involved in a show called Ergascopia which was run at the Lyceum after Winsor's demonstrations had finished their run. Their claim is based on a book, Wilkinson's Theatrum Illustrata printed twenty years after the fact, which says 'Windsor' was at the head of this German production. There is no contemporary evidence that Winsor had anything to do with this show. The advertisements for the show list Messrs. Schirmer and Schale (or Scholl) as the organizers. ${ }^{49}$ No advertisement for Ergascopia ever mentioned Winsor, nor anything about establishing a company. Gas illuminations were but a minor part of the Ergascopia show. There also also some claims that Winsor toured the country giving lectures, and settled in Bristol, but this is likely a confusion with Heard's activity during these two years. ${ }^{50}$

\footnotetext{
49 "Pantascopia and Ergascopia," The Times, Jan 01 1805.. See also Terry Castle, "Phantasmagoria and modern reverie," in The Horror Reader, ed. Ken Gelder (New York, London: Routledge, 2000), 35.

50 "Comments on Mr. Wm. Henry's Experiments on the Gases obtained from the Distillation of Wood, Peat, and Pit-Coal."
} 


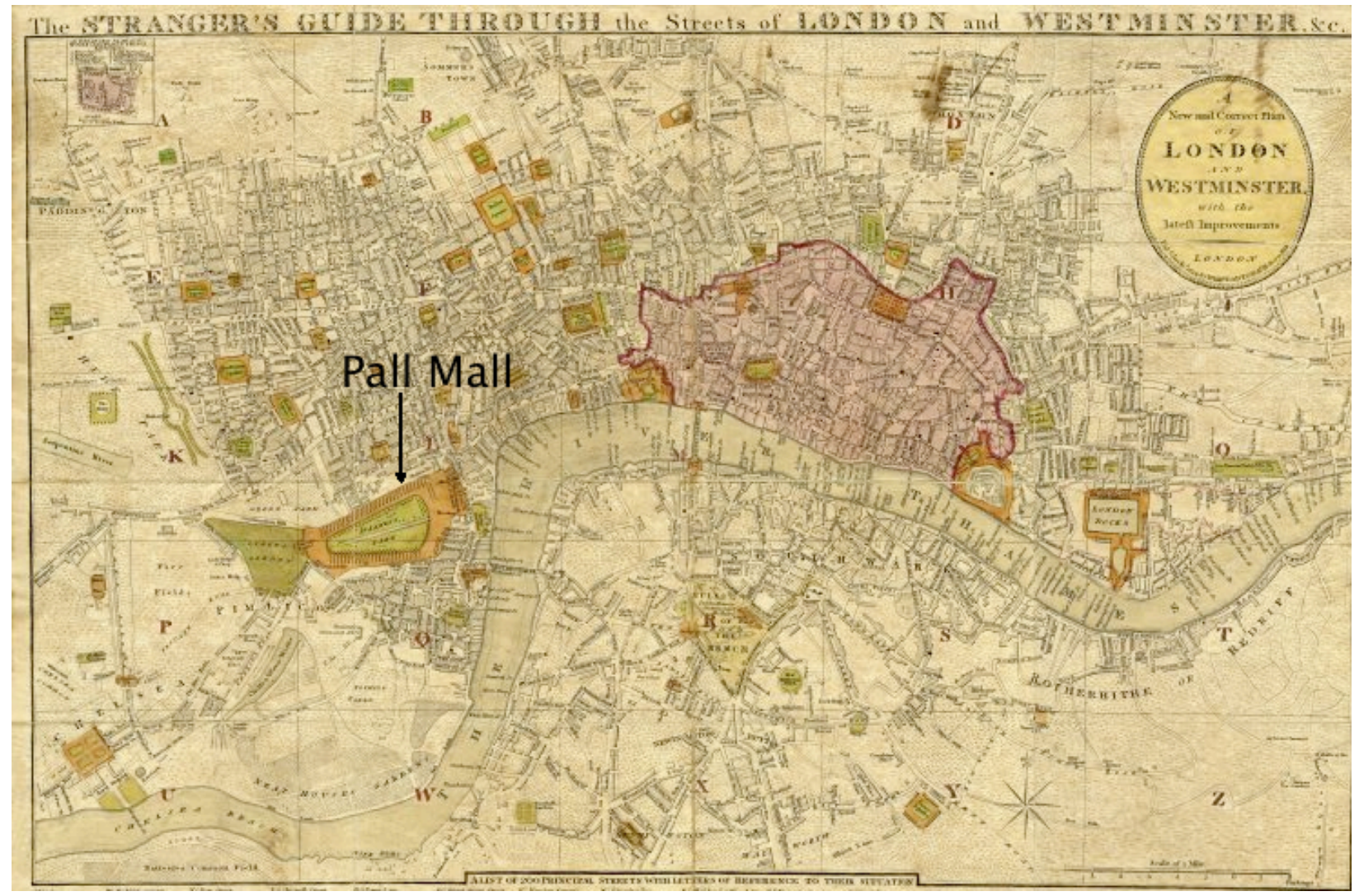

Figure 4.2 The Strangers Guide Through the Streets of London and Westminster \& $c$ (1814)

\subsection{The campaign of $1806-1807$ and the first general meeting of 1807}

The period from mid 1806 to mid 1807 marked a new chapter in Winsor's drive towards establishing a company. During 1805-6, he and his backers devised a business plan which they brought to the public towards the end of summer 1806, when they launched a campaign that had two distinct phases. First, they engaged in a wide ranging canvassing to raise more funds for the National Heat and Light Company, as 
they now called the venture. The lobbying of Parliament to grant a charter for the new company was the second phase of the campaign, and it proved to be far more difficult than finding interested investors. The two phase campaign was remarkable in its scale and for its success. Advertisements for the company were placed almost daily in many London newspapers and journals, and Winsor also printed bills which he cast as widely as his advertisements. He advertised outside London, with country bankers collecting deposits for shares. ${ }^{51}$ From the investment perspective, in the space of a few months in 1806 , the company managed to find buyers for 5000 shares at $£ 50$ each, with $£ 5$ payable immediately. The shares sold soon reached 10,000 in early 1807 , and finally 20,000 in by May 1807 . The ability of Winsor and company to attract so much money in such a short time is a remarkable testament to how much money was available in London for a new venture, how willing people were to place their money with a company based on a new technology, and finally how effective Winsor was at generating interest and keeping the venture in the public eye. The promoters of the National Heat and Light Company were also riding a boom in joint-stock companies that was sweeping Britain in the early years of the nineteenth century. The Canal Mania of 1791-4 had subsided, but new boom that ran from 1807-11 had started with tens of companies been promoted. In January of 1808 alone, there were 42 new joint-stock companies formed that had been promoted over the previous years. ${ }^{52}$ Unlike the canal boom, the current one featured a broader range of companies, and did not come to a crashing halt. The creation of new companies continued after the torrid pace of the intense years

\footnotetext{
51 "National Light and Heat Compnay, for the Introduction of Coke and Gas-Lights," Hampshire Telegraph and Sussex Chronicle, Monday, February 91807.

52 Charles Poor Kindleberger, A financial history of western Europe (Oxford University Press, 1993), 193.
} 
had subsided, Winsor and the National Heat and Light Company were right in the thick of the boom. ${ }^{53}$

53 See Ron Harris, Industrializing English law : entrepreneurship and business organization, 1720-1844 (New York, 2000). for a broader discussion of the trends in business organization at this time. p. 216-7 


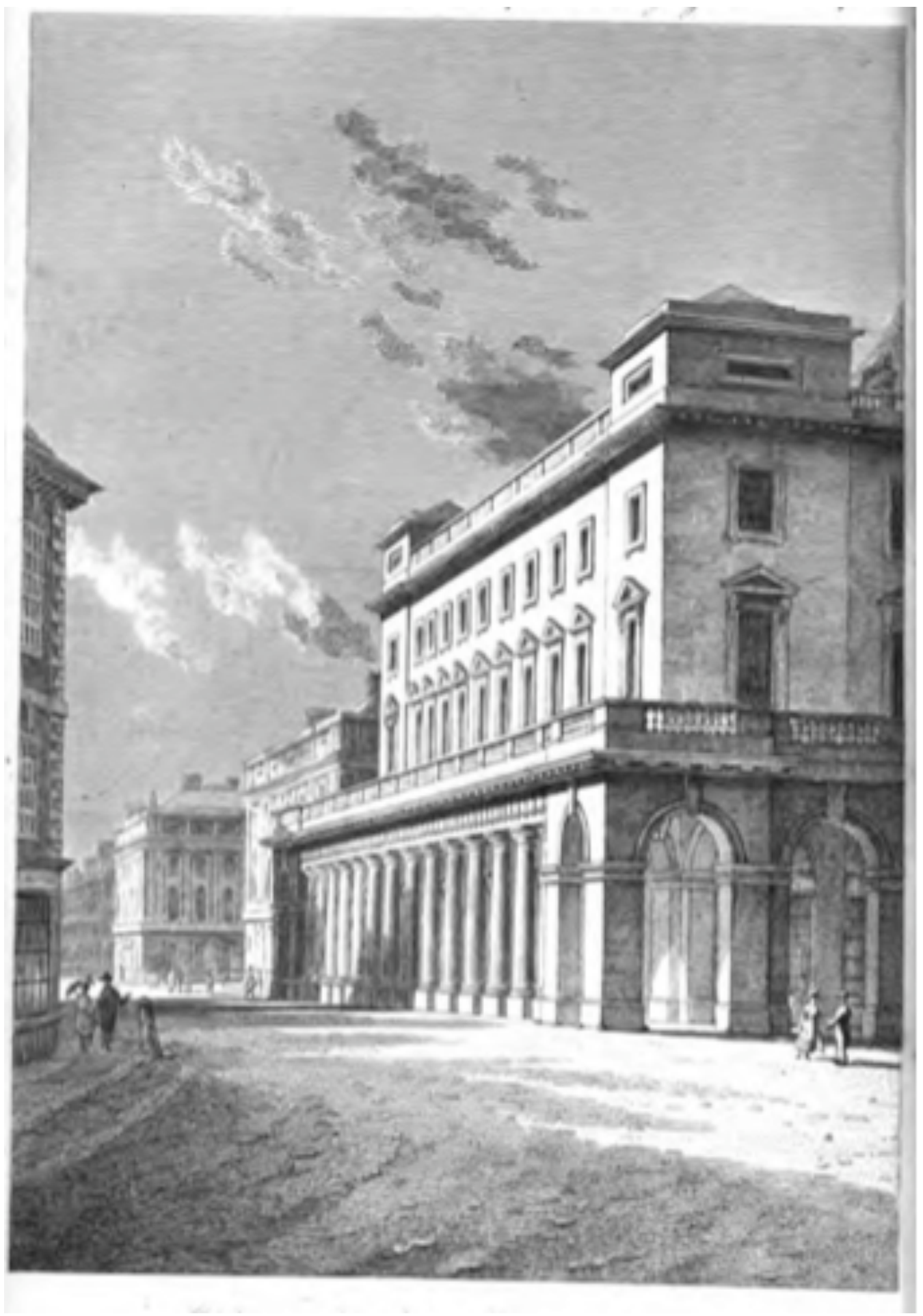

Figure 4.3 The Opera House Colonnade and Waterloo Place, Pall Mall, from the frontispiece of the The European Magazine and London Review July, 1817, Vol. 72 
Early in 1806, Winsor leased a house at 98 Pall Mall and moved his residence and offices there. The choice of Pall Mall indicates how much Winsor's ambitions had grown even since 1804. The location placed him close to the seat of the government at Whitehall and Parliament, as well as a number of houses and palaces of nobility and royalty, such as Marlborough House, Carlton House, and the official residence of the king at that date: St. James Palace. He restarted lectures, and with the backing of investors, continued to experiment. ${ }^{54} \mathrm{He}$ wanted to make his demonstrations even more extensive, and placed an order for 5600 feet of earthen tubes during the summer of 1806 , with the intention of laying them under a number of street the following year, perhaps intending this to be a decisive prelude to the permanent operations of the new company. ${ }^{55}$ As the year progressed, Winsor contracted Frank Hardie to take over giving his lectures at Pall Mall in order to free himself up for his other activities. ${ }^{56}$ Around this time, he leased the neighbouring building at 97 Pall Mall for more space, making the new building the official address of the company while keeping his personal address at 98. ${ }^{57}$ Hardie was a lecturer in natural philosophy, specializing in electrical phenomena. He had been giving lectures in his own quarters in 1804 when the demand became such that he moved them to the another hall of the Lyceum theatre at the same time Winsor was there. Hardie's lectures in 1804 included some demonstrations that

\footnotetext{
${ }^{54}$ GLCC MCD b1 p. 19, 91, 96-7

55 Grant and Accum, The report of James Ludovic Grant, 118.

56 Winsor, To be sanctioned by act of parliament [1806], xi.

57 The first mention of 97 is in "Theatre of Science, No. 76 Pall Mall," The Morning Chronicle, Monday, July 28 1806.. The copies of Winsor's first To be sanctioned pamphlet in the British Library are also corrected by Winsor personally, changing the address from 98 to 97 Pall Mall.
} 
included lighting with gas, ${ }^{58}$ and it it likely that Winsor and Hardie formed some association at that time. Hardie's lectures for Winsor do not seem to have lasted too long and he was out of the picture by 1807 , probably forced out by the committee of trustees. 59

58 "Galvanism and electricity," The Times, Aug 18 1804. "Galvanism and electricity." "Positively the last time. Galvanism and electricity," The Times, Sep 281804.

59 Minutes of the Court of Directors 1813/03/19 p. 97: London Metropolitan Archives B/GLCC/1/1 


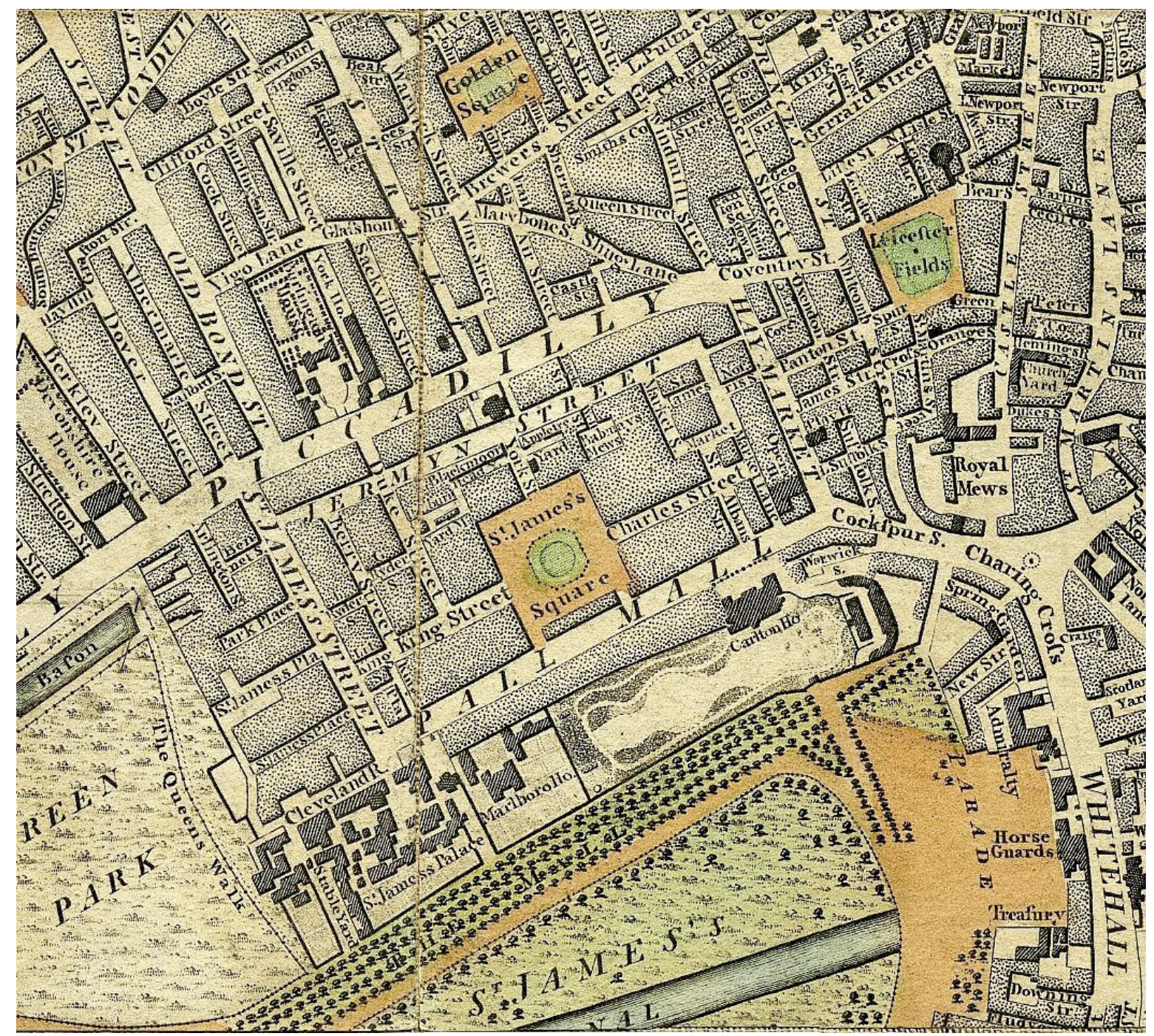

Figure 4.4. London around Pall Mall, from Wallis's Plan Of The Cities Of London And Westminster (1801).

Carlton House can be seen on the south side of Pall Mall, just where it reaches Cockspur Street 
With the new house ready and the lectures running, Winsor and his backers launched their drive to accumulate the much larger pool of capital from many investors and establish a very large joint-stock company with limited liability. Incorporated companies in England at this time were limited in the number of shareholders they could have, and the shareholders were all personally liable for the company's debts, meaning that the bankruptcy of a firm would often spell the ruin of its shareholders as well. The only way out of this situation was to incorporate a company by act of Parliament which specifically limited the liability of the shareholders in the company. Winsor had thought of obtaining such an act even as early as 1804 . He was now willing to try again, but to do so successfully he would need the backing of politically influential individuals, some of whom he could already find among his backers.

Winsor's new marketing campaign made his first one of 1804 look minor and subdued. In mid 1806, he published a new 48 page pamphlet entitled To be sanctioned by act of parliament. A National Light and Heat Company for Providing our Streets and Houses with Light and Heat, on Similar Principles, as they are now Supplied with Water, Demonstrated with the Patentee's Authority and Instructions, by Professor Hardie, at the Theatre of Sciences, No. 98.60 This pamphlet with its subsequent edition contained the most wildly inflated claims that Winsor had yet made, and it is striking that merchants and business interests allied with Winsor allowed him to retain such control of the process and speak in such hyperbole. He claimed, for example, that a modest annual profit estimate for his company was $£ 131,583,333$ and that the tax the company paid

\footnotetext{
60 Winsor, To be sanctioned by act of parliament [1806]., "Theatre of Science, No. 76 Pall Mall." "Theatre of Science, No. 67 [sic] Pall Mall," The Morning Chronicle, Thursday, August 71806.
} 
would eliminate the national debt in short order. It is unlikely that any of his backers really believed these figures, but they probably recognized that Winsor was extraordinarily effective at publicity and many of them had been attracted by the size of Winsor's profit forecasts, all the while realizing that their grand scale was illusory. Many more subscribers were still needed, and the more thorny problem of gaining parliamentary approval had not yet been solved. Whatever Winsor could do to generate talk and excitement was going to help their cause. The wild talk was, however, to have its consequences. It allowed Winsor's opponents to portray him plausibly as a quack, and the perception of building up a short-lived investment bubble, such as the still infamous South Sea Company Bubble of 1720 , contributed to their defeat in the House of Commons in 1809.

The title of the pamphlet indicates that Winsor was now thinking of establishing a gas company on a utility model, much like water supply, an analogy he consciously drew, stating in the pamphlet that 'the National Light and Heat Company must chiefly be conducted on the principles of the Water Companies'. ${ }^{61}$ By this he was thinking primarily of their investment model of large initial expenditure of capital and time to establish a supply infrastructure which, once operating, provided reliable service and healthy dividends. Winsor of course thought his National Heat and Light Company had far more benefits than water companies. The idea of selling stoves had receded somewhat, although the manufacturing of stoves and gas apparatus for sale was still present. It was this aspect of their business plan that irked Boulton \& Watt in particular and provoked them to reaction and forceful opposition.

61 Winsor, To be sanctioned by act of parliament [1806], 7. 
Winsor and company proposed in 1806 to raise $£ 1,000,000$ by finding 20,000 subscribers at $£ 50$ per share. The initial payment was $£ 5$, and Winsor promised the rest would not have to be paid as dividends would soon cover the amount owing. The share sale went at a brisk pace. By November when advertisements started appearing in newspapers, Winsor was reporting that 2000 of the shares had been taken, meaning he had raised $£ 10,000.62$

Winsor now raised the intensity level of his marketing campaign. He advertised in many of the major London papers almost daily from November 1806 through the first half of $1807 .{ }^{63}$ He placed advertisements in society journals and provincial newspapers. ${ }^{64}$ He published more pamphlets, putting at least five into circulation before April 1807,65 such as Plain Questions and Answers in January, ${ }^{66}$ and Analogy between Animal and Vegetable Life. Demonstrating the Beneficial Application of the Patent Light Stoves to all Green and Hot Houses sometime later. ${ }^{67}$ He sent copies of these pamphlets to influential people as he had in 1804 . The copies of his pamphlets in the

\footnotetext{
62 "National Light and Heat Company," The Times, Nov 22 1806. "National Heat and Light Company," The Morning Chronicle, Wednesday, November 261806.

63 There are advertisements in the Times on November 22, 28, December 2, 4, 10, 11, 12, 15, 16, 18, 27 , 29, January 1, 9, 16, 29, Feb 10, 27, 28, March 24, April 4, 6, May 8, 14, 15, June 4, 16, 18, 20, 23, July $13,15,16$. This is not a complete list, and Winsor advertised in other papers as well.

64 See, for example, La Belle Assemblée: Or, Court and Fashionable Magazine Nov. 1807, Advertisements p. 33

65 "National Light and Heat Company," The Morning Chronicle, Monday, March 23 1807. "National Light and Heat Company," The Times, Saturday, Apr 04 1807. Not all of these pamphlets survive.

66 "National Light and Heat Company," The Times, Thursday, Jan 29 1807. This pamphlet, like many others, probably had more than one edition, as the British Library copy has resolution from the July 1807 meeting appended.

${ }^{67}$ Frederick Albert Winsor, Analogy between Animal and Vegetable Life. Demonstrating the beneficial application of the patent light stoves to all green and hot houses, etc. (London: Richardson, 1807).
} 


\section{British Library are ones he sent to Sir Joseph Banks and others and these include a} personal dedication. Winsor tried to get notables to attend his experiments with some success, as on the occasion of the visit of Lord Minto, Lord Petty and others on January 17, 1807, which prompted a short review to appear in The Times.68

At approximately this time in 1807 , an Irish student who was staying in London visited Winsor's lectures and described them and his impression of the project in a letter to his father:

I have visited the rooms, and attended the lectures, of Mr. Winsor, the projector of the National Light and Heat Company. [...] The lights by which his rooms are illuminated are certainly very vivid; but the inconvenience and disagreeable appearance of the tubes through which the gas passes, and the lights being from necessity, in general, stationary, will, in my humble opinion, prevent this philosophical application, for discovery it cannot be called, from ever being used for domestic purposes. [...] The lecture was delivered in a damp and dreary subterraneous room, I believe a cellar, rudely fitted up as a little theatre. The lecture unfolded the nature, and origin of gas light, and the great national uses to which it may be applied. I should think that streets might be illuminated with the gas to great advantage; as the light is large, beautiful, vivid; but then the same danger of total darkness ... presents itself. The amount of the shares in this speculation are invested in banking-houses, of the first eminence, from which the ingenious projector is paid the amount of all expences arising from experiments connected with the project, as a national scheme. Mr. Winsor has injured his philosophical project, by the stupid puffs which he is continually inserting in the papers; he appears to be a foreigner, and not without talent. One day in the week is appropriated to an exhibition of his experiments to the members of both houses and their families: in this he is very politic, as, hereafter, his

68 "Inspection of Mr. Winsor's discovery at Pall Mall," The Times, Wednesday Jan 211807. 
plan of lighting the capital must be submitted to the consideration of the senate [meaning Parliament], and, if approved of, be made the subject of an act of parliament before it can be carried into effect. 69

During this intense campaign, Winsor and company attracted much attention, both friendly and hostile. His rhetoric was bound to make him the butt of many jokes, such as the satirical pamphlet An Heroic Epistle to Mr. Winsor, ${ }^{70}$ but there were also more serious critics. William Nicholson (1753-1815), a prominent scientific journalist and publisher, was asked by a reader of his journal in January of 1807 for his opinion of this new project, and in response he provided a withering commentary. The invention, Nicholson claimed, for which Winsor had got a patent, was not original, having been voided by the precedents of Dundonald, Diller, Murdock, and others. Besides, a patent could only be jointly held by five individuals, not thousands as Winsor hoped to do by founding a company. His profit calculations were beneath contempt, but even if they were correct, Parliament would never grant an act for such extortion. Finally, Winsor did not name his major supporters as any honest entrepreneur would..$^{71}$ Perhaps as a way to reinforce the non-originality of Winsor's claims, Nicholson ran an article a month later about how carbonated hydrogen gas had been observed in the seventeenth century. ${ }^{72}$

69 Letters from an Irish student in England to his father in Ireland, (London: Cradock \& Joy, 1809), 230-3. 70 James] [Sayers, Heroic epistle to Mr. Winsor, the patentee of the hydrocarbonic gas lights and founder of the National light and heat company (London: R. Spencer, Great Ormond Street, 1808). Many minor satirical references can be found, such as in "Horace in London," The Poetical register, and repository of fugitive poetry for 1808-1809 7 (1808 [1812?]). Woburn-Abbey georgics, or, The last-gathering : a poem, in four cantos. Canto I and II, 2nd ed. (London: Printed for C. Chapple, 1813), 35.

71 William Nicholson, "Remarks on Mr. Winsor's projected Heat and Light Company," A Journal of natural philosophy, chemistry and the arts 16, no. 65 (1807).

72 John Webster, "Account of the discovery of the means of illumination by gas from coal," $A$ Journal of natural philosophy, chemistry and the arts 16 (1807). 
Winsor responded to this attack, as one might expect, by writing a pamphlet, in which he included a long discussion about patent law and protesting that Nicholson had attacked him unjustly. ${ }^{73}$ Nicholson's brief riposte appeared in the April 1807 edition of his journal. Without bothering to refute Winsor's latest pamphlet, Nicholson merely dismissed it and asked again for the names of his committee of supporters. ${ }^{74}$

Another example of the sort of derision and scorn directed at Winsor is found in the May 1807 issue of the Anti-Jacobin Review in a review of Samuel Parkes' Chemical Catechism. The gaslight scheme was dismissed as 'quackery', not because it was not founded on solid scientific principles, but because it was being promoted by ignoramuses who positively rejected science:

$[T]$ his gas ... is used to produce what is vulgarly called gas-lights, of which the public have heard so much and understand so little. The practicability of using gas for such purposes with some advantage cannot be doubted; but if any considerable saving of expence is designed, it must depend greatly on the profound and extensive scientific knowledge of those who attempt to apply it to general use. Should many persons, however, be disappointed, as is most probable, in their sanguine expectations from the use of this gas, they have only themselves to blame. It is too much to expect an extensive and important application of chemical knowledge from persons avowedly ignorant of the first principles of the science, and who profess to make money, and to despise even a knowledge of the very subject which gave existence to all their delusive

\footnotetext{
73 Winsor, Mr. W. Nicholson's attack.

74 William Nicholson, "A few remarks on a pamphlet entitled "Mr. W. Nicholson's attack, in his Philosophical Journal, on Mr. Winsor and the National Light and Heat Company: with Mr. Winsor's defence"," A Journal of natural philosophy, chemistry and the arts 16 (1807).
} 
speculations. Quackery and avarice have seldom appeared so conspicuous, or so reprehensible. ${ }^{75}$

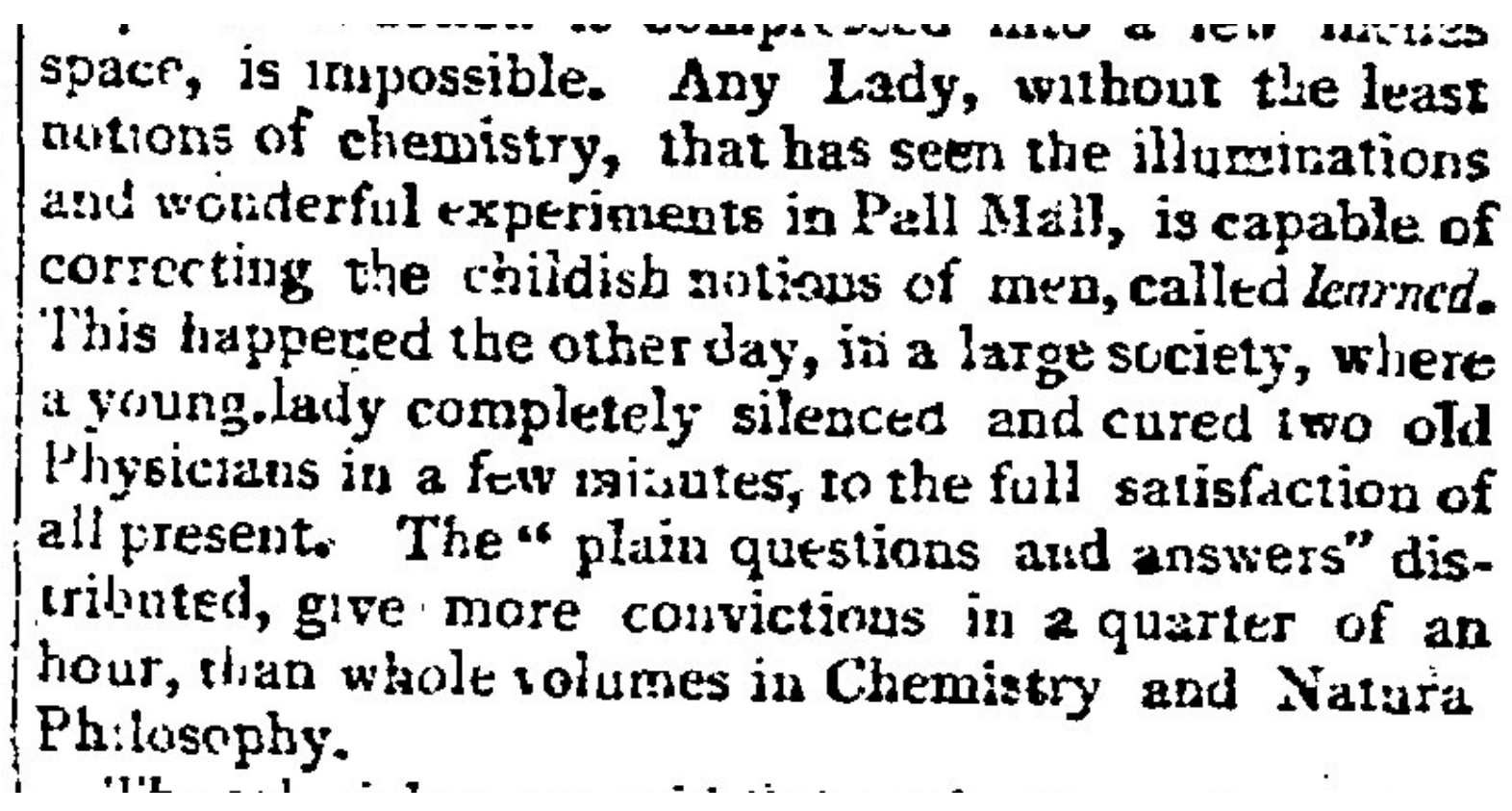

The Times, March 24, 1804

Winsor had opened himself to charges of being unscientific by running some advertisements where he scoffed at the persuasiveness and utility of 'volumes of Chemistry and Natural Philosophy', hinting that stuffy old 'Physicians' were merely hidebound conservatives. ${ }^{76}$ The irony of the Anti-Jacobin Review's comment is that while they were correct in thinking that despite his pretensions Winsor was indeed mostly ignorant of scientific principles, he was nevertheless instrumental in the founding of the Gas Light and Coke company. Winsor either overreacted to these charges of quackery and other criticisms, as he did in the case of Nicholson's comments, or put on airs of aloofness and condescension, as he did with the Anti-Jacobin Review's.

\footnotetext{
75 "Review of Parkes' Chemical Catechism," The Anti-Jacobin review and magazine 27, no. 107 (1807). 76 "A National Light and Heat Company!," The Times, Tuesday, Mar 241807.
} 
He was not, however, without defenders. The Times printed a short piece not long after the Anti-Jacobin Review's comments became available stating that 'truth must ever triumph over falsehood', and comparing the invention of gaslight to that advent of navigation in terms of its importance to Britain. ${ }^{77}$ In addition, as The Times pointed out, the share subscription was going well to the point that due to great demand for shares Winsor in January 1807 allowed subscribers to buy multiple shares. ${ }^{78} \mathrm{He}$ moved rapidly onto the next stages of the corporate plan, and plans were made to hold a general meeting of subscribers that would pass basic resolutions such as seeking an act of Parliament.79 Winsor was increasingly targeting the political arena with his marketing. There had been less scope to do this before February 1807 as Parliament was not in session. There had been an election at the end of 1806 , with the last members being returned towards the end of December, and when Parliament opened its new session on February 13,1807 , Winsor immediately began running advertisements inviting members of Parliament to see his experiments, with free admission. ${ }^{80}$ Winsor and his backers also submitted a petition to Parliament, which the Lords agreed to hear on April $9,1807.81$

\footnotetext{
77 "Truth or falsehood of Gas Light," The Times, Thursday, May 14 1807. Actually not clear Winsor wrote this. Correct.

78 "National Light and Heat Company," The Times, Friday, Jan 16 1807. "National Heat and Light Company," The Morning Chronicle, Saturday, January 101807.

79 "Truth was deemed a libel, but never a falsehood," The Times, Jan 091807.

80 "Mr. Winsor has the honour to invite all Members of Parliament," The Times, Friday, Feb 27 1807. "Mr. Winsor has the honour to invite all Members of Parliament," The Morning Chronicle, Thursday, February 12 1807. "Inspection of Gas Lights, \&c.," The Morning Chronicle, Wednesday, March 41807.

81 "The Parliamentary register; or, an impartial report of the debates that have occurred in the two Houses of Parliament, in the course of the First (and only) session of the Third Parliament of the United Kingdom of Great Britain and Ireland," (London: Stockdale, 1807), 474.
} 
M R. HlNSUR las the homour to invite all Q Blombers of Parlianent, and their-Ladtes, for every Thursd :y ev'ning, at 8 o'clock, during I his ivonth, to sce his knoms jilmuthated, and watness his EXPERIALEN is with GAS LIGHTS. The Learied of the Fuctily and Chenistry mat also recence gra. Euttuis admissiun cards, at the Otice, to enable them to judge and appreciate the ros yalue of lhe discovery, and the establisliment fondew,-NATIONAL LIGHT and HEA COAL'ANY' for tha jntroducion of Coke and Gas Light.-Niany respectable Subscrilyers, secing niy fixperincute, have upplied fir an increase of Shates on the following scale of Deposits, which l cheerfully sıbnit to the i ubic, as the nost fiaterime testimony of the enconrage ment of my rlin: Five Shures to puy 3l. deposit each, and have che vote. Filteen Sliares io pay gl. for. depersit each, and have twa volos. Thin!y Shares io phy at. depessit each, and have three vot:s, Sixly Shares to pay 11. deposit each, and have four votex. One inundred Shares, and upwards, to pay 10s. depesit each, andhase five sotes. Thuse bartites and Gentemen who have already subscribed for a number of Sharrs, may have their doposits allowed for an increase on the nbove scale.

Subscriprions continue to be reccived at the Banks of Sir M. istoxam and $C^{\circ}$. Gracechurch-struet; Messrs. Devaynes. and Co.; the Citice, I'ail-mull. Altendance in the Conmitte Room, for Explunition, Sic from 10 till 4 ; and Plans at the Clerk's Office, durng the sitne lours. Experiments and lfluminations on Monciav, Ferinesday, and Friday evenings, at 8 o'clnck. Non-Sub. scraber's ?ickets 5o. each.

ب7, Jall mall:". WLNGOR, Inventor, Palestece Se Foninder.

The Times, February 24, 1807

Winsor now called the first general meeting for April 30, 1807,82 but this never took place, probably because political instability derailed his plans. Lord Grenville's newly elected government rapidly lost the king's support over the issue of admission of 
Catholics into the military, and after a month of futile efforts to find a replacement government, Parliament was dissolved on April 27, 1807. New elections were called and the ambitions of the National Heat and Light Company had to be deferred until the new Parliament could be convened. The general meeting of subscribers was rescheduled for June 26, 1807.

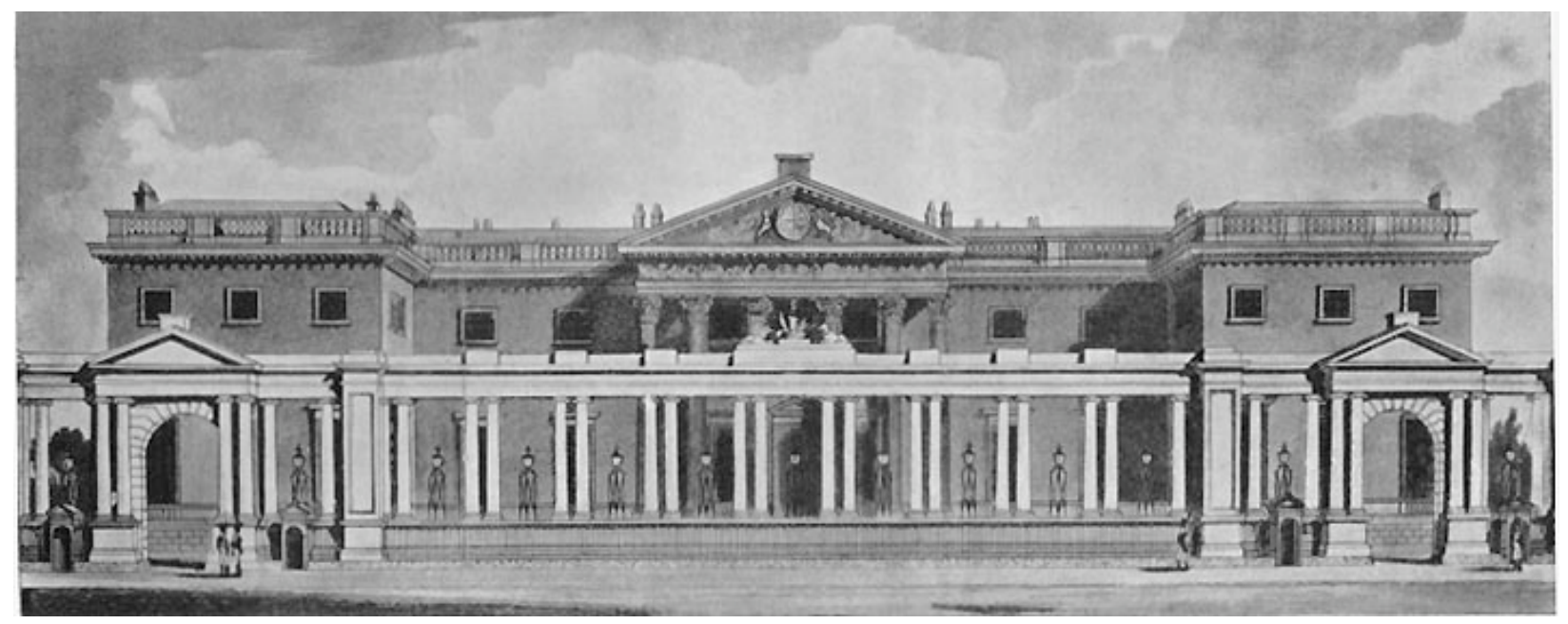

Figure 4.5 Carlton House in the early nineteenth century

While waiting for the general meeting and for the new Parliament to be elected and convene, Winsor prepared his next exposition of his gaslights. ${ }^{83} \mathrm{He}$ had always had a eye for finding opportunities of latching onto anything that might win his work prestige or status. His moving to Pall Mall, an upscale street, was one such move. He now approached the Prince of Wales, the future Prince Regent and King George IV, a 
neighbour of Winsor's who had built himself a palatial house in the late eighteenth century on Pall Mall known as Carlton House. The Prince agreed to have the house gardens lit by gas. Winsor had been thinking of an outdoor display such as this, and had advertised an experiment called 'How to light a Street', which, however, he had cancelled due to 'the unfavourable state of the weather'. ${ }^{84}$ The Carlton House gardens spectacle would be an even better opportunity for a public display. The date was set for June 4, George III's birthday. 85 In May 1807, pipes were laid from Winsor's buildings under Pall Mall to Carlton House gardens. The pipes went under the garden wall and surfaced on the other side. They were then affixed to the wall, running along its length towards the west where some lamps were attached to the wall. The pipes then passed over the wall into Pall Mall again to feed some more lamps on the back gate in the street. Ensconced there was a four flame burner in 'imitation of the prince's feathers'. The pipes then went back into the gardens where burners backlit a cut glass plate, referred to as a 'transparency', displaying stars crowned with the letters G. R. ${ }^{86}$

\footnotetext{
84 "National Light and Heat Company."

85 "Gas Lamps and General Meeting," The Morning Chronicle, Monday, June 11807.

86 "Account of the First Experiment of the Public Use of Gas Lights," The Monthly magazine, or, British register 23 , no. 6 (1807). contains a fairly detailed description of the display.
} 


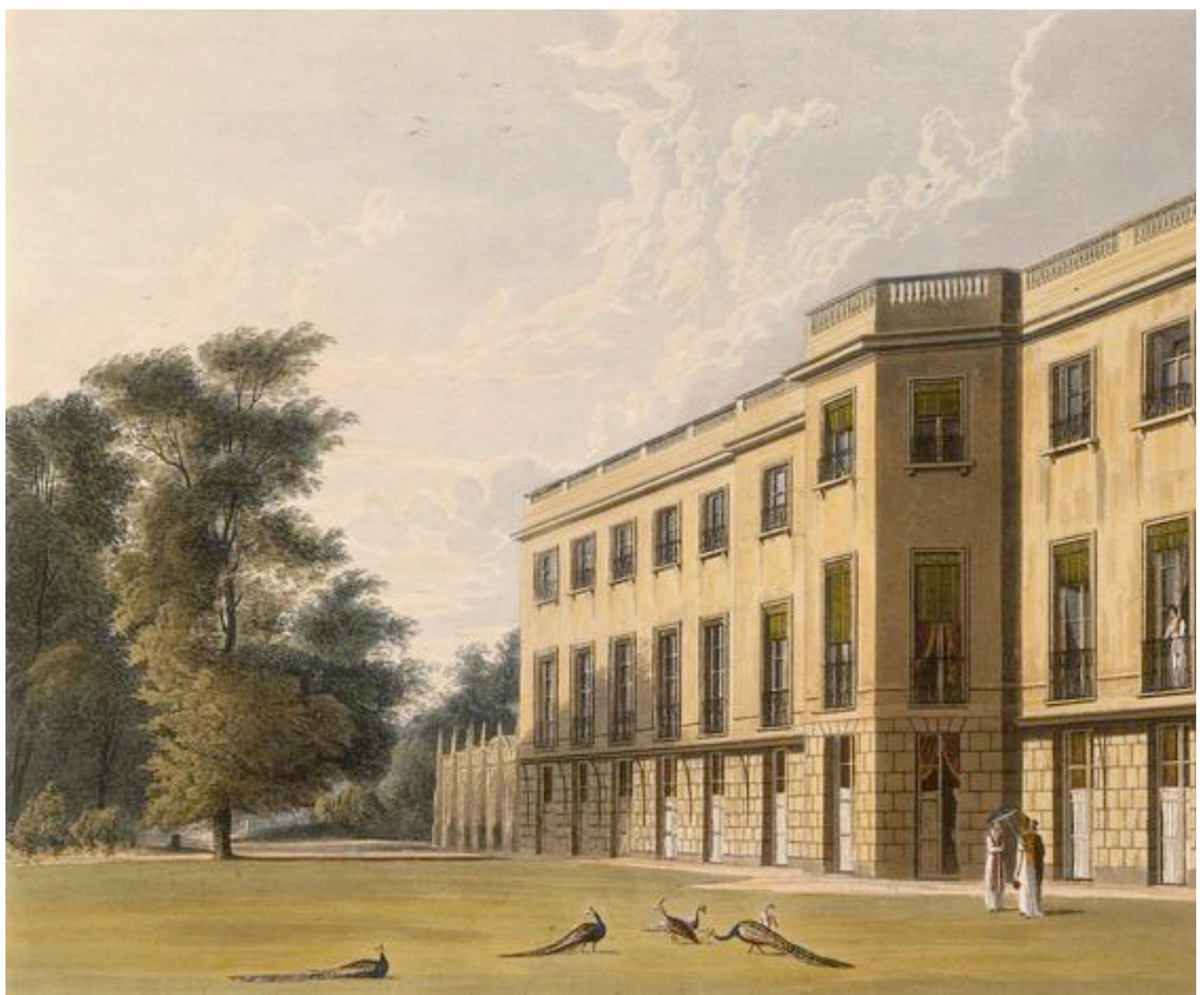

Figure 4.6 Carlton House Gardens in the early nineteenth century

Winsor tested the lights successfully on a number of occasions, which he naturally could not resist advertising. ${ }^{87}$ The night of June 4,1807 , itself proved to be quite successful. The lamps were lit around eight o'clock by a lamp lighter in front of an assembled crowd. At some point during the night the glass plate was turned around to reveal a poem celebrating the king. The lights continued on until midnight, with a large 
number of onlookers still present present on Pall Mall, 'much amused and delighted'. The Monthly Magazine commented that 'from the success of this considerable experiment, in point of number of lights, the distance and length of pipes, hopes may now be entertained, that this long-talked of mode of lighting our streets may at length be realized.' 88 Some pranksters decided to annoy Winsor by pouring 'liquor of assafoetida' along the garden walls, and trying to break the glass plate with stones. Winsor responded, predictably, in an advertisement by stating that 'they may bark at their own scents, but they can never bite my Gas Lights.' 89 On the whole, however, Winsor achieved his aim of a public demonstration that generated positive commentary in the press.

With this success behind them, Winsor and his supporters turned their attention to the upcoming general meeting of subscribers as well as the freshly elected parliament. Winsor's printed many notices in the newspapers and the general meeting was held at the Crown \& Anchor Tavern on June 26, 1807. The subscribers resolved to seek an act of Parliament incorporating the company with limited liability for its shareholders, and nominated a provisional committee to prepare formal resolutions for the approval by the subscribers at a new meeting called for July $24,1807.90$ The provisional committee was also asked to verify that Winsor's experiments and apparatus were on solid footing and could indeed provide the basis around which the new company would operate. A

\footnotetext{
88 "Monthly magazine."

89 "National Light and Heat Company," The Times, Tuesday, Jun 16 1807. Winsor also advertised his success: "National Light and Heat Company," The Morning Chronicle, Wednesday, June 171807.

90 "Intended National Light and Heat Company," The Times, Saturday, Jul 18 1807. "Intended National Light and Heat Company," The Morning Chronicle, Monday, July 201807.
} 
special delegation of the provisional committee met with Winsor on July 3 and 4, 1807 where he demonstrated his apparatus, the details of which he had in general tried not to reveal in public. Numerical results were later published, and they show that Winsor was working on a very small scale at this point. He carbonized two pecks $(36 \mathrm{lb})$ of Newcastle coal. Considering that Boulton \& Watt's apparatus at this time could carbonize several hundredweight of coal per charge, Winsor's apparatus was far behind theirs. The special committee decided that his technology was indeed solid and usable enough to pursue the founding of the company. ${ }^{91}$ Among the six members of this special committee were James Ludovic Grant and James Hargreaves who were to be on the governing court of the Gas Light and Coke company once it was finally constituted.

When the subscribers reconvened at the Crown \& Anchor Tavern on July 24, 1807 the committee presented a number of resolutions. The most important of these were that $£ 20,000$, being one fifth of the fund's capital, be vested in a committee which was given the mandate of lobbying parliament to get the charter; that the provisional committee be made permanent, with the same members; that the resolutions should be available at the Pall Mall office so that subscribers could sign them; that the committee be given the power to appoint any honorary members it saw fit; and finally to thank the chairman of the committee, James Ludovic Grant, for all his work in the intervening month.92 They also asked Winsor to prepare a more extensive demonstration that

91 Considerations on the nature and objects of the intended Light and Heat Company : published by authority of the committee., (London: Printed for James Ridgway by T. Davison, 1808), 93., Grant and Accum, The report of James Ludovic Grant, 107.

92 "Resolutions of forming a National Light and Heat Company," The Times, Thursday, Sep 241807. Grant and Accum, The report of James Ludovic Grant. gives a different version, more detailed in some respects, but also omitting some of the resolutions. 
included lighting many public buildings, the most prominent of which were the Parliament buildings..$^{93}$

The list of the members of the committee shows how far Winsor's campaign had reached. There were three lords on the committee: The Duke of Athol (John Murray 1755-1830, member of the privy council 179794), Lord Viscount Anson (Thomas Anson 1767-1818, MP 1789-1806), and Baron Wolff (probably Sir Jacob Wolff, a baronet and a merchant, son of a wealthy émigré German merchant). Among the remainder, at least three had been or were members of parliament: Sir Matthew Bloxam (banker), Sir William Paxton (1743/4-1824, banker95), William Devaynes (banker and member of the board of the East India Company96), and perhaps John Williams. The background of the rest is more difficult to establish, but many were certainly members of London's business community. Grant himself was the son of Francis Ludovic Grant, a lieutenantgeneral. Grant's sister had married the Duke of Athol's brother and Grant had got the Duke involved with Winsor.97

\footnotetext{
93 "Intended National Light and Heat Company," The Morning Chronicle, Tuesday, August 181807.

94 Joseph Haydn, The book of dignities; containing rolls of the official personages of the British Empire ... from the earliest periods to the present time ... together with the sovereigns of Europe, from the foundation of their respective states; the peerage of England and Great Britain (London: Longmans, Brown, Green, and Longmans, 1851), 569.,

95 Willem G. J. Kuiters, "Paxton, Sir William (1743/4-1824)," in Oxford Dictionary of National Biography, ed. H. C. G. Matthew and Brian Harrison (Oxford: Oxford University Press, 2004).

96 Robert Beatson, A chronological register of both houses of the British Parliament, from the union in 1708, to the third Parliament of the United Kingdom of Great Britain and Ireland, in 1807 (London: printed for Longman, Hurst, Rees, and Orme [by J. Chalmers \& Co.], 1807), 75. A William Devaynes, perhaps the current one's father, was also the chairman or deputy chairman of the East India Company sporadically 1774-1794. Haydn, The book of dignities; containing rolls of the official personages of the British Empire ... from the earliest periods to the present time ... together with the sovereigns of Europe, from the foundation of their respective states; the peerage of England and Great Britain, 273.
}

97 "Murray, Lord George (1761-1803)," in The dictionary of national biography : from the earliest times to 1900 Vol. 39 Morehead - Myles, ed. Sidney Lee (New York: MacMillan and Co., 1894). 
All the while the subscribers were taking care of their internal affairs, the marketing campaign carried on as before. Winsor was inviting 'those affected with Coughs, \& c.' to inhale his gases. He once again offered free admissions to his lectures for the member of parliament, 98 and printed another shortened version of his To be Sanctioned pamphlet, without, however, tempering his profit calculations. ${ }^{99}$ In July 1807 Winsor stepped up his campaign, offering two lectures per day. ${ }^{100}$ He railed against possible competitors, which by this point included not only his former assistant, Edward Heard, whom he accused of infringing on his patent, ${ }^{101}$ but also a new target, the Golden Lane Brewery. The brewery had taken Winsor and company by surprise, when, on July 11, 1807, they put on their own quite extensive display of gaslight. Although it seemed to be more modest than Winsor's at Carlton House gardens, the lighting did generate some publicity, with reports in The Athenaeum ${ }^{102}$ and The Monthly Magazine.103 The brewery's apparatus consisted of approximately 700 feet of pipe in two adjoining streets serving 11 lamps with gas. ${ }^{104}$ The Athenaeum, never very friendly to Winsor, even

98 "To the members of the new parliament," The Times, Saturday, Jun 201807.

99 Frederick Albert Winsor, To be sanctioned by act of parliament. A National Light and Heat Company, for providing our streets and houses with hydrocarbonic gas-lights, on similar principles, as they are now supplied with water, four tables of calculation, founded on official experiments, prove the immense national profits and increase of revenue by the adoption of this plan, which is to be had at the National Light \& Heat Company's office, no.97, Pall Mall, new ed. (London: Printed for F.A. Winsor, the patentee, by Watts \& Bridgewater, 1807).

100 "National Light and Heat Company," The Times, Thursday, Jul 161807.

101 "Truth was deemed a libel." "Truth was deemed a libel," The Morning Chronicle, Saturday, December 27 1806. A report on his patent was published in "Monthly magazine."

102 "Some Account of the Experiment made at Golden-Lane to illuminate Streets by Coal-Gas Lights," The Athenaeum, a magazine of literary and miscellaneous information 2, no. 8 (1807).

103 "Lighting of the Golden Lane Brewery," The Monthly magazine, or, British register 24, no. 2 (1807). There was also reports in Germany: "Einige Nachrichten aus England über Erleuchtung im Grossen mit Thermolampen."

104 "The Athenaeum." 
suggested that the brewery had beat Winsor at his own game. Winsor's response was to make dark allusions of patent infringement once again, and to warn the public that gaslight could be quite dangerous if handled by the wrong person since 'Gas explodes like gunpowder'. ${ }^{105}$ He publicly disavowed any connection to the 'bungling attempts to light Golden lane and Beech-street', stating that 'the insidious report of my having provided the stove, \&c. are utterly false.'106

In August 1807, Winsor reported in the papers that 15,000 shares had been sold, and the remaining 5000 would be sold at a $50 \%$ premium, or $£ 7$ and 10 s. ${ }^{107}$ So many people were coming to see his demonstrations in Pall Mall, that he had to discontinue free admission for subscribers and raise the entrance fees for everyone. ${ }^{108}$ The ambitions of Winsor and company, however, were checked once again when Parliament was prorogued in September, but the special Tuesday evening demonstrations continued to be reserved for MPs, to which the nobles and gentlemen among Winsor's supporters could invite their peers. ${ }^{109}$ September 15, 1807 saw Winsor score another publicity coup, when a number of important people came to his house in Pall Mall to see the gaslights. The Times reported it the following week:

The first rank and beauty in town met on Friday evening, at Mr Winsor's, in Pall-mall, to see the beauty and brilliancy of Gas Lights. In the elegant circle we noticed the Duchess

\footnotetext{
105 "National Light and Heat Company."

106 "Caution respecting gas lights," The Times, Wednesday, Jul 151807.

107 "Intended National Light and Heat Company," The Times, Tuesday, Sep 15 1807. and "Intended National Light and Heat Company," The Times, Thursday, Aug 201807.

108 "Intended National Light and Heat Company."

109 "Intended National Light and Heat Company."
} 
of St. Alban's, Ladies Beauclerk, Castlereagh, Forster, Dysart, Cooper, and their Lords, who seemed highly entertained, and staid [sic] till a later hour, to witness several surprising experiments with Gas flames, which are far superior to any flame produced by the most costly combustible, such as wax, spermaceti, \&c. ${ }^{110}$

By October, Winsor and company were moving to close the share subscriptions and asked all country bankers to send in share subscriptions before December 1 , 1807. 111 The last 2000 shares were being sold at $£ 10$, double the original asking price, to 'defray all extra costs'. ${ }^{112}$ The excitement surrounding Winsor and the National Heat and Light Company is captured well in a letter the Countess of Bessborough wrote to Lord Granville on September 7, 1807, and it is worth quoting in its entirety, weak French included:

La lumière et la chaleur vivifie la nature entière, aussi ne peut on vivre sans lumière et sans chaleur, mais c'est maintenant la première fois je crois, qu'on s'avise de les vendre - dorénavant le soleil sera superflu à moins qu'on n'obtienne une patente pour le Palais jusqu'au plus mince artisan de Londres, la vue quinquagénaïre renouvelé, sans un lot de lumière et de chaleur-point de salut. I was interrupted, but must begin again where I left off, and indeed, as there is no other subject thought of or talk'd of, I may as well write of it too, Is it the seizure of Zealand? No! The investing of Copenhagen? No! The Invasion? Oh no! War with Russia? Nothing like it. America? Still less. What can occasion such a ferment in every House, in every street, in every shop, in every Garret about London? It is the Light and Heat Company. It is Mr. Winsor, and his Lecture, and his gas, and his patent, and his shares - these famous shares which are to make the fortune of all who

\footnotetext{
110 "Meeting at Pall-Mall," The Times, Tuesday, Sep 221807.

111 "Intended National Light and Heat Company," The Times, Thursday, Oct 151807.

112 "Resolutions of forming a National Light and Heat Company," The Times, Wednesday, Sep 301807.
} 
hold them, and probably will involve half England in ruin, me among the rest, and prove a second South Sea Scheme. Yet it promises fair if it did not promise too much-six thousand a year for every seven guineas seems more than can be possible but were it hundreds instead of thousands it is immense. 17 thousand shares have been sold within these ten days: they were first a guinea, then 3 , five, seven; they will be twenty, fifty, a hundred, for there is scarcely means of passing thro' Pall Mall for the crowds of carriages, and people on foot and Horseback. Ld. Anson has 100, the D. of Athol 200, the Royal family 200 , Ld. Choly 20 -every body some, and I five. There is no resisting it and I long for you to have some. At first I dreaded its hurting the holders of Coal mines, but now they say it will raise the coal trade, as, if it passes, all London will be lit from Coal instead of oil. I am not light headed, and only talking to you as every body talks ever where at this moment. I went last night to a very large party; I never saw so off a looking place-something like a cellar with crucibles and strange looking instruments, resembling an Alchymist's Shop in Tenier's picture, and there, mix'd and squeez'd together, were fine Ladies, a few Rabbis, Merchants, Peers, blue Ribbons, and tallow Chandlers-all raving for shares and entreating to sign their names first, lest none should be left. That Shining Lamp which has lit up Pall Mall for this year past has all at once blaz'd up into a comet that bears every thing along with it. I only stipulate to know the amount of the forfeit in case of failure, and not answer for the debt of the Company. He only wants a million to begin with, and has almost got it already. ${ }^{113}$

Winsor's attention drifted somewhat at the beginning of November 1807. He published a pamphlet on the importance to commerce of having a national deposit bank

\footnotetext{
113 Granville (1st Earl Granville) Leveson-Gower and Henrietta-Frances (Countess of Bessborough) Ponsonby, Lord Granville Leveson Gower (first earl Granville): private correspondence, 1781 to 1821 Vol. 2, ed. Castalia Rosalind Campbell Leveson-Gower Granville (London: J. Murray, 1916), 281-2.
} 
in the country, ${ }^{114}$ build on two books of his which he had published in 1799 during his previous stay in England. ${ }^{115} \mathrm{He}$ even hatched a plan to found such a bank and advertised a share subscription. ${ }^{116}$ This scheme panicked some of his supporters in the gas venture, and resulted in a testy exchange of public letters in the Morning Chronicle, during which Winsor referred to the subscriber as 'a pitiful and designing fellow, below ... my further notice'.117 Despite Winsor's hostility towards the subscriber, the exchange drew the committee's attention to Winsor's activities, ${ }^{118}$ and the deposit bank was not heard from again.

Towards the end of November 1807, the committee of trustees took more serious steps to establish the first gas works and large scale demonstrations that had been discussed at the July 1807 general meeting and which did not seem to be drawing Winsor's full attention. ${ }^{119}$ The committee was hoping to be able to provide gaslights for the immediate area, including the Parliament buildings, the Treasury, the East India House, and other places, but finding that the expense and complication of doing so

\footnotetext{
114 Frederick Albert Winsor, National deposit bank, or, The bulwark of British security, credit and commerce, in all times of difficulty, changes, and revolutions with the mercantile policy of separating the discounts of merchants and manufacturers from the law of national interest, as practised in the first commercial cities on the continent (London : Printed for the author, G. Sidney, 1807).
}

115 Winsor, Prosperity of England midst the clamors of ruin. Frederick Albert Winsor, Addresse aux souverains de l'Europe etc. etc en deux parties (Londres : Chez G.G. \& J. Robinson, Wm. Richardson \& Co., 1798).

116 "National deposit, interest, \& credit bank," The Times, Thursday, Nov 191807.

117 "To his Grace the Duke of Athol," The Morning Chronicle, Friday, November 20 1807. "To the man who signs himself a proprietor of the Intended National Light and Heat Company," The Morning Chronicle, Saturday, November 21 1807. "To his Grace the Duke of Athol," The Morning Chronicle, Tuesday, November 241807.

118 "Intended National Light and Heat Company," The Morning Chronicle, Tuesday, December 11807.

119 Grant and Accum, The report of James Ludovic Grant, 3. 
would be great, they limited their plans to Pall Mall. ${ }^{120}$ Winsor finally gave up his public demonstrations to concentrate exclusively on this ambitious new project. ${ }^{121}$ The leases at 97 and 98 Pall Mall were purchased to be able to use the location as a plant for the new company. ${ }^{122}$ 'At no inconsiderable personal pains', ${ }^{123}$ the committee requested permission from local residents and the paving authorities for St. James parish to place immediately outside of the Pall Mall offices two decorative lampposts holding three lamps each in glass globes affixed to separate arms. Without such an authorization, the lampposts would have been by law 'deemed public nuisances ... liable to abatement, by any individual who felt any hostility or objection'.124 The local authorities prevaricated, however, and finally decided to see Winsor's gaslight for themselves. ${ }^{125}$ The visit must have been a success because Winsor ordered lampposts and pipes on November 1 , 1807. ${ }^{126}$ The supplies were delivered and by December 1807, 13 lampposts were erected on the south side of Pall Mall, from the company's office westwards to St.

\footnotetext{
120 "Intended National Light and Heat Company." Grant and Accum, The report of James Ludovic Grant, 4.

121 "Intended National Light and Heat Company," The Times, Saturday, Oct 221807.

122 Ibid.

123 Grant and Accum, The report of James Ludovic Grant, 5.

124 Ibid.

125 "Pall Mall, South Side, Past Buildings: Nos 93-95 Pall Mall: F.A. Winsor and the development of gas lighting," in Survey of London: volumes 29 and 30: St James Westminster, Part 1, ed. F. H. W. Sheppard (London: Published for the London County Council by the Athlone Press, 1960).

126 Grant and Accum, The report of James Ludovic Grant, 118.
} 
James Street. ${ }^{127}$ The committee wanted to extend the pipes to Boodle's, an exclusive gentlemen's club up St. James Street, but were prevented by the paving authorities. ${ }^{128}$

This demonstration using true prototype lamps made a deep impression on some observers, because up until then, Winsor's demonstrations consisted of apparatus which were evidently not production models. These street lights, on the other hand, gave a real sense of the brilliance gaslight could provide as compared to the old kinds of lamps. An example of this sort of reaction appeared in The Monthly Magazine, which ran the following review:

We state with much satisfaction that the Gas Lights which have been so ridiculously puffed and vulgarly advertised in the public papers for several years past, have been proved to answer the promised purpose. Part of the south side of Pall-Mall has for a few weeks been lighted with the Gas, and the effect is beyond all dispute infinitely superior to the old method of lighting our streets. One branch of the lamps illuminated with gas affords a greater intensity of light than twenty common lamps lighted with oil. The light itself is beautifully white and brilliant, and the lamp emits neither smoke nor smell. In a word, we can justly say, that every person who has viewed this first public application of the gas lights, has been delighted by the anticipation of seeing our streets and pubic buildings illuminated in this simple, cheap, and brilliant manner. ${ }^{129}$

\footnotetext{
127 "Pall-Mall illuminated by Coal Gas Lights," The Athenaeum, a magazine of literary and miscellaneous information 3, no. 13 (1808).

128 Grant and Accum, The report of James Ludovic Grant, 5.

129 "Lighting of the Pall Mall," The Monthly magazine, or, British register 24, no. 6 (1808).
} 
The Athenaeum was more doubting as always, but still conceded that Winsor had shown that 'at least the whole of Pall-Mall at both sides might be lighted by the Gas produced by one furnace'. ${ }^{130}$

As usual, Winsor and company received their share of derision and opposition. When someone put gunpowder into one of the lamps in Pall Mall, causing an explosion when the lamp lighter came to ignite the gas, ${ }^{131}$ Winsor was forced to hire two night watchmen to guard his lampposts. ${ }^{132}$ More seriously, some people, probably associated with lamplighters who felt their livelihood threatened, or those related to the oil trade in some way, were calling into question the safety of gaslight. Winsor's chief antagonist was a certain Mr. Hyde, probably a chemist or instrument maker, who had taken it upon himself to give an 'Exposition of Gas Lights, in which the insalubrity of the Carbonated Hydrogen Gas and the fallacy of the pretended Inventor's assertions will be proved by the most unerring and conclusive experiments, together with the Evils that must inevitably result from the introduction of Gas Lights', followed by a display of the philosophical fireworks. ${ }^{133}$

As one can imagine, this provoked Winsor into making vitriolic and hostile commentaries in the press. Winsor printed a series of notices towards the end of December 1807 where he accused the 'empirics', 'catchpenny philosophers who are

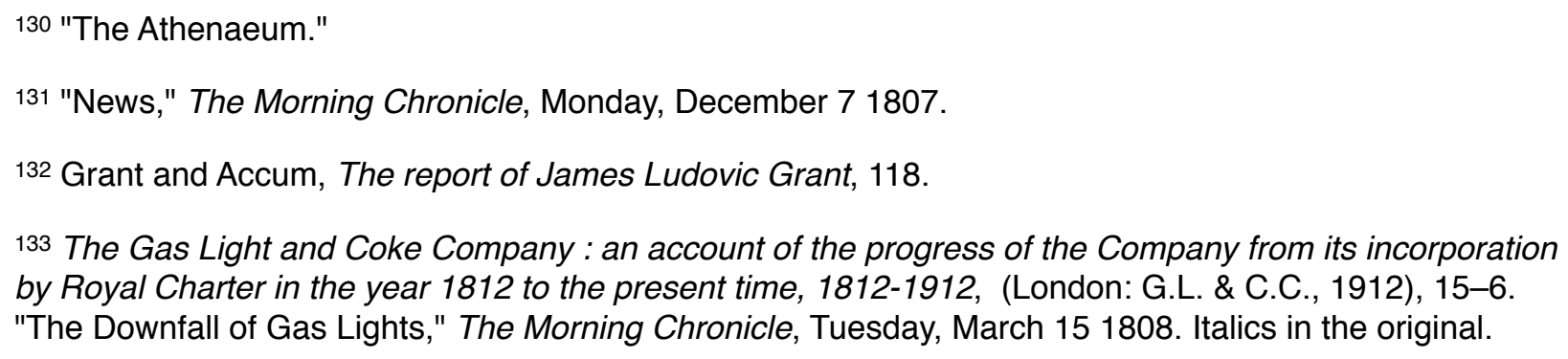


without names or abodes', 'advertising quacks', 'wiseacres', 'the chemical sadler and his learned colleagues' of misrepresenting the situation when they claimed that a malicious person could place 'oxigen and gunpowder' into the Pall Mall lamps causing an explosion. Hyde had also stated (in this case correctly) that 'gas was pernicious to inhale', but Winsor retorted that all apothecary's apprentices knew the contrary (one must pity these apprentices), and he himself was curing people of coughs with his gas. Winsor finished the notice by promising that he would 'render them full as notorious, as their attacks on Gas-lights are ignorant; because clowns, the most happy in blundering, will shew by accident all what these quacks exhibit, to frighten, if possible, fools and old women.' ${ }^{134}$ Hyde's accusations even prompted the normally invisible committee to print a notice-in calmer tones than Winsor's - reassuring the public of the safety of gaslight, 135 because they had found 'the public mind much agitated by alarms which had been excited for the safety of individuals ... from the apparatus and tubes necessary for making and conducting ... hydro-carbonic gas'. ${ }^{136}$ Sensing a wonderful opportunity for an entertaining evening, the British Forum arranged a public debate between Hyde and Winsor for January $7,1808 . .^{137}$ There is no report as to who won, but it was no doubt entertaining. In any case, Hyde continued his lectures at Winsor's old haunts at the

\footnotetext{
134 "Empirics in Gas light," The Times, Saturday, Dec 26 1807.. Also Dec 23, 24 "Empirics in Gas Lights," The Morning Chronicle, Saturday, December 261807.

135 "Committee of trustee appointed to help Mr. Winsor," The Times, Saturday, Jan 021808.

136 Grant and Accum, The report of James Ludovic Grant, 6.

137 "Hyde vs Winsor," The Times, Thursday, Jan 071808.
} 
Lyceum theatre and at a house in Picadilly during early 1808 , and even invited members of parliament to attend. ${ }^{138}$

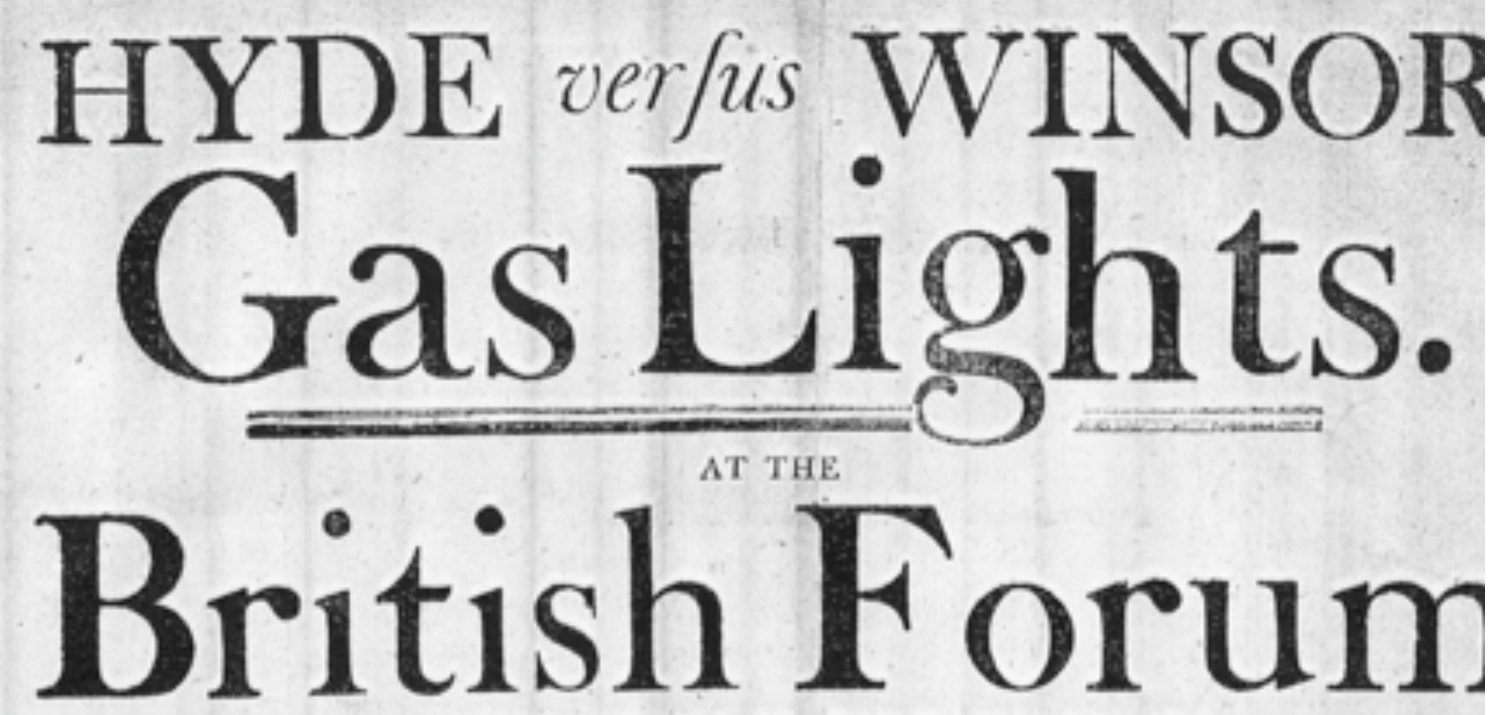

REMOVED FROM 22, PICCADILLY, TO

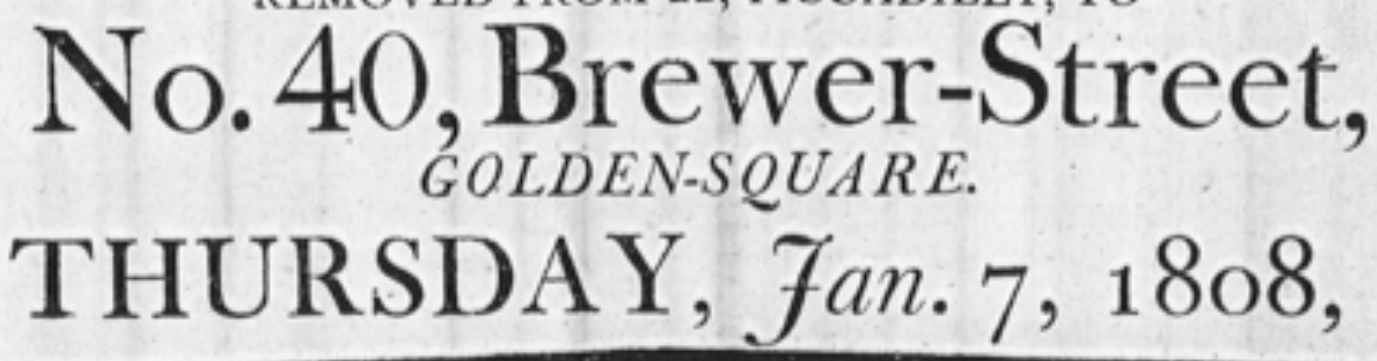

\section{QUESTION.}

"Ought the recent Advertifement of Mr. Winsor, the Proprietor of the "Gas Lights," be applauded as a manly Affertion of the fuperior Merits of a beneficial Difcovery agai: the Attacks of his Opponents; or reprobated as a fcurrillous and perfonal Infult; deftitt nlike of sood Manners and common Senfe?"

In January of 1808 , perhaps somewhat rattled by the Hyde incident, the committee retained Friedrich (Frederick) Christian Accum (1769-1838), a lecturer in chemistry, instrument maker, and author of a number of books on chemical subjects, to evaluate

138 The Gas Light and Coke Company : an account of the progress of the Company from its incorporation by Royal Charter in the year 1812 to the present time, 1812-1912, 15-6. "Petition to Parliament," The Morning Chronicle, Wednesday, March 231808. 
Winsor's apparatus and procedures and to answer a long series of questions regarding the chemistry of the process which the committee put to him. ${ }^{139}$ The questions included 'whether it is possible to produce ignition or even a single spark in a vessel or tube abundantly supplied with compressed inflammable air?' and others about the circumstances under which explosions could occur. Accum's answers were generally reassuring, repeatedly pointing out that explosions could only happen if oxygen and inflammable air were present in the correct proportions, a circumstance not found in sealed pipes or vessels. ${ }^{140}$ This marked the beginning of a lengthy association between Accum and the company. Accum became the company's chemistry expert-Winsor not really being credible - and eventually made it onto the board of governors of the Gas Light and Coke Company.

\footnotetext{
139 Accum and Winsor, Traité pratique de l'éclairage par le gaz inflammable, 22. Grant and Accum, The report of James Ludovic Grant, 31-7.

140 Grant and Accum, The report of James Ludovic Grant, 31-2.
} 


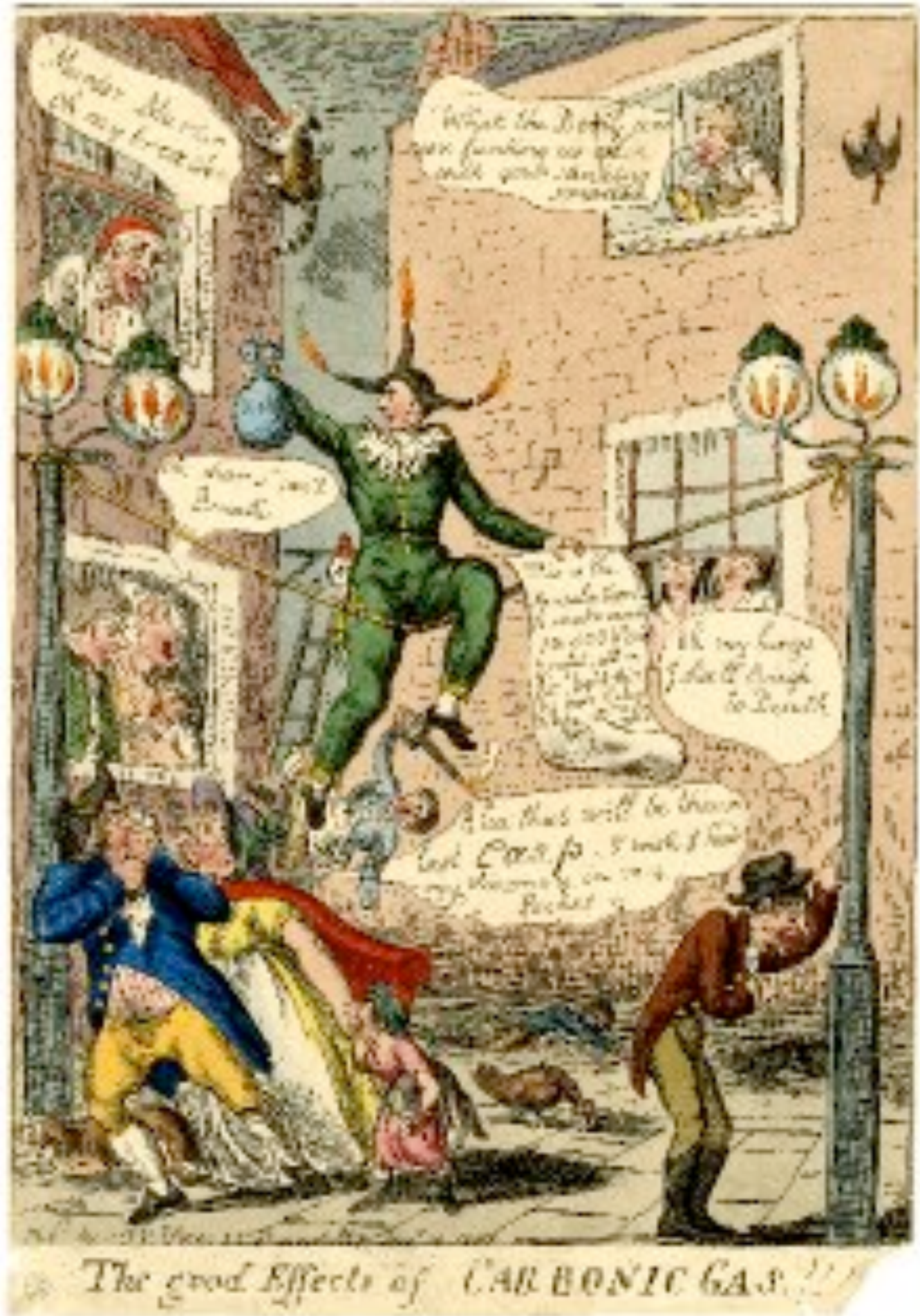

Figure 4.7 George Cruikshank. "The good effects of carbonic gas!!!". London: Fores, S. W., 1807. 


\subsection{Boulton \& Watt and the Royal Society 1808}

The year 1808 marked a new phase in the effort to establish a gaslight company. This period ushered in changes both within and without the company. Inside the camp of promoters, there was a definite shift in who had the initiative, away from Winsor and towards the business interests who desired a different approach than what Winsor could provide. Winsor was talented in generating attention, and had been spectacularly successful in promoting gaslight. He had gathered around him a large number of investors with much capital. But with this milestone behind them, Winsor was reined in by the committee of trustees led by James Ludovic Grant, and they took a more active role in promoting the company's interests in the public forum and especially in Parliament. A more gentle and suave touch was needed, and Winsor's bombast could prove to be a liability. Winsor's advertisements and pamphlets were generally halted, and the new ones printed for the cause were authored by hard-nosed lawyers and businessmen, not by the voluble and larger-than-life Winsor. He was in fact never to regain the prominent role he had held from 1804 to 1807 .

Outside the company, new players, much more influential than any who had opposed the National Heat and Light Company until now, entered the scene and forced the company into a tactical retreat. Rather than the amateur chemists and satirists poking fun at Winsor's rhetoric, the new opponent was the respected and influential firm of Boulton \& Watt, who had much experience in litigation and lobbying Parliament. Boulton \& Watt marshalled their powerful allies to deal a blow to the threat they 
perceived in this upstart and megalomaniacal company. The initial weapon of choice was the Royal Society through their friendship with Sir Joseph Banks, and, at least for 1808 , they effectively halted the company in its tracks.

By late 1807, the committee of trustees were making moves to sideline Winsor gently. The process can ultimately be traced back to the general meeting of July 24 , 1807 when the committee to aid Winsor was constituted and took on some share in the responsibility for establishing the company. Although they probably as a body did not explicitly want to push Winsor aside, the complexity of the situation called for more people and professional expertise to be involved, and this became more apparent with time, especially after Winsor's November 1807 foray into banking. The committee had in any case been meeting more and more frequently over the course the year, weekly by November $1807 . .^{141}$ In that month, the committee hired a lawyer, John Pedder of Middle Temple to spearhead the legal work needed to get the charter to incorporate the company. ${ }^{142}$ Surveyors were also hired to prepare systematic plans of streets and squares for eventual lighting. ${ }^{143}$

The committee of trustees had a pamphlet written in February of 1808-the author is unknown - to make more moderate claims about gaslight and to make clear that the unpredictable Winsor was no longer heading the affair. This was of course a necessary

\footnotetext{
141 "Intended National Light and Heat Company," The Times, Saturday, Nov 281807.

142 Grant and Accum, The report of James Ludovic Grant, 117. James Hall, "Select Committee on GasLight and Coke Company's Bill to incorporate Persons for procuring Coke, Oil, Tar, Pitch, Ammoniacal Liquor and Inflammable Air from Coal: Minutes of Evidence," in HOUSE OF COMMONS PAPERS; REPORTS OF COMMITTEES III.315 (1809), 37.
}

143 Grant and Accum, The report of James Ludovic Grant, 118. 
first step in convincing Parliament that the gaslight company could be trusted with a charter and would not descend into bankruptcy in short order. The pamphlet was entitled Considerations on the Nature and Objects of the Intended Light and Heat Company and it openly sought to eschew Winsor's hyperbole. The pamphlet began by acknowledging Winsor's many precursors, and gave the nod to Murdoch as being 'the first who conceived the idea of conducting coal-gas through tubes for the purposes of artificial illumination' but 'the practice was discontinued at Soho, or exhibited only as a philosophical curiosity'. The work at Philips \& Lee was also acknowledged, but the 'mode of preparing it is still so imperfect, that [Lee] is obliged, from time to time, to take his tubes to pieces to clear them from impurities.' ${ }^{144}$ In these affairs, the pamphlet claimed, the important point was not that someone 'hints obscurely at the truth, discovers some of its bearings, or illustrates it by a few barren experiments', but rather that the experiments are pressed 'on a great scale', which 'shews that it is capable of extensive applications.' Winsor's contribution was not that he made a new discovery, 'he did not even invent the mode of conducting it through tubes'. Rather, he simplified the apparatus and lessened the associated cost. It is true, the pamphlet went on, that his 'publications, indeed, are but ill adapted to promote his cause; and the exaggerated calculations which the sanguine mind ... is naturally disposed to indulge in, have ... thrown an air of ridicule and improbability on the whole scheme.' In fact, had Winsor not been present, the author claimed, the project would have advanced more rapidly. Now, however, the project was in new hands, 'intelligent and respectable gentlemen' who had

${ }^{144}$ Considerations on the nature and objects of the intended Light and Heat Company, 4-5. 
verified Winsor's experiments. ${ }^{145}$ At this point, 'more abilities and greater capital than any one individual can command' were needed 'to combat the prejudices and interests combined against it, and to apply it on the extensive scale of which it is capable'. For this, an act of Parliament was needed to grant and charter incorporating the company. ${ }^{146}$

Just as this pamphlet was published, Boulton \& Watt struck back at the National Heat and Light Company. The countermove had been building for some time. They had been aware of Winsor as early as 1804 because Winsor himself had sent them promotional material and asked them to buy shares in his first venture. ${ }^{147}$ They took little note of it then and likely forgot about him. Once Winsor upped the intensity of his marketing campaign late in 1806, it was only a question of time before his ambitions came to Boulton \& Watt's attention. The latest they could have found out about was January 1807 when one of their potential customers let them know that 'Mr. Winsor very modestly claims the invention and first application.' 148 Watt junior did not give it his immediate attention, but when he heard reports from London at the end of February 1807 that Winsor was about to apply for charter from Parliament, he hurried to London to investigate the situation. ${ }^{149}$ It was a false report, as it turned out, but Watt junior had now experienced the vastness of Winsor's talk and ambitions firsthand, and kept on his guard for specific action on the part of the 'quacks' in London, asking his London lawyer,

\footnotetext{
145 Ibid., 6-7.

146 Ibid., 18.

${ }^{147}$ BWA MS 3147/3/539 \#38, AM-IR series 1 part 15 reel 285

148 William Balston to B+W 1807/01/23, BWA MS 3147/3/42 \#24, AM-IR series 1 part 12 reel 203

149 James Watt jr to Lee 1807/05/04, BWA JWP 6/62 p. 148, AM-IR series 3 part 2 reel 40
} 
Ambrose Weston, to keep him informed should there be any activity requiring his attention. ${ }^{150} \mathrm{He}$ returned to Birmingham reassured and went on a 'planting expedition'. ${ }^{151}$

Once back home, Watt junior cogitated over the situation for some time and concocted a plan to crush Winsor's pretensions to being the inventor of gaslight: the Royal Society could award the Rumford Medal to Murdock. The medal had been endowed by Count Rumford in 1796 to be given by the Royal Society to the European scientist who had made significant contributions in research into heat and light in the preceding years. This would demonstrate with all the authority of the Royal Society that Winsor was an impostor and mountebank who was trying swindle Murdock out of his just claim of being the inventor of the economical application of gaslight. Parliament would then not dare grant a charter to a project based on a fraud's wild claims and Boulton \& Watt's business would be secure. To get this medal, Murdock would have to write a paper, or at least would have to put his name to a paper to be read at the Royal Society. Watt junior must have reasoned that the plan had fair chance of succeeding because of both Matthew Boulton's and James Watt's friendship with the president of the Royal Society, Sir Joseph Banks.

The paper had to be written, and for this, Boulton \& Watt needed some numbers to put to Murdock's claims. Since they could not state outright that Murdock had invented gaslight-by now it was well known that others before him had tried something like itthey would need to claim that he was the first to apply it in an industrial context, and for

\footnotetext{
150 Ambrose Weston to James Watt jr 1807/04/26, BWA MIV /W11, AM-IR series 1 part 8 reel 126

151 James Watt jr to Lee 1807/05/04, BWA JWP 6/62 p. 148, AM-IR series 3 part 2 reel 40
} 
this, they would need information about how the apparatus was functioning at Philips \& Lee's mill. Some information was collected by June 1807 and Watt junior felt they could put something together fairly quickly, so he wrote his father who was in London at the time, asking him to broach the question of Murdock's paper with Sir Joseph Banks. ${ }^{152}$ James Watt briefly replied five days later that it was too late this year and that they would have to try for next. ${ }^{153}$ Watt junior then dropped the subject again for a few months.

Gaslight and the Winsorite threat came into focus once again late in 1807 when Winsor's campaign reached another crescendo in London. This resurrected the Royal Society plan, and Boulton \& Watt began collecting information. The December 1807 to February 1808 experiments first at Soho and then at Philips \& Lee by Creighton working with Lee and William Henry were described in chapter three. These experiments were coupled with an economic analysis to form the basis of the paper that was submitted to the Royal Society in February. Almost all figures in the paper, including the economic analysis, were prepared by Creighton. Watt junior's changes-resisted by Creighton and Lee-were to make the financial picture seem rosier than Creighton's and Lee's reckoning suggested.

Simultaneous with the scientific and technological work, Watt junior wrote to Thomas Wilson, an employee based in Cornwall, asking him to gather what historical evidence he could by interviewing people who might have know Murdock when he was there in 1792-1798, the period in which he first developed gaslight. This would be used

\footnotetext{
152 James Watt jr to James Watt 1807/06/04, BWA MII /13/1, AM-IR series 1 part 6 reel 82 153 James Watt to James Watt jr 1807/06/09, BWA MIV Box 16/15, AM-IR series 1 part 8 reel 135
} 
to bolster Murdock's priority claims over Winsor. Wilson wrote back two letters giving details about what he learned from various people. ${ }^{154}$

Watt junior proceeded to draft a paper based on these results, working with Ambrose Weston and with the blessing of Sir Joseph Banks. Murdock looked it over and corrected in a few places. ${ }^{155}$ It was then sent of to Banks who read it before the Royal Society on February 25, 1808.156 The following day, Watt junior from London wrote his father a remarkable letter that demonstrates that the intention behind the paper was to claim priority for Murdock over Winsor, and that Watt junior had worked with Banks to come up with a paper best suited to secure the Rumford Medal for Murdock, which he would indeed win in a few months' time:

My time has been a good deal occupied in ascertaining what sort of paper would be most likely to answer Sir Joseph Banks' wishes, and secure Mr. Murdock the Rumford Medal. And I have, with some assistance from Mr. A. Weston, drawn up one which fully met Sir Joseph's approbation and by his interest, was last night read at the Royal Society, and I suppose will be published in the next volume of the Transactions, it being the desire of Sir Joseph, that it should appear before the public, as early as possible.

I think however, that although it will undoubtedly affect [sic] its intended purpose of securing to Mr. Murdock the claim to the original idea, and first practical application of the Gas from coal to economical purposes it may be wrested to serve the views of the

\footnotetext{
154 John Charles Griffiths, The Third Man: the Life and Times of William Murdoch, 1754-1839, the Inventor of Gas Lighting (London: A. Deutsch, 1992). p. 224-249 for summary of what Wilson found. The letters are:

Wilson to B+W 1808/01/27 and 29, BWA MS 3147/3/363 \#10 and 11, AM-IR series 1 part 13 reel 236

155 Draft of RS paper 1808/02/22, BWA MS 3147/3/480 \#24 series 1 part 14 reel 273

156 William Murdoch, "An Account of the Application of the Gas from Coal to Economical Purposes," Philosophical Transactions of the Royal Society of London 98 (1808).
} 
National Heat + Light Company, by the proof it affords of the Gas Light being already successfully introduced upon so considerable a scale, and consequently shewing that their pretensions, as far as utility is concerned, are not altogether nugatory.

But this is a danger, which there was no means of avoiding, consistently with Mr.

Murdock's wishes + Sir Joseph's intentions and it will not be a very easy matter for the Gas Committee to reduce their statements to correspond with our matters of fact. ${ }^{157}$

The effect of the paper's publication was deep and pervasive. With the full weight of the Royal Society's prestige behind it, whose effect was multiplied when the Rumford Medal was finally granted on November $21,1808,158$ the Murdock paper became an object of great interest. The fury conjured up by Winsor had created an intense curiosity about gaslight among the general public, and now the Royal Society had waded in, giving its approbation to the technology. The extent of the interest in Murdock's paper and gaslight more generally is reflected by the number of publications that picked up and reprinted the paper in whole or part after it was printed in the Philosophical Transactions in July 1808. It appeared in at least fourteen serial

\footnotetext{
157 James Watt jr to James Watt 1808/02/26, BWA MII /13/2, AM-IR series 1 part 6 reel 83

158 Griffiths, The Third Man: the Life and Times of William Murdoch, 1754-1839, the Inventor of Gas Lighting, 261., MRB to Joseph Banks 1808/12/26, BWA Lunar Society \#149, AM-IR series 1 part 1 reel 12; James Watt jr to Joseph Banks[?] 1809/01/18, BWA JWP 6/65 p. 288, AM-IR series 3 part 2 reel 40
} 
publications over the next year, and more instances could likely be found. ${ }^{159}$ Not all of these were journals that usually carried scientific papers, but did so because of the great interest in gas.

As Watt junior had planned, the Royal Society, by printing the paper, had also acknowledged Murdock as the true inventor of gas. It had effectively rejected the validity of Winsor's assertions to any patent rights and thrown into question the value of the National Heat and Light Company which was based on the premise of working with Winsor and his patents. As The Athenaeum commented, '[t]his paper of Murdoch proves incontestably ... his being the original inventor of the method of using coal-gas to produce light, and of the consequent insufficiency of any patents for the invention to others.' 160

The impact on the Winsor camp, however, was not all negative. Watt junior had recognized in his letter to his father even before the paper's publication that it was a two edged sword. It would refute Winsor's pretensions in regard to priority, but it would also

\section{9}

The Annual review and history of literature, for 1808 , Vol. 7, p. 703

The Annual Register, Or, A View of the History, Politics, and Literature for the Year 1808, p. 131

The Athenaeum, Vol. 3, No. 16 Apr 1808 p. 372. and Vol. 4, No. 20, Aug 1808 p. 153-55

The Belfast Monthly Magazine Dec 1808, Vol. 1, No. 4, p. 280-1

The British Critic: A New Review, March 1809, Vol. 33, p. 258,

The Critical Review, Or, Annals of Literature, Jan 1809, Vol. 16, No. 1, p. 33

The Eclectic Review, Vol 5, part 1, May 1809, p. 443

A Journal of Natural Philosophy, Chemistry and the Arts, Oct 1808, Vol. 21, No. 92, p. 94

The Literary Panorama Sept. 1808, Vol. 4, p. 1157-1160

Monthly Magazine, Jan 1, 1809, Vol. 26, p. 546

The New Annual Register, or General Repository ... for the year 1808 (1809) p. 250

The Philosophical Magazine, Dec 1808, Vol. 32, No. 127, p. 113

The Repertory of Patent Inventions, Sept 1808, 2nd series, Vol. 13, No. 76, p. 262

The Universal magazine, 1808, Vol 10, p. 58

160 "An account of the application of Gas from coal to economical purposes, by Mr. Wm. Murdoch," The Athenaeum, a magazine of literary and miscellaneous information 4, no. 20 (1808): 154. 
give the Royal Society's stamp of legitimacy to the technology, and perhaps make the National Heat and Light Company's project more acceptable, even as it undermined its patent underpinning. There is no doubt that this indeed occurred as the number of reprints of the paper shows. It probably also contributed to the relatively quick acceptance of gaslight in England. In any case, from Watt junior's point of view, the paper and the medal closed the affair and he dropped the subject again.

The promoters of the National Heat and Light Company now decided to try a different tack than the one they had been following for the past year. Rather than asking Parliament to pass a bill approving a charter from the king, through the privy council they would apply to the king directly for a charter. It may be that they felt that there was now popular pressure on Parliament not to recognize a perceived usurper because of Murdock's paper. It is more likely, however, that they had started to think this way even before the paper was published. Even as Watt junior was collecting names of MPs who would take their side in a battle in Parliament, he was watching to see when the Winsor camp would submit their petition, but he noted that they missed what he thought was the cut off date. ${ }^{161}$ The Winsorites had probably thought that they could save considerable expense and effort if they could bypass seeking Parliamentary approval, although they had prepared the Considerations pamphlet for just that purpose, and had even prepared a draft of the act.162 Winsor had also restarted

\footnotetext{
161 James Watt to James Watt jr 1808/02/22, BWA JWP LB/4 202, AM-IR series 3 part 1 reel 9 James Watt jr to James Watt 1808/02/26, BWA MII /13/2, AM-IR series 1 part 6 reel 83 162 Grant and Accum, The report of James Ludovic Grant, 9.
} 
demonstrations at Pall Mall exclusively for members of Parliament in anticipation of new session which had begun on January $20,1808 .{ }^{163}$

In March of 1808 , with the assistance of Thomas Myers, a 'gentleman with just views on political economy', the committee drew up a report on the financial benefits accruing to the nation's finances from the founding of a large gas company, and submitted it to the Chancellor of the Exchequer, Spencer Perceval, for his consideration. The Chancellor then forwarded it on to the privy council. The king asked the Attorney General (Sir Vicary Gibbs) to study the matter and report back as to what steps would be appropriate. He responded on March 19, 1808 'that such a charter could not properly be effected from his Majesty, and that an act of Parliament would be required to carry it into execution.' ${ }^{164}$

It was now incontrovertible that the only way forward for the National Heat and Light Company was through Parliament. Wary of the expense of having to do this and the lateness of the session, the committee once again wrote to the Chancellor of the Exchequer, Spencer Perceval, to ask his opinion about their chances. Perceval's reply came on March 26, 1808, and it was not favourable. He 'was not sufficiently convinced of the public utility or importance of a Light and Heat Company, to induce him to give his parliamentary support ... particularly in the advanced state of the present session.' Grant wrote back asking for the nature of Perceval's doubts, but received no reply. ${ }^{165}$

\footnotetext{
163 "Experiments with pure gas lights," The Times, Saturday, Jan 20 1808. "Experiments with pure Gas Lights," The Morning Chronicle, Wednesday, January 6 1808. "To the Enlightened Legislators of the United Kingdom," The Morning Chronicle, Monday, January 251808.

164 Grant and Accum, The report of James Ludovic Grant, 9.

165 Ibid., 10.
} 
The committee was forced to concede defeat, and on May 11, 1808 called a general meeting for the 26th of the same month. ${ }^{166}$

Winsor, during all this time, had not been inactive, even if he was no longer leading the effort. He concentrated his time on his research work and extending the lighting of Pall Mall. In January 1808, he built a new furnace in the 'front house' at Pall Mall, and installed a condenser for the apparatus. ${ }^{167} \mathrm{He}$ even took out another patent, granted on March 3, 1808, for improvements to his stove, although for reasons that are not clear, he renounced it in August. ${ }^{168}$ During February of 1808 , he hired stokers to keep the furnaces at Pall Mall running during the night and ran some overnight demonstrations and experiments, in one case carbonized 11 bushels of coal in a 24 hour period during which he kept 200 lamps burning. ${ }^{169}$ These tests did not last long, and the committee felt that there was little to be gained from continuing the lighting of Pall Mall and, perhaps because feeling some pressure from the St. James paving commissioners, they discontinued it on April 16, 1808.170

In preparations for the general meeting of May 26, 1808, Grant and the committee prepared and printed a report for the subscribers. After summarizing everything done to

166 "Intended light and heat company," The Times, Apr 121808.

167 Grant and Accum, The report of James Ludovic Grant, 118.

168 Patents for inventions. Abridgments of specifications relating to the production and applications of gas, (London: Printed by G.E. Eyre and W. Spottiswoode, 1860), 11. Chandler and Lacey said it was due to restrictions the Patent Office had placed on his forming a company based on the patent. See Chandler and Lacey, The rise of the gas industry in Britain, 32.

169 Grant and Accum, The report of James Ludovic Grant, 118-9. Considerations on the nature and objects of the intended Light and Heat Company : published by authority of the committee. with improvements and additional experiments, 2nd ed. (London: Printed for James Ridgway by T. Davison, 1808), 27-8.

170 "Intended light and heat company." also grant 
date and recounting their ultimate failure, they made a report on Winsor. He had worked under various circumstances, such as 'the frequent fluctuations of his hopes and fears, and the anxieties occasioned by his pecuniary embarrassments, his personal fatigue and mental sufferings', and making allowances 'for this accumulated pressure upon an ardent and irritable mind', the committee suggested that Winsor's expenses to date be paid, which ran to $£ 6000$ over the last four years. ${ }^{171}$ They then left it up to subscribers to decide if another attempt should be made to obtain a charter, or whether the funds should be returned.

When the subscribers gathered at the Crown \& Anchor Tavern on May 26, 1808, they were unsure as to how exactly to proceed, but they were determined to try again. ${ }^{172}$ Winsor proposed that he prepare a new plan, but the subscribers wanted a thorough legal study done to assess his proposal. A report was to be made to the subscribers at a new meeting, scheduled for June 30,1808 , but it would turn out that since Winsor did not have sufficient time to gather all the information and procure a legal opinion, the meeting was called off. 173 The committee of trustees was reconstituted by the subscribers to push ahead with the effort in Parliament. It now included Grant, Pedder, Accum, and others. They were mostly inactive until Parliament reconvened in 1809.

171 Grant and Accum, The report of James Ludovic Grant, 14.

172 "Intended Light and Heat Company," The Times, Jun 29 1808. "Intended Light and Heat Company," The Morning Chronicle, Saturday, July 231808.

173 "Intended Light and Heat Company." "Intended Light and Heat Company," The Morning Chronicle, Wednesday, June 291808. 
Winsor settled into some of his usual activities, albeit with a lower profile than before. He advertised shares for sale, now requiring a £25 payment, or five times the original sum demanded. ${ }^{174}$ The king's birthday was approaching, and Winsor requested permission from the St. James paving authorities to light Pall Mall once again, which he received, and the lamps came on on the night of June 4, 1808.175 Other than this, he tinkered some more with his stoves, almost burning down the Pall Mall houses at one point, ${ }^{176}$ and applied for another patent, which was granted on February 7, 1809. ${ }^{177} \mathrm{He}$ also worked on a 'moveable Telegraphic light house'. ${ }^{178}$ For the moment, it was mostly a question of waiting for the National Heat and Light Company.

\footnotetext{
174 "Intended light and heat company." "Intended Light and Heat Company."

175 "Gas lights on his majesty's birth-day," The Times, Saturday, Jun 041808.

176 1813/03/19 GLCC Minutes of the Court of Directors Book 1 p. 97: London Metropolitan Archives B/ GLCC/1/1.

177 Patents for inventions. Abridgments of specifications relating to the production and applications of gas, 11.

178 "Intended Light and Heat Company."
} 


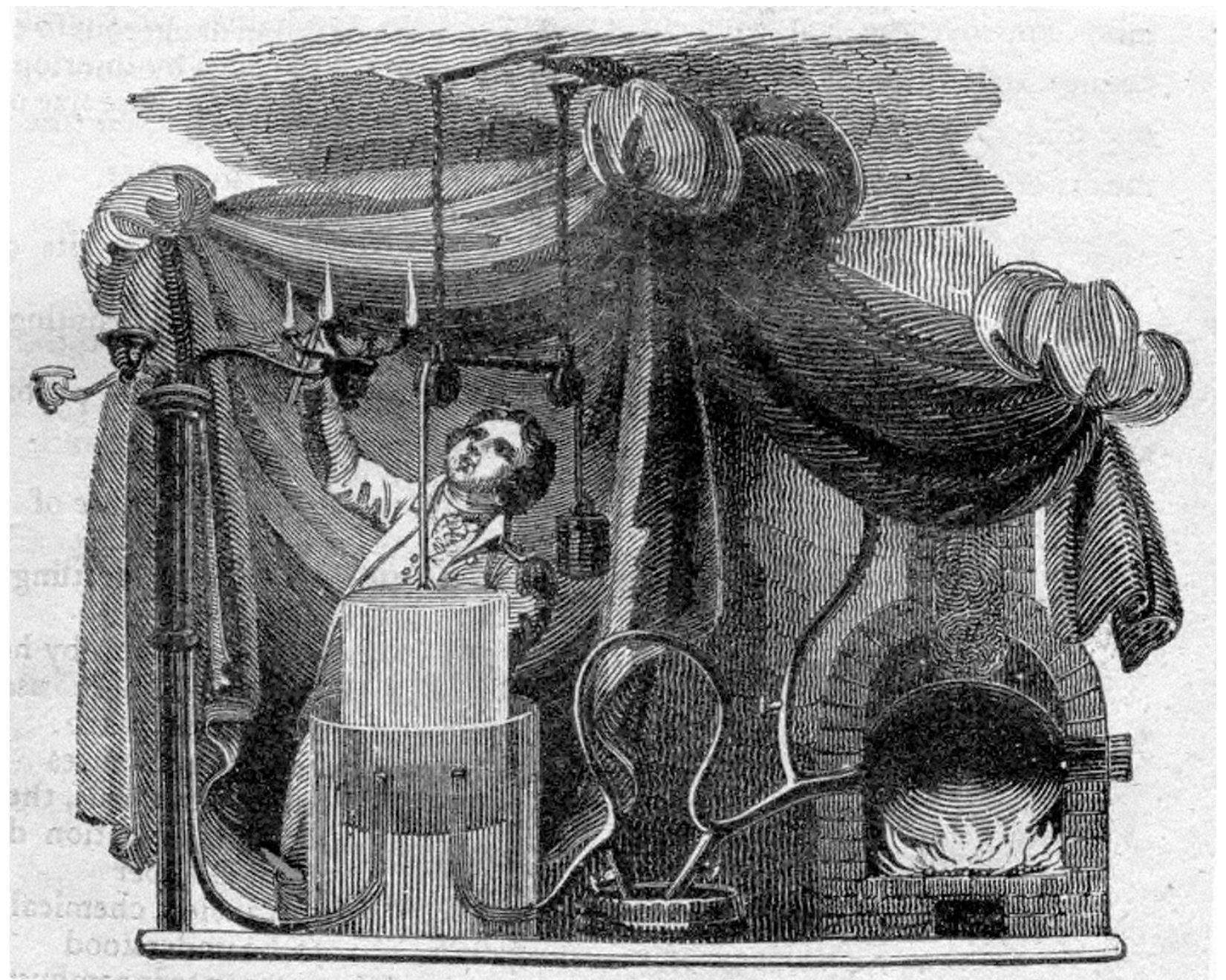

Figure 4.8 A display of gaslight, from Samuel Parkes. The chemical catechism London, England (1808).

Although it is not stated, the inspiration for this was almost certainly Winsor's displays.

\subsection{The Parliamentary Battle of 1809}

For the National Light and Heat Company, 1809 was the year when it finally made a concerted effort to get an act passed by Parliament. The previous years had seen 
them accumulate lots of capital and important backers, put together a team to seek the charter, including professionals such as Accum and Pedder, and finally draft an act and sound out the legal and political environment. Their setback in 1808 was as much due to Murdock's Royal Society paper as to their lack of experience in executing something as difficult as getting a charter from Parliament. The new Parliamentary session in 1809 was different. Everything was in place for a determined effort.

Boulton \& Watt, of course, had not exited the field. They had assumed their victory of 1808 had put them in a good position, but when the Winsorites tried again in 1809, they struck back with even greater resources than in 1808. The clash that resulted, in contrast to 1808, was fought almost exclusively in and about Parliament. The battle in the public sphere was over. It was no longer a question of priorities or viability of the technology. These questions had been settled. In 1809 it was purely a political battle fought with rhetorical weapons. The irony of the battle was that a solution was negotiated even as the parties were waging their war. A compromise that was agreeable to both parties was effectively worked out, but the battle had reached such a pitch that it was beyond the two sides to end it at that point by implementing the compromise. Even if the National Heat and Light Company was defeated again in 1809, they knew, after they recovered from the shock of their defeat, that success was within their grasp in 1810 by resurrecting the compromise they had forged the previous year.

Parliament opened the new session on January 19, 1809, and the committee retained William Mellish (1764?-1838), a wealthy banker and MP for Middlesex, to 
promote their cause. Mellish might also have been a subscriber to the gas company fund. On February 24, 1809, Mellish put forward a motion for the gas company, but was rejected on a technicality. 179 This attempt caught the attention of the lawyer James Weston, Ambrose Weston's brother, who also worked for Boulton \& Watt. He wrote a letter to Watt junior on March 9, 1809 informing him of the new petition and sending him a copy. ${ }^{180}$ Watt junior got the letter the next day, and immediately sent it on to Boulton who was then at Bath. ${ }^{181}$ Boulton though that the 'effrontery' of the bill would lead to its defeat, but that it would be prudent to present a counter-petition arguing that as Boulton \& Watt had spent large sums on developing the technology, it would be unjust for the benefits to fall to a third party. ${ }^{182}$

On March 27, 1809, Mellish tried to present his petition again, and this time it was accepted. The bill was read for the first time and the second reading was set for a few days later. James Weston got a hold of a copy of the proposed bill, and sent this also to Watt junior. He thought that since 'it claims no merit of invention and it seems proper that it should be opposed on public Grounds rather than be an Individual at his own Expence', but awaited Watt junior's instructions. ${ }^{183}$ Boulton had by now hurried to London to investigate the situation personally, and had come to much the same conclusion as James Weston. Rather than submitting a counter-petition, it would be

\footnotetext{
179 Frederick Clifford, A history of private bill legislation (London: Butterworth's, 1885), 205. parl register 7 180 James Weston to James Watt jr 1809/03/09, BWA MS 3147/3/480 \#1, AM-IR series 1 part 14 reel 273. 181 James Watt jr to MRB 1809/03/10, BWA Lunar Society \#115, AM-IR series 1 part 1 reel 6. 182 MRB to James Watt jr 1809/03/13, BWA MIV /B6, AM-IR series 1 part 8 reel 116. 183 James Weston to James Watt jr 1809/03/30, BWA MS 3147/3/480 \#2, AM-IR series 1 part 14 reel 273.
} 
better to allow the bill to be opposed on public grounds, and to come in as witnesses when the time came to investigate what had been done already. ${ }^{184}$

Watt senior, normally unconcerned with gaslight, also opined on the matter when he replied to Ambrose Weston, in lieu of Watt junior who had gone to Wales on other business, that they should print advertisements declaring that Boulton \& Watt already supplied such apparatus. ${ }^{185}$ Ambrose Weston agreed (on the same day!) and thought that copies of Murdock's paper should be printed as well. ${ }^{186}$ After he read the bill, Watt senior told his son that since it made no 'monopolizing claims', it was none of their business, although it was a 'shameful bill'. ${ }^{187}$

Watt junior agreed with Boulton's proposed course of action of not submitting a counter-petition. ${ }^{188}$ Boulton remained in London to monitor the progress of the bill, and wrote to Watt junior a week later appraising him of new developments. The Westons also agreed with not presenting a counter-petition in Parliament, and Boulton was getting ready to marshal allies in Parliament to speak against the bill. The first person he would visit was William Wilberforce, the anti-slavery crusader, to whom Boulton had given 50 guineas to support his election in $1807 .{ }^{189}$ Boulton hope to make 'a convert of so able \& zealous an apostle.' He was afraid, however, the bill 'now divested of its

\footnotetext{
184 MRB to James Watt jr 1809/03/31, BWA MS 3147/3/43 \#5, AM-IR series 1 part 12 reel 203.

185 James Watt to Ambrose Weston 1809/04/03, BWA JWP LB/4 257, AM-IR series 3 part 1 reel 9.

186 Ambrose Weston to James Watt 1809/04/03, BWA JWP 4/86, AM-IR series 3 part 2 reel 27.

187 James Watt to James Watt jr 1809/04/05, BWA MIV Box 16/16, AM-IR series 1 part 8 reel 135.

188 James Watt jr to MRB 1809/04/05, BWA Lunar Society \#116, AM-IR series 1 part 1 reel 6.

189 Woodward to James Watt 1807/05/26, BWA MII /13/1, AM-IR series 1 part 6 reel 82.
} 
former pretensions to the merits of invention may be pushed thro' the House by the influence of the gulled subscribers'. The pamphlet was needed now, and Boulton asked Watt junior for 'this assistance from your pen as it has already been exerted with so much success in the same cause \& can from its better acquaintance with the subject effect the purpose in view with more ease than any other quill.' ${ }^{190}$ Watt junior responded that '[a]lthough I am flattered ... I do not feel any inspiration upon the subject and indeed it will take some time to renew my acquaintance with it." ${ }^{191} \mathrm{He}$ also provided some more names of Parliamentarians who could help Boulton.

The bill, in the meantime, suffered a minor setback in the House when it was rejected on the second reading because it gave the king the authority to dissolve the company, effectively granting him authority over Parliament in this case. It had to be withdrawn to be reintroduced a few days later once the 'obnoxious clause' had been struck. ${ }^{192}$ The committee, catching wind that Boulton \& Watt were mounting a resistance, hastily wrote and printed a pamphlet directed at MPs arguing their case and attacking Boulton \& Watt for their work. ${ }^{193}$ They now openly renounced any claim to invention, but at the same time, claimed the Murdock had not invented anything either. All he had done was 'to add to the length of Mr. Diller's pipes, and proposed lighting a manufactory'. ${ }^{194}$ Even if he had first thought of applying it for 'Economical purposes',

\footnotetext{
190 MRB to James Watt jr 1809/04/13, BWA Lunar Society \#117, AM-IR series 1 part 1 reel 6 and BWA MS 3147/3/43 \#6, AM-IR series 1 part 12 reel 203.

191 James Watt jr to MRB 1809/04/20, BWA Lunar Society \#118, AM-IR series 1 part 1 reel 6.

192 "Gas Light Bill," The Times, Aug 081809.

193 Remarks upon the bill for incorporating the Gas light and Coke company, (London: Printed by George Sidney, 1809). Page 16 speaks of the haste of publication.

194 Ibid., 4.
} 
was his method in fact 'safe and œconomical .... without evident and serious risk?' The committee protested against charges of creating a monopoly, on the basis that it was nowhere to be found in the bill's stipulations. ${ }^{195}$ More importantly, the bill was necessary because a company was needed to light the metropolis: no individuals such as 'Messrs. Bolton and Watt, respectable as they might be,' could provide the assurances needed to light a city like London. Only a large company could do that. Besides, Boulton \& Watt had only managed to light a few factories in the last few years, that 'bear no comparison even to a small parish ... something much more vigorous and effectual than the isolated efforts of individuals is now requisite.'196

With the gas company's pamphlet on the street and in the hands of MPs, Boulton felt that the situation was getting out of hand. He addressed Watt junior again on April 22,1809 , describing the arguments laid out in the pamphlet. He added that:

A gentleman of the name of Grant, a nabob is particularly active \& seems to be one of the principal patrons of the scheme. [...] The general opinion of the members whom we have seen is certainly adverse to the granting of the petition upon the grounds that the necessity of required protection is not proved; on the others hand the petitioners possess considerable parliamentary influence \& by the activity of their counsels may get their bill through. The arguments [presented?] by the advocates ... [are] that they are possessed of some improvements peculiarly applicable to the lighting of streets, by guarding against the danger of large reservoirs of gas as in the apparatus constructed by us. The benefit of these ... will be communicated to the the public by means of the act of incorporation in which they will own and to give the public the full advantage of them, in a more desirable

195 Ibid., 5.

196 Ibid., 8. 
manner than by a patent; for if they have recourse to this protection they will of course consider themselves at liberty to derive from the public the usual exorbitant profits of patentees. That they claim no exclusive privilege. In short that the public advantage is [the?] object they have in view \& that ... it cannot be promoted so officiously as by the institution of an incorporated company they [propose?] that the opposition of [?]+ sordid manufacturers will not be allowed to prevent the attainment of their patriotic views. ${ }^{197}$

Boulton suggested that they should be prepared in the committee to explain what has been done at Boulton \& Watt and why more was not achieved. He also thought that getting Lee involved would aid their cause as he would appear more impartial. Finally, they needed to retain counsel before the committee met and suggested Henry Brougham (1778-1868).

Watt junior wrote a note back to Boulton ${ }^{198}$ and a letter to Lee asking for his help a few days later. ${ }^{199}$ Lee responded that he was 'glad you have taken up the Subject of the Winsorites which have already advanced too far unnoticed', and pledged his help, writing to MPs he knew and suggesting Gott could help with the Yorkshire ones. ${ }^{200}$ Watt junior then made preparations to go to London himself with Murdock, departing on April $29,1809,201$ and leaving instructions to Lawson and Southern to prepare figures that could be presented in the Parliamentary committee. ${ }^{202}$

\footnotetext{
197 MRB to James Watt jr 1809/04/22, BWA MS 3147/3/43 \#8, AM-IR series 1 part 12 reel 203.

198 James Watt jr to MRB 1809/04/27, BWA Lunar Society \#121, AM-IR series 1 part 1 reel 6. 199 James Watt jr to Lee 1809/04/27, BWA JWP 6/63 p. 232, AM-IR series 3 part 2 reel 40.

200 Lee to James Watt jr 1809/04/29, BWA MS 3147/3/480 \#4, AM-IR series 1 part 14 reel 273.

201 James Watt jr to MRB 1809/04/28, BWA Lunar Society \#121, AM-IR series 1 part 1 reel 6. 202 Experiment notes 1809/04/29, BWA MS 3147/3/480 \#5, AM-IR series 1 part 14 reel 273.
} 
The month of May 1809 was one of frenetic activity for both sides as the bill went to committee, third reading, and final vote in the House. Watt junior's first point of business was to write a pamphlet with Murdock responding to the committee's pamphlet. It was printed as a letter from Murdock to MPs. ${ }^{203}$ He prefaced it by saying that, in reference to the gas committee's pamphlet, 'had it not been avowed as coming from a committee of gentlemen, I must have considered as the production of an anonymous calumniator.'204 They then proceeded to respond to the various assertions of the first pamphlet. Murdock had never claimed invention. The 'German Diller ... exhibited for the amusement of the curious and ignorant', but did not 'make the application of gas to purposes of public and private utility ... proceeding with all the mercenary caution of a juggler'.205 This 'puppet-show entertainment', of which Murdock was ignorant, had nothing to do with gaslight as implemented at Soho and Philips \& Lee. The subject has now been 'enveloped by Winsor and his friends in mysterious obscurity, and exaggerated and delusive estimates.'206 It was Winsor who was 'the successor of Mr. Diller'.207 In regard to the aspersions cast on the safety and economy of the Boulton \& Watt gaslights, three year of safe operation contradicted them. ${ }^{208}$ The 'claim-balancing-committee' was making absurd profit predictions, and threatened to

\footnotetext{
203 William Murdoch, A letter to a member of Parliament, from Mr. William Murdock in vindication of his character and claims, in reply to a recent publication by the committee for conducting through Parliament a bill for incorporating a gas-light \& coke company (s.n.,; (London :; Galabin and Marchant), 1809).

204 Ibid., 3.

205 Ibid., 5.

206 Ibid., 7.

207 Ibid., 10.

208 Ibid., 8.
} 
cause another 'South-Sea Bubble'. Boulton \& Watt, as well as Lee, have provided invaluable co-operation and encouragement as the technology was developed with 'caution and judicious steps ... which the committee, not very considerately, have stigmatized with the character of delay.'209 They finished by attacking the project on the grounds that many of those things which the putative company wanted to sell are already available from Boulton \& Watt, who do not enjoy the protection of a limited liability charter.

Both sides now frantically prepared their next steps in view of the committee hearings which were scheduled to begin the next day, May 5, 1809. Watt junior sent for Murdock's Rumford medal, perhaps to serve as a visible reminder of whom the Royal Society had supported in this confrontation. ${ }^{210}$ The gas company prepared their witnesses. The parliamentary committee was chaired by the geologist and MP for Cornwall Sir James Hall, who was 'decidedly Winsorian'.211 The MPs acting as counsel for the bill were Charles Warren and William Harrison. Boulton \& Watt initially tried to get their allies in the House to help in committee, but, as Watt junior explained, 'we found it so difficult to get our friends to attend the Committee to listen to the nonsense that was going on; and to make those that did attend put any questions properly', ${ }^{212}$ that they were forced to retain Brougham as counsel. Only Sir Robert Peel would show up

209 Ibid., 12-3.

210 John Southern to James Watt jr 1809/05/04 and 05, BWA MS 3147/3/332 \#8 and 9, AM-IR series 1 part 13 reel 230.

211 Ambrose Weston to James Watt 1809/05/10, BWA JWP 4/86, AM-IR series 3 part 2 reel 27.

212 James Watt jr to John Southern 1809/05/12, BWA MS 3147/3/60 \#16, AM-IR series 1 part 12 reel 206. 
with some consistency for Boulton \& Watt, ${ }^{213}$ and even one MP, Isaac Hawkins Browne, whom they had thought was their ally, ${ }^{214}$ was there but never spoke, and they even suspected him of siding with Winsor. ${ }^{215}$

The first witness was Frederick Accum, and the strategy that Harrison and Warren pursued with him was to have Accum and some tradesmen they also called claim some sort of superiority for Winsor's stoves and the products produced by them. The coke produced by them, Accum claimed, was 'far superior' to others because it yielded no smoke or dirt, and had 'none of the sulpherous smell' common with other coke. ${ }^{216}$ It generated more heat.217 Winsor's tar was as good as any for ship's caulking, and had greater penetrating power. ${ }^{218} \mathrm{His}$ asphaltum was as good as the best from Russia.. ${ }^{219}$ His ammonia could be used as a mordant and for fertilizer. ${ }^{220}$ Sal ammoniac could be used in making tin and brass, caustic ammonia for silk and alum. Essential oil for paint and varnish without smells. ${ }^{221}$ The company's counsels also discussed the lighting of

213 Ambrose Weston to James Watt 1809/05/10, BWA JWP 4/86, AM-IR series 3 part 2 reel 27.

214 Browne to James Watt 1809/04/24, BWA JWP 4/86, AM-IR series 3 part 2 reel 27; James Watt to Browne 1809/04/26, BWA JWP LB/4 266, AM-IR series 3 part 1 reel 9; James Watt jr to MRB 1809/04/27, BWA Lunar Society \#120, AM-IR series 1 part 1 reel 6.

215 Ambrose Weston to James Watt 1809/05/10, BWA JWP 4/86, AM-IR series 3 part 2 reel 27.

216 Hall, "Select Committee on Gas-Light."

217 Ibid., 8-9.

218 Ibid., 12-14.

219 Ibid., 15-16.

220 Ibid., 17-21.

221 Ibid., 22-25.. Some of these claims were actually believed. See William Playfair and Joshua Jepson Oddy, A sketch for the improvement of the political, commercial, and local interests of Britain as exemplified by the inland navigations of Europe in general, and of England in particular : including details relative to the intended Stamford Junction navigation, to unite the Eastern, with the midland and western Counties of the kingdom : illustrated with a canal map (London: Printed for J.J. Stockdale, 1810), 24-5. 
city streets. With Winsor's stoves, the parish of St. James could be lighted for $£ 26,500.222$ In a statement that revealed just how far behind Boulton \& Watt the National Heat and Light company was in terms of experience and technological maturity, Accum stated that no reservoirs or gasometers would be needed in Winsor's plan.223

The talk about the wonderful properties of Winsor's stoves and their products caught Watt junior by surprise. The Winsor camp, while they had mentioned the many products of coal distillation, had not really been using this as a major advantage in arguing for a charter. Now, in the House of Commons committee, they had made it the most important element of their case. Moreover, Boulton \& Watt had been ignoring the other products that Accum had praised so highly.

Watt junior wrote to Southern back in Soho to find out anything he could about coke, tar, ammonia and varnish. Southern received the letter on May 7, 1809, and went to see the senior Watt to collect what wisdom he may have to offer on the subject. Watt senior could not recollect perfectly, but he thought that coal-tars were tried and rejected for naval use because it destroyed the oakum, were more water soluble, and rubbed off more easily. ${ }^{224}$ Southern also set in motion a feverish series of experiments that ran for a few days trying to determine the heating value of coals and cokes, sending Watt junior

\footnotetext{
222 Hall, "Select Committee on Gas-Light," 38.

223 Ibid., 29.

224 John Southern to James Watt jr 1809/05/09 BWA MS 3147/3/332 \#11 AM-IR series 1 part 13 reel 230, James Watt to Ambrose Weston 1809/05/09, BWA JWP LB/4 266, AM-IR series 3 part 1 reel 9.
} 
results as soon as he could get them out. ${ }^{225}$ Watt junior even had a boy go to Winsor's office in Pall Mall to buy some coke to test it. Although the people at the office seemed to guess the true origin of their visitor's request, they parted with some coke, which was duly analysed by Murdock and Lawson in London.226 They found that Winsor's coke was not as spectacular as Accum had claimed. As the information came in from various sources, Watt junior felt more confident. He wrote to Southern on May 12, 1809:

\begin{abstract}
I have received your three letters ... which are very satisfactory, as tending to refute the absurdities which have been advanced here and to confirm the general notions before entertained upon the subject.
\end{abstract}

Winsor's case is now closed, and a more compleat [septum?] of falsehoods + imposture was perhaps never before brought forward. [...] They have listed properties equally extraordinary of all the other products of coal except the gas which they do not pretend to be superior to ours + seem willing to admit, at least they have not very boldly denied $\mathrm{M}[\mathrm{udoc}] \mathrm{ks}$ claims to be the first œconomical application. We are not prepared with evidence to refute their assertions respecting the generalities of their ammoniacal liquor which is likely according to them to prove the grand panaceum. We must therefore simply affirm our ignorance of the facts and indeavour to discredit their witnesses, whose testimony has been in the highest degree suspicious. In short it would appear either that

\footnotetext{
225 John Southern to James Watt jr 1809/05/08, 09, 10 BWA MS 3147/3/332 \#10, 11, 12, and 13 AM-IR series 1 part 13 reel 230. See also James Watt to Ambrose Weston 1809/05/09, BWA JWP LB/4 266, AM-IR series 3 part 1 reel 9; James Watt to Ambrose Weston 1809/05/09, BWA MIV Box 16/16, AM-IR series 1 part 8 reel 135 .

226 note 1809/05/09, BWA MS 3147/3/479 \#1, AM-IR series 1 part 14 reel 273; James Watt jr to John Southern 1809/05/12, BWA MS 3147/3/60 \#16, AM-IR series 1 part 12 reel 206; William Henry also contributed some evidence regarding ammonia, but it came too late to make any difference Lee to James Watt jr 1809/05/30, BWA MS 3147/3/480 \#19, AM-IR series 1 part 14 reel 273; William Henry to James Watt jr 1809/05/29, BWA MS 3147/3/480 \#18, AM-IR series 1 part 14 reel 273.
} 
Winsor + Accum have deceived the Gas Committee, or that the latter are themselves indeavouring to impose on Parliament. ${ }^{227}$

Brougham began the questioning with George Augustus Lee for Boulton \& Watt on May 12, 1809. Lee gave a history of the gaslight as applied in his mills, insisting that there were no problems with it, and that competition in the manufacturing of gaslight apparatus would be harmed with the emergence of a corporate body with large capital and limited liability.228 In order to refute the safety fears raised by the opposing side, an insurance agent from the Albion Fire and Life Insurance Company was called to testify that he judged the gaslight at Philips \& Lee to be 'diminish the risk of fire considerably.'229 Humphry Davy, whom the Winsor camp had tried to recruit to their side, ${ }^{230}$ was called in to say that Winsor's coke was not markedly different than any other he had tried. ${ }^{231}$ Lawson confirmed this as well.232 A manufacturer of coal-tar and paint colour testified that this was nothing new, having been introduced by Dundonald in 1787, and whose patent had just expired. ${ }^{233}$ The hearings were finished off with lengthy testimony from Watt junior, who presented the history of the invention, emphasizing that they never took out a patent for gaslight because of prior work from Dundonald and others. He insisted that there had been no unnecessary delays in providing apparatus

\footnotetext{
227 James Watt jr to John Southern 1809/05/12, BWA MS 3147/3/60 \#16, AM-IR series 1 part 12 reel 206. 228 Hall, "Select Committee on Gas-Light," 38-45, 47-8.

229 Ibid., 46.

230 MRB to James Watt jr 1809/04/22, BWA MS 3147/3/43 \#8, AM-IR series 1 part 12 reel 203.

231 Hall, "Select Committee on Gas-Light," 45-6.

232 Ibid., 50.

233 Ibid., 49.
} 
to those interested. They had needed to experiment with Lee's apparatus before they were ready to sell others. He strongly resisted the idea of incorporating the company because it would create a competitor invested with large capital and shielded from bankruptcy laws, giving it the option of running many more risks, hiring away Boulton \& Watt's employees, and probably forcing them to quit the business. During the line of question by the opposing counsel, one question was placed to Watt junior whose response the promoters of the company evidently picked up on. It was whether Boulton \& Watt would do business with the new company if they did not manufacture apparatus, limiting themselves to lighting the town. Watt junior responded that they would then not be interfering in their interests. ${ }^{234}$

The committee finished gathering testimony, and voted in favour of passing the bill on May $15,1809.235$ Boulton \& Watt had lobbied to get MPs to attend the committee by distributing invitations, but as usual, not many showed up. ${ }^{236} \mathrm{~A}$ favourable report was given to the House on May 17.237 The final decision was now to be made at the impending third reading, and each side lobbied furiously. Watt junior was feeling much more optimistic now, with the gas company having been made to look foolish with their claims about wonderful byproducts:

We have completely overturned their evidence + established our case, and they are now moving heaven + earth to prevent the evidence from being presented. [...] Every moment

\footnotetext{
234 Ibid., 51-62.

235 "Gas Light Bill."

236 Invitation, BWA MS 3147/3/481 \#26, AM-IR series 1 part 14 reel 273.

237 Clifford, A history of private bill legislation, 207.
} 
must now to be dedicated to canvassing, in which we seem likely to be successful, having got most of the leading members of both parties. ${ }^{238}$

Boulton \& Watt scored a stroke on May 19, 1809, when William Wilberforce (supported by Haskins Browne) managed to lay the committee evidence before the House, an unusual move, but important because it would give more prominence to the testimony, generally favourable to Boulton \& Watt.239 Watt junior now wrote and printed another 13 page pamphlet, ${ }^{240}$ attacking the company on the basis that they had made no invention, had done nothing in terms of applying the technology, and that such a company was hardly necessary considering that the technology was already being sold. ${ }^{241}$ In short, 'Mr. Winsor's puffs and projects have at last failed'. ${ }^{242}$ This they sent together with copies of the evidence collected in the committee to as many MPs as they could, such as Sir Vicary Gibbs the Attorney General, 243 Archibald Colquhoun the Lord advocate for Scotland, 244 and many others. ${ }^{245}$ By May 27,1809 , Watt junior was able to report to his father that they had seen 100 MPs in the intervening period. ${ }^{246}$

\footnotetext{
238 James Watt jr to James Watt 1809/05/18, BWA MII /13/2, AM-IR series 1 part 6 reel 83. 239 "Gas Light Bill." "Parliamentary Intelligence," The Morning Chronicle, Saturday, May 201809. 240 Brougham to James Watt jr 1809/05/17, BWA MS 3147/3/480 \#8, AM-IR series 1 part 14 reel 273; Rickman to Humphry Davy 1809/05/17, BWA MS 3147/3/480 \#7, AM-IR series 1 part 14 reel 273.

241 In Parliament: Gas-light bill, (s.n., 1809). 242 Ibid., 10. 243 James Watt jr to Thomas Plummer 1809/05/20, BWA MS 3147/3/480 \#9, AM-IR series 1 part 14 reel 273.

244 James Watt to James Watt jr 1809/05/22, BWA MIV Box 16/17, AM-IR series 1 part 8 reel 135 245 Duckworth to James Watt jr 1809/05/23, BWA MS 3147/3/480 \#10, AM-IR series 1 part 14 reel 273; P Wilson to James Watt jr 1809/05/27, BWA MS 3147/3/480 \#15, AM-IR series 1 part 14 reel 273. 246 James Watt jr to James Watt 1809/05/27, BWA MII /13/2, AM-IR series 1 part 6 reel 83.
} 
The gas company camp started to panic. They realized that, although the vote had gone in their favour in the committee, they had been bested in the actual testimony. Inevitably, they responded to Boulton \& Watt's pamphlet with a very brief one of own, two pages in length, affirming that the bill gave them no monopoly. ${ }^{247}$ They tried to seek a compromise with Watt junior. On May 26, 1809, Harrison made an approach to Brougham and James Weston to propose that they reduce the powers the bill granted to the company. ${ }^{248}$ Watt junior described the offer to his father:

It is certain they are much alarmed, as their counsel has been endeavouring to get us to agree to modifications of the Bill of his suggesting. They would now be willing to make it a local bill for the lighting of London and Westminster, or a part of these cities only, and perhaps to give up the manufacturing part, and to limit their capital to a lesser [sum] than the $£ 300,000$ which is fixed in the Bill. But it is now too late for any thing to be done unless by the House itself, as it appears to us we are pledged to go on with our opposition; and should we fail in the Commons, we must follow them to the Lords. ${ }^{249}$

On the whole, Watt junior, the two Westons, and Brougham were inclined to accept the offer, but understood that having opposed the bill with such energy to date, it would hardly be credible to suddenly drop all opposition. They sent Harrison a negative answer, ${ }^{250}$ and Watt senior concurred with the move. ${ }^{251}$

247 Remarks on the gas light and coke bill, (s.n., 1809).

248 Clauses to be inserted, from Pedder 1809/05/28, BWA MS 3147/3/480 \#33, AM-IR series 1 part 14 reel 273.

249 James Watt jr to James Watt 1809/05/27, BWA MII /13/2, AM-IR series 1 part 6 reel 83.

250 Brougham to James Watt jr 1809/05/26, BWA MS 3147/3/480 \#12 and 13, AM-IR series 1 part 14 reel 273; James Weston to James Watt jr 1809/05/26, BWA MS 3147/3/480 \#14, AM-IR series 1 part 14 reel 273; Ambrose Weston to James Watt jr 1809/05/28, BWA MS 3147/3/480 \#17, AM-IR series 1 part 14 reel 273.

251 James Watt to James Watt jr 1809/05/22, BWA MIV Box 16/17, AM-IR series 1 part 8 reel 135. 
There was now nothing left but to fight to the end, which came fairly quickly. More publications were printed, this time in the form of the speeches given by Brougham, Harrison, and Warren in the committee. ${ }^{252}$ Both of these were over 30 pages in length, and it is hard to conceive they had much effect, being so rhetorical in nature and available only a couple of days before the vote. The gas committee decided to try to introduce the proposed clauses-specifically restricting the company's ability to manufacture gas apparatus for sale-and printed a last circular describing the changes. ${ }^{253}$ Watt junior even drafted a response to the new clauses, but this was mercifully never printed. ${ }^{254}$

The final vote was delayed from June 1, 1809 to the following day. Mellish presented the bill and proposed the new clauses, but these were refused on the basis that the House had not had time to consider them. Davies Giddy (later Davies Gilbert), a Boulton \& Watt ally, strongly condemned the bill as monopolizing, creating another South Sea Bubble, and unnecessary. William Wilberforce then stood up and opposed the bill as a 'gambling project' and presented one of Winsor's pamphlets with its extravagant claims as evidence. The bill was put to a vote and lost by 52 to 38.255

\footnotetext{
252 Henry Brougham, Speeches of Henry Brougham, Esq delivered before a committee of the Honourable House of Commons, in opposition to a bill, for incorporating certain persons by the name of the Gas Light and Coke Company (London: Strahan and Preston, 1809)., Charles Warren and William Harrison, Speeches of Charles Warren, Esq. and William Harrison, Esq. delivered before a committee of the Honourable House of Commons in support of a bill, to authorise His Majesty to grant a charter of incorporation to certain persons, by the name of the Gas Light and Coke Company (London: G. Woodfall, 1809).

253 Gas light bill third reading, Friday, June 2, 1809, (The Company,; (London :; G. Sidney), 1809).

254 Further remarks in opposition to the Gas Light Bill 1809/06/01, BWA MS 3147/3/480 \#31, AM-IR series 1 part 14 reel 273.

255 "Gas Light Bill." Wilberforce to James Watt jr 1809/05/27, BWA MS 3147/3/480 \#16, AM-IR series 1 part 14 reel 273.
} 
Boulton \& Watt and their allies were triumphant, and Watt junior offered the following assessment of their victory to his father:

\begin{abstract}
You will see that we have not treated the Promoters of the Bill with much respect, and indeed I believe we owe our success as much to the ridicule we have bestowed upon them, as to the intrinsic merits of our opposition for very few indeed of the members have troubled themselves to read the evidence, or to make themselves masters of the general principles of political œconomy, upon which alone, perhaps, this question ought to have been decided. We have however experienced great civility and attendance from all parties in the House, ministers not excepted, who in general took no part in the affair, but I apprehend are very glad to have got rid of the Bill. Our Canvass has been extensive and there are very few of our acquaintances and friends but what have rendered us some assistance..$^{256}$
\end{abstract}

Watt junior received congratulatory letters from many people, including Ewart, Lee, and Southern. Lee thought the 'Gang of Schemers + Swindlers' were now finished, as did Watt senior. ${ }^{257}$ Southern added, however, that in his opinion 'it did not deserve so much of your attention as you have I daresay paid to it, and has probably taken more than you calculated upon.' ${ }^{258}$ Watt junior concurred. In his own words, he was 'able to think and attend to nothing else whilst it has lasted',259 and from this point forwards the

\footnotetext{
256 James Watt jr to James Watt 1809/06/06, BWA MII /13/2, AM-IR series 1 part 6 reel 83.

257 Ewart to James Watt jr 1809/06/05, MS 3147/3/249 \#82, AM-IR series 1 part 12 reel 213; James Watt to James Watt jr 1809/06/10, BWA MIV Box 16/17, AM-IR series 1 part 8 reel 135; Lee to James Watt jr 1809/06/05, BWA MS 3147/3/480 \#23, AM-IR series 1 part 14 reel 273.

258 John Southern to James Watt jr 1809/06/05, BWA MS 3147/3/332 \#17, AM-IR series 1 part 13 reel 230.

259 James Watt jr to James Watt 1809/06/06, BWA MII /13/2, AM-IR series 1 part 6 reel 83.
} 
subject of gaslight is almost completely absent from his letters. He had had enough of it to last him a lifetime. 


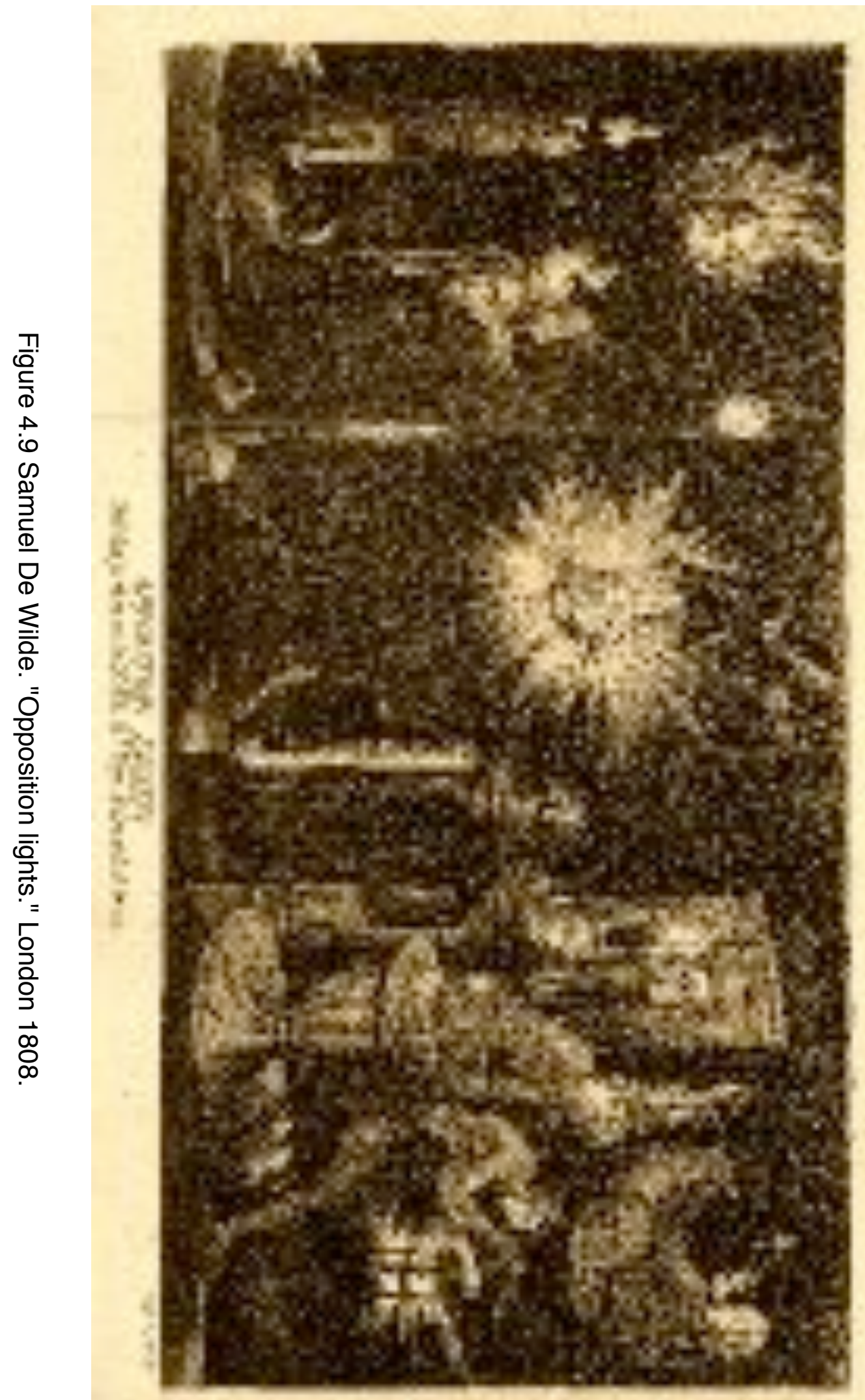




\subsection{Despair, Recovery, and Final Success 1809-1812}

The gas committee and their supports were to a large extent despondent and despairing. In the days immediately following their defeat in the House, the committee, without consulting the supporters, took steps to wind down the entire affair, and placed notices in newspapers calling in their debts and proposed to liquidate all the assets belonging to the putative company, planning to terminate the project in the near future. ${ }^{260}$ Winsor himself was uncertain as to what to do, although he was still generally optimistic that a company could be founded. On June 9,1809 , he sent out a letter to the subscribers of the fund asking them if they would support him in a subsequent project, should he try again.261 Not all subscribers, however, agreed with the plan of killing off the fund and the current effort, and even saw behind the liquidation a plot on the part of some of the trustees, notably Grant, to dispossess the subscribers of any claim over Winsor's patents and technology and to reconstitute a new fund with very few subscribers. ${ }^{262} \mathrm{~A}$ prominent London merchant and one of the largest investors in the company, ${ }^{263}$ John Van Voorst, took it upon himself to rally the subscribers and to get the decision to shut down the fund reversed. He found a few allies who also mistrusted the motives of the committee, and, after a visit to the Pall Mall offices to take stock of the

\footnotetext{
260 James Watt jr to James Watt 1809/06/06, BWA MII /13/2, AM-IR series 1 part 6 reel 83; "Gas Light and Coke Company," The Times, Jul 05 1809. [James Box], An account of the Society, denominated the Associated Proprietors of the Gas Light and Coke Company containing particulars of the rise, the progress, the principles, the object, and the usefulness of that society (Printed and sold for the author, 1817), 9.

261 Hamilton to James Watt jr 1809/07/02, BWA MIV /H1 series 1 part 8 reel 119.

262 [Box], An account of the Society, denominated the Associated Proprietors of the Gas Light and Coke Company, 8.

263 John Van Voorst, An address to the proprietors of the intended Gas Light and Coke Company to which is annexed, an epitome of the evidence taken before the committee of the House of Commons (Printed for the author, 1809), iii.
} 
situation, ${ }^{264}$ together they called a unsanctioned meeting for all subscribers to take place on July 6,1809 , at the City of London Tavern. ${ }^{265}$ The announcement caught the committee and Winsor by surprise, and fearing some sort of coup or worse, they gave notice that they had not called this meeting.266 Van Voorst met with Winsor and members of the committee whom they trusted to allay their fears and some of them, such as Winsor himself and Sir Matthew Bloxam, went to the meeting at the tavern.267

At the meeting, Van Voorst gave a speech which, in keeping with gaslight tradition, he later had printed as a pamphlet. ${ }^{268}$ By his own admission, Van Voorst was motivated not by an 'romantic ideas of self-devotion or patriotism', but 'by a prospect ... of personal remuneration'.269 He was convinced of the practicability, utility, 'and great pecuniary returns' which 'this great discovery' could yield if pursued, and thought it would be a grave error to drop the project at this point. He thought, in fact, that the company did not even require an act of incorporation from Parliament, and in this he was correct, as many unincorporated gas companies were formed and survived after the GLCC was incorporated. The clauses that were proposed at the end of the parliamentary debate by the gas committee were an error, Van Voorst argued, and had the act including these additions passed, the subscribers would have 'in an infinitely worse situation than the 264 [Box], An account of the Society, denominated the Associated Proprietors of the Gas Light and Coke Company, 8-11.

265 "Gas Light Company," The Times, Jul 031809.

266 "Gas Light and Coke Company."

267 [Box], An account of the Society, denominated the Associated Proprietors of the Gas Light and Coke Company, 11.

268 Van Voorst, An address to the proprietors of the intended Gas Light and Coke Company. "Gas Light and Coke Company."

269 Van Voorst, An address to the proprietors of the intended Gas Light and Coke Company, iii. 
one' in which they now found themselves. ${ }^{270}$ Although feeling 'considerable embarrassment', Van Voorst felt it was his duty to call 'into question the propriety' of the conduct of Boulton \& Watt, although their 'general character stands so deservedly high.' They were wrong to travel all the way from Birmingham to oppose the bill, there being nothing wrong with the large capital the company was seeking. In addition, the new gas company, once incorporated, would not go to Birmingham to hire away their workmen, there being an ample supply in London (in fact, when the time came, they would go farther afield to Manchester).271

Van Voorst was largely successful in rallying the 'very numerous' shareholders who attended his unsanctioned meeting, and they resolved to push the committee to follow the same line. Winsor and Sir Matthew Bloxam, Winsor's banker since 1804, acquitted themselves in a 'manly' and 'upright' way, and were thanked in the meeting's minutes. A general meeting was demanded of the committee for August 3, 1809, when these resolutions could be made official and binding on the committee. ${ }^{272}$ It proved unnecessary, however, because Van Voorst, confident now of the backing of so many shareholders met with the committee of trustees at the Pall Mall offices on July 10, 1809 , and they agreed to suspend the decision to liquidate, a feat he jubilantly announced in public notices. ${ }^{273}$

\footnotetext{
270 Ibid., vii.

271 Ibid., vii-viii.

272 "Gas Light and Coke Company."

273 Ibid.
} 
The next general meeting of shareholders was held on August 29, 1809 at the Crown and Anchor Tavern once again. 274 The printed report of the committee made no recommendation about whether to try again, although it did state that there was 'some hope of success' ${ }^{275}$ It is possible that some members of committee may have tried to convince the shareholders not to proceed, ${ }^{276}$ but whatever happened, the sentiment in favour of trying again was strong. It was also later reported that Van Voorst had communicated with William Wilberforce, 'to whose exertions the Loss of the Bill was by every one chiefly attributed', and had convinced him that the project was practicable. Apparently, Wilberforce 'expressed his sorrow for the part he took on that occasion' and was willing to make amends by supporting a new bill, although it is not evident from contemporary sources that this indeed happened. 277 In any event, the subscribers supported Van Voorst and resolved to try again once Parliament opened its next session. The committee was now reconstituted for this purpose.278 The split between the clique around James Ludovic Grant within the committee of trustees and the activist shareholders following John Van Voorst was not, however, healed. Despite Van

274 "Gas Light Bill." James Ludovic Grant, The second report of James Ludovic Grant, Esq. Chairman, and the other acting trustees of the fund for assisting Mr. Winsor in his experiments to the subscribers of that fund, at a meeting convened at a meeting convened by public advertisements, at the Crown and Anchor Tavern in the Strand, on the 29th of August 1809 (London: Printed by G. Woodfall, 1809).

275 Grant, The second report of James Ludovic Grant, 10.

276 [Box, An account of the Society, denominated the Associated Proprietors of the Gas Light and Coke Company, 12.

277 Ibid., 11-12.

278 "Gas Light and Coke Bill," The Times, Aug 301809. 
Voorst's death in $1815,{ }^{279}$ a disaffected group of shareholders claiming to be Van Voorst heirs became a feature of the Gas Light and Coke Company's politics for some years. 


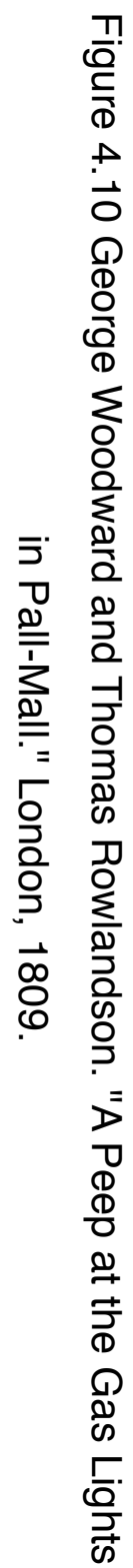

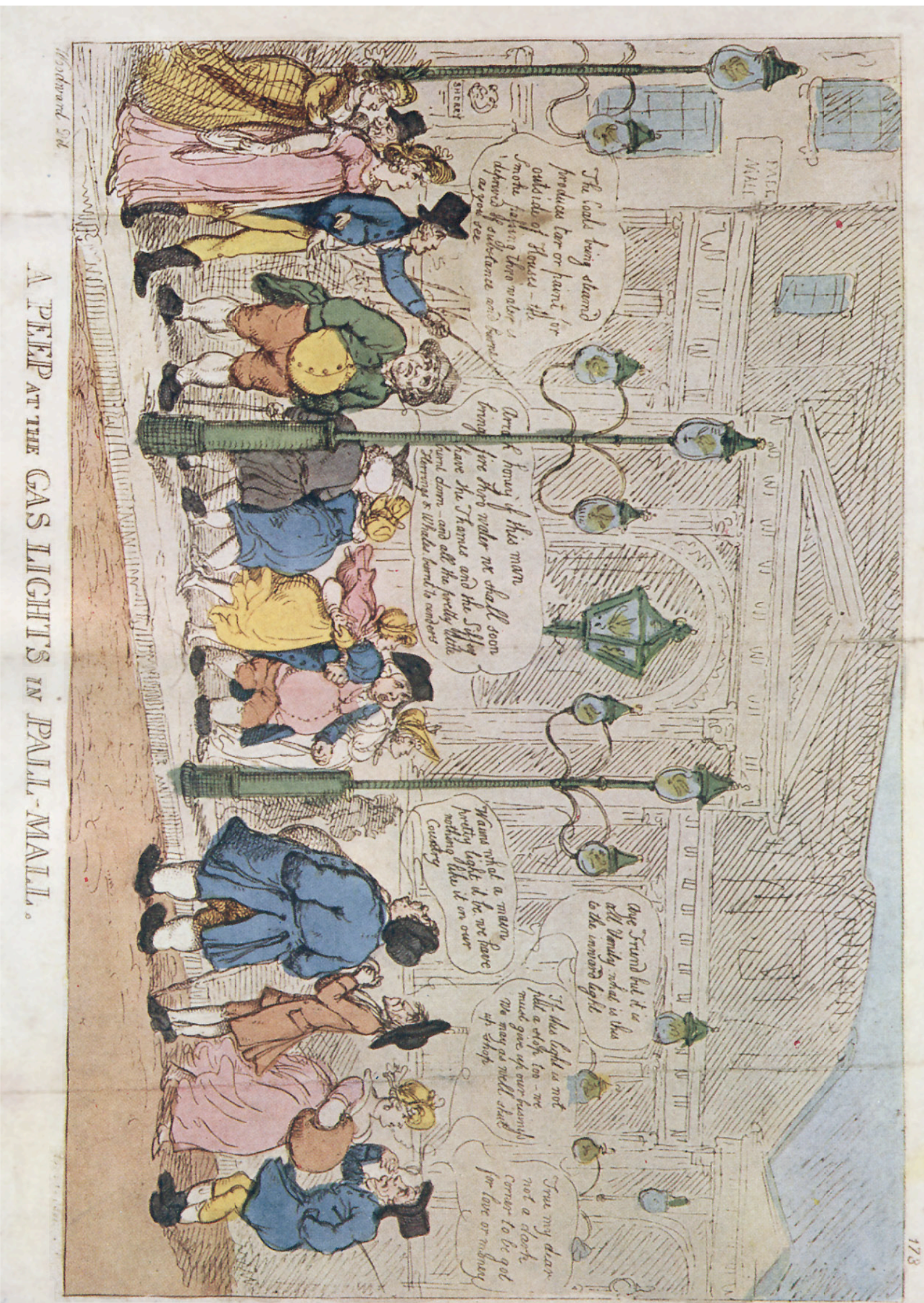


All was quiet without even any advertisement from Winsor for the next few months (although Winsor's bank of Bloxam \& Co. went bankrupt in September 1809). ${ }^{280}$ When Parliament opened its new session in January 1810, Mellish was ready with a fresh bill, this time seeking a company with less capital, $£ 200,000$; a sphere of operation limited to Westminster, London, and Southwark; and with a prohibition on the manufacture of apparatus for sale. ${ }^{281}$ The bill was introduced on February 20, 1810, and progressed rapidly from there. ${ }^{282}$ Once he got wind of the impending bill, Brougham wrote to Watt junior encouraging resistance, 283 as did Peter Ewart, who even went as far as encouraging his friends who knew MPs to lobby them into resisting the bill.284 Watt junior had had enough of the matter, and did nothing, especially as John Pedder, the gas committee's lawyer, sent him a copy of the bill in March to ensure that it contained nothing offensive to Boulton \& Watt.285 There evidently was nothing, because Boulton \& Watt were silent as the bill wended its way through Parliament. Even Davies Giddy, the Boulton \& Watt ally and strong opponent of the bill in 1809 now supported it with some provisos. $^{286}$

280 "Commission against Bloxam, Wilkinson, and Bloxam," The Times, Sep 181809.

281 An act [50 Geo.III cap. clxiii] for granting certain Powers and Authorities to a Company to be incorporated by Charter, to be called The Gas Light and Coke Company for making Inflammable Aire for the lighting of the Streets of the Metropolis, and for procuring Coke, Oil, Tar, Pitch, Asphaltum, Ammoniacal Liquor, and essential Oil, from Coal, and for other Purposes relating thereto, (9 June 1810). Articles I, XXVIII

282 "Parliamentary intelligence," The Times, Feb 211810.

283 Brougham to James Watt jr 1810/02/08, BWA MIV /B7 series 1 part 8 reel 117.

${ }^{284}$ Ewart to James Watt jr 1810/02/18, BWA MIV /E2, AM-IR series 1 part 8 reel 118.

285 Copy of bill and note 1810/03/15, BWA MS 3147/3/481 \#26 and 27, AM-IR series 1 part 14 reel 273. 286 "Gas Light Bill 2nd reading," The Times, Mar 15 1810. "Gas Light Bill presented in the Commons," The Times, Mar 071810. 
The bill passed through the House quietly, moving to the Lords on April 4, 1810,287 where it was greeted by the bitter complaining of the Marquess of Buckingham, who had had gaslight at his home for the past three years, and was unimpressed by the odours. ${ }^{288}$ The passage through the House of Lords was shepherded by the Duke of Athol. There was a brief committee examination on May 18, 1810, which consisted of evidence from Accum and a few tradesman regarding the properties of coal-gas and various byproducts. ${ }^{289} \mathrm{~A}$ delay was prompted at the third reading over concerns that the bill would create a monopoly, 290 but the bill passed on June 1, 1810 without fanfare, almost without comment, in such marked contrast to the previous year. ${ }^{291}$ The bill granted an act of incorporation on condition that $£ 100,000$ was raised, ${ }^{292}$ which took the next two years to accomplish. The king granted the company's charter on April 30, $1812 .^{293}$

287 "Gas Light Bill 3rd reading," The Times, Apr 10 1810. "Gas Light Bill presented in the Lords," The Times, Apr 111810.

288 "Imperial Parliament," Caledonian Mercury, Saturday, April 141810.

289 "Minutes of Evidence taken before the Lords Committees to whom was referred the Bill, intitled, "An act for enabling His Majesty to incorporated by Charter, to be called The Gas Light and Coke Company for making Inflammable Air for the lighting of the Streets of the Metropolis, and for procuring Coke, Oil, Tar, Pitch, Asphaltum, Ammoniacal Liquor, and essential Oil, from Coal, and for other Purposes relating thereto," in HOUSE OF LORDS PAPERS; REPORTS OF COMMITTEES (1810).

290 "Parliamentary Intelligence," The Morning Chronicle, Wednesday, May 231810.

291 "Gas Light Bill introduced in the Lords," The Times, May 12 1810. "Gas Light Bill 3rd reading," The Times, Wednesday, May 23 1810. "Gas Light Bill 3rd reading." "Gas Light Bill 2nd reading," The Times, Wednesday, May 161810.

292 An act [50 Geo.III cap. clxiii] for granting certain Powers and Authorities to a Company, Article III. 293 Recital of the Act for granting certain powers and authorities to a Company to be incorporated, called "The Gas Light and Coke Company", (30 April 1812). 


\subsection{Conclusion}

The Gas Light and Coke Company was the first gaslight utility, and its form, before it ever produced a puff of gas, was ensconced in its charter, which restricted its activity to a certain geographical area, and more importantly, to a certain activity: providing manufactured gas to consumers. The manufacturing of gaslight apparatus for sale was explicitly excluded by its charter. This company was then to become the model of subsequent gaslight companies. It was to a great extent within the GLCC that gaslight as a technology begot gaslight as an industry. The technological ideas and prototypes that Lebon, Winsor, and even Murdock and Boulton \& Watt had developed and deployed were not the technological forms of the gaslight industry of the nineteenth century, which were fundamentally large scale utilities, and it was the GLCC that played the archetypical role. Even if the process of technological development at Boulton \& Watt was undeniably crucial to history of gaslight apparatus before the founding of the GLCC, bequeathing a heritage the GLCC made extensive use of, it was the GLCC that became the centre point of the new industry, not Boulton \& Watt or any other equipment manufacturer. And so the process of formation of the GLCC as a utility, the story of this chapter, is of considerable importance. The battle left a lasting legacy to the GLCC, and the full of effects of the some of clauses in its charter would only become evident as it grew. These are described in the next chapter.

The founding of the Gas Light and Coke Company was a tortuous process that took ten years to accomplish, from Winsor's first experience with Lebon's thermolamp in 1802 , to the granting of the charter in 1812 . This process was primarily a social and political one, driven on one hand by people who did not have the technological 
sophistication of Boulton \& Watt, explicitly so in the case of Grant and the committee, and in the case of Winsor, despite his pretension. On the other hand, the process was outside the control of anyone, being a conflict played out in the press and especially within Parliamentary circles, even if not always in Parliament itself. The prosecution of the company's cause resulted in a conflict with Boulton \& Watt whose ultimate outcome was negotiated in the very midst of the political battle of 1809 , and settled with great calm in 1810. The result was the legal form of the GLCC's charter.

Winsor was irreplaceable in this process, as he managed to create with spectacular success a frenzy of interest, both among the curious and among possible investors, which led to the creation of a powerful group comprising prominent businessmen and nobility, bent on the founding of a gas company, as well as a willing market for the company's gas once it started operation. In this way, Winsor became a point around which a group of investors that eventually became the company and its users coalesced. He was a visionary, one whose vision was not really believed to its full extent by any of his followers, but believed enough due to outside circumstances such as Boulton \& Watt's work to set in motion powerful social forces that soon pushed him aside, and eventually ruined him. 


\section{Chapter 5: \\ The Gas Light and Coke Company}

$\begin{array}{ll}5.1 \text { Introduction } & 428\end{array}$

5.2 A disastrous start 1812-1813 432

5.3 Changing of the guard 1813

5.4 Retrenchment and recovery 1814

5.5 Building a network 1814-1820 476

5.5.1 Retorts and gas generation 477

$\begin{array}{ll}\text { 5.5.2.1 Purification } & 491\end{array}$

$\begin{array}{ll}\text { 5.5.2.2 Purification and pollution } & 508\end{array}$

5.5.3 Gas supply 518

5.5.3.1 Wells, syphons, and valves $\quad 519$

5.5.3.2 Pressure regulation $\quad 526$

5.5.3.3 Leak mitigation

5.5.3.4 Supply management 538

5.6 Opposition from the oil trade 543

5.7 Users 557

5.7.1 Local lighting authorities $\quad 559$

5.7.2 Public buildings $\quad 560$

5.7.3 Shops and houses $\quad 569$

5.7.3.1 Shops and houses: fitters 571

5.7.3.2 Shops and houses: expectations and control 576

5.8 Conclusion 582 


\section{Chapter 5: The Gas Light and Coke Company}

It is a very different thing to make a practical system and to introduce it. A few experiments in the laboratory would prove the practicability of a system long before it could be brought into general use. You can take a pipe and put a little coal in it, close it up, heat it and light the gas that comes out of the stem, but that is not introducing gas lighting, I'll bet that if it were discovered to-morrow in New York that gas could be made out of coal it would be at least five years before the system would be in general use.

---Thomas Edison, quoted in the New York Herald January 30, 1879. ${ }^{1}$

\subsection{Introduction}

When the Gas Light and Coke Company began operating in April of 1812, it was the only gas utility in the world, but it was far from being able to function as one. The little technology it possessed was almost useless for its mandate of lighting streets and homes in London on a large scale. It employed no one with experience in implementing gaslight. Frederick Winsor, the only person who had some practical acquaintance with gaslight, had an uncertain relationship with the company, and even what experience he could offer was of little consequence in comparison with what Boulton \& Watt or Samuel Clegg had achieved. Winsor had never implemented a production gaslight apparatus. He had only ever done what he was really good at: public demonstrations of gas apparatus, and this was a far cry from building a functioning gas utility.

\footnotetext{
1 New York Herald Jan 30, 1879 in Batchelor Scrapbooks: Cat. 1241, item 1119 [TAED MBSB2:110] from http://edison.rutgers.edu/singldoc.htm
} 
The company was not, however, without resources. Thanks to a tremendous expenditure of time and money, the company's promoters had incorporated a joint-stock company with $£ 100,000$ of capital at its disposal and a royal charter to provide light to the streets and buildings of London, Westminster, and Southwark. The immediate legal and financial obstacles had been cleared away.

The next stage in the history of gaslight is the story of the technology's implementation within this corporation, the Gas Light and Coke Company, with its specific legal and corporate form, and within the city of London. The technology had never been deployed as a network utility, as a very large integrated system. It had certainly reached a large scale in some of Boulton \& Watt's customers' factories, but even that was small in comparison what was necessary for the lighting of entire districts with all their streets and buildings. There were still many doubts about just how large the technology could be made. Even the GLCC's original plans called for a plant on every few streets and the idea of building a network that supplied gas to a large part of the city were very new and untested.

The transformation of gaslight technology from the various mill test plants that Boulton \& Watt and other early manufacturers such as Clegg had built into the large network integrated into an urban environment displays the characteristics that Thomas Hughes described in the creation of electrical networks at the end of the nineteenth century. Hughes argued that large technological systems acquire stability not only through internal technological logic, but also by adapting to and changing the social and political environments in which they operate. This same process occurred with the 
development of the new gas network in London. Unlike Edison who looked to gas for inspiration, the builders of the first gas networks had no prior network to use as a model for their own, and they had little idea of the challenges facing them. The first wave of directors who were eventually dismissed failed partly because they had no success in building such a network. The next group of directors succeeded by taking better control of the technological and social aspects of the network.

The process of adapting gaslight technology to these new circumstances, both in terms of scale, but also within the specific human and physical geography of London, changed gaslight technology's form. ${ }^{2}$ The development work done by Boulton \& Watt was indispensable-many of their innovations were adopted by the industry and remained for many years - but gaslight was now to move into a different phase when it became much larger, and adapted to a very different context from the textile mills of northern England. The demands, both human and technological, were different, and this led to a different form for the technology and an entirely new form for the industry.

Technologically, the process of scaling up continued, and many of the problems that Boulton \& Watt had identified and passed over or solved only in part had to be addressed. These included the purification of the gas; retort shape, life span and arrangement; pressure balancing and regulation; gas measurement; pipe maintenance; and others. Within ten years of the foundation of the company, many of these problems had been solved. Had the industry not become a utility servicing industrial and

\footnotetext{
2 Hughes describes this as development. See Thomas Parke Hughes, "The evolution of large technological systems," in The Social construction of technological systems : new directions in the sociology and history of technology, ed. Wiebe E. Bijker, Thomas Parke Hughes, and T. J. Pinch (Cambridge, Mass.: MIT Press, 1987), 62-4.
} 
residential customers, some of problems would not have been sufficiently pressing to warrant the immediate attention they received.

On the human side, the company had to adapt the technology to very different circumstances from what was found in the mills in the North. There the operator and ultimate user were the same: the mill owner. In London, however, the company operated the equipment, but the users were now their customers. The company very quickly realized that they had to deal with many different sorts of consumers in different ways, and in particular, controlling how gas was used, something which mill owners had no problems in doing in their circumstances, became a very important issue for the company. It had to build up methods for control, such as stopcocks, inspectors, and standards. This chapter tells the story of how the almost uncontrolled burning of gas forced the company to change its mode of operations.

Just as the step from the observation that inflammable gases can be had from coal to a gas plant was not trivial, so too the step from a factory gas plant to an urban network represented much development work, something which has been underestimated by some historians. Schivelbusch, when describing this process, wrote that 'the technical principle behind a central gas supply for a whole city is the same as the one behind a thermolamp supplying a single house. The only difference is the size of the system, and the length of the pipes. ${ }^{3}$ In this, however, he is mistaken. While the commonalities are evident, there is a great gulf between the two, and it took the GLCC years to cross it.

\footnotetext{
3 Wolfgang Schivelbusch, Disenchanted night : the industrialization of light in the nineteenth century
} (Berkeley: University of California Press, 1988), 27. 
The story of the GLCC's early years is split into two major parts. The first runs to the end of 1813, and featured the leadership of James Ludovic Grant and James Hargreaves. By their own admission, these men knew little about the technology. They proved unequal to the task of building up the company, and brought it to the very brink of insolvency and complete disaster. At the end of 1813, after an explosion had rocked the Peter Street works, the old Court of Directors were largely forced out and replaced by more competent managers who put the company on solid footing, marking a new phase in the company's history. The new Court, led by the lawyer David Pollock, retrenched and regrouped, before launching into a successful expansion throughout London, founded on much more careful management of the company. The period of weakness, however, allowed competitors to emerge and take parts of London before the GLCC could get there.

\subsection{A disastrous start $1812-1813$}

The first year and a half of the Gas Light and Coke Company's existence was marked by some of the same potent enthusiasm for gaslight that was a feature of the heady days of 1806-7 when Winsor had whipped up a storm assembling supporters and funds. Enthusiasm served the company's promoters well in that period, allowing them to attract attention and money, and eventually sufficient support to receive a bill authorizing a charter. Once the company got its charter in 1812, however, enthusiasm

for the venture was to serve the company's cause less well: it brought the project to the brink of total failure, from which it recovered only slowly. The initial corporate period 
featured frenzied and frenetic activity on the part of the GLCC directors, who scrambled around seeking customers and marketing opportunities, but with no sense of strategy, no business acumen, and little understanding of the technology or how to deploy it on a large scale. By the end of 1813 , the company was almost insolvent, the directors were all ejected, and the shareholders were feeling cheated and despairing. The GLCC had singularly failed to light anything with gas, except a few demonstration lamps around the Parliament buildings. It was also rent by infighting. The solution to this disastrous state of affairs came about only after a new slate of directors was elected that retrenched the company and extricated it from this morass into which the first group had plunged the company.

On April 30, 1812, the Gas Light and Coke Company received its charter from the King, though the Prince Regent. ${ }^{4}$ Some of the members of the committee led by James Ludovic Grant and who had been guiding the political process over the last few years managed to get their names inserted into the charter, ensuring that they would be the directors of the newly formed company. They then began the process of formally launching the company by calling a meeting of proprietors for June $1,1812 .{ }^{5}$ Although there are no surviving records, the meeting seems to have confirmed the committee's transformation into the first directors and the group of nine men took office, with Grant as governor and James Hargreaves as deputy governor. ${ }^{6}$ The lawyer Pedder continued

\footnotetext{
${ }^{4}$ Recital of the Act for granting certain powers and authorities to a Company to be incorporated, called "The Gas Light and Coke Company", (30 April 1812).

5 "Gas Light, May 12, 1812," The Morning Chronicle, Friday, May 151812.

${ }^{6}$ Minutes of the Proceedings of the General Court of Proprietors 1812/06/24 p. 1: London Metropolitan Archives (hereafter LMA) B/GLCC/64/1
} 
his association with the company with an appointment as secretary. The backgrounds of the directors are not easy to determine, but they were not the nobility who figured prominently in the committee, and were likely gentry or industrialists. There were two knights, Sir William Paxton and Sir Charles Cockerell, partners in the same banking firm. Among the rest, many owned homes in both London and elsewhere in the country, indicating substantial wealth. Frederick Accum was the odd man in this group, being a 'practical chemist'.

The managerial style of the first group of directors was chaotic and not concerned with the strategic direction of the company. They were both managing the company and involved in day-to-day operations, in many case personally directing works, and negotiating with customers and suppliers. This personal involvement in the daily matters distracted the directors from the more important job of strategic planning, and their failure in this regard caused the firm serious harm. The impression the minutes of the Court of Directors gives of the first group of directors is that of people who had never really run a large enterprise such as the GLCC, perhaps only being involved with family or small joint-stock firms that could be run and operated by a small group of owner managers.

The task facing the directors was daunting. They had a thicket of obstacles to negotiate, beginning with the political geography of London. At this period, it was a patchwork of local jurisdictions, which encompassed various mandates. Many of the circumscriptions had origins in the Middle Ages, and with the passing of time, their

\footnotetext{
7 Recital of the Act for granting certain powers and authorities to a Company to be incorporated, called "The Gas Light and Coke Company", 2-3. gives a very few details about the directors.
} 
existence outlasted the original logic behind their physical configuration, resulting in sometimes bizarre local divisions. Besides the City of London itself, the most important local entities were the civil parishes, such as St. Pancras and St. Marylebon, but there were also liberties, small zones independent of the parishes originally derived for some special situation, such as the presence of an abbey. In addition, there were many areas which fell under the control of an institution, such as the Parliament buildings, the Tower of London, the Inns of Court, the Foundlings' Hospital, etc. All of these jurisdictions were responsible for providing street light in their respective zone, and, according to the GLCC's act of incorporation, needed to be petitioned before the streets could be broken and mains laid. An added complication was that by the act of incorporation, the company had to offer street lights brighter and cheaper than oil lamps to the municipalities, and could not light buildings without also lighting the surrounding streets. To assemble a large, rationally designed technological system in this labyrinth of jurisdictions and restrictions would have taken a very well laid out and carefully executed strategy. The GLCC, however, had no strategy at all, at least at first.

If the political and business challenges were formidable, the technological ones were also great. Boulton \& Watt, with their years of experience working with technology and with gaslight, struggled to increase the scale of gasworks from Murdock's home lights to the mill-sized apparatus of 1806 and beyond. For the directors of the GLCC, who had very little experience with gaslight technology, moving from Winsor's small demonstrations to fulfilling their mandate of lighting the streets and buildings of London with gas was practically impossible. Lacking a clear strategy of how to proceed, they stumbled along trying many different options simultaneously, causing needless 
expenditures, such as leasing properties and ordering goods in a rush and with no tendering process. The result was that by the end of 1813 , they had acquired a large amount of expensive and almost useless equipment. The uncontrolled purchasing was made all the worse by the prohibition against manufacturing apparatus imposed on them by their charter, stemming from their battle with Boulton \& Watt. The GLCC had to buy everything, and until purchasing was carefully managed (which was not done for the first year) costs would run up unchecked.

The confluence of these factors led to considerable tensions within the company, and eventually with the shareholders. To make things worse, Winsor's own relationship with the company was uncertain. The committee, now reconstituted as the Court of Directors, had diminished Winsor's role in the past four years, and continued to hold him at a distance now that the company was incorporated. Winsor was not made a director nor was he attending the Court's meetings. He was, however, the only person with any experience within the company's circle of acquaintances, and so the directors had little choice but to try to work with him.

The nature of the difficulties the directors experienced suggest that incompetence was not the only reason for their eventual failure. It seems that the business required a more sophisticated management structure than what the first group of directors had experience with. Railways have been identified as catalysts for the development new approaches to business organization and management in the British economy, ${ }^{8}$ and most famously by Alfred Chandler in the rise of the modern corporation with

8 J. F. Wilson, British business history, 1720-1994 (Manchester: New York, 1995), 37-41. 
sophisticated management structures. ${ }^{9}$ To what degree these new approaches in British railways represented a break with the traditional models of management has been debated, and this is not the place to review the literature. ${ }^{10}$ Suffice it to say that whatever aspects of traditional business practices remained in railways, the nature of the technologies they used forced some changes in business practices, such as greater use of salaried professional managers and more developed accounting practices due to the size of the companies. A similar observation can be made about gas utilities. Changes occurred in management practices and business organization driven in part by the nature of the gas utilities' technology, and these changes are revealed in comparing how the two Courts of directors ran the GLCC during their respective stints in control. The second Court was less involved in operations, and instituted more lines of control over purchasing and their contractors, adopted better accounting methods, and worked to follow some strategy in getting new customers and laying mains. The first Court of Directors in contrast were weak in all these areas.

One of the first Court's initial acts after being constituted was, on July 10, 1812, to summon Winsor to present whatever plans he had for lighting a parish and state his

\footnotetext{
${ }_{9}^{9}$ Alfred Dupont Chandler, The visible hand : the managerial revolution in American business (Cambridge, Mass.: Belknap Press, 1977).

${ }^{10}$ Chandler characterized the British business model as personal capitalism because it was dominated by families that maintained control over the firm their ancestors had founded. Management tended to be personal. Alfred D. Chandler and Hikino Takashi, Scale and scope : the dynamics of industrial capitalism (Cambridge, Mass.: Belknap Press, 1990).. For a counterpoint see Geoffrey Channon, Railways in Britain and the United States, 1830-1940 : studies in economic and business history (Burlington, VT: Ashgate, 2001).. See also Maurice. W. Kirby, "Big business before 1900," in Business enterprise in modern Britain : from the eighteenth to the twentieth century, ed. Maurice. W. Kirby and Mary B. Rose (London: New York, 1994)., especially p. 127-133
} 
salary expectations. ${ }^{11}$ After a delay, Winsor gave the Court copies of plans, ${ }^{12}$ which, however, were not sufficiently detailed for the Court to build upon. They asked Winsor whether he had any other plans, as well a series of questions about his proposal, ${ }^{13}$ which Winsor answered in some detail, but mostly by referring the directors to his lectures. ${ }^{14}$ It is clear from the exchange that Winsor's equipment was still not comparable to Boulton \& Watt's, apparently small enough to fit into a house. ${ }^{15}$

Not wanting to be tied to Winsor, the Court launched out in other directions, with some of the directors themselves trying their hand at making gas apparatus. Frederick Accum could at least claim significant experience in chemistry, and he was asked by the Court to do experiments ${ }^{16}$ and to buy two of Winsor's stoves for a plant to be built at 96 Pall Mall, ${ }^{17}$ a house the company had purchased from Winsor. ${ }^{18}$ Accum's plan when it was prepared was rejected because of the cost and the 'delipidations [sic] it would occasion in the House', which the Court thought would 'require the consent of the landlord'.19 Two other directors, James Hargreaves ${ }^{20}$ and James Barlow ${ }^{21}$ also tried

\footnotetext{
11 1812/07/10 Minutes of the Court of Directors Book 1 (hereafter MCD b1) p. 9: LMA B/GLCC/1/1 
doing experiments at the company's considerable expense, but these came to little in the long run, at least for the company's benefit, although both of them pursued careers in the gaslight industry in some way after they left the GLCC.

Accum soon announced he had an alternate plan, this one based on the machinery from 'a Philosopher on the other side of the Water'.22 Who this might have been was never revealed, but since Accum was German and had many contacts in Germany, it could have been Winzler, the only person at this time who was making apparatus of any scale on the continent. In order to investigate the feasibility of Accum's plan, a new committee of chemistry was constituted in November 1812, composed of a few directors. After some back-and-forth between the committee and Accum, and some discussions over the ownership of the idea, the committee, two days after they had been given the Accum's plan, concluded that it was viable and that the company could now advertise for lighting contracts, all without Accum ever having built the tiniest part of the apparatus. ${ }^{23}$ Confident they had no need of him, Winsor was sent a rejection letter by the Court.24

\footnotetext{
22 1812/09/04 MCD b1 p. 28; For some prior discussion, see 1812/08/14 and 28 MCD b1 p. 24, 27; 1812/10/10 and 11/07 MCD b1 p. 37, 40.

23 1812/09/16 MCD b1 p. 45 and Chemistry Minutes 1812/09/16 p. 5: LMA B/GLCC/146.

24 1812/12/11-12 MCD b1 p. 54-5 and 1812/12/04 Chemistry Minutes p. 13.
} 


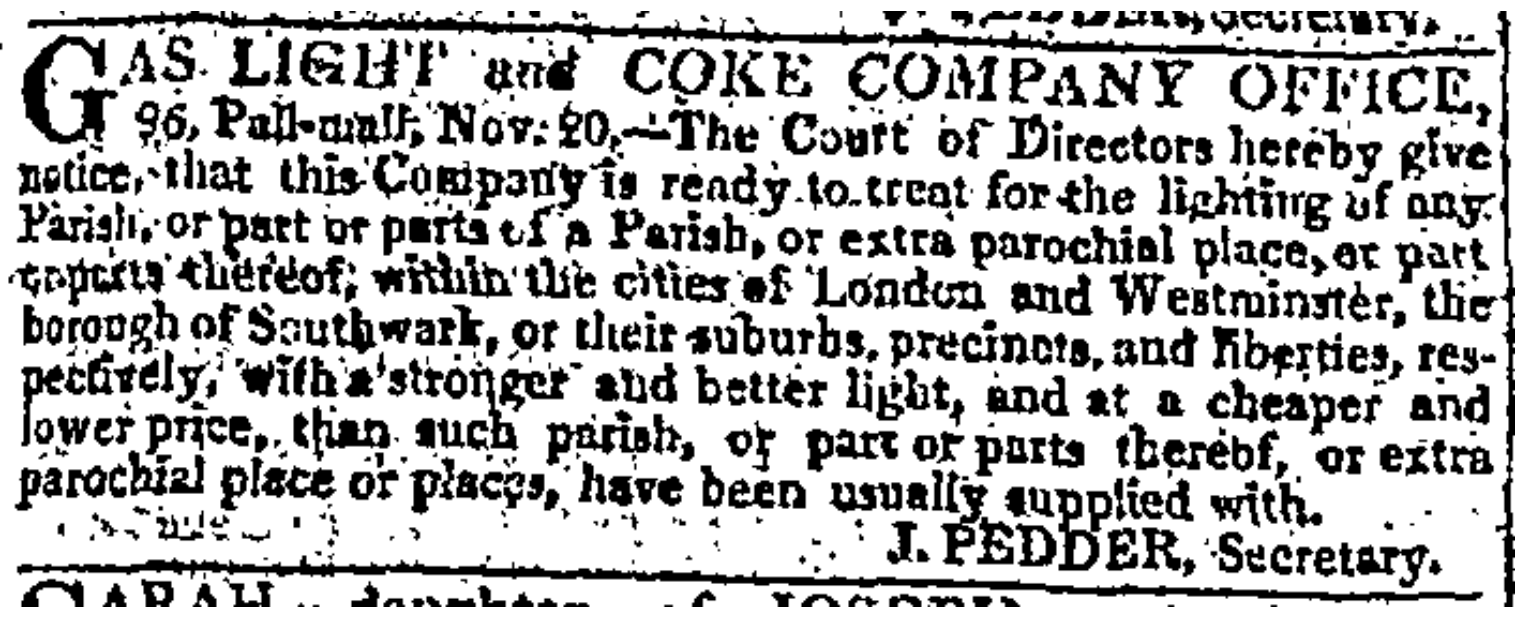

The Times, November 23, 1812

With the furor of the past years still fresh in people's mind, it did not take long for various parties to express interest in lighting with gas. The parish of St. Pancras in the city of Westminster ${ }^{25}$ and the City of London ${ }^{26}$ both sent letters, as did the parish of St. Margaret and St. John, also in Westminster, and the liberty of Norton Folgate, ${ }^{27}$ a tiny administrative unit north-east of the City of fairly obscure origins, perhaps relating to a medieval priory. ${ }^{28}$ There were also discussions with the postmaster general29 begun by the company, as well as with the paving commissioners in the city of Westminster, which the GLCC approached on their own initiative in order to be able to light the Parliament

\footnotetext{
25 1812/11/20 and 12/01 MCD b1 p. 47, 50.

26 1812/11/28 MCD b1 p. 48.

27 1812/12/04 MCD b1 p. 51.

28 "The Manor and Liberty of Norton Folgate," in Survey of London: volume 27: Spitalfields and Mile End New Town, ed. F. H. W. Sheppard (London: Published for the London County Council by the Athlone Press, 1957).

29 1812/12/10 MCD b1 p. 53.
} 
buildings and a nearby house of one of the company's directors. ${ }^{30}$ The offer to Parliament was a marketing move. ${ }^{31}$ The Court, thinking in Winsorite terms, was hoping to provide the Parliament gaslights at no cost, thinking that the public notice given to gaslights from their presence around the buildings would be sufficient to justify the expense. ${ }^{32}$

Among the potentially paying customers, Norton Folgate was the most forward in their application, with most of the rest hesitating. The contract with Norton Folgate was for a mere 50-60 street lamps, quite a small number and one that caused some concern as to whether the contract was worth pursuing. It was decided that the possibility of lighting the houses within Norton Folgate made it worthwhile, and an offer was made. ${ }^{33}$ The directors suggested a 14 year contract (the term required by their charter), whereby the GLCC bound itself to charge $5 \%$ less than oil lamps now and in the future, should the price of oil change. It would be at least six months before the contract was finally signed on these terms, stipulating a price of $£ 1.8 \mathrm{~s} .6 \mathrm{~d}$. per lamp per year. ${ }^{34}$

The contract was to be very much in the Norton Folgate's advantage because in addition to what soon proved to be a great bargain on the yearly fees they did not have to pay any capital costs. The company came to realize (but only after the current Court

\footnotetext{
30 1812/11/07 MCD b1 p. 40 and 1813/12/01 MCD b1 p. 225.

31 1813/02/16 MCD b1 p. 80.

32 1812/11/07 MCD b1 p. 40.

33 1812/12/11 MCD b1 p. 55.

34 1813/05/07 MCD b1 p. 125.
} 
was dismantled) that contracts where the customers paid none of the capital cost of the project would bankrupt the GLCC in short order. At this very early stage, they were still thinking of themselves as a direct substitute for oil lamp contractors, who would tender to light and maintain the lamps in a given parish. Gaslight, because of the infrastructure required to support it, was too different as a business from the oil lamp contractors to be able to function in that way. The GLCC and other gas companies soon started to charge the capital costs of laying mains and installing gas lamps to the parishes and other customers. The advantages of gaslight and their long term economy came to be so well recognized that within a year or two there was no shortage of customers willing to pay these upfront capital costs. For the moment, however, this was not the case, and the GLCC's shareholders paid a steep price for being the first gas utility and having to establish which pricing model worked. 


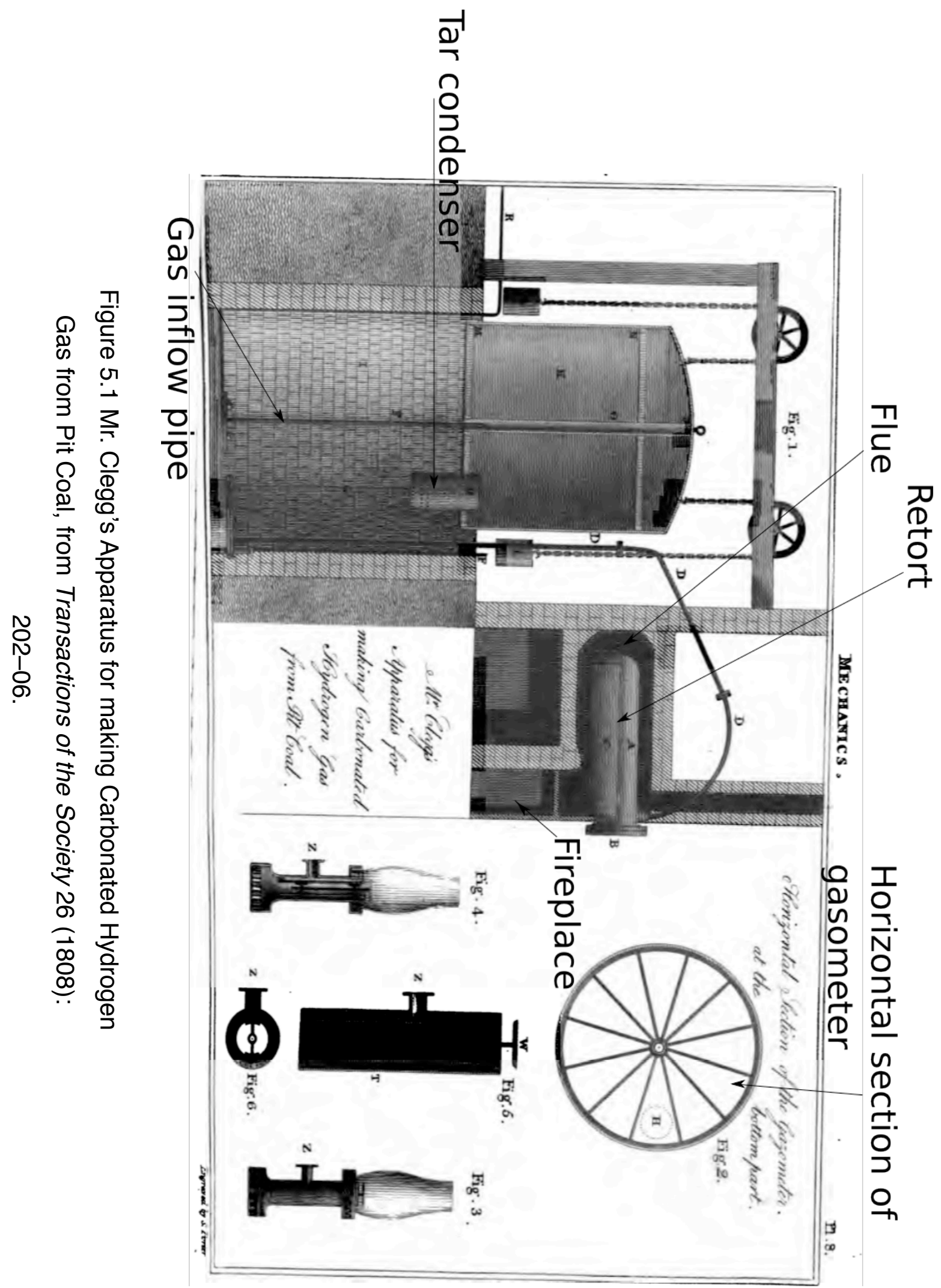


In December 1812 the Court hired Samuel Clegg for the post of company engineer, paying him a salary of $£ 500.35$ Clegg had been involved with gas projects ever since his tenure at Boulton \& Watt, and then independently when he installed a gas apparatus at Henry Lodge's mill near Halifax in 1805-6. He subsequently built apparatus for other mills and for Stonyhurst College in Lancashire, where he worked on lime purification. In 1809 he was awarded a medal from the Society for the Arts for his design of a gas plant, one which was widely reprinted in journals, driven by the contemporary excitement over the gaslight bill. ${ }^{36}$ From there he went on to install gas apparatus at other mills, before going to London in 1812 where he build a gas plant for Rudolph Ackermann's print shop. ${ }^{37}$ Frederick Accum described this plant in great detail in his 1815 book on gaslight. ${ }^{38}$ At this point, Clegg was one the very few gas engineers active, and outside of Boulton \& Watt, the only one with extensive experience in

35 1812/12/11 MCD b1 p. 56.

36 Samuel Clegg, "Improved Apparatus for extracting Carbonated Hydrogen Gas from Pit Coal," Transactions of the Society, Instituted at London, for the Encouragement of Arts, Manufactures, and Commerce 26 (1808).

37 "Materials for a memoir of Mr. Samuel Clegg, and Authentic History of the Art of Gas-Lighting," Mechanics' magazine and journal of science, arts, and manufactures 22, no. 607 (1835). Clegg, $A$ practical treatise on the manufacture and distribution of coal-gas : its introduction and progressive improvement, illustrated by engravings from working drawings, with general estimates (London: J. Weale, 1841), 13-16. William Matthews, An historical sketch of the origin, progress, \& present state of gaslighting (London: R. Hunter, 1827), 52. Samuel Clegg, Description of an apparatus, by which twenty-five thousand cubit feet of gas, are obtained from each chaldron of coal,: without producing either tar or ammoniacal liquor (London: Sold by R. Ackerman ... 1820), 3-5. have details about Clegg's career. Dean Chandler and A. Douglas Lacey, The rise of the gas industry in Britain (London: British Gas Council, 1949). and Arthur Elton, "Gas for Light and Heat," in A History of Technology, Volume IV: The Industrial Revolution c. 1750 to c. 1850, ed. Charles Singer, et al. (Oxford, England: Oxford University Press, 1958). summarize these.

38 Frederick Christian Accum, A practical treatise on gas-light; exhibiting a summary description of the apparatus and machinery best calculated for illuminating streets, houses, and manufactories, with carburetted hydrogen, or coal-gas; with remarks on the utility, safety, and general nature of this new branch of civil economy (London: Printed by G. Hayden for R. Ackermann [etc.], 1815), 166ff. 
gaslight. With Clegg also came in early 1813 some of his workmen from his time before his employment with the GLCC. ${ }^{39}$ This influx of talent and experience gave the company at least some solid footing in the technology, but lacking an effective strategy from the Court, Clegg's experience availed the company little.

39 1813/02/09 MCD b1 p. 77. 


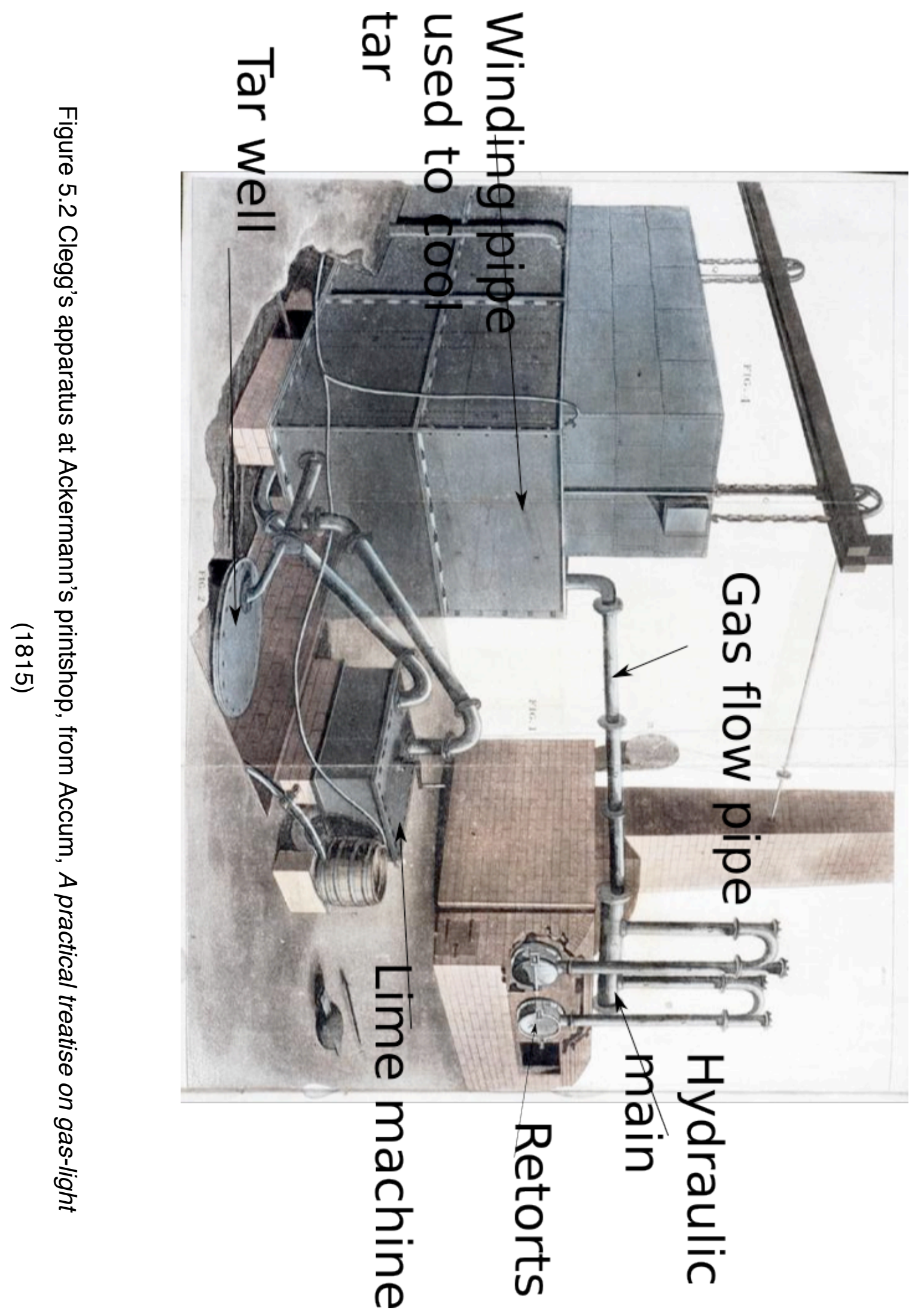


Clegg's hiring brought other, less positive changes. The divisions between the Court and Winsor were growing deeper over time. The Court's initially aloof attitude towards Winsor changed into open hostility once they thought they had no further need of him. Winsor's own financial situation was becoming precarious as many investors who had worked with him directly over the years started making inquiries about where they stood as shareholders in the new company. ${ }^{40}$ Winsor was additionally burdened with properties, such as the two other Pall Mall houses next door to the GLCC offices and a warehouse on Milbank Street, none of which he could afford. ${ }^{41}$ When Winsor started making further inquiries with the Court about his own situation with the company and the agreements that the committee of trustees had made with him prior to the charter, the Court responded that the Court bore no relation to the pre-1812 committee, and did not recognize its agreements. It added further injury by rescinding payment for some stoves it had recently purchased from Winsor on the grounds that their ownership status was ambiguous. ${ }^{42}$ Winsor pestered the Court with letters, which produced only further rejections and payment refusals. ${ }^{43}$ The Court of Directors then took their hostility towards Winsor to the proprietors, when during a general meeting on January 9, 1813,

\footnotetext{
40 1812/08/05 MCD b1 p. 15.

41 1813/02/25 Proprietors p. 10; 1813/03/19 MCD b1 p. 96-8.

42 1812/11/13 MCD b1 p. 43-4.

43 1812/11/20 MCD b1 p. 47. 1812/12/12 MCD b1 p. 55; Chem 1812/12/11 p. 12. 1812/12/22 MCD b1 p. 61.
} 
they publicly stated that the GLCC's business was referable to the charter alone, and not to anything that may have happened before it. 44

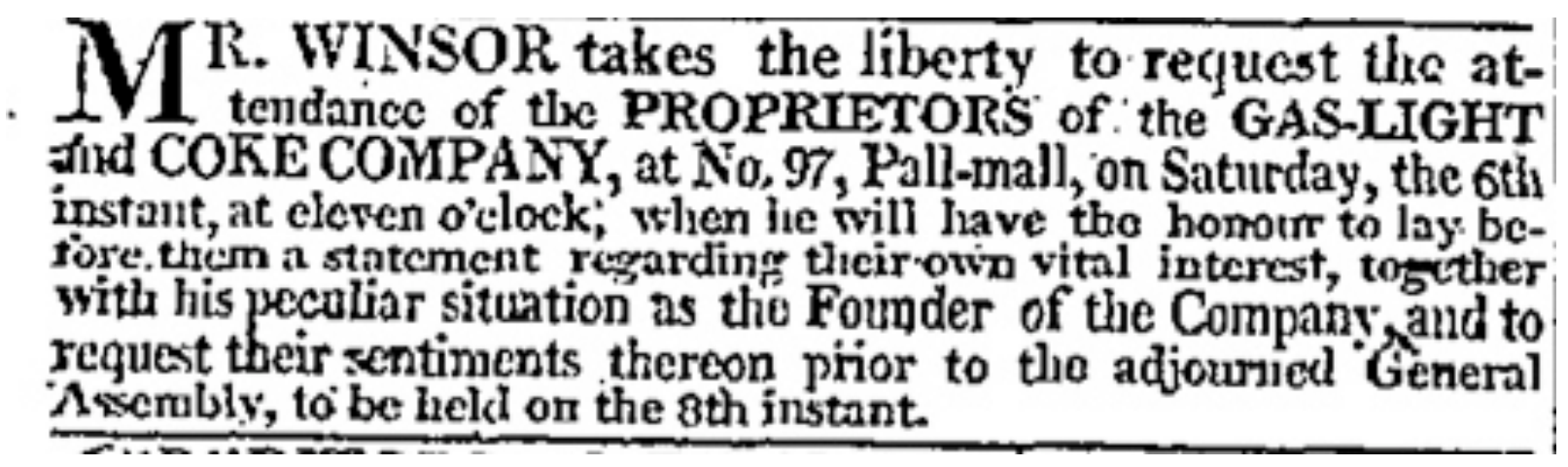

The Times, February 5, 1813

It was now clear to Winsor that he would get nowhere with the Court, and appealed directly to the proprietors by holding a meeting on February 6,1813 at his own home two days before a scheduled meeting of the proprietors. ${ }^{45}$ He presented his version of events to the assembled proprietors, and convinced them of the justice of his claims. The directors responded at the official meeting on February 8,1813 , by attacking Winsor in a public letter read there, ${ }^{46}$ but the proprietors were not so easily convinced and voted to form a specially committee to look into his claims, ${ }^{47}$ headed by

\footnotetext{
44 1813/01/09 Proprietors p. 2.

45 "Mr. Winsor requests attendance of proprietors of the Gas-light and Coke Company," The Times, Friday, Feb 051813.

46 1812/02/09 MCD b1 p. 77.

47 1813/02/08 Proprietors p. 9.
} 
David Pollock, a lawyer with some presence in corporate London. ${ }^{48}$ The committee did its work, and when the proprietors convened once again to hear its report on February 25, 1813, it did not go well for the directors. The Pollock committee vindicated Winsor in all his claims, clearly calling him the 'originator' of the company ${ }^{49}$ and thereby repudiating the directors' stance of a rupture between the company and whatever preceded it. They made a series of recommendations that were clearly a blow to the directors: that Winsor be granted an annuity of $£ 600$ per year, transferable to his wife or son after his death, to provide advice to the company; that he be a paid director; that, once dividends were paid, he receive $1 \%$ of the company's profits to a maximum of $£ 5000$ per year. The committee also made clear that they thought Winsor should be elected a director soon, a step which required him to hold sufficient shares, a condition he did not meet at that point.

The recommendations were to be put to a vote at a May 1813 meeting of the proprietors, but in the intervening months, the Court of Directors' hostility towards Winsor remained unabated. Winsor's financial situation was worsening, and he applied once again to the Court to relieve him of some of the properties he had leased for the cause from 1807.50 The Court on March 19, 1813, once again firmly rejected the idea

\footnotetext{
$48 \mathrm{He}$ was also the son of George III's saddle maker. Jackson's Oxford Journal (Oxford, England), Saturday, December 19, 1807; Issue 2851 refers to his wedding.

The Morning Chronicle (London, England), Saturday, August 25, 1810; Issue 12884 mentions his involvement at the Charing Canal Co. meeting.

The Morning Chronicle (London, England), Monday, November 18, 1811; Issue 13269

Stirling Everard, The history of the Gas Light and Coke Company, 1812-1949 (London: Benn, 1949), 114. Kenneth Hutchinson, "The Royal Society and the Foundation of the British Gas Industry," Notes and Records of the Royal Society of London 39, no. 2 (1985): 260ff. all have more details.

49 1813/02/25 Proprietors p. 10.

50 1813/03/09 MCD b1 p. 19, 91, 96-7.
} 
that Winsor had any claims on the company for those expenses. ${ }^{51}$ This harsh rebuff ended all contact between Winsor and the Court, and desperate for some income, Winsor was forced to begin public lectures at his Pall Mall house, which he now dubbed the National Scientific Institution. He was joined by his son and Frank Hardie, whom he had worked with in 1806, as well as invited speakers. ${ }^{52}$

When the general meeting of the proprietors came on May 17, 1813, the directors moved unsuccessfully to delay the vote on Winsor's remuneration, perhaps hoping that he would go bankrupt soon. ${ }^{53}$ The proprietors sided with Winsor, and all the recommendations were adopted. These resolutions would have made Winsor quite wealthy in a few years' time, but the intervening lean period ruined him before he could benefit from the committee's and shareholders' kindness to him. Immediately after the meeting, the chastened directors sent a letter to Winsor offering to pay the $£ 600$ he had been awarded, but he was still excluded from the company's day-to-day affairs. ${ }^{54}$ The next meeting of proprietors on July 6, 1813 featured an election of new directors to fill two vacancies, to which John Warren, one of the group of shareholders siding with Winsor, as well as Winsor himself were elected. ${ }^{55}$ The proprietors resolved that Winsor's technological plans be considered, ${ }^{56}$ amounting to a definitive reversal of the Court of

\footnotetext{
51 1813/03/19 MCD b1 p 98.

52 "National Scientific Institution," The Morning Chronicle, Thursday, March 25 1813.. See also March 27, 29, 31 April 1, 6. "National scientific institution," The Times, Friday, Apr 16 1813. and April 17, May 1.

53 1813/05/17 Proprietors p. 16-7.

54 1813/05/18 MCD b1 p. 131.

55 1813/07/06 Proprietors p. 18-20.

56 1813/07/22 MCD b1 p. 162.
} 
Directors' view of Winsor's abilities. From then on, in what must have been a strained situation, Winsor started attending the regular meetings of the directors and being involved in the daily affairs of the company. The original directors, led by Grant, still did not show interest much in Winsor's technology although ordered to do so on a number of occasions by the shareholders. ${ }^{57}$

This year long conflict was about more than simply friction between the eccentric Winsor and the Court of Directors led by the sometimes abrasive Grant. It saw the proprietors publicly doubt the judgement of the directors, eventually overruling them, and laid seeds of further doubts in the proprietors' minds, doubt which became alarm in the last half of 1813. The original committee looking into Winsor's claims in effect became a dissident group of shareholders, which by the end of 1813 forced out the directors once the extent of the technical and business debacle became clear. The first of the dissident shareholders to become a director was Warren, but more would follow.

All the while the battle with Winsor was raging, the company continued its mostly strategy-less activity. Accum, Barlow, Clegg and Hargreaves were all working on unrelated apparatus in various ways. Clegg was building a fairly small plant at the company's wharf property on Cannon Row, while the rest were building or designing various parts or systems on their own. At the beginning of 1813 , the company still had little idea where it would start providing gas lights, other than free ones around Parliament. The various attempts at finding customers or even volunteers continued with no geographical coherence among the possible users. The company negotiated

57 1813/11/01 Proprietors p. 25; 1813/07/22 MCD b1 p. 162; 1813/11/02 MCD b1 p. 209. 
intermittently with the Theatre Royal on Drury Lane, and looked to lease land next to it for a plant. 58 They offered to light Berkely square gratis, which was accepted, but as with the theatre, they had no idea how or where the gas could be generated. ${ }^{59}$

58 1813/02/16 MCD b1 p. 81; MCD b1 1813/05/06 p. 124.

59 1813/05/04 MCD b1 p. 123; For negotiation with theatres, parish of St. Margaret's, and Berkley square for free, see MCD b1 p. 80-3. For the Drury Lane Theatre see MCD b1 p. 81, 85, 87 and 116. 


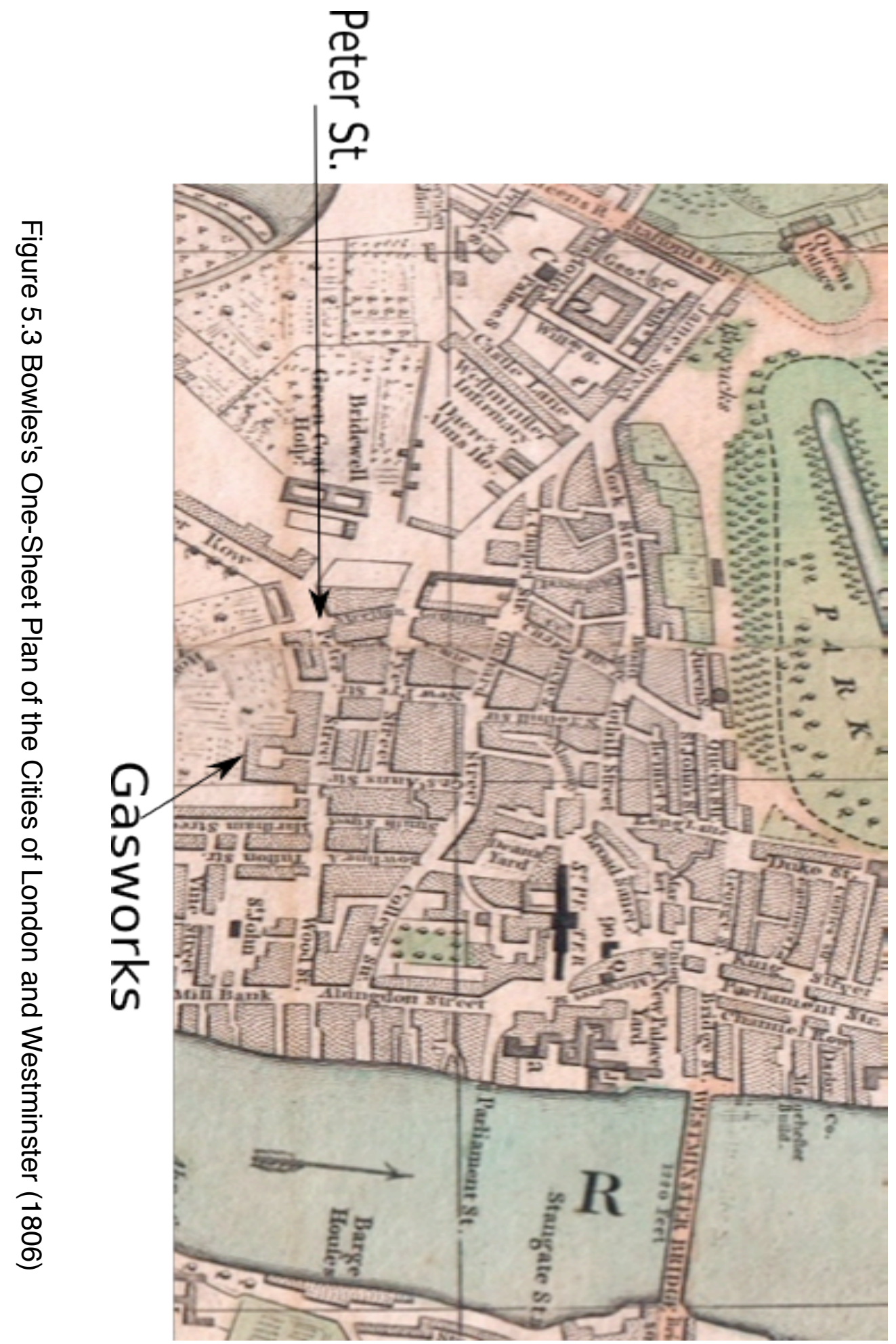


The directors did, however, make some steps in 1813 that would bring the company a permanent base and the beginnings of a viable plan. On February 19, 1813, the company purchased large plot of land on the south side of Great Peter Street in Westminster from one of its own directors. ${ }^{60}$ The lot was well located, close to some of their potential users such as the Parliament buildings, ${ }^{61}$ but farther from the water than their Cannon Row lot, which posed problems for receiving coal and disposing of waste, as they would discover. Given the advantages of the new site, the plant at the wharf in Cannon Row, purchased a few months previous at the cost of $£ 1700^{62}$ was abandoned and put up for sale, ${ }^{63}$ and what little apparatus was salvageable was transferred to the Peter Street location. Hargreaves was given direction of the plant at Peter Street, with Clegg working under him, ${ }^{64}$ and Clegg was asked to prepare plans and estimates for laying pipes in the streets to be served from the new plant site, beginning at the station to the yards and roads around the Parliament buildings. ${ }^{65}$ The company then applied for 66 and received permission in late May 1813 from the parish of St. Margaret and St. John, under whose jurisdiction lay most of streets on the line to the Parliament, to place their mains under the pavement. ${ }^{67}$

\footnotetext{
$601813 / 02 / 19$ MCD b1 p. 82; 1813/03/04 MCD b1 p. 90.

61 1813/03/04 MCD b1 p. 90.

62 1812/07/31 MCD b1 p. 14.

63 wharf 1813/03/24 MCD b1 p. 99; 1813/04/20 MCD b1 p. 117.

64 1813/04/15 MCD b1 p. 116.

65 1813/03/25 MCD b1 p. 100.

66 1813/03/05 and 16 MCD b1 p. 90, 94.

67 1813/03/25 MCD b1 p. 100; 1813/05/25 MCD b1 p. 133; also the secretary of the Treasury had to given permission. See 1813/04/06 and 06/04 MCD b1 p. 110 and 138.
} 
The work at the Westminster site proceeded rapidly enough with Clegg working there that by August 1813, the company was finally ready to lay pipes, and even suggested putting them above ground at the Parliament buildings. 68 Posts for 25 lamps were ordered on August 20,1813,69 and sometime in September, more than a year after it had been incorporated, the company managed to provide its first gaslights. ${ }^{70}$ The Court did not, however, record the exact day in the minutes. The first paying contract that the company actually fulfilled was with the church of St. John, just down the street from the Peter street works. As the pipes to Parliament were to pass by the church, the directors approached the church and people living on those streets, offering them gaslights. ${ }^{71}$ The church vestry was interested, and after some negotiations, the two parties came to an agreement in November $1813 .{ }^{72}$

\footnotetext{
68 1813/08/10 MCD b1 p. 171.

69 1813/08/13 and 20 MCD b1 p. 173 and 176.

70 Everard, The history of the Gas Light and Coke Company, 1812-1949, 35.. I can find no evidence for exactly when the lights were turned on.

71 1813/10/12 and 14 MCD b1 p. 198-9; 1813/11/19 and 23 MCD b1 p. 220 and 222.

72 1813/11/23 and 26 MCD b1 p. 222-3.
} 


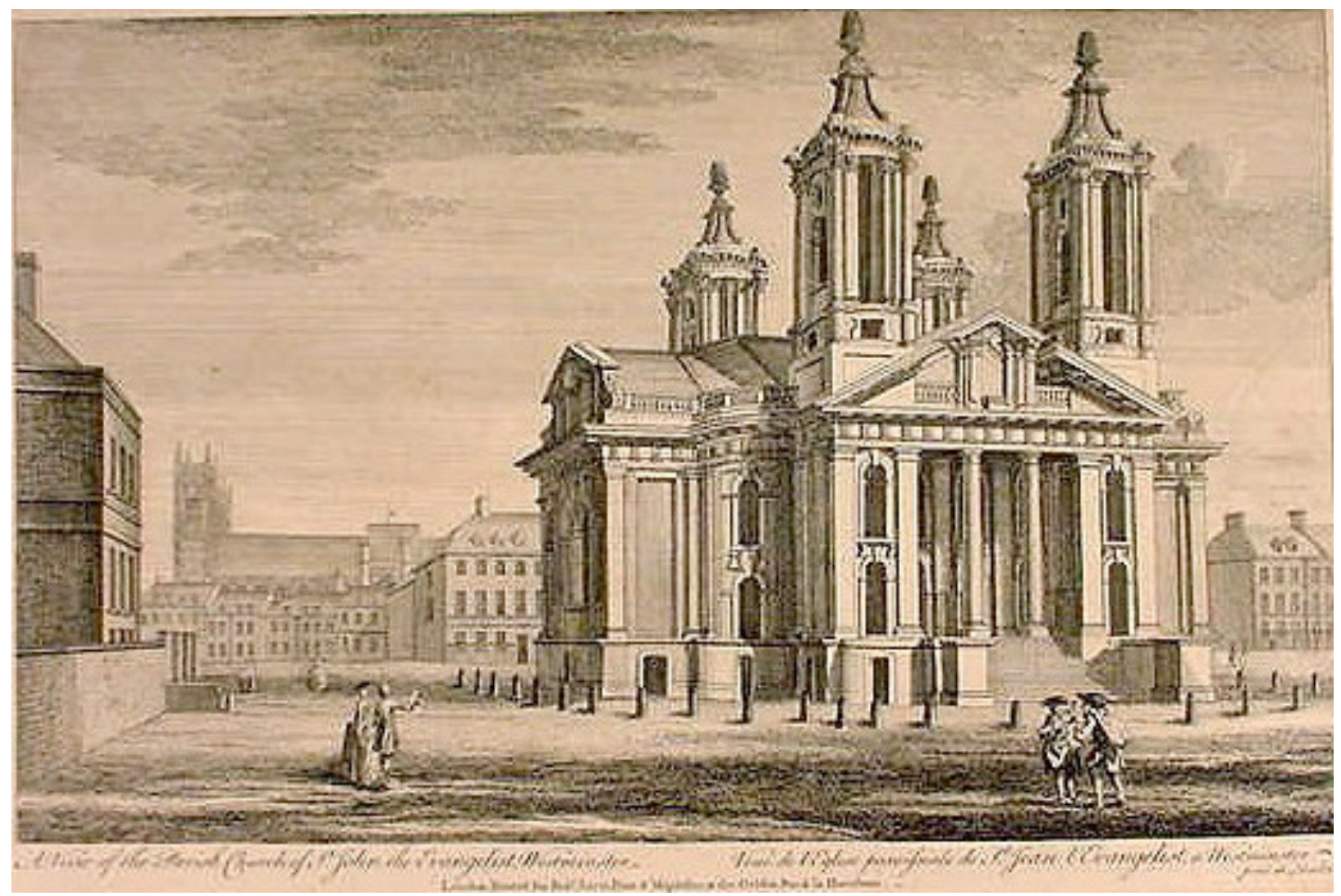

Figure 5.4 St. John's church in the eighteenth century

On the east end of the city, the negotiations for the Norton Folgate contract, begun in 1812, dragged on for the first half of 1813 over minor technical points, before the contract was finally signed on May 7 , binding the company to begin providing gaslight on September 29 of the same year, a wildly optimistic-not to say foolhardy in the extreme-move on the part of the directors, given that they had not yet acquired land in the area to build a plant. ${ }^{73}$ Accum and others had been looking for some time, as early as December $1812,{ }^{74}$ but it was only in early June 1813 that they found and leased a

73 1813/03/13 MCD b1 p. 92 and 1813/05/07 MCD b1 p. 125.

74 1812/12/12 MCD b1 p. 56-7 and 1813/04/13 MCD b1 p. 115. 
small lot at 74 Curtain Road, ${ }^{75}$ followed by a second adjoining one. ${ }^{76}$ This left the company barely over three months to get a plant in operation, which of course created panic. Accum was give charge of directing work at the new plant, and as in so many other moments, the work was rushed and chaotic, with orders for materials and parts given with no tendering. During the construction, Accum complained repeatedly to the Court that people unconnected to the company were entering the grounds for unknown reasons. ${ }^{77}$ Despite the rush, Accum still managed to convince the Court that to try an experimental set of retorts at Curtain Road. ${ }^{78}$ The urgency also caused some of the work to be poorly executed. In September, the gasometer cistern collapsed during construction, ${ }^{79}$ and Clegg was called in from Peter Street to take care of repairing it. ${ }^{80}$ The result was that the apparatus was nowhere near being ready when the contract was due to begin on September 29, 1813, and the company had no choice but to provide oil lamps for Norton Folgate at the company's expense. ${ }^{81}$

The Folgate fiasco was a part of the broader crisis in the company that had been slowly building from the beginning of 1813 , founded ultimately on their ignorance about the basics of gaslight. By July, the directors were starting to feel distinctly uneasy about the progress of their two plants. Perhaps realizing no one had yet sized or designed a

\footnotetext{
75 1813/05/28 and 06/08 MCD b1 p. 135, 9.

76 1813/07/15 MCD b1 p. 155.

77 1813/07/26 MCD b1 p. 165; 1813/10/07 and 08 MCD b1 p. 196, 197.

78 1813/10/14 MCD b1 p. 200.

79 1813/09/03 MCD b1 p. 181; 1813/10/15 MCD b1 p. 201.

80 1813/11/13 MCD b1 p. 217.

81 1813/09/23 MCD b1 p. 191.
} 
plant nor a distribution system with any specifics in mind, they finally resolved to come up with a plan to do so. It seems, however, that this was done with no prior work to estimate the potential load on the station, and so the directors gave an arbitrary figure for the production capacity of $60,000 \mathrm{ft}^{3}$ per day. The directors turned to Winsor to present a plan based on this figure, partly on the insistence of the shareholders, ${ }^{82}$ but Winsor was not really capable of producing such a plan. A little over a month later in September 1813 , it had finally become clear even to the directors that they had never understood the basics of the technology sufficiently to be able to make decisions about the scale of works and machinery. They then put together a list of very basic questions such as how much coal is needed to charge retorts and how much gas is produced, which a new committee was supposed to answer. ${ }^{83}$ These were questions Boulton \& Watt had investigated repeatedly over several years, and now the directors, having practically no industrial experience, hoped to recreate the results in the midst of accepting contracts that were to begin very soon. In fact, the committee never really managed to produce any meaningful answers, and although more people were added to the committee on September 23,1813 , they never reported back. ${ }^{84}$ In terms of the technical details of the gasification process, they were not even certain about whether to use lime purification, an invention that their own engineer had come up with, but also something which Winsor was set against. ${ }^{85}$

\footnotetext{
82 1813/07/22 MCD b1 p. 162.

83 1813/09/02 MCD b1 p. 180.

84 1813/09/23 MCD b1 p. 191.

85 1813/07/29 MCD b1 p. 166.
} 


\subsection{Changing of the guard 1813}

The committee that had looked into Winsor's claims and repeatedly overruled the Court of Directors in the first half of 1813 never really disbanded, although they ceased to be an official committee. They first approached the directors in April to talk about the state of the company and in particular about who could be a director as well as about directors' salaries. The directors answered after a month's time by referring the proprietors to the charter and the company's by-laws. ${ }^{86}$ In May 1813, these same shareholders requested permission to visit some of the works in progress, which they were granted. ${ }^{87}$ What they saw there did little to reassure them that the company was in good hands, and they started to get involved in the company's business. For example, they requested and received permission from one of the local paving authorities around Norton Folgate to lay pipes, something that was useful and accepted by the directors. ${ }^{88}$

In July 1813 , they became concerned with the progress of the Curtain Road station, indicating to the directors that the excavations were unstable and had partly collapsed, damaging a neighbouring house. ${ }^{89}$ Thomas Livesey, an important member of the group, further added in a letter that the expenses were out of control, with purchases being made at $20-50 \%$ premiums over what could have been easily obtained. The directors looked into the matter further, and on the charge of wasteful

\footnotetext{
86 1813/04/13 and 15 MCD b1 p. 115-6; 1813/05/14 MCD b1 p. 128.

87 1813/05/11 MCD b1 p. 127.

88 1813/07/01 MCD b1 p. 149.

89 1813/07/15 and 17 MCD b1 p. 155, 157.
} 
expenditure, it turned out that Livesey had made the accusation mostly out of indignation at the perceived inefficiencies, because he could produce only a single example of extravagant expense. The directors then dismissed the complaint and vindicated Accum who was in charge of Curtain Road. 90

Suffering this small tactical defeat, the concerned proprietors then held back for a few months, but they were by no means satisfied that the directors were competent in their work. Affairs came to a head once again, when, on the night of October 25, 1813, there was an explosion at the Peter Street works. The explosion occurred because a damaged gasometer and purifier started leaking gas when the lime water was being replenished, and when the escaped gas came into contact with a flame somewhere, it exploded. Clegg was present at the time and was badly burnt. ${ }^{91}$ The newspapers carried many reports about the explosion, and the directors sent a letter to them explaining what had happened and trying to reassure the public that everything at the works was safe..$^{92}$ It was with the shareholders, however, that they had the most problems. They immediately received a letter from 54 of them, demanding that a

\footnotetext{
90 1813/07/15 and 17 MCD b1 p. 155, 157; 1813/07/17 MCD b1 p. 160.

91 Joseph Banks, "Report of Royal Society on Gas-Lights; Report of Inspectors on Gas-Light Establishments in the Metropolis," in HOUSE OF COMMONS PAPERS; ACCOUNTS AND PAPERS (London: House of Commons, 1823), 4.; Matthews, An historical sketch of the origin, progress, \& present state of gas-lighting, 67-68.; 1813/11/02 MCD b1 and 09 p. 207 and p. 212-3; 1813/11/01 Proprietors p. 24; "Minutes of Evidence taken before the Lords Committees to whom was referred the Bill, intitled, "An act to alter and enlarge the Powers of Two Acts of His present Majesty for granting certain Powers to the Gas Light and Coke Company," in HOUSE OF LORDS PAPERS; REPORTS OF COMMITTEES (1816), 8-9.

92 1813/10/27 MCD b1 p. 203.
} 
special committee determine if the directors still held the confidence of the proprietors, and a general meeting was called for November 1, 1813.93

93 1813/10/29 MCD b1 p. 205. 


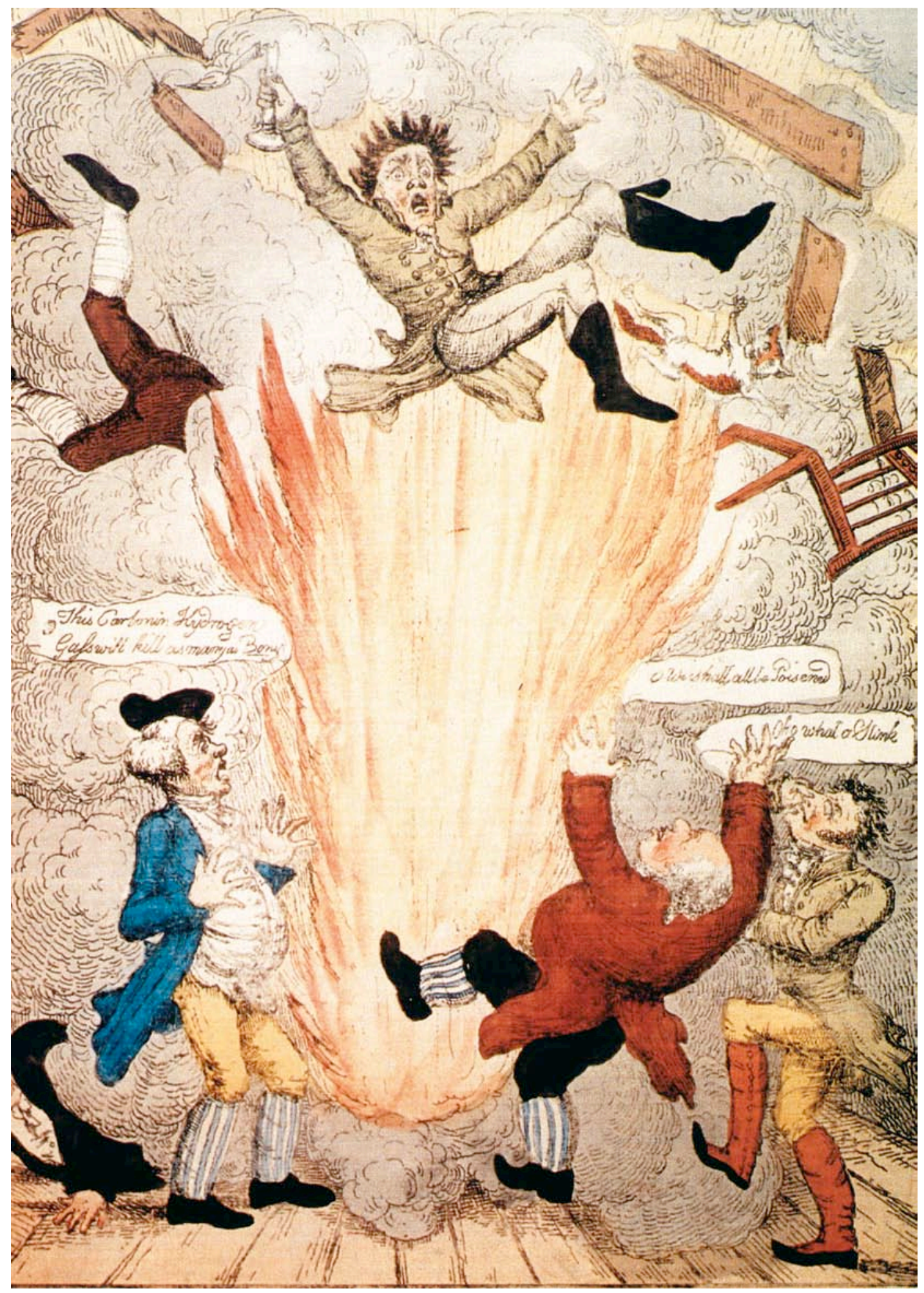

Figure 5.5 The Blessed Effects of Gas Lights or a new method of Lighting as practised in Great Peter Street, London.' published by S W Fores (50 Piccadilly) 10 November 1813. 
The meeting began with the election of David Pollock the dissident shareholder as a director. After a report on the accident was delivered, James Ludovic Grant offered his resignation, perhaps as a bluff, together with that of the entire board of directors. These were accepted effective the next general meeting. ${ }^{94}$ Grant had done this in a way that typified how the company's affairs had been run: he had not bothered to consult the other directors, and they mostly repudiated the resignations over the succeeding days, eventually including Grant himself. ${ }^{95}$ Accum, however, resigned, clearly feeling exhausted by the experience of the last year and a half. 96 When the next meeting took place of November 30,1813, the special committee appointed at the previous meeting reported their findings of the company's affairs. They stated that the expenses were out of control, and gave many examples of wasteful practices and incidents. These included the 'wholly useless' property at Cannon Row; the use of brick construction when wood would have sufficed, incurring $£ 3000$ in extra expense; not consulting an engineer when items were purchased; not keeping a proper paper record for purchases; the lack of clarity in regard to purchasing authority; no foremen used at works.

Although Grant was not forced out at this meeting, the report had been a damning indictment of his tenure as governor, and his position was precarious. He resigned a few days later on December 10, 1813, 'on account of indisposition in his family', ${ }^{97}$ which was not, however, merely a pretext, as his wife died in January $1814 .{ }^{98} \mathrm{He}$ and

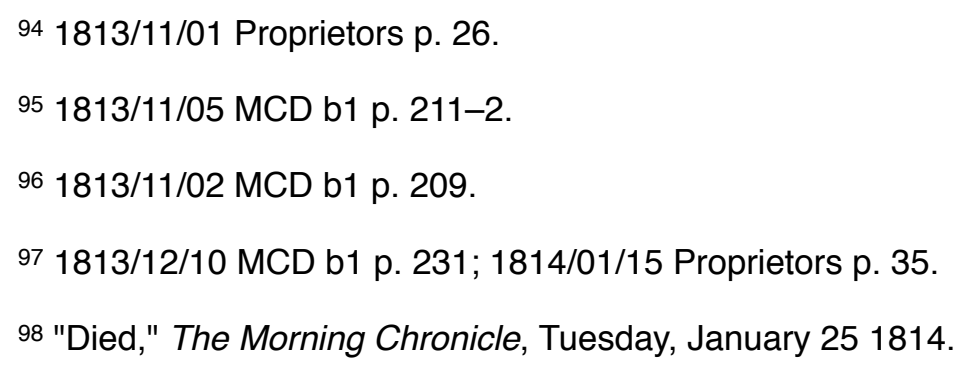


Hargreaves joined the City of London Gas Light Company in June 1814, but were both forced out again the following year. ${ }^{99}$ The gaslight experience had turned into a very bitter one for Grant. He had put enormous time and resources into making the company work, and was finally ejected from the project he had devoted himself to over the last six or seven years. He was also financially troubled. His niece recounted many years later in her memoirs that Grant's house in Southampton was auctioned off not long after the incident. 100

With Grant and Hargreaves (who was disqualified after he sold his shares ${ }^{101}$ ) out of the picture, the special committee had control of the company, and their first task was to stave off its complete destruction. By the end of November 1813, its funds were almost completely exhausted. It had burned through the first deposit of the subscribers, as well as a $£ 10$ capital call on all shares payable on May $5,1813.102 \mathrm{~A}$ second $£ 5$ call was announced for November 1813 , but many shareholders were reluctant to pay it, feeling that at this point, they were throwing money away. Pollock pleaded with the shareholders to pay the call, stating that without it, 'the welfare of the concern and the charter itself will be hazarded, and the past great Expenditure rendered nugatory. ${ }^{1}{ }^{103} \mathrm{He}$

\footnotetext{
99 Joseph Nightingale, London and Middlesex; or, An historical, commercial, \& descriptive survey of the metropolis of Great-Britain: including sketches of its environs, and a topographical account of the most remarkable places in the above county, 4 vols., vol. 3 (London: Printed by W. Wilson, for Vernor, Hood, and Sharpe [etc.], 1815), 748.

100 Amelia M. Murray, Recollections from 1803 to 1837 : with a conclusion in 1868 (London: Longmans, Green, 1868), 45-7. It may have been this house: "Sale by Auction. A Freehold and Copyhold Estate," The Morning Chronicle, Wednesday, June 161819.

101 1814/01/15 Proprietors p. 35.

102 1813/03/29 Proprietors p. 13.

103 1813/11/30 Proprietors p. 28-9.
} 
was confident that with a retrenchment in the company's operations and expenses, it would not only survive the current crisis, but also begin prospering, if only the shareholders supported it by paying the further call.

Despite the GLCC's very public difficulties, interest in gaslight continued to be strong. It was not only in London where it was being implemented, and even in London, prominent places such as Ackermann's shop gave the public a fairly constant example of how it could work. Even in the depths of its troubles, the company received numerous expressions of interest from various sides, such as businesses or individuals seeking gaslight for their homes.104 The parish of St. Margaret and St. John continued negotiating with the company despite the explosion, and signed a contract with the GLCC on November 4, 1813, right after the explosion at the Peter Street works, to provide some lamps on its streets. ${ }^{105}$ Work to lay pipes and install lamps continued through the rest of the year. ${ }^{106}$ The contract with the St. John's Church was finalized on November 26,107 and the lamps were soon burning from 10 am every Sunday morning, making the church the first paying customer the company had. 108 The parishioners suffered from their church's willingness to try such a new technology when a 'disagreeable effluvia' issued from the lamps. The company tried to solve the problem

\footnotetext{
104 1813/12/17 MCD b1 and 21 p. 234 and 237; 1814/01/04 MCD b1 p. 246.

$1051813 / 11 / 05,19,23$, and 26 MCD b1 p. 211, 221-3.

106 1813/12/03, 10 and 21 MCD b1 p. 227, 231 and 238.

107 1813/11/04 MCD b1 and 05 p. 210-1.

108 1813/12/10, 21 and 24 MCD b1 p. 231, 237 and 241.
} 
by using Cannel coal, which Lee had also identified as a low-sulphur variety, ${ }^{109}$ but at least one further complaint about odours was received from the church. ${ }^{110}$

\subsection{Retrenchment and recovery 1814}

Once Pollock, Livesey, and the other dissident shareholders had taken control, they pursued a policy of cutting back and stabilization, with a view to expanding once current customers were supplied on a consistent basis. The rejuvenation program was divided into two somewhat overlapping stages. The first included the restructuring of the company's management that started with new directors, and the second was the devising and implementation of a more coherent plant for the technology itself. The general meeting of proprietors of January 7,1814 marked the beginning of this program. Grant having left in December, Pollock and the others did a thorough assessment of what had happened over the course of the past year and a half. They reported that the company had entered a 'state of apathy and torpor on one hand, and heavy expenditure and unprofitable experiment on the other'. The new Court was faced with 'very peculiar disadvantages and difficulties', which were 'neither few nor small'. The Peter Street works were running up large bills, which the directors had tried to rein in by cutting off the free lights they had been providing to Parliament once the session ended in mid December. ${ }^{111}$ Of the two contracts to be serviced by that station, only the church of St. John's was being fulfilled. The lighting of parts of the parish of St.

\footnotetext{
109 1814/01/07 MCD b1 p. 249.

110 1814/02/22 MCD b1 p. 274.

111 "Gas Lights discontinued," The Morning Chronicle, Monday, December 20 1813., 1813/12/14 MCD b1 p. 232
} 
Margaret were to have started on December 25, 1813, but the company had missed the deadline, ${ }^{112}$ and the Court believed it would not be prudent to start lighting despite having some functioning apparatus. They were afraid, based on Clegg's advice, that with only a single gasometer, the danger of the lights going out was too great. It was better to suspend the contract than to run the risk of a gas failure. ${ }^{113}$

The situation at Curtain Road was even worse. The site had been acquired later than the Peter Street works, and was not ready for making gas. As at Peter Street, only one gasometer had been finished, and a recommendation made in October 1813 to build a second one was seemingly ignored. Worse still than all the delays at the two stations was the lack of any complete plan for the apparatus.

There were, however, some hopeful signs. Many requests for gaslight had been received. A petition had also been made to Parliament to amend the company's charter, specifically to remove the requirement to provide street lighting before the houses on a given street could be lit. Once this was removed, it would free the company's hands to find many new customers, without having to negotiate with the sometimes prickly local authorities. ${ }^{114}$

Changes came quickly following the January 1814 meeting on every level. An experienced accountant, Lonkin, was hired to look over the books to bring them up to

112 1814/01/07 Proprietors p. 32.

113 There are many references in history of gaslight to the commencement of lighting on Westminster Bridge on the night of December 31, 1813. There is no contemporary evidence for this, and the directors report of January 7, 1814 contradicts it: the minutes make clear that St. John's church was the only customer the company had. MCD b1 p. 262. In fact, the commissioners inquired about lighting the bridge in July 1814, see MCD b1 p. 383 . Samuel Clegg jr. was the first to make the 1813 claim.

114 1814/01/07 Proprietors p. 32. 
date, ${ }^{115}$ and he went through all the company's prior finances. He worked with a special committee of accounts which delivered its report on April 26, 1814. The committee had found little evidence of fraud, but made a series of important recommendations for the company's bookkeeping, such as what sorts of accounts should be used, and the adoption of double-entry accounting. ${ }^{116}$

The company's works also progressed more evenly in the first half of 1814 . Its mains were extended from where they ended at the Parliament buildings up Whitehall to Charing Cross, which was to become the most important point of divergence for the company's mains. In a few years' time, important feeder mains would spread from a large cylinder installed at Charing Cross along the Strand, Pall Mall, and other nearby streets. The apparatus at the two stations were completed with the extra gasometers Clegg had recommended, and by April 1814, the company was able to discontinue the oil lamps and begin supplying gas to Norton Folgate and the parish of St. Margaret's. ${ }^{117}$

The company worked on improving the design of the gasworks. Many of the old retorts were judged 'extravagant' and abandoned, probably because they were too big and were conical, a shape never used elsewhere. ${ }^{118}$ In January 1814, Clegg tried a new

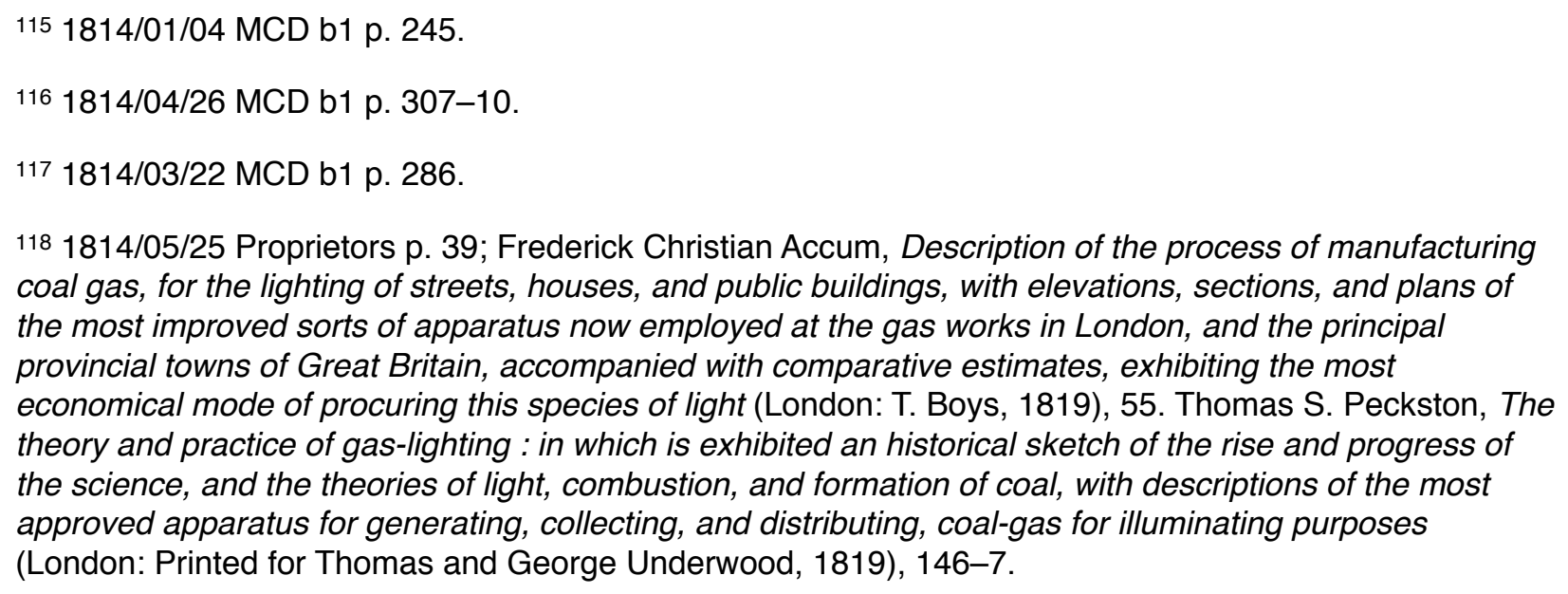


plan for the retorts, heating four of them at once with a single fire, with two rows of two retorts sitting one on top of the other. ${ }^{119}$ This was done to increase the fuel efficiency, or the carbonization ratio, a recently minted parameter which was the proportion of coal burned to the quantity gasified. In the first year, this ratio was measured at $100 \%$, meaning the company was burning as much coal as it was gasifying, a sure sign that their retorts were too large. The first tests of the new retorts setting in January 1814 immediately brought a decrease of the ratio to $45 \% .^{120}$ Further improvements were to come, and the new Court of Directors reported in May 1814 that with careful management and the arrangement of the new retort (referred to as setting), they had managed to bring the carbonization ratio down to $20 \%$, an improvement of over $70 \%$ from the previous settings. ${ }^{121}$ They thought they could have found even further improvements, but the extreme cold of the winter had hampered their abilities to experiment as the water in the cistern below the small gasometer used for experiments froze regularly. ${ }^{122}$ There was in fact much more experimental work to do. The validity of these carbonization figures is suspect, as later work would show, but they had undoubtedly squeezed out greater efficiencies. In addition, the directors admitted they still did not know how much gas was being produced from a given quantity of coal in their production retorts. The gasometers were simply too leaky to be able to come up

\footnotetext{
119 1814/01/07 MCD b1 p. 248; Folgate 1814/03/01 and 25 MCD b1 p. 278, 287; 6 old ones reset 1814/02/08 MCD b1 p. 266.

120 1814/01/28 MCD b1 p. 257-8.

121 1814/05/25 Proprietors p. 40, 42.

122 1814/05/25 Proprietors p. 39; 1814/05/06 MCD b1 p. 318.
} 
with a reasonably accurate figure. ${ }^{123}$ Until they had some idea, they could not really find out what the gas they were selling to their customers actually cost them. ${ }^{124}$

The interest in gaslight was quite intense, and the company had relatively little difficulties in finding new customers. In January 1814 , the company approached the Treasury Board about providing gaslight for the medieval Westminster Hall in the Parliament buildings, this time for a fee. ${ }^{125}$ The Board was interested, and after the company sized the room and sent the estimate to the Board, an agreement was reached. The company would replace the existing 74 oil lamps with 14 gaslights which would give twice as much light, for a yearly cost of $£ 206 . .^{126}$ The fittings cost $£ 103$, although it is not evident from the minutes whether this was paid by the Treasury Board. ${ }^{127}$ Although there were no other new customers paying for gas in the first half of 1814 , the directors were able to report that they had been received £108 on the GLCC's four contracts (St. John's Church, Norton Folgate, St. Margaret's parish, Westminster Hall). ${ }^{128}$ The new customers were coming, however, especially for street lighting. In April 1814, the parish of Shoreditch next to Norton Folgate indicated to the company that they wanted to have all their street lamps, about 1000 in total, replaced with

\footnotetext{
$1231813 / 12 / 28$ MCD b1 p. 242; Lewell hired to do investigations 1813/12/10 MCD b1 p. 232; full report on coal usage needed 1813/12/24 MCD b1 240; Lewell's report 1814/01/04 and 07 MCD b1 p. 245, 249; Winsor estimated cost for home lighting 1813/12/17 MCD b1 p. 235; Winsor was asked to come up with table of fees for home lamps 1813/12/21 MCD b1 p. 237.

124 1814/05/25 Proprietors p. 40.

125 approach made $1814 / 01 / 18$ and 28 MCD b1 p. 250, 258-9; agreement 1814/02/15 MCD b1 p. 268; 1814/03/01, 04 and 18 MCD b1 p. 278, 279, 284-5; Millbank lamp added 1814/11/18 MCD b1 p. 485.

126 1814/02/04 MCD b1 p. 262-3.

127 1814/02/18 MCD b1 p. 270.

128 1814/07/05 MCD b1 p. 366.
} 
gaslight. ${ }^{129}$ St. Luke's parish likewise entered into negotiations with the GLCC. ${ }^{130}$ The company signed a contract to light Cornhill in May for $£ 130$ per year, ${ }^{131}$ and tendered for street lighting in St. Margaret's and St. John's for 3 guineas per lamp, although the final decision was delayed until September. ${ }^{132}$ Westminster Bridge asked for an estimate in July $1814 . .^{133}$

Nor were local lighting authorities the only parties seeking gaslight. After the start of gaslight on the streets of Norton Folgate and Westminster in April 1814, the company received many expressions of interest from homes and shops in the adjoining areas, which the company acceded to as soon as they could, beginning with the house of one of their own directors. ${ }^{134}$ The company now started to charge their customers the price of fitting up their homes, an important step towards financial viability. ${ }^{135}$ To meet the request of a cluster of 10 shops, pipes were expressly laid from Folgate towards Shoreditch church. ${ }^{136}$ Many institutions, such as the East India House, ${ }^{137}$ Lincoln's Inn

\footnotetext{
129 1814/04/26, 29 MCD b1 p. 306-7, 311.

130 1814/05/27 MCD b1 p. 336.

131 1814/04/29 MCD b1 p. 314; 1814/07/[08] MCD b1 p. 371; Guildhall. The mains went from Folgate to Bishopsgate to Leadenhall.
}

132 1814/07/29 MCD b1 p. 385, 7; St. John 1814/08/03 MCD b1 p. 388.

133 1814/07/26 MCD b1 p. 383; survey 1814/08/12 MCD b1 p. 397; apply to lay pipes 1814/08/19 MCD b1 p. 399, 403; lay pipes 1814/08/30 MCD b1 p. 411 and 1814/09/02 MCD b1 p. 415; when ready? 1814/09/06 MCD b1 p. 419; 1814/10/21 MCD b1 p. 460; decision to light on Jan 1, 1815 1814/11/25 MCD b1 p. 495.

134 1814/04/01 MCD b1 p. 291; Work done in house 1814/04/15 MCD b1 p. 302; Holt + Son 1814/05/24 MCD b1 p. 332; duke of richmond 1814/03/25 MCD b1 p. 288; summer's house 1814/04/07 and 15 MCD b1 p. 296, 303.

\footnotetext{
135 1814/04/01 MCD b1 p. 294.

136 1814/05/10 MCD b1 p. 324.

137 1814/05/10 MCD b1 p. 324.
} 
Fields, ${ }^{138}$ and Carlton House ${ }^{139}$ were also interested, but the company simply could not keep up, although it was laying pipes rapidly under streets. Some parties were told that they would have to wait until the company could bring their mains closer to their location.

There was one new major contract for gaslight that ended in disaster, a scheme prepared by Sir William Congreve. ${ }^{140}$ Various leaders of the states allied against Napoleon were to visit London in August 1814, and there was to be illuminations to mark the occasion and to celebrate their victory over Napoleon. The directors of the company suggested to Congreve that they could provide gaslight as part of the illuminations. Their idea was to light the front of Carlton House, a perennial favourite for gaslight, and hopefully, the Prince Regent could become a permanent customer thereafter. ${ }^{141}$ The plan was soon expanded to include a pagoda to be built in St. James Park. The number of gas flames was to be enormous, at least 20,000 at one shilling each for the single night, although the final number was 9900 lamps. ${ }^{142}$ The company had to expand their gas generating capacity to meet the demand, ${ }^{143}$ and purchased an old brewing vat to increase gasometer volume. ${ }^{144}$ Pipes were laid to St. James Park,

\footnotetext{
138 1814/05/27 MCD b1 p. 336.

139 1814/05/25 MCD b1 p. 333; 1814/06/03 MCD b1 p. 341, 342.

140 1814/05/03 MCD b1 p. 315; 1814/07/31 MCD b1 p. 386-7.

141 1814/05/20 and 24 MCD b1 p. 330, 2; 1814/06/03 MCD b1 p. 341.

142 Total paid was $£ 495: 1816 / 03 / 12$ Minutes of the Court of Directors 2 (hereafter MCD b2) p. 838, 840: LMA B/GLCC/2/1 1815/11/16 MCW b87 p. 309900 lamp pricing 1815/11/25 MCW b87 p. 35.

143 1814/06/03 MCD b1 and 10 p. 343-347.

144 1814/06/21 MCD b1 p. 356.
} 
and the lamps were tested successfully two days before the show. ${ }^{145}$ Everything functioned marvellously.

Unfortunately for the GLCC, Congreve took a great interest in rockets, having invented some for military use. On the night of August 1, 1814, with large crowds assembled in the park, he fired off a few even before the pagoda lamps could be lit, and set the pagoda on fire. Its flaming remnants soon collapsed ingloriously into the nearby pool, killing two people on the pagoda. ${ }^{146}$ Rumours circulated blaming the fire on gaslight. For the company, this had the potential for another possibly public relations disaster, coming so soon after the October 1813 explosion at the Peter Street work. In the days following the debacle, the company ran notices in the papers that the fire had started even before the gaslights were on, and that gas had nothing to do with the conflagration. In general, the public's demand for gaslight does not seem to have been adversely affected either by the incident or the explosion.

The explosion at the Peter Street plant, did, however, generate official notice and the Home Office decided to investigate the company's technology. Lord Sidmouth, the Home Secretary, sent a letter on January 21,1814 , to the company announcing that an investigation into the safety of gaslight to be carried out by the Royal Society. Sidmouth was reassuring, however, saying that he thought the inquiry would 'establish the company in the good opinion of the public, and to strengthen them in their progress', rather than do them harm. ${ }^{147}$ The company arranged the details of the inquiry with the

\footnotetext{
145 1814/07/31 MCD b1 p. 386.

146 Caledonian Mercury (Edinburgh, Scotland), Saturday, August 6, 1814; Issue 14455.

147 1814/01/21 and 2528 MCD b1 p. 252, 4, 6.
} 
president of the Royal Society Sir Joseph Banks, ${ }^{148}$ who was soon on friendly terms with some of the directors. Shortly after their first contact, Banks sent a letter to the company asking for gaslights to be installed outside the front door of his own home, and the company obliged in short order. ${ }^{149}$ As for the inquiry, a delegation came from the Royal Society to visit the works on April 1, 1814, ${ }^{150}$ and a report was delivered to the Home Office which contained a series of recommendations on how to make gasworks safer. These were that gasometers should not be emptied of gas by driving it out with atmospheric air; gasometers should be no larger than 6,000 cubic feet; gasworks should be distant from surrounding buildings; and gasworks should be encircled by earthen embankments. In its report, the committee noted somewhat clinically that a gasometer such as that at the Peter Street works could explode with the strength of between 5 and 10 barrels of gunpowder. ${ }^{151}$ The report was not published at the time, and would not be for another nine years, but the committee was allowed to see some extracts. ${ }^{152}$

When the subscribers had their semi-annual meeting in July 1814 , the tone was more optimistic and the directors' report contained much to cheer the beleaguered

\footnotetext{
148 1814/02/04 and 08 MCD b1 p. 261-2 4.

$1491814 / 02 / 22$ and 25 MCD b1 p. 274, 6; 1814/03/11 MCD b1 p. 282. The lights were stopped for the holidays 1814/08/19 MCD b1 p. 401.

150 There is a story repeated in almost every history of gaslight about how Clegg astounded the assembled committee by puncturing a hole in the gasometer and lighting the gas streaming out, in order to prove how safe the apparatus was. This, like the story of Westminster Bridge, originated with Clegg junior in 1841, and once again, there is no contemporary evidence.

151 Banks, "Report of Royal Society on Gas-Lights; Report of Inspectors on Gas-Light Establishments in the Metropolis."

$1521814 / 04 / 26$ MCD b1 p. 306; 1814/05/10 ,13, 17, 20 MCD b1 p. 322, 5, 7, 8.
} 
shareholders. The bill to amend to company's charter had passed in June 1814, although not without some opposition that forced the directors to weaken the company's proposed powers to break pavement. ${ }^{153}$ The most important amendments extended the charter's term and crucially gave the company power to light homes without being compelled to provide street lights. ${ }^{154}$ The shares, which had been almost worthless six months previous, now had real value.155 The directors also spoke of how the 'increase in interest ... [was] so considerable', and 'the demands ... so numerous', that there was good cause for congratulations. ${ }^{156}$ The directors then suggested a whole raft of new bylaws for the company to improve governance procedures, which were all adopted..$^{157}$

By the middle of 1814 , the GLCC had recovered from its nadir following the explosion at the end of 1813 . The company was in new, more competent hands, and it was no longer haemorrhaging cash, although it had to make several more capital calls in the following years as its network expanded. The morale within the company was improving, and shareholders had confidence in the Court of Directors. The challenge for the next few years no longer lay in internal politics and company organization. Those issues were solved. David Pollock, already effectively in charge, would be elected Governor in 1815 , and would remain in the post until 1846 . He was elected to

\footnotetext{
153 1814/02/24 and 04/26 MCD b1 p. 276, 306.

${ }^{154}$ An act [54 Geo. 3 cap. 116] for enlarging the powers of an act of His Present Majesty for granting certain powers and authorities to the Gas Light and Coke Company, (17 June 1814).

155 1814/07/04 Proprietors p. 45.

156 1814/07/04 Proprietors p. 44 .

157 1814/08/05 Proprietors p. 54.
} 
the Royal Society in 1829.158 Thomas Livesey likewise stayed with the company as Deputy Governor from 1815 to $1840 . .^{159}$ The two of them together formed a bastion of stability for the internal affairs of the company over these years, although controversies with some shareholders inevitably occurred. Winsor, however, by now 'extremely embarrassed' in his financial situation, and had to flee the country in 1815 , losing his annuity and eventually his directorship. He tried to found another gas company in Paris and took out more gas patents there. ${ }^{160} \mathrm{He}$ was ejected from the new venture, and he was forced to write the GLCC a letter in 1820 asking for charity due to his extreme poverty. The proprietors voted him a stipend of $£ 200$ per year until his death, which came in $1830 .{ }^{161}$

\subsection{Building a network $1814-1820$}

With the company's internal travails mostly past, the following years witnessed the maturation of the GLCC with its technology into an urban utility. As its mains spread under London's streets in 1814 , and at an increasing rate thereafter, the company encountered many new challenges in scaling the technology into a large technological network in an urban environment. These included how to generate gas more constantly and efficiently, how to purify the gas better, and how to distribute it evenly with the least

\footnotetext{
158 Hutchinson, "The Royal Society and the Foundation of the British Gas Industry," 262.

159 Everard, The history of the Gas Light and Coke Company, 1812-1949, 114-5.

160 Jean-Pierre Williot, Naissance d'un service public : le gaz à Paris (Paris: Rive droite-Institut d'histoire de l'industrie, 1999), 28.

161 1820/11/07 and 09 Proprietors p. 146-7. See also N. K. Hill, "The history of the Imperial Continental Gas Association 1824-1900, a study in British economic enterprise on the continent of Europe in the 19th century" (Ph.D., University of London, 1950), 16-17.
} 
losses. None of the these were simple, and problems surrounding purification in particular came close to breaking the industry. The other challenges were no less significant, and it was with experimentation over the years 1814-1819 that complex and workable solutions were found, solutions that remained in use or were the basis of gaslight technology for the following decades.

The transformation of the GLCC into a utility was accompanied by the birth of a new industry as many other gas companies were incorporated, and the development of the new discipline of gas engineering. This process is recorded and reflected in the growing body of literature on gas engineering in the period 1815-1820. These published works reveal a great deal about how the industry matured and make an important complement to the records of the GLCC. The most important published texts were Frederick Accum's A Practical Treatise on Gas-light (four editions 1815-8) and its successor Description of the Process of Manufacturing Coal Gas (two editions 181920); and Thomas Peckston's The Theory and Practice of Gas-lighting (1819 and 1823). ${ }^{162}$

\subsubsection{Retorts and gas generation}

The scaling issues of gaslight apparatus began with the retorts. The volume of gas the company was generating very quickly surpassed anything the largest of the Boulton \& Watt mills supplied. Whereas the mills typically had less than 10 retorts in

\footnotetext{
162 See the bibliography for a complete list. Peckston worked for the GLCC but was fired by the court in 1819. See $1819 / 08 / 16$ MCW b88 p. $214 ; 1819 / 06 / 29$ MCD b4 p. 341 ; He was writing his book during March-May 1819.
} 
operation, and usually fewer than 5, the GLCC soon had 40, 50 and even more at its plants. The same issues of extending retort life span that concerned the mill owners was soon pressing on the company, but on a much larger scale.

The question was not, however, simply one of adopting retort designs and stoking practices that would extend life span. A complicating factor was that the highest gasification efficiency or carbonization ratio did not occur in the same circumstances as longest retort life span, and typically, the hottest fires generated the most gas and produced shortest retort life spans. A slow fire lengthened retort life span considerably, but decreased efficiency and gas quality, as well as increasing labour costs. ${ }^{163}$ The company's directors and engineers then faced the question of balancing these important opposing parameters, all of which depended on retort structure, heating practice, and the type of coal used. Retort cost and life span, labour costs, and coal use in turn combined to give the cost of generating gas. ${ }^{164}$

In terms of design, there were two major points gas engineers could change to look for improvements in the retorts. They were in the retort design itself (shape, size), and how the retorts were set in regard to each other and the fireplace. Both of these were changed a great deal, by, for example, trying different retort cross-sections, material, lengths, etc., as well as many different arrangements or settings for the retorts. Experimentation was, however, very expensive, as resetting a fireplace involved extensive brickwork.

163 Accum, Description of the process of manufacturing coal gas [1819], 60. 164 Ibid., 51. 
Setting cost was not the only challenge in designing better retorts. Gas engineers soon realized that coming up with reliable figures for all the variables related to gas production was not a question of performing a few experiments on small experimental apparatus. They came to understand that the only way to have any degree of confidence in their figures was to base them on complete production results obtained from full scale apparatus, preferably over the course of a winter when production was at its maximum. As Peckston wrote in 1819: 'In vain may it be attempted, by experiments made in the small way, to come at any thing near the truth; for when those experiments are brought in comparison with the larger and more extended process, experience has taught that no dependence can be placed on them.'165

Since retorts tended to endure for months, a specific trial would typically last for six months to a year before the company could come to any conclusion. ${ }^{166}$ Even then, the conditions in a full production setting were hardly controllable, and so it is not surprising that in the first decade of large scale gas production, no one form of retort design and setting came to dominate, ${ }^{167}$ nor indeed would it ever happen that one form was used to the exclusion of all others. Another challenge was that ascertaining the efficiency of a given set of retorts when in production was difficult since the gas they produced was mixed with that coming from other retorts. Isolating them completely was the only way to come up with figures, but this was only possible for a day or two, as these test retorts

\footnotetext{
165 Peckston, The theory and practice of gas-lighting [1819], xii.

166 Accum, Description of the process of manufacturing coal gas [1819], 57-8. described how comparative trials are needed running for months together, and that bad observations are frequent.

167 Henry Creighton, "Gas-Lights," in Encyclopaedia Britannica, or:: A dictionary of arts, sciences and miscellaneous literature. Supplement to the Fourth, Fifth, and Sixth Editions (Edinburgh: A. Constable, 1824), 451.
} 
would not be producing gas for sale. ${ }^{168}$ This is not to say the company made no real gains in efficiency and retort life. They did make important improvements and acquired an understanding of the various issues involved in retort design, and how they interacted, but it came at a great cost.

Even before the first board of directors had been dissolved, some experimental work was done on the retorts. Accum recounts that Grant and Hargreaves tested conical and cylindrical retorts to find the best shape, settling finally on the latter. ${ }^{169}$ Cylindrical retorts had already been used by Boulton \& Watt and Clegg, and so the GLCC's early work was a reproduction of results already known elsewhere. The experimentation continued with the new board, under the direction of Clegg and some its technically minded directors, such as John Warren, although the retrenchment limited the company's financial resources and willingness to take risks. ${ }^{170}$ After the first conical retorts were dispensed with, the new retorts had a more efficient circular cross-section, and were about 6.5 feet long, made of cast iron. ${ }^{171}$

\footnotetext{
168 1815/06/25 MCD b2 p. 670.

169 Accum, Description of the process of manufacturing coal gas [1819], 55.

$1701814 / 03 / 25$ MCD b1 p. 287; 1814/06/03 MCD b1 p. 343; 1814/06/07 MCD b1 p. 345; 1814/07/12 MCD b1 p. 375.

171 Accum, Description of the process of manufacturing coal gas [1819], 54-7.
} 


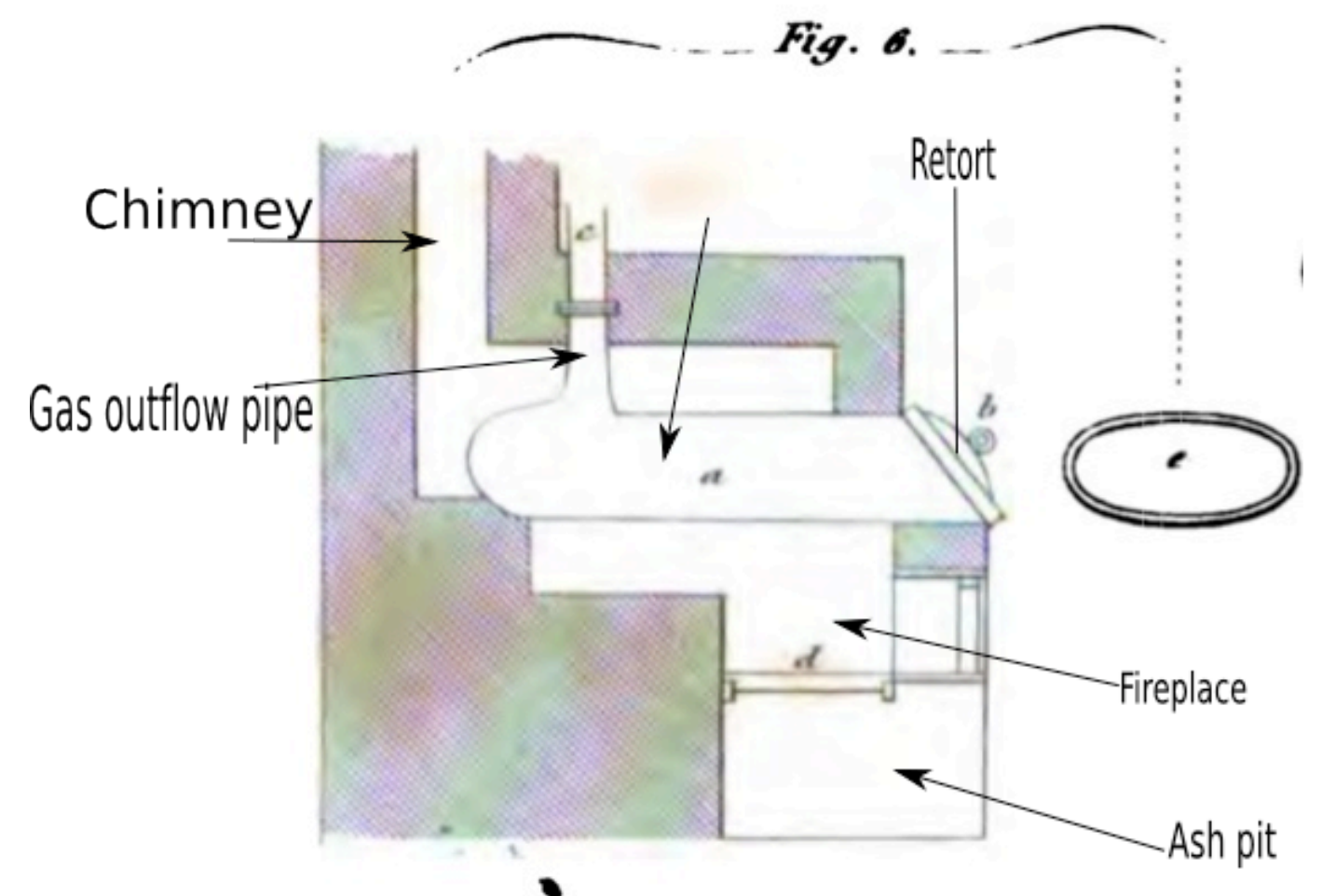

Figure 5.6 Retort on the flue plan, Creighton "Gas-Lights." in the Encyclopaedia Britannica (1824)

All retorts from the beginning up to 1817 were set on what was called the 'flue plan'. ${ }^{172}$ This meant that the hot gases and flame from the furnace were led by flues that snaked back and forth under and then above the retort before being exhausted to a chimney. The retorts were not protected by fire brick and came into more or less direct contact with the flame. The carbonization efficiency of these new setting was estimated 
to be about $30-36 \%$, depending on the number of retorts used. ${ }^{173}$ The first settings had one or two retorts heated by a single fire.

A few more experiments were done in 1815 , but these were small in scale. ${ }^{174}$ In 1816, the company had settled down sufficiently to feel ready for a great number of wider ranging experiments. The directors asked Clegg to monitor coal usage on a weekly basis, ${ }^{175}$ and to try to determine which retorts were lasting the best. ${ }^{176}$ Perhaps guessing that greater fuel efficiency could be achievable if the more retorts were heated by one fire, the company tried setting them in groups of three. A large number of retorts -66 at Peter and 30 at Curtain - were set and this way and tried for four months. The test showed that the carbonization efficiency was no better, and the retorts were destroyed in two thirds the time..$^{177}$ The company also tried four retorts to a fire, ${ }^{178}$ but this gave even worse results. The fuel efficiency decreased $25 \%$, and the retorts deteriorated even more rapidly. ${ }^{179}$ Setting a large number of retorts to a single fire had the additional disadvantage that when one retort burnt out, the others also went out of service, or if it was retained but not used, the fire would lose half its efficiency. ${ }^{180}$

\footnotetext{
173 Ibid.

174 1815/06/23 MCD b2 p. 666; 1815/07/15 MCD b2 p. 687.

175 1815/02/07 MCW b87 p. 5.

176 1816/04/18 MCW b87 p. 117.

177 1816/07/16 2325 MCD b3 p. 30, 37, 40 Accum, Description of the process of manufacturing coal gas [1819], 62. These described extensive tests of 2, 3, 4 retorts/fire.

178 1816/06/21 MCD b3 p. 14 07/12 MCD b3, 26.

179 Accum, Description of the process of manufacturing coal gas [1819], 63-4.

180 Ibid., 65.
} 
The company in 1816 tried modifying the shape and path of the flues, and moving the fireplace to the back side of the retort bench, so that the retorts and fireplace were accessed from different sides. One plan with a shorter flue and the furnace to the front gave the same life span, but with a $5 \%$ efficiency gain. ${ }^{181}$ In another case, in a what was a complete departure from the traditional retort design, Clegg patented a rotary retort, ${ }^{182}$ a very complicated scheme that featured moving parts. He persuaded the company to try them, and a few rotary retorts were set at Peter Street. 183 Within a year, although the fuel efficiency was good, they were judged to be a complete failure because of their complexity and high cost. ${ }^{184}$ Clegg tried them again at the Royal Mint to whom he was acting as a consultant, but that was the end of them.

By the end of summer 1816, the directors were disappointed with all the company's experiments, but were still willing to try new designs, ${ }^{185}$ such as ones with a square cross-section, originally designed for the Surrey Co., a new gas company south of the Thames. ${ }^{186}$ They likewise tried flat retorts, which supposedly produced less sulphur, ${ }^{187}$ as well as earthen and wrought iron retorts, ${ }^{188}$ but none of these were heard

\footnotetext{
181 1816/05/16 MCD b2 p. 833, 5.

182 1816/08/26 MCW b87 p. 181 1816/09/12 MCW b87 p. 194.

183 1816/12/12 MCW b87 p. 232.

$1841817 / 06 / 12$ MCW b87 p. 294; For a description of these rotary retorts, see Accum, Description of the process of manufacturing coal gas [1819]., and "Specification of the Patent granted to Samuel Clegg," The repertory of arts, manufactures, and agriculture 2nd series 30, no. 175, 176, 177 (1816).

185 1816/08/15 MCW b87 p. 175.

186 1817/01/21 MCD b3 p. 169.

187 1817/02/18 MCD b3 p. 190.

188 1817/07/18 and 26 MCD b3 p. 302306.
} 
from again. The company tried to keep a log of all the retorts in use with pertinent information, such as shape, manufacturer, etc., ${ }^{189}$ so as to glean a firmer notion of which retorts lasted the longest. ${ }^{190}$

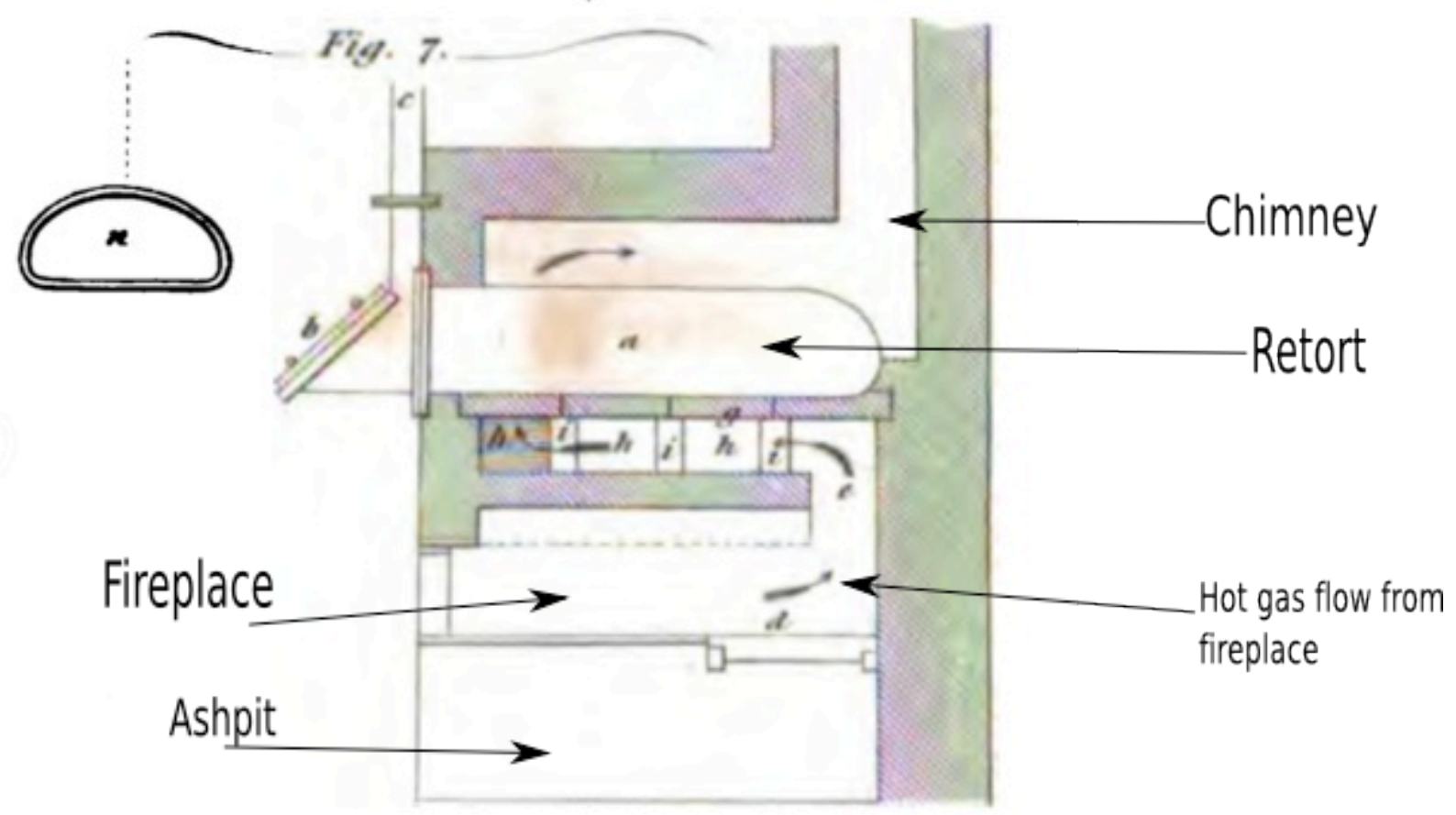

Figure 5.7 Flue plan, with protection from fire bricks. Creighton "Gas-Lights." in the Encyclopaedia Britannica (1824)

In the summer of 1817 , the company decided to try a different flue layout that included with greater protection of the retorts against the flames provided by fire bricks. The exact details are not clear from the company's minutes, but it included having the

189 1816/12/13 MCD b3 p. 134.

190 1816/12/24 MCD b3 p. 149. 
furnace mouths set on the opposite side of the bench as the retort mouths. The new setting achieved some greatly increased retort life spans, but required a bit more fuel. By the time the deepest part of the winter had passed in February 1818, the results were judged to be so positive that some of the other production retorts were reset on this plan, although the fireplace and retorts could not be facing in opposite directions due to lack of space. ${ }^{191}$ The positive results were confirmed once again a month later. ${ }^{192}$ This version of the plan was not, however, to remain in use much longer because it was combined with another idea that came from outside the company after 1818 .

Just as the company was moving to a new form of a flue plan in the spring of 1817 an inventor, Andrew Rackhouse, approached the company ${ }^{193}$ with what he claimed was a revolutionary new retort setting that would do wonders, saving the company $£ 1000$ a year. He soon revised his savings prediction to $£ 2000 .{ }^{194}$ After some negotiations, ${ }^{195}$ the company decided to try his idea. It consisted of using ovens, heated directly by fires, instead of flues to heat the retorts. The retorts were supported and heated in an oven, and not by hot gases that travelled through flues around the retorts. Rackhouse's plan called for five retorts to be set inside a single oven, heated by three fires, and the company chose to build four of these groups. ${ }^{196}$ Rackhouse, however, does not seem to have done much planning work before approaching the company, because after he was

\footnotetext{
191 1818/02/05 MCW b88 p. 11.

192 1818/03/02 MCW b88 p. 18.

193 1817/04/10 MCW b87 p. 267.

194 1817/04/14 MCW b87 p. 270, 272.

195 1817/04/15 MCD b3 p. 229; 1817/04/29 MCD b3 p. 239.

196 1817/05/01 MCW b87 p. 278.
} 
retained, he admitted the plan was not ready, ${ }^{197}$ although he sent some details a week later. ${ }^{198}$

There was then a long delay until October 1817, when the company and Rackhouse finally agreed to erect the new ovens at Peter Street. ${ }^{199}$ They were still not ready two months later, and the company, which had planned for those retorts to be in service for the winter, grew impatient with Rackhouse, and sent him a letter demanding that he finish, which he did fairly soon thereafter. ${ }^{200}$ It did not take long for problems to emerge, however, and by January 1818, the superintendent of the Peter Street works wrote that although Rackhouse's plan was promising, no bricks had been used to protect bottom retorts from the flames, and they were deteriorating rapidly. 201 Two weeks later, the retorts had completely failed, and the company, although frustrated by the experience, had judged that the oven plan had some value and was probably better than the flue plan. 202

\footnotetext{
197 1817/04/21 MCW b87 p. 274.

198 1817/04/24 MCW b87 p. 276.

199 1817/10/30 MCW b87 p. 330.

200 1817/12/22 MCW b87 p. 346.

201 1818/01/15 MCW b88 p. 3.

202 1818/02/02 and 05 MCW b88 p. 9.
} 


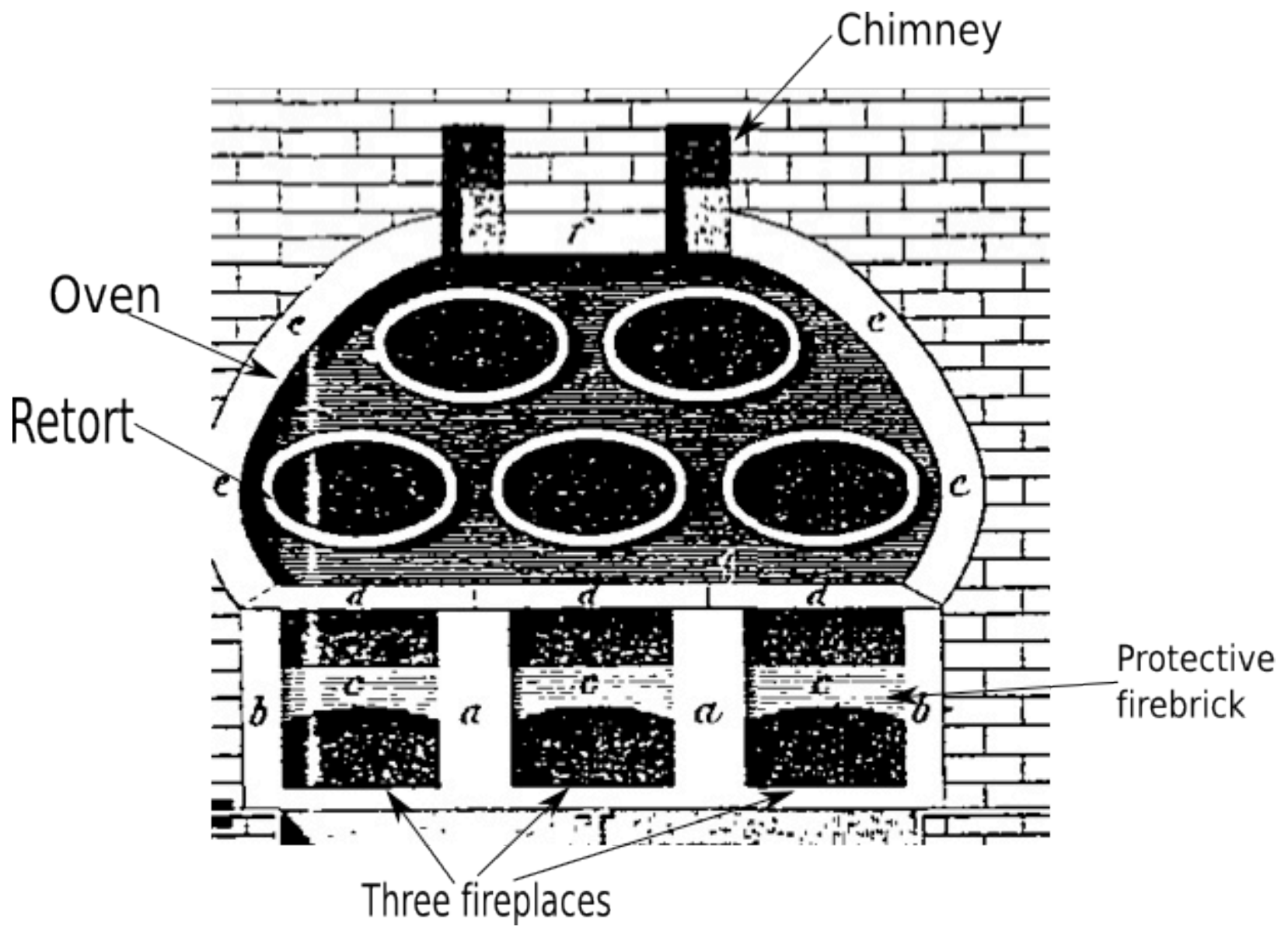

Figure 5.8 Front view of elliptical retorts set on the oven plan Peckston The theory and practice of gas-lighting (1819) 


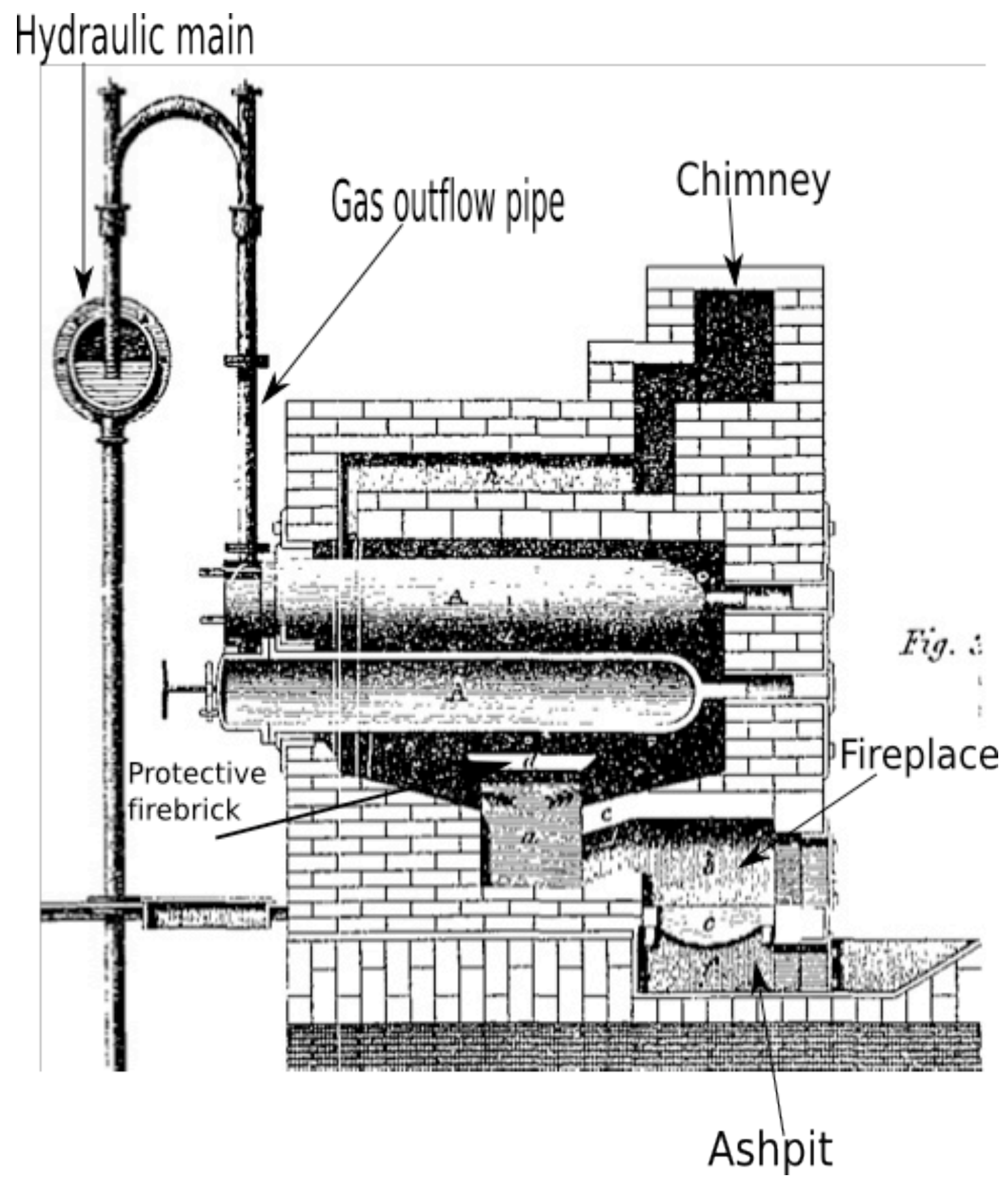

Figure 5.9 Side view of elliptical retorts set on oven plan. Note that the furnace mouths are on the opposite of the setting as the retorts, and that the retorts are protected by fire brick. Peckston The theory and practice of gas-lighting (1819) 
In March 1818, the decision was made to replace the recently expired retorts with new ones on the oven plan, but with bricks protecting the bottom retorts from underneath. ${ }^{203}$ This model combined the two new ideas the company had been trying during the winter of 1817-8. The results came quickly, and when the superintendent reported a month later, he stated that these retorts were lasting well, although not as well the flue plan ones. There was, however, a major gain in fuel efficiency, as these retort used $22 \%$ less fuel. Richard Leadbetter, the superintendent of the Peter Street works, reported that he thought this advantage could tip the scales in the newest settings favour, despite the shorter retort life.204 During the summer season, all the retorts were set on the protected oven plan, and when the results were reported at the end of the winter in March 1819, they were clearly in favour of the new setting. Although retorts were destroyed more rapidly (320 destroyed per year versus 210 using the protected flue plan), the fuel efficiency gain (65\%) meant that it made sense economically. ${ }^{205}$ It was then adopted as the standard. ${ }^{206}$ The modified oven plan was in vigour for many years and Clegg junior described it in his book in 1841.207 Ironically,

203 Accum, Description of the process of manufacturing coal gas [1819], 67-8. flame does not act directly forcibly on retorts.

$2041818 / 04 / 06$ MCW b88 p. 32-33 34 36; The carbonization ratio decreased from $47 \%$ to $16 \%$, a huge drop.

205 1819/03/29 MCW b88 p. 165ff Accum, Description of the process of manufacturing coal gas [1819], 60-1.

$206 \mathrm{Ibid}$., 76. Thomas S. Peckston, Cursory observations on different processes adopted for the distillation of coal, drawn from actual experiment. By Thomas S. Peckston; of the Chartered Gas Light and Coke Company's Establishment, Peter Street, Westminster (Southampton: Printed by T. Baker for I. Fletcher, 1819), 6. The company was experimenting with 7 to 10 retorts to one oven in 1820 . See $1820 / 08 / 11$ and 18 MCD b5 p. 156, 158.

207 Clegg, A practical treatise on the manufacture and distribution of coal-gas, 69. Peter Nicholson, Practical masonry, bricklaying and plastering, both plain and ornamental; containing a new and complete system of lines for stone-cutting. For the use of workmen (London: T. Kelly, 1838), 138. 'by far the most general mode adopted'. 
Rackhouse was given credit, although his actual work for the company proved to be a complete failure. It was only the company's own internal work that included combining it with another test plan that made it viable.

A third innovation, besides the oven plan and the use of fire bricks, that was added to the mix in early 1818 was elliptical retorts. ${ }^{208}$ The company's minutes do not reveal the source of the idea, but it was hardly original as many different cross-sections had been tried, even at Boulton \& Watt. The idea here was to spread the coal into a thinner layer and thereby expose it to more even heating. The results were mixed, ${ }^{209}$ however, and the company used both circular and elliptical retorts for the coming years. ${ }^{210}$ This invention was erroneously attributed to John Malam by his brother-in-law, Thomas Peckston, something frequently repeated in histories of gaslight. This is not true, and it was pointed out at the time as well. ${ }^{211}$

There were many other ideas that came and went for retorts, from long time veterans such as Accum who had set up a novel apparatus at the Royal Mint and

\footnotetext{
208 1818/02/09 MCW b88 p. 14.

209 1819/06/21 MCW b88 p. 195; 1819/06/22 and 29 MCD b4 p. 334 and 340.

210 See, among many others, 1819/03/26 MCD b4 275.

211 "Gas Lighting," Mechanics' magazine and journal of science, arts, and manufactures 8 (1828). See p. 207.
} 
offered his ideas to the company, ${ }^{212}$ to new inventors, such as William Congreve ${ }^{213}$ and John Outhett 214 who both approached the company, but whose ideas were not pursued. As Accum wrote in 1819, there had been 'much assiduous inquiry ... and in no branch of the new art of procuring light, has a greater variety of plans of improvement been submitted to the several directing boards of gas works, or more labour and expence been incurred in experiments conducted on a large scale, to ascertain the relative merits of these plans'.215

\subsubsection{Purification}

The basic methods for purification used in the first years of the GLCC had been worked out before the company had received its charter, and consisted basically of a three stage process: the hydraulic main, the condenser, and the lime purifier. Boulton \& Watt had washed the gas with water to remove tar and ammonia, and this was also used by Clegg in his installations. He is credited with the invention of the hydraulic main, but how it differs from anything Boulton \& Watt did is not evident. The hydraulic main evolved very little over the early years. It consisted simply of a large diameter pipe

\footnotetext{
212 Accum reported a better mode of carbonizing was implemented at the Mint 1818/10/09 MCD b4 p. 165; The Court decided that it would not work, but tried one element of it, which was to spread the coals more thinly in the retorts. 1818/10/13 MCD b4 p. 168.

213 Congreve retorts 1819/07/02 and 16 MCD b4 p. 343; William Congreve and J. Whiting, A short account of a patent lately taken out by Sir William Congreve, Bart. : for a new principle of steam engine ; and also of a new mode which he has adopted for the saving of fuel \& the consumption of smoke in the production of steam, the generation of gas, and in various other operations, being also the subject of a patent (London: Printed by J. Whiting, published by T. Egerton, 1819).

214 Outhett's patent 1819/11/16 MCD b4 p. 425 and 440; Patents for inventions. Abridgments of specifications relating to the production and applications of gas, (London: Printed by G.E. Eyre and W. Spottiswoode, 1860), 28-9.

${ }^{215}$ Accum, Description of the process of manufacturing coal gas [1819], 52.
} 
half filled with tar and water. The product coming from the retorts were led by pipes into the water. The gases bubbled to the surface, while the condensed tar was drawn off.
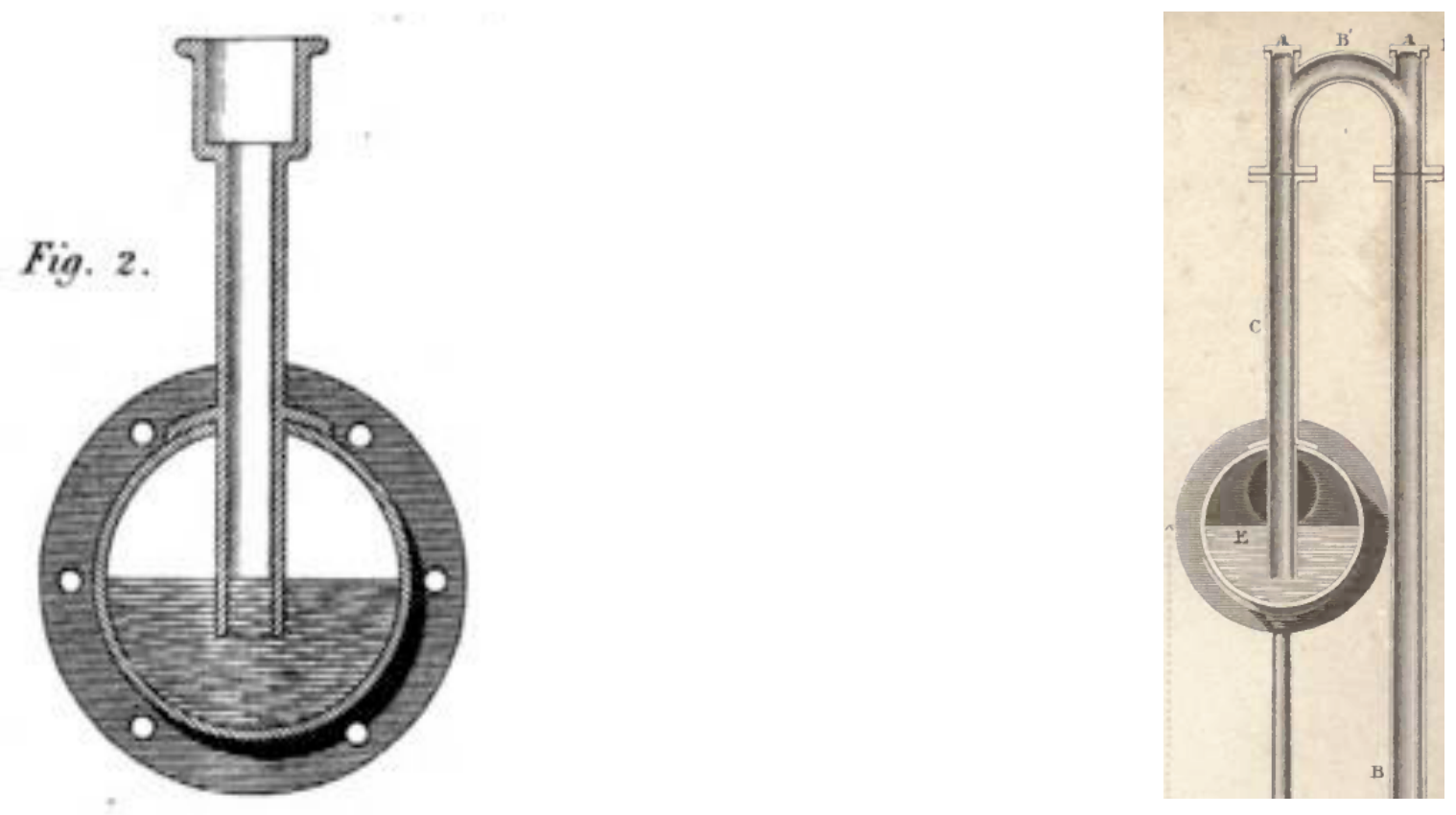

Figure 5.10 Hydraulic main. From Peckston, The theory and practice of gas-lighting (1819) and Clegg (1841)

The second stage of purification was the condenser. The condenser served to cool and separate whatever tar passed through the hydraulic main, as well as other condensible fluids, which included the ammoniacal liquor. Winsor had used a cooler, which he called a refrigeratory, as did Boulton \& Watt. The apparatuses Clegg built before joining the GLCC included long pipes that circled the gasometer in the cistern that contained water. The condensed liquids were separated from the gases by running them down an incline, while the gas were sent upwards to the lime machine for further 
purification, this time of carbonic acid (carbon dioxide $\mathrm{CO}_{2}$ ) and sulphuretted hydrogen (hydrogen sulphide $\mathrm{H}_{2} \mathrm{~S}$ ). These pipes were liable to be clogged and cleaning them entailed burdensome work. ${ }^{216}$

216 Peckston, The theory and practice of gas-lighting [1819], 186. 


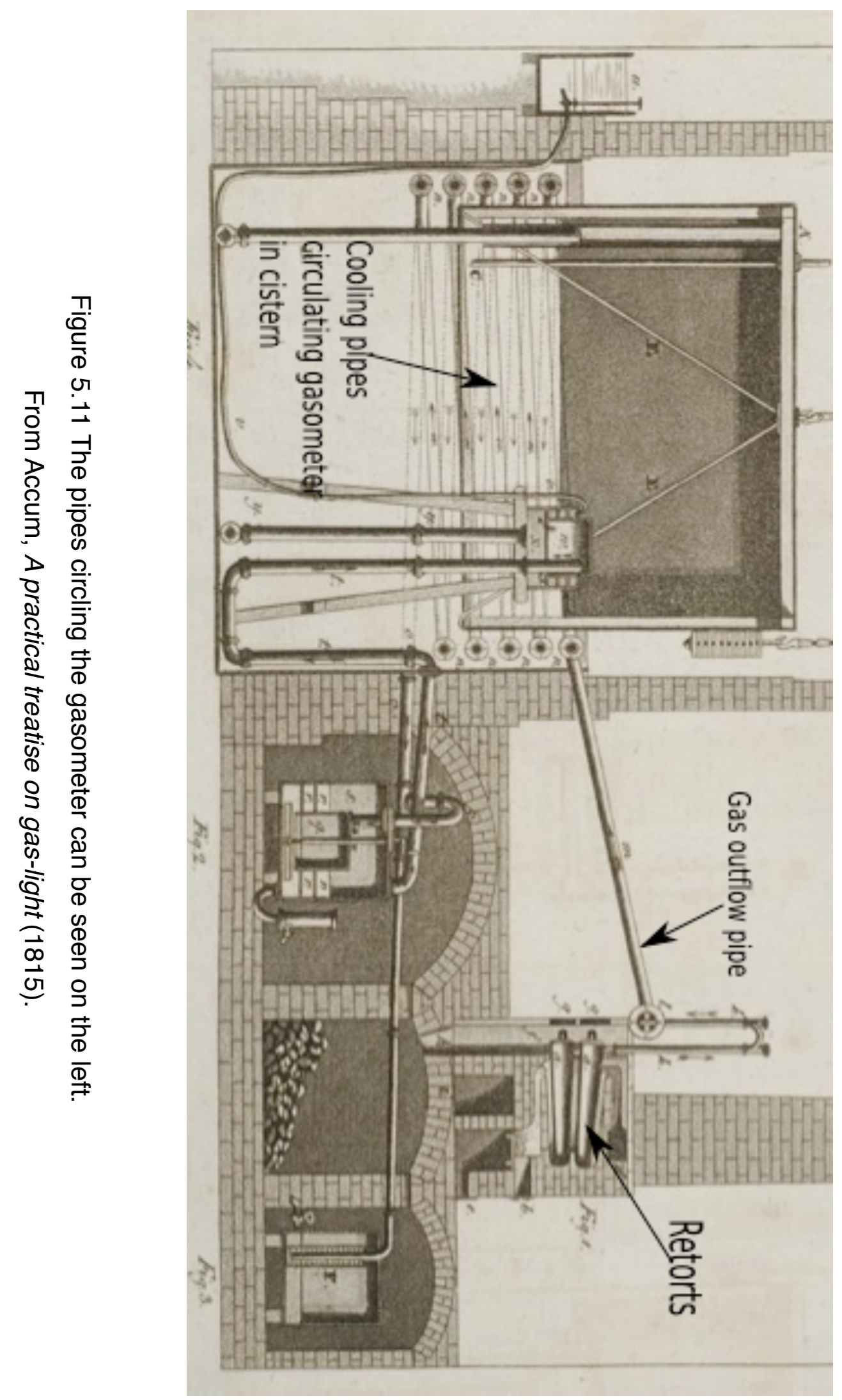


The company introduced a more complicated self-standing condenser in 1817 , after it made tests in which the gas was condensed more than usual before sending it to the purifier. ${ }^{217}$ The tests indicated that condensed gas could be more easily purified, and the directors resolved to build proper condensers. ${ }^{218}$ These were square units that sent the gas back and forth through large vanes immersed in water. ${ }^{219}$ The condensed tar and oil was drawn off at the base of the condenser. Although there were slight modifications made to this condenser, 220 it was abandoned in early 1818 in favour of one that featured replaced the vanes with many pipes going up and down immersed in water. This design had the advantage of increasing the distance the gas travelled while exposed to cool water, and it worked very well, increasing the effectiveness of the purifiers as well. ${ }^{221}$ The design had been patented in 1817 by John Perks,,222 an employee of the City of London Gas Company, and he claimed the GLCC was infringing on his patent, a charge which the company denied. ${ }^{223}$ Although a few other designs

\footnotetext{
217 1817/03/21 MCD b3 p. 214.

218 1817/03/24 MCW b87 p. 261l installed 1817/04/24 MCW b87 p. 276.

219 Matthews, An historical sketch of the origin, progress, \& present state of gas-lighting, 22-3.

220 William Matthews, Compendium of gas-lighting, adapted for the use of those who are unacquainted with chemistry; containing an account of some new apparatus lately introduced (London: R. Hunter, 1827), 22-3.

221 1818/02/02 MCW b88 p. 8; 1818/02/05 MCW b88 p. 11 It is not evident that this is the condenser referred to in these minutes, but the timing of its introduction is correct.

222 Peckston, The theory and practice of gas-lighting [1819], 128.

223 1819/07/30 MCD b4 p. 360, 373, 376.
} 
were tried, 224 the Perks design became the most common one used in gas works. ${ }^{225}$ By 1819 , these were quite large, in one case $10 \mathrm{ft} \times 30 \mathrm{ft} \times 6 \mathrm{ft}$ deep. ${ }^{226}$

224 1819/12/20 MCW b88 p. 274; 1819/12/31 MCD b4 p. 458.

225 Matthews, Compendium of gas-lighting, 21-4.

226 1819/03/27 MCW b88 p. 164. 
PLATE VI.
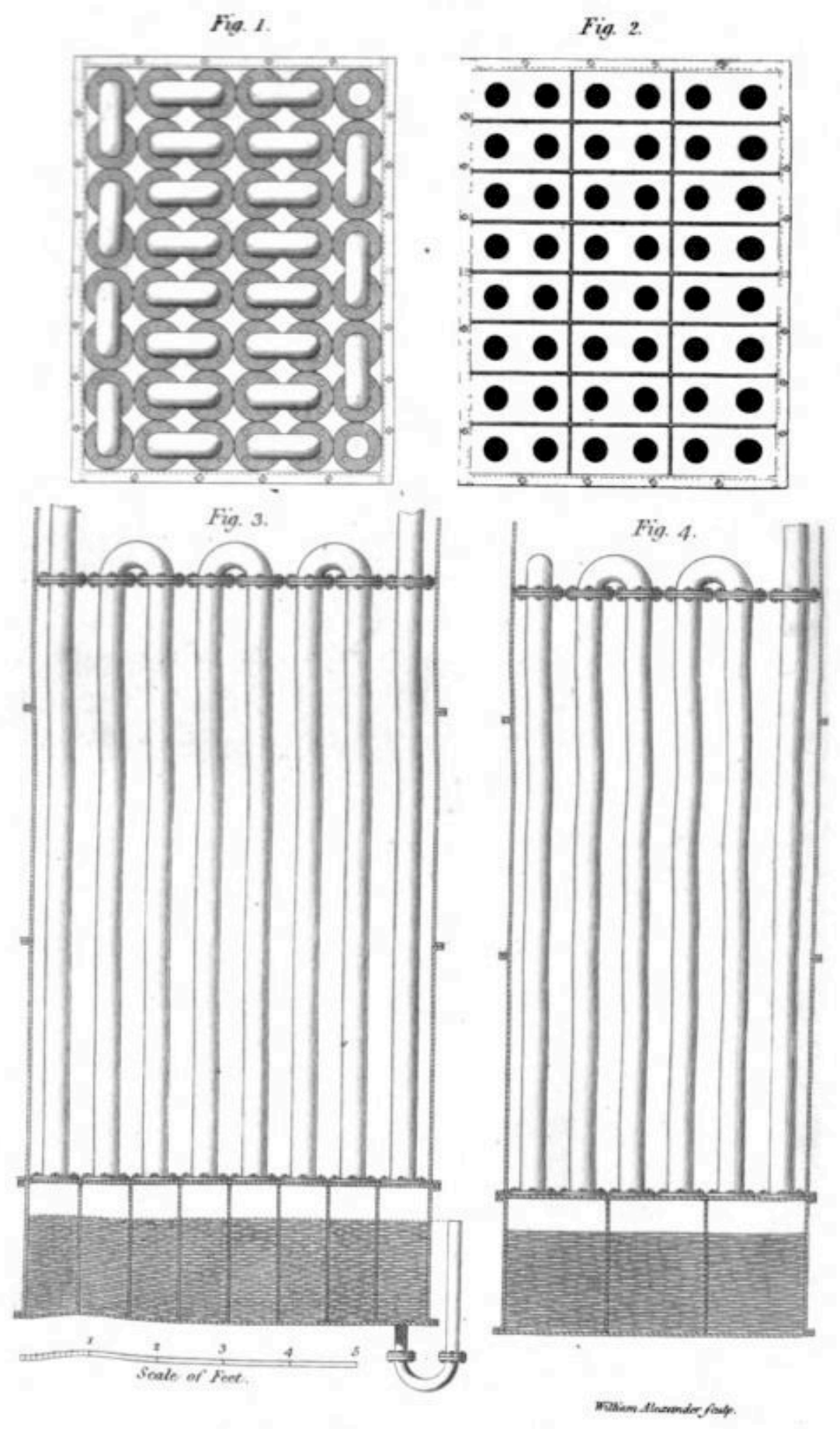

Figure 5.12 A Perks condenser. From Peckston, The theory and practice of gaslighting (1819) 
Clegg is frequently given credit with the invention of lime purification, the third stage in the process, but this is a simplification. As was discussed in chapter one, the reaction between sulphuretted hydrogen and lime was observed by Scheele and others after him long before 1800. Edward Heard, Winsor's unfortunate assistant,227 in 1806 was the first person to take out a patent for removing sulphuretted hydrogen from coalgas with lime. ${ }^{228} \mathrm{He}$ was never able to make any money from the invention, and in his later years when he became impoverished, he petitioned gas companies for money for the invention, but it was fundamentally a request for charity. Boulton \& Watt had apparently tried lime too,229 but this could have been no more than a minor attempt, given the absence of any record of it in the archives, and that it was not part of any plans that survive.

Clegg applied lime purification at one of the first apparatuses he built.230 His first purifiers merely bubbled the gas through lime water in various ways, but they were

227 Despite some important work in developing lime purification and founding gas companies, he became impoverished. See chapter four.

228 "Specification of the Patent granted to Edward Heard, of London, Chemist, for a Discovery of certain Means of obtaining inflammable Gas from Pit-Coal in such a State that it may be burned wihtout producing any offensive Smell," The repertory of arts, manufactures, and agriculture 2nd series 10, no. 56 (1807).

229 Matthews, Compendium of gas-lighting, 25. William Henry, a good friend of Boulton \& Watt, described how he used lime water to purify gases. See William Henry, "Experiments on the gases obtained by the destructive distillation of pit coal, \&c., with a view to the theory of their combustion when employed as sources of artificial light," A Journal of natural philosophy, chemistry and the arts 11 (1805): 68-9. and Henry, "Description of an Apparatus for the Analysis of the Compound Inflammable Gases by Slow Combustion; With Experiments on the Gas from Coal, Explaining Its Application," Philosophical Transactions of the Royal Society of London 98 (1808): 302-3. Clegg junior bitterly accused Henry of stealing his father's idea, but they were both preceded by Heard, and the basic principle was, of course, hardly new.

230 Clegg, Description of an apparatus, by which twenty-five thousand cubit feet of gas, are obtained from each chaldron of coal,: without producing either tar or ammoniacal liquor, 3-5. for a few details of his first lime purifiers. 
liable to becoming clogged. In 1809 , Clegg designed and built an apparatus for a mill in Coventry that included a paddle to stir the lime, thereby keeping it fresher as the gas bubbled through it. ${ }^{231}$ It was this sort of purifier that Clegg built at Ackerman's shop in 1812. These early purifiers had an uneven effect on purification because as the lime became progressively fouled by sulphur, it could absorb less. There was also the danger that they could clog up, and causing increasing back pressure on the retorts. ${ }^{232}$

When Clegg was hired by the GLCC, his first purifiers there were likely much the same as the one he build at Ackerman's. The company did not seem to have built more than two for the first couple years, although they had to replace the one at Peter Street that exploded in October 1813. The orders in 1814 do not show much variation in design, although a double machine, presumably one with two chambers, was ordered in February 1815.233 The rest of 1815 featured no special activity when ordering new machines. ${ }^{234}$

Clegg was, however, quite active in 1815 in designing new inventions. This was the year that saw him introduce his rotary retorts, and he also invented a complicated lime machine, which, like the retorts, he attempted to sell to the company. ${ }^{235}$ The company was at this point embroiled in various lawsuits over poisoning their neighbours

\footnotetext{
231 Matthews, An historical sketch of the origin, progress, \& present state of gas-lighting, 52. Clegg, "Improved Apparatus for extracting Carbonated Hydrogen Gas from Pit Coal." does not mention lime purification.

232 Accum, Description of the process of manufacturing coal gas [1819], 141-3.

$2331815 / 05 / 12$ MCD b2 p. 632.

234 1815/05/26 MCD b2 p. 643; order circular lime vessel 1815/07/15 MCD b2 p. 687.

235 1815/11/14 MCD b2 p. 758; 1815/11/16 MCW b87 p. 28; Clegg asked when new purifying machine will be ready 1816/06/03 MCW b87 p. 146.
} 
(see below), and Clegg, no doubt angling to get the company to build one of his new retorts, suggested to the directors that unless the company found a way to reduce the lime used, they would exposed to serious risk of failure. ${ }^{236}$ The directors were evidently keen to find a solution to their legal woes, but were not ready to authorize a radical new design for the purifier. Clegg was by now doing consulting work outside the company. He built one of his new purifying machines at another site, probably the Royal Mint, 237 and the company sent Leadbetter to inspect the machine. ${ }^{238}$ Although the GLCC had Clegg build a new lime machine during the last months of 1816,239 it was not very successful, and was cleared away in June 1817, after Clegg had left the company.240

\footnotetext{
236 1815/11/14 MCD b2 p. 758.

237 "Specification of the Patent granted to Samuel Clegg." Accum, Description of the process of manufacturing coal gas [1819], 149-57. Chandler and Lacey, The rise of the gas industry in Britain, 62.

238 1816/07/25 MCW b87 p. 165.

239 1816/09/16 MCW b87 p. 197.

$2401817 / 06 / 19$ MCW b87 p. 298
} 


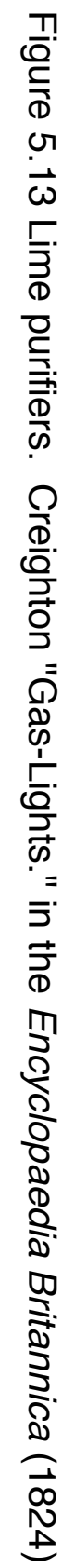

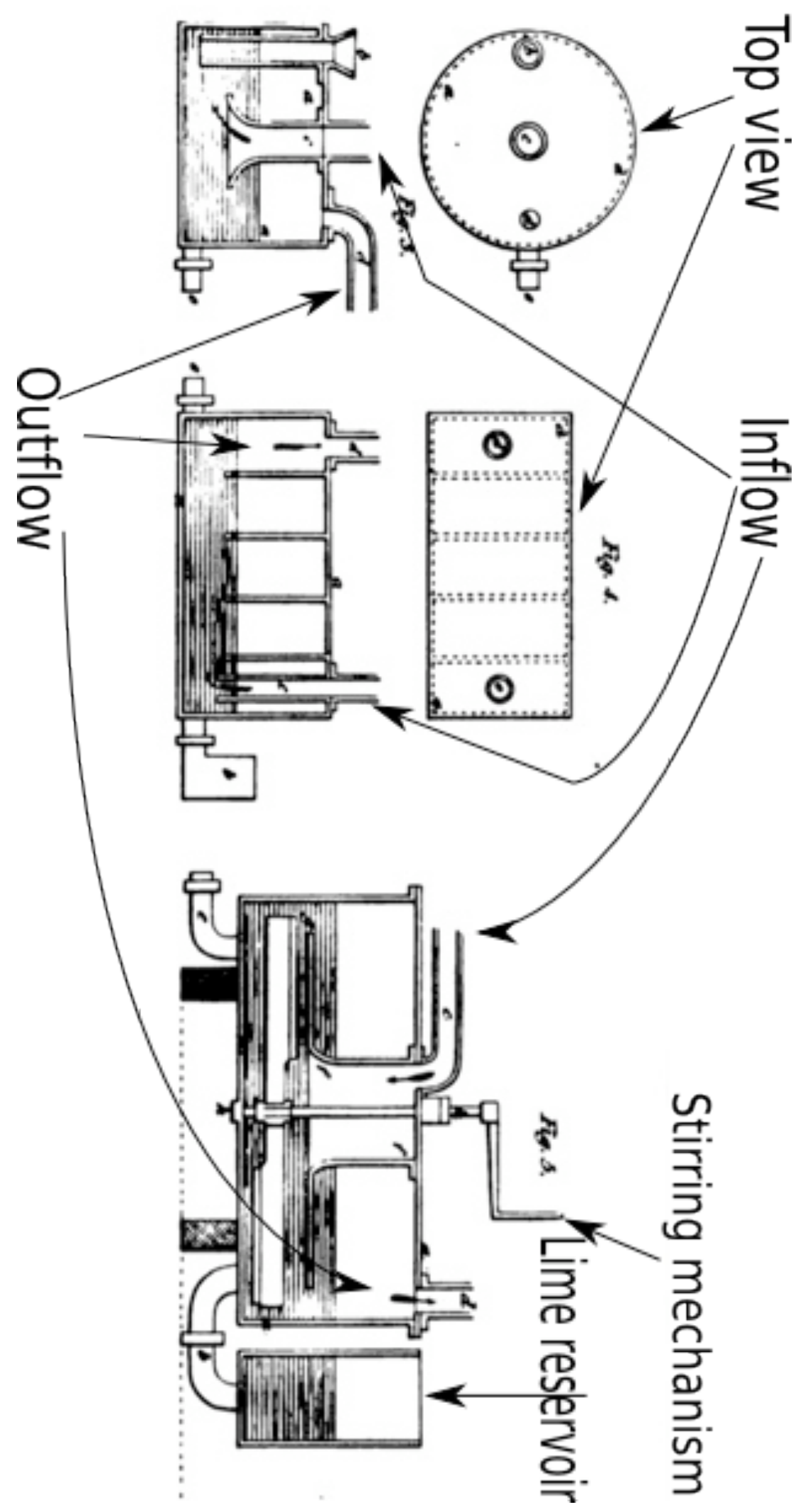


In October 1816, simultaneously with Clegg's complicated purifier, the company started using lime in a semi-fluid state, sometimes called dry lime. The results were very good, both in the old and the new purifiers the company had. ${ }^{241}$ The directors ordered weekly tests of gas purity with 'acetite of lead' and water to monitor the effectiveness of the new method. ${ }^{242}$ The tests were positive enough that the company built a dry lime machine at Peter Street, although held off building more until they had sufficient experience with it. ${ }^{243}$ When further tests of gas purity were performed a few months later in March 1817, the results were less positive, and the company started look for another sort of purifier.244

The seed of a new plan for the purifier was laid when the company made note in December 1816 that when purifiers were being recharged, gas entered the gasometer directly and therefore unpurified. A second lime machine after the gasometer and before the main street valve would be needed to prevent this from happening. ${ }^{245}$ Nothing was done immediately, but Clegg's successor as engineer, John Malam, in April 1817 designed a purifier that had three stages instead of the single stage models. He claimed it would save money and use less lime. The company was interested and

\footnotetext{
241 1816/10/29 MCD b3 p. 101.

242 1816/10/29 MCD b3 p. 101.

$2431816 / 11 / 22$ MCD b3 p. 116.

244 1817/03/14 MCD b3 p. 209; 1817/03/18 MCD b3 p. 212.

245 1816/12/24 MCD b3 p. 147.
} 
asked him in June of 1817 for an estimate. ${ }^{246} \mathrm{~A}$ few days later, Clegg's purifier was deemed a failure and Malam ordered to replace it with his. ${ }^{247}$ Parts were ordered, ${ }^{248}$ and although some problems with the delivered parts caused delays, ${ }^{249}$ the machines were ready by $1818 .{ }^{250}$

246 1817/04/10 MCW b87 p. 268; 1817/06/13 and 17 MCD b3 p. 274 and 277142.

247 1817/06/09 MCW b87 p. 293; 1817/06/19 MCW b87 p. 298.

248 1817/08/07 MCW b87 p. 307.

249 1817/10/31 MCD b3 p. 365.

250 1818/05/12 MCD b4 p. 70. 

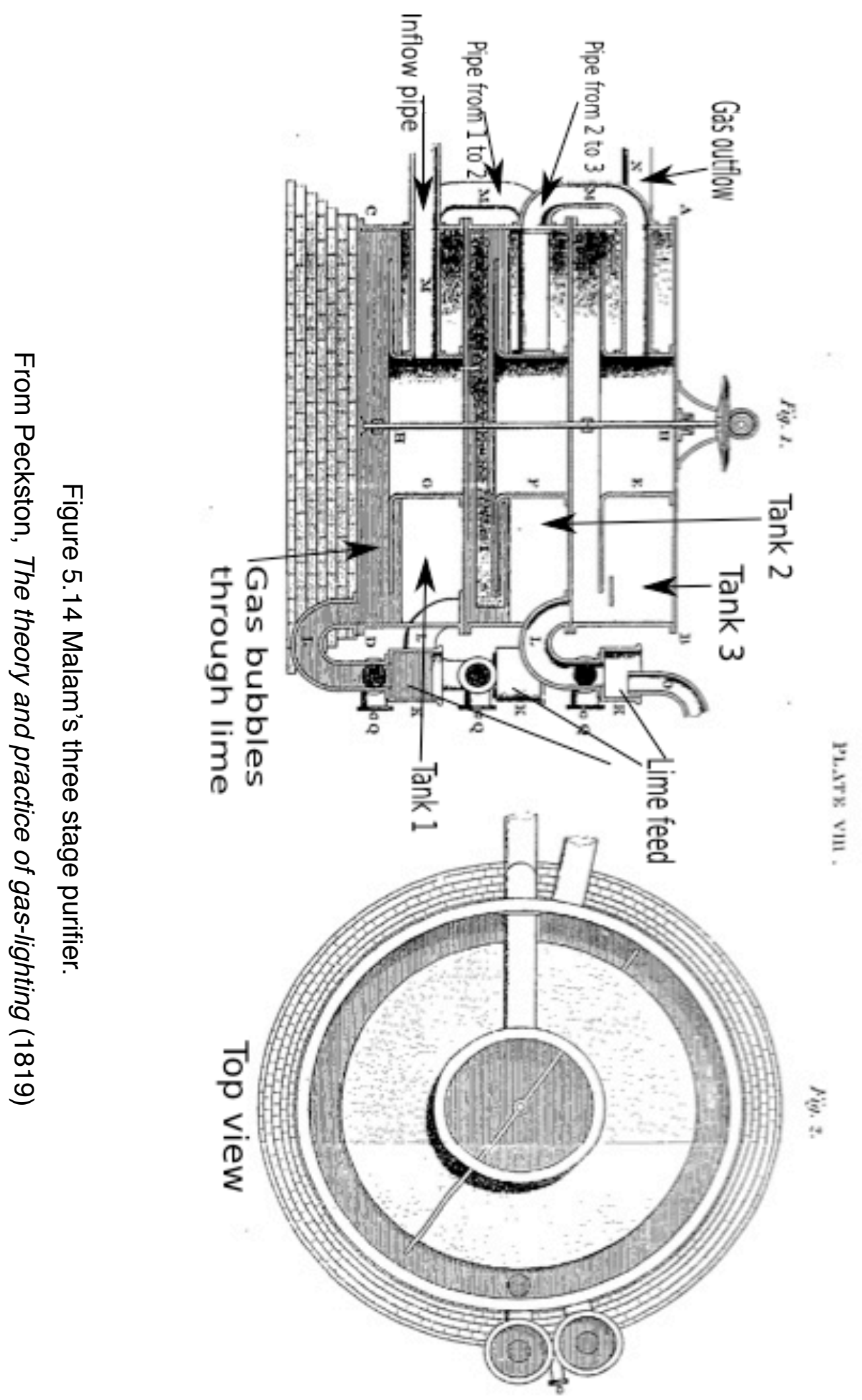
Still not satisfied with the purification, probably due to some complaints, the directors wanted to determine in June of 1818 just how pure the gas was, and whether the situation could be improved by using two purifiers instead of just one. They ordered a series tests for purity to be made at various points during the day for a few days running. ${ }^{251}$ Once completed, they showed that one machine, with lime changed every 12 hours, was less effective than two used in series, each replenished every 24 hours. The Court then ordered that two be used instead of one, and that Malam's purifier be changed into three separate ones. ${ }^{252}$ In fact, Malam's three stage purifier became the most widespread among gas companies, 253 and the one the GLCC used most frequently. By the end of the decade, the purifiers were about 9 feet in diameter. ${ }^{254}$

The company also tried other methods of purification, generally with little success. Daniel Wilson, from Ireland, invented, or at least thought about a new method that involved mixing the gas with 'ammonical gas', and then bubbling it through water. ${ }^{255}$ In December 1816, he made the company a fairly complicated offer of a new machine, which was accepted for the Brick Lane station, a third station the GLCC had purchased in $1815 .{ }^{256} \mathrm{He}$ drew up the details of the design and got to work, ${ }^{257}$ but by August 1817 ,

\footnotetext{
251 1818/06/04 MCW b88 p. 54.

252 1818/06/11 MCW b88 p. 56; 1818/06/15 2529 MCW b88 p. 5758 and 6162.

253 Matthews, Compendium of gas-lighting, 24-31.

254 1820/04/10 MCW b88 p. 323.

255 "Specification of the Patent granted to Daniel Wilson," The repertory of arts, manufactures, and agriculture 2nd series 32, no. 187 (1817).

256 1816/12/24 MCD b3 p. 145 see also 11/29 MCD b3 p. 124.

257 1817/03/18 MCD b3 p. 212.
} 
the company ordered it removed as it had 'proven useless'. ${ }^{258}$ Another attempt was made by Reuben Philips in Exeter. ${ }^{259}$ He patented a dry lime purifier in 1817, similar to what the GLCC had tried at the end of 1816 , as described above. It consisted of mixing the lime with as little water as possible to allow greater freedom of passage for the gas. It also had the very important advantage of not producing the vile liquid waste that so plagued the company and especially its neighbours. In October 1817 Philips approached the company, which sent a delegation to Exeter to see what he had to offer. ${ }^{260}$ The delegation was sufficiently impressed that the directors wrote to Philips, asking for his terms. ${ }^{261}$ After some negotiation, ${ }^{262}$ that included a visit on the part of Philips, ${ }^{263}$ the company decided to turn him down. ${ }^{264}$ The purifier, was however, adopted at a few gas works in England, ${ }^{265}$ and became much more popular later in the century when it was improved.

One other method for purification was suggested which, although not adopted at this point, was used around mid-century. It consisted of using heated iron.266 The

258 1817/08/22 MCD b3 p. 320.

259 "Specification of the Patent granted to Rueben [sic] Phillips," The repertory of arts, manufactures, and agriculture 2nd series 33, no. 194 (1818).

260 1817/10/07 MCD b3 p. 350.

261 1817/10/28 MCD b3 p.362.

262 1817/12/23 MCD b3 p. 403.

263 1818/03/07[?] MCD b3 p. 448-9.

264 1818/06/02 MCD b4 p. 61.

265 Matthews, Compendium of gas-lighting, 29.

266 "Specification of the Patent granted to George Holworthy Palmer," The repertory of arts, manufactures, and agriculture 2nd series 34, no. 202 (1819). 1818/04/16 MCW b88 p. 38.

For other method, see 1819/03/26 MCD b4 p. 274. Charcoal and muriate of lime were also used to purify, suggested by Grafton 1819/10/29 MCD b4 p. 410413. 
company was interested in this technique by certain Palmer in February 1818,267 and ordered experiments. ${ }^{268} \mathrm{~A}$ small machine was subsequently built, but the idea was abandoned. ${ }^{269}$ In the middle of the century, iron oxide proved to be a good way of purifying gas, and had the great advantage of producing only gaseous by-products because the iron could be revivified simply be exposing it to air. It apparently saved the gas industry as by then regulations against the disposal of spent lime had multiplied. ${ }^{270}$ It was a very different situation in 1819 , and the company was satisfied with its existing purifiers. 271

Purifiers were less difficult to design and improve than retorts, but had a far greater impact outside of the company. For the company, the question of retort design was driven fundamentally by economics, and it influenced the gas company's customers only to the extent that the retort design had a direct bearing on the price of gas. Purifier design, however, was a very different affair. Although it had an effect on price, it was nowhere near as important as the retorts. Purifiers affected the gas quality, but perhaps even more importantly, the urban environment as a whole, because of the foul byproducts that flowed from purifiers. Disposal of these by-products became a serious nuisance for the company and its neighbours.

267 1818/02/05 MCW b88 p. 14.

268 1818/02/26 MCW b88 p. 18.

269 1818/02/23 MCW b88 p. 17; Palmer set up a purifier at a gasworks in Macclesfield which some directors visited, but concluded the purifier did little good. 1820/08/18 MCD b5 p. 157, 1820/09/01 MCD b5 p. 167-8.

270 W. R. Bowditch, The analysis, technical valuation, purification and use of coal gas (London: E. and F.N. Spon, 1867), 16-7, 19-21.

271 1819/06/18 MCD b4 p. 331. 


\subsubsection{Purification and pollution}

Purification posed the company very different sorts of challenges than gas generation. The very cost of coal and retorts meant that design questions surrounding generation were about minimizing expense. While purification could be somewhat expensive, the costs were much less. Purifiers did not need to be replaced every few months, and lime was not used in the same quantities as coal. Purification did, however, pose serious environmental problems. The company was at first oblivious to these environmental effects, and only reacted to them once outraged neighbours forced them to act through legal means. Even then, the reaction extended little beyond hiding the worst aspects of the pollution in the vicinity of the plant. This was but a short term fix because the larger scale environmental effects were such that it prompted a broader political reaction, including proposals for some of the first environmental legislation. Purification then became a matter of great importance for the gas industry.

When the company built its plant on Great Peter Street, it made no provision for disposing of the spent lime, which was in fluid form and mixed with putrid sulphur compounds. The neighbours' early opinion of the gas works can be gleaned from the order given in February 1814 to brick up a window over lime vessel. ${ }^{272}$ Worse than the gases were the liquids, which were simply allowed to run into the street sewer. It did not take long before all the neighbours on Peter Street became aware of the presence of sulphur compounds running almost constantly in their sewers. When the company was

272 1814/02/05 MCD b1 p. 265. 
only lighting the streets around Parliament and St. John's Church, the quantities were small, but as the company took on more customers in early 1814 , the volume of effluent increased to the point that some neighbours were more vocal in expressing their displeasure. In March of 1814 , company first thought of putting a pipe in the sewer to take the spent lime directly to the Thames at the low water mark. To do so, however, the company needed the permission of the Commissioners of Sewers, to whom they directed a request to that effect. ${ }^{273}$ The Commissioners were unsure what this would entail, and so they asked for more information, which Clegg provided in person. ${ }^{274}$ The problem was becoming more acute, because not only was the sewer being fouled, but the spent lime cistern at the plant had been overflowing for some time, and poisoning a well at the plant to the 'great annoyance of the neighbours'. The directors solved the immediate problem by paying haulers to take the lime away, presumably to be dumped into the river. ${ }^{275}$

All was quiet until November of 1814 , and the Thames pipe idea was forgotten among other business, when the sewer pipe from the plant into the main Peter Street sewer became clogged. The company needed to repair it, but again required authorization from the paving commissioners to take up pavement. ${ }^{276}$ In the meantime, their solution was to dig hole at the plant, and let the waste lime water run into it. Once it had dried, it could be hauled off at some later date. ${ }^{277}$

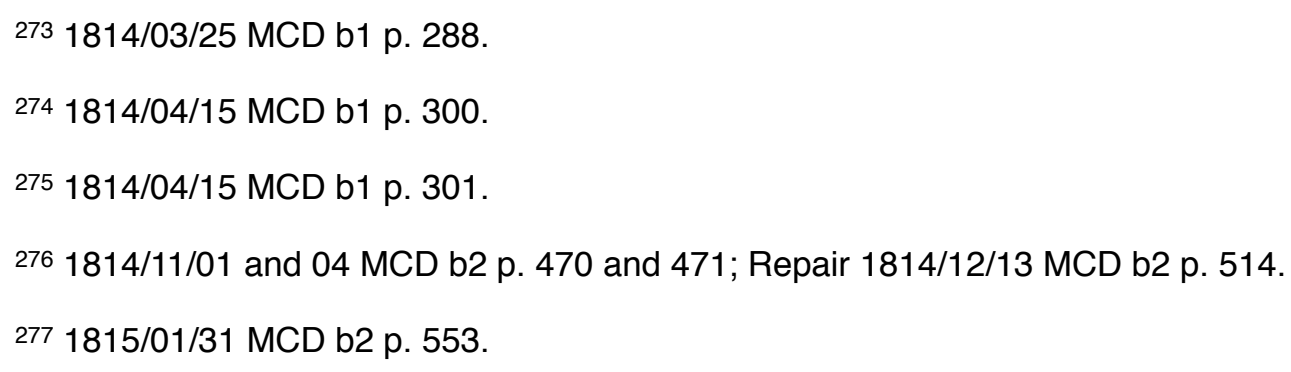


The neighbours, however, were not as satisfied as the company that all was taken care of, and occasional complaints continued to arrive at the station (including one that the gasometer counterweight had punctured the neighbour's roof ${ }^{278}$ ). In January 1816 , the Committee of works at the station recommended that the Court of Directors look into laying a pipe to the Thames as originally planned, and another application was made for permission to do so. ${ }^{279}$ Preparations were underway when Clegg was asked to report how much drop was needed for the Thames pipe, and what volume of water it could be expected to carry.280 A plan was soon ready and presented to the directors, but they had in the meantime started to consider purchasing another plot of land for the plant, closer to the river, where a drain pipe would not be necessary, and so the plan was postponed. 281

The plans for the purchase of new property were cancelled due to a political setback when the House of Lords changed clauses in an act to alter the company's charter, ${ }^{282}$ and the drain pipe scheme came alive once again. The directors contacted the Committee for the Navigation of Thames, which had authority over the river and any works that could affect its course. The navigation committee was interested in knowing the size of the pipe the company proposed to lay. ${ }^{283}$

\footnotetext{
278 1816/01/31 MCW b87 p. 80.

279 1816/01/24 MCW b87 p. 74 01/25 MCD b2 p. 811.

280 1816/01/31 MCW b87 p. 79; To high water mark 1816/02/08 MCW b87 p. 86.

281 1816/02/06 MCD b2 p. 818.

282 1816/04/05 MCD b2 p. 858.

283 1816/03/05 MCD b2 p. 832.
} 
The company's dithering finally exhausted the patience of some locals, and the governor, David Pollock, was indicted in April 1816 by Johnson, Son \& Brice, an immediate neighbour on Peter Street, probably to the east, for damage to their property caused by waste. More forbearing neighbours sent further letters of complaint about waste water in sewers. ${ }^{284}$ Another neighbour, Cosser, claimed that the company's waste had damaged his property. The company did not deny the claim and began negotiations for payment of compensation with Cosser, ${ }^{285}$ and then with Cosser's attorney about the nuisance.286

By June 1816, the situation was quite serious, and complaints about waste water in the sewers were reaching a crescendo. 287 The company could only respond by paying haulers to take away the spent lime in barrels, which they were doing at the rate of 55 loads per week. ${ }^{288}$ The company became frantic over the need to lay the pipe,,289 because Cosser had in the meantime won a Court case against the GLCC. ${ }^{290}$ In the other lawsuit, Johnson \& Co. approached the GLCC about selling their land because they had come to understand that it would be impossible to clean the lime that had leached onto their property. The directors very gladly accepted their offer, and the

\footnotetext{
284 1816/04/11 MCD b2 p. 864.

285 1816/04/18 MCW b87 p. 119.

286 1816/04/25 MCD b2 p. 875.

287 1816/05/27 MCW b87 p. 143.

288 1816/06/03 MCW b87 p. 145.

289 1816/06/07 MCD b3 p. 4.

290 1816/06/07 MCD b3 p. 4.
} 
matter was referred to independent surveyors, although the case against the company was not dropped pending the sale.291

The matter of the pipe still did not reach an immediate conclusion. ${ }^{292}$ In August 1816, the complaints about the lime were constantly coming in, ${ }^{293}$ and as they did, the committee of works urged the Court of Directors to take immediate action on the matter, and the pipe was finally ordered.294 To remedy the immediate problem, the Court solution was to sell the spent lime, but unsurprisingly, found no buyers. ${ }^{295}$ They could only haul it away as before. ${ }^{296}$

For reasons that are not clear, the pipe was delayed once again. Workers were ready to receive orders in August 1816, but none was forthcoming, perhaps because the most pressing legal action from Cosser was concluded.297 The company's works continued to expand all the while, and in October 1816, the single purifier was ordered to be replaced with three, prompting the committee of works to ask the Court about the Thames pipe once again, accompanied by new plans for one.298 The Court obliged by

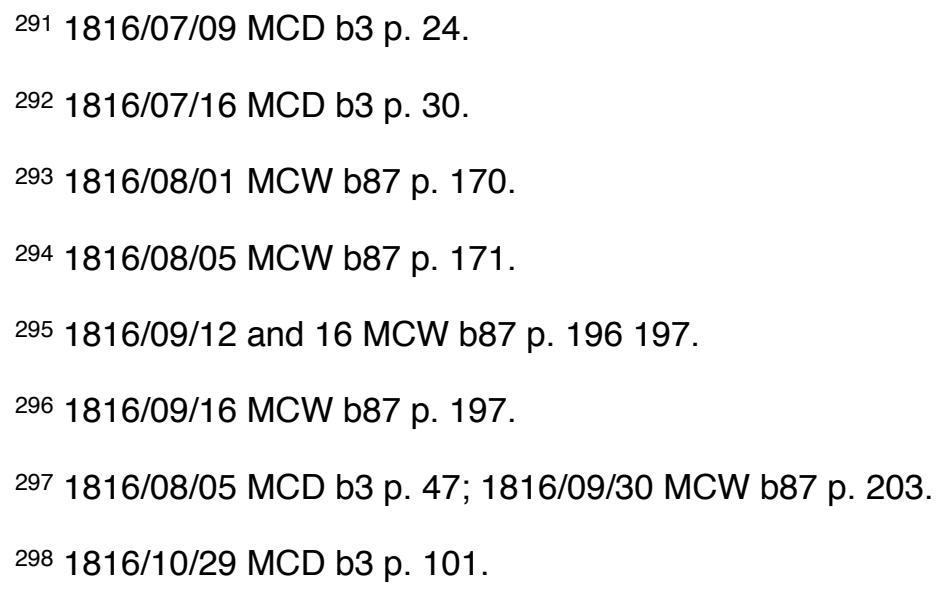


approving them. ${ }^{299}$ The matter soon took on a greater urgency because the hauler the company was using was facing an indictment if he dumped any more waste lime. ${ }^{300}$

Applications were made to the vestry of St. John and St. Margaret to lay pipe to the Thames under Horseferry Road immediately to the south of the Peter Street work. The application was approved with some conditions, 301 but before they could be communicated to the company, opposition to the pipe had built among locals, and the vestry called another special meeting, which Pollock attended. ${ }^{302}$ After some debate, the drain pipe was re-approved in November 1816, with conditions that would be communicated to the company shortly. ${ }^{303}$ These were set in January 1817 , and included the company providing a $£ 500$ bond, and that the GLCC take away the pipe should it be found to be causing a nuisance. ${ }^{304}$ The company got to work right away, and although accidently infringing on Lord Grosvenor's land and the long suffering Johnson \& Co.'s property with the pipe, a problem they quickly rectified, the drain was operating by mid 1817.305

This did not, however, resolve their immediate problems. In March 1817, the spent lime was accumulating at the plant again, and was being dumped into a waste water

\footnotetext{
st. p. 110.

300 1816/10/31 MCW b87 p. 214.

301 1816/11/07 and 12 MCW b87 p. 216218219.

302 1816/11/14 MCW b87 p. 222.

303 1816/12/12 and 23 p. 232235.

304 1817/01/09 MCW b87 p. 239.

305 1817/02/25 MCD b3 p. 194.
}

299 new estimate 1816/10/28 MCW b87 p. $213215 ; 1816 / 11 / 01$ MCD b3 p. 105 not supervised by Peter 
well. The neighbours started to worry, but the company was not too sympathetic. In the case of Johnson \& Co., who were still occupying their premises, it was decided that the waste water well did not need to be lined, as the water was a safe two feet below Johnson \& Co.'s building. ${ }^{306}$ Cosser complained of the smells once again, claiming that waste water was in the sewer again. The GLCC retorted that a water tight syphon has been in use for ten days, and so Cosser had no cause of complaint. Cosser, however, felt otherwise, and was soon sick in bed, and initiating another Court action against the company. ${ }^{307}$ Pollock and Clegg were named in the indictment. ${ }^{308}$

The company responded the only way they knew how, by asking for tenders to cart away lime, which were soon accepted. ${ }^{309}$ They also tried the somewhat desperate move of trying to renew the lime by burning it in a kiln. ${ }^{310}$ The two legal actions against the company were soon resolved, and the GLCC came to terms with Johnson \& Co. in May 1817 that saw them agree to pay Johnson \& Co. several thousand pounds for their property, in addition to the Court penalty which also ran into the thousands, the exact figures not being recorded. ${ }^{311} \mathrm{~A}$ judgement against the company in the Cosser case came in June 1817, which, in addition to financial penalties and legal fees, ordered the company to remediate the damage done to his property. ${ }^{312}$ Cosser was paid $£ 750$ in

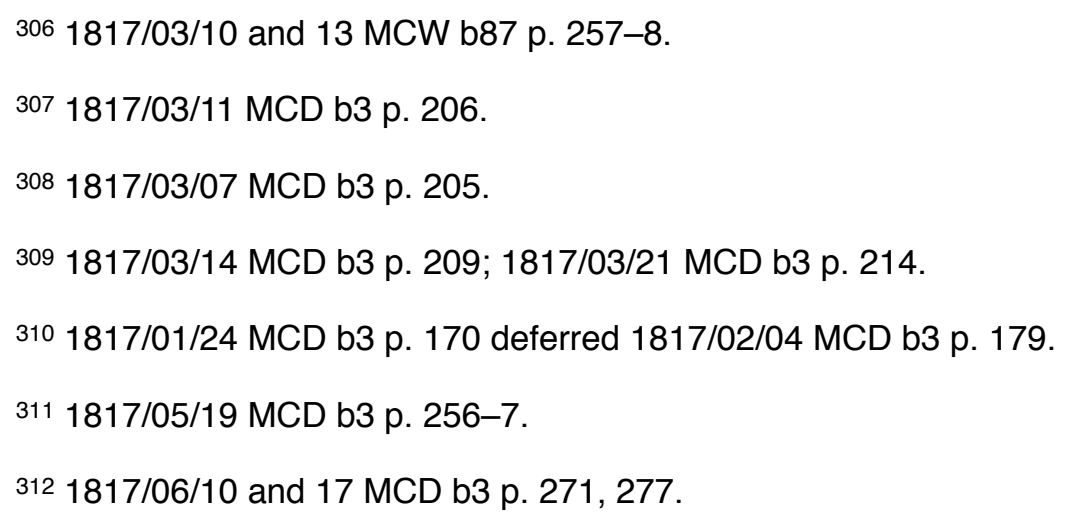


1818,313 but the company found the remediation order too difficult to execute, and had to negotiate with him to find another solution. ${ }^{314}$ Cosser, however, was not heard from again in the company's minutes, so perhaps he died or moved away.

The incorporation of Johnson \& Co.'s land into the plant proceeded after the purchase agreement was signed. 315 Johnson \& Co. had tenants, and although the company wanted to pull down the buildings on the estate, the only way they could do so was to purchase the leases. ${ }^{316}$ These negotiations also dragged on, ${ }^{317}$ but Johnson \& Co. finally moved out in July 1817 , probably with the tenants as well. ${ }^{318}$

The immediate problems were solved, and the Thames pipe was operating, delivering fouled lime and sulphuric acid to the river. The committee of works reported triumphantly in February 1818 that the complaining had ceased. ${ }^{319}$ They were correct, at least for the moment, but other neighbours had to be bought out, 320 and it was not long before yet another neighbour won a judgement against the company, ordering them to prevent seepage onto his land. ${ }^{321}$ There were also other complaints about

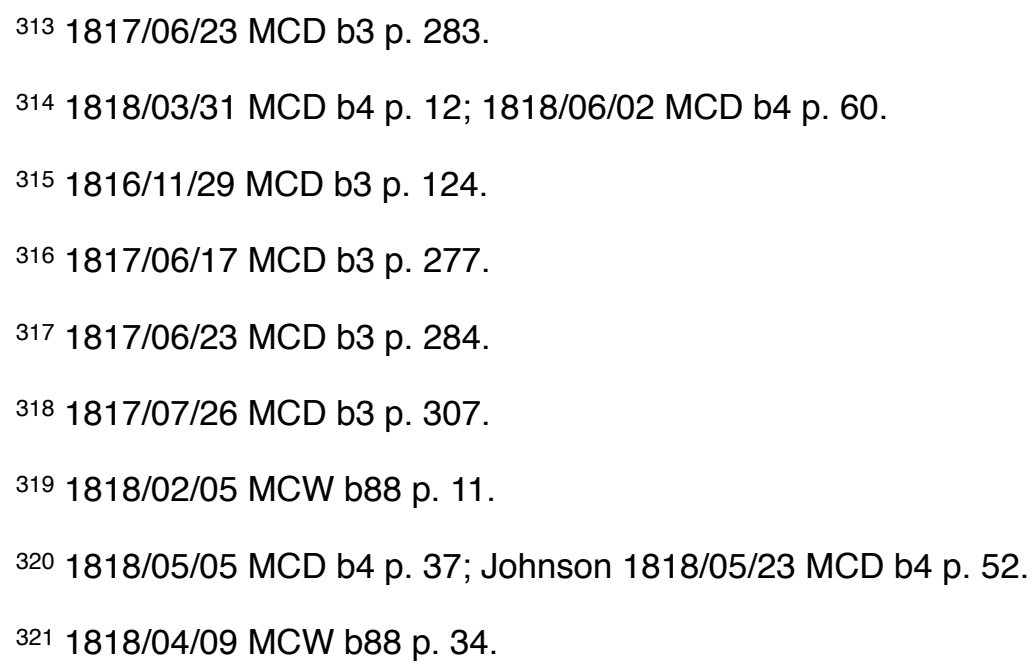


effluvia in sewers, but these were not significant compared to the company's problems in $1814-1817.322$

The longer term effects of dumping the effluent into the river were terrible. The Thames fishery, which apparently still existed in the early nineteenth century, collapsed not long after the gas industry started using the river as its chemical dump. The great irony is that the worst of the water pollution came from the purifiers used to remove sulphur from the coal-gas. The purifiers were effective, but with tragic consequences which the industry consistently showed no interest in addressing, except when forced by the courts or by law. For the industry, gaslight ended with gas, and there was no sense at all-or at least no recognition-that the technology's effects, which were very profound, went beyond providing gas for light.

The company's attitude towards purification was typical of the industry. ${ }^{323}$ Even as early as 1819 , Accum, a defender of the gas industry and someone who made money both as a consultant and an author on gas matters, advocated in his text on gaslight that the government pass laws preventing this practice.

If attempts are made to convey the waste substances into the common sewers or drains of the neighbourhood, the proprietors of gas works are exposed to indictments for a nuisance at the suit of the inhabitants, and when the near proximity of any river or lake induces an attempt to convey the waste material thither, the most serious injury may be

\footnotetext{
322 1819/12/13 MCW b88 p. 271.

323 The other gas company north of the Thames, the City of London Gas Light Company, was similarly embroiled in many lawsuits from neighbours aggrieved by foul smoke and effluvia from their plant. See, for example, "London Adjourned Session, Nov. 18," The Morning Chronicle, Monday, November 201815. "The Inhabitants of St. Bride's v. The Gas Light Company," The Times, Wednesday, Jan 311816.
} 
done to the water, which becoming impregnated with hydrosulphuret of lime is rendered unfit not only for domestic but for many manufacturing purposes. The latter evil indeed is one which operated also in a greater or lesser degree, even when the fœtid refuse or hydrosulpheret is discharged into the common sewers, all of which ultimately empty themselves into some water course, rivulet or lake. I would here beg to suggest, that considering how rapidly the new mode of procuring light is extending throughout Britain, and how much the waters of the country are liable to be contaminated, from the discharging into them the noxious refuse from the process of purifying coal-gas, so as to be rendered proportionably unfit for the various purposes of domestic and manufacturing economy, it is well deserving the attention of the legislature, whether such contamination ought not to be guarded against by prohibiting enactments. 324

The pollution provoked a political reaction that eventually resulted in an 1822 bill 'To prevent Washings, or other Substances arising in the making [of] Gas, being conveyed into any River, Brook, Stream, or Waters'. The preamble to the bill makes clear what the gas industry's effects on watercourses were: 'Whereas the suffering or permitting of the Washings ... arising from ... the manufacture of Gas from Coal ... to run ... into any river ... is not only noxious and destructive to the health of individuals and animals, but also kills and destroys the fish therein; and suffering the escape of such Gas infects the air with a fœtid and noisome effluvia.' 325 The bill did not, however, make it into law, and it would be sometime more before the government made effective

324 Accum, Description of the process of manufacturing coal gas [1819], 147-8.

${ }^{325}$ Bill to prevent Washings, or Substances from Making of Gas, being conveyed into Rivers, 1822, (480). 
moves to prevent the practice. ${ }^{326}$ Later regulations, beginning with the Lighting and Watching Act of 1833 were passed, which prevented gas companies from running the lime into rivers and even having it hauled away during the day by carts. ${ }^{327}$

\subsubsection{Gas supply}

As the GLCC's network of pipes expanded through London, the company was presented with a whole new set of problems in providing even supply to all customers. The network, at first small and limited to a few customers, grew constantly from 1814, and supply problems became a persistent issue. The company had to pursue an active approach to managing supply, which included using and improving gasometers, pressure regulators, leak mitigation, valves, main sizing and placement, interconnections, customer management, and area isolation, all techniques and measures that were developed on the fly, and were really only mastered with years of experience. Supply management was made more difficult because the system was not static and predictable. The gas, generated constantly at the retorts, was stored during the day in the gasometers, and the main valve to the supply network was opened at the beginning of the evening. The company soon learned that the notion that the network of

\footnotetext{
326 See also "Thames Water Question," The Westminster review 12, no. 23 (1830). and "Com. for inquiring into State of Supply of Water to Metropolis; Correspondence between Coms. and Home Dept," in Document type: HOUSE OF COMMONS PAPERS; ACCOUNTS AND PAPERS (1828). Peter M. Roget, "Royal Com. on State of Supply of Water in Metropolis. Report, Appendix," in Document type: HOUSE OF COMMONS PAPERS; REPORTS OF COMMISSIONERS (1828).

327 Joseph Reeson, The acts relating to the supply of gas \& water by companies and local authorities with reference notes and full index (London: Butterworth, 1902), 11-24. The provision including penalties for poisonous effluent are sections XLIX, L, and LXXIV. See also Bowditch, The analysis, technical valuation, purification and use of coal gas, 19. Everard, The history of the Gas Light and Coke Company,

1812-1949, 84.. For a counterpoint, see David Sunderland, "'Disgusting to the imagination and destructive of health'? The metropolitan supply of water, 1820-52," Urban History 30, no. 3 (2003).
} 
mains was mostly airtight during the day, and would begin delivering the gas smoothly once the main valve was opened, was fanciful. Leaks, thieves, and uneven ground all conspired against uniform distribution, and guaranteeing an even supply when gas entered a depleted main network was very difficult. In this regard, Clegg junior wrote in 1841:

There is no branch of science connected with the subject of gas engineering so highly important as that which relates to its conveyance and distribution through pipes. [....] The interests of the Company are not best served simply by increasing the quantity of gas from the same quantity of coal, or improving the lime machine, etc. The laying of streetmains forms the most considerable item in the outlay, and, by a judicious arrangement in the first instance, much may be saved both at first and last. 328

\subsubsection{Wells, syphons, and valves}

The most basic problem was obstructions in the mains, usually from coalescing impurities in the gas. Boulton \& Watt's customers were well acquainted with the water, tar, and other substances that would make their way into the distribution pipes, even with careful purification. Water in the pipes was particularly problematic because it was almost always present in the gas. When it condensed and pooled, it could cause the lamp flames to vibrate annoyingly, or if enough of it was present, it could occlude the pipes completely. Factories could cope with water by removing sections of pipes as needed, or by installing a single drain at the base of the staircase where the pipes

${ }^{328}$ Clegg, A practical treatise on the manufacture and distribution of coal-gas, 166. 
ascended to the upper floors. The GLCC had no such luxury as its pipes were buried under streets. The implications of this were not, however, realized immediately.

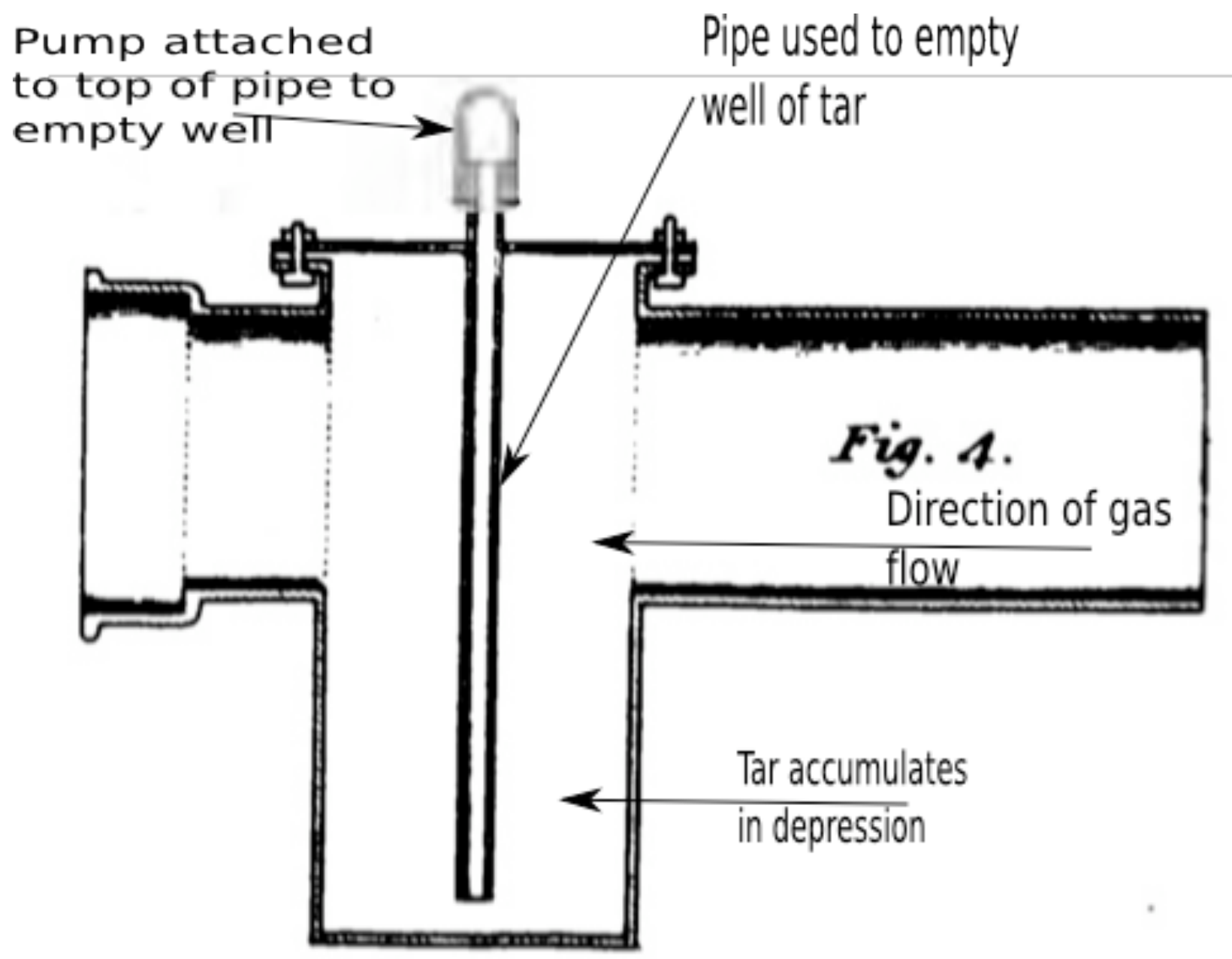

Figure 5.15 Tar well from Peckston The theory and practice of gas-lighting (1819)

When the company initially laid pipes under the street, it simply left some sections of pipe accessible from the street level, covered by easily removable bricks or wood. A section of the pipe could be unscrewed and water and tar drained from it. Even with just the four customers the company had in June 1814, it became evident that this 
manner of draining the mains was too cumbersome. A new way had to be found, ${ }^{329}$ and Clegg proposed a method, which, while not clear from the minutes, was probably what was called a tar well in the gas industry. ${ }^{330}$ It consisted of a cylindrical depression placed at various points along the street mains, into which condensed tar and water could flow. The street mains had to have a certain incline down towards the wells to ensure that the water could collect there. The tar wells then had to be pumped out regularly, although surprisingly enough, the first wells and syphons could only be accessed by breaking the pavement, and it took a resolution from the committee of works to install them in such a way that this was not necessary. ${ }^{331}$

329 1814/06/10 MCD b1 p. 348.

330 Syphons were definitely in use a few months later. See 1814/12/09 MCD b2 p. 506.

331 1815/05/19 MCW b87 p. 13. 


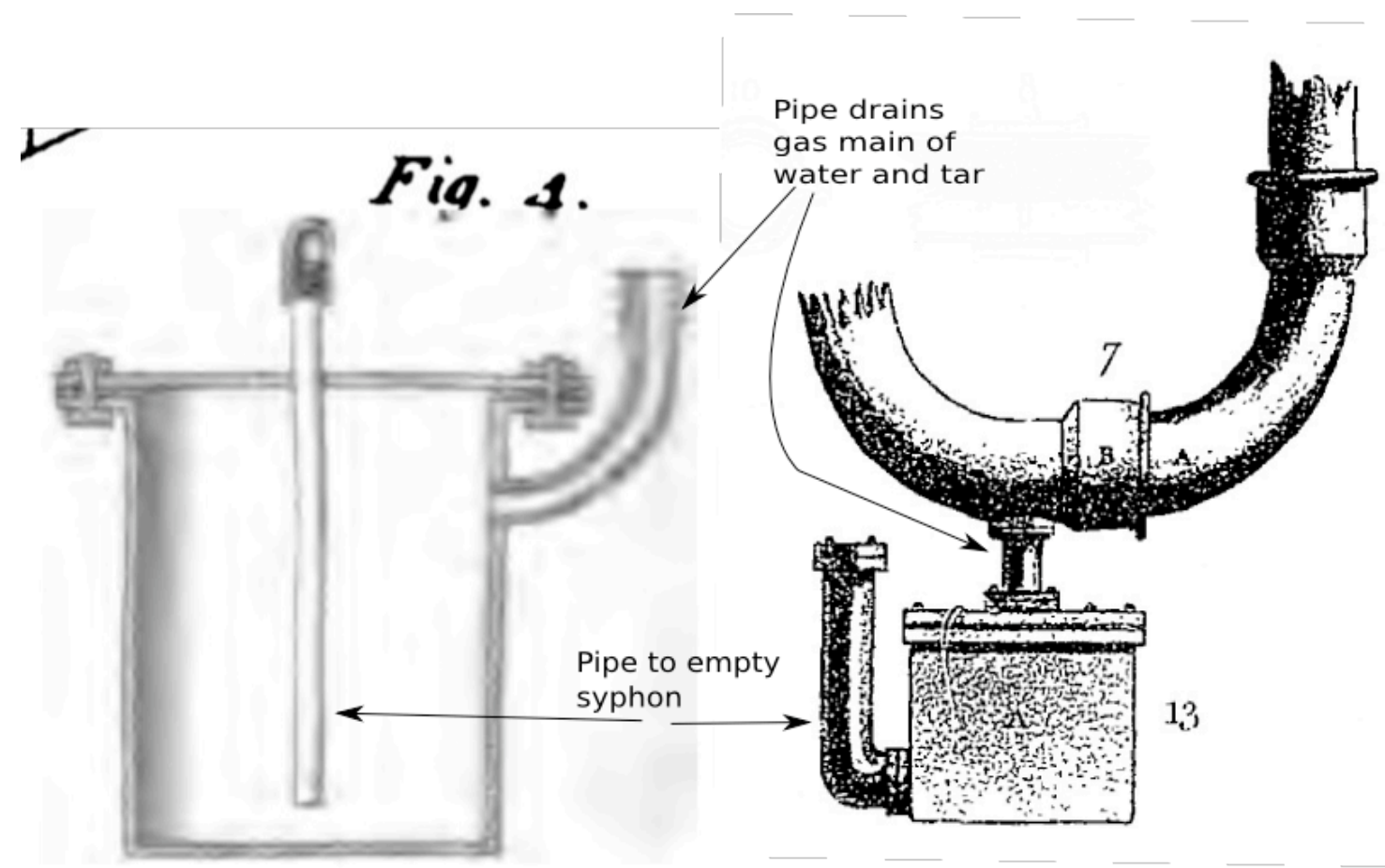

Figure 5.16 Syphon from Peckston The theory and practice of gas-lighting (1819)

Due to their large size, tar wells were only installed along major pipes, but water condensation continued to be a present in smaller mains, and a somewhat different vessel, called a syphon, (though not actually functioning as one) was adopted for these case. ${ }^{332}$ Instead of being integrated with the main as the well was, the syphon drained the water out of the main with a smaller drain pipe. Syphons had to be pumped out from the streets on a regular, even daily basis,, 333 and so the company tried to avoid using them to the extent possible. ${ }^{334}$ If the pumping was neglected, the street lights

332 The syphon in the gas industry is not what is normally called a syphon. For a rant against gas industry naming conventions, see Peckston, The theory and practice of gas-lighting [1819], 279-80.

333 The GLCC decided to use portable pumps to empty syphons $1816 / 11 / 12$ MCW b87 p. 219; $1816 / 11 / 15$ MCD b3 p. 114; This became a daily routine. 1817/02/25 MCD b3 p. 195.

334 1818/01/20 MCD b3 p. 416. 
could decrease in strength or fluctuate noticeably, ${ }^{335}$ and sometimes would even go out. ${ }^{336} \mathrm{~A}$ smaller version was introduced for use in the service pipes leading to buildings. Unlike the street syphons, gas passed through some versions of the house syphons. ${ }^{337}$

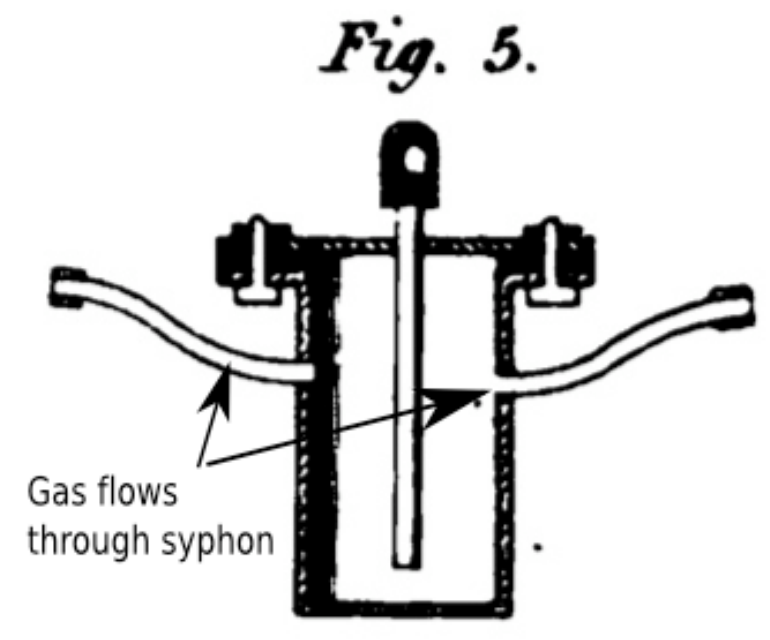

Figure 5.17 House syphon from Peckston The theory and practice of gas-lighting (1819)

335 1817/06/17 MCD b3 p. 278, 1817/06/20 MCD b3 p. 281.

336 1817/05/15 and 22 MCW b87 p. 287.

337 Peckston, The theory and practice of gas-lighting [1819], 279-82. 


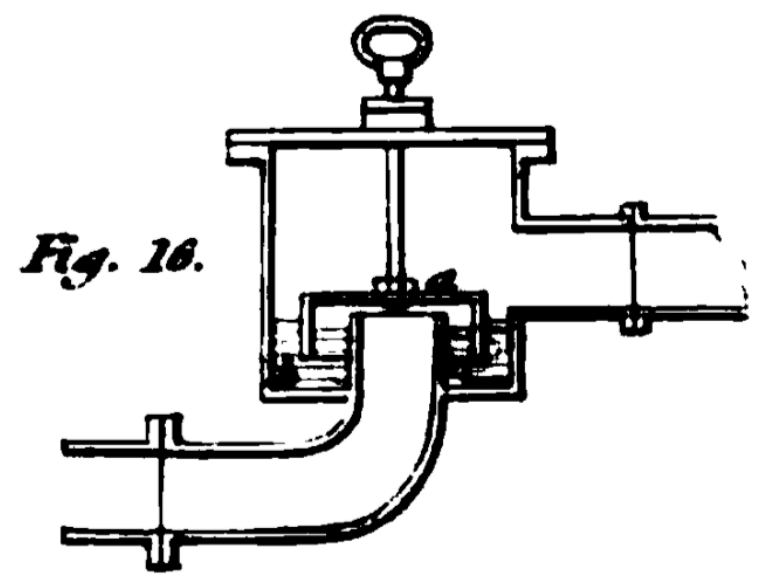

Figure 5.18 Hydraulic valve from Creighton "Gas-Lights." in the Encyclopaedia Britannica (1824)

As the company tried to gain better control over gas flow, it started using stopcocks and pressure regulators in 1814 . The stopcock or valve was attractive because the company discovered not long after it signed up domestic users that being able to cut off a delinquent or abusive customer was an important option to have. In 1814 , the company hired inspectors to monitor gas usage, ${ }^{338}$ and considered making valves a mandatory part of fittings to provide means to make good on threats to cut off abusers. ${ }^{339}$ It did not do so, however, because the first valves it installed proved to be leaky and susceptible to the 'meddling of any curious persons', a situation which, with

338 1814/09/02 MCD b1 p. 415; 1814/09/06 MCD b1 p. 420.

339 1814/09/02 MCD b1 p. 415; 1814/09/06 MCD b1 p. 420. 


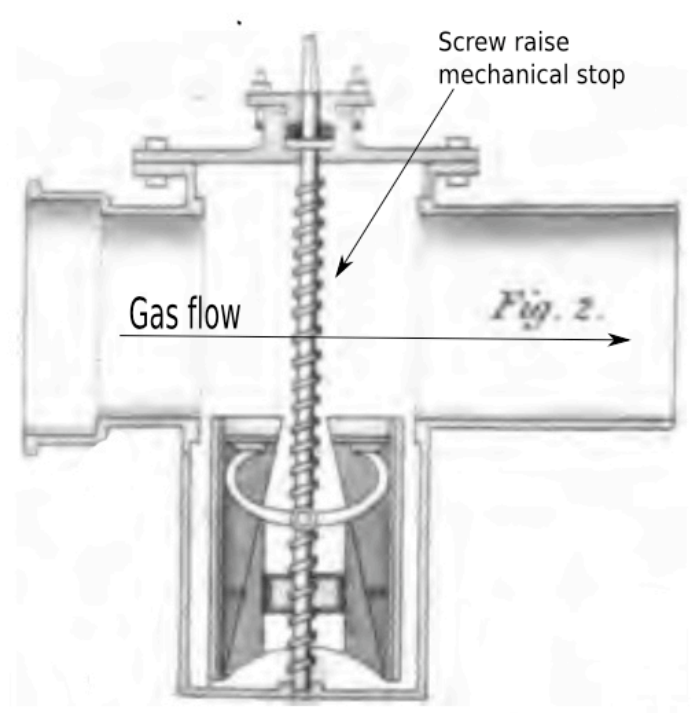

Figure 5.19 Pneumatic valve, Plate XI, from Peckston (1819) the 1813 explosion still fresh in people's minds, did not meet with a welcoming reception. The company redesigned the valves in November 1814 and tried again, ${ }^{340}$ but valves were not still consistently installed at every building where gas was provided. In May of 1815, the company adopted a policy of having them at all buildings that had two or more lights, or where service pipes had been laid, but no gas contract was as yet in

place. ${ }^{341}$ By the end of 1815 , the company decided that all users had to have stopcocks installed, and refused to take new customers until existing customers lacking them had been provided with one. ${ }^{342}$ The company then hired more people to regularly monitor and adjust the stopcocks to ensure that no customers was receiving more gas than required. ${ }^{343}$ In terms of actual construction, two valve types were used. House valves were mechanical, and simply obstructed the flow of gas with a mechanical stop, ${ }^{344}$ while valves on larger mains where having the ability to block the flow completely was more important were hydraulic, meaning they contained water to create a perfect seal.

\footnotetext{
340 1814/11/15 MCD b2 p. 482-3; Stopcocks made part of estimates 1814/12/02 MCD b2 p. 500.

341 1815/05/19 MCW b87 p. 13.

342 1815/10/15 MCD b2 p. 739; 1815/10/20 MCD b2 p. 743.

343 1815/10/27 MCD b2 p. 748.

344 is it MCD b2 p. 804 ? p. 855 See also $1817 / 06 / 10$ MCD b3 p. 270 for improvements.
} 


\subsubsection{Pressure regulation}

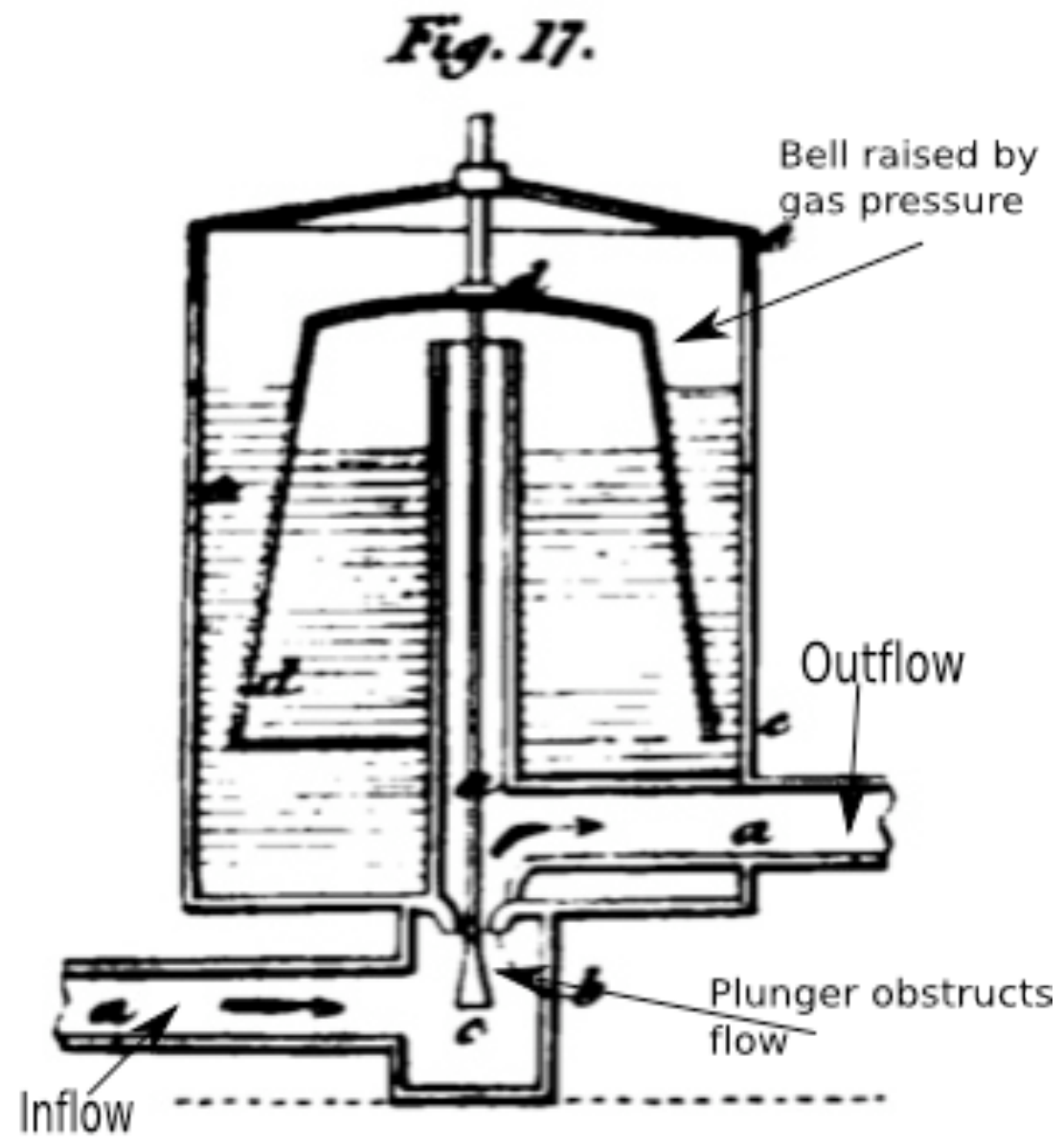

Figure 5.20 Small regulator, from Creighton, "Gas-Lights." in the Encyclopaedia Britannica (1824)

The pressure regulator, sometimes called a governor, was adopted in conjunction with the stopcock. ${ }^{345}$ It was introduced in 1814 by Clegg, and he had an important part in its improvement. The regulator was a fairly simple device that consisted of a bell floating on water, encased in cylinder. Gas entered the bottom of the external cylinder, and communicated with the underside of the bell. The gas continued out one side of 
the cylinder. As the gas pressure increased, it drove the bell upwards, engaging a choke on the gas inflow pipe, and causing the outflow pressure to drop. These regulators were very effective at preventing excessive gas flow, and the directors made it a mandatory part of every fitting in December 1814.346 The order was unevenly applied, but because the regulator worked very well, and the company had a campaign in 1817 to have them installed for every customer to save gas in times of supply problems. ${ }^{347}$ The company thought it was so important that any customer refusing one had his gas supply cut off. 348 Regulators were also used on large street mains to control pressure in entire supply areas. ${ }^{349}$ The design of the regulators remained almost unchanged for decades, although the material of the plunger was changed to clay from metal to prevent corrosion. 350

\footnotetext{
346 1814/12/02 MCD b2 p. 500.

347 1817/06/05 MCW b87 p. 292.

348 1817/07/22 MCD b3 p. 304; Uniformity important: those with regulator get less gas than without: 1817/10/06 MCW b87 p. 324.

349 1817/04/03 MCW b87 p. 265.

350 1817/05/15 MCW b87 p. 286.
} 
Fig. 2 .

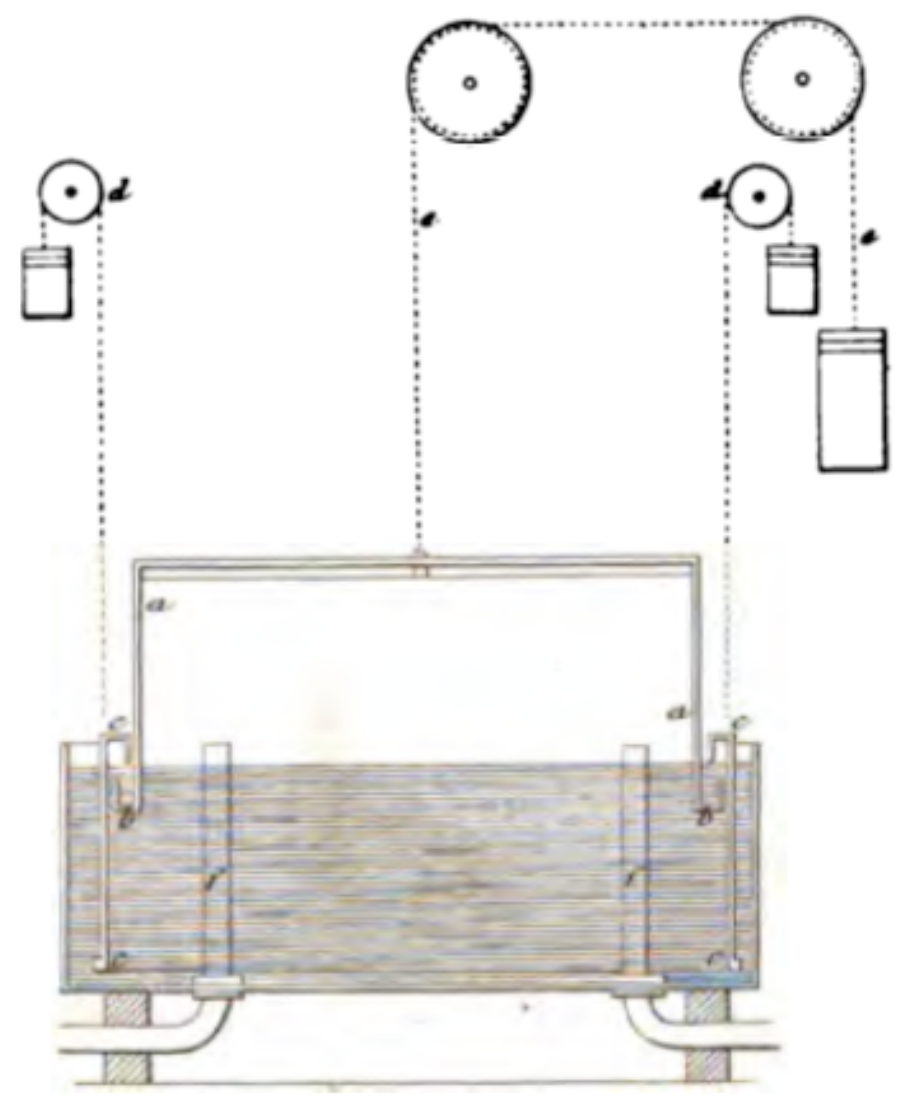

Figure 5.21 Gasometer with three counterweights from Creighton, "Gas-Lights." in the Encyclopaedia Britannica (1824)

The home regulator could really only prevent local overpressure, and other techniques were needed to control flow and pressure in the entire system. To supply gas at constant pressure, Boulton \& Watt's and other early gas apparatus used counterweights on the gasometers, effectively the same method used to regulate pressure on the scientific instrument version of the gasometer. ${ }^{351}$ This could work, but 
required careful calibration of the chains and counterweights. If the counterweight mechanism was not perfectly calibrated, weights had to be loaded on the balance when the gasometer was filled, and removed when the gas was driven into the street mains. ${ }^{352}$ As gasometers grew in size, the chains and weights became more expensive and difficult to adjust, and there were fears that if the chain broke, there would be a pressure spike with unpleasant consequences for consumers as their flames became raging torches. The first gasometers at the GLCC all had counterweights, but in 1815 Clegg developed a version of the pressure regulator that could serve to replace the counterweight system. ${ }^{353}$ Although the development path is not clear, it is almost certainly derived from the simpler regulator described above. It functioned in basically the same way as its smaller relative, but it had an exterior balance with counterweight to dampen the motion of the choke valve and allow for finer adjustment of the pressure. Various versions of this regulator were soon current, but gasometers with counterweights were still in use for many years, probably on small apparatus. ${ }^{354}$

352 Clegg, A practical treatise on the manufacture and distribution of coal-gas, 133-4.

353 "Specification of the Patent granted to Samuel Clegg." The date stated in this article is 1816, but the actual date was 1815. See Patents for inventions. Abridgments of specifications relating to the production and applications of gas, 16. among others.

354 See Peckston (1819), Accum (1819), Creighton (1824) and Matthews (1827). Even Clegg jr still mentions them. Clegg, A practical treatise on the manufacture and distribution of coal-gas, 133-4. Thomas S. Peckston, "Review: The Theory and Practice of Gas-lighting, in which is exhibited a Historical Sketch of the Rise and Progress of the Science," Philosophical Magazine and Journal 53 (1819). takes Peckston to task for discussing counterweights as if they were still relevant. 
F. 5.

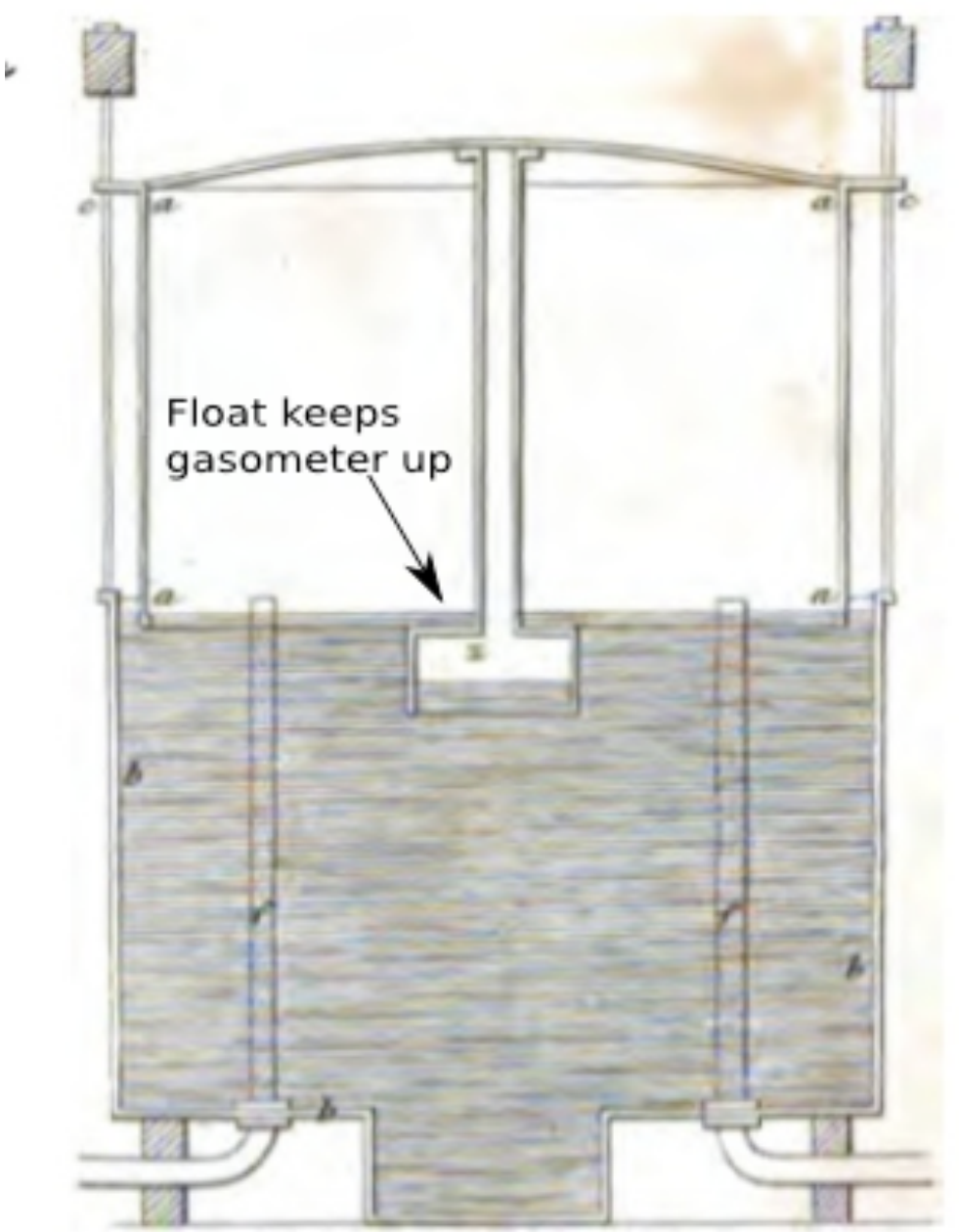

Figure 5.22 Gasometer with no counterweights

from Creighton, "Gas-Lights." in the Encyclopaedia Britannica (1824) 


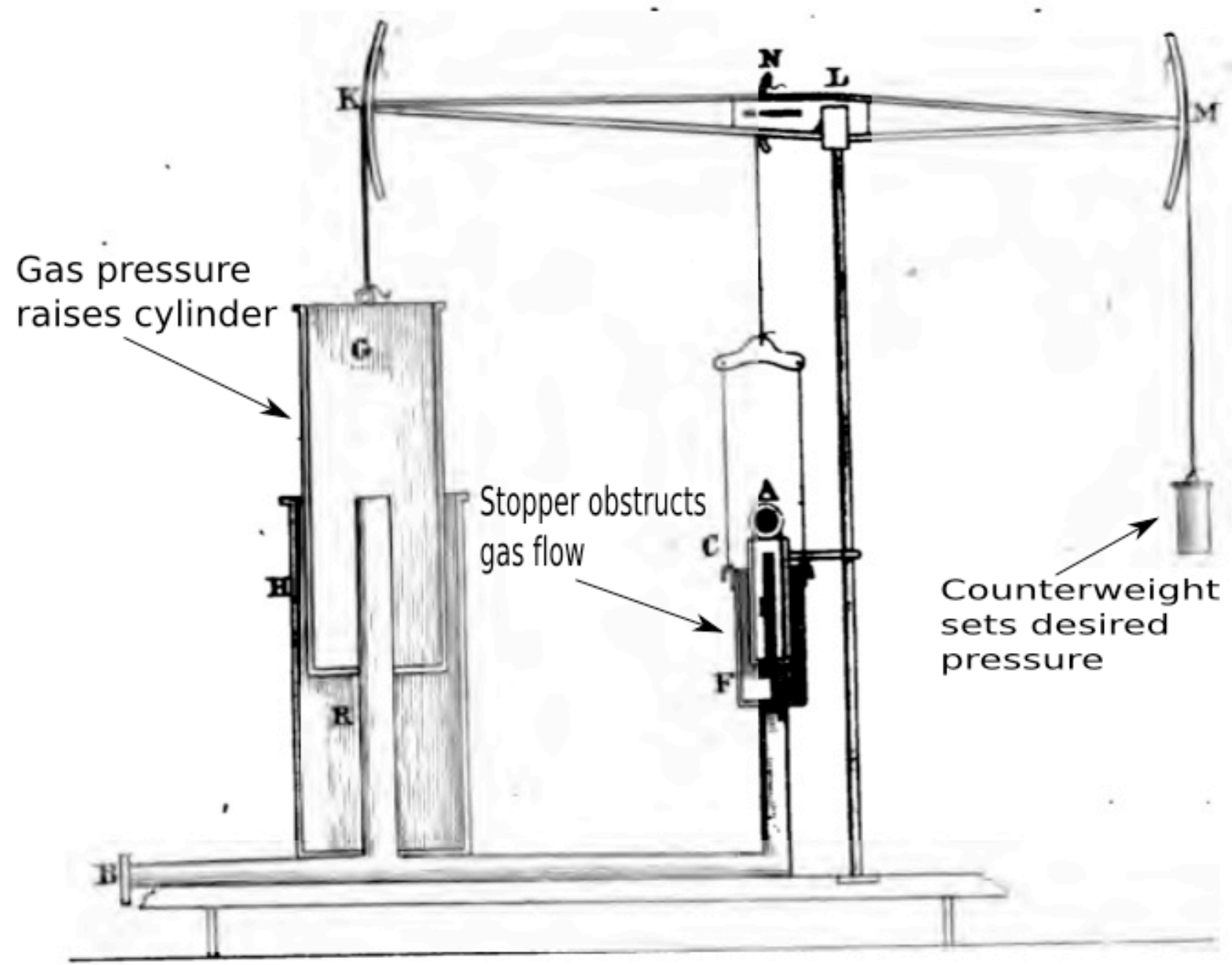

Figure 5.23 Large regulator

from "Specification of the Patent granted to Samuel Clegg." The repertory of arts, manufactures, and agriculture 2nd series 30, no. 175, 176, 177 (1816): 1-10, 65-75, 129-37, reprinted in Quarterly Journal (1817) 


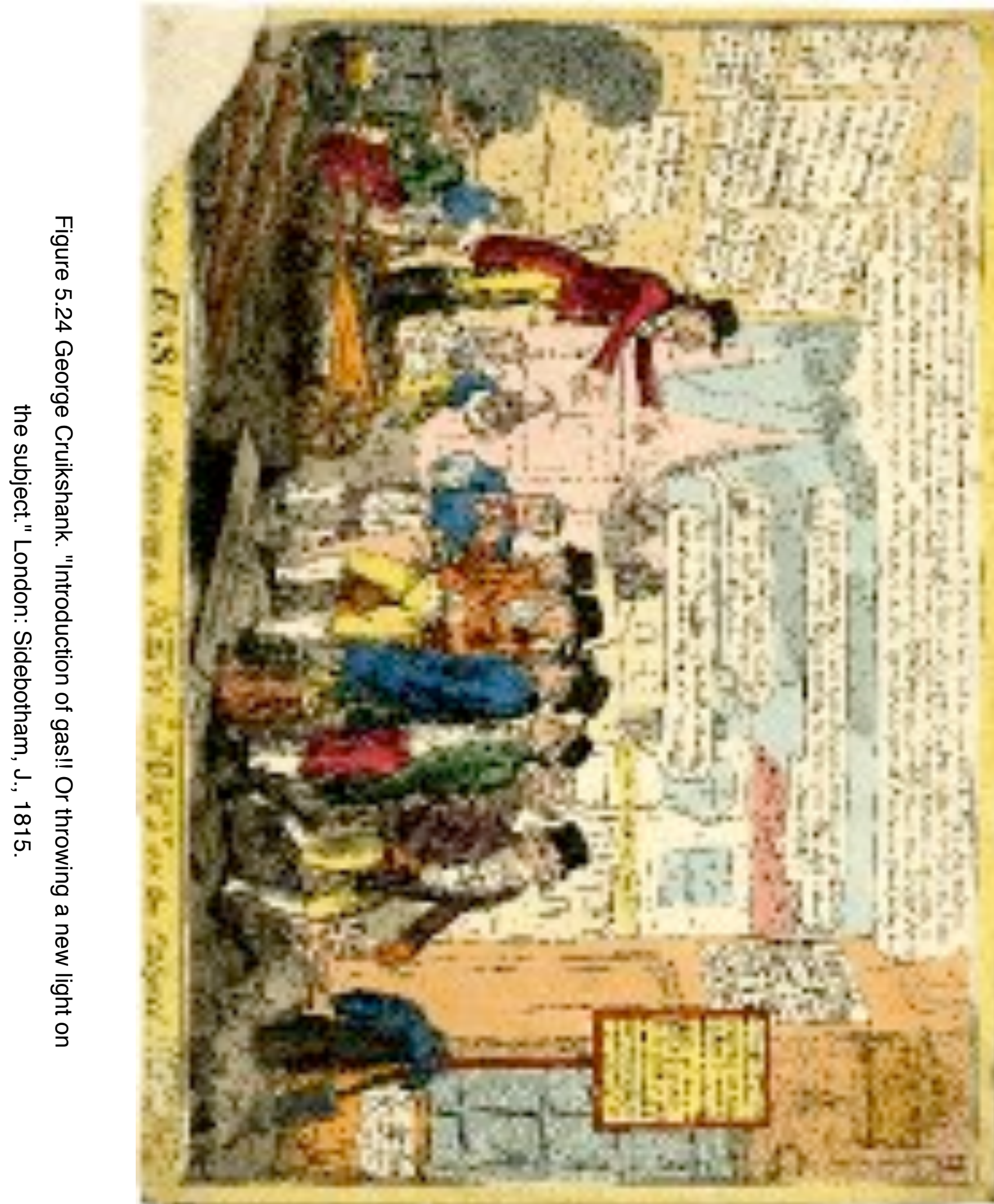




\subsubsection{Leak mitigation}

Leaks from holes that developed over time and from burners that were left open were a constant problem for the company, and in the first few years it developed ways of preventing and dealing with them. If the leaks were large enough, air would also enter the pipe network and cause further problems, such as sputtering or dying flames. ${ }^{355}$ In homes, leaky fittings were also a source of complaint from customers due to the smells the gas created. Leaks caused the greatest problem right when the main valve to the street network was opened in the afternoon because it was then that users turned on their gas, only to get air from their burners. It would take some time before the gas from the station would drive the air out and allow for normal use, but by then, the customers were quite upset.
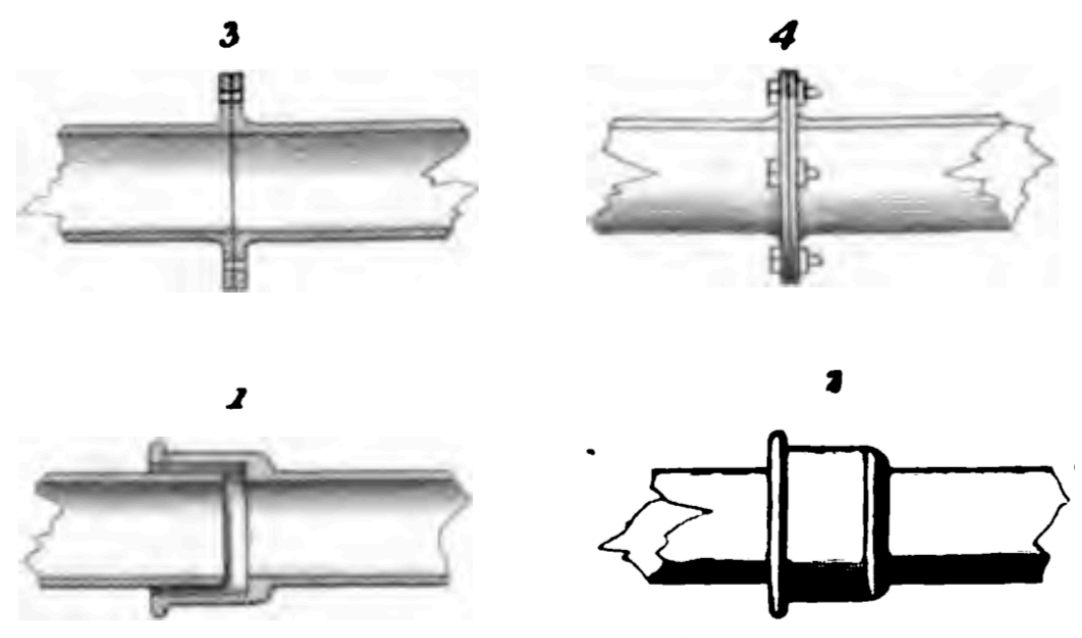

Figure 5.25 Pipe connections, from Peckston The theory and practice of gas-lighting (1819) 
One of the first steps the company took to aid in fixing leaks was to introduce easier ways of connecting pipes. The company at first used pipes with flanged ends that could be screwed together and sealed with cement, but replaced this method for most situations with socket joints, also known as spigot and faucet, on Clegg's recommendation. These were tried in the second half of $1814,{ }^{356}$ and adopted as the standard in October 1814.357

The problem with leaks became acute in 1815 . Within two years of laying having been installed, some of the street mains had to be dug up to be repaired. ${ }^{358}$ Clegg reported in May 1815 that there were 'many very bad joints' and that the network from the Curtain Road station was losing $200 \mathrm{ft}^{3}$ per hour to leaks. ${ }^{359}$ As a preventive measure, the company adopted pressure testing of pipes before any were installed in the streets, ${ }^{360}$ but in the meantime, it was left with little choice but to 'feed the leaks' during the day. ${ }^{361}$ The directors ordered Clegg to determine what the leakage in the whole system was, ${ }^{362}$ and when it proved to be substantial, he was ordered to isolate each main to identify the worst leaks and fix them. ${ }^{363}$ To mitigate leaks in the fittings inside buildings, the company in March 1815 started to do pressure tests of fittings with

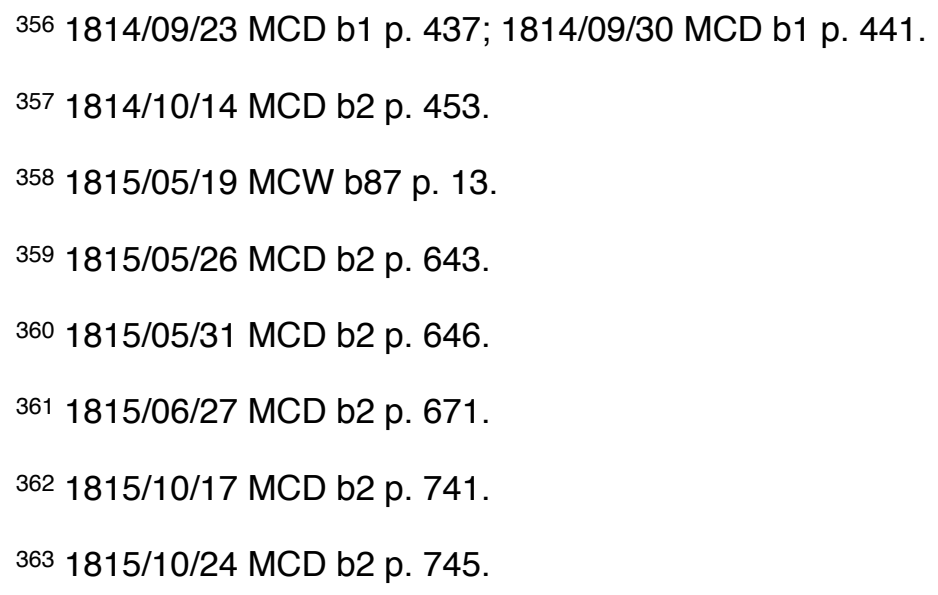


an air pump before connecting them to the system, ${ }^{364}$ and the Court of Directors many times reiterated the need to test fittings before new customers were connected. ${ }^{365}$ In November 1815 , the company started finding people using gas with whom it had never entered into any contract, and who had very poorly installed fittings that leaked much gas. Stopcocks were immediately installed and the gas cut off. The inspectors were ordered to be vigilant for this sort of this situation. ${ }^{366}$

With winter and longer nights fast approaching, the supply situation looked stark, especially since the company had failed to finish a new gasometer in November 1815 as planned. A greater number of customers started to complain about low pressure that month. 367 By December 1815, despite all the efforts to find and fix leaks, the company was in a supply crisis. The many remaining leaks were frantically sought, and more inspectors hired to ensure that customers, especially the 'Public Houses' did not burn with flames greater than six inches in length. ${ }^{368}$ The opening time for the main street valve was moved up to $1: 00 \mathrm{pm}$ to bring the network up to pressure as early as possible. ${ }^{369}$ The company limped through the rest of the winter, and when spring and longer days came again in 1816 , the directors evaluated what could be done to reduce the leakage which had crippled them, and nearly caused very embarrassing supply failures. In April 1816, Clegg made a series of recommendations. He suggested that

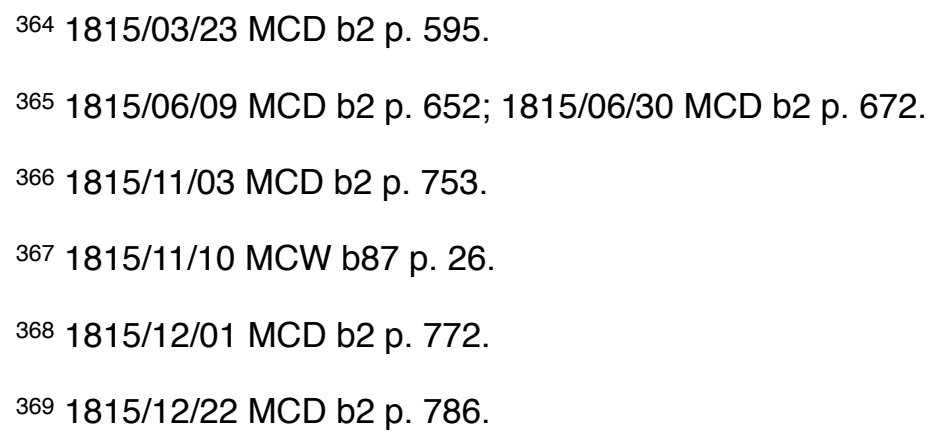


hydraulic valves be placed 'at least every 60 yards' along new mains, and that they be tested against leaks two weeks after being laid, using a portable gasometer to pressurize the pipes. ${ }^{370}$ After considering the cost, the directors adopted Clegg's plan. ${ }^{371}$

Clegg's plan worked for preventing some of the worst of the main leaks in new sections, but the committee of works was of the opinion that 'the great loss of gas is ... from some cause or other not yet exactly ascertained. 372 The rest of 1816 featured the consideration and sometimes adoption of a whole series of new measures to reduce the loss of gas to leakage. The company thought about providing large customers such as theatres their own gasometers on site to mitigate their impact on the surrounding mains, ${ }^{373}$ an idea floated the previous year for individual streets, ${ }^{374}$ but never adopted. In addition to the mains, pressure testing of new syphons and valves before installation was started. ${ }^{375}$ All valves were replaced with hydraulic ones that were less prone to leaks. ${ }^{376}$ The 'gun barrels' or service pipes were to be tarred once a year, ${ }^{377}$ and tar was to be applied to the joints where the service pipes were connected. ${ }^{378}$ These measures and others helped, but the company experienced occasional failures and continued

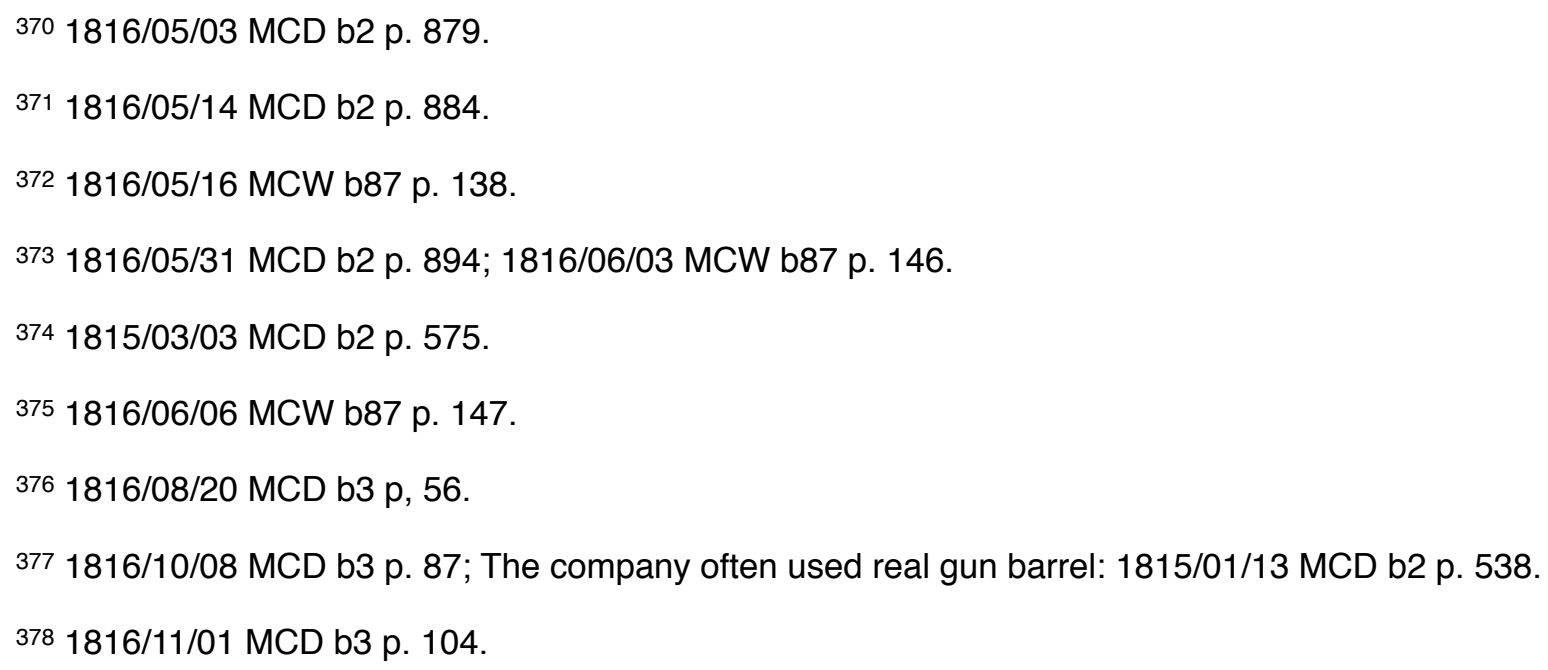


leakage. In one case in 1818, the company's mains in Westminster, their oldest ones, has so much air in them that the vandalism was suspected. ${ }^{379}$ In another case that happened in September and October 1818, many customers in Oxford and Bond streets were complaining about low pressure. .800 Tests confirmed that the supply was indeed weak in the area, and the company at first thought it was because they were low lying. They tried to remedy the problem by planning another supply main to the area. ${ }^{381}$ Just before the work was to commence, a large pressure drop was discovered in a 12 inch main in Wardour Street. Further investigation revealed that water collecting in the main was obstructing gas flow. The removal of 340 gallons caused a doubling of pressure in the affected areas, ${ }^{382}$ and a valve had to be inserted in the feeder main to lower the pressure. ${ }^{383}$ With the problem was solved, the committee of works investigate why, despite regular tests, the pressure drop was not detected, and the answer was that although the main was checked, the sample points were not sufficiently near to make the obstructions evident. ${ }^{384}$

The company was also more careful in hunting down people who let air into the mains by leaving the burners open during the day. When a neighbour of the Duke of Marlborough on St. James Street complained that his lights were going out frequently, it was discovered that the duke's servants were neglecting to turn the valves off during

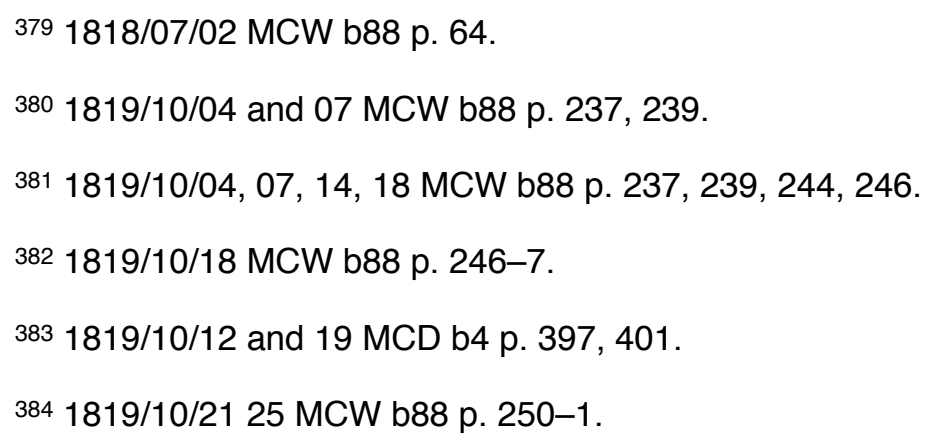


the day, emptying the surrounding mains of gas. The company appointed one of their own employees to shut off the street valve to the duke's house every day. ${ }^{385}$ This solution worked for large consumers such as a stately house, but such behaviour was common. Many consumers simply burned during the day, or left their lamp valves open, depleting the system pressure and causing problems for the coming night. ${ }^{386}$ The company responded by using inspectors, and by shutting down valves at major junctions during the day to limit the extent of gas depletion. 387

\subsubsection{Supply management}

In terms of ensuring adequate supply to the whole system and specific supply zones on a larger scale, the company at first simply tried to estimate the best main size before installing it, but lacking any information or even plans about future expansion, these could have been little more than a guess. ${ }^{388}$ Later, when fresh mains were laid on streets, the company would calculate the maximum demand for gas assuming all buildings along the street would eventually subscribe. ${ }^{389}$ Longer term strategy for mains was not really present for the first couple of years, and the company was basically reacting to customers. This mostly directionless activity did not long survive because supply problems soon appeared, with individual customers and sometimes entire areas

\footnotetext{
385 1817/01/27 MCW b87 p. 245.

386 1819/11/08 MCW b88 p. 257.

387 1819/11/11 MCW b88 p. 258.

388 see, for example, 1814/09/09 MCD b1 p. 423-4, where Clegg suggested basic rules of thumb for main size. Four times the current load, if there are no lamps attached, and eight time if there are.

389 1814/10/07 MCD b2 p. 448.
} 
complaining of lacking sufficient supply. The company began to be more judicious in laying mains and understanding and controlling the network they had built.

More controlled management started in March and April 1815, when all the existing mains including the location of syphons were mapped. ${ }^{390}$ The directors resolved in December of that year to keep log books including as many details as possible about their network, such as main locations and sizes, location and size of all burners, number, type and location of all valves, syphons, and stopcocks, information which formed the basis of more effective supply management. ${ }^{391}$ Following through on such an order was essential for supply management, but unfortunately for the company, it was not kept faithfully enough, as later events were to show. The desire for more even supply did produce some results, such as the adoption of pressure regulators described above. Another was the move made later in the year to increase the number of junctions between areas to make gas supplies more robust. 392 These measures were adequate for the moment, but the network in the first 3 or 4 years was still quite small, and more serious problems would emerge as the pipes spread to areas with different elevation.

Methane and hydrogen are both lighter than air, and flow upward in the pipes when the ends are open to the atmosphere, as happens with burners. This was well known, and was the reason why gasometers had to be situated in pits. For Boulton \& Watt and their customers, the final number of burners and their location were planned

\footnotetext{
390 1815/03/17 MCD b2 p. 588; 1815/04/28 MCD b2 p. 617; Repeat order 1815/07/11 MCD b2 p. 684. 391 1815/11/20 MCD b2 p. 770-1.

392 1815/10/13 MCD b2 p. 738; 1817/10/09 MCW b87 p. 325.
} 
before the plant was constructed, and so locating the gasometer at a sufficient depth below the burners was perfectly adequate to ensure even supply. It was, however, a different question for the gas company in London. Although the gasometers could be dug low enough into the ground to ensure it was lower than most of the city, new supply areas higher or lower than the average would receive particularly strong or weak supply, and have an impact on surrounding areas. One of the first instances of this was on Tothill Street in Westminster in April 1817. Although not very elevated, it was sufficiently so to pose a problem because it drained the surrounding area of gas and lamps there easily produced long flames. It was suggest to isolate the street from the rest of the network with a regulator, ${ }^{393}$ and the idea worked well. ${ }^{394}$ This technique was applied at other streets, such as on the Strand, ${ }^{395}$ and other locations, ${ }^{396}$ and the use of regulators to isolate the network in elevated zones eventually became the industry standard practice. 397

The other important factor in ensuring adequate supply was main size, and the company did not have a firm grasp of the capacity of its network until supply problems forced them to look into it. When demand on a street had outgrown the main's capacity, the company began laying double mains, ${ }^{398}$ which evidently helped a great deal. ${ }^{399}$ This

\footnotetext{
393 1817/04/03 MCW b87 p. 265.

394 1817/07/14 MCW b87 p. 302.

395 1819/11/04 MCW b88 p. 254.

396 1818/08/28 MCD b4 p. 129; 1820/03/09 MCW b88 p. 308.

397 Clegg, A practical treatise on the manufacture and distribution of coal-gas, 169.

398 1817/11/03 MCW b87 p. 331.

399 1818/09/03 MCW b88 p. 83.
} 
measure was adequate for individual streets, but the strong overall growth in demand for gas meant that the largest supply mains going back to the stations were not entirely satisfactory, a situation which came to the fore in the second half of 1818 . Supply deficiencies started happening with greater frequency, and the directors ordered a major report of the pressure and cross-sectional area of the mains at Charing Cross, the major originating junction for all the mains supplied by the Peter Street works. ${ }^{400}$ Remarkably, the report revealed that the outflow mains from Charing Cross had a total crosssectional area twice that of the inflow main, meaning that the pressure dropped by a half through the junction. The directors immediately ordered an extra inflow main from the station to Charing Cross. 401

Further investigations revealed that the weak supply problem was also a dynamic one. The company on a specific day took extra measures to ensure that none of their daytime gas thieves were allowed to turn their lamps on, and once the main valve was opened, the gas pressure was good all night. The conclusion was that imbalances were created in the system during the day when pipes were drained too soon, and the system never had a chance to reach a steady state during the night, causing local deficiencies. The company tried to open the main valve early, 402 but this proved to be of little value because the gas thieves turned their lamps on at 2:00 pm, too early for the company. The company's next response was to hire another inspector, ${ }^{403}$ and a month later to

\footnotetext{
400 1818/08/31 MCW b88 p. 79-81.

401 1818/09/01 MCD b4 p. 132. There was hesitation before this.

402 1818/10/05 MCW b88 p. 94-96.

403 1818/10/22 26 MCW b88 p. 106109.
} 
segment the supply network with more major valves. ${ }^{404}$ This limited the dynamic effect of daytime depletion to certain zones, and gave greater stability to the whole network.

In the end, these measures were still not enough, and the company understood that the Peter Street works simply did not have sufficient generating capacity. ${ }^{405}$ A new solution came by transferring some of its load to another station. The mains from the stations reached each other in 1817 , and although they were connected that year, no gas was allowed to flow between the respective systems. ${ }^{406}$ Another supply crisis in the winter of $1818-9$ prompted the transfer of a large area to the Brick Lane station. ${ }^{407}$

The net results of all these measures, from local valves to system wide pressure regulations, and from inspectors and threats to leak mitigation, allowed the company to build a sprawling network of mains many miles in lengths feeding thousands of lamps. The achievement may seem simple after the fact with 200 years of existence, but for the company and its engineers, building a robust system required constant innovation and vigilance. Before the system was built, the model envisaged by the company, as presented to the House of Commons in 1809 , was that of smaller plants providing gas for a few homes or streets. What emerged a decade later was much grander in scale. As Peckston wrote in 1819: 'A few years ago, had any one advanced as his opinion, the possibility of lighting, from one gas manufactory, a combination of streets of many miles in length, he would have been looked upon as little better than a madman. Indeed,

404 1819/11/11 MCW b88 p. 258.

405 1818/10/12 MCW b88 p. 100-101.

406 1817/09/26, 28, 30 MCD b3 p. 340, 344.

407 1819/10/08 MCD b4 p. 395; 1819/10/21 MCW b88 p. 249. Moving to curved junctions rather than right angle ones helped as well. 1817/04/11 MCD b3 p. 226. 
when the gas was first conveyed to the distance of about half a mile from the manufactory it was considered as a wonderful performance.' 408 Within ten years of its incorporation, the GLCC and many other gas companies had succeeded through much trial and error.

\subsection{Opposition from the oil trade}

New technologies frequently encounter resistance, and gaslight is no exception. 409 The spread of gaslight was rapid, and since it served the already existing purpose of lighting, it caused massive disruptions in the industry it displaced, the oil trade. At the beginning of the nineteenth century, the oil trade was substantial, including hundreds of ships plying the oceans hunting whales for their blubber. The owners of these ship were quite wealthy, and they were not content to allow their wealth and means of livelihood to be destroyed by a new technology without opposing it in some way. Though less concentrated than Boulton \& Watt, these whaling interests fought the company's charter leading up to 1809 , usually by claiming that if gaslight destroyed the whaling industry, it would also destroy the training field for most of England's seamen, and hence undermine English naval supremacy and the very existence of the nation. ${ }^{410}$ Winsor and his backers felt the need to refute their charges that gas would destroy the

408 Peckston, The theory and practice of gas-lighting [1819], 283.

409 There seemed to regular episodes of lamps being smashed, as every amendment to the GLCC's charter mentioned the penalties to those caught damaging the company's properties.

410 The opposition before 1810 is mentioned in Thomas Cooper, Some information concerning gas lights (Philadelphia: Published by John Conrad \& Co. J. Maxwell: printer., 1816), 177. 
'nursery of seamen' in their literature leading up to the act of incorporation. ${ }^{411}$ The Hyde episode described in chapter four also appears to be connected with the oil trade.

The confrontation between oil and gas was unintentionally exacerbated by how the controversy surrounding the GLCC's incorporation influenced the form of its charter. One of the more frequent objections raised against the company during parliamentary battles of $1808-1810$ concerned its supposed monopoly powers. The company, so the argument went, being some sort of corporate behemoth dreamt up by the megalomaniac Winsor, would have far too much pricing power over the local lighting authorities. A clause intended to blunt these criticism was inserted in the charter. It required that the company provide brighter lamps for a better rate than the equivalent oil lamps, and for fourteen year contracts to any local lighting authority that requested it. 412 In point of fact, the monopoly threat proved to be nugatory, and requests for gaslight from local authorities flooded into the company's offices. Gaslight was better than oil lamps and consumers had no hesitation in switching. The requirement to provide cheap light to the lighting authorities meant, however, that the already tense situation in regard to the whale fisheries became a real confrontation as lighting authorities had very little reason not to switch to gas. From the time the company was in operation and taking contracts from oil merchants, the struggle against gas became a question of survival for

\footnotetext{
411 Frederick Albert Winsor, Plain Questions and Answers (London: G. Sydney, Northumberland Street, Strand, 1807), [238] 3. Considerations on the nature and objects of the intended Light and Heat Company : published by authority of the committee., (London: Printed for James Ridgway by T. Davison, 1808), 24.

412 An act [50 Geo.III cap. clxiii] for granting certain Powers and Authorities to a Company to be incorporated by Charter, to be called The Gas Light and Coke Company for making Inflammable Aire for the lighting of the Streets of the Metropolis, and for procuring Coke, Oil, Tar, Pitch, Asphaltum, Ammoniacal Liquor, and essential Oil, from Coal, and for other Purposes relating thereto, (9 June 1810), XXIV-XXV.
} 
the incumbent industry. The first decade of the company's existence saw periodic bursts of opposition from the whaling industry in various ways.

The oil trade's first attack on the company after its incorporation came at the end of 1814 in a series of letters published anonymously in The Times. The letters do not have an overt motivation other than being opposed to gaslight for safety reasons, and so may have been from sources outside the oil trade, but the gas company certainly did not think so. The inaugural letter was by Civis, who wanted to warn 'the public against a danger to which they will soon be exposed, and of which as yet they seem to be unconscious. The general and extensive preparation now making for the introduction of Gas Lights into use ... render it of considerable importance ... that they should be acquainted with the possible danger to which they are exposed from ignorance or inattention on the part of those to whom the care of the light is to be intrusted.' He pointed out that gas could not only burn, but even explode 'with all the violence of gunpowder'. Such accidents 'may readily happen, and probably do so not unfrequently', especially if a gas flame was accidently extinguished by a draft of air, creating an explosive mixture in a closed room. Civis saw no such danger if gas were confined to outdoor use, but quite conveniently, the GLCC could make no money that way. ${ }^{413}$

Someone responded to Civis using the pseudonym Gabriel Gas Light by affirming 'that the valuable and beautiful fluid is not only innocuous, but promises to be in every point of view, highly beneficial.' He insisted that even if a sealed room should have gas 
leaking into it for several days, no such explosive mixture would be created. A Parliamentary inquiry had established the safety of this technology, as had a subsequent investigation by the Royal Society (following the explosion at the gas works, he did not add). He concluded with the observation that as 'these lights have been used in many parts of the country ... for years ... without the least accident, I hope they are now too well established to be hurt by uninformed writers. ${ }^{314} \mathrm{~A}$ rebuttal to this missive came from The Chemist's Friend a few days later. He argued that a simple experiment with a bladder filled with inflammable air easily refuted Gabriel Gas Lights' naive view of the safety of gas. Anyone who could come up with a way to make gas safe indoors should get a perpetual patent, having discovered the philosopher's stone..$^{415}$

Sure enough, a few days later, Verax wrote in defending the gas company against those with 'a determination to prejudice the public mind ... against the undertaking, and thereby deprive the Company of their well-merited reward.' He repeated that Parliament had already thoroughly investigated the safety of gaslight. To show just how absurd the accusations of danger were, he proposed counter-experiments to the exploding bladders of Chemist's Friend. He suggested that people bring burning candles close to curtains to see them go up in flame as they were ignited. The argument being that gas is indeed dangerous, but in much the same way as candles are. ${ }^{416} \mathrm{~A}$ riposte came not from Chemist's Friend, but the Chemist himself, who wrote that 'Verax, by his letter, has

\footnotetext{
414 "Gas Lights: To the Editor of the Times, from Gabriel Gas Light," The Times, Nov 81814. 415 "To the Editor of the Times, from the Chemist's Friend," The Times, Dec 211814. 416 "To the Editor of the Times, from Verax," The Times, Dec 241814.
} 
not ventured to contradict the fact; but exhibits a mere childish playfulness - a puerile conceit that bears no analogy to the subject on the tapis; and therefore wholly unworthy of farther notice.' He emphasized that the matter 'calls loudly for the attention and interference of Government, to whom the public safety, and public weal, are equally confided.' Verax had treated such a serious matter 'ludicrously', and 'trembled' for those who had the 'misfortune to live near that mine of mischief, Verax's gasometer.' He finished by pointing out that oxygen and hydrogen gas, when mixed in the right ratio, are always explosive. 'Now let the wise beware.'417

The repartee dragged into the new year. Investigator wrote in to say that the crux of the matter was whether gas or candles were more dangerous, and he came down against candles. Gas could not really explode because a flame would never travel down the small bore pipes used in homes, whereas candles posed a constant fire hazard and had to be tended by snuffing and trimming. 'Chemistry' Investigator concluded, 'as the most extensively useful of the sciences, has now become a subject of so general attention; but truth, or the real state of things, is still often rendered obscure, by the clouds of prejudice, vanity, or sordid interest.'418 Hydrogeno added his voice to Investigator's when he wrote that the previous corespondent (Chemist) 'is certainly not a chemist: he looks more like a whale, and notwithstanding all his assertions to the contrary, smells very strong [sic] of oil.' Chemist was right: gas does burn with oxygen. If it did not, then 'the Gas Light Company would be blown up indeed.' The gasometer 'bids fair to be one of the greatest improvements this country ever

\footnotetext{
417 "To the Editor of the Times, from A Chemist," The Times, Dec 291814.

418 "To the editor of The Times, from Investigator," The Times, Jan 31815.
} 
enjoyed', and living next to one was no more dangerous than living over an oil-shop. ${ }^{419}$ Finally, A Friend to the Truth added his voice against Chemist assuring his readers that, while gasometers could explode, 'they were under the immediate inspection of the most intelligent of [the Company's] men', and so were perfectly safe. He concluded by relaying that he had heard that 'some shop-keepers in Bishopgate street have said, that if any person would give them oil to burn for nothing, they would yet prefer to pay for the use of gas-light.' ${ }^{\prime} 20$

Predictably, responses soon followed. The seemingly neutral Spectator urged The Times to get some prominent chemist such as Wollaston, Brande, or others to put the matter of the danger of gaslight to rest, before finishing his letter with his observation that 'the danger of using gas-lights appears to be too plain to admit of a doubt.' ${ }^{421}$ The concluding letter is this tedious exchange came from Common Sense. He argued that since gas could only explode in certain proportions with air, outdoor use was perfectly safe, and even indoor use was safe, because it was unlikely that a room was sufficiently air-tight to allow such a correct proportion to be reached. $422 \mathrm{~A}$ parting shot to this exchange came from Accum whose book on gaslight was published a few months later. He dismissed hostility towards gaslight as Luddism: 'the common clamour that is always set up against every new means of abridging labour, to which had the public listened, an

\footnotetext{
419 "Gas-lights. To the editor of The Times, from Hydrogeno," The Times, Jan 31815.

420 "Gas-Lights: To the Editor of the Times, from A Friend to Truth," The Times, Wednesday, Jan 041815.

421 "Gas-Lights: To the Editor of the Times, from Spectator," The Times, Jan 91815.

422 "To the Editor of the Times, from Common Sense," The Times, Jan 141815.
} 
interdict would have been laid upon the spinning and threshing machines, the steam engine, and a thousand other improvements in machinery.' ${ }^{423}$

All was quiet on the oil front until 1816, when the company applied to Parliament for an amendment to its charter. ${ }^{424}$ The whaling interests allied with tallow chandlers, and did all the could to prevent the bill's passage or at least weaken it. They submitted a formal petition against the bill and hired counsel to act for them in Parliament. ${ }^{425}$ The bill witnessed some fierce opposition from anonymous writers in the press who put forward many reasons why the bill should not be allowed to pass, such as the company's supposed monopoly status, the unfair advantages the company would get from the bill, as well as its supposed abilities to enter houses at will for no reason. Most of these anonymous pieces also mentioned that should the company be allowed to expand to the detriment of the Greenland, Davis Straight, and South Sea whale trade, it would threaten the 'nursery of seamen' necessary for English naval power, as well as imperil the great capital invested in that successful trade. 426 The company printed a bill to counter the various accusations by the oil interests, insisting that the growth of the gas industry would not harm the trade, and that the north country coal trade was 'the

\footnotetext{
${ }^{423}$ Accum, A practical treatise on gas-light [1815], 171. Accum 1815 published on May 101815. 424 "House of Commons: Gas-Lights Bill," The Times, Wednesday, Jun 12 1816. "Minutes of Evidence taken before the Lords Committees to whom was referred the Bill, intitled, "An act to alter and enlarge the Powers of Two Acts of His present Majesty for granting certain Powers to the Gas Light and Coke Company," 3.

425 See preface to "Minutes of Evidence taken before the Lords Committees to whom was referred the Bill, intitled, "An act to alter and enlarge the Powers of Two Acts of His present Majesty for granting certain Powers to the Gas Light and Coke Company."

426 "Private bills: Gas Light Company," The Times, Thursday, May 30 1816. "Monopolies," The Times, Jun 4 1816. "The Gas-Light Monopoly," The Times, Jun 15 1816. "Gas Light Bill," The Times, Jun 181816. "Gas Light in the City," The Times, Jun 211816.
} 
best and only nursery' of seaman for the Navy, not the Greenland trade. ${ }^{427}$ The opposition managed to have some of the clauses the GLCC originally planned removed in the House of Commons. ${ }^{428}$ The clause extirpating the charter's expiry date was struck and replaced with one granting a 30 year extension, and more importantly, the suppression of the requirement to provide cheaper and better light to local lighting authorities was successfully opposed and the requirement remained. ${ }^{429}$ Whether this was beneficial for the oil trade, however, is doubtful. A third clause, empowering the company to install fittings in homes, which they were hitherto forbidden from doing, was removed in the Lords, and among the three, this one caused the company the greatest harm (see below). ${ }^{430}$ Despite the desire of the of whaling trade to have the bill thrown out entirely, it nevertheless passed in its weakened form in July 1816.431

The sniping between the gas and oil industry continued in print on various occasions. The most concerted attack from the oil trade came in 1817 in the form of a lengthy pamphlet authored by someone using the pseudonym Candidus: Observations on gas-lights being an impartial inquiry concerning the injurious effects on the health of the community, from the use of coal-gas for lighting the metropolis. The arguments put forward in the pamphlet show that by this time, the oil trade could not engage in the

427 Remarks and Considerations on the Gas Light and Coke Company's Bill Now Before Parliament, (London: Reynell, 1816).

428 Bill to enlarge Powers of Acts for granting Powers to Gas-Light and Coke Company, (452).

429 "Minutes of Evidence taken before the Lords Committees to whom was referred the Bill, intitled, "An act to alter and enlarge the Powers of Two Acts of His present Majesty for granting certain Powers to the Gas Light and Coke Company," 16.

430 "Gas Light Bill," The Times, Tuesday, Jun 251816.

431 An act [56 Geo.III cap. Ixxxvii] to alter and enlarge the Powers of Two Acts of His Present Majesty, for granting certain Powers to the Gas Light and Coke Company, (2 July 1816). 
same sort of fear-mongering it had used in $1814-5$. The clear advantage of gas over oil in luminosity were too evident, and more subtle arguments were needed. These included that gas was more harmful to the atmosphere in a room than either oil or tallow. There were two reasons for this, argued Candidus. The first was that gas was more fit for combustion and hence consumed more oxygen than either oil or tallow, and second was that it had greater greater levity and hence tended to escape unconsumed. ${ }^{432}$ Unconsumed gas, containing sulphuretted hydrogen, was 'highly noxious', and if the gas was consumed, it 'greatly vitiated' the atmosphere because it used more oxygen. ${ }^{433}$ Further arguments were heaped up, including that the walls of rooms where gas was used soon became coated with 'noxious effluvia' and soot.434 Candidus allowed that gaslight was good for outdoor use, and perhaps open shops, but certainly not for indoor use, especially those frequented by people in numbers. ${ }^{435}$ Candidus, by his own admission, knew well that gas was not economical if used only on streets. He finished the screed with an attack on the corporate model, describing the company as a 'scheme', put forward by 'adventurers' and 'projectors', inducing the 'middling classes ... to embark all their small savings ... in ruinous speculation'. ${ }^{436}$ And of course, gaslight threatened the oil trade, which was the nursery of British seamen. 'The future welfare, and even existence of the country may be said to be compromised, by

\footnotetext{
432 Candidus, Observations on gas-lights being an impartial inquiry concerning the injurious effects on the health of the community, from the use of coal-gas for lighting the metropolis (Printed for T. and G.

Underwood,; (London :; S. Gosnell), 1817), 25.

433 Ibid., 29.

434 Ibid., 31.

435 Ibid., 32.

436 Ibid., 34.
} 
any measure which operates to exterminate or abandon these hardy defenders of their native isles.' 437 The gas industry did not respond to the pamphlet directly, indicating a greater degree of confidence than in 1814-5. A few later comments tried to allay fears over the danger to the 'nursery of seamen' by suggesting that the expansion of the coastal coal trade would offset whatever was lost in the whaling trade. ${ }^{438}$ Candidus was the last gasp in the oil trade's frontal assault on the safety of coal-gas.

Throughout 1817, it was becoming clearer that oil's days were numbered as the dominant form of illumination, and this was epitomized by the removal of the last oil lamps from the Parliament buildings. ${ }^{439}$ The battle between oil and coal-gas, however, did not stop and took on a new twist with advent of oil-gas as alternate to coal-gas. A certain J. B. Emmett of Hull made experiments in 1816 on gasifying oil and reported the next year that the light was even more brilliant than that produced by coal-gas, gave off no smoke, and exhaled no unpleasant odours. This would be the revenge of oil on coal-gas, as Emmett pointed out 'that fish oil has long been banished almost entirely from private homes and shops - and that in the shape of a gas light its safety and œconomy may again introduce into these places, and thus increase in no inconsiderable degree the consumption of oil.' 440

437 Ibid., 36.

438 Peckston, The theory and practice of gas-lighting [1819], 400.

439 1817/01/21 MCD b3 p. 169.

440 "Gas from Oil," Philosophical Magazine and Journal 49 (1817). 
The Royal Institution then weighed in on the side of oil-gas and would remain firmly with oil-gas from next decade or more. ${ }^{441}$ Morris Berman observed that the Royal Institution was often motivated by the commercial interests of its directors, and it is likely that a major player or two in the oil trade could be found on its board at this time, although Berman does not provide any specific information on this point. ${ }^{442}$ Its intervention began with an article published in 1819, praising an 1815 patent for making gas from oil (although the patent was not specifically about oil-gas), ${ }^{443}$ describing oil-gas as 'very superior in quality to gas from coal ... much brighter and denser flame ... more effectual'. The article spoke about its 'facility and cleanliness', and how much smaller gasometers were when oil-gas was used. 444

Other articles from the Royal Institution soon followed, such as William Thomas Brande's Bakerian lecture to the Royal Society in November 1819, where he claimed that oil-gas was almost three times as effective in lighting as coal-gas. ${ }^{445}$ In another article where Accum's and Peckston's treatises on gaslight were reviewed, the author praised the advantages of oil-gas, adding that the 'employing of coal instead of oil for the purpose of illumination has an injurious effect on one of the most important

\footnotetext{
441 Morris Berman, Social Change and Scientific Organization: the Royal Institution, 1799-1844 (Ithaca, N.Y.: Cornell University Press, 1978), 148-51.

442 lbid., 148.

443 "Specification of the Patent granted to John Taylor," The repertory of arts, manufactures, and agriculture 2nd series 28, no. 163 (1815).

444 "On the Production of Gas for Illumination from Oil," Quarterly journal of science, literature and art 6, no. 11 (1819).

445 William Thomas Brande, "The Bakerian Lecture: On the Composition and Analysis of the Inflammable Gaseous Compounds Resulting from the Destructive Distillation of Coal and Oil, with Some Remarks on Their Relative Heating and Illuminating Powers," Philosophical Transactions of the Royal Society of London 110 (1820): 24.
} 
branches of trade a maritime country can possess; and in proportion as coal-gas is used, our Fisheries are injured. ${ }^{\prime 46}$ Momentum for oil-gas built with a new invention in 1819 by David Gordon and Winsor's old assistant Edward Heard of a portable gas lamp for use with oil-gas. ${ }^{447}$ Further inventions and improvement related to oil-gas soon followed, and it became a seemingly viable technology with oil-gas plants coming into use in 1819.448 Enthusiasm for oil-gas was building, so that when Sir William Congreve delivered his report to the government on gas works in London in January 1822 , he wrote that 'The most important feature in the use of [oil] gas is its safety ... it is scarcely possible that an accident can occur. To this may be added the superior brilliancy of its lights ... the comparative simplicity of the apparatus ... and that it may be generated in the largest quantities, without any residuum whatever. [...] The smell also of the oil-gas is far less offensive. ${ }^{\prime} 449$

446 "A few facts relating to Gas Illumination," Quarterly journal of science, literature and art 7, no. 14 (1819).

447 "Account of a new Portable Gas Lamp, invented by David Gordon, Esq. Edinburgh," Edinburgh Philosophical Journal 1, no. 2 (1819). "Specification of the Patent granted to David Gordon and Edward Heard," The repertory of arts, manufactures, and agriculture 2nd series 36, no. 216 (1820). "Recent Patent to David Gordon and Edward Heard for an Invention of a Portable Gas Lamp," The London journal of arts and sciences 1, no. 2 (1820).

448 1819/12/03 MCD b4 p. 439.

449 Banks, "Report of Royal Society on Gas-Lights; Report of Inspectors on Gas-Light Establishments in the Metropolis," Second report, 10. 


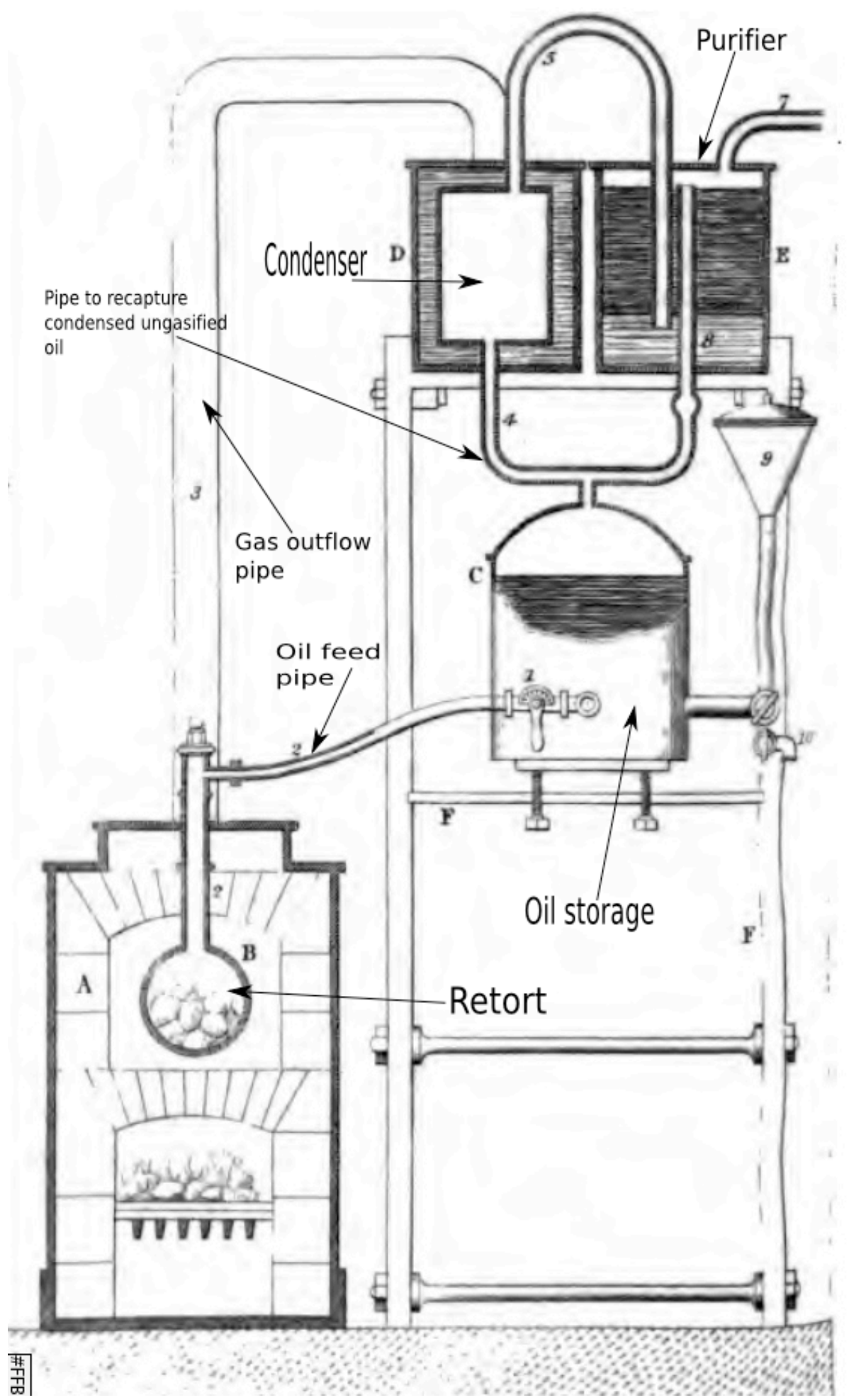

Figure 5.26 An oil-gas plant, from Matthews, Compendium of gas-lighting (1827) 
Many oil-gas companies were incorporated in the years from 1822-1830, but the ultimate attempt at revenge by the oil trade came in 1824, when the London and Westminster Oil-Gas Company with $£ 1,000,000$ capital was proposed. It sought a charter from Parliament, and a massive battle ensued with the coal-gas companies, including the GLCC, resisting fiercely. Despite the support of the Royal Institution through the testimony of Richard Phillips, Humphry Davy and William Brande as expert witnesses in committees, it went down to defeat. ${ }^{450}$ It was estimated that the gas companies spent $£ 15,000$ each in their opposition to the bill. 451 With the bill's defeat, oilgas' prospects as a serious competitor to coal-gas were at an end, but the technology, although floundering, survived for a few years yet. ${ }^{452}$ The Bristol Oil Gas Company, which had been chartered in 1823 , found oil-gas was not profitable, and changed its act to make gas from coal. Other oil-gas companies were incorporated for Liverpool, Norwich, Plymouth, Colchester, Hull, Edinburgh and other towns. Many of them, such as the ones in Colchester and Edinburgh very quickly suffered the same fate as the Bristol company and merged with or became coal-gas companies. 453 The Liverpool Oil Gas Company seems to have survived well into the 1830 s before it too changed to coal-

\footnotetext{
450 For contemporary details see Matthews, An historical sketch of the origin, progress, \& present state of gas-lighting, 156-234. John Williams, An historical account of sub-ways in the British metropolis, for the flow of pure water and gas into the houses of the inhabitants, without disturbing the pavements: including the projects in 1824 and 1825 (London: Carpenter \& son [etc.], 1828), 158-74.

451 Williams, An historical account of sub-ways in the British metropolis, for the flow of pure water and gas into the houses of the inhabitants, without disturbing the pavements: including the projects in 1824 and 1825, 171.

452 See Matthews, Compendium of gas-lighting, 37-43.

453 "Comparative merits of cola and oil gas," Glasgow mechanics' magazine, and annals of philosophy 1 , no. 22 (1824). Frederick Clifford, A history of private bill legislation (London: Butterworth's, 1885), 214.
} 
gas and became Liverpool New Gas Company, before merging with the other gas concern in Liverpool in 1849.

\subsection{Users}

When Boulton \& Watt were selling apparatus to mills, the operators of the gas plant and the user of gas were the same: mill owners. There was no tension between the user and the operator, at least at the level of the person paying the bills. What the workers in mills thought about the smells of the largely unpurified gas was an altogether different question. Once the business model shifted to a utility, the provider-consumer dynamic changed decisively with important effects on how the technology was used and deployed. The consumers were very separated from the process of gas manufacture, and were little concerned with how their usage of the gas might affect the rest of the network. Mill owners with their individual plants had every interest in making sure that whole system work properly and that usage did not unnecessarily strain the system. In the case of the GLCC, the users (who were not always paying customers) were interested in gas for light, and the other details of the process, including the company's finances and its shareholders, concerned them very little. This soon meant that issues about control of usage that had never been present for mill owner became very pressing for the GLCC. The orderly behaviour the GLCC at first expected from its customers did not materialize in many cases, and customers started acting in ways very different than what the GLCC needed for its original operating model to function. It soon emerged that consumers were not going to be bound by their agreements limiting their gas usage 
to specific times of the day, and excluded Sunday use. The GLCC had to develop ways to maintain control over gas usage or risk repeated failures in supply or financial hardship. Even the means of control the company deployed-the ultimate was the threat of cutting off supply-was dependent on the company's willingness to carry it out, but it sometimes undermined itself when other factors came into play, such as the desire to avoid a very public fight.

The relationship also changed in the other direction. For the GLCC, all its customers were not simply consumers of gas to be treated on an equal basis. Some consumers were much more profitable than others. This applied most clearly to street lighting. The GLCC maintained throughout the first years of its existence that street lighting was not profitable due to the cheap supply clause in its charter. Nor was profit the only consideration. Consumers were also treated differently because of their public prominence. The GLCC was very happy to provide gas to any building, which, because of its public prestige, would somehow share its glory with gas, as the various Carlton House episodes demonstrate. The converse of this attitude was that it was also extremely reluctant to get into any sort of public battle with a prominent but delinquent customer. While it had relatively few qualms in cutting off individual consumers, large public buildings, even if their accounts were notoriously in arrears, were simply not treated with the same harshness. 


\subsubsection{Local lighting authorities}

Local lighting authorities were in some way the easiest to deal with. All the lights were exterior, with no problems with smells. The company had complete control of street lamps, since providing lamplighters formed part of lighting contracts. The company made very sure lamps were lit and extinguished on time, and that the valves were closed during the day, although it did have to install locked valves to prevent idle hands from playing with them. ${ }^{454}$ The most difficult aspect of street lighting for the company was the political power of the local authorities, which was significant and needed some management, especially when, after a couple of years of operation, the company largely stopped providing street lighting except where its mains were already in place, or where many domestic customers were requesting gaslight as well. 455 The company denied it operated this way in Parliament, but its minute book reveal many decisions made on this basis. The company's avoidance of street lighting coupled with the desire of lighting authorities to have it led to some political maneuvering, especially when the company and the local authorities were not on the best of terms. Each one tried to use its leverage to achieve their aims. In the case of the GLCC, it encouraged residents to lobby the local authorities to grant the company permission to lay mains in the streets leading to their homes. The parishes, on the other hand, could refuse permission to the GLCC to take up the pavement unless the company would agree to provide street lighting, although this was not common. Usually, some agreement was reached to the satisfaction of both parties.

\footnotetext{
454 1815/08/25 MCD b2 p. 705.

455 1817/07/11 MCD b3 p. 296.
} 
One such altercation occurred with the parish of St. Marylebone in 1815. A number of residents of Oxford Street, located in that parish, asked the company for light. The company wanted to accede to the request and met with paving commissioners about laying their mains in May 1815.456 When the vestry met in July, they refused the company permission to break the pavement, and the company responded by organizing the residents to petition the vestry. 457 The public demand was strong, and the vestry had little choice but to give in, but not before it exacted a little revenge in a fit of pique. The company's new request was rejected on the grounds that it was too informal: it was addressed to paving committee instead of Right Honourable and Honourable Vestrymen. ${ }^{458}$ The company duly resubmitted, and permission was given in November 1815.459

\subsubsection{Public buildings}

Public buildings were always treated with particular attention by the company. They were the most lucrative customers, usually requiring many lights with contracts that could easily exceed $£ 50$ per year, with the largest ones over $£ 100$. Unlike street lamps, the responsibility for maintenance lay with customer, and the company did not need to provide lamplighters to tend them. The prestige and exposure of having a wellknown public building lit by gas was also important for the company. Providing free

\footnotetext{
456 1815/05/09 MCD b2 p. 631.

$4571815 / 07 / 11$ MCD b2 p. 683.

458 1815/10/17 MCD b2 p. 740.

459 1815/11/03 MCD b2 p. 753.
} 
lighting around the Parliament buildings in 1813 was evidently part of this thinking, and it continued thereafter when they started paying. The commencement of gaslight at an important building, such as that of Guildhall in November 1815, could be an occasion of some solemnity and generate notice in the papers. ${ }^{460}$ There was, however, a downside involved with some public buildings, although usually not with the government offices which were well behaved, using gas on schedule and paying their bills. Many of the rest turned out to be quite demanding on the company, in terms of fittings, gas usage, and payments. Fitting up a new building could be an extensive and expensive proposition, running into the hundreds of pounds and taking days or weeks worth of work for the larger ones, although it was the customer, not the company, that paid the charge. Large customers would sometimes modify these fittings, much to the company's chagrin, as this would cause their gas usage to change dramatically. Being the GLCC's largest customers also meant that these public buildings had significant leverage with company, both financially, but also because the company did not want to be associated with a public spat with an important customer.

In what can only be described as a love-hate relationship, the users that brought out these various elements the most strongly were the West End Theatres, and in particular the Covent Garden theatre, one of the two theatres with a royal patent for performing drama in London. Most of the theatres became customers in the two or three years after the company's mains reached the parish of St. Paul Covent Garden where they were located in early $1815,{ }^{461}$ and the Covent Garden Theatre was one of

460 "News," The Morning Chronicle, Friday, November 31815.

$4611814 / 11 / 08$ MCD b2 p. 474. 
the very first. It asked for exterior lamps in April 1815.462 The company complied with their request and extended their mains from the Peter Street station's network expressly for the theatre. ${ }^{463}$ Gas supply was ready in September 1815, in time for the beginning of the new season, with around 80 lamps installed at the theatre. ${ }^{464}$ The company, perhaps sensing it would be in their own best interest, suggested that Clegg's newly invented measuring machines ${ }^{465}$ be installed so that billing could be by volume rather than by burner, which was the standard at the time. ${ }^{466}$ The meters, however, were nowhere near ready for use in a working environment and were not used. ${ }^{467}$

The Covent Garden experience did not go well for the company. The relationship between the company and the theatre ultimately turned around two points. One was the relatively greater importance the company placed on the public perception surrounding the use of gas at the theatre over their desire for profit from the lighting contract, and the other was the theatre's unwillingness or inability to abide by its contract and its understanding that the company needed the theatre for prestige. The seeds of the conflict were sown over the course of the inaugural season of $1815-6$, but were not yet apparent. During this first year, the company was particularly sensitive to how the public received lighting at the theatre. A hint of problems arose when a report

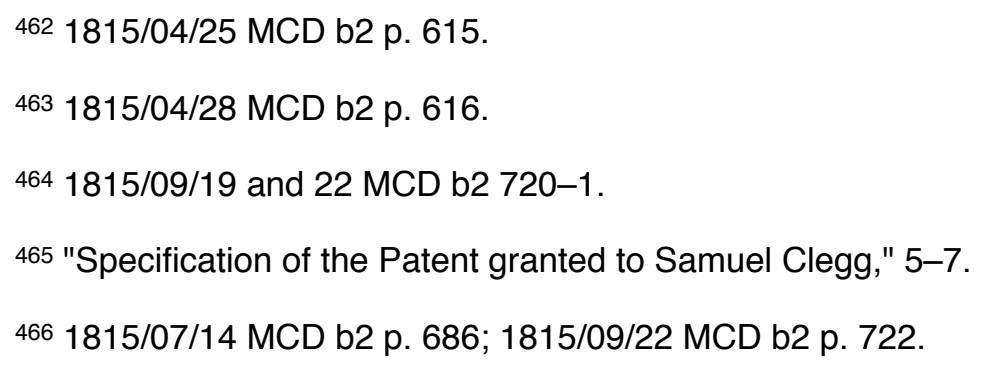
act to alter and enlarge the Powers of Two Acts of His present Majesty for granting certain Powers to the Gas Light and Coke Company," 37.; Tried again in 1818 with the same outcome 1818/08/11 and 25 MCD b4 p. 116, 128; 1818/09/29 MCD b4 158; 1818/10/23 MCD b4 p. 176. 
was printed in the Morning Chronicle and other papers in December 1815 that the light would be discontinued at the theatre due to smells. ${ }^{468}$ The directors immediately responded by placing an advertisement contradicting the reports. ${ }^{469}$ The lights stayed on, but someone was clearly unhappy about the gaslight because the fittings were vandalized in January 1816 . When some of the directors met about the matter with Harris, one of the co-proprietor of the theatre, he convinced them to rebuild the fittings on a grander scale. ${ }^{470}$ Harris was in fact quite a manipulator in his relations with the GLCC, and this was but one of many occasions when the the directors allowed themselves to convinced by Harris to act in ways that were not in their best interests, as later events were to show. In any case, the interior lights were discontinued in March 1816, probably because the company was having a hard time providing an even supply from the time the theatre opened, which was well before the main valve joining the street mains to the gasometers was opened. 471 If the main valve was opened early it caused unnecessary leakage and usage everywhere in its system.

With the end of the season in 1816, the GLCC and the theatres made preparations for the coming year. For its part, the company thought about how it could reduce the demands of the theatres on its network and provide better supply. It suggested installing a small gasometer at Covent Garden to avoid this effect, 472 and when it quoted for the Drury Lane Theatre which asked for gas, the company included a gasometer in

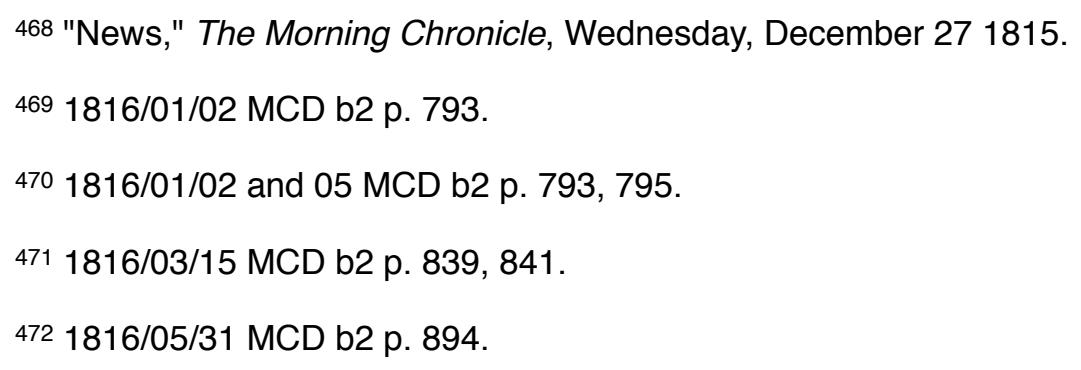


its price estimate. ${ }^{473}$ For its part, Covent Garden ordered a very large chandelier for its main hall which the company built for it over the summer. ${ }^{474}$

The first of the disputes over billing occurred in summer of 1816, although from the beginning, the company was aware that the theatre was burning much more gas than what the original contract had laid out by using burners for many hours a day. ${ }^{475}$ In the summer of 1816, when the company's engineers and accountants tried to come up with a figure for the previous season, the theatre's management-meaning Harris-disputed it.476 Unfortunately for the company, it was not in a good position to make demands. The many changes at the theatre over the last year had created havoc in its records, and so it could not prove its claims. ${ }^{477}$ The committee of works at the Peter Street station clearly felt that they could get nowhere with the theatre and the whole matter was referred to the Court of Directors to deal with. For their part, the directors decided to bill the theatre $£ 550$ for the whole year, a sum they were confident was far less than the actual figure, but one which they accepted because of the chaos in the record keeping. ${ }^{478}$ This bill was submitted to Harris, but when he rejected it, the Court asked Pollock and Warren to look into it. When Warren went to see Harris on appointment, he managed to be absent. ${ }^{479}$ By this point, it was September 1816 and the season was

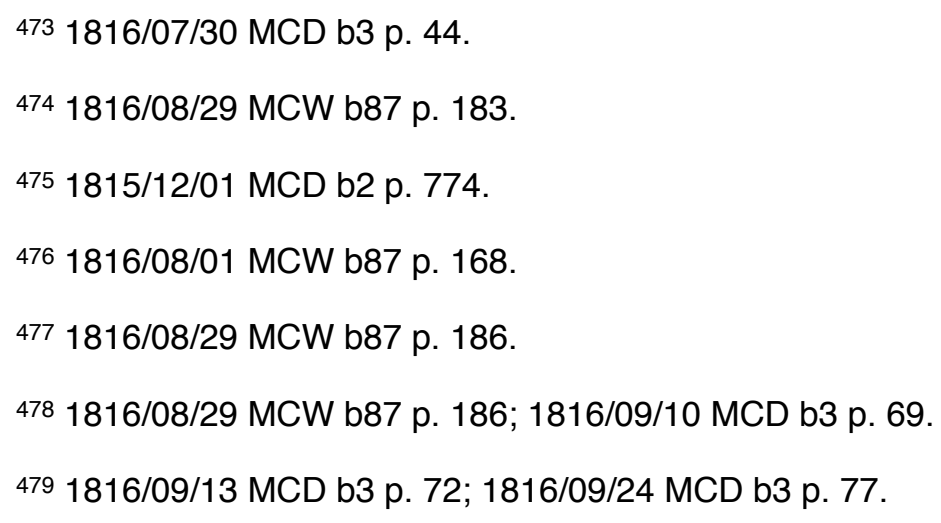


starting again. Harris seems to have evaded the issue altogether and blackmailed the company into keeping the gas on because of the negative effects a cut-off would have on the company's public image, always a sensitive point for the directors. Harris' evasion bought him some time, but the company sent him a letter in November 1816 demanding payment for this year as well as the $£ 550$ owing from the previous. ${ }^{480}$

The next few months saw little action, and the theatre continued its profligate ways, keeping some of its lamps burning for 21 hours per day, a gross violation of some of the basic terms it had agreed to when it signed an agreement with the GLCC. 481 Harris probably relieved some pressure from the company by paying a few smaller instalments. In April 1817, with the end of the season approaching, the directors again turned their attention to the theatre. ${ }^{482} \mathrm{~A}$ bill was sent, but Harris only paid $£ 100$ of the amount owing, and in June 1817 the directors referred the matter to their lawyers. ${ }^{483}$ The company now thought it prudent to have a valve installed on the main leading to the theatre. ${ }^{484}$ As usual, Harris managed to obfuscate sufficiently and pay enough to prevent the gas from being cut off, but nowhere near the amount owed.

September 1817 brought a new season, and another cycle of evasion of full payment from Covent Garden, ultimately made possible by the company's indulgence of its behaviour. It was not as bad as previous years, however, because the company

\footnotetext{
$4801816 / 11 / 12$ MCD b3 p. 112.

481 1816/09/09 MCW b87 p. 192.

482 1817/04/01 MCD b3 p. 222.

483 1817/06/20 MCD b3 p. 281.

484 1817/07/22 MCD b3 p. 303.
} 
demanded weekly payments and the debt did not run up as much. ${ }^{485}$ Despite all the difficulties the theatre had caused the company, the directors clearly thought it was one of their marquee customers and at this point still gave it preferential treatment. A new main was laid from the Brick Lane station (the previous supply was from Peter Street) to ensure that the Covent Garden and Drury Lane theatres had sufficient gas on nights of particularly high demand. ${ }^{486}$

The 1818 season saw the theatre request that payments be made monthly as they had been before the weekly regime was instituted, and the company, having a short memory, agreed. ${ }^{487}$ By November 1818 the theatre was in arrears. ${ }^{488}$ Harris, always the negotiator, agreed to pay $£ 100$ per week, and the directors gave strict orders to cut off the gas if any payment was missed. ${ }^{489}$ The inevitable first missed payment came in February 1819 and the company, instead of stopping supply, was soon demanding payment again. ${ }^{490}$ The theatre made a payment of $£ 50$ to put off the company, ${ }^{491}$ but matters came to a head once again towards the end of the season in June 1819. The company sent an ultimatum with June 26,1819 as the final cut off date, a resolution they reinforced the day before the deadline ${ }^{492}$ Instead of going to see the company

\footnotetext{
485 1817/09/05 MCD b3 p. 328.

486 1817/09/30 MCD b3 p. 344.

487 1818/10/02 MCW b88 p. 92.

488 1818/11/16 MCW b88 p. 116; 1818/11/17 MCD b4 p. 194.

489 1818/11/24 MCD b4 p. 198.

490 1819/02/01 MCW b88 p. 145.

491 1819/04/22 MCW b88 p. 175.

492 1819/06/18 MCD b4 p. 332; 1819/06/25 MCD b4 p. 337.
} 
personally, Harris sent his secretary to plead, and the directors, incapable as always of being caught in a public spat with the popular theatre, caved in and did not cut the gas. The month of July 1819 saw the theatre and the company come to terms about a schedule of payment, whereby the theatre would discharge its entire debt of $£ 635$ in two payments over the next three months. ${ }^{493}$

The directors had fooled themselves into believing the same empty assurances that Covent Garden has offered so often before, and when the time came in September 1819 at the start of another season to deposit the first cheque of $£ 200$, it was returned by the bank as an unauthorized payment. The directors were shocked, and asked the theatre to make good on the bounced cheque. It also moved payment terms back to weekly. ${ }^{494}$ This was an entirely hollow demand, and the theatre made no payment. ${ }^{495}$ In October 1819, the directors referred the matter to their lawyer, ${ }^{496}$ and in November wrote that the 'temporizing conduct has completely exhausted patience of directors', and that unless payment was forthcoming on the 9th, gas would be cut off on the 11th. 497 Harris now responded to this letter feigning complete ignorance of the communication between the company and his secretary, professing surprise that affairs had reached such a point. Touching on the very point that made the directors powerless in their dealings with the theatre, Harris also included a warning about the harm it would do the public if the gas was discontinued during the season. Harris even

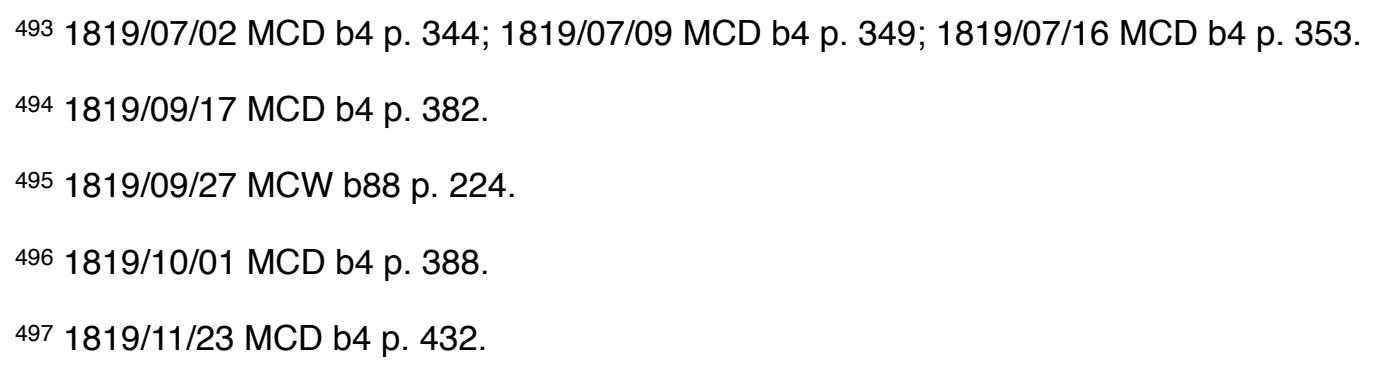


had the temerity to suggest that company should be grateful to the theatre for using gas because of the theatre's prestige, and that it should be happy to provide gas at no charge. ${ }^{498}$ As a final insult, the theatre's management had turned to the gas company's old enemy, and installed an oil-gas plant at the theatre without informing the company. 499 In a move that beggars belief, the directors suggested new terms of payment, and agreed in December 1819 to negotiate payment with the theatre. 500 The theatre seems to have made a few payments over the rest of the season.

The company ignored the theatre's use of oil until July 1820, when an explosion occurred at the theatre involving the oil-gas apparatus. Somewhat pathetically, the directors threatened to stop the gas supply unless the theatre got rid of its oil-gas plant, feeling that they would be blamed for the theatre's negligence with oil-gas. 501 The theatre of course ignored the demand, ${ }^{502}$ and further letters were similarly ineffectual. ${ }^{503}$ When the season started again in September 1820, the oil-gas plant was still in place, and company repeated its threat to cut off. ${ }^{504}$ This time, it actually managed to make good on it, probably because the directors knew well that there would be no public scandal over it.505 Demands for payment of the $£ 963$ owing were blithely ignored by the

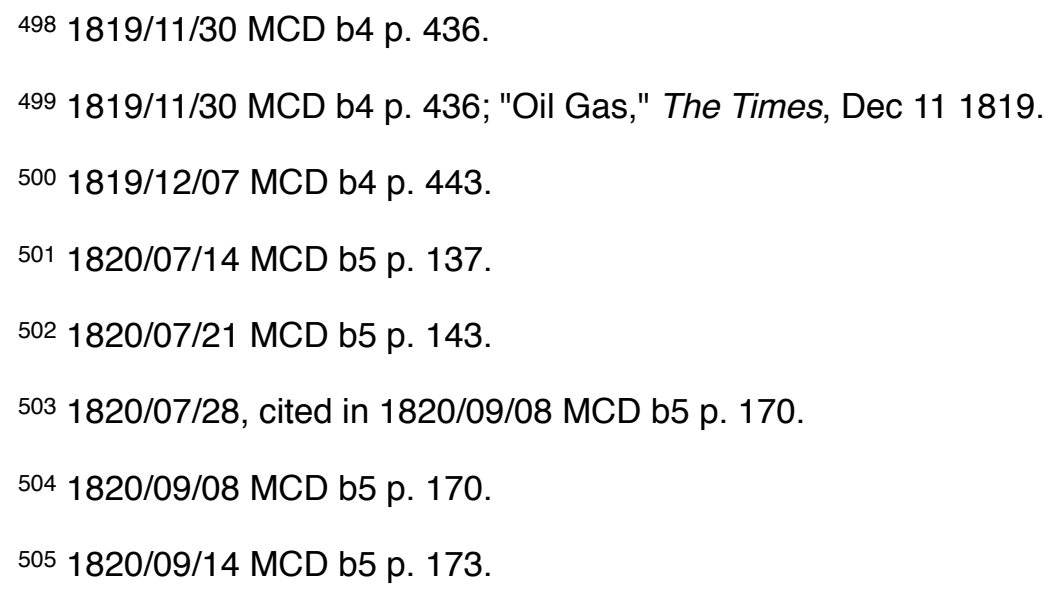


theatre. ${ }^{506}$ The theatre went its own way with the oil-gas apparatus, and burned down a few years later.

\subsubsection{Shops and houses}

The company's relationship with smaller consumers-houses and shops-was very different than what it had with large public buildings and lighting authorities. In this case, no individual customer was so important that the company could not afford to lose him, and it did cut off many smaller customers for late payments or abusing their gas supply. On the other side, controlling them was no simple affair and small conflicts flared up with some frequency. The sources of these conflicts were twofold. First, the company had a very hard time installing reliable fittings in homes, and like the cheap street lighting clause, this problem also had roots in the Parliamentary battles over the company's incorporation. In the 1808-9 battle, the GLCC had conceded the manufacture and sale of apparatus to Boulton \& Watt to buy peace, but the way the clause was framed to prevent it from doing so also stopped the company from selling and installing fittings in homes and shops. The result was that the company had to use outside contractors called 'fitters up' to install gas fittings in buildings, and the company had no end of problems with the fitters and their work.

The second source of conflict with smaller consumers was the difference in attitudes towards proper use of gas for light. For customers who had been used to burning oil and candles whenever they pleased, the move to gas with restricted hours of 
use was not going to be easy. They generally treated gas like candles and lamps and burned whenever they pleased. In addition to deeply ingrained habits, they had a further disincentive for moderation, which was the flat rate they paid for their gas. Small consumers had little economic reasons to moderate their use of gas. These reasons, the habitual and the economic, caused the company many problems with abusers. Its response was twofold: it tried to educate its customers in what they considered to be the appropriate use of gas, and to better control gas usage at shops and homes with standardization and the use of inspectors and penalties.

In Disenchanted Night, Wolfgang Schivelbusch speaks of 'the loss of domestic autonomy' that the introduction of gaslight entailed. Whereas prior to gaslight, the home was in control of its light sources, such as candles, lamps, or fireplaces, the new technology transferred some degree of control to an outside influence. 'Fire had always remained clearly and physically recognisable as not merely a product, but also the soul of the house.' The introduction of gaslight, he argues, ceded some element of this domestic autonomy. ${ }^{507}$ Although he puts it in a somewhat dramatic way, he makes a good point. The introduction of gaslight meant that GLCC had to control its use in various ways or risk bankruptcy. The need to control entangled the company with its users, especially it smaller ones, in an intimate way. This section explains how this happened.

507 Schivelbusch, Disenchanted night : the industrialization of light in the nineteenth century, 28-9. 


\subsubsection{Shops and houses: fitters}

The company only gradually became aware of the potential for problems with their smaller customers. Smaller users started to sign on with the company soon after a few shops fitted up for display purposes in April 1814,508 although a very few homes had had gas even before this. As the requests for gas came in and the company started laying service pipes, they also began a log book of customers to keep track of the contracts, which were typically a few pounds per burner per year. ${ }^{509}$ The company soon realized that it would be to its advantage to control gas usage in homes and shops, and in August 1814 standardized the burners it would supply to these locations. ${ }^{510}$ This was not adequate, however, and soon the company become aware that there was 'a great expenditure of gas in several shop \& c.' that, unless brought under control, would destroy whatever profit they could have made on the contracts. Part of the problem must have been improper fittings - perhaps lacking burners - because the directors resolved not to turn the gas on at customers until the fittings had been inspected. ${ }^{511}$ In January 1815 , the directors, 'with a view to the safety and œconomy of fitting up', asked their fitters to give the company a list of charges and materials they were using for their work, ${ }^{512}$ implying that up to this point, the company had not had a clear idea what the fitters were actually installing or what their fees were. This was really just the beginning of the company's problems were their fitters. In March 1815, Clegg reported to the

\footnotetext{
508 1814/04/05 MCD b1 p. 294.

509 1814/06/21 and 24 MCD b1 p. 356, 9; 1814/08/26 MCD b1 p. 407.

510 1814/10/04 MCD b2 p. 446.

511 1814/12/30 MCD b2 p. 530.

512 1815/01/13 MCD b2 p. 538.
} 
board that 'I find very great carelessness in the different shops now fitting up, and even some of the Gun Barrel ends from our main left open, if these things are not more strictly attended to, the consequence may be of a serious nature. [...] I would likewise give notice to each Person employed by the Company to fit up Houses, that if after repeated instances of carelessness and leaks being detected in their work, that they be immediately dismissed'. His proposed solution, adopted by the Court, was to keep another logbook of shops and their fittings, together with a note about who had installed them. ${ }^{513}$ Not all fitters complied with the order and the company had to send threatening letters to fitters who were not reporting their work..$^{514}$

Further problems with fitters followed shortly. In June 1815, Clegg reported that there were 'continually complaints coming from the different Shops lighted with Gas about the smell which arises from leaks, and the fitters up have been repeatedly told of them, but it generally happens that the fitters up have been paid for the Work and will not have any thing more to do with it. [T]he Joints are usually daubed with paint which serves for a while and then the Work is thrown off their Hands.' As examples he referred to the Attorney General's house and the Ship Tavern, the latter of which had cost the company twice the original cost of fitting to find and fix leaks. The director's response was to order that no fitter be paid until his work had been inspected. ${ }^{515}$ To take some work out of the hands of fitters, the company took over the job of laying service pipes,

\footnotetext{
513 1815/03/03 MCD b2 p. 575.

514 1815/03/31 MCD b2 p. 601.

515 1815/06/09 and 30 MCD b2 p. 652, 672.
} 
called gun barrels, and stopcocks from the fitters in August 1815.516 This was prompted by incidents of caps not being placed on gun barrels, leading to gas loss and lamps going out. 517

Poor workmanship was not the only problems with fitters. Sometimes they neglected (or perhaps knowingly omitted to avoid inspection) to report their work to company, such as in November 1815 when two houses were found to be fitted up without approval, and in a very bad state. The response was to shut the gas off right away. ${ }^{518}$ Throughout 1815 and the first half of 1816 , reports of problems with fitters poured in. Some were sanctioned for shoddy work or using poor materials, ${ }^{519}$ while others installed extra burners without letting the company know, 520 or even put up burners not supplied by the company. ${ }^{521}$ Some others charged their customers extravagantly, leaving the customer to complain to the company which had nothing to with the installation fees. ${ }^{522}$ They also continued to ignore requests to repair leaky fittings after they had left a work site. ${ }^{523}$ One measure the company tried to bring fitters

\footnotetext{
516 1815/08/18 MCD b2 p. 702.

517 1815/09/29 MCD b2 p. 728.

518 1815/11/03 MCD b2 p. 753.

519 1815/11/22 MCW b87 p. 33.

520 1816/07/04 MCW b87 p. 161.

521 1816/12/05 MCW b87 p. 219.

522 1817/05/01 MCW b87 p. 279.

523 1815/10/27 MCD b2 p. 747.
} 
under control was to order them not to fit up any shop without prior notice to the company, but this availed the company little with their problems with fitters. ${ }^{524}$

The situation could clearly not continue, and the company decided in August 1816 to recognize only the work of fitters it had certified, and who had agreed to take responsibility for their own work, using only company approved components. ${ }^{525}$ In order to become certified, fitters were asked to prepare a house, which if judged after inspection to be adequate, would allow the fitter to be added to the approved list. ${ }^{526}$ Any house or shop fitted up by a non-certified (or decertified) fitter would have the gas supply refused. The company sent notices advising people of this new policy to all buildings along the company's mains,, 527 and similar notes were sent out in areas where it was laying new mains. From then on, when it happened that people were found using lamps installed by unauthorized fitters, they would be cut off. 528

The new policy of using only approved fitters helped a great deal, but some problems still remained. When fitters were found to have connected homes without proper notification or with faulty fittings, they were threatened with de-certification and prosecution. ${ }^{529}$ Leaky pipes were still reported regularly, and the company's superintendents were becoming exasperated with having to deal with endless

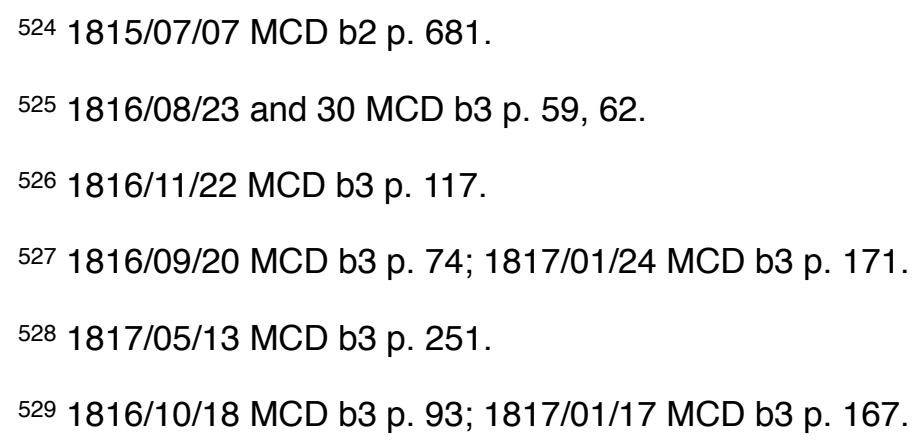


complaints from consumers. Matters came to a head at the end of 1818 , when the directors, judging that the fitters were doing great harm to the company's reputation, halted the certification of new fitters. ${ }^{530}$ They asked Leadbetter, the superintendent of the Peter street station to prepare a report on fitters, which he delivered on December, 21, 1818. In it, he wrote:

I consider it a matter of the most vital Importance to the company that some immediate Steps should be take to check the alarming Evils accumulating from the very infamous Manners in which several of the Tradesmen execute their Work (for the Reception of Gas into the Houses of the Consumers) who make use of every Evasion to elude the Regulations laid down by the Company and if the Size of Tubing be adhered to consider their Instructions sufficiently complied with, and that they are at Liberty to affix Brass Work of any Description at the End of it, completely defeating the Intention of carrying an ample supply to the Burner, by connecting the Tubing to Work whose Orifices in most Instances do not exceed one sixth, and in many not one tenth Part of it. and in almost every Instance where it is requisite to place Cocks, the Gas' way through the Plugs is constrained in a Manner to render it impossible a competent supply can reach the Burners under almost any Pressure. [...] Few Houses can be found where the Interference of the Company's Servants does not become necessary to remedy some material Defect; [...] it is not for me to question the wisdom or Policy of issuing Regulations to the several Tradesmen respecting Modes of fitting, by which the Company in the Opinion of the Public, incur all the Responsibility of their Errors, or the Imputation of not furnishing a competent Supply. ${ }^{531}$

530 1818/09/18 MCD b4 p. 148.

$5311818 / 12 / 21$ MCW b88 p. 130-1. 
Leadbetter suggested that the fitters be required to test their work at 1/10 an inch of pressure, and be liable for repairs to it for one or two years after completion. In fact, this sort of suggestion had been made previously to solve this seemingly intractable problem, and so the Court of Directors created a committee composed of some of the directors, including Pollock, to propose a way forward. The committee took almost a year in its investigation, and when it did so on November 12, 1819, it seemed to exculpate the fitters. Its recommendations concerned the types of pipes that were being used. Apparently, it was corrosion, probably caused the the sulphur in the gas, that was eating the pipes and creating the leaks. After trying many different sorts of pipes, the committee suggested a copper pipe lined with lead on the inside, as well as new form of T-junction that was less difficult to drill out and tap while avoiding leaks. ${ }^{532}$ While this was not the end of problems with fittings, the company had progressed a great deal since 1814.

\subsubsection{Shops and houses: expectations and control}

The company's relationship with small customers similarly evolved. After the problems with some customers using gas after hours emerged in early 1815 , the company hired a Mr. Perks in March to be the 'inspector of the fittings up and regulating burners'. ${ }^{333}$ His job included going 'along the Line of the Company's Mains one Night in every Week to observe in what Houses the Gas is found burning after 10 o'Clock at

\footnotetext{
532 1819/11/12 MCD b4 p. 419.

$5331815 / 03 / 21$ MCD b2 p. 592; 1815/03/31 MCD b2 p. 602; Later service pipes would be made of wrought iron or pewter. See Clegg, A practical treatise on the manufacture and distribution of coal-gas, 186.
} 
Night'. ${ }^{534}$ Typically, contracts with small consumers specified that the consumer could begin using gas when the main valve was opened, which varied according to the season, but could be as early as $4 \mathrm{pm}$, until about about 10 at night. Later use entailed extra billing. The inspector's reports must not have been very cheering, because in May and July 1815 the directors had special meetings to look into the current state of the company's machinery, partly with a view to preventing 'any waste or fraudulent use' of the gas, ${ }^{535}$ and one of the results was the decision to begin installing stopcocks at customers with more than two lamps, or where the gas had not been ordered but a gun barrel had nonetheless been installed.536 By October 1815, Perks had more work than he could keep up with and another man was hired to go with him to act as inspector and to turn the stopcocks down to the right pressure. ${ }^{537} \mathrm{~A}$ third one soon followed to take over one of the other stations, ${ }^{538}$ and even more in December $1815 .{ }^{539}$ The inspectors were kept constantly busy. The company supplemented their policing by communicating to their customers what they considered to be reasonable usage, such as a notice that explained that flames should be 1.75 inches long. ${ }^{540}$

The company's minute books are a chronicle of the many problems it had with customers. In one case, the inspectors found a shop where the gas was being burned

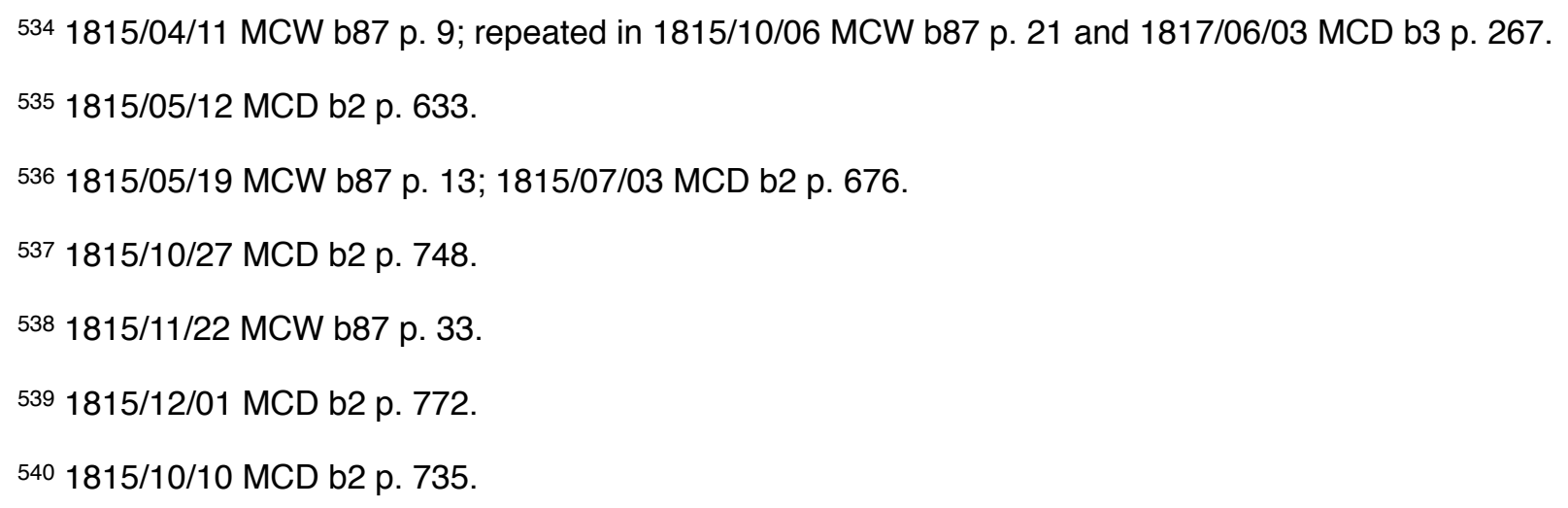


directly from the tubes, ${ }^{541}$ and another where lamps were used without glasses. ${ }^{542}$ In 1816, it was reported that the 'Public Houses' were burning ten hours a day and usually with flames greater than six inches. ${ }^{543}$ The inspectors even found one case of some people stealing gas through an unauthorized service pipe and burning it in their cellar.544 One person had enlarged the holes in his burners and when he refused to have them fixed, he was cut off.545 These were, however, some of the more unusual cases. By far the most frequent problem was the burning after the stipulated end time (usually 10) or on Sundays. The inspectors at first verbally warned the offenders, but if they proved unrepentant, they were sent notices that they would be charged for their extra usage or even cut off unless the practices were rectified. 546 In 1815 , the company reminded its consumers through notices that anyone caught using gas extravagantly would be cut off, ${ }^{547}$ and in early 1816 added a clause to its agreement with its customers that anyone found burning after hours or on Sundays would be charged for the whole quarter at a higher rate. ${ }^{548}$ This did not deter people, and in 1816 consumers continued to be discovered regularly burning late, even until one or two in the morning. They were duly billed for the whole quarter. 549 The problem of excessive burning was so present for the

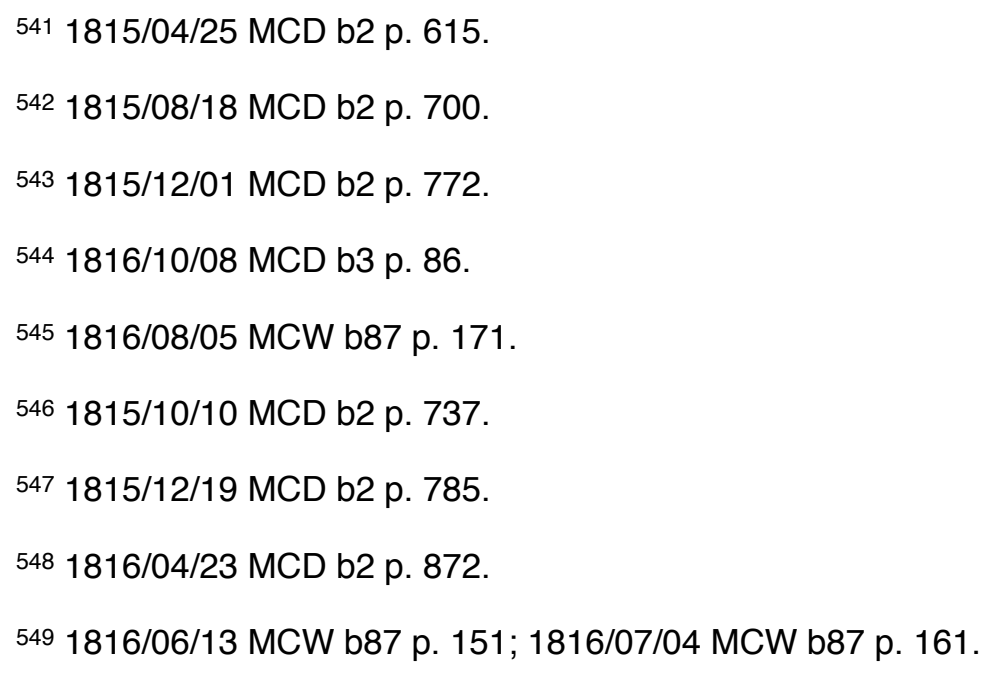


company that some zealous shareholders volunteered in 1817 to act as inspectors, but were politely declined. 550

Inspectors and threats were one approach, but the company frequently tried other solutions as well. One was charging by volume, the solution that ultimately solved most of the company's problems in this regard. Together with many other improvements to gas apparatus, Clegg had invented in 1815-6 a small measuring machine for use in houses. 551 The company tried them out at a few homes in May 1816,552 but in June, they were already proving to be problematic and their use was suspended. ${ }^{553}$ It took some more years of development work before the gas meter was reliable enough to be useful, and it became the subject of a lawsuit between Malam's and Clegg's respective claims to invention. ${ }^{554}$ Gas companies started using large gasworks meters to measure total production in $1823,{ }^{555}$ with deployment of smaller consumer meters beginning slowly after that. It was only in the mid 1830s that gas companies made a determined effort to ensure that all their consumers had them installed, and it was the late 1840s

\footnotetext{
$5501817 / 02 / 07$ and 11 MCD b3 p. 181, 4.

551 "Specification of the Patent granted to Samuel Clegg," 5-7.

552 1816/05/14 MCD b2 p. 884.

553 1816/06/13 MCW b87 p. 153; 1816/06/21 MCD b3 p. 10; 1816/07/01 MCW b87 p. 159.

554 "Specification of the Patent granted to Samuel Clegg." "John Malam's Improved Gas-Meter," Transactions of the Society, Instituted at London, for the Encouragement of Arts, Manufactures, and Commerce 37 (1820). "Crossley v. Beverley," in Law reports of patent cases. [1602-1842], ed. William Carpmael (London: A. Macintosh, 1843). "Crossley v. Beverley," in Decisions on the law of patents for inventions rendered by English Courts since the beginning of the seventeenth century, ed. Benjamin Vaughan Abbott (Washington: Charles R. Brodix Law Publisher, 1887).
}

555 Clegg, A practical treatise on the manufacture and distribution of coal-gas, 127. 
before they were universally used for consumers. ${ }^{556}$ For the moment, however, the GLCC had to try other options and decided to install stopcocks at all houses and shut off gas every day, 557 but this must have been too labour intensive and the practice seems to have stopped, if it was ever really implemented.

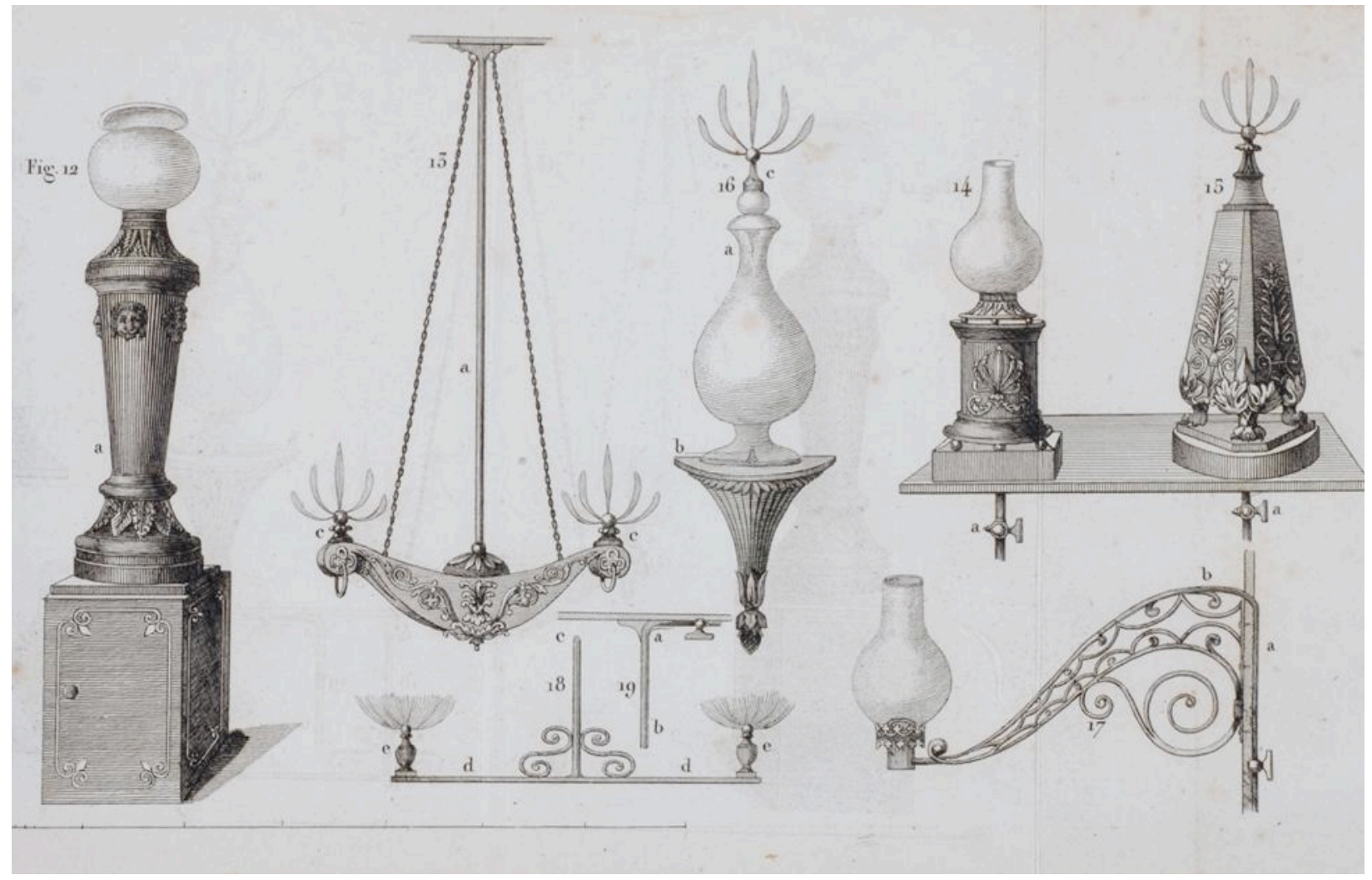

Figure 5.27 Gas burners, from Accum, A practical treatise on gas-light (1815)

556 See Matthews, Compendium of gas-lighting, 44-6. Derek Matthews, "The London gasworks : a technical, commercial and labour history to 1914" (Ph.D., University of Hull, 1983), 37-42. Matthews, "Laissez-faire and the London Gas Industry in the Nineteenth Century: Another Look," The Economic History Review 39, no. 2 (1986): 253.

557 1817/03/04 MCD b3 p. 201. 
Another way to control gas usage was by standardizing fittings as much as possible, and like many matters, the standards were established in the first few years. The company had already chosen its standard lamps in 1814,558 and in March 1815 asked Clegg to draw up a list of standard tubes based on the number and type of lamps used in shops and homes. ${ }^{559}$ To help consumers choose, the company had a room at each station fitted up with a set of sample burners. ${ }^{560}$ The standardization was made more precise when Clegg was asked to prepare drawings of all the parts to be used in homes and shops, ${ }^{561}$ and a copy of these drawings was given to every fitter to follow. 562 The company even regulated the sorts of seals and solders fitters could use, such as when they were ordered to use leather collars instead of white lead as a sealant. ${ }^{563}$ By the end of 1815 , the fitters were expected to get all their supplies from the company, especially service pipes and lamps. Gas would not be turned on homes where the lamps did not bear the company's mark,, 54 and fitters were sanctioned for installing noncompany burners. ${ }^{565}$

\footnotetext{
558 1814/10/04 MCD b2 p. 446.

559 1815/03/28 MCD b2 p. 598.

$5601815 / 06 / 02$ MCD b2 p. 649.

561 1816/09/24 MCD b3 p. 79.

562 1816/11/19 MCD b3 p. 116.

563 1815/10/20 MCD b2 p. 742.

564 1815/10/20 MCD b2 p. 742.

565 1816/03/01 MCD b2 p. 830.
} 


\subsection{Conclusion}

The Gas Light and Coke Company had undergone a gradual progression from 1812 to 1820 . It has started with the idea of providing gas on a large scale, lots of money, and some examples of gas manufacture, mostly from Boulton \& Watt. After a disastrous start in 1812-3, the company recovered under new directors who oversaw its development on various fronts. Technologically, the company improved most elements of its apparatus from the retorts to the burners, and almost none of these developments came from any dramatic new invention. In fact, most radically new ideas, such as Clegg's rotary retorts and complicated purifier, were failures. Only through trial and error, and combining many different ideas, did the company built up a robust system of producing, distributing, and supplying gas. The protected oven plan for the retorts, the three stage purifier, the tar well, syphons, and regulators, and the stopcocks and burners were all part of the broad evolution of the technology over the first years that made the utility model viable. The irony of these developments is that histories of gaslight tend to attach particular names to new inventions, such as Andrew Rackhouse to the oven plan for retorts, but in many cases, it is impossible to find where the ideas came from, or as in the case of Rackhouse, the final product was a amalgam of ideas from various sides that were matured with time, with Rackhouse's own being an important part, but one that failed completely when tried on its own.

The technological artifacts were but one part of the evolving system. The human elements were just as important as the technical requirements in driving the company's development, and the two evolved together. The seemingly interminable problems the 
company had with its fitters was one important example. The company had to bring the fitters under better control through reporting, and when this failed, by instituting a certification program for the fitters. Even this apparently failed, but when the company did a thorough analysis, it found its own material were mostly to blame, as the pipes corroded quickly. The solution lay with using lead lined pipes.

The situation with consumers similarly evolved both technologically and humanly. The way some users behaved, especially smaller shops and homes, was very much at odds with the company's idea of ordered flames used for limited hours. These small consumers saw gaslight as a natural replacement for oil and candles and used them in the same way. Tolerating this usage, given the fixed rate contracts the GLCC signed with its early customers, would have entailed further financial hardship, and the company had little choice but to control its customers. This was done by technical means, such as the increasing use of standards and the deployment of stopcocks, and by hiring inspectors coupled with threats of discontinued supply.

Not all customers, however, came in for the same treatment. From its earliest days, the company and its promoters were sensitive to public opinion, especially given the constant accusations of danger from the whale oil interests. The introduction of gas into a prominent public building, such as the Parliament buildings, was an effective way to dispel whatever suspicions the oil trade might stir up in the public mind. The company actively sought and gave preferential treatment to these sorts of customers for this reason and because they paid well. The difference in attitude shown to small and 
large customers came into strongest relief in the case of the Covent Garden Theatre, a notoriously delinquent customer to which the company never managed to cut supply.

By 1820 , gaslight technology had developed to the point that it could be transferred to other countries, something that had not really been done successfully before. Winsor attempted in 1817 to found a company in Paris after he fled England, but this had failed in 1819, although he continued to hold a French patent, with which he sued a Parisian gas company. ${ }^{566}$ The GLCC's success also generated notice in German publications before 1820,567 and a few attempts were made to introduce the technology there, but without notable success. ${ }^{568}$ The picture, however, changed completely after 1820. In Paris, many new companies were founded, including the Compagnie Anglaise in 1821. It was supported by English capital and eventually became the largest gas company in Paris. 569 Two important English promoters of the company were a forge owner, Aaron Manby, and a civil engineer, Daniel Wilson, both of whom played an important role in transferring the English technology to France. Nor was the Compagnie Anglaise the only one to have English supporters with technical knowledge. John Grafton, who held gas patents in England and later in France, was

\footnotetext{
566 Williot, Naissance d'un service public, 55. Hill, "The history of the Imperial Continental Gas Association 1824-1900, a study in British economic enterprise on the continent of Europe in the 19th century", 16-17.

567 J. S. C. Schweigger, "Ueber Gasbeleuchtung in London, Wilson's Hygrometer, etc.," Journal für Chemie und Physik 17 (1816).

568 J. J. Prechtl, "Aus mehreren Briefen," Annalen der Physik 58 (1818). speaks of lighting in Vienna, but the description is of a building or two. Lampadius also did some work in Dresden.
}

569 Williot, Naissance d'un service public, 34, 50, 55. 
also a shareholder in the Compagnie de l'Ouest. 570 Many of the new French companies were successful, and gas lighting flourished in Paris and France, albeit at a somewhat slower rate than in England. From France, the technology spread to Spain in the 1840s. 571

The story is similar in other countries. The first company in Denmark also had English origins. 572 The first German companies were generally English as well. William Congreve banded with a large number of investors in 1823 to form the Imperial Continental Gas Association with the mandate of establishing gas utilities on the continent, a purpose they successfully pursued, bringing English technology with them. They signed contracts with four cities in Germany in 1825, and were operating in Hannover in the same year, followed by Berlin in 1826. Other cities, including Antwerp, Brussels, Rotterdam, Amsterdam and Vienna followed, and the company became a very important part of the continental gas industry. .73 The irony of the situation is that while the technology can find its roots in France and Germany perhaps more than in

570 lbid., 62-3. "Specification of the Patent granted to John Grafton for an improved Process or Method of making carburetted hydrogen Gas, for the Purpose of Illumination," The repertory of arts, manufactures, and agriculture 2nd series 38, no. 227 (1821).

571 Mercedes Arroyo Huguet, La industria del gas en Barcelona, 1841-1933 : innovación tecnológica, territorio urbano y conflicto de intereses (Barcelona: Ediciones del Serbal, 1996).

572 H. J. Styhr Petersen, "Diffusion of coal gas technology in Denmark, 1850-1920," Technological Forecasting and Social Change 38, no. 1 (1990): 37.

573 Johannes Körting, Geschichte der deutschen Gasindustrie mit Vorgeschichte und bestimmenden Einflüssen des Auslandes (Essen: Vulkan-Verlag, 1963). There does not seem to be a proper history of the ICGA. There is a PhD thesis on the subject written with an economic focus. Hill, "The history of the Imperial Continental Gas Association 1824-1900, a study in British economic enterprise on the continent of Europe in the 19th century". The records of the ICGA are, however, well preserved. See also Hutchinson, "The Royal Society and the Foundation of the British Gas Industry," 256-8. W. Treue, "Die Entwicklung der chemischen Industrie von 1770 bis 1870," Chemie Ingenieur Technik 39, no. 17 (1967): 1006. Pim Kooij, "'Where the Action is'. The Introduction and Acceptation of Infrastructural Innovations in Dutch Cities 1850-1950," in World Economic History Conference (Helsinki: 2006), 5-6. 
England, it matured into a large scale industry there before being transferred back to France and Germany. 


\section{Conclusion: Gaslight, a technology worthy of study}

In this thesis, I have outlined the origins of the manufactured gas industry. The story of its genesis can be divided into several parts. The first consisted of the development of pneumatic chemistry, not only as a theoretical and experimental science, but also as it spread from the centres where the new knowledge, techniques, and apparatus were created outward to a broader educated public. The newly generated knowledge of inflammable gases did not remain confined to a small group, but passed through the channels provided by the public scientific culture of the eighteenth century, such as Diller's demonstrations and Volta's lectures, and was codified in the extensive literature on the subject from the 1770 s onwards. The newly forged knowledge was recorded not only in books, however. Volta's inflammable air lighter rvealed the possibilities that the new knowledge of inflammable gases had opened up, and this was further expanded by its descendants such as Bienvenu's lamp or Diller's fireworks, which became so well known that they were eventually treated as commonplace. By the last decade of the eighteenth century, an understanding of inflammable gases and the possibility of lighting with them had reached a fairly widespread diffusion within a certain segment of the population of Europe, especially in France, Britain, Germany, Austria, and Italy. Pneumatic chemistry had prepared a fertile ground for gaslight, and the manner in which people such as Winzler and many others such as the unnamed Scottish users of $1804-5$ created some version of the technology indicates that the fundamental knowledge about gases was widely present. The 
invention of gaslight was not a case of inspiration with no prior history that could have happened at any time before the late eighteenth century as some have suggested. Rather, there are very good reasons why it happened then and not earlier, and these reasons have everything to do with pneumatic chemistry.

The second phase of the origin of gaslight began with the group of people who took the knowledge and apparatus and tried to apply for commercial ends. If there is something that sets Murdock and Lebon apart from their various precursors and contemporaries in gaslight, it is their clear commercial purpose. They invested a great deal of time and money into commercializing gaslight. Both of them came to gaslight through the investigation of distillation processes, and only later turned to the possibilities of lighting. In Mudrock's case, gaslight remained secondary and even neglected for years as he and his employers, Boulton \& Watt, gave their attention to their core business of steam engines. Lebon was the first person to bring to the public in an explicit and forceful way the possibility of commercial gaslight. Although he failed, his public work set in motion a chain of events that would lead to the technology's commercialization as it prodded Boulton \& Watt into action as well as inspiring Winsor and a host of others.

The various German episodes with the thermolamp, and Winzler's in particular, demonstrate that the technology's successful development was not merely a question of will or ingenuity. Winzler spent years on its development, and demonstrated an understanding of many of the technical solutions adopted later by the gas industry, such as lime purification and gasometers, but he ultimately failed. His failure was partly due 
to the devastation of the Napoleonic wars, but also because the wood which he used was less apt for gasification, producing one sixth as much gas as coal. Had he had access to coal in large quantities, he would very likely have used it: contemporary commentators both in Britain and Germany observed that the thermolamp should prosper in Britain because of its abundant coal reserves. It also seems possible that the Germans had a harder time scaling up the apparatus because of a less developed iron industry on the Continent. What is certain is that the technology relied very heavily on the iron industry in Britain to provide almost all the components of gas apparatus. A closer analysis of how Winzler built his apparatus, especially his largest ones, would validate this conclusion. It is not clear, however, whether enough archival material survives to make this possible.

The third stage in the technology's development was its transformation into a usable system, begun in large part at Boutlon \& Watt. Murdock's first small scale proofof-concept apparatus was nowhere close to what was needed to light a large mill, let alone city districts. Boulton \& Watt, working closely with George Augustus Lee, set about make a series of experiments and developing the apparatus, identifying along the way what issues needed to be addressed to make gaslight workable on a large scale. Although they did not solve all the problems, they innovated enough to put together a number of plant for their mill customers. In this way, they demonstrated that gaslight was a viable technology. Even if Boulton \& Watt lost interest in gaslight, they left an enduring legacy with the host of technical problems they did solve, as well as the training and experience they imparted to many people in gas matters, whether 
contractors, employees, or customers. Many of these people would go on to build the industry.

The formation of the Gas Light and Coke company was the fourth step in the technology's birth, and the first step into the form it would take for much of the nineteenth century. This form was determined by a political battle between Boulton \& Watt on one hand, and Winsor and his supports on the others. Winsor is a somewhat unusual figure in the history of gaslight. Seen from the technological perspective, he had no contribution to make. At the beginning, he seems hardly to have understood the scientific foundations upon which the thermolamp rested, and over time, despite all his patents, he made no innovations that were even tried by the company. Despite this, through his expansive marketing campaigns, he became the point around which willing investors coalesced into a coherent body, one that eventually became the Gas Light and Coke Company. The extensive remuneration offered to Winsor by a shareholders' committee in 1813 in vindication of his claims over the hostile court of directors was a clear sign that the shareholders recognized in Winsor a founder of the company, although he had no real technical competence.

The battle over the granting of the company's charter from 1808 to 1810 was about control of the technology. Although they were somewhat ambivalent about it at first, Boulton \& Watt eventually felt they had to combat the charter to protect the investment they had made in developing the technology. To do so, they marshalled the Royal Society to give Murdock a medal for a paper he did not really write, and in which the economic data was fudged to look better than the results they had generated within 
the firm. Boutlon \& Watt used the Royal Society's prestige to fight the Winsor group, but thereby confirmed the viability of the technology in the public's eyes, a fact that Watt junior recognized even before the medal was given.

The final stage in the birth of the new industry was the Gas Light and Coke Company's transformation into a functioning utility. The notion of a network industry came to Winsor only slowly, as did the emphasis on gaslight. He likely modelled his idea on water companies, a comparison he drew in his pamphlets. Whatever the original source, the compromise with Boulton \& Watt entrenched the network model into the company's charter, preventing from manufacturing apparatus for sale. The ultimate form of the gaslight industry was then partly a result of a political battle. While the network model would probably have developed in any case, the dispute over the charter made it come about more rapidly.

The creation of gaslight as a large network within the city of London involved developing not only the technological elements, something which was not simple, but also negotiating the complex local political situation and coming to some sort agreement with its customers about what the proper use of gaslight was. The users of gaslight usually saw it as a replacement for oil lamps and candles, and burned the gas whenever they pleased. This was an impossible situation for the company, which did not have the capacity to supply gas constantly. The situation with its users was made all the worse by non-manufacturing clauses in the charter which prevented the company from installing fittings. It had to employ fitters, causing the company no end of problems during its first decade. Gaslight also encountered resistance, partly from the people 
affected by pollution, and partly from the oil trade. The pollution question was very serious, and could have destroyed the industry had political forces put more pressure more quickly on the industry, but action was slow enough that the industry survived until new forms of purification, notably with iron oxide, were found. The oil trade on the other hand fought the gaslight industry as a matter of survival, first by questioning its safety, and then by adopting the gasification mould. Although some oil-gas companies were incorporated, and an attempt at creating an enormous one in London was made, oil-gas soon proved too expensive to survive.

It is my hope that the story of the origins of gaslight I have presented in this thesis goes some way to bringing gaslight into the historiography of the Industrial Revolution. The relative neglect of this technology in this context is somewhat strange, and I have wondered if perhaps it is due to its disappearance. Whereas most of the industries of the Industrial Revolution still exist in some form today, manufactured gas and gaslight in particular no longer exist, although coal gasification is experiencing a resurgence. Perhaps the disappearance of its infrastructure, and its transformation into natural gas for power and heating has not left enough physical presence to make it attractive. Whatever the cause, it raises the possibility that there are other technologies from this period outside the standard group that have not been sufficiently explored to see what they might have to reveal about the Industrial Revolution. 


\section{Bibliography}

\section{Archival sources}

London Metropolitan Archives

40 Northampton Rd

London, EC1R OHB

Records of the Gas Light and Coke Company B/GLCC

North Thames Gas Predecessors B/NTG

London Gas Companies LMA/4438

National Gas Archive

Unit 1, Europa Court

Europa Boulevard

Warrington, WA5 7TN

Gas Light and Coke Company NT:GAL

National Archives

Birmingham Central Library

Chamberlain Square

Birmingham, B3 $3 \mathrm{HQ}$

The Boulton and Watt Collection

mostly as found on microfilm from Adam Matthew publishers

\section{Unpublished dissertations}

Hill, N. K. "The history of the Imperial Continental Gas Association 1824-1900, a study in British economic enterprise on the continent of Europe in the 19th century." Ph.D., University of London, 1950.

Austerfield, Peter J. "The development of large-scale production and utilisation of lighter-than-air gases in France, Britain and the low countries from 1783 to 1821 with reference to aeronautics and the coal-gas industry." Ph.D., University of London, 1981.

Matthews, Derek. "The London gasworks : a technical, commercial and labour history to 1914." Ph.D., University of Hull, 1983. 
Bouman, Mark J. "'City Lights and City Life: A Study of Technology and Urbanity."." University of Minnesota 1985.

Brusque, M. C. "Éclairage urbain: enjeux et instruments d'actions." UNIVERSITÉ PARIS 8, 2003.

\section{Published primary source to 1900}

The philosophical transactions (from the year 1732, to the year 1744) abridged. 1747. Vol. 9: printed for W. Innys, C. Hitch, T. Astley, T. Woodward, C. Davis, and R. Manby and H.S. Cox.

As there is something curious in relation to Coal Pits, in the following extract of a Letter from Whitehaven, dated May 16, we have therefore given it our Readers. 1747. The British magazine: or, the London and Edinburgh intelligencer 1:249-280.

The beauties of nature and art displayed, in a tour through the world ... Illustrated and embellished with copper plates. 1763. printed for J. Payne.

Seconde problème de chymie a résoudre: déterminer s'il y a plusieurs espèces de Gas inflammable, ou s'il n'y en a que d'une seule espèce. 1777. Observations sur la physique, sur l'histoire naturelle et sur les arts 9:321-322.

Lettres de M. Alexandre Volta. 1778. Le journal des sçavans:1,068-1090, 1,252-1,269.

Review: Lettres de M. Alexandre Volta. 1778. The Monthly review or Literary Journal 59 (4):301-2.

Description \& usage de quelques Lampes a air inflammable. 1780. Le journal des sçavans:1132-1134.

Les mèches de M. Leger. 1783. Observations sur la physique, sur I'histoire naturelle et sur les arts 22:62-65.

Extrait des registres de l'Académie Royales des sciences. 1787. Observations sur la physique, sur l'histoire naturelle et sur les arts 31:188-195.

Report from the Royal Society on Diller's invention. 1787. The Critical review, or, Annals of literature 64:380-381.

Divers articles d'inventions dans les arts, \& de découvertes dans les sciences, \&c. 1787. Journal encyclopédique ou universel 6 (3):153.

SOIE. 1787. In Dictionaire critique de la langue française, edited by J.-F. Féraud. A Marseille: Chez Jean Mossy Pere et Fils ..., Place: France; Marseille. 
Mercredy 27 Juin 1787; Mercredy 4 Juillet 1787. 1787. In Procès-verbaux, volume 106: Académie royale des sciences.

Des feux d'air inflammable. 1788. Observations sur la physique, sur l'histoire naturelle et sur les arts 33:72-73.

Philosophical Fire. 1788. The Scots magazine 50:164.

Among the Nouvelles Literaires of this month, is a Notice des feux d'Air inflammable. 1788. The Analytical review, or History of literature, domestic and foreign, on an enlarged plan 2:503-504.

Foreign literary intelligence. 1788. The Critical review, or, Annals of literature 66:408.

Nachrichten von einer Lampe für brennbare Luft des Hrn. Bienvenu. 1788. Magazin für das Neueste aus der Physik und Naturgeschichte 5 (4):89.

Herr Diller. 1788. Magazin für das Neueste aus der Physik und Naturgeschichte 5 (1): 171-172.

Samedy 24 Mai 1788. 1788. In Procès-verbaux, volume 107: Académie royale des sciences.

Les expériences de M. Diller. 1789. In Mémoires secrets pour servir à l'histoire de la république des lettres en France, depuis MDCCLXII jusqu'à nos jours; ou, Journal d'un observateur v. 35, edited by L. P. d. Bachaumont, M. F. P. d. Mairobert and d. A. Mouffle. A Londres: chez J. Adamson.

A catalogue of optical, mathematical, and philosophical instruments, made and sold by Willm. and Saml. Jones, at their shop, No. 135, next Furnival's Inn, Holborn, London. 1793. London.

Specification of the Patent granted to Earl of Dundonald. 1794. The repertory of arts and manufactures 1 st series 1 (3):145-148.

Specification of the Patent granted to Mr. Robert Street, Varnishmaker; for his Invention to produce an inflammable Vapour Force, for communicating Motion to Engines, Pumps, and Machinery. 1794. The repertory of arts and manufactures 1st series 1:154-156.

Specification of the Patent granted to John Miles for invention of making lamps in different forms so as to give perfect light. 1795. The repertory of arts and manufactures 1st series 3 (15):151-158.

A catalogue of optical, mathematical, and philosophical instruments, made and sold by Willm. and Saml. Jones, at their shop, No. 135, next Furnival's Inn, Holborn, London. 1795. London. 
Observations and Experiments on the Light, Expence and Construction of Lamps and Candles, and the Probability of rendering Tallow a Substitute for Wax. 1797. A Journal of natural philosophy, chemistry and the arts 1:67-73.

A catalogue of optical, mathematical, and philosophical instruments, made and sold by Willm. and Saml. Jones, at their shop, No. 135, next Furnival's Inn, Holborn, London. 1797. London.

Chymistry. 1797. In The new encyclopædia; or, modern universal dictionary of arts and sciences. On a new and improved plan. In which all the respective sciences are arranged into complete systems, the arts digested into distinct treatises, and philosophical subjects introduced in separate dissertations, edited by W. H. Hall and T. A. Lloyd. London: Printed for C. Cooke.

Specification of the Patent granted to Mr. John Barber, in the parish of Nuneaton. 1798. The repertory of arts and manufactures 1st series 8:371-376.

Electricity: XLVI. The Inflammable Air-Lamp. 1798. In Encyclopaedia; or, A dictionary of arts, sciences, and miscellaneous literature, edited by J. Akin. Philadelphia: Printed by Thomas Dobson, at the stone House, no 41, South Second Street.

Specification of the Patent granted to Mr. William Murdock, of Redruth, in the Country of Cornwall, Gentleman for a Method of making (from the same Materials, and by Processes entirely new,) Copperas, Vitriol, and different Sorts of Dye or dying Stuff, Paints, and Colours ; and also a Composition for preserving the Bottoms of all Kinds of Vessels, and all Wood required to be immersed in Water, from Worms, Weeds, Barnacles, and every other Foulness which usually does or may adhere thereto. Dated May 2, 1791. 1798. The repertory of arts and manufactures 1st series 9:97-99.

Specification of the Patent granted to John Crooks. 1800. The repertory of arts, manufactures, and agriculture 1st series 13 (74):81-95.

Specification of the Patent granted to Mr. William Bolts, for new Modes of improving the Form, Quality, and Use of Candles, and other Lights made of Tallow, Wax, Spermaceti or any other solid inflammable Subftances. 1800. The repertory of arts, manufactures, and agriculture 1st series 12 (72):368-382.

Lampe, elektrische. 1800. In Physikalisches Wörterbuch; oder, Erklärung der vornehmsten zur Physik gehörigen Begriffe und Kunstwörter so wohl nach atomistischer als auch nach dynamischer Lehrart betrachtet mit kurzen beygefügten Nachrichten von der Geschichte der Erfindungen und Beschreibungen der Werkzeuge in alphabetischer Ordnung. Band 3, edited by J. C. Fischer. Göttingen: J.C. Dieterich.

Review: An Essay on the Means hitherto employed for lighting Streets and the Interior of Houses. 1801. The Monthly review or Literary Journal 34 (1):108-109. 
Mr. Cruickshank on gaseous oxide of carbon. 1801. Philosophical Magazine and Journal 11:89-90.

Account of Mr. Mushet's new Method of making Steel of various Qualities. 1801. Philosophical Magazine and Journal 9:235-239.

Mr. Cruickshank on gaseous oxide of carbon. 1801. Philosophical Magazine and Journal 9:286-288.

Lebons Thermolampen. Absonderung und Waschung der brennbaren Luft. Flamme in der Krystallkugel. Uebrige Zurichtungen und Wirkungen. . 1801. London und Paris 8:206-213.

Nützliche Entdeckungen. 1801. Der Genius des neunzehnten Jahrhunderts 3:261-262.

Thermolampe. 1802. Der Verkündiger, oder, Wochenschrift zur Belehrung, Unterhaltung und Bekanntmachung für alle Stèande 6 (35):273-276.

Account of Quantities of Oil, Blubber and Spermaceti imported and exported from Great Britain, 1790-92 and 1799-1802. 1802. In HOUSE OF COMMONS PAPERS; ACCOUNTS AND PAPERS.

Auszüge aus Briefen und ein Paar Zeitungsartikel. 1802. Annalen der Physik 10 (4): 488-510.

Cartwright (John). 1802. In The Thespian dictionary, or, Dramatic biography of the eighteenth century : containing sketches of the lives, productions, \&c., of all the principal managers, dramatists, composers, commentators, actors, and actresses, of the United Kingdom: interspersed with several original anecdotes; and forming a concise history of the English stage. London: Printed by J. Cundee for T. Hurst; [etc.].

Full and Interesting Account of the Various Ascents of Messrs. Garnerin, Sowden, Locker, \&c. in Balloons. 1802. Sporting magazine; or, Monthly calendar, of the transactions of the turf, the chace, and every other diversion interesting to the man of pleasure, enterprize and spirit 20 (4):196.

Thermolampe und Phlogoscop. 1802. Der Genius des neunzehnten Jahrhunderts 5:298-305.

Bagatelles relating to the Pneumatic Apparatus. 1803. A Journal of natural philosophy, chemistry and the arts 4 (1):4-7.

Lebon's Thermolampe in Paris. 1803. The Anti-Jacobin review and magazine 16:389-390.

Art. IX. Gemeinnüzige Anzeigen. 1803. Gnädigst-privilegirtes Leipziger intelligenz-blatt auf das jahr (38):304-305. 
Versuch mit der Thermo-Lampe. 1803. Magazin der Handels- und Gewerbskunde 1:514-515.

Specification of the Patent granted to Frederick Albert Winsor for an improved Oven, Stove, or Apparatus, for the Purpose of extracting Air, Oil, Pitch, Tar, and Acids, from, and reducing into, Coke and Charcoal, all Kinds of Fuel. 1804. The repertory of arts, manufactures, and agriculture 2nd series 5 (27):172-174.

Winzlers Thermolampe. 1804. Physikalisch-ökonomische Bibliothek 22 (3):343-354.

Lampe a Gaz Inflammable. 1805. In Encyclopédie Méthodique: Chimie Et Métallurgie, edited by A.-F. Fourcroy. Paris: Pancoucke.

Comments on Mr. Wm. Henry's Experiments on the Gases obtained from the Distillation of Wood, Peat, and Pit-Coal. 1805. Retrospect of philosophical, mechanical, chemical and agricultural discoveries 1 (2):129-134.

Useful improvements and discoveries. 1805. The Literary magazine, and American register 3 (19):296-297.

Mr. Winsor's Thermolampen-Ofen in London. 1805. London und Paris 15:109-112.

Some Account of the Experiment made at Golden-Lane to illuminate Streets by CoalGas Lights. 1807. The Athenaeum, a magazine of literary and miscellaneous information 2 (8):187-188.

Mr. Edward Heard's Discovery. 1807. The Monthly magazine, or, British register 23 (1): 67.

Note on Mr. Winsor. 1807. The Monthly magazine, or, British register 23 (3):267.

Account of the First Experiment of the Public Use of Gas Lights. 1807. The Monthly magazine, or, British register 23 (6):520.

Lighting of the Golden Lane Brewery. 1807. The Monthly magazine, or, British register 24 (2):193.

Specification of the Patent granted to Edward Heard, of London, Chemist, for a Discovery of certain Means of obtaining inflammable Gas from Pit-Coal in such a State that it may be burned wihtout producing any offensive Smell. 1807. The repertory of arts, manufactures, and agriculture 2nd series 10 (56):31-32.

Specification of the Patent granted to Richard Lorentz for certain inventions (communicated to him by Foreigners residing abroad), of different MAchines or Instruments, one of which will produced instantaneous Light, and the other instantaneous Fire. 1807. The repertory of arts, manufactures, and agriculture 2nd series 111 (64):250-253. 
Lamp (Inflammable air). 1807. In The new encyclopaedia, or, Universal dictionary of arts and sciences. London: Vernor, Hood, and Dharpe.

Patent granted to Frederick Albert Winsor for an improved oven, stove, furnace, or apparatus for the extracting of inflammable air or gas and oil-tar from different kinds of fuel. 1807. The repertory of arts, manufactures, and agriculture 2nd series 10:320.

The Parliamentary register; or, an impartial report of the debates that have occurred in the two Houses of Parliament, in the course of the First (and only) session of the Third Parliament of the United Kingdom of Great Britain and Ireland. 1807. London: Stockdale.

Account of the Method of Carbonising Turf used by M. A. Thillaye Platel, from the Annales de Chemie [sic]. 1807. The Athenaeum, a magazine of literary and miscellaneous information 2 (8):187.

Review of Parkes' Chemical Catechism. 1807. The Anti-Jacobin review and magazine 27 (107):26.

Pall-Mall illuminated by Coal Gas Lights. 1808. The Athenaeum, a magazine of literary and miscellaneous information 3 (13):74.

Economy of Coal-Gas Lights at Messrs. Phillips' factory, and farther extension of those at Pall Mall. 1808. The Athenaeum, a magazine of literary and miscellaneous information 3 (16):372.

An account of the application of Gas from coal to economical purposes, by Mr. Wm. Murdoch. 1808. The Athenaeum, a magazine of literary and miscellaneous information 4 (20):153-155.

Lighting of the Pall Mall. 1808. The Monthly magazine, or, British register 24 (6):581.

Consideration on the nature and objects of the intended Gas Light and Heat Company. 1808. London: J. Ridgeway.

Sur une nouvelle Manière d'éclairer les Rues et les Appartemens, à l'aide du Charbon de terre, inventée et mise à exécution en Angleterre par M. F. A. Winsor, de Londres. 1808. Annales des Arts et Manufactures 28 (3):225-245.

Letter from Mr. Murdoch to the Royal Society. 1808. Philosophical Magazine and Journal 30:92.

Review: An Heroic Epistle to Mr. Winsor. 1808. The Monthly review or Literary Journal 54:97-99. 
Mr. Heard's Patent for obtaining Inflammable Gas from Pitcoal, in such a State, that it may be burned without producing any offensive smell. 1808. Retrospect of philosophical, mechanical, chemical and agricultural discoveries 3 (8):83-86.

To the editor of the Monthly Magazine: joint stock companies. 1808. The Monthly magazine, or, British register 25:133-4.

Einige Nachrichten aus England über Erleuchtung im Grossen mit Thermolampen. 1808. Annalen der Physik 30 (12):406-414.

Considerations on the nature and objects of the intended Light and Heat Company : published by authority of the committee. 1808. London: Printed for James Ridgway by T. Davison.

Considerations on the nature and objects of the intended Light and Heat Company : published by authority of the committee. with improvements and additional experiments. 1808. 2nd ed. London: Printed for James Ridgway by T. Davison.

Économie forestière: Améliorations, économie du combustible. 1808. In Annales forestières, faisant suite au Mémorial forestier, ou, Recueil complet des lois, arrêts et instructions relatifs à l'Administration forestière. A Paris: Chez Arthus.Bertrand.

Horace in London. 1808 [1812?]. The Poetical register, and repository of fugitive poetry for 1808-1809 7:246.

Remarks upon the bill for incorporating the Gas light and Coke company. 1809. London: Printed by George Sidney.

Gas light bill third reading, Friday, June 2, 1809. 1809. The Company,; (London :; G. Sidney).

Remarks on the gas light and coke bill. 1809. s.n.

Description of an Apparatus, for producing Inflammable Gas from Pit Coal, constructed by Mr. S. Clegg, Steam Engine Manufacturer, Manchester. 1809. The Athenaeum, a magazine of literary and miscellaneous information 5 (29): 441-442.

Gas. 1809. In The British encyclopedia; or, Dictionary of arts and sciences. Comprising an accurate and popular view of the present improved state of human knowledge, edited by W. Nicholson. London: Longman, Hurst, Rees, and Orme [etc.].

Sur l'application du gaz tiré de la houille aux usages économiques. 1809. Annales des Arts et Manufactures 33 (97):66-78.

In Parliament: Gas-light bill. 1809. s.n. 
Letters from an Irish student in England to his father in Ireland. 1809. London: Cradock \& Joy.

Minutes of the proceedings of a meeting of the Gas-light and Coke Shareholders at the City of London Tavern, on Thursday, 6th July, 1809. 1809. London.

An act [50 Geo.III cap. clxiii] for granting certain Powers and Authorities to a Company to be incorporated by Charter, to be called The Gas Light and Coke Company for making Inflammable Aire for the lighting of the Streets of the Metropolis, and for procuring Coke, Oil, Tar, Pitch, Asphaltum, Ammoniacal Liquor, and essential Oil, from Coal, and for other Purposes relating thereto. 9 June 1810.

Specification of the Patent granted to John Maiben. 1810. The repertory of arts, manufactures, and agriculture 2nd series 17 (100):193-197.

The Parliamentary register; or, an impartial report of the debates that have occurred in the two Houses of Parliament, in the course of the Fourth session of the Fourth Parliament of the United Kingdom of Great Britain and Ireland. 1810. London: Stockdale.

Electricity. 1810. In Encyclopædia Britannica, or, A Dictionary of arts, sciences, and miscellaneous literature [Vol. 7], edited by J. Millar. Edinburgh: Printed by A. Bell for A. Constable [et al.].

Correspondance. Suite de la correspondance de M. Boudet, Pharmacien en chef. 1810. Bulletin de pharmacie 2 (6):283-288.

Minutes of Evidence taken before the Lords Committees to whom was referred the Bill, intitled, "An act for enabling His Majesty to incorporated by Charter, to be called The Gas Light and Coke Company for making Inflammable Air for the lighting of the Streets of the Metropolis, and for procuring Coke, Oil, Tar, Pitch, Asphaltum, Ammoniacal Liquor, and essential Oil, from Coal, and for other Purposes relating thereto. 1810. In HOUSE OF LORDS PAPERS; REPORTS OF COMMITTEES.

Gas lights used in the manufactories in Scotland. 1810. The Tradesman, or, Commercial magazine 4 (24):547.

Eclairage par le Gaz Hydrogène. 1810. Bibliothèque physico-économique, instructive et amusante a l'usage des villes et des campagnes 8:110-111.

Specification of the Patent granted to Frederick Albert Winsor. 1811. The repertory of arts, manufactures, and agriculture 2nd series 18 (103):6-14.

Patent for Improvements in his Oven Stove, or Apparatus fur carbonising all Sorts of raw Fewel, \&c. and for extracting the Oil, Tar, pyrolignous Acid, and ammoniacal Coal Liquids, and for extracting and refining also the inflammable Air or Gas. 
1811. Retrospect of philosophical, mechanical, chemical and agricultural discoveries 6:419-421.

Avis - Thermolampe. 1811. Mercure de France 48 (74):240.

Vermischte Schriften. 1811. Allgemeine Literatur-Zeitung 1811-4 (20):155.

Sociétés savantes. Sociétés de Liége. Nouvel éclairage. 1811. Bulletin de pharmacie 12 (6):573-575.

Recital of the Act for granting certain powers and authorities to a Company to be incorporated, called "The Gas Light and Coke Company". 30 April 1812.

Proprietors' Meetings B/GLCC/64/1. 1812. In (Chartered) Gas Light and Coke Company. London: London Metropolitan Archives.

Specification of the Patent granted to Frederick Albert Winsor for a method of employing raw and refined sugars. 1812. The repertory of arts, manufactures, and agriculture 2nd series 20:128.

Anwendung der deutchen Thermolampe im Großsen. 1812. Vaterländische Blätter für den österreichischen Kaiserstaat (97):581-583.

Woburn-Abbey georgics, or, The last-gathering : a poem, in four cantos. Canto I and II. 1813. 2nd ed. London: Printed for C. Chapple.

Explosion at Woolich. 1813. Annals of Philosophy 1 (6):377-378.

Méthode perfectionnée pour l'éclairage par le gaz de la houille; vernis pour les métaux; asphalte d'une excellente qualité. 1813. Annales des Arts et Manufactures 48 (144):225-239.

Gas light company. 1813. The Monthly magazine, or, British register 35:533-534.

An act [54 Geo. 3 cap. 116] for enlarging the powers of an act of His Present Majesty for granting certain powers and authorities to the Gas Light and Coke Company. 17 June 1814.

An account of Improvments made in Gas Light. By Messrs. Sobolewsky and Horrer, at Petersburgh. 1814. The repertory of arts, manufactures, and agriculture 2nd series 24 (143):315-318.

List of patents for 1812. 1814. The Edinburgh annual register 5, pt 2:341-342.

Specification of the Patent granted to John Taylor. 1815. The repertory of arts, manufactures, and agriculture 2nd series 28 (163):1-7. 
Extracts from the Proceedings of the General Half-Yearly Meeting of the Court of Proprietors, July 10, 1815. 1815. London: Gas Light and Coke Company.

1816. Bill to enlarge Powers of Acts for granting Powers to Gas-Light and Coke Company. (452).

An act [56 Geo.III cap. Ixxxvii] to alter and enlarge the Powers of Two Acts of His Present Majesty, for granting certain Powers to the Gas Light and Coke Company. 2 July 1816.

Coal Gas. 1816. Annals of Philosophy 7 (2):159-160.

Specification of the Patent granted to Samuel Clegg. 1816. The repertory of arts, manufactures, and agriculture 2nd series $30(175,176,177): 1-10,65-75$, 129-137.

Minutes of Evidence taken before the Lords Committees to whom was referred the Bill, intitled, "An act to alter and enlarge the Powers of Two Acts of His present Majesty for granting certain Powers to the Gas Light and Coke Company. 1816. In HOUSE OF LORDS PAPERS; REPORTS OF COMMITTEES.

Remarks and Considerations on the Gas Light and Coke Company's Bill Now Before Parliament. 1816. London: Reynell.

An act [57 Geo.3 cap. xxiii] for better lighting the streets and houses of the metropolis with gas. [City of London Gas, Light \& Coke Co. act]. 23 May 1817.

Further Account of Mr. Samuel Clegg's Improvements of the Apparatus used in Gas Illumination. 1817. The Quarterly journal of science and the arts 2 (3):132-8.

Improvements in Physical Science during the Year 1816. 1817. Annals of Philosophy 9 (1):25.

Specification of the Patent granted to Daniel Wilson. 1817. The repertory of arts, manufactures, and agriculture 2nd series 32 (187):11-16.

Gas from Oil. 1817. Philosophical Magazine and Journal 49:309.

Vermischte Schriften. 1817. Allgemeine Literatur-Zeitung 1817-4 (102):814.

Note respecting the improvements in the Covent Garden Theatre. 1818. The Quarterly journal of science and the arts 4 (8):383-384.

Specification of the Patent granted to Rueben [sic] Phillips. 1818. The repertory of arts, manufactures, and agriculture 2nd series 33 (194):67-70.

Improvements in the Purification of Coal-Gas. 1818. Philosophical Magazine and Journal 51:312-313. 
On Purifying Coal Gas. 1818. Philosophical Magazine and Journal 52:467.

A brief account of the economy and utility of gas-light illumination. 1818. Blandford: Printed by J. Shipp.

The Imperial Tourists. 1818. The Literary gazette and journal of belles lettres, arts, sciences, etc for the year 18182 (57):113-4.

1819. A bill to alter and enlarge the powers of The Gas Light and Coke Company and to amend three acts of His present Majesty, relating to the said company.

A few facts relating to Gas Illumination. 1819. Quarterly journal of science, literature and art 7 (14):312-318.

On the Production of Gas for Illumination from Oil. 1819. Quarterly journal of science, literature and art 6 (11):108-111.

Gas light. 1819. In The cyclopedia; or, Universal dictionary of arts, sciences, and literature, edited by A. Rees. London: Longman, Hurst, Rees, Orme \& Browne [etc.].

Specification of the Patent granted to George Holworthy Palmer. 1819. The repertory of arts, manufactures, and agriculture 2nd series 34 (202):196-198.

An Act [59 Geo. 3 cap. 20] to alter and enlarge the powers of The Gas Light and Coke Company and to amend three acts of His present Majesty, relating to the said company. 7 April 1819.

Account of a new Portable Gas Lamp, invented by David Gordon, Esq. Edinburgh. 1819. Edinburgh Philosophical Journal 1 (2):373-376.

Bakerian Lecture at the Royal Society. 1819. Philosophical Magazine and Journal $54: 461$.

Analyses of Coal. 1820. The Quarterly journal of science and the arts 8 (15):162-164.

Description of Messrs. Taylors and Martineau's Patent Apparatus, for the production of Gas from Oil. 1820. The Quarterly journal of science and the arts 8 (15):120-124.

Analytical and Critical Account of Accum's Description of the process of manufacturing coal gas. 1820. Annals of Philosophy 15 (88):286-296.

On the Volatility and Inflammability which Fish and other Fixed Oils acquire by continued Exposure to certain High Temperatures. 1820. The London journal of arts and sciences 1 (3):188-198.

Recent Patent to John Grafton for new Method of Distilling off the Products of Coal. 1820. The London journal of arts and sciences 1 (5):330-331. 
Recent Patent to David Gordon and Edward Heard for an Invention of a Portable Gas Lamp. 1820. The London journal of arts and sciences 1 (2):95-96.

Specification of the Patent granted to Samuel Clegg for an improved Gasometer or Gas-holder. 1820. The repertory of arts, manufactures, and agriculture 2nd series 37 (220):193-199.

Specification of the Patent granted to David Gordon and Edward Heard. 1820. The repertory of arts, manufactures, and agriculture 2nd series 36 (216):339-348.

Specification of the Patent granted to Uriah Haddock for an improved Method of producing inflammable Gas from Pit Coal. 1820. The repertory of arts, manufactures, and agriculture 2nd series 37:332-333.

To John Grafton, Engineer of the Gas Light Works, Edinburgh, for a New and Improved Apparatus for purifuing Gas used for Illumination. 1820. The London journal of arts and sciences $1(2): 81-83$.

Illuminating power of Gases. 1820. Edinburgh Philosophical Journal 2:184.

Clegg's New Method of producing Coal-Gas. 1820. Edinburgh Philosophical Journal 2:384.

An Act [57 Geo. III. Cap XXIX] for better paving, improving, and regulating the Streets of the Metropolis, and removign and preventing nuisances and bstructions therein. [Pased 16th June 1817.]. 16th June 1817.

John Malam's Improved Gas-Meter. 1820. Transactions of the Society, Instituted at London, for the Encouragement of Arts, Manufactures, and Commerce 37:167-171.

An act [1 \& 2 Geo.IV cap. li] for incorporating the South London Gas Light and Coke Company situate in the Parish of Saint Saviour.

An act [1 \& 2 Geo.IV cap. cxvii] to establish an additional company [the Imperial Gas Light and Coke Company] for lighting certain parts of the metropolis ... with gas.

Oil Gas. 1821. Philosophical Magazine and Journal 57:67.

1821. Bill for further Regulation of Supply of Water to Cities of London and Westminster, and North of Thames. (661).

Recent Patent to John Malam for certain Improvements on Gas Meters. 1821. The London journal of arts and sciences 2 (8):81-86.

Specification of the Patent granted to John Grafton for an improved Process or Method of making carburetted hydrogen Gas, for the Purpose of Illumination. 1821. The repertory of arts, manufactures, and agriculture 2nd series 38 (227):272-275. 
House of Commons (UK). 1822. Bill to prevent Washings, or Substances from Making of Gas, being conveyed into Rivers. 1822, (480).

On Olefiant Gas. 1822. Annals of Philosophy New Series 3 (1):37-39.

New Method of Illuminating Houses with Gas. 1822. Edinburgh Philosophical Journal 6:299-300.

Gas from Coal Tar. 1822. Philosophical Magazine and Journal 59:460-461.

Return of Amount of Duty on Candles in England, Scotland and Ireland, 1711-1822. 1822. In HOUSE OF COMMONS PAPERS; ACCOUNTS AND PAPERS.

Account of Quantity of Candles charged with Excise Duty, 1710-1821. 1822. In HOUSE OF COMMONS PAPERS; ACCOUNTS AND PAPERS.

An act [4 Geo.IV cap. cxix] to enlarge the powers of the Gas Light and Coke Company.

1823. Bill for Regulation of Gas Establishments in Metropolis. (428).

Oil Gas in France. 1823. Philosophical Magazine and Journal 61:147.

Projects and Projectors. 1823. The New monthly magazine and literary journal 5:120-123.

Specification of the Patent granted to John Grafton. 1824. The repertory of arts, manufactures, and agriculture 2nd series 44 (264):324-329.

Dritte Classe der Kohlen. Die Thermolampen Kohlen. 1824. In Darstellung des fabriksund gewerbswesens in seinem gegenwärtigen zustande, vorzüglich in technischer, mercantilischer und statistischer beziehung, edited by S. v. Keess. Wien: M^rschner und Jasper.

Comparative merits of cola and oil gas. 1824. Glasgow mechanics' magazine, and annals of philosophy 1 (22):345-349.

An address to the shareholders of the Gas-light and Coke Company, on the financial accounts of that corporation. 1825. London: [Printed for C. and J. Rivington].

History of Gas-Lighting. 1827. The London magazine and review (36):502-515.

Substance of a memorial presented by the ... Company to the Commissions of Sewers, London. 1828. [London: The Company.

Supply of Water in the Metropolis. Report of the Commissioners appointed by His Majesty to inquire into the State of the Supply of Water in the Metropolis. 1828. London Medical Gazette 2 (35):271-275, 305-8. 
Account of Money invested and Profits of Imperial Gas-Light and Coke Company. 1828. In HOUSE OF COMMONS PAPERS; ACCOUNTS AND PAPERS.

Com. for inquiring into State of Supply of Water to Metropolis; Correspondence between Coms. and Home Dept. 1828. In HOUSE OF COMMONS PAPERS; ACCOUNTS AND PAPERS.

Gas Lighting. 1828. Mechanics' magazine and journal of science, arts, and manufactures 8:306, 341-3, 395-7, 414-5, 445-7.

Com. for inquiring into State of Supply of Water to Metropolis; Correspondence between Coms. and Home Dept. 1828. In Document type: HOUSE OF COMMONS PAPERS; ACCOUNTS AND PAPERS.

Review: An Historical Sketch of the Origin, Progress and Present State of Gas-Lighting. 1829. The Westminster review 11 (12):290-303.

Crossley against Beverley. 1829. The repertory of arts, manufactures, and agriculture 3rd series 8:122-124.

Account of Monies set apart from Profits of Imperial Gas-Light and Coke Company. 1830. In HOUSE OF COMMONS PAPERS; ACCOUNTS AND PAPERS.

Supplement to Correspondence relating to Supply of Water to Metropolis. 1830. In HOUSE OF COMMONS PAPERS; ACCOUNTS AND PAPERS.

Treasury Minutes relating to Employment of Mr. Telford, and Report on best Mode of supplying Metropolis with Pure Water. 1830. In HOUSE OF COMMONS PAPERS; ACCOUNTS AND PAPERS.

Thames Water Question. 1830. The Westminster review 12 (23):31-42.

Obituary: Mr. Winsor. 1830. Gentlemen's Magazine 100:89-90.

Lamp (Argand). 1830. In The Edinburgh encyclopædia, edited by D. Brewster. Edinburgh: Printed for W. Blackwood.

Obituary: Mr. William Clarke. 1830. Gentlemen's Magazine 86:469.

An act [10 Geo. IV cap. xii] to alter ... two acts ... for establishing and regulating the Imperial Gas Light and Coke Company.

History of Gas. 1834. The Penny magazine of the Society for the Diffusion of Useful Knowledge 3:373-493.

Materials for a memoir of Mr. Samuel Clegg, and Authentic History of the Art of GasLighting. 1835. Mechanics' magazine and journal of science, arts, and manufactures 22 (607):470-472. 
Winzler, Zachäus Andr. 1835. In Oesterreichische National-Encyklopädie, oder, Alphabetische Darlegung der wissenswürdigsten Eigenthümlichkeiten des österreichischen Kaiserthumes, edited by J. J. H. Czikann and F. Gräffer. Wien: Auf Kosten der beyden Herausgeber, in Commission der F. Beck'schen Universitäts-Buchhandlung.

Salm, Hugo Franz Altgraf. 1836. In Oesterreichische National-Encyklopädie, oder, Alphabetische Darlegung der wissenswürdigsten Eigenthümlichkeiten des österreichischen Kaiserthumes, edited by J. J. H. Czikann and F. Gräffer. Wien: Auf Kosten der beyden Herausgeber, in Commission der F. Beck'schen Universitäts-Buchhandlung.

Books on Gas Lighting. 1842. Mechanics' magazine and journal of science, arts, and manufactures 26 (980):387-393.

Crossley v. Beverley. 1843. In Law reports of patent cases. [1602-1842], edited by W. Carpmael. London: A. Macintosh.

Thermolampe. 1844. In Oekonomisch-technologische Encyklopädie, oder allgemeines System der Staats- Stadt- Haus- und Landwirthschaft und der Kunstgeschichte Vol 183, edited by W. D. Korth. Berlin: Leopoeld Wilhelm Krause.

1848. Chancery. Symonds v. The Gas Light and Coke Company. November 7-8, 1848.

Ehrmann, Frédéric-Louis. 1858. In Nouvelle biographie générale depuis les temps les plus reculés jusqu'à nos jours, avec les renseignements bibliographiques et l'indication des sources à consulter (Vol 15), edited by M. Hoefer. Paris: Firmin Didot fréres, fils et cie.

Patents for inventions. Abridgments of specifications relating to the production and applications of gas. 1860. London: Printed by G.E. Eyre and W. Spottiswoode.

Weber, Josef. 1875. In Allgemeine deutsche Biographie (Vol 41). Leipzig: Historische Commission bei der Königl. Akademie der Wissenschaften.

Gilbert, Ludwig. 1875. In Allgemeine deutsche Biographie (Vol 9). Leipzig: Historische Commission bei der Königl. Akademie der Wissenschaften.

Crossley v. Beverley. 1887. In Decisions on the law of patents for inventions rendered by English Courts since the beginning of the seventeenth century, edited by $\mathrm{B}$. V. Abbott. Washington: Charles R. Brodix Law Publisher.

Gas and Gas-Lighting. 1890. In The Encyclopaedia britannica;: a dictionary or arts, sciences, and general literature, edited by T. S. Baynes. New York: Funk \& Wagnalls. 
Murray, Lord George (1761-1803). 1894. In The dictionary of national biography : from the earliest times to 1900 Vol. 39 Morehead - Myles, edited by S. Lee. New York: MacMillan and Co.

[Box, James]. 1817. An account of the Society, denominated the Associated Proprietors of the Gas Light and Coke Company containing particulars of the rise, the progress, the principles, the object, and the usefulness of that society: Printed and sold for the author.

[Pillans, James]. 1809. Gas Lights. The Edinburgh review 13 (26):477-488.

[Sayers, James]. 1808. Heroic epistle to Mr. Winsor, the patentee of the hydrocarbonic gas lights and founder of the National light and heat company. London: R. Spencer, Great Ormond Street.

Accum, Frederick Christian. 1804. Description of an improved Gazometer. The repertory of arts, manufactures, and agriculture 2nd series, 5:179-182.

- - - 1815. On the Method of Illuminating the Streets by Coal Gas. Annals of Philosophy 6 (1):16-19.

- - - 1815. A practical treatise on gas-light; exhibiting a summary description of the apparatus and machinery best calculated for illuminating streets, houses, and manufactories, with carburetted hydrogen, or coal-gas; with remarks on the utility, safety, and general nature of this new branch of civil economy. London: Printed by G. Hayden for R. Ackermann [etc.].

- - . 1815. Review: A practical Treatise on Gas Light. Philosophical Magazine and Journal 45:372-374.

- - - 1815. A practical treatise on gas-light; exhibiting a summary description of the apparatus and machinery best calculated for illuminating streets, houses, and manufactories, with carburetted hydrogen, or coal-gas; with remarks on the utility, safety, and general nature of this new branch of civil economy. 2nd ed. London: Printed by G. Hayden for R. Ackermann [etc.].

- - . 1816. A practical treatise on gas-light: exhibiting a summary description of the apparatus and machinery best calculated for illuminating streets, houses and manufactories, with carburetted hydrogen, or coal-gas: with remarks on the utility, safety, and general nature of this new branch of civil economy. 3d ed. London: Stereotyped and printed by Davies, Michael, and Hudson, for R. Ackermann [etc.].

- - . 1817. Review: A Practical Treastise on Gaz [sic]-light. Journal des savans (1): 12-21. 
- - - 1818. A practical treatise on gas-light exhibiting a summary description of the apparatus and machinery best calculated for illuminating streets, houses, and manufactories, with carburetted hydrogen, or coal-gas. 4th ed. London: Printed for R. Ackerman, W. Clowes).

- - . 1819. Description of the process of manufacturing coal gas, for the lighting of streets, houses, and public buildings, with elevations, sections, and plans of the most improved sorts of apparatus now employed at the gas works in London, and the principal provincial towns of Great Britain, accompanied with comparative estimates, exhibiting the most economical mode of procuring this species of light. London: T. Boys.

--- . 1819. Review: Description of the Process of manufacturing Coal-Gas for the Lighting of Streets, Houses, and public Buildings. Philosophical Magazine and Journal 53:453-455.

Accum, Friedrich Christian. 1820. Description of the process of manufacturing coal gas for the lighting of streets houses, and public buildings with elevations, sections, and plans of the most improved sorts of apparatus now employed at the gas works in London, and the principal provincial towns of Great Britain; accompanied with comparative estimates, exhibiting the most economical mode of procuring this species of light : with seven plates. 2nd ed: London : Printed for Thomas Boys.

Accum, Frederick Christian, and Frederick Albert Winsor. 1816. Traité pratique de l'éclairage par le gaz inflammable contenant une description sommaire de l'appareil et du mécanisme employés pour l'illumination des rues, des maisons, et des manufactures à l'aide du gaz hydrogène carburé, tiré du charbon de terre. Paris: Chez L'Auteur.

Achard, F.K. 1783. Ueber ein neues Mittel, durch wenige Kohlen oder andere brennbare Körper eine so ansehnliche Hitze hervorzubringen, daß sie der von den Brennspiegeln gleich gesetzt werden kann. Magazin für das Neueste aus der Physik und Naturgeschichte 2 (1):64-67.

Adams, George. 1784. An essay on electricity : in which the theory and practice of that useful science, are illustrated by a variety of experiments, arranged in a methodical manner. To which is added, An essay on magnetism. London: Printed for and sold by the author, at Tycho Brahe's Head ...

-- - 1794. Lectures on natural and experimental philosophy : considered in it's [sic] present state of improvement : describing, in a familiar and easy manner, the principal phenomena of nature, and shewing, that they all co-operate in displaying thegoodness, wisdom, and power of God. London: Printed by R. Hindmarsh. 
Austin, William, and Charles Blagden. 1788. Experiments on the Formation of Volatile Alkali, and on the Affinities of the Phlogisticated and Light Inflammable Airs. By William Austin, M. D. Fellow of the College of Physicians; Communicated by Charles Blagden, M. D. Sec. R. S. Philosophical Transactions of the Royal Society of London 78:379-387.

- - - 1790. Experiments on the Analysis of the Heavy Inflammable Air. By William Austin, M. D. Fellow of the College of Physicians; Communicated by Charles Blagden, M. D. Sec. R. S. Philosophical Transactions of the Royal Society of London 80:51-72.

Bailey, John. 1810. General view of the agriculture of the County of Durham with observations on the means of its improvement; drawn up for the consideration of the Board of agriculture and internal improvement. London: Richard Phillips (Printed by E. Walker).

Banks, Joseph. 1823. Report of Royal Society on Gas-Lights; Report of Inspectors on Gas-Light Establishments in the Metropolis. In HOUSE OF COMMONS PAPERS; ACCOUNTS AND PAPERS. London: House of Commons.

Barbier de Tinan. 1780. Lettre á M. Neret fils, sur les Airs inflammables. Observations sur la physique, sur l'histoire naturelle et sur les arts 15:144-148.

- - - 1782. Lettre á M. Neret fils, sur les Airs inflammables. Observations sur la physique, sur l'histoire naturelle et sur les arts 19:454-459.

Barbier-Vémars, J.-N. 1810. Sur l'application du gaz tiré de la houille à divers usages économiques, et sur-tout à l'éclairage. Annales des Arts et Manufactures 35 (105):292-309.

- - . 1814. Produits tiré de la houille. Annales des Arts et Manufactures 51 (152): 212-223.

- - - 1814. Éclairage des villes et des maisons particulières par le gaz hydrogène. Annales des Arts et Manufactures 54 (162):318-321.

- - . 1815. Nouvelles inventions de tout genre. Annales des Arts et Manufactures 55 (165):301-302.

Baynes, Thomas Spencer. 1890. The Encyclopaedia britannica;: a dictionary or arts, sciences, and general literature. New York: Funk \& Wagnalls.

Beatson, Robert. 1807. A chronological register of both houses of the British Parliament, from the union in 1708, to the third Parliament of the United Kingdom of Great Britain and Ireland, in 1807. London: printed for Longman, Hurst, Rees, and Orme [by J. Chalmers \& Co.]. 
Beck, J. 1839. Lighting Gas Lamps by Electricity. Mechanics' magazine and journal of science, arts, and manufactures 30.

Beddoes, Thomas, and James Watt. 1795. Considerations on the medicinal use, and on the production of factitious airs. Bristol: Printed by Bulgin and Rosser for J. Johnson, London.

Berthollet, Claude-Louis. 1776. Observations sur l'air. Se trouve à Paris: Chez P. Fr. Didot le jeune ...

- - - 1785 [1788]. Suite des recherches sur la nature des substances animales, et sur leurs rapports avec les substances végétables. Histoire de l'Académie royale des sciences:331-349.

- - 1785 [1788]. Mémoire su l'Acde marin déphlogistiqué. Histoire de l'Académie royale des sciences:276-295.

- - - 1798. Observations sur l'hydrogène sulfuré. Annales de Chimie, ou, Recueil de mémoires concernant la chimie et les arts qui en dépendent 25:233-272.

- - . 1800. Cinquante-deuxième séance: Chimie. Séances des écoles normales 5:244-268.

Berzelius, Jacob. 1813. An Attempt to determine the definite and simple Proportions, in which the constituent Parts of unorganic Substances are united with each other. Philosophical Magazine and Journal 42:171-175.

Black, Joseph. 1756. Experiments upon Magnesia Alba, Quick-Lime, and other Alcaline Substances. Essays and observations, physical and literary of the Philosophical Society of Edinburgh.

Blagdon, Francis William. 1803. Paris as it was and as it is; or, A sketch of the French capital, illustrative of the effects of the revolution, with respect to sciences, literature, arts, religion, education, manners, and amusements; comprising also a correct account of the most remarkable national establishments and public buildings. London: C.and R. Baldwin.

Bolton, Charles. 1819. On the Purification of Coal Gas. Philosophical Magazine and Journal 53:138-139.

Borgnis, J. A. b ca. 1818. Traité complet de mécanique appliquée aux arts, contenant l'exposition méthodique des théories et des expériences les plus utiles pour diriger le choix, l'invention, la construction et l'emploi de toutes les especes de machines. Paris: Bachelier.

Bouguer, Pierre. 1760. Traité d'optique sur la gradation de la lumière : ouvrage posthume. A Paris: H.L. Guerin \& L.F. Delatour. 
Bourgeois. 1744 [1748]. Des nouvelles Lanternes a réverbere construites par M. Bourgeois. Histoire de l'Académie royale des sciences:62.

- - - 1777. Lanternes a réverbere invente par $\mathrm{M}$. Bourgeois de Chateaublanc. Machines et inventions approuvées par l'Académie royale des sciences, depuis son établissement jusqu'à présent; avec leur description 7:273-274.

Bowditch, W. R. 1867. The analysis, technical valuation, purification and use of coal gas. London: E. and F.N. Spon.

Boyle, Robert. 1672. Tracts written by the Honourable Robert Boyle containing New experiments, touching the relation betwixt flame and air, and about explosions, an hydrostatical discourse occasion'd by some objections of Dr. Henry More against some explications of new experiments made by the author of these tracts : to which is annex't, An hydrostatical letter, dilucidating an experiment about a way of weighing water in water, new experiments, of the positive or relative levity of bodies under water, of the air's spring on bodies under water, about the differing pressure of heavy solids and fluids: London : Printed for Richard Davis, book-seller in Oxon.

Boyle, Robert, and Robert Sharrock. 1663. Some considerations touching the vsefulnesse of experimental naturall philosophy propos'd in familiar discourses to a friend, by way of invitation to the study of it. Oxford: Printed by Hen. Hall ... for Ric. Davis.

Brande, William Thomas. 1816. Observations on the Application of of Coal Gas to the Purposes of Illumination. The Quarterly journal of science and the arts 1 (1): 71-80.

- - - 1816. Some Account of Mr. Samuel Clegg's Improvments of the Apparatus employed in Gas Illumination. The Quarterly journal of science and the arts 1 (2): 278-283.

- - - 1820. The Bakerian Lecture: On the Composition and Analysis of the Inflammable Gaseous Compounds Resulting from the Destructive Distillation of Coal and Oil, with Some Remarks on Their Relative Heating and Illuminating Powers. Philosophical Transactions of the Royal Society of London 110:11-28.

- - . 1820. Account of a Portable Gas Lamp. The Quarterly journal of science and the arts 8 (16):233-234.

- - . 1820. On a Substance Produced during the Distillation of Coal Tar. Quarterly journal of science, literature and art 8 (15):287-290.

Brisson, Mathurin-Jacques. 1797. Traité élémentaire ou principes de physique; fondés sur les connoissances les plus certaines, tant anciennes que modernes, \& confirmés par l'expérience. 2nd ed. 3 vols. Vol. 2. Paris: Moutard. 
Brougham, Henry 1809. Speeches of Henry Brougham, Esq delivered before a committee of the Honourable House of Commons, in opposition to a bill, for incorporating certain persons by the name of the Gas Light and Coke Company. London: Strahan and Preston.

Brown, John. 1823. The historical gallery of criminal portraitures, foreign and domestic: containing a selection of the most impressive cases of guilt and misfortune to be found in modern history. Manchester: J. Gleave.

Brownrigg, William. 1748. The art of making common salt, as now practised in most parts of the world : with several improvements proposed in that art, for the use of the British dominions. London : Printed, and sold by C. Davis: A. Millar ; and R. Dodsley.

- - - 1765. An Experimental Enquiry into the Mineral Elastic Spirit, or Air, Contained in Spa Water; As Well as into the Mephitic Qualities of This Spirit. By William Brownrigg, M. D. F. R. S. Philosophical Transactions (1683-1775) 55:218-243.

Buchanan, Robertson. 1810. Practical and descriptive essays on the economy of fuel, and management of heat. Glasgow: Hedderwick.

Bünger, Carl Gottfried. 1802. Abbildung und Beschreibung einer Thermolampe : Nebst einem zweckmässigen Apparat zur Zimmerbeleuchtung. Pirna: Bei Friedrich G. Pinther.

Bünger, Karl. 1803. Neue Einrichtung der Thermolampe zum pharmaceutischen Gebrauche. Annalen der Physik 15 (2):231-234.

Burdett, Francis Sir. 1828. Select Committee on System of supplying Water to Metropolis. Report, Minutes of Evidence, Appendix. In HOUSE OF COMMONS PAPERS; REPORTS OF COMMITTEES.

Cabral de Mello, Americo. 1814. On Gas Light, as far as it regards the Products obtainable from Pit-coal by this new Method of Illumination and its œconomical Application. Philosophical Magazine and Journal 42 (199):368-370.

Candidus. 1817. Observations on gas-lights being an impartial inquiry concerning the injurious effects on the health of the community, from the use of coal-gas for lighting the metropolis: Printed for T. and G. Underwood,; (London :; S. Gosnell).

Carra. 1784. Lettre écrite le 8 du mois dernier a $M .{ }^{* * *}$, membre de plusieurs académies, par M. Carra, pour réclamer la priorité de l'invention de deux ballons dans les expériences de nautique aérienne proposées à l'académie des sciences de Paris. Journal encyclopédique ou universel 2 (2):503-509. 
Cavendish, Henry. 1766. Three Papers, Containing Experiments on Factitious Air, by the Hon. Henry Cavendish, F. R. S. Philosophical Transactions (1683-1775) 56:141-184.

Cawood, John. 1819. Mr. Cawood on gas Retorts. Quarterly journal of science, literature and art 6 (11):71-73.

Cecil, W. 1820. On the application of hydrogen gas to produce a moving power in machinery. Transactions of the Cambridge Philosophical Society 1 (2):217-239.

Chapman, Robert of Glasgow. 1820. The topographical picture of Glasgow in its ancient and modern state; with sketches of a tour to the lakes and romantic scenery in the shires of Dumbarton, Argyll, and Perth, and to the Falls of Clyde. 3rd, enl. ed. Glasgow: R. Chapman.

Chaptal, Jean-Antoine-Claude. 1791. Elements of chemistry. Translated by W. Nicholson. London: Printed for G. G. J. and J. Robinson.

Chaussier, Francois. 1777. Mémoire de physique expérimentale, sur quelques propriétés de l'air inflammable, lu à la Séance publique de l'Académie des Sciences \& Belles-Lettres de Dijon 17 Aout 1777. Observations sur la physique, sur l'histoire naturelle et sur les arts (10):309-321.

Christison, Robert, and Edward Turner. 1825. On the Construction of Oil and Coal Gas Burners and the circumstances that influences the Light emitted by the Gases during their Combustion. Edinburgh Philosophical Journal 13 (25):1-39.

- - - 1825. On the Comparative Advantages of Oil and Coal Gas. Philosophical Magazine and Journal 66 (329):206-210.

Christobal, José María. 1805. Curso de química general aplicada a las artes. Paris: [s.n.].

Clayton, John. 1693. A Letter from Mr. John Clayton Rector of Crofton at Wakefield in Yorkshire to the Royal Society, May 12. 1688. Giving an Account of Several Observables in Virginia, and in His Voyage Thither, More Particularly concerning the Air. Philosophical Transactions (1683-1775) 17:781-795.

- - . 1739. An Experiment concerning the Spirit of Coals, Being Part of a Letter to the Hon. Rob. Boyle, Esq; from the Late Rev. John Clayton, D. D. Communicated by the Right Rev. Father in God Robert Lord Bishop of Corke to the Right Hon. John Earl of Egmont, F. R. S. Philosophical Transactions (1683-1775) 41:59-61.

Clegg, Samuel. 1808. Improved Apparatus for extracting Carbonated Hydrogen Gas from Pit Coal. Transactions of the Society, Instituted at London, for the Encouragement of Arts, Manufactures, and Commerce 26:202-206. 
- - . 1809. Description of an Apparatus for making carburetted Hidrogen Gas from Pit-coal and lighting Manufactories with it. A Journal of natural philosophy, chemistry and the arts 23:85-89.

- - . 1809. Description of an Apparatus for making Carbonated Hydrogen Gas from Pit Coal, for the Purpose of lighting Factories therewith. Philosophical Magazine and Journal 33:217-220.

- - . 1809. Description of an Apparatus for making Carbonated Hydrogen Gas from Pit Coal, for the Purpose of lighting Factories therewith. The repertory of arts, manufactures, and agriculture 2nd series, 15:278-290.

- - . 1809. Specification of the Patent granted to Samuel Clegg for a rotative Engine, the Piston of which makes a complete Revolution at a Distance from the revolving Axis Shaft, or Cylinder. The repertory of arts, manufactures, and agriculture 2nd series, 15 (90):321-327.

- - . 1820. Description of an apparatus, by which twenty-five thousand cubit feet of gas, are obtained from each chaldron of coal,: without producing either tar or ammoniacal liquor. London: Sold by R. Ackerman ...

- - . 1820. Review: Description of an Apparatus, by which 25,000 cubic Feet of Gas are obtained from each Chaldron of Coal. Philosophical Magazine and Journal 55:138-144.

--1841 . A practical treatise on the manufacture and distribution of coal-gas : its introduction and progressive improvement, illustrated by engravings from working drawings, with general estimates. London: J. Weale.

- - - 1853. A practical treatise on the manufacture and distribution of coal-gas,: its introduction and progressive improvement; illustrated by engravings from working drawings, with general estimates. London: Weale.

Clement, and Desormes. 1802. Experiments on Charcoal. Philosophical Magazine and Journal 13:67-73,155-164.

Clement-Desomes. 1824. Theorie der Beleuchtung mit künstlichem Lichte. Annalen der Physik 76 (2):149-164.

Clément-Desormes. 1819. Appréciation du procédé d'éclairage par la gaz hydrogène du charbon de terre. Paris: Delaunay.

Clifford, Frederick. 1885. A history of private bill legislation. London: Butterworth's.

Coffin, R. S. 1826. Oriental harp. Poems of the Boston bard. Providence: R.I., Printed and published by Smith \& Parmenter, agents for the sale of the Oriental harp. 
Congreve, William. 1823. Observations on Gas Light Establishments. Annals of Philosophy New Series 5 (6):411-426.

Congreve, William, and J. Whiting. 1819. A short account of a patent lately taken out by Sir William Congreve, Bart. : for a new principle of steam engine; and also of a new mode which he has adopted for the saving of fuel \& the consumption of smoke in the production of steam, the generation of gas, and in various other operations, being also the subject of a patent. London: Printed by J. Whiting, published by $\mathrm{T}$. Egerton.

Cook, Benjamin. 1808. On the advantages of employing coal gas for lighting small manufactories and other purposes. A Journal of natural philosophy, chemistry and the arts 21:291-297.

--- . 1809. Second letter on the advantages of coal gas for lights. A Journal of natural philosophy, chemistry and the arts 22:145.

Cook, B. 1811. Method for producing Heat, Light, and various useful Articles, from Pitcoal. The repertory of arts, manufactures, and agriculture 2nd series 19 (109): 19-31.

Cooke, Benjamin. 1809. On employing Coal Gas for Lighting small Manufactures, and for other purposes, from a paper by Mr. B. Cook, of Caroline Street, Birmingham. The Athenaeum, a magazine of literary and miscellaneous information 5 (25): 72-74.

- - . 1809. Second communication on the advantages of Coal Gas Lights, by Mr. B. Cook, of Caroline Street, Birmingham. The Athenaeum, a magazine of literary and miscellaneous information 5 (27):253-254.

Cooke, Benjamin (?). 1811. Method of producing Heat, Light, and various useful Articles, from Pit-Coal. Philosophical Magazine and Journal 37 (157):332-339.

Cooper, Thomas. 1816. Some information concerning gas lights. Philadelphia: Published by John Conrad \& Co. J. Maxwell: printer.

Corry, John. 1820. The English metropolis, or, London in the year 1820 : containing satirical strictures on public manners, morals, and amusements ; a young gentleman's adventures ; and characteristic anecdotes of several eminent individuals who now figure in this great theatre of temporary exhibition. London: Printed by Barnard and Farley.

Creighton, Henry. 1824. Gas-Lights. In Encyclopaedia Britannica, or;: A dictionary of arts, sciences and miscellaneous literature. Supplement to the Fourth, Fifth, and Sixth Editions. Edinburgh: A. Constable.

Cruikshank, George. 1807. The good effects of carbonic gas!!! London: Fores, S. W. 
---.1815 . Introduction of gas!! Or throwing a new light on the subject. London: Sidebotham, J.

Daisenberger, Johann Michael. 1802. Beschreibung der Daisenberger'schen Thermolampe oder eines Sparofens, welcher alle Zimmer im ganzen Hause heitzen und beleuchten kann: Stadtamhof Selbstverl.

Dalton, John. 1806. On the Absorption of Gases by Water and other Liquids. Philosophical Magazine and Journal 24:15-24.

- - . 1808. A new system of chemical philosophy. Manchester: R. Bickerstaff.

Davis, J. W. 1809. A few Hints concerning the Benefit that may be expected from the Nature of Coal Gas. Philosophical Magazine and Journal 33 (134):432-438.

Davy, Humphry. 1800. Researches, chemical and philosophical, chiefly concerning nitrous oxide or dephlogisticated nitrous air, and its respiration. London: J. Johnson.

- - . 1816. Farther Experiments on the Combustion of Explosive Mixtures Confined by Wire-Gauze, with Some Observations on Flame. Philosophical Transactions of the Royal Society of London 106:115-119.

- - - 1817. Some Researches on Flame. Philosophical Transactions of the Royal Society of London 107:45-76.

- - - 1817. Some New Experiments and Observations on the Combustion of Gaseous Mixtures, with an Account of a Method of Preserving a Continued Light in Mixtures of Inflammable Gases and Air without Flame. Philosophical Transactions of the Royal Society of London 107:77-85.

- - . 1817. Notice of some Experiments and new Views respecting Flame. The Quarterly journal of science and the arts 2 (3):124.

de Carro. 1806. Nachricht von einer in der Kattunfabrik des Barons von Fries zu Kettenhof eingerichteten Thermolampe. Zusatz des Herausgebers. Enigw Erfahrungen enthaltend, über die Thermolampe, und deren Anwendung, vom Dr. Kretschmar in Sandersleben. Annalen der Physik 22 (1):79-83.

de Saussure, Theodore. 1815. Observations on the Absorption of the Gases by Different Bodies. Annals of Philosophy 6 (4):241-255.

De Wilde, Samuel. 1808. Opposition lights. London: Tipper, S.

--- 1809. The school of projects. London: Tipper, S.

Delas. 1781. Lettre de M. Delas, Prêtre de l'Oratoire, Professeur de Physique à Arras, à M. Pilatre de Rozier, sur quelques Experiences électrique \& sur l'origine du 
Tonnerre. Observations sur la physique, sur l'histoire naturelle et sur les arts $17: 469-470$.

Dewey, Thomas. 1823. Remarks on different Gasworks and the Substances from which Gas is usually prepared. Annals of Philosophy New Series 6 (6):401-407.

Donndorff, Johann August, and Bern Dibner. 1784. Die Lehre von der Elektricität :theoretisch und praktisch aus einander Gesezt zum gemeinnützigen Gebrauch, auch für solche die keine Gelehrte sind. Erfurt: Bey Georg Adam Keyser.

Dryeux. 1806. Description of M. Baurel's new Apparatus for making Gaseous Oxide of Carbon. Philosophical Magazine and Journal 23:317-319.

du Carla. 1785. Review: Senebier's Recherches analytiques sur la nature de l'air inflammable. The Monthly review or Literary Journal 71:510-516.

Dumotiez. 1789. Les feux d'air inflammable de M. Diller. Observations sur la physique, sur l'histoire naturelle et sur les arts 34:18.

Dundonald, Archibald Cochrane. 1784. Account of the qualities and uses of coal tar and coal varnish with certificates from ship-masters and others: W. Smellie.

Ebel, Johann Gottfried. 1795. Instructions pour un voyageur qui se propose de parcourir la Suisse de la maniere la plus utile et la plus propre à lui procurer toutes les jouissances dont cette contrée abonde (Vol 2): Basle [Basel] J.J. Tourneisen.

Ehrmann, Friedrich Ludwig. 1780. Déscription et usage de quelques lampes à air inflammable: A Strasbourg: J.H. Heitz.

Ehrmann, Friedrich Ludwig Fontallard Jean FranÁois de Lavoisier Antoine Laurent, and ou air vital Meusnier Jean Baptiste Marie Essai d'un art de fusion a l'aide de l'air du feu. 1787. Essai d'un art de fusion a l'aide de l'air du feu, ou air vital. A Strasbourg: Chez J.G. Treuttel ...; ¿ Paris : Chez Cuchet ..., Place: France; Strasbourg.

Elliot, Gilbert 1874. Life and letters of Sir Gilbert Elliot, first earl of Minto, from 1751 to 1806, when his public life in Europe was closed by his appointment to the viceroyalty of India. Vol. 1. London: Longmans, Green and Co.

Elliott, John. 1823. On Phaenomena observed in the making of Oil Gas. Philosophical Magazine and Journal 61 (302):401-405.

Faraday, M. 1825. On New Compounds of Carbon and Hydrogen, and on Certain Other Products Obtained during the Decomposition of Oil by Heat. Philosophical Transactions of the Royal Society of London 115:440-466. 
Farey, John. 1817. General view of the agriculture of the county of Derbyshire drawn up for the consideration of the Board of Agriculture and Internal Improvement, edited by B. o. A. a. I. Improvement: London.

Faujas-de-Saint-Fond, Barthélemy. 1783-4. Description des expériences de la machine aérostatique de MM. de Montgolfier, et de celles auxquelles cette découverte a donné lieu. Paris: Cuchet.

- - - 1790. Essai sur le goudron du charbon de terre, sur la manière de l'employer pour caréner les Vaisseux, \& celle d'un faire usage dans plusieurs arts : sur les différens produits de ce combustible fossile tel que le bitume solide, I'huile minérale, le naphte, l'alkali volatil, l'eau styptique propre à la préparation des cuirs, le noir de fumée, le coaks ou charbon épuré : précédé de recherches sur l'origine \& les différentes sortes de charbons de terre. Paris: Imprimerie Royale.

- - - 1791. Review: Essai sur le goudron du charbon de terre. Annales de Chimie, ou, Recueil de mémoires concernant la chimie et les arts qui en dépendent 10:29-37.

Favre. 1703 [1720]. Plusieurs Lampes \& Lanternes construites \& présentées par le sieur Rabiqueau. Histoire de l'Académie royale des sciences: 136.

Fourcroy, Antoine-François. 1782. Leçons élémentaires d'histoire naturelle et de chimie. 2 vols. Paris: Sous le privilège de la Société Royale de Medicine.

- - . 1784. Mémoires et observations de chimie. Paris: Cuchet.

- - . 1793. Elémens d'histoire naturelle et de chimie. Cinquième édition. ed. A Paris: Chez Cuchet ...

- - - 1797. Extract of a Memoir concerning three different Species of Carbonated Hydrogenous Gas, obtained from Ether and Alcohol by different Processes. $A$ Journal of natural philosophy, chemistry and the arts 1:44-45, 49-55.

- - . 1800. Elements of chemistry and natural history To which is prefixed, the philosophy of chemistry. By A. F. Fourcroy. Fifth edition, with notes, by John Thomson ed: printed by Mundell \& Son; for Longman \& Rees, and J. Johnson, London; and for Mundell \& Son, Edinburgh.

- - . 1800. Systême des connaissances chimiques, et de leurs applications aux phénomènes de la nature et de l'art. Vol. 1. Paris: Baudouin.

Fourcroy, Antoine-François, Claude-Louis Berthollet, and Louis-Nicolas Vauquelin. 1808. Verkohlung und Erleuchtung im Grossen, mit Thermolampen - Oefen. Bericht über eine Abhandlung der Herren Mollerat, von der Verkohlung des Holzes in verschlossenen Gefässen, und den verschiedenen Produkten, die dabei gewonnen werden. Annalen der Physik 30 (12):393-414. 
- - - 1808. Rapport d'un mémoire de MM. Mollerat, concernant la carbonisation du bois en vaisseaux clos, et l'emploi de différens produits quelle fournit. Annales de Chimie, ou, Recueil de mémoires concernant la chimie et les arts qui en dépendent 58 (2):128-148.

Freemantle, William Henry. 1821. Select Committee on Past and Present State of Supply of Water to Metropolis, and Petitions and Minutes of Evidence on W. Middlesex Waterworks Bill in 1819. Report. In HOUSE OF COMMONS PAPERS; REPORTS OF COMMITTEES.

- - - 1821. Select Committee on Past and Present State of Supply of Water to Metropolis, and Petitions and Minutes of Evidence on W. Middlesex Waterworks Bill in 1819: Minutes of Evidence, Appendix. In HOUSE OF COMMONS PAPERS; REPORTS OF COMMITTEES.

Fyfe, Andrew. 1824. On the comparative Value of Oil and Coal gas. Edinburgh Philosophical Journal 11:171-186.

- - . 1824. On the Illuminating power of Coal-Gas, and Oil-Gas. Edinburgh Philosophical Journal 11:367-376.

Genssane, de. 1770. Traité de la fonte des mines par le feu du charbon de terre; ou, Traité de la construction \& usage des fourneaux propes à la fonte \& assinage des métaux \& des minéraux par le feu du charbon de terre, avec la manière de rendre ce charbon prope aux mêmes usages auxquels on emploie le charbon de bois. Paris: Vallat-la-Chapelle.

- - - 1779. Sur le Dessourement du Charbon-de-Terre \& sur la construction des Fourneaux propres à cette opération. Observations sur la physique, sur I'histoire naturelle et sur les arts 14 (2):337-343.

Gilbert, Ludwig. 1799. Von den veschiedenen Gasmessern, und Beschreibung des von Seguin erfundenen Gazometers. Annalen der Physik 2 (2):185-193.

- - - 1799. Versuche des Gesellschaft Amsterdammer Physiker über drei verschiedene Arten von Kohlenhaltigem Wasserstoffgas, welche sich aus Alkohol und Aether entwickeln lassen. Annalen der Physik 2 (2):201-215.

- - - 1804. Eine Memerkung uber den Schwefel-Kohlenstoff. Annalen der Physik 17 (1):111-114.

- - - 1806. Ueber die sogenannten Thermolampen und den ersten Erfinder derselben. Annalen der Physik 22 (1):51-57.

- - . 1824. Eine Memerkung über Gaslicht aus Oel und aus Steinkohlen. Annalen der Physik 76 (2):165-170. 
Gillespie, Richard. 1810. Gas light at Richard Gillespie's. The Edinburgh Monthly Magazine and Review 1 (1):63.

Girard. 1798. Appareils à la manière de Wolf et sans luts, par le cit. Girard. Annales de Chimie, ou, Recueil de mémoires concernant la chimie et les arts qui en dépendent 32:283.

- - . 1801. The Apparatus of Woulfe improved, so as not to require luting. A Journal of natural philosophy, chemistry and the arts 4:41-42.

- - - 1822. Sur l'écoulement uniforme de 'Air atmosphérique et du Gaz hydrogene carboné, dans des tuyaux de conduite. Archives des découvertes et des inventions nouvelles faites dans les sciences, les arts et les manufactures tant en France que dans les pays étrangers 15:106-107.

Glasgow, A. G. 1897. Notes on carburetted water gas. London: Humphreys.

Glauber, Johann Rudolf. 1651. A description of new philosophical furnaces, or A new art of distilling, divided into five parts. Whereunto is added a description of the tincture of gold, or the true aurum potabile; also, the first part of the mineral work. Set forth and published for the sakes of them that are studious of the truth. By John Rudolph Glauber. Set forth in English, by J.F. D.M.

Glauber, Johann Rudolf, and John French. 1651. A description of new philosophical furnaces, or A new art of distilling, divided into five parts. Whereunto is added a description of the tincture of gold, or the true aurum potabile; also, the first part of the mineral work. Set forth and published for the sakes of them that are studious of the truth. By John Rudolph Glauber. Set forth in English, by J.F. D.M. London: Printed by Richard Coats, for Tho: Williams, at the signe of the Bible in LittleBritain.

Gmelin, Johann Friedrich. 1798. Geschichte der Chemie seit dem Wiederaufleben der Wissenschaften bis an das Ende des achtzehnden Jahrhunderts. Vol. 2. Göttingen: J.G. Rosenbusch.

Gmelin, J. F. 1801. On the chemical Knowledge which the Philosophers of the 16th and 17th Centuries had of the different Gases. Philosophical Magazine and Journal 11 (43):193-202.

Gordon, James Edward Henry 1884. A Practical Treatise on Electric Lighting. New York: D. Appleton.

Grant, James Ludovic. 1809. The second report of James Ludovic Grant, Esq. Chairman, and the other acting trustees of the fund for assisting Mr. Winsor in his experiments to the subscribers of that fund, at a meeting convened at a meeting convened by public advertisements, at the Crown and Anchor Tavern in the Strand, on the 29th of August 1809. London: Printed by G. Woodfall. 
Grant, James Ludovic, and Frederick Christian Accum. 1808. The report of James Ludovic Grant, Esq. Chairman, and the other acting trustees of the fund for assisting Mr. Winsor in his experiments to the subscribers of that fund, at a meeting convened ... on the 26th of May, 1808. London: Printed by G. Sidney.

Gray, Samuel Frederick Porter Arthur Livermore. 1830. The chemistry of the arts; being a practical display of the arts and manufactures which depend on chemical principles. Philadelphia: Carey \& Lea.

Gregory, George. 1796. The economy of nature explained and illustrated on the principles of modern philosophy. London: Printed for J. Johnson.

Gujon, L. J. M. 1809. Sur la carbonisation du bois, et sur les produits de sa distillation en grand. In Mémorial forestier, ou recueil complet des lois, arrêtés et instructions relatifs à l'Administration forestière, edited by Goujon. Paris: ArthusBertrand.

Guyot, Edme-Gilles. 1799. Nouvelles récréations physiques et mathématiques, contenant ce qui a été imaginé de plus curieux dans ce genre et qui se découvre journellement; auxquelles on a joint les causes, leurs effets, la manière de les construire, et l'amusement qu'on en peut tirer pour étonner et surprendre agréablement. Nouv. éd. Par m. Guyot ed. 3 vols. Vol. 2: Paris.

Guyton de Morveau, Louis Bernard, and Francois Chaussier. 1784. Description de l'aérostate l'Academie de Dijon : contenant le détail des procédés, la théorie des opérations, les dessins des machines \& les procès-verbaux d'expérieces. Dijon: Causse.

Guyton de Morveau, Louis Bernard, Lavoisier Antoine Laurent, Claude-Louis Berthollet, Antoine-François Fourcroy, J. H. Hassenfratz, and Pierre-Auguste Adet. 1787. Méthode de nomenclature chimique. Paris: Cuchet.

Guyton de Morveau, Louis Bernard, Antoine Laurent Lavoisier, Antoine-François Fourcroy, Claude-Louis Berthollet, Pierre-Auguste Adet, and J. H. Hassenfratz. 1788. Method of chymical nomenclature proposed by Messrs. De Morveau, Lavoisier, ... To which is added, a new system of chymical characters, ... by Mess. Hassenfratz and Adet. Translated from the French, ... by James St. John, M.D.: printed for G. Kearsley.

Hales, Stephen. 1727. Vegetable staticks: or, an account of some statical experiments on the sap in vegetables: being an essay towards a natural history of vegetation. Also, a specimen of an attempt to analyse the air. London: printed for W. and J. Innys, and T. Woodward.

Hall, James. 1809. Select Committee on Gas-Light and Coke Company's Bill to incorporate Persons for procuring Coke, Oil, Tar, Pitch, Ammoniacal Liquor and 
Inflammable Air from Coal: Minutes of Evidence. In HOUSE OF COMMONS PAPERS; REPORTS OF COMMITTEES III.315.

Hamberger, Georg Christoph 1827. Winzler (Zachäus Andreas). In Das gelehrte Teutschland oder Lexikon der jetzt lebenden teutschen Schriftsteller, edited by J. S. Ersch. Lemgo: Meyer.

Handy, Abel. 1808. Speculations. The spirit of the public journals 12:290-292.

Harris, James, and James Harper. 1815. Gas Lights. Philosophical Magazine and Journal 46:317.

Hart, John. 1844. Contribution to the history of gas lighting. The Mechanics' magazine, museum, register, journal, and gazette 40 (1088):410-412.

Harvey, Eliab Sir. 1823. Select Committee on Report of Royal Society on Gas-Lights, and Reports on Gas-Light Establishments. Report, Minutes of Evidence, Appendix. In HOUSE OF COMMONS PAPERS; REPORTS OF COMMITTEES.

Hassenfratz, J. H. 1807. Memoir on the Proportion of Light produced by different combustible Substances, and on the Degrees of Brightness obtained from different Lamps, according to the Nature of the Oil employed. The repertory of arts, manufactures, and agriculture 2nd series $111(64,65): 303-305,363-378$.

Hatchett, Charles. 1805. Observations on the Change of some of the proximate Principles of Vegetables into Bitumen. Philosophical Magazine and Journal 21:40-51,147-151.

Haydn, Joseph. 1851. The book of dignities; containing rolls of the official personages of the British Empire ... from the earliest periods to the present time ... together with the sovereigns of Europe, from the foundation of their respective states; the peerage of England and Great Britain. London: Longmans, Brown, Green, and Longmans.

Heard, Edward. 1805. Summary account of an improved method for illuminating theatres, assembly-rooms, public gardens, streets, light-houses, public offices, dwelling-houses, \&c, \&c, \&c with the philosophical lights, produced without candles!!! spirits!!! or oil!!! : a new and valuable application of a known principle, to which is annexed a proposal for carrying the same into effect respectfully submitted to the consideration of the inhabitants of Bristol by Edward Heard. Bristol: Printed by R. Jenkins.

Hedley, Joseph. 1828. Letter to the Right Hon. the Lord Mayor on the supply of gas to the city of London containing the official documents laid before the Commissioners of Sewers ... an account ... on the application of the chartered Gas-Light and Coke Company: J.M. Richardson,; (London :; C.M. Willich). 
Henry, William. 1799. Electrische Versuche mit kohlenhaltigem Wasserstoffgas. Annalen der Physik 2 (2):194-200.

-- . 1802. An epitome of chemistry. Philadelphia: Printed by J. Humphreys.

- - - 1802. A Review of some Experiments which have been supposed to Disprove the Materiality of Heat. Memoirs of the Literary and Philosophical Society of Manchester 5, Part 2:603-621, 679.

--1 . 1805. Experiments on the gases obtained by the destructive distillation of pit coal, \&c., with a view to the theory of their combustion when employed as sources of artificial light. A Journal of natural philosophy, chemistry and the arts $11: 65-74$.

- - . 1805. Response to Mr. Northern. The Monthly magazine, or, British register 19 (128):313.

- - . 1808. Description of an Apparatus for the Analysis of the Compound Inflammable Gases by Slow Combustion; With Experiments on the Gas from Coal, Explaining Its Application. Philosophical Transactions of the Royal Society of London 98:282-303.

- - . 1808. An epitome of chemistry : in three parts. From the 4th English : much enl. and illustrated with plates; to which are added notes by a professor of chemistry in this country. ed. New York: Printed by Collins \& Perkins for themselves, and for Beers and Howe, Newhaven.

- - . 1809. Description of an Apparatus for the Analysis of the Compound Inflammable Gases by Slow Combustion; With Experiments on the Gas from Coal, Explaining Its Application. A Journal of natural philosophy, chemistry and the arts 22 (97):83-100.

- - . 1813. Description of a Eudiometer, and of other Apparatus employed in experiments on the Gases. Annals of Philosophy 2 (1):57.

- - . 1813. Description of a Eudiometer, and of other Apparatus employed in experiments on the Gases. Memoirs of the Literary and Philosophical Society of Manchester 2nd Series 2:384-390.

- - . 1819. Experiments on the Gas from Coal, Chiefly with a View to its Practical Application. Memoirs of the Literary and Philosophical Society of Manchester 2nd series, 3:391-429.

- - - 1819. Experiments on the Gas from Coal, Chiefly with a View to its Practical Application. Annals of Philosophy 19 (5):335-344, 32-39. 
- - . 1821. On the Aeriform Compounds of Charcoal and Hydrogen; With an Account of Some Additional Experiments on the Gases from Oil and from Coal.

Philosophical Transactions of the Royal Society of London 111:136-161.

- - . 1821. Dr Henry on Coal and Oil Gas. Edinburgh Philosophical Journal 5:223-224.

- - - 1821. Paper at the Royal Society by Dr. Henry. Philosophical Magazine and Journal 57:303-305.

- - - 1824. On the Action of Finely Divided Platinum on Gaseous Mixtures, and Its Application to Their Analysis. Philosophical Transactions of the Royal Society of London 114:266-289.

- - . 1826. The elements of experimental chemistry. 10th ed. 2 vols. London: Printed for Baldwin, Cradock and Joy : R. Hunter.

- - . 1831. The elements of experimental chemistry. 11th ed. Philadelphia: Robert Desilver.

Henry, William, and Thomas Henry. 1797. Experiments on Carbonated Hydrogenous Gas; With a View to Determine Whether Carbon be a Simple or a Compound Substance. By Mr. William Henry. Communicated by Mr. Thomas Henry, F. R. S. Philosophical Transactions of the Royal Society of London 87:401-415.

Herapath, William. 1823. Experiments on Oil and Coal Gas. Philosophical Magazine and Journal 61 (302):424-431.

- - . 1824. Resultate einger vergleichenden Versuche mit Steinkohlgas und mit Oelgas. Annalen der Physik 76 (2):157-164.

Higgins, Bryan. 1786. Experiments and observations relating to acetous acid, fixable air, dense inflammable air, oils and fuel, the matter of fire and light, metallic reductions, combustion, fermentation, putrefaction, respiration, and other subjects of chemical philosophy. London: Printed for T. Cadell.

Higgins, William. 1789. A comparative view of the phlogistic and antiphlogistic theories. London: J. Murray.

- - . 1791. A comparative view of the phlogistic and antiphlogistic theories With inductions. The second ed: printed for J. Murray.

Hill, John. 1751. A history of the materia medica. Containing descriptions of all the substances used in medicine; their origin, their characters when in perfection, the signs of their decay, their chymical analysis, and an account of their virtues, and of the several preparations from them now used in the shops. London: T. Longman, C. Hitch and L. Hawes [etc.]. 
Holmes, J. H. H. 1816. Explosion of Coal Gas in a Ship. Annals of Philosophy 8 (3): 213-215.

- - . 1816. A treatise on the coal mines of Durham and Northumberland : with information relative to the stratifications of the two counties: and containing accounts of the explosions from fire-damp, which have occurred therein for the last twenty years; their causes, and the means proposed for their remedy, and for the general improvements of the mining system, by new methods of ventilation, \&c. London: printed for Baldwin, Cradock, and Joy, 47, Paternoster Row, (C. Baldwin, Printer, New Bridge-street, London).

Hughes, Samuel. 1853. A treatise on gas-works and the practice of manufacturing and distributing coal gas : with some account of the most improved methods of distilling coal in iron, brick, and clay retorts, and of the various modes adopted for purifying coal gas : included also a chapter on the hydrocarbon or water gas, and on the rating of gas-works in parochial assessments. London: J. Weale.

Ingenhousz, Jan. 1779. Account of a New Kind of Inflammable Air or Gass, Which Can Be Made in a Moment without Apparatus, and is as Fit for Explosion as Other Inflammable Gasses in Use for That Purpose; Together with a New Theory of Gun-Powder. By John Ingen-Housz, Body Physician to Their Imperial Majesties, and F. R. S. Philosophical Transactions of the Royal Society of London 69:376-418.

- - . 1782. Vermischte Schriften phisisch-medizinischen Inhalts. Wien: Bei Johann Paul Krauss.

- - - 1785. Description d'une lampe a air inflammable. In Nouvelles expériences et observations sur divers objets de physique. Paris: T. Barrois le jeune.

Jars, Gabriel. 1774. Voyages metallurgiques; ou, Recherches et observations sur les mines \& forges de fer, la fabrication de l'acier, celle du fer-blanc, \& plusieurs mines de charbon de terre, faites depuis l'année 1757 jusques \& compris 1769, en Allemagne, Suéde [sic], Norvege, Angleterre \& Ecosse. Suivies d'un mémoire sur la circulation de l'air dans les mines, \& d'une notice de la jurisprudence des mines de charbon dans le pays de Liege, la province de Limbourg \& le Comté de Namur. Paris: L. Cellot [etc.].

Jones, Bence. 1871. The Royal Institution, its founder and its first professors. London: Longmans, Green, and Co.

Jones, William. 1801. The theological, philosophical and miscellaneous works of the Rev. William Jones ... : to which is prefixed a short account of his life and writings. . 12 vols. Vol. 10. London: F. and C. Rivington.

Keir, James. 1777. A treatise on the various kinds of permanently elastic fluids or gases. London: Printed for T. Cadell. 
- - - 1779. A treatise on the various kinds of permanently elastic fluids, or gases. The second edition, revised ed. London: printed for T. Cadell, and P. Elmsley.

Kirby, R. S. 1805. Kirby's wonderful and eccentric museum; or, Magazine of remarkable characters. Including all the curiosities of nature and art, from the remotest period to the present time. Drawn from every authentic source; ... illustrated with elegant engravings. Vol. 3. London: R.S. Kirby.

Kirwan, Richard. 1782. Continuation of the Experiments and Observations on the Specific Gravities and Attractive Powers of Various Saline Substances. By Richard Kirwan, Esq. F. R. S. Philosophical Transactions of the Royal Society of London 72:179-xxxv.

- - . 1786. Experiments on Hepatic Air. By Richard Kirwan, Esq. F. R. S. Philosophical Transactions of the Royal Society of London 76:118-154.

- - - 1794. Elements of mineralogy. 2 nd with considerable improvements and additions ed. London: Printed by J. Nichols.

- - - 1798. Experiments on the Composition and Proportion of Carbon in Bitumens and Mineral Coal. A Journal of natural philosophy, chemistry and the arts 1:487-496.

Klaproth, M. H. , and Wolff F. 1810. Hydrogene Carbone. In Dictionnaire de chimie. Paris: Klostermann fils. Original edition, Chemische Wörterbuch.

Klügel, G. S. 1806. Encyclopädie, oder, zusammenhängender Vortrag der gemeinnützigsten, insbesondere aus der Betrachtung der Natur und des Menschen gesammelten Kenntnisse. Berlin.

Kretschmar. 1803. Vervollkommung der sogenannten Thermolampe zum Gebrauche für das Haus-, Fabrik- und Hüttenwesen. Annalen der Physik 13 (1):498-502.

Kretschmar, Friedrich. 1806. Zusatz des Herausbegers. Einige Erfahrungem enthaltend, über die Thermolampe, und deren Answendungen. Annalen der Physik 22 (1): 83-95.

Krünitz, Johann Georg. 1793. Lampe. In Oekonomische-Technologische Encyclopädie; oder, Allgemeines System der Land-, Haus-, und Staats-Wirthschaft, in alphabetischer Ordnung; aus dem Französischen übersetzt und mit Anmerkungen und Zusätzen verhmehrt, auch nöthigen versehen Band 59, edited by J. G. Krünitz. Berlin: J. Pauli.

La Métherie, Jean-Claude de. 1785. Essai analytique sur l'air pur et les différentes espèces d'air. Paris: [s.n.].

- - . 1815. Review: A practical teatise on Gaz-Light. Journal de physique, de chimie d'histoire naturelle et des arts 81:378-379. 
Lampadius, W. 1813. Ueber Strassenbeleuchtung mit Steinkohlen durch die Thermolampe vorzüglich in Hinsicht ihrer Anwendung in Grossen. Journal für Chemie und Physik 8 (1):38-48.

--- . 1815. Fortgesetzte Nachrichten aus dem chemischen Laboratorio in Freyberg von W. A. Lampadius. Journal für Chemie und Physik 15 (2):142-147.

Lampadius, Wilhem August. 1801. Handbuch der allgemeinen Hüttenkunde. 2 vols. Göttingen: H. Dietrich.

Langenbucher, Jakob. 1780. Beschreibung einer beträchtlich verbesserten Elektrisiermaschine: sammt vielen Versuchen und einer ganz neuen Lehre vom Laden der Verstärkung. Mit 8. Kupfertafeln. Augsburg: Bey Mathäis Riegers sel. Söhnen.

Langford, John Alfred. 1868. A century of Birmingham life: or, A chronicle of local events, from 1741 to 1841. Vol 2. Birmingham: E.C. Osborne; London, Simpkin, Marshall \& Co.

Lassone, Joseph Marie de. 1776 [1779]. Sur les gas aériens. Histoire de l'Académie royale des sciences:29, 686-696.

Lavoisier, Antoine Laurent. 1767. Sur les différents moyens qu'on peut employer pour éclairer une grande ville. In Oeuvres Vol. 3 [1865]. Paris: Imprimerie Impériale.

- - - 1777. Expériences sur la combinaison de l'alun avec les matières charbonneuses. In Oeuvres Vol. 2 [1865]. Paris: Imprimerie Impériale.

- - - 1778. Description de deux mines de charbon de terre. In Oeuvres Vol. 2 [1865]. Paris: Imprimerie Impériale.

- - - 1778. Sur l'air inflammable. In Oeuvres Vol. 5 [1865]. Paris: Imprimerie Impériale.

- - - 1781. Mémoires sur la formation de l'acide nommé air fixe ou acide crayeux, et que je désignerai désormais sous le nom d'acide du charbon. In Oeuvres Vol. 2 [1865]. Paris: Imprimerie Impériale.

- - - 1781. Mémoire sur les manières d'éclairer les salles de spectacle. In Oeuvres Vol. 3 [1865]. Paris: Imprimerie Impériale.

- - - 1781 [1784]. Mémoires sur la formation de l'acide nommé air fixe ou acide crayeux, et que je désignerai désormais sous le nom d'acide du charbon. Histoire de l'Académie royale des sciences:25-27, 448-467.

- - - 1783. Réflexions sur les points principaux qui doivent occuper les commissaires nommés pour les machines aérostatique. In Oeuvres Vol. 3 [1865]. Paris: Imprimerie Impériale. 
- - . 1783. Sur la nature de l'Eau. Observations sur la physique, sur l'histoire naturelle et sur les arts 23 (2):452-455.

- - - 1784 [1787]. Mémoires sur la combinaison du principe oxygine, avec l'esprit-devin, I'huile, \& differens corps combustilbes. Histoire de l'Académie royale des sciences:593-608.

---1790 . Elements of chemistry in a new systematic order, containing all the modern discoveries. Translated by R. Kerr: printed for William Creech, and sold in London by G. G. and J. J. Robinsons.

Lavoisier, Antoine Laurent, and Marie-Anne-Pierrette Lavoisier. 1789. Traité élémentaire de chimie, présenté dans un ordre nouveau et d'après les découvertes modernes; avec figures. Paris: Cuchet.

Le Roy, Jean-Baptiste. 1778. Lettre de M. de Le Roy, de l'Académie des Sciences, adressée à l'auteur de ce recueil relative aux expériences sur l'air inflammable des marais découvert par M. Volta. Observations sur la physique, sur l'histoire naturelle et sur les arts 11:401.

Lebon, Philippe. 1799. Moyens nouveaux d'employer les combustibles plus utilement \& à la chaleur \& à la lumière, \& d'en recueillir leur sous-produits. In Masse: Le Gaz (1914) Annexe I, p. 234-247. France.

- - - 1801. Thermolampes, ou poêles qui chauffent, eclairent avec economie, et offrent, avec plusiers produits precieux, une force motrice applicable à toute espèce de machines. Paris: Pougens.

- - . 1801. Additions. In Masse: Le Gaz (1914) Annexe I, p. 234-247. France.

- - - 1801. Thermolampes. Journal général de la littérature de France : ou répertoire méthodique des livres nouveaux, cartes géographiques, estampes et oeuvres de musique 4 (8):253.

Lewis, William. 1763. Commercium philosophico-technicum; or, The philosophical commerce of arts: designed as an attempt to improve arts, trades, and manufactures. London: Printed by $\mathrm{H}$. Baldwin, for the author.

Lowe, George. 1818. On purifying Coal-Gas, and increasing the Quantity produced from a given Weight of Coals. Philosophical Magazine and Journal 52:371-373.

- - . 1819. On the Purification of Coal Gas; on the ammoniacal Liquor of Coal Gas; and on some singular Products obtained from the ammoniacal Liquor. Philosophical Magazine and Journal 53:262-266.

- - . 1820. Remarks on an Article entitled "A few Facts relating to Gas illumination," published in No. 14 of The Quarterly Journal. Philosophical Magazine and Journal 55:37-46. 
---.1821 . On the Application of the explosive Power of Coal Gas as a First Mover in Machinery. Philosophical Magazine and Journal 57:93-95.

- - - 1821. Observations on Statements made by Mr. Ricardo ansd others, "On comparative Advantages of illuminating by Gas produced from Oil and from Coal". Philosophical Magazine and Journal 57 (276):241-249.

Lowry, William. 1829. On the Rev. W. Taylor's Experiments on the Combustion of CoalGas, and on the best Form for Gas-burners. Philosophical Magazine and Journal 2nd series, 5:375-377.

Lowther, James. 1733. An Account of the Damp Air in a Coal-Pit of Sir James Lowther, Bart. Sunk within 20 Yards of the Sea; Communicated by Him to the Royal Society. Philosophical Transactions (1683-1775) 38:109-113.

MacCulloch, J. 1815. On certain Products obtained in the Distillation of Wood, with some Account of bituminous Substances, and Remarks on Coal. Philosophical Magazine and Journal 45:203-217, 269-274.

Mackenzie, Colin. 1821. One thousand experiments in chemistry; with illustrations of natural phenomena; and practical observations on the manufacturing and chemical processes at present pursued in the successful cultivation of the useful arts. London: Printed for Sir R. Phillips and Co.

Macquer, Pierre Joseph. 1778. Dictionnaire de chymie, contenant la théorie \& la pratique de cette science, son application à la physique, à l'histoire naturelle, à la médecine \& aux arts dépendans de la chymie. Seconde éd., revue \& considérablement augmentée ed. Paris: P. Fr. Didot.

Macquer, Pierre Joseph, and Giovanni-Antonio Scopoli. 1783. Dizionario di chimica. Paria: Nella Stamperia del R.I. Monastero di S. Salvatore, per G. Bianchi.

Magnier, D. 1899. Nouveau manuel complet de l'éclairage et du chauffage au gaz; ou, Traité élémentaire et pratique destiné aux ingénieurs, aux directeurs at aux contremaîtres d'usines à gaz d'éclairage, suivi de l'aide-mémoire de l'ingénieurgazier Vol. 1. Nouvelle éd., corr., augm. et entièrement refondue ed. Paris: L. Mulo.

Maiben, John. 1813. A statement of the advantages to be derived from the introduction of coal gas into factories and dwelling houses, as a substitute for the lights now in use : together with observations on the methods of making and using it. Perth: Printed by R. Morison.

Malam, John. 1820. Mr. Malam's Gas, Water, and Steam Valve. The London journal of arts and sciences 1 (2):133-135. 
- - . 1821. Description of the improved Patent Gas Meter. Edinburgh Philosophical Journal 5 (9):129-130.

Marchais, Jean Baptiste Charles. 1801. Note sur la 1ere expérience du thermolampe. In Mémoires des sociétés savantes et littéraires de la République française. Paris.

Matthews, Arthur. 1899. A biography of William Matthews, the expositor of gas and water engineering. London [The Author: privately printed].

Matthews, William. 1827. Compendium of gas-lighting, adapted for the use of those who are unacquainted with chemistry; containing an account of some new apparatus lately introduced. London: R. Hunter.

- - - 1827. An historical sketch of the origin, progress, \& present state of gas-lighting. London: R. Hunter.

- - . 1830. A sketch of the principal means which have been employed to ameliorate the intellectual and moral condition of the working classes at Birmingham. London: Simpkin and Marshall.

- - . 1832. An historical sketch of the origin and progress of gas-lighting. 2 nd ed. London: Simpkin \& Marshall.

Matthews, William , and Joseph Hedley. 1828. A letter to the Right honourable the Lord mayor of London in reply to the letter ... addressed to him by Mr. Jos. Hedley, with remarks upon the prospectus ... issued for forming a West London gas company and also upon the delusive nature of many of the projects for gas lighting. London: R. Hunter.

Maud, John, and James Luther. 1736. A Chemical Experiment by Mr. John Maud, Serving to Illustrate the Phoenomenon of the Inflammable Air Shewn to the Royal Society by Sir James Lowther, Bart as Described in Philosoph. Transact. Numb. 429. Philosophical Transactions (1683-1775) 39:282-285.

Meredith, Nicholas. 1810. Rudiments of chemical philosophy : in which the first principles of that useful and entertaining science are familiarly explained and illustrated. London: Printed for the author and sold by Hatchard; Scatchard and Letterman; and Sherwood, Neely, and Jones.

Merrick, S. V. 1834. Report, upon an examination of some of the gas manufactories in Great Britain, France, and Belgium, under a resolution passed by the Select and Common Council of the City of Philadelphia, January 2, 1834 ... in the event of Councils determining to adopt a plan for lighting the city with gas. Philadelphia, Pa.: Printed by order of Councils.

Meusnier, Jean Baptiste. 1782 [1785]. Description d'un appareil propre a manoeuvrer différentes espèces d'airs. Histoire de l'Académie royale des sciences:466-475. 
- - - 1784 [1787]. Mémoire sur les moyens d'opérer une entière combustion de I'Huile, \& d'augmenter la lumière des Lampes. Histoire de l'Académie royale des sciences:390-398.

Milles, Jeremiah. 1759. A Further Account of Some Experiments Made on the Bovey Coal. Philosophical Transactions (1683-1775) 51:941-944.

- - . 1759. Remarks on the Bovey Coal: In a Letter to the Right Honourable George Earl of Macclesfield, President of the Royal Society. By Jeremiah Milles, D. D. F. R. S. Philosophical Transactions (1683-1775) 51:534-553.

Millington, John. 1818. On Street Illumination. The Quarterly journal of science and the arts 5 (9):177-181.

Minckelers, Jean Pierre. 1784. Mémoire sur l'air inflammable tiré de différentes substances: Louvain.

Morand, Jean-François-Clément. 1768. L'art d'exploiter les mines de charbon de terre. 4 vols, Description des arts et métiers. Paris: Saiilant et Nyon.

Morren, Charles. 1835. Invention de l'éclairage au gas. Bulletins de l'Académie royale des sciences, des lettres et des beaux-arts de Belgique 2:162.

--1 . 1839. Notice sur la vie et les travaux de Jean Pierre Minkelers. Annuaire de l'Académie royale des sciences et belles-letres de Bruxelles 5:84-91.

Murdoch, A. 1892. Light without a wick : a century of gas-lighting, 1792-1892 : a sketch of William Murdoch, the inventor. Glasgow: R. Maclehose.

Murdoch, William. 1808. An Account of the Application of the Gas from Coal to Economical Purposes. Philosophical Transactions of the Royal Society of London 98:124-132.

- - . 1809. A letter to a member of Parliament, from Mr. William Murdock in vindication of his character and claims, in reply to a recent publication by the committee for conducting through Parliament a bill for incorporating a gas-light \& coke company: s.n.,; (London :; Galabin and Marchant).

Murray, Amelia M. 1868. Recollections from 1803 to 1837 : with a conclusion in 1868. London: Longmans, Green.

Murray, John. 1810. Elements of chemistry. Edinburgh: Printed for W. Creech [etc.].

Mushet, David. 1808. Analysis of various Kinds of Pit-Coal. Philosophical Magazine and Journal 32 (126):140-145.

- - - 1808. Experiments relative to Coals and Cokes obtained from Wood and Pitcoal. Philosophical Magazine and Journal 32:309-315. 
Neret. 1777. Nouveau Réchaud d'un amateur de physique. Observations sur la physique, sur l'histoire naturelle et sur les arts 9:57-58.

- - - 1779. Sur une nouvelle espèce de Gas inflammable. Observations sur la physique, sur l'histoire naturelle et sur les arts 14:126-133.

- - - 1779. Second Mémoire Sur le principe de I'Inflammabilité des corps combustible, ou Gas inflammable huileux Observations sur la physique, sur I'histoire naturelle et sur les arts 14:292-297.

- - - 1780. Réponse de M. Neret fils a la Lettre de M. Barbier de Tinan, sur l'Air des Marais \& les différents espèces de Gaz inflammable. Observations sur la physique, sur l'histoire naturelle et sur les arts 15:487-492.

- - . 1782. Réponse de M. Neret fils a la seconde Lettre de M. Barbier de Tinan, sur I'Air des Marais \& les différents espèces de Gaz inflammable. Observations sur la physique, sur l'histoire naturelle et sur les arts 19:459-462.

Nesbitt, Thomas. 1817. Report and Estimate by Coms. of Paving on lighting City of Dublin with Gas. In HOUSE OF COMMONS PAPERS; ACCOUNTS AND PAPERS.

Neumann, Caspar Lewis William. 1759. The chemical works of Caspar Neumann containing the later discoveries and improvements made in chemistry and the arts depending thereon by William Lewis. London: Printed for W. Johnston, G. Keith, A. Linde, P. Davey, B. Law, T. Field, T. Caslon, and E. Dilly.

Newbigging, Thomas. 1870. The gas manager's handbook : consisting of tables, rules, and useful information for gas engineers, managers, and others engaged in the manufacture and distribution of coal gas. London: William B. King.

Newbigging, Thomas, W. T. Fewtrell, and William Boughton King. 1878. King's treatise on the science and practice of the manufacture and distribution of coal gas. London: William B. King.

Newton, Isaac. 1704. Opticks, or, A treatise of the reflexions, refractions, inflexions and colours of light also two treatises of the species and magnitude of curvilinear figures. London: Printed for S. Smith and B. Walford.

Nicholson, Peter. 1838. Practical masonry, bricklaying and plastering, both plain and ornamental; containing a new and complete system of lines for stone-cutting. For the use of workmen. London: T. Kelly.

Nicholson, William. 1795. A dictionary of chemistry. London: printed for G. G. and J. Robinson.

- - . 1800. A Description of the Hydrostatic Lamp of Mr. Peter Keir. A Journal of natural philosophy, chemistry and the arts 3:467-470. 
- - - 1807. Remarks on Mr. Winsor's projected Heat and Light Company. A Journal of natural philosophy, chemistry and the arts 16 (65):73-75.

- - - 1807. Remarks on Mr. Winsor's projected Heat and Light Company. The Athenaeum, a magazine of literary and miscellaneous information 1 (2):186-187.

- - . 1807. A few remarks on a pamphlet entitled "Mr. W. Nicholson's attack, in his Philosophical Journal, on Mr. Winsor and the National Light and Heat Company: with Mr. Winsor's defence". A Journal of natural philosophy, chemistry and the arts 16:308-310.

Nightingale, Joseph. 1815. London and Middlesex; or, An historical, commercial, \& descriptive survey of the metropolis of Great-Britain: including sketches of its environs, and a topographical account of the most remarkable places in the above county. 4 vols. Vol. 3. London: Printed by W. Wilson, for Vernor, Hood, and Sharpe [etc.].

Nimmo, James. 1826. Account of a newly invented and rotary Gas-Burner. Edinburgh Philosophical Journal 14 (28):325-326.

Northern, J. 1805. Experiments on Pit Coal. The Monthly magazine, or, British register 19 (127):235.

Parker, Samuel. 1818. New Method for purifying Coal Gas, and at the same time increasing the Product from a given Quantity of Coals. Philosophical Magazine and Journal 52:292-293.

Parkes, Samuel. 1807. A chymical catechism : or, the application of chymistry to the arts, for the use of young people, artists, tradesmen and the amusement of leisure hours, to which are added a vocabulary of chymical terms, some useful tables, and a variety of amusing experiments. Philadelphia: Printed and sold by J. Humphreys.

- - . 1808. The chemical catechism, with notes, illustrations, and experiments. 3rd, containing the new discoveries and other considerable additions. ed. London, England: Printed for the author and sold by Lackington, Allen.

- - - 1810. The rudiments of chemistry illustrated by experiments, and eight copperplate engravings of chemical apparatus. Philadelphia: Bradford \& Inskeeps, J. Maxwell); United States; Pennsylvania; Philadelphia.

- - . 1810. The rudiments of chemistry; illustrated by experiments, and eight copperplate engravings of chemical apparatus. London: Printed for the author; and sold by Lackington, Allen. 
- - . 1816. The chemical catechism, with notes, illustrations, and experiments. From the 6th English , with emendations and considerable additions. ed. New York: Printed \& sold by Collins and Co.

- - . 1823. Chemical essays : principally relating to the arts and manufactures of the British Dominions. 2d, greatly enl., and illus. with twenty-four plates, of machinery and chemical apparatus. ed. 2 vols. London: Printed for tha author, and published by Baldwin, Cradock, and Joy.

Parkinson, James. 1807. Notice respecting New Books: The Chemical Pocket Book 4th ed. Philosophical Magazine and Journal 28:265-269.

Parrot, Friedrich. 1811. Ueber Gasometrie nebst einigen Versuchen über die Verschiebbarkeit der Gase. Dorpat.

Peckston, Thomas S. 1819. The theory and practice of gas-lighting : in which is exhibited an historical sketch of the rise and progress of the science, and the theories of light, combustion, and formation of coal, with descriptions of the most approved apparatus for generating, collecting, and distributing, coal-gas for illuminating purposes. London: Printed for Thomas and George Underwood.

- - . 1819. Cursory observations on different processes adopted for the distillation of coal, drawn from actual experiment. By Thomas S. Peckston; of the Chartered Gas Light and Coke Company's Establishment, Peter Street, Westminster. Southampton: Printed by T. Baker for I. Fletcher.

- - . 1819. Review: The Theory and Practice of Gas-Lighting. Philosophical Magazine and Journal 53:455-460.

- - . 1819. Review: The Theory and Practice of Gas-lighting, in which is exhibited a Historical Sketch of the Rise and Progress of the Science. Philosophical Magazine and Journal 53:455-460.

- - - 1823. The theory and practice of gas lighting containing much original matter relative to coal-gas, and an entirely new treatise on the economy of the gases, procured for illuminating purposes from oil, turf, \&c. 2nd ed. London: Printed for T. \& G. Underwood.

Péclet, Eugène. 1827. Traité de l'éclairage. Paris: A la Librairie scientifique et industrielle de Malher et cie ...

Pelletan, Pierre. 1817. Mémoire sur l'éclairage par le gaz tiré du charbon de terre, pour servir de complément à l'ouvrage de M. Accum, sur le même sujet. Lu à l'Académie Royale des sciences, le 9 décembre 1816. Paris: J.G. Dentu, Imprimeur-Libraire. 
Pennant, Thomas White Benjamin. 1790. A tour in Scotland, and voyage to the Hebrides, MDCCLXXII. Part I [-II]. 2 vols. Vol. 1. London: Printed for Benj. White.

Pepys, William Hasledine. 1801. Description of an improved Chemical Apparatus for preserving separate the Gaseous Products evolved in many Processes. Philosophical Magazine and Journal 11:253-257.

- - . 1802. Description of a new Gas-holder. Philosophical Magazine and Journal 13 (50):153-155.

Pepys, William Hasledine, and William Allen. 1808. On the Quantity of Carbon in Carbonic Acid, and on the Nature of Diamond. Philosophical Magazine and Journal 29:315-319.

Phillips, J. 1829. New Experiments on the Combustion of Coal-Gas. Philosophical Magazine and Journal 2nd series, 5:150-151.

Pickering, Danby. 1795. The statutes at large from the Magna Charta, to the end of the eleventh Parliament of Great Britain, anno 1761 [continued to 1806] Anno tricesimo quinto Georgii III. Regis, being the fifth session of the Seventeenth Parliament of Great Britain (1795). Vol. 40, part 1. Cambridge: Printed by J. Bentham.

Platel. 1806. On making turf into charcoal. The repertory of arts, manufactures, and agriculture 2nd series 9:371-375, 420-425.

Playfair, William, and Joshua Jepson Oddy. 1810. A sketch for the improvement of the political, commercial, and local interests of Britain as exemplified by the inland navigations of Europe in general, and of England in particular : including details relative to the intended Stamford Junction navigation, to unite the Eastern, with the midland and western Counties of the kingdom : illustrated with a canal map. London: Printed for J.J. Stockdale.

Pole, W. 1839. Rule for Ascertaining the Pressure of Gasholders of Different Dimensions. Mechanics' magazine and journal of science, arts, and manufactures 31 .

Poppe, Johann Heinrich Moritz von. 1811. Geschichte der technologie seit der wiederherstellung der wissenschaften bis an das ende des achtzehnten jahrhunderts. Vol. 3. Göttingen: Bey J.F. Röwer.

Porret, R. 1817. Observations on the Flame of a Candle. Annals of Philosophy 9 (5): 337-341.

Powys, Caroline Girle Mrs P. L. Powys Climenson Emily J., and ed. 1899. Passages from the diaries of Mrs. Philip Lybbe Powys of Hardwick house, Oxon. A.D. 1756-1808. London: New York, Bombay, Longmans, Green, and Co. 
Prechtl, J. J. 1818. Aus mehreren Briefen. Annalen der Physik 58:111.

Preuss, Justus. 1824. Oekonomisch-physikalische Vergleichung der verschiedenen gebräuchlichen Beleuchtungs Arten etc. Annalen der Physik 76 (2):113-148.

- - - 1825. On Oil Gas. Philosophical Magazine and Journal 66 (329):203-206.

Priestley, Joseph. 1769. The history and present state of electricity, with original experiments. 2 ed. London: J. Dodsley [etc.].

- - - 1774. On the Noxious Quality of the Effluvia of Putrid Marshes. A Letter from the Rev. Dr. Priestley to Sir John Pringle. Philosophical Transactions (1683-1775) 64:90-95.

- - . 1775. Experiments and observations on different kinds of air The second edition correct ed: printed for J. Johnson.

- - - 1776. Experiments and observations on different kinds of air Vol. II. By Joseph Priestley. The second edition. ed: printed for J. Johnson.

- - - 1777. Experiments and observations on different kinds of air Vol.III. By Joseph Priestley: printed for J. Johnson.

- - . 1777. Experiments and observations on different kinds of air Vol.III. By Joseph Priestley: printed for J. Johnson.

- - - 1779. Experiments and observations relating to various branches of natural philosophy with a continuation of the observations on air. By Joseph Priestley: peinted [sic] for J. Johnson.

- - - 1781. Experiments and observations on different kinds of air By Joseph Priestley. The third edition, correct ed: printed for J. Johnson, no.72, St. Paul's Church-Yard.

- - - 1786. Experiments and observations, relating to various branches of natural philosophy with a continuation of the observations on air. Vol. III. By Joseph Priestley: printed by Pearson and Rollason, and sold by J. Johnson, London.

--1790 . Experiments and observations on different kinds of air and other branches of natural philosophy, connected with the subject. In three volumes; being the former six volumes abridged and methodized, with many additions. By Joseph Priestley: printed by Thomas Pearson; and sold by J. Johnson, London.

Priestley, Joseph, and William Hey. 1772. Observations on Different Kinds of Air. By Joseph Priestley, L L. D. F. R. S. Philosophical Transactions (1683-1775) 62:147-264. 
Pringle, John Sir. 1774. A discourse on the different kinds of air delivered at the anniversary meeting of the Royal Society, November 30, 1773. By Sir John Pringle Bart. President. Published at their request: printed for the Royal Society.

Proudfoot, William Jardine, and James Dinwiddie. 1868. Biographical memoir of James Dinwiddie, L.L.D., astronomer in the British Embassy to China, 1792, '3, '4, afterwards professor of natural philosophy in the College of Fort William, Bengal : embracing some account of his travels in China and residence in India. Liverpool: E. Howell.

Proust. 1800. On the Proportions of Charcoal, or Oxyd of Carbon, contained in certain Kinds of Wood and in Pit-Coal; and on a Carburet of Sulphur newly discovered. Philosophical Magazine and Journal 8:169-170.

Rabiqueau. 1759 [1765]. Plusieurs Lampes \& Lanternes construites \& présentées par le sieur Rabiqueau. Histoire de l'Académie royale des sciences:234-235.

Reichenbach, Karl Freiherr. 1880. Caroline von Linsingen, die gattin eines englischen prinzen. Leipzig: Duncker \& Humblot.

Ricardo, M. 1821. On the Comparative Advantages of Illuminating Gas Produced from Oil and from Coal. Annals of Philosophy New Series 1 (3):209-215.

- - - 1821. Remarks on Oil and Coal Gas, in answer to Mr. Low. Annals of Philosophy New Series 2 (1):44-48.

- - - 1823. Observations on Sir W. Congreve's Report on Gas Light establishments. Annals of Philosophy New Series 6 (1):1-12.

- - . 1823. Observations on the Advantages of Oil Gas Establishments. Annals of Philosophy New Series 5 (3):218-223.

Roget, Peter M. 1828. Royal Com. on State of Supply of Water in Metropolis. Report, Appendix. In HOUSE OF COMMONS PAPERS; REPORTS OF COMMISSIONERS.

- - . 1828. Royal Com. on State of Supply of Water in Metropolis. Report, Appendix. In Document type: HOUSE OF COMMONS PAPERS; REPORTS OF COMMISSIONERS.

Rouland. 1784. Tableau historique des propriétés et des phénomènes de l'air, considéré dans ses différens états et sous ses divers rapports. Paris: Gueffier.

Ryss-Poncelet. 1811. Sur l'éclairage par le gaz hydrogène de la houille. Annales des Arts et Manufactures 41 (121):53-81.

Scheele, Carl Wilhelm. 1782. Chemische abhandlung von der luft und dem feuer. Second ed. Leipzig: W. Engelmann. 
Schmidt, Georg Christoph. 1784. Verschiedener Handluftpumpen. Kleiner aerostatischer Kugeln. Elektrischer Feuerzeuge oder Lampen. In Beschreibung gemeinnütziger Maschinen Jena: Bey Johann Rudolph Crökers seel. Wittbe.

Schubarth, Ernst Ludwig. 1831. Elemente der technischen Chemie : zum Gebrauch beim Unterricht im Königl. Gewerbinstitut und den Provinzial-Gewerbschulen. Berlin: August Rücker.

Schweigger, J. S. C. 1816. Ueber Gasbeleuchtung in London, Wilson's Hygrometer, etc. Journal für Chemie und Physik 17:376-383.

Seguin. 1790. Extrait de l'article Air, rédigé par M. Morveau \& inséré dans le nouveau Dictionnaire Encyclopédique. Annales de Chimie, ou, Recueil de mémoires concernant la chimie et les arts qui en dépendent 7:46-51.

- - - 1799. Account of the New Gazometer. A Journal of natural philosophy, chemistry and the arts 3:405-406.

Senebier, Jean. 1783. Recherches sur l'influence de la lumière solaire pour métamorphoser l'air fixe en air pur par la végétation avec des expériences \& des considérations propres à faire connoître la nature des substances aëriformes. Geneve: B. Chirol, (Bonnant).

- - - 1784. Recherches analytiques sur la nature de l'air inflammable. A Geneve: Chez B. Chirol.

Shirley, Thomas. 1666. The Description of a Well, and Earth in Lanchashire, Taking Fire by a Candle Approached to It. Philosophical Transactions (1665-1678) 2:482-484.

Sigaud de La Fond, Joseph Aignan. 1779. Essai sur différentes especes d'air qu'on désigne sous le nom d'air fixe pour servir de suite \& de supplément aux Élémens de physique du même auteur. Paris: P.Fr. Gueffier.

Silliman, Benjamin. 1812. A journal of travels in England, Holland and Scotland, and of two passages over the Atlantic, in the years 1805 and 1806. 2nd Place: United States; Massachusetts; Boston.; United States; New York; New York. ed. 2 vols. Boston : Howe and Deforest: New Haven [Conn.].

Simond, Louis. 1817. Journal of a tour and residence in Great Britain, during the years 1810 and 1811. $2 \mathrm{~d}$, corrected and enlarged: to which is added an appendix on France, written in Dec. 1815, and Oct. 1816. ed. Vol. 2. Edinburgh: Printed by J. Ballantyne and Co., for A. Constable and Co. [etc.].

Sinclair, John. 1814. Appendix to the General report of the agricultural state and political circumstances of Scotland: Edinburgh : Sold by A. Constable, (Edinburgh : D. Willison). 
Smith, Edward. 1695. An Account of a Strange Kind of Earth, Taken up Near Smyrna, of Which is Made Soap, together with the Way of Making It, Communicated by Dr. Edward Smith, F. R. S. Philosophical Transactions (1683-1775) 19:228-230.

Smith, Henry Ecroyd. 1878. Annals of Smith of Cantley, Balby, and Doncaster, County York : embracing elaborate pedigrees of the connected families and biographical notices of their more eminent members. Sunderland: Hills and Co.

Sobolewsky, S., and O. Horrer. 1812. De Thermolampes, et de la perfection que leur ont donnée à Saint Pétersbourg, MM Sobolewky et Horrer. Bibliotéque Britannique; ou Recueil Extrait des Ouvrages périodiques et autres 49:251-260.

- - . 1813. Perfectionnement des thermolampes. Annales des Arts et Manufactures 48 (144):252-257.

Southern, John. 1785. A treatise upon aerostatic machines : containing rules for calculating their powers of ascension, a demonstration of the forces which have a tendency to distend or burst them, and an extensive table, by which the power and weight of any one, from ten to one hundred feet diameter, may readily be found. Also an expeditious method of constructing them of any round form, such as a globe, a vase, or an urn, with directions for filling them, and making inflammable air, \&c. \&c. [England?: s.n.], Pearson and Rollason).

Steevens, Joseph. 1806. A simple and accurate Mode of constructing Gasometers for Purposes where unifomr Pressure is essential, by the Application of the Hydrostatic Regulator. Philosophical Magazine and Journal 24:163-164.

- - - 1807. Description of a Compound Gasometer, for Purposes where uniform Pressure is essential, by the Application of the Hydrostatic Regulator. Philosophical Magazine and Journal 27:34-36.

Sugg, William. 1871. Modern street lighting. London: Vincent works.

Surr, T. S. 1815. The magic of wealth. A novel. In three volumes. 3 vols. Vol. 2. London: Printed for T. Cadell \& W. Davies by G. Sidney.

Tardin, Jean. 1618. Histoire naturelle. De la fontaine qui brusle près de Grenoble. Avec la recherche de ses causes, \& principes, \& ample traicté des feux sousterrains. Tournon: G. Linocier.

Thillaye-Platel, Antoine. 1806. Carbonisation de la tourbe. Annales de Chimie, ou, Recueil de mémoires concernant la chimie et les arts qui en dépendent 58 (2): 128-148.

Thillaye-Platel, Antony. 1807. Carbonization of Turf, or Process by which all possible Advantage may be derived from Products hitherto neglected in tha Operation. $A$ Journal of natural philosophy, chemistry and the arts 16 (2):131-141. 
Thiville, J. G. J. B. Count. 1800. An essay on the means hitherto employed for lighting streets, and the interior of houses and on those which may be substituted with advantage in their stead, intended as an attempt towards the improvement of this branch of domestic economy, by increasing the effects of light, and diminishing it's expence with explanatory figures. London: Sold by Richardson (T. Bentley).

Thompson, Benjamin. 1794. An Account of a Method of Measuring the Comparative Intensities of the Light Emitted by Luminous Bodies. By Lieutenant-General Sir Benjamin Thompson, Count of Rumford, F. R. S. In Two Letters to Sir Joseph Banks, Bart. P. R. S. Philosophical Transactions of the Royal Society of London 84:67-106.

- - . 1798. An Inquiry concerning the Chemical Properties That Have Been Attributed to Light. By Benjamin Count of Rumford, F. R. S. M. R. I. A. Philosophical Transactions of the Royal Society of London 88:449-468.

Thomson, Thomas. 1802. A system of chemistry. Edinburgh: [Printed by J. Brown].

- - - 1807. On the Inflammable Gas found during the distillation of peat. A Journal of natural philosophy, chemistry and the arts 16:241-270.

- - . 1807. On the Gaseous Combinations of Hidrogen and Carbon. A Journal of natural philosophy, chemistry and the arts 28 (Supplement):321-335.

- - . 1810. A system of chemistry: in five Volumes. 4th ed. 5 vols. Edinburgh: Bell \& Bradfute; sold by J. Murray, London.

- - . 1811. On the Gaseous Combinations of Hidrogen and Carbon. A Journal of natural philosophy, chemistry and the arts 28 (Supplement):321-335.

- - - 1811. On the Gaseous Combinations of Hydrogen and Carbon. Philosophical Magazine and Journal 37 (156):260-272.

- - . 1819. Experiments to Determine the Composition of the Different Species of PitCoal. Annals of Philosophy 14 (2):81-96.

--1831 . On a new combustible gas. Transactions of the Royal Society of Edinburgh 11:15-22.

- - . 1843. On Coal Gas. Proceedings of the Philosophical Society of Glasgow 1 (9): 165-175.

Turner, Edward, and Robert Christison. 1825. On the Comparative Advantages of Oild and Coal Gas. Annals of Philosophy New Series 10 (3):190-193.

Ure, Andrew. 1822. On the Ultimate Analysis of Vegetable and Animal Substances. Philosophical Transactions of the Royal Society of London 112:457-482. 
- - . 1824. A dictionary of chemistry. [2nd, rev.] ed. London: Printed for Tegg.

Van Marum, Blumenbach Johann Friedrich. 1792. Lettre à Berthollet, contentant la description d'un Gazomètre, construit d'une manière différente de celui de Lavoisier et de Meusnier, et d'un appareil pour faire très exactement l'expérience de la composition de l'eau, par combustion continuelle, avec plus de facilité et moins de frais. Annales de Chimie, ou, Recueil de mémoires concernant la chimie et les arts qui en dépendent 12:113-140.

Van Marum, M. Blumenbach Johann Friedrich. 1798. Description de quelques appareils chimiques nouveaux ou perfectionnés de la Fondation teylerienne, et des expériences faites avec ces appareils / Uniform Title: Beschryving van eenige nieuwe of verbeterde chemische werktuigen behoorende aan Teyler's stichtung. French. À Haarlem: Chez Jean Jacques Beets,; Netherlands; Haarlem.

Van Voorst, John. 1809. An address to the proprietors of the intended Gas Light and Coke Company to which is annexed, an epitome of the evidence taken before the committee of the House of Commons: Printed for the author.

Vestrumb. 1791. Sur I'Air inflammable pesant. Observations sur la physique, sur I'histoire naturelle et sur les arts 39 (2):366-367.

Vincent, William Thomas. 1888. The records of the Woolwich district. Woolwich, England J.P. Jackson.

Volta, Alessandro. 1777. Lettere del Signor Don Alessandro Volta ... sull'aria infiammabile nativa delle paludi. Milano: Nella stamperia di G. Marelli.

- - - 1777. Lettere del Signor Don Alessandro Volta ... sull'aria infiammabile nativa delle paludi p. 9. Milano: Nella stamperia di G. Marelli.

- - - 1778. Descrizione ed uso di un accendilume ad aria infiammabile. In Le opere di Alessandro Volta Vol. 7 [1918]. Milano: Hoepli.

- - - 1778. Due lettere a Jean Senebier sopra esperienze e considerazioni sull'aria infiammabile. In Le opere di Alessandro Volta Vol. 6 [1918]. Milano: Hoepli.

- - - 1778. Lettres sur l'Air inflammable des Marais. Observations sur la physique, sur l'histoire naturelle et sur les arts 11:152, 219.

- - - 1778. Lettres de Mr. Alexandre Volta sur l'air inflammable des marais auxquelles on a ajouté trois lettres du mème auteur tirées du Journal de Milan : traduites de l'italien. Strasbourg: J.H. Heitz.

- - - 1778. Briefe über die natürlich entstehende entzündbare Sumpfluft. Winterthur: $\mathrm{H}$. Steiner und compagnie. 
- - - 1783. Seconds Partie du memoire de M. de Volta sur les Isolements Imparfaits. Observations sur la physique, sur l'histoire naturelle et sur les arts 23 (2):3-16.

- - - 1784. Memoria sopra i fuochi de' terreni e delle fontane ardenti in generale, e spora quelli di Pietra-Mala in particolare. Memorie di matematica e fisica della Società italiana 2 (2):662.

--- 1784. Memoria sopra i fuochi de terreni e delle fontane ardenti in generale, e sopra quelli di Pietra-Mala in particolare. Opuscoli scelti sulle scienze e sulle arti : tratti dagli atti delle accademie, e dalle altre collezione filosofiche, e letterarie, dalle opere più recenti inglesi, tedesche, francesi, latine, e italiane, e da manoscritti originali, e inediti 7 (5):321-333.

Volta, Alexander, and Hon George. 1782. Del Modo di Render Sensibilissima la piu Debole Elettricita sia Naturale, sia Artificiale. By Mr. Alexander Volta, Professor of Experimental Philosophy in Como, \&c. \&c.; Communicated by the Right Hon. George Earl Cowper, F. R. S. Philosophical Transactions of the Royal Society of London 72:237-xxxiii.

von Saussure, Theodor. 1812. Analyse des ohlerzeugenden Gas, und Beweis, dass es das wahre Kohlen-Wasserstoffgas ist. Annalen der Physik 42 (4):349-375.

Wagner, Johan. 1802. Versuche über Lebons Thermolampen, und deren Beschreibung. Annalen der Physik 10 (4):491-499.

Wankel, Heinrich. 1882. Bilder aus der mährischen Schweiz und ihrer Vergangenheit. Wien: Druck und Verlag von Adolph Holzhauser.

Warren, Charles, and William Harrison. 1809. Speeches of Charles Warren, Esq. and William Harrison, Esq. delivered before a committee of the Honourable House of Commons in support of a bill, to authorise His Majesty to grant a charter of incorporation to certain persons, by the name of the Gas Light and Coke Company. London: G. Woodfall.

Watson, Richard. 1771. An essay on the subjects of chemistry, and their general division. By R. Watson. Cambridge: printed by J. Archdeacon.

- - . 1781. Chemical essays. 5 vols. Cambridge: Printed by J. Archdeacon for T. \& J. Merrill.

Watson, William. 1745. Experiments and observations tending to illustrate the nature and properties of electricity: printed by Jacob llive, for the author.

Weber, Joseph. 1779. Beschreibung des Luftelektrophors nebst angehängten neuen Erfahrungen, neuen Instrumenten, einem Unterrichte von Zubereitung der brennbaren Luft, und verschiedener Versuche mit derselben ... Sammt drey 
Kupfertafeln. Neueste mit der Beschreibung der elektrischen Lampe verm. Aufl. ed. Augsburg: Bey Eberhard Kletts sel. Wittwe und Franck.

Webster, John. 1807. Account of the discovery of the means of illumination by gas from coal. A Journal of natural philosophy, chemistry and the arts 16:83.

- - . 1811. Elements of chemistry. London: Printed for the author, and sold by Johnson and Co., and Crosby and Co.

Webster, John, and W. T. Brande. 1826. A manual of chemistry, on the basis of Professor Brande's; containing the principal facts of the science, arranged in the order in which they are discussed and illustrated in the lectures at Harvard university, N.E. Compiled from the works of Brande, Henry, Berzelius, Thomson and others. Boston: Richardson \& Lord.

Wenzler, Johannes Baptista. 1802. Beschreibung einer Thermo-Lampe, oder eines Leucht- und Spar-Ofens, welcher alle Zimmer im ganzen Hause heissen, und leleuchten kann. Mit einer Kupfer-Tafel. Passau: Gedruckt bei Ambrosi.

Williams, John. 1828. An historical account of sub-ways in the British metropolis, for the flow of pure water and gas into the houses of the inhabitants, without disturbing the pavements: including the projects in 1824 and 1825. London: Carpenter \& son [etc.].

Wilson, John. 1812. General view of the agriculture of Renfrewshire; with observations on the means of its improvement, and an account of its commerce and manufactures. Paisley: Printed by S. Young.

Winsor, Frederick Albert. 1798. Addresse aux souverains de l'Europe etc. etc en deux parties: Londres : Chez G.G. \& J. Robinson, Wm. Richardson \& Co.

- - . 1799. Prosperity of England midst the clamors of ruin: [England?] : Printed for the author.

- - - 1802. Description of the Thermolamp invented by Lebon, of Paris, published with remarks by F. A. W. Braunschweig: Friedrik Vieweg.

- - - 1804. Account of the most ingenious and important National Discovery for some Ages. British Imperial Patent Light Ovens and Stoves, respectfully dedicated to both Houses of Parliament, and all Patriotic Societies; and recommended to all the learned in Physics and Chemistry. London: Printed for the author, and sold by Messrs. Richardsons, Royal Exchange; Mr. Miller; Principal Booksellers in Town and Country. T. Maiden, printer.

- - - 1804. The superiority of the new patent coke over the use of coals. London: Richardson. 
- - . 1806. To be sanctioned by act of parliament. A national light and heat company for providing our streets and houses with light and heat, on similar principles, as they are now supplied with water, demonstrated with the patentee's authority and instructions, by Professor Hardie, at the Theatre of Sciences, No. 98, Pall Mall, where it is proved by positive experiments and decisive calculation, that the destruction of smoke would open unto the empire of Great Britain new and unparalelled sources of inexhaustible national wealth, at this most portentous crisis of Europe, worth the whole century of inventions of the celebrated Marquis of Worcester. first ed. London: Printed, for the patentee, by Watts \& Bridgewater.

- - - 1807. To be sanctioned by act of parliament. A National Light and Heat Company, for providing our streets and houses with hydrocarbonic gas-lights, on similar principles, as they are now supplied with water, four tables of calculation, founded on official experiments, prove the immense national profits and increase of revenue by the adoption of this plan, which is to be had at the National Light \& Heat Company's office, no.97, Pall Mall. new ed. London: Printed for F.A. Winsor, the patentee, by Watts \& Bridgewater.

-- - 1807. Mr. W. Nicholson's attack, in his Philosophical Journal, on Mr. Winsor and the National Light and Heat Company: with Mr. Winsor's defence. London.

- - - 1807. Plain Questions and Answers. London: G. Sydney, Northumberland Street, Strand.

- - . 1807. Analogy between Animal and Vegetable Life. Demonstrating the beneficial application of the patent light stoves to all green and hot houses, etc. London: Richardson.

- - . 1807. Report to shareholders. London: National Heat and Light Company.

- - - 1807. National deposit bank, or, The bulwark of British security, credit and commerce, in all times of difficulty, changes, and revolutions with the mercantile policy of separating the discounts of merchants and manufacturers from the law of national interest, as practised in the first commercial cities on the continent: London : Printed for the author, G. Sidney.

- - . 1808. Report to shareholders. London: National Heat and Light Company.

--- . 1809. Letter to subcribers.

- - . 1812. Analysis and dissection of the Gaso-coko project, recommended to the attentive perusal of all the subscribers to the gaseous fund, particularly at this time when called on for a levy on their subscriptions. London: Printed for the Author, by S. Smith, and sold by J. Hearne.

- - - 1816. Notice historique sur l'utilisation du gaz hydrogène pour l'éclairage, avec un extrait du procès-verbal d'enquête faite par le parlement d'Angleterrë sur cet 
éclairage, et l'application aux arts et métiers des produits tirés de la distillation du charbon de terre. Paris: Nouzou.

Winzler, Zacheus Andr. 1803. Berichtigungs-Magazin der Einwürfe, Zweifel und Bedenklichkeiten gegen den neu erfundenen Koch- Heiz- Leucht- und Sparofen, oder die deutsche Thermolampe. Wien: In der v. Schönfeldischen k. k. priv. Buchdruckerey.

- - . 1803. Die Thermolampe in Deutschland : oder, vollständige, sowohl theoretischals praktische Anleitung, den ursprunglich in Frankreich erfundenen, nun aber auch in Deutschland entdekten Universal- Leucht- Heiz- Koch-Sud-Destillir- und Sparoven zu errichten. Mit vier Kupfertafeln. Brünn: Gedruckt bei Franz Karl Siedler ...

Witty, Richard J. L. 1831. A practical treatise on the nature of fire, and the valuable advantages to be derived by the manufacturers of Great Britain, from the application of the patent gas furnace, pointing out the errors of the present system : together with remarks on the quality of coal, and the means of ascertaining the respective value of it. Nottingham: [Printed by G. Stretton].

Woodward, George Moutard, and Thomas Rowlandson. 1809. A Peep at the Gas Lights in Pall-Mall. London.

Woulfe, Peter. 1767. Experiments on the Distillation of Acids, Volatile Alkalies, \&c. Shewing How They May be Condensed without Loss, and How Thereby We May Avoid Disagreeable and Noxious Fumes: In a Letter from Mr. Peter Woulfe, F. R. S. to John Ellis, Esq; F. R. S. Philosophical Transactions (1683-1775) 57:517-536.

Wright, G. J. 1803. Remarks on the present State of Aerostation. Philosophical Magazine and Journal 15:19-23.

- - . 1805. Response to Mr. Northern and Mr. Henry. The Monthly magazine, or, British register 19:427-428.

zu Salm-Reiferscheid, Hugo. 1808. Holzverkohlung im Grossen vermittelst der Thermolampe; geschrieben. Annalen der Physik 30 (12):402-403.

\section{Secondary sources}

The Gas Light and Coke Company : an account of the progress of the Company from its incorporation by Royal Charter in the year 1812 to the present time, 1812-1912. London: G.L. \& C.C., 1912. 
"Little things that matter. XXIII, Gas lighting and heating." Architects' journal, vol 158 (1923): 915-16.

L'Industrie du gaz en France : 1824-1924. Paris: Devambez, 1924.

Report of the Joint Committee on Gas Undertakings (Powers of Investment),: together with the Proceedings of the Committee, Minutes of Evidence, and Appendices. London: H.M.S.O., 1932.

Report from the Joint Committee on Gas Undertakings (Basic prices),: together with the Proceedings of the Committee and Minutes of Evidence. London: H.M.S.O., 1933.

"The Manor and Liberty of Norton Folgate." In Survey of London: volume 27: Spitalfields and Mile End New Town, edited by F. H. W. Sheppard, 15-20. London: Published for the London County Council by the Athlone Press, 1957.

"Pall Mall, South Side, Past Buildings: Nos 93-95 Pall Mall: F.A. Winsor and the development of gas lighting." In Survey of London: volumes 29 and 30: St James Westminster, Part 1, edited by F. H. W. Sheppard, 352-54. London: Published for the London County Council by the Athlone Press, 1960.

Symposium über die Historische Entwicklung der Gasversorgung, Köln, 1979. Schriftenreihe der Frontinus-Gesellschaft ;; Heft 3;. Frankfurt/Main: ZfGW-Verlag, 1980.

Industrial revolution a documentary history. microfilm reels ; $35 \mathrm{~mm}$. + guide vols. Marlborough, Wiltshire, England: Adam Matthew Publications, 1992.

Industrial revolution : a documentary history. Series One : The Boulton and Watt Archive and Matthew Boulton Papers from the Birmingham Central Library. Marlborough, Wiltshire, England: Adam Matthews, 1992.

Feuer und Flamme für Berlin : 170 Jahre Gas in Berlin, 150 Jahre Städtische Gaswerke. Vol. 16, Berliner Beiträge zur Technikgeschichte und Industriekultur. Berlin: Nicolaische Verlagsbuchhandlung, 1997.

Industrial revolution, a documentary history. Series Three, The papers of James Watt and his family formerly held at Doldowlod House. Marlborough, England: Adam Matthews, 1998.

Gli Strumenti di Alessandro Volta: Il Gabinetto di fisica dell'Università di Pavia. Milano, Pavia Università degli studi di Pavia, Editore Ulrico Hoepli, 2002.

Abele, J. Die Lichtbogenlampe, Technikgeschichte. Munchen: Deutsches Museum, 1995.

Adry, Eg. Un siècle d'éclairage, 1824-1924. Anvers: Ratinckx frères, 1925. 
Allen, Robert C. "The British Industrial Revolution in Global Perspective: How Commerce Created The Industrial Revolution and Modern Economic Growth." Oxford: Nuffield College, 2006.

Anderson, Alan Garrett. Report by the Joint select committee of the House of Lords and House of Commons on gas prices,: together with the Proceedings of the Committee and Minutes of evidence. London: H.M.S.O., 1937.

Armstrong, Christopher, and H. V. Nelles. Monopoly's moment : the organization and regulation of Canadian utilities, 1830-1930, Technology and urban growth;. Philadelphia: Temple University Press, 1986.

Armstrong, John. Carbonisation technology and engineering.: A practical exposition of the processes employed for the carbonisation of coal and wood by high and low temperature methods, with an account of the by-products obtained. London: $\mathrm{C}$. Griffin, 1929.

Arroyo Huguet, Mercedes. La industria del gas en Barcelona, 1841-1933 : innovación tecnológica, territorio urbano y conflicto de intereses. Barcelona: Ediciones del Serbal, 1996.

- - - "Estrategias empresariales y redes territoriales en dos ciudades españolas, Barcelona y Madrid (1832-1923)." Historia Contemporánea [Spain], no. 1 (2002): 137-60.

Ashley, Percy. "The Water, Gas, and Electric Light Supply of London." Annals of the American Academy of Political and Social Science 27 (1906): 20-36.

Ashton, John. The dawn of the XIXth century in England, a social sketch of the times. 5th ed. London: T.F. Unwin, 1906.

Ashton, T. S. The Industrial Revolution, 1760-1830. 1st revised ed. New York: Oxford University Press, 1964.

Austerfield, Peter J. "From hot air to hydrogen: filling and flying the early gas balloons." Endeavour 14, no. 4 (1990): 194-200.

Awty, Brian G. "The introduction of gas-lighting to Preston." Transactions of the Historic Society of Lancashire and Cheshire 125, no. 1974 (1974): 82-118.

Bach, Penny Balkin. "To Light up Philadelphia: Lighting, Public Art, and Public Space." Art Journal 48, no. 4 (1989): 324-30.

Baldwin, Peter C. "In the Heart of Darkness: Blackouts and the Social Geography of Lighting in the Gaslight Era." Journal of Urban History 30, no. 5 (2004): 749-68.

Barefoot, Guy. Gaslight melodrama : from Victorian London to 1940s Hollywood. New York: Continuum, 2001. 
Barty-King, Hugh. New flame : how gas changed the commercial, domestic and industrial life of Britain between 1813 and 1984. Tavistock, Devon: Graphmitre, 1984.

Beacall, Thomas, Frederick Challenger, Geoffrey Martin, and Henry Julius Salomon Sand. Dyestuffs \& coal-tar products;: their chemistry, manufacture and application; including chapters on modern inks, photographic chemicals, synthetic drugs, sweetening chemicals, and other products derived from coal tar. London: C. Lockwood, 1916.

Beaver, S. H. "Coke Manufacture in Great Britain: A Study in Industrial Geography." Transactions and Papers (Institute of British Geographers), no. 17 (1951): 133-48.

Beckett, J. V. "Dr William Brownrigg, F.R.S.: Physician, Chemist and Country Gentleman." Notes and Records of the Royal Society of London 31, no. 2 (1977): 255-71.

- - - Coal and tobacco: the Lowthers and the economic development of West Cumberland, 1660-1760: New York, 1981.

Bekar, C., and R. G. Lipsey. "Science, Institutions, and the Industrial Revolution." 2003.

Bennett, J. A. "Instrument Makers and the 'Decline of Science in England': The Effects of Institutional Change on the Élite Makers." In Nineteenth-century scientific instruments and their makers : papers presented at the Fourth Scientific Instrument Symposium, Amsterdam, 23-26 October 1984, edited by P. R. De Clercq, 13-27. Leiden : Museum Boerhaave: Amsterdam, 1985.

Berg, Maxine. "The Genesis of 'Useful Knowledge'." History of Science 45 (2007): 123-33.

Berlanstein, Lenard R. "Managers and Engineers in French Big Business in the Nineteenth Century." Journal of Social History 22, no. 2 (1988): 211-36.

- - - Big business and industrial conflict in nineteenth-century France : a social history of the Parisian Gas Company. Berkeley: University of California Press, 1991.

Berman, Morris. "The Early Years of the Royal Institution 1799-1810: A Re-Evaluation." Science Studies 2, no. 3 (1972): 205-40.

- - - Social Change and Scientific Organization: the Royal Institution, 1799-1844. Ithaca, N.Y.: Cornell University Press, 1978.

Bolton, Kate. "The Great Awakening of the Night: Lighting America's Streets." Landscape 23, no. 3 (1979): 41-47. 
Bössner, Franz. Die Verwerthung der ausgebrauchten Gesreinigungsmassen auf Blutlaugensalz, Ammoniak- und Rhodanverbindungen.: Nebst einem Anhang enthaltend die neuen Methoden der nassen Cyangewinnung aus Leuchtgas. Leipzig: F. Deuticke, 1902.

- - - "Luxury and Control: the Urbanity of Street Lighting in Nineteenth-Century Cities." Journal of Urban History 14, no. 1 (1987): 7-37.

- - - "The "Good Lamp is the Best Police" Metaphor and Ideologies of the Nineteenth-Century Urban Landscape." American Studies 32, no. 2 (1991): 63-78.

Bourne, R. "The beginnings of electric street lighting in the City of London." Engineering Science and Education Journal 5, no. 2 (1996): 81-88.

Bowers, Brian. Lengthening the day : a history of lighting technology. New York: Oxford University Press, 1998.

Brenni, Paolo. "Volta's electric lighter and its improvements: The birth, life and death of a peculiar scientific apparatus which became the first electric household appliance." In From the itinerant lecturers of the 18th century to popularizing physics in the 21st century-exploring the relationship between learning and entertainment. Pognana sul Lario, Italy 2003.

Brereton, Austin. The Lyceum and Henry Irving. London : Lawrence \& Bullen: New York, 1903.

Bret, Patrice. "Un bateleur de la science : Le « machiniste-physicien » François Bienvenu et la diffusion de Franklin et Lavoisier." Annales historiques de la Révolution française, no. 338 (2004): 95-127.

Bright, Arthur Aaron. The electric-lamp industry: technological change and economic development from 1800 to 1947. New York: Macmillan Co., 1949.

Broomham, Rosemary. First light : 150 years of gas. Sydney: Hale \& Iremonger, 1987.

Browne, Charles Albert. "The Life and Chemical Services of Frederick Accum." Journal of Chemical Education 2, no. 10-12 (1925): 829-51, 1008-34, 140-149.

Brownlie, David. "The Early history of the Coal Gas Process." Transactions of the Newcomen Society 3 (1923): 57-68.

Bruland, Kristine. "Technology Selection and Useful Knowledge: A Comment." History of Science 45 (2007): 179-83.

Buckley, W., and A. McCulloch. "Leaves from an Old notebook: A Record of Some Early Experiments on the Carbonisation of Oil and Coal, by Dr. W. Henry, F. R. S. 
(1808-1824)." Memoirs of the Literary and Philosophical Society of Manchester 74 (1929): 67-74.

Burns, D. Thorburn "Changes in the Methods of Teaching and Learning Chemistry Over the Period 1650-1850." Microchimica Acta 142, no. 3 (2003): 143 - 52.

Busch, Jane. "Cooking Competition: Technology on the Domestic Market in the 1930s." Technology and Culture 24, no. 2 (1983): 222-45.

Butt, John. "Technical Change and the Growth of the British Shale-Oil Industry (1680-1870)." The Economic History Review 17, no. 3 (1965): 511-21.

Butterfield, William John Atkinson. The chemistry of gas manufacture,: a practical handbook on the production, purification, and testing of illuminating and fuel gas, and on the bye-products of gas manufacture. London,IbGriffin,Ic1904.: Griffin, 1904.

- - - Lectures on chemistry in gas-works. London, 1913.

Campbell, W. A. "Gas lighting in Newcastle." Archaeologia Aeliana, vol 13, no. 201 (1985): 197-201.

Caron, François Paris et ses réseaux: naissance d'un mode de vie urbain, XIXe-XXe siècles. Paris: Hôtel d'Angoulême-Lamoignon, 1990.

Cartwright, F. F. "The Association of Thomas Beddoes, M.D. with James Watt, F.R.S." Notes and Records of the Royal Society of London 22, no. 1/2 (1967): 131-43.

Castaneda, Christopher James. Invisible fuel : manufactured and natural gas in America, 1800-2000. New York: Twayne, 1999.

Castaneda, Christopher James, and Joseph Pratt. "New Markets, Outmoded Manufacturing: the Transition from Manufactured Gas to Natural Gas by Northeastern Utilities After World War II." Business and Economic History 18 (1989): 238-47.

Castle, Terry. "Phantasmagoria and modern reverie." In The Horror Reader, edited by Ken Gelder, 29-48. New York, London: Routledge, 2000.

Cavendish, Henry. "Experiments on Factitious Air Part IV: Containing experiments on the air produced from vegetable and animal substances by distillation." In The scientific papers of the Honourable Henry Cavendish vol 2, edited by James Clerk Maxwell, Joseph Larmor and T. E. Thorpe, 307-16. Cambridge: The University Press, 1921.

Chandler, Alfred Dupont. The visible hand : the managerial revolution in American business. Cambridge, Mass.: Belknap Press, 1977. 
Chandler, Alfred D., and Hikino Takashi. Scale and scope : the dynamics of industrial capitalism. Cambridge, Mass.: Belknap Press, 1990.

Chandler, Dean, and A. Douglas Lacey. The rise of the gas industry in Britain. London: British Gas Council, 1949.

Channon, Geoffrey. Railways in Britain and the United States, 1830-1940 : studies in economic and business history. Burlington, VT: Ashgate, 2001.

Chantler, Philip. "The London Sliding Scale: Incentive and Efficiency in the British Gas Industry." The Journal of Land \& Public Utility Economics 12, no. 3 (1936): 228-37.

- - - The British gas industry; an economic study. Manchester, UK: Manchester University Press, 1938.

Chapman, Stanley D. The early factory masters: the transition to the factory system in the Midlands textile industry. Newton Abbot (Devon): David \& Charles, 1967.

Chatterton, D. A. "State Control of Public Utilities in the Nineteenth Century: The London Gas Industry." Business History 14, no. 2 (1972): 166-78.

Chatzis, Konstantinos, and Olivier Coutard. "Water and gas: Early developments in the utility networks of Paris." Journal of Urban Technology 12, no. 3 (2005): 1-17.

Clendinning, Anne. "'Deft fingers' and 'persuasive eloquence': the 'lady demons' of the English gas industry, 1888-1918." Women's History Review 9, no. 3 (2000): 501-37.

- - - Demons of domesticity : women and the English gas industry, 1889-1939. Aldershot, Hants, England ; Burlington, VT: Ashgate, 2004.

Clifton, Gloria C. Turner Gerard L'Estrange. Directory of British scientific instrument makers, 1550-1851. London: Zwemmer in association with the National Maritime Museum, 1995.

Clow, Archibald, and Nan L. Clow. The Chemical Revolution; a Contribution to Social Technology. Freeport: N.Y., Books for Libraries Press, 1970.

Coaton, J. R. "The genesis of incandescent lamp manufacture." Engineering Science and Education Journal 11, no. 1 (2002): 17-24.

Cole, R. J. "Friedrich Accum (1769-1838). A biographical study." Annals of Science 7, no. 2 (1951): $128-43$.

Collins, Frederick Lewis, John Herman Groesbeck Pierson, and Peter J. Eckel. Consolidated gas company of New York : a history published by the company in the fiftieth year of its existence as a corporation and the one hundred and tenth 
year of continuous service to the people of the city of New York. New York: S.L., 1934.

Cotterill, M. S. "The Development of Scottish Gas Technology 1817-1914: Inspiration and Motivation." Industrial Archaeology Review [Great Britain] 5, no. 1 (1981): 19-40.

Cripps, F. Southwell. The earliest works on gas lighting : a list of books, pamphlets, and important references prior to the year 1840. London, England: s.n., 1907.

Crosland, Maurice P. Gay-Lussac : scientist and bourgeois. Cambridge: New York, 2004. Reprint, 2004.

Crowley, John E. The invention of comfort : sensibilities \& design in early modern Britain \& early America. Baltimore, Md.: London : Johns Hopkins University Press, 2001.

Darwin, Erasmus , and King-Hele Desmond. The collected letters of Erasmus Darwin: New York : Cambridge University Press, 2007.

De Clercq, Peter. "Science at Court: the Eighteenth-century Cabinet of Scientific Instruments and Models of the Dutch Stadholders." Annals of Science 45 (1988): 113-52.

Dillon, Maureen. Artificial sunshine : a social history of domestic lighting. London: National Trust, 2002.

Dotterweich, Frank Henry. Colloidal properties of iron oxide in the removal of hydrogen sulphide from gas. Baltimore, 1938.

Elton, Arthur. "Gas for Light and Heat." In A History of Technology, Volume IV: The Industrial Revolution c. 1750 to c. 1850 , edited by Charles Singer, E. J. Holmyard, A. R. Hall and Trevor Illtyd Williams, 258-75. Oxford, England: Oxford University Press, 1958.

English, Peter J. "Glowing on for ever? Britain's gas lamp heritage." Country Life 19, no. 87 (1987): 96-97.

Erlick, David P. "The Peales and Gas Lights in Baltimore." Maryland Historical Magazine 80, no. 1 (1985): 9-18.

Evans, Chris, and Göran Rydén, eds. The industrial revolution in iron : the impact of British coal technology in nineteenth-century Europe: Burlington, VT, 2005.

Everard, Stirling. The history of the Gas Light and Coke Company, 1812-1949. London: Benn, 1949.

Falkus, Malcolm E. "The British Gas Industry before 1850." The Economic History Review 20, no. 3 (1967): 494-508. 
- - - "Lighting in the dark ages of English economic history: town streets before the industrial revolution." In Trade, government and economy in pre-industrial England, edited by Donald Coleman and Frederick Fisher, 248-73. London: Weidenfeld \& Nicolson, 1976.

- - - The British gas industry in the early nineteenth century. London: Social Science Research Council, 1980.

- - - "The Early Development of the British Gas Industry, 1790-1815." The Economic History Review 35, no. 2 (1982): 217-34.

Farrar, W. V. "Richard Laming and the coal-gas industry, with his views on the structure of matter." Annals of Science 25, no. 3 (1969): 243-53.

Farrar, W. V., K. R. Farrar, and E. L. Scott. "The Henrys of Manchester: William Henry and the Gas Industry." Ambix [Great Britain] 22, no. 3 (1975): 186-204.

Farrar, Wilfred Vernon Brock W. H., and Richard Leslie Hills. Chemistry and the chemical industry in the 19th century : the Henrys of Manchester and other studies : Wilfred Vernon Farrar, 1920-1977. Brookfield, Vt.: Variorum, 1997.

Fayol, Amédée. ...Philippe Lebon, inventeur du gaz declairage. Paris: Les Publications techniques, 1953.

Feldhaus, Franz Maria. Die Technik der Vorzeit, der geschichtlichen Zeit und der Naturvölker : ein Handbuch für archäologen und Historiker, Museen und Sammler, Kunsthändler und Antiquare. Leipzig usw.: Wilhelm Engelmann, 1914.

Fenoaltea, Stefano. "The Growth of the Utilities Industries in Italy, 1861-1913." The Journal of Economic History 42, no. 3 (1982): 601-27.

Fernandez, Alexandre. "Cambio Tecnologico y Transformaciones Empresariales: Gas y Electricidad En Bilbao y En Burdeos (Ca. 1880-Ca. 1920)." Historia Contemporanea [Spain], no. 2 (2002): 319-42.

Fitchen III, John F. "The Problem of Ventilation through the Ages." Technology and Culture 22, no. 3 (1981): 485-511.

Fouquet, Roger, and Peter J. G. Pearson. "Long Run Trends in Energy Services: The Price and Use of Light in the United Kingdom (1500-2000)." Centre for Energy Policy and Technology Imperial College London, 2003.

- - - "Five Centuries of Energy Prices." World Economics 4, no. 3 (2003): 93-119.

Fox, Robert. "Thomas Edison's Parisian campaign: incandescent lighting and the hidden face of technology transfer." Annals of Science 53, no. 2 (1996): 157-93. 
Franklin, Benjamin. The works of Benjamin Franklin, including the private as well as the official and scientific correspondence together with the unmutilated and correct version of the Autobiography. Edited by John Bigelow. 12 vols. Vol. 11. New York: London, G.P. Putnam's Sons, the Knickerbocker Press, 1904.

Freeman, Mark, Robin Pearson, and James Taylor. "The Politics of Business: Joint Stock Company Constitutions in Britain, 1720-1844." Hull: University of Hull, 2003.

Fremdling, Rainer. "Transfer patterns of British technology to the Continent: The case of the iron industry." European Review of Economic History 4, no. 02 (2000): 195-222.

Fullmer, June Z. "Technology, Chemistry, and the Law in Early 19th-Century England." Technology and Culture 21, no. 1 (1980): 1-28.

Gillispie, Charles C. "The Discovery of the Leblanc Process." Isis 48, no. 2 (1957): $152-70$.

- - - "The Natural History of Industry." Isis 48, no. 4 (1957): 398-407.

Goldfarb, Stephen J. "A Regency Gas Burner." Technology and Culture 12, no. 3 (1971): 471-76.

Goodall, Francis. "Appliance Trading Activities of British Gas Utilities, 1875-1935." The Economic History Review 46, no. 3 (1993): 543-57.

- - - "Gas in London: a Divided City." London Journal [Great Britain] 27, no. 2 (2002): 34-50.

Gracie, J. "All gas and craters." Scots Magazine 155, no. 5 (2001): 528-30.

Grand, H. E. Le. "Lavoisier's oxygen theory of acidity." Annals of Science 29, no. 1 (1972): 1 - 18.

Griffiths, John Charles. The Third Man: the Life and Times of William Murdoch, 1754-1839, the Inventor of Gas Lighting. London: A. Deutsch, 1992.

- - - "Murdock , William (1754-1839)." In Oxford Dictionary of National Biography, edited by H. C. G. Matthew and Brian Harrison. Oxford: Oxford University Press, 2004.

Guerlac, Henry. "Joseph Black and Fixed Air: a bicentenary retrospective, with some new or little known material." Isis 48, no. 2 (1957): 124-51.

- - - . "Joseph Black and Fixed Air: Part II." Isis 48, no. 4 (1957): 433-56. 
Guillerme, A. . "L'Émergence du concept de réseaux 1820-1830." In Réseaux territoriaux, edited by G. Dupuy, 33-50. Caen: Paradigme, 1988.

Haber, Ludwig Fritz. The chemical industry during the nineteenth century;: a study of the economic aspect of applied chemistry in Europe and North America. Oxford: Clarendon Press, 1969.

Hall, A. Rupert. "What did the Industrial Revolution in Britain owe to Science?" In Historical perspectives : studies in English thought and society, in honour of J. $\mathrm{H}$. Plumb, edited by Neil McKendrick, 129-51. London: Europa, 1974.

HalvaDenk, Helma. "Bedeutende Südmährer." Offizielle Homepage des Südmährischen Landschaftsrats (1991), www.suedmaehren.eu.

Hamper, Martin. "Manufactured Gas History and Processes." Environmental Forensics 7, no. 1 (2006): 55-64.

Hanseth, Ole, Eric Monteiro, and Morten Hatling. "Developing Information Infrastructure: The Tension between Standardization and Flexibility." Science, Technology, \& Human Values 21, no. 4 (1996): 407-26.

Harris, J. R. "Skills, Coal and British Industry in the eighteenth century." History 61, no. 202 (1976): 167-82.

- - - Industrial espionage and technology transfer : Britain and France in the eighteenth century. Aldershort, Hants, England: Brookfield, VT, 1998.

Harris, Ron. Industrializing English law : entrepreneurship and business organization, 1720-1844: New York, 2000.

Hatheway, Allan. "Hatheway." www.hatheway.net.

Hilaire-Perez, Liliane. "Technology as a Public Culture in the Eighteenth Century: The Artisans' Legacy." History of Science 45 (2007): 135-53.

Hills, Richard Leslie. James Watt. 1st ed. Ashbourne, England: Landmark Pub., 2002.

Holmes, Frederic Lawrence. "Phlogiston in the Air." In Nuova Voltiana : studies on Volta and his times, edited by Fabio Bevilacqua and Lucio Fregonese, ? Milano, Pavia Università degli studi di Pavia, Editore Ulrico Hoepli, 2000.

Holmes, Frederic Lawrence, and Trevor Levere. Instruments and experimentation in the history of chemistry. Cambridge, Mass.: MIT Press, 2000.

Home, Roderick W. "Volta's English Connections." In Nuova Voltiana : studies on Volta and his times, edited by Fabio Bevilacqua and Lucio Fregonese, 115-32. Milano, Pavia Università degli studi di Pavia, Editore Ulrico Hoepli, 2000. 
Horn, Jeff. The path not taken : French industrialization in the age of revolution, 1750-1830. Cambridge, Mass.: MIT Press, 2006.

Horn, Jeff Ph D. The Industrial Revolution. Westport, Conn. : Greenwood: Northam, 2007.

Hughes, Thomas Parke. "British Electrical Industry Lag: 1882-1888." Technology and Culture 3, no. 1 (1962): 27-44.

- - . Networks of power : electrification in Western society, 1880-1930. Baltimore: Johns Hopkins University Press, 1983.

- - - "The evolution of large technological systems." In The Social construction of technological systems : new directions in the sociology and history of technology, edited by Wiebe E. Bijker, Thomas Parke Hughes and T. J. Pinch, 51-82. Cambridge, Mass.: MIT Press, 1987.

Hunt, Charles. A history of the introduction of gas lighting. London: W. King, 1907.

Hutchinson, Kenneth. "The Royal Society and the Foundation of the British Gas Industry." Notes and Records of the Royal Society of London 39, no. 2 (1985): 245-70.

Hyldtoft, Ole. "Modern Theories of Regulation: An Old Story: Danish Gasworks in the Nineteenth Century." Scandinavian Economic History Review 42, no. 1 (1994): 29-53.

Inkster, lan. "Technology in World History: Cultures of Constraint and Innovation, Emulation, and Technology Transfers." Comparative Technology Transfer and Society 5, no. 2 (2007): 108-27.

Jacob, Margaret C. The cultural meaning of the scientific revolution. 1st ed. Philadelphia: Temple University Press, 1988.

- - - Scientific culture and the making of the industrial West: Oxford University Press, 1997.

- - - "Mechanical Science on the Factory Floor: The Early Industrial Revolution in Leeds." History of Science 45 (2007): 197-221.

Jacob, Margaret C., and David Reid. "Technical knowledge and the mental universe of Manchester's early cotton manufacturers." Canadian Journal of History 36, no. 2 (2001): 283-304.

Jacob, Margaret C., and Larry Stewart. Practical matter : Newton's science in the service of industry and empire, 1687-1851: Harvard University Press, 2004. 
Jaspers, P. A. Th. M. J.P. Minckelers, 1748-1824. Maastricht: Stichting Historische Reeks, 1983.

Jaspers, P. A. Th. M., and J. Roegiers. "Le Mémoire sur l'air inflammable de J. P. Minckelers (1748-1824)." Lias 10, no. 2 (1983): 217-52.

Jenkins, Andrew. "Government Intervention in the British Gas Industry, 1948 to 1970." Business History [Great Britain] 46, no. 1 (2004): 57-78.

Jervis, F. R. "Gas and Electricity in Britain: A Study in Duopoly." Land Economics 24, no. 1 (1948): 31-39.

John, Richard R. "Elaborations, Revisions, Dissents: Alfred D. Chandler, Jr.'s, "The Visible Hand" after Twenty Years." The Business History Review 71, no. 2 (1997): 151-200.

Kelly, Thomas. "The Origin of Mechanics' Institutes." British Journal of Educational Studies 1, no. 1 (1952): 17-27.

Keyser, Barbara Whitney. "Between science and craft: The case of Berthollet and dyeing." Annals of Science 47, no. 3 (1990): 213 - 60.

Kim, Mi Gyung. "The Analytic Ideal of Chemical Elements: Robert Boyle and the French Didactic Tradition of Chemistry." Science in Context 14, no. 3 (2001): 361-95.

- - - "'Public' Science: Hydrogen Balloons and Lavoisier's Decomposition of Water." Annals of Science 63, no. 3 (2006): 291 - 318.

Kindleberger, Charles Poor. A financial history of western Europe: Oxford University Press, 1993.

Kirby, Maurice. W. . "Big business before 1900." In Business enterprise in modern Britain : from the eighteenth to the twentieth century, edited by Maurice. W. Kirby and Mary B. Rose, 113-37. London: New York, 1994.

Klein, Ursula. "Technoscience avant la lettre." Perspectives on Science 13, no. 2 (2005): 226-66.

- - - "Shifting ontologies, changing classifications: plant materials from 1700 to 1830." Studies In History and Philosophy of Science Part A 36, no. 2 (2005): 261-329.

Koftelev, V. T. "150th Anniversary of the publication of the world's first work on powder metallurgy." Powder Metallurgy and Metal Ceramics 17, no. 10 (1978): 815-20.

Konvitz, Josef W., Mark H. Rose, and Joel A. Tarr. "Technology and the City." Technology and Culture 31, no. 2 (1990): 284-94. 
Kooij, Pim. "'Where the Action is'. The Introduction and Acceptation of Infrastructural Innovations in Dutch Cities 1850-1950." In World Economic History Conference. Helsinki, 2006.

Körting, Johannes. Geschichte der deutschen Gasindustrie mit Vorgeschichte und bestimmenden Einflüssen des Auslandes. Essen: Vulkan-Verlag, 1963.

Landes, David S. The unbound Prometheus : technological change and industrial development in Western Europe from 1750 to the present. 2nd ed. Cambridge, New York: Cambridge University Press, 2003.

Lange, Kurt Reinhold. The by-products of coal-gas manufacture. Translated by Chas. Salter. London: Scott Greenwood, 1915.

Langins, Janis. "Hydrogen production for ballooning during the French Revolution: An early example of chemical process development." Annals of Science 40, no. 6 (1983): 531 - 58.

Latta, Nisbet. American producer gas practice and industrial gas engineering. New York: Van Nostrand, 1910.

Levere, Trevor. "The role of instruments in the dissemination of the Chemical Ravolution." Éndoxa: series filosóficas 19 (2005): 227-42.

- - - "Lavoisier's Gasometer and others: Research, Control, and Dissemination." In Lavoisier in perspective, edited by Marco Beretta. Munich: Deutsches Museum, 2005.

- - - "Dr. Thomas Beddoes (1760-1808): Chemistry, Medicine, and Books in the French and Chemical Revolutions." In New narratives in eighteenth-century chemistry : contributions from the First Francis Bacon Workshop, 21-23 April 2005, California Institute of Technology, Pasadena, California, edited by Lawrence Principe, 157-76. Dordrecht: Springer, 2007.

Levere, Trevor Harvey. Transforming matter : a history of chemistry from alchemy to the buckyball: Johns Hopkins University Press, 2001.

Leveson-Gower, Granville (1st Earl Granville), and Henrietta-Frances (Countess of Bessborough) Ponsonby. Lord Granville Leveson Gower (first earl Granville): private correspondence, 1781 to 1821 Vol. 2. Edited by Castalia Rosalind Campbell Leveson-Gower Granville. London: J. Murray, 1916.

Lynn, Michael R. Popular science and public opinion in eighteenth-century France. Manchester, UK: New York, 2006.

Macfarlan, J. "George Dixon: Dicoverer of Gas Light from Coal." Transactions of the Newcomen Society 5 (1925): 53-55. 
MacLeod, Christine. Inventing the Industrial Revolution : the English patent system, 1660-1800. Cambridge: Cambridge University Press, 1988.

- - - "The Paradoxes of Patenting: Invention and Its Diffusion in 18th- and 19thCentury Britain, France, and North America." Technology and Culture 32, no. 4 (1991): 885-910.

- - - "Strategies for Innovation: The Diffusion of New Technology in NineteenthCentury British Industry." The Economic History Review 45, no. 2 (1992): 285-307.

- - - "The European Origins of British technological predominance." In Exceptionalism and industrialisation : Britain and its European rivals, 1688-1815, edited by Leandro Prados de la Escosura, 111-26. New York: Cambridge University Press, 2004.

- - - Heroes of invention : technology, liberalism and British identity : 1750 - 1914. Cambridge UK: Cambridge University Press, 2007.

MacLeod, Christine, Jennifer Tann, James Andrew, and Jeremy Stein. "Evaluating inventive activity: the cost of nineteenth-century UK patents and the fallibility of renewal data." Economic History Review 56, no. 3 (2003): 537-62.

Maril, Nadja. American lighting, 1840-1940. West Chester, PA: Schiffer Pub., 1989.

- - . American lighting, 1840-1940. Atglen, PA: Schiffer Pub., 1995.

Masse, René. Le gaz. 3 vols. Paris: Liège, 1914.

Mathias, Peter. "Who Unbound Prometheus? Science and Technical change, 1600-1800." In Science, Technology, and Economic Growth in the Eighteenth Century, edited by A. E. Musson, 69-96. London: Methuen, 1972.

- - - The first industrial nation : the economic history of Britain, 1700-1914. London: New York, 2001.

Matthews, Derek. "Rogues, Speculators and Competing Monopolies: The Early London Gas Companies, 1812-1860." London Journal 11, no. 1 (1985): 39-50.

- - - "Laissez-faire and the London Gas Industry in the Nineteenth Century: Another Look." The Economic History Review 39, no. 2 (1986): 244-63.

- - - "The Technical Transformation of the Late Nineteenth-Century Gas Industry." Journal of Economic History 47, no. 4 (1987): 967-80.

- - - "Profit-sharing in the gas industry, 1889-1949." Business History 30 (1988): 306-28. 
Meade, Alwyne. Modern gasworks practice. London: Benn, 1921.

Milan, Sarah. "Refracting progress: the slow acceptance of domestic gas lighting, London 1800-1890." Royal Society of Arts (Great Britain). RSA journal 146, no. 2 (1998): 122-23.

- - - "Refracting the Gaselier: Understanding Victorians Responses to Domestic Gas Lighting." In Domestic Space: Reading the nineteenth-century interior, 84-102. Manchester: University of Manchester Press, 1999.

Milbourne, Charles Gordon. The removal of hydrogen sulphide from gas by means of iron oxide: with special reference to humidity conditions. Baltimore,Ic1930., 1930.

Millburn, John R. Adams of Fleet Street : instrument makers to King George III. Aldershot: Burlington, VT, 2000.

Miller, Davide Philip. Discovering Water: James Watt, Henry Cavendish, and the Nineteenth Century 'Water Controversy': Ashgate Publishing, Ltd., 2004.

Miller, David Philip, and Trevor H. Levere. "Inhale it and See? The Collaboration between Thomas Beddoes and James Watt in Pneumatic Medicine." Ambix 55 (2008): 5-28.

Mills, Mary. "George Livesey and profit sharing: a comment on some recent literature." Business History 33 (1991): 87-90.

- - - The early East London gas industry and its waste products : how were they used? London: M. Wright, 1999.

- - - Places and people in the early East London gas industry. London: M. Wright, 2001.

Millward, Robert. "The Market Behaviour of Local Utilities in Pre-World War I Britain: The Case of Gas." The Economic History Review 44, no. 1 (1991): 102-27.

Millward, Robert, and Robert Ward. "The Costs of Public and Private Gas Enterprises in Late 19th Century Britain." Oxford Economic Papers 39, no. 4 (1987): 719-37.

- - - "From Private to Public Ownership of Gas Undertakings in England and Wales, 1851-1947: Chronology, Incidence and Causes." Business History 35, no. 3 (1993): 1-21.

Mokyr, Joel. The Lever of Riches: Technological Creativity and Economic Progress. New York: Oxford University Press, 1990.

- - - "Technological Change, 1700-1830." In The Economic history of Britain since 1700. Volume 1: 1700-1860, edited by Roderick Floud and Deirdre N. 
McCloskey, 12-43. Cambridge, New York: Cambridge University Press 2nd ed, 1994.

- - - "Editor's Introduction: The New Economic History and the Industrial Revolution." In The British industrial revolution : an economic assessment, edited by Joel Mokyr, 1-127. Boulder, Colo.: Oxford, 1999.

- - - The Gifts of Athena: Historical Origins of the Knowledge Economy. Princeton: Princeton University Press, 2002.

- - - "The Intellectual Origins of Modern Economic Growth." The Journal of Economic History 65, no. 2 (2005): 285-351.

- - - "The European Enlightenment, the Industrial Revolution, and Modern Economic Growth." In Max Weber Programme. European University Institute: Badia Fiesolana, 2007.

- - - "The Institutional Origins of the Industrial Revolution." Northwestern University, 2007. Unpublished.

- - - "Knowledge, Enlightenment, and the Industrial Revolution: Reflections on The Gifts of Athena." History of Science 45 (2007): 185-96.

- - - "Entrepreneurship and the Industrial Revolution in Britain." 2008. Unpublished.

Morrison-Low, A. D. Making scientific instruments in the Industrial Revolution. Aldershot: Ashgate, 2007.

Murphy, Brian, Taryn Sparacio, and Walter Shields. "Manufactured Gas PlantsProcesses, Historical Development, and Key Issues in Insurance Coverage Disputes." Environmental Forensics 6, no. 2 (2005): 161-73.

Musson, A. E., and E. Robinson. "Science and Industry in the Late Eighteenth Century." The Economic History Review 13, no. 2 (1960): 222-44.

Musson, A. E. , and Eric Robinson. Science and technology in the Industrial Revolution. Toronto: University of Toronto Press, 1969.

Nead, Lynda. Victorian Babylon : people, streets and images in nineteenth-century London. New Haven: Yale University Press, 2000.

Nef, John Ulric. The rise of the British coal industry. London: G. Routledge, 1932.

- - - "The Progress of Technology and the Growth of Large-Scale Industry in Great Britain, 1540-1640." The Economic History Review 5, no. 1 (1934): 3-24.

Newbigging, Thomas. Handbook for gas engineers and managers. London; New York: W. King; D. Van Nostrand Co., 1904. 
Nuvolari, Alessandro. "Collective invention during the British Industrial Revolution: the case of the Cornish pumping engine." Cambridge Journal of Economics 28, no. 3 (2004): 347-63.

O'Dea, William Thomas. The social history of lighting. London: Routledge and K. Paul, 1958.

Oconnor, Henry, and Arts Royal Scottish Society of. Gas manufacture and lighting. London: King, 1910.

Pancaldi, Giuliano. Volta : science and culture in the Age of Enlightenment: Princeton University Press, 2003.

Paquier, Serge, and Jean-Pierre Williot. L'industrie du gaz en Europe aux XIXe et XXe siècles : l'innovation entre marchés privés et collectivités publiques. Bruxelles: PIE-Peter Lang, 2005.

Parascandola, John, and Aaron J. Ihde. "History of the Pneumatic Trough." Isis 60, no. 3 (1969): 351-61.

Partington, J. R. A History of Chemistry. Vol 3. London: Macmillan; New York, St. Martin's Press, 1961.

Passer, Harold. "The Electric Light and the Gas Light: Innovation and Continuity in Economic History." Explorations in Entrepreneurial History 1, no. 3 (1949): 1-9.

Pearson, Robin. "Shareholder Democracies? English Stock Companies and the Politics of Corporate Governance during the Industrial Revolution." English Historical Review 117, no. 473 (2002): 840-66.

- - - Insuring the industrial revolution : fire insurance in Great Britain, 1700-1850. Aldershot, Hants, England: Burlington, VT, 2004.

Pearson, Robin, and David Richardson. "Business Networking in the Industrial Revolution." The Economic History Review 54, no. 4 (2001): 657-79.

Perrin, C. E. "A Lost Identity: Philippe Frederic, Baron de Dietrich (1748-1793)." Isis 73, no. 4 (1982): 545-51.

Petersen, H. J. Styhr. "Diffusion of coal gas technology in Denmark, 1850-1920." Technological Forecasting and Social Change 38, no. 1 (1990): 37-48.

Prados de la Escosura, Leandro. Exceptionalism and industrialisation : Britain and its European rivals, 1688-1815. New York: Cambridge University Press, 2004.

Quilliam, Gary. "Gaslight." Old house journal, vol 17, no. 2 (1989): 44-47.

Ratcliffe, Gae. "Fanning an old flame." Traditional homes, vol 5, no. 2 (1988): 68-70. 
Reeson, Joseph. The acts relating to the supply of gas \& water by companies and local authorities with reference notes and full index. London: Butterworth, 1902.

Rice, Wallace. 75 years of gas service in Chicago. Chicago: Peoples Gas Light and Coke Co., 1925.

Riello, G., and P. K. O'Brien. "Reconstructing the Industrial Revolution: Analyses, Perceptions and Conceptions Of Britain's Precocious Transition to Europe's First Industrial Society." (2004).

Rippy, J. Fred. "Notes on Early British Gas Companies in Latin America." The Hispanic American Historical Review 30, no. 1 (1950): 111-14.

Roberts, Lissa Louise, Simon Schaffer, and Peter Robert Dear. The mindful hand : inquiry and invention from the late Renaissance to early industrialisation. Amsterdam : Edita: Bristol, 2007.

Robinson, Eric. "James Watt and the Law of Patents." Technology and Culture 13, no. 2 (1972): 115-39.

Rosenberg, Nathan. Inside the black box : technology and economics: New York, 1982.

Royle, Harold M. The chemistry of gas manufacture. London: Crosby, 1907.

Russell-Wood, J. "A biographical note on William Brownrigg, M.D., F.R.S. (1711-1800)." Annals of Science 6, no. 2 (1949): 186 - 96.

- - - "The scientific work of William Brownrigg, M.D., F.R.S. (1711-1800) - I." Annals of Science 6, no. 4 (1950): 436 - 47.

- - - "The scientific work of William Brownrigg, M.D., F.R.S. (1711-1800) - III." Annals of Science 7, no. 2 (1951): 199 - 206.

- - -. "The scientific work of William Brownrigg, M.D., F.R.S. (1711-1800) - II." Annals of Science 7, no. 1 (1951): 77 - 94.

Santangelo, Georgia, and Carla Garbarino. "General Bibliography on Alessandro Volta." In Nuova Voltiana : studies on Volta and his times, edited by Fabio Bevilacqua and Lucio Fregonese, 117-80? Milano, Pavia Università degli studi di Pavia, Editore Ulrico Hoepli, 2000.

Schivelbusch, Wolfgang. Disenchanted night : the industrialization of light in the nineteenth century. Berkeley: University of California Press, 1988.

Schofield, Robert E. The Lunar Society of Birmingham; a social history on provincial science and industry in eighteenth-century England. Oxford: Clarendon, 1963. 
Schrøder, Michael. The Argand burner. Its origin and development in France and England 1780-1800. An epoch in the history of science illustrated by the life and work of the physicist Ami Argand (1750-1803). Odense: Odense University Press, 1969.

Siegfried, Robert. From elements to atoms: a history of chemical composition. Vol. 92, part 4. Philadelphia: American Philosophical Society, 2002.

Sim, Andrew. "Gas lamps \& gargoyles [The Park, Nottingham]." Traditional homes, vol 6, no. 1 (1989): 16-19.

Smith, John Graham. The origins and early development of the heavy chemical industry in France. Oxford : Clarendon Press: New York, 1979.

Stein, A. L. "The Chicago Gas Case." The Journal of Land \& Public Utility Economics 16, no. 2 (1940): 236-41.

Stewart, David M. "Cultural Work, City Crime, Reading, Pleasure." American Literary History 9, no. 4 (1997): 676-701.

Stewart, Larry. The rise of public science : rhetoric, technology, and natural philosophy in Newtonian Britain. New York: Cambridge University Press, 1992.

- - - "Experimental Spaces and the Knowledge Economy." History of Science 45 (2007): 155-77.

Storrs, F. C. "Lavoisier's technical reports: 1768-1794 Part I." Annals of Science 22, no. 4 (1966): 251-75.

Stotz, Louis, and Alexander Jamison. History of the gas industry. New York: Stettiner bros, 1938.

Stradling, D., and Peter Thorsheim. "The Smoke of Great Cities: British and American Efforts to Control Air Pollution, 1860-1914." Environmental History 4, no. 1 (1999): 6-31.

Sullivan, Richard J. "The Revolution of Ideas: Widespread Patenting and Invention During the English Industrial Revolution." The Journal of Economic History 50, no. 2 (1990): 349-62.

Sunderland, David. "'Disgusting to the imagination and destructive of health'? The metropolitan supply of water, 1820-52." Urban History 30, no. 3 (2003): 359.

Szabadváry, Ferenc. History of analytical chemistry. 1st English ed. Oxford: New York, Pergamon Press, 1966.

Taylor, E. G. R. The mathematical practitioners of Hanoverian England, 1714-1840. London: Cambridge U.P. for the Institute of Navigation, 1966. 
Thorsheim, Peter. "The Paradox of Smokeless Fuels: Gas, Coke and the Environment in Britain, 1813-1949." Environment and History [Great Britain] 8, no. 4 (2002): 381-401.

- - - Inventing pollution : coal, smoke, and culture in Britain since 1800: Ohio University Press, 2006.

Todd, Edmund N. "A Tale of Three Cities: Electrification and the Structure of Choice in the Ruhr, 1886-1900." Social Studies of Science 17, no. 3 (1987): 387-412.

Toms, Steven, and John F. Wilson. "Scale, Scope and Accountability: Towards a New Paradigm of British Business History." Business History 45 (2003): 1-23.

Treue, W. "Die Entwicklung der chemischen Industrie von 1770 bis 1870." Chemie Ingenieur Technik 39, no. 17 (1967): 1002 - 08.

Troesken, Werner. "The Chicago gas industry, 1887-1913 : an economic analysis of institutional change." vii, 114 leaves: Washington University, 1992.

- - - Why regulate utilities? : the new institutional economics and the Chicago gas industry, 1849-1924. Ann Arbor: University of Michigan Press, 1996.

- - - "The Sources of Public Ownership: Historical Evidence from the Gas Industry." Journal of Law, Economics, \& Organization 13, no. 1 (1997): 1-25.

Turner, Michael J. "Gas, police and the struggle for mastery in Manchester in the eighteen-twenties." Historical Research 67, no. 164 (1994): 301-17.

Uglow, Jennifer S. The lunar men : the friends who made the future, 1730-1810. London: Faber and Faber, 2002.

Van Der Vleuten, Erik. "Infrastructures and Societal Change. A View from the Large Technical Systems Field." Technology Analysis \& Strategic Management 16, no. 3 (2004): 395-414.

Veillerette, François. Philippe Lebon, ou, L'homme aux mains de lumière : la vie et l'oeuvre de l'illustre inventeur français du gaz d'éclairage et du chauffage au gaz. Colombey-les-Deux-Eglises: N. Mourot, 1987.

Volta, Alessandro. Le opere di Alessandro Volta. Milano: Hoepli, 1918.

- - - Epistolario di Alessandro Volta. Bologna: N. Zanichelli, 1949.

Vrbka, Anton. Zach. Andreas Winzler und seine Thermolampe in Znaim 1802. Znaim: Znaimer Museum, 1919.

Webber, William Hosgood Young. Gas \& gas making : growth, methods, and prospects of the gas industry. London: Pitman, 1918. 
Wengenroth, Ulrich. "Science, Technology, and Industry." In From natural philosophy to the sciences : writing the history of nineteenth-century science, edited by David Cahan, 221-53. Chicago: University of Chicago Press, 2003.

Werrett, Simon. "From the grand whim to the gasworks: 'philosophical fireworks' in Georgian England." In The mindful hand : inquiry and invention from the late Renaissance to early industrialisation, edited by Lissa Louise Roberts, Simon Schaffer and Peter Robert Dear, 325-46. Amsterdam : Edita: Bristol, 2007.

Wertime, T. A. "The Discovery of the Element Carbon." Osiris 11 (1954): 211-20.

White, John H., Jr. "'A Perfect Light Is a Luxury": Pintsch Gas Car Lighting." Technology and Culture 18, no. 1 (1977): 64-69.

Williams, Trevor Illtyd. A history of the British gas industry. New York: Oxford University Press, 1981.

Williot, Jean-Pierre. "La fabrication du gaz et l'innovation sous le second empire." Sources: Travaux Historiques [France], no. 11 (1987): 37-48.

- - - . Naissance d'un service public : le gaz à Paris. Paris: Rive droite-Institut d'histoire de l'industrie, 1999.

Wilson, J. F. Lighting the town : a study of management in the North West gas industry, 1805-1880. London: P. Chapman Pub., 1991.

- - - "Ownership, Management and Strategy in Early North-West Gas Companies, 1815-30." Business History [Great Britain] 33, no. 2 (1991): 203-21.

- - - British business history, 1720-1994. Manchester: New York, 1995.

Woronoff, Denis. Histoire de l'industrie en France : du XVle siècle à nos jours Paris: Editions du Seuil, 1994.

Wrigley, E. A. "The Supply of Raw Materials in the Industrial Revolution." The Economic History Review 15, no. 1 (1962): 1-16.

--- Continuity, chance and change : the character of the industrial revolution in England: New York, 1988. 